$3^{\text {rd }}$ INTERNATIONAL SCIENTIFIC CONFERENCE

\title{
CHEMICAL TECHNOLOGY AND ENGINEERING
}

\section{PROCEEDINGS}
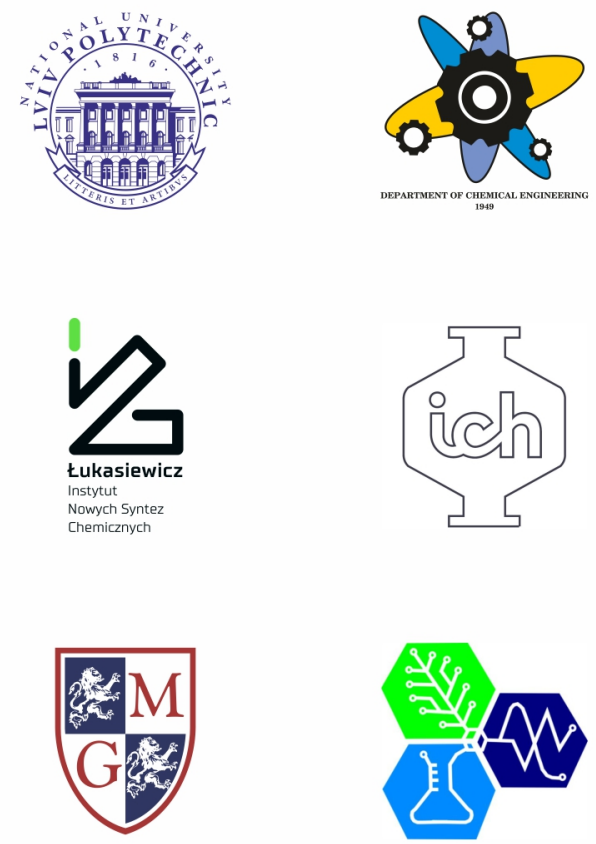

ISSN $2664-1275$

UKRAINE, LVIV, JUNE 21-24 $4^{\text {th }}, 2021$ 
Ministry of Education and Science of Ukraine Lviv Polytechnic National University

\title{
$3^{\text {rd }}$ International Scientific Conference «Chemical Technology and Engineering»
}

\author{
P R O C E E D I N G S
}

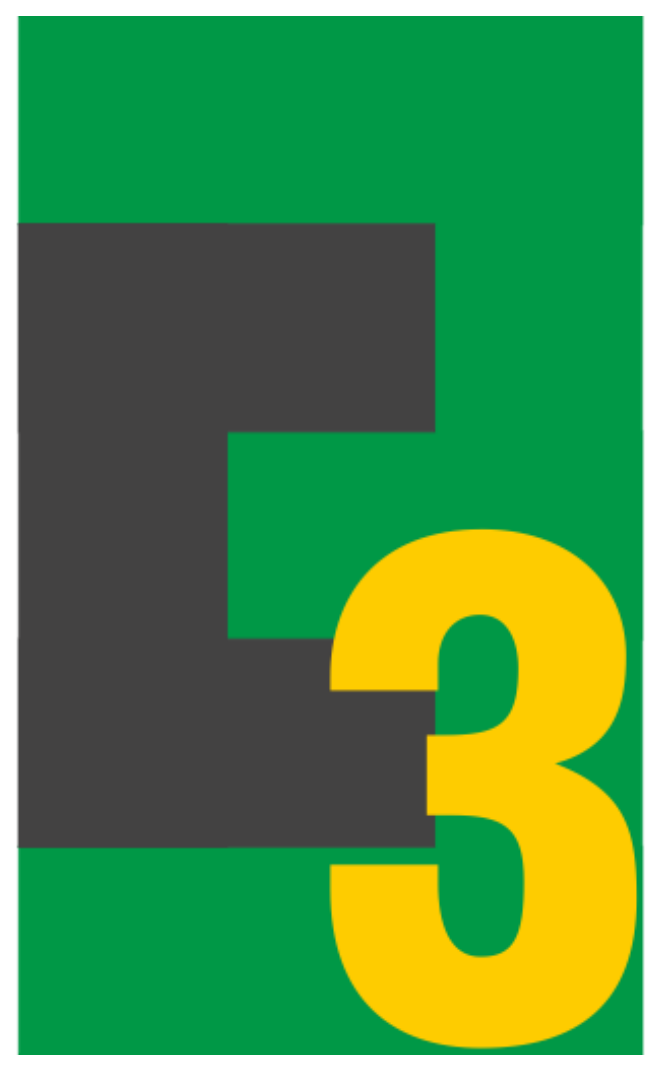

Ukraine, Lviv, June 21-24 $4^{\text {th }}, 2021$

ISSN: 2664-1275 (Online) 


\section{The event is supported by Lviv Convention Bureau and co-financed by Programme «Support package for development of conference industry in Lviv»}

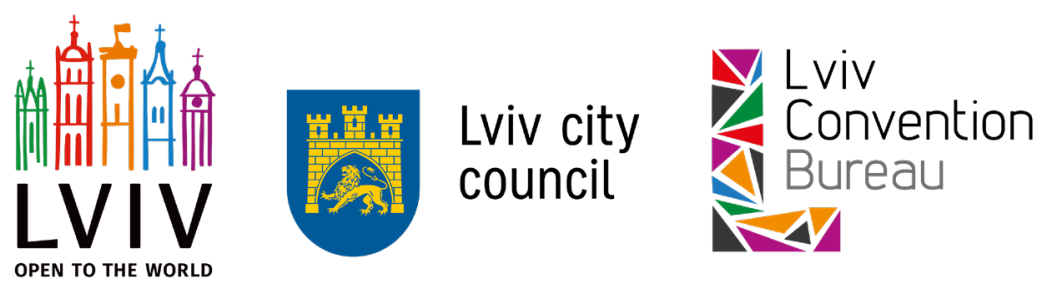

The Conference Organizers:

Department of Chemical Engineering, Institute of Chemistry and Chemical Technologies, Lviv National Polytechnic University (Lviv, Ukraine);

Łukasiewicz Research Network - New Chemical Syntheses Institute (Pulawy, Poland);

Faculty of Chemical and Process Engineering, Warsaw University of Technology (Warsaw, Poland);

Warsaw College of Engineering and Health (Warsaw, Poland)

Department of Informatics and Environment Quality Research, Faculty of Building Services, Hydro and Environmental Engineering, Warsaw University of Technology (Warsaw, Poland)

$$
\text { with the participation of }
$$

Scientific Society of Students, Doctoral Candidates and Young Researchers of Institute of Chemistry and Chemical Technologies of Lviv National Polytechnic University;

Alumni Association of Lviv Polytechnic National University.

$3^{\text {rd }}$ International Scientific Conference «Chemical Technology and Engineering»: Proceedings. - June 21-24 , 2021, Lviv, Ukraine. - Lviv: Lviv Polytechnic National University, 2021. -248 p.

The Proceedings contain materials of the $3^{\text {rd }}$ International Scientific Conference «Chemical Technology and Engineering».

All information presented in the Proceedings is the intellectual property of authors and may not be used without their consent. All materials are submitted in the authors' edition.

All papers included in the Proceedings were a subject of open peer review (by at least two independent reviewers) and selected by the International Scientific Board.

All papers included in the Proceedings are licensed under a Creative Commons Attribution 4.0 International (CC BY 4.0) License and published in open access on the conference websites: www.cte.org.ua and www.openreviewhub.org/cte.

ISSN: 2664-1275 (Online)

(C) Lviv Polytechnic National University, 2021 
Greetings of the Program Committee's Chairman of the $3^{\text {rd }}$ International Scientific Conference «Chemical Technology and Engineering», Rector of Lviv Polytechnic National University, DSc, Professor Yuriy Bobalo

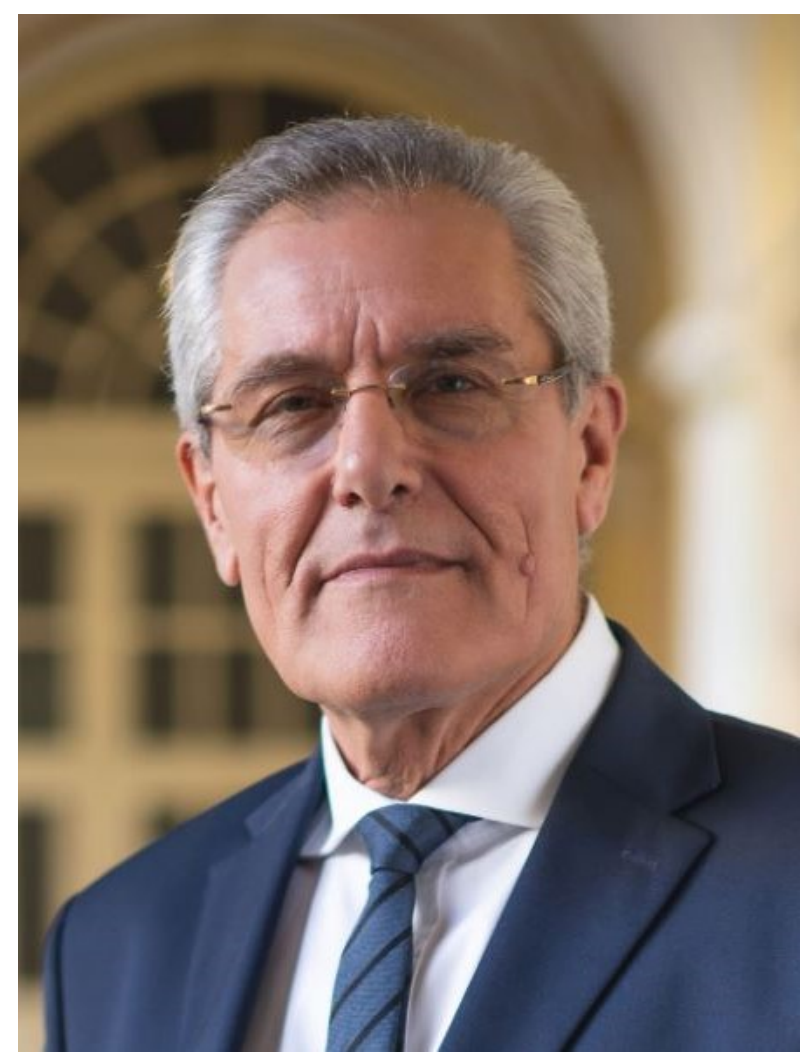

Dear participants!

Despite the challenges posed by the global pandemic, Lviv Polytechnic National University continues to organize scientific events to develop and unite the research community.

Scientists must continue to communicate - to demonstrate and discuss achievements even in a remote format.

I wish all of you fruitful work and new attainments in the field of chemical technology and engineering! 
Greetings of the Organizing Committee's Chairman of the $3^{\text {rd }}$ International Scientific Conference «Chemical Technology and Engineering», Head of the Department of Chemical Engineering, Lviv Polytechnic National University, DSc, Professor Volodymyr Atamanyuk

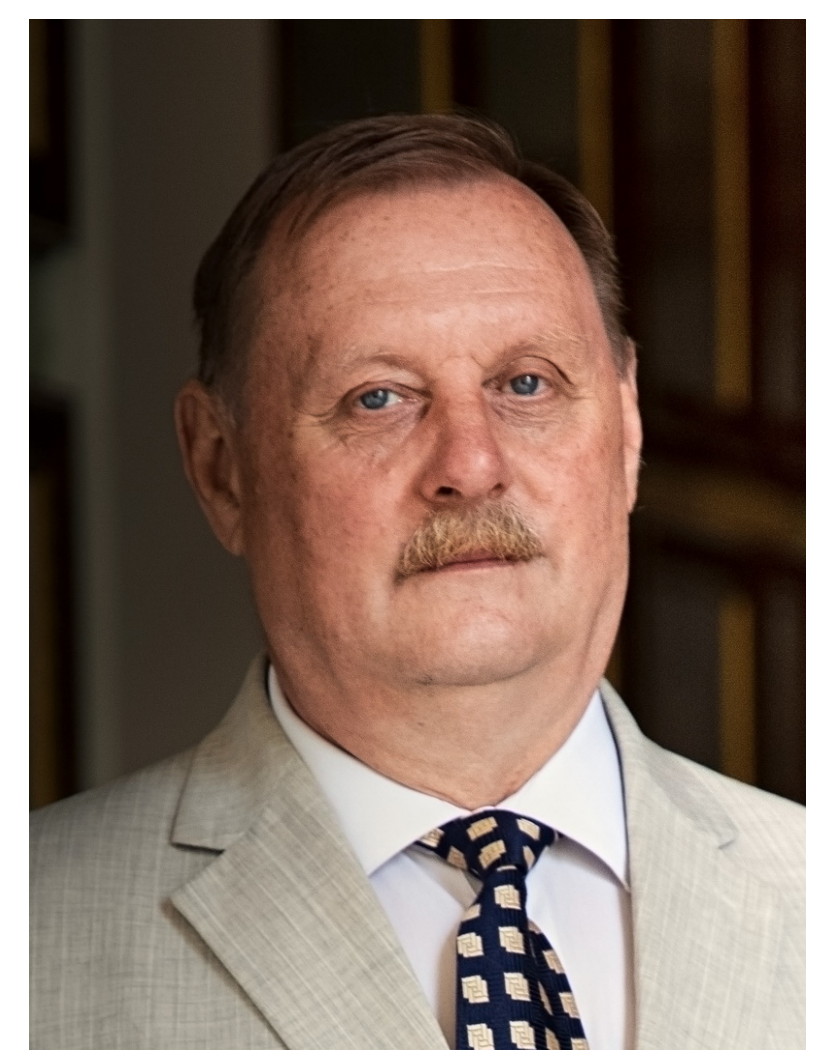

Dear colleagues!

I am glad to welcome you at our traditional conference, which is traditionally dedicated to topical issues of chemical technology and engineering!

Unfortunately, we are not meeting in person this June - but we will be able to see each other thanks to online technologies. I sincerely believe that distance will not interfere with interesting presentations, exciting discussions and knowledge exchange.

I appreciate all the participants who joined the conference and wish new bright discoveries and scientific achievements! 


\section{THE PROGRAM COMMITTEE}

Chairman

Yuriy Bobalo, DSc, Professor, Rector of Lviv Polytechnic National University, Ukraine

\section{Co-Chairman}

Wojciech Zielinski, DSc, Professor, Doctor honoris causa of Lviv Polytechnic National University, Rector of Silesian University of Technology, Poland

\section{Vice-Chairmen}

Volodymyr Atamanyuk, DSc, Professor, Head of the Department of Chemical Engineering, Lviv Polytechnic National University, Ukraine

Artur Badyda, DSc, Professor, Head of the Department of Informatics and Environment Quality Research, Warsaw University of Technology, Poland

Janusz Igras, DSc, Professor, General Director of Łukasiewicz - New Chemical Syntheses Institute, Poland

Monika Sadowska, DSc, Professor, Vice-Rector for Scientific Research of Warsaw College of Engineering and Health, Poland

Volodymyr Skorokhoda, DSc, Professor, Director of the Institute of Chemistry and Chemical Technologies, Lviv Polytechnic National University, Ukraine

Tomasz Sosnowski, DSc, Professor, Vice-Dean for Scientific Affairs of the Faculty of Chemical and Process Engineering, Warsaw University of Technology, Poland

\section{Members}

Dorota Antos, DSc, Professor, Dean of Faculty of Chemistry, Head of the Department of Chemical and Process Engineering, Rzeszow University of Technology, Poland

Mykhaylo Bratychak, DSc, Professor, Head of the Department of Chemical Technology of Oil and Gas Processing, Lviv Polytechnic National University, Ukraine

Oleg Burdo, DSc, Professor, Head of the Department of Processes, Equipment and Energy Management, Odessa National Academy of Food Technologies, Ukraine

Anna Chrobok, DSc, Professor, Vice-Dean for Science and International Cooperation of the Faculty of Chemistry, Silesian University of Technology, Poland

Giancarlo Cravotto, DSc, Professor, Head of the Department of Drug Science and Technology, University of Turin, Italy

Bogdan Dziniak, DSc, Professor, Deputy Director of the Institute of Chemistry and Chemical Technologies, Lviv Polytechnic National University, Ukraine

Bryan Enderle, PhD, Professor of the Chemistry Department, University of California, Davis, USA

Alan Flowers, DSc, Professor, Faculty of Science, Engineering and Computing, Kingston University, United Kingdom

Oleg Grynyshyn, DSc, Professor, Dean for Master's Studies of the Institute of Chemistry and Chemical Technologies, Lviv Polytechnic National University, Ukraine 
Jaroslaw Gumnitsky, DSc, Professor, Department of Ecology and Sustainable Environmental Management, Lviv Polytechnic National University, Ukraine

Izabella Jasicka-Misiak, PhD, Associate Professor, Department of Analytical Chemistry and Environmental, Faculty of Chemistry, University of Opole, Poland

Mara Jure, DSc, Professor, Vice-Dean of the Faculty of Materials Science and Applied Chemistry, Head of the Department of Chemical Technology of Biologically Active Compounds, Riga Technical University, Latvia

Valentina Klebanova, $\mathrm{PhD}, \mathrm{CEO}$ of the Private Institute for Applied Biotechnology, Lichtenstein

Jiri Jaromir Klemes, DSc, Head of Sustainable Process Integration Laboratory, Czech Republic

Marcin Konkol, Deputy Director for Research, Łukasiewicz Research Network - New Chemical Syntheses Institute, Poland

Roman Kresinski, PhD, Senior Lecturer, Materials Research Group, School of Life Sciences, Pharmacy and Chemistry, Kingston University, United Kingdom

Teobald Kupka, DSc, Professor, Department of Physical Chemistry and Molecular Modeling, Faculty of Chemistry, University of Opole, Poland

Vira Lubenets, DSc, Professor, Acting Head of the Technology of Biologically Active Substances, Pharmacy and Biotechnology, Lviv Polytechnic National University, Ukraine

Anna Malm, DSc, Professor, Dean of the Faculty of Pharmacy with Medical Analytics Division, Medical University of Lublin, Poland

Myroslav Malovanyy, DSc, Professor, Head of the Department of Ecology and Sustainable Environmental Management, Lviv Polytechnic National University, Ukraine

Stepan Melnyk, DSc, Professor, Dean for Bachelor's Studies of the Institute of Chemistry and Chemical Technologies, Lviv Polytechnic National University, Ukraine

Vytautas Mickevicius, DSc, Professor, Department of Organic Chemistry, Kaunas University of Technology, Lithuania

Oleg Nagurskyy, DSc, Professor, Head of the Department of Civil Safety, Lviv Polytechnic National University, Ukraine

Dorota Neugebauer, DSc, Professor, Department of Physical Chemistry and Technology of Polymers, Faculty of Chemistry, Silesian University of Technology, Poland

Wolfgang Nowick, DSc, Professor, President of the Private Institute for Applied Biotechnology, Lichtenstein

Larysa Paniwnyk, PhD, Associate Director, Faculty of Health and Life Sciences, The Sonochemistry Centre at Coventry University, United Kingdom

Roman Petrus, DSc, Professor, Department of Chemical and Process Engineering, Rzeszow University of Technology, Poland

Zorian Pikh, DSc, Professor, Head of the Department of Organic Products Technology, Lviv Polytechnic National University, Ukraine 
Ewa Poleszak, DSc, Professor, Chair and Department of Applied Pharmacy, Medical University of Lublin, Poland

Edward Roj, DSc, Associate Professor, Head of the Supercritical Extraction Department, Łukasiewicz - New Chemical Syntheses Institute, Poland

Viktor Reutskyy, DSc, Professor, Department of Organic Products Technology, Lviv Polytechnic National University, Ukraine

Yevgen Semenyshyn, DSc, Professor, Department of Chemical Engineering, Lviv Polytechnic National University, Ukraine

Vsevolod Sklabinskyy, DSc, Professor, Head of the Department of Processes and Equipment of Chemical and Petroleum Industries, Sumy State University, Ukraine

Yuriy Sniezhkin, DSc, Professor, Academician of National Academy of Sciences of Ukraine, Director of Institute of Engineering Thermophysics of National Academy of Sciences of Ukraine, Ukraine

Volodymyr Starchevskyy, DSc, Professor, Department of Physical, Analytical and General Chemistry, Lviv Polytechnic National University, Ukraine

Wolodymyr Suprun, DSc, Project Leader, Institute of Chemical Technology, University of Halle, Germany

Sergii Tsygankov, DSc, Senior Research Fellow, Deputy Director of the Research, Head of Biotechnology Renewable Raw Materials and Alternative Fuels of the Institute of Food Biotechnology and Genomics, National Academy of Sciences of Ukraine, Ukraine

Maris Turks, DSc, Professor, Director of the Institute of Technology of Organic Chemistry, Faculty of Materials Science and Applied Chemistry, Riga Technical University, Latvia

Stanislav Voronov, DSc, Professor, Head of the Department of Organic Chemistry, Lviv Polytechnic National University, Ukraine

Piotr Wieczorek, DSc, Professor, Dean of the Faculty of Chemistry, University of Opole, Poland

Malgorzata Wojtkowska, DSc, Professor, Department of Informatics and Environment Quality Research, Warsaw University of Technology, Poland

Valeriy Zazhigalov, DSc, Professor, Corresponding Member of National Academy of Sciences of Ukraine, Head of the Department of Catalytic Oxidation Processes, the Institute for Sorption \& Problems of Endoecology of National Academy of Sciences of Ukraine, Ukraine

Zenoviy Znak, DSc, Professor, Head of the Department of Chemistry and Technology of Inorganic Substances, Lviv Polytechnic National University, Ukraine 


\section{THE ORGANIZING COMMITTEE}

\section{Chairman of the Organizing Committee}

Volodymyr Atamanyuk, DSc, Professor, Head of the Department of Chemical Engineering, Lviv Polytechnic National University, Ukraine

\section{Vice-Chairmen of the Organizing Committee}

Janusz Igras, DSc, Professor, General Director of Łukasiewicz - New Chemical Syntheses Institute, Poland

Diana Kindzera, $\mathrm{PhD}$, Associate Professor, Deputy Head of the Department of Chemical Engineering, Lviv Polytechnic National University, Ukraine

Monika Sadowska, DSc, Professor, Vice-Rector for Scientific Research, Warsaw College of Engineering and Health, Poland

Tomasz Sosnowski, DSc, Professor, Vice-Dean for Scientific Affairs of the Faculty of Chemical and Process Engineering, Warsaw University of Technology, Poland

Volodymyr Starchevskyy, DSc, Professor, Department of Physical, Analytical and General Chemistry, Lviv Polytechnic National University, Ukraine

Anna Tynska, Head of Research Support Department, Łukasiewicz - New Chemical Syntheses Institute, Poland

\section{Conference Secretary}

Oleksandr Ivashchuk, PhD, Senior Research Fellow, Associate Professor, Department of Chemical Engineering, Lviv Polytechnic National University, Ukraine

\section{Members of the Organizing Committee}

Oleksandr Berezko, PhD, Associate Professor, Department of Social Communication and Information Activities, Lviv Polytechnic National University, Ukraine

Roman Chyzhovych, Master Student, Department of Chemical Engineering, Lviv Polytechnic National University, Ukraine

Oksana Dobrovetska, PhD, Lecturer, Department of Chemical Engineering, Lviv Polytechnic National University, Ukraine

Vasyl' Duleba, PhD, Associate Professor, Department of Chemical Engineering, Lviv Polytechnic National University, Ukraine

Zoriana Gnativ, PhD, Associate Professor, Department of Chemical Engineering, Lviv Polytechnic National University, Ukraine

Ruslana Guminilovych, PhD, Associate Professor, Department of Physical, Analytical and General Chemistry, Lviv Polytechnic National University, Ukraine

Roman Havryliv, PhD, Associate Professor, Department of Chemical Engineering, Lviv Polytechnic National University, Ukraine

Anna Hlukhaniuk, Master Student, Department of Chemical Engineering, Lviv Polytechnic National University, Ukraine 
Iryna Huziova, $\mathrm{PhD}$, Associate Professor, Department of Chemical Engineering, Lviv Polytechnic National University, Ukraine

Iryna Kostiv, PhD, Associate Professor, Department of Chemical Engineering, Lviv Polytechnic National University, Ukraine

Oksana Orobchuk, $\mathrm{PhD}$, Senior Lecturer, Department of Technology of Organic Products, Lviv Polytechnic National University, Ukraine

Roman Nebesnyi, PhD, Head of R\&D Department, Lviv Polytechnic National University, Ukraine

Volodymyr Reutskyy, PhD, Associate Professor, Department of Physical, Analytical and General Chemistry, Lviv Polytechnic National University, Ukraine

Nadiya Tsiura, Lecturer, Department of Chemical Engineering, Lviv Polytechnic National University, Ukraine

Ivan Tymchuk, PhD, Associate Professor, Department of Ecology and Sustainable Environmental Management, Lviv Polytechnic National University, Ukraine 


\section{PLENARY PRESENTATIONS}




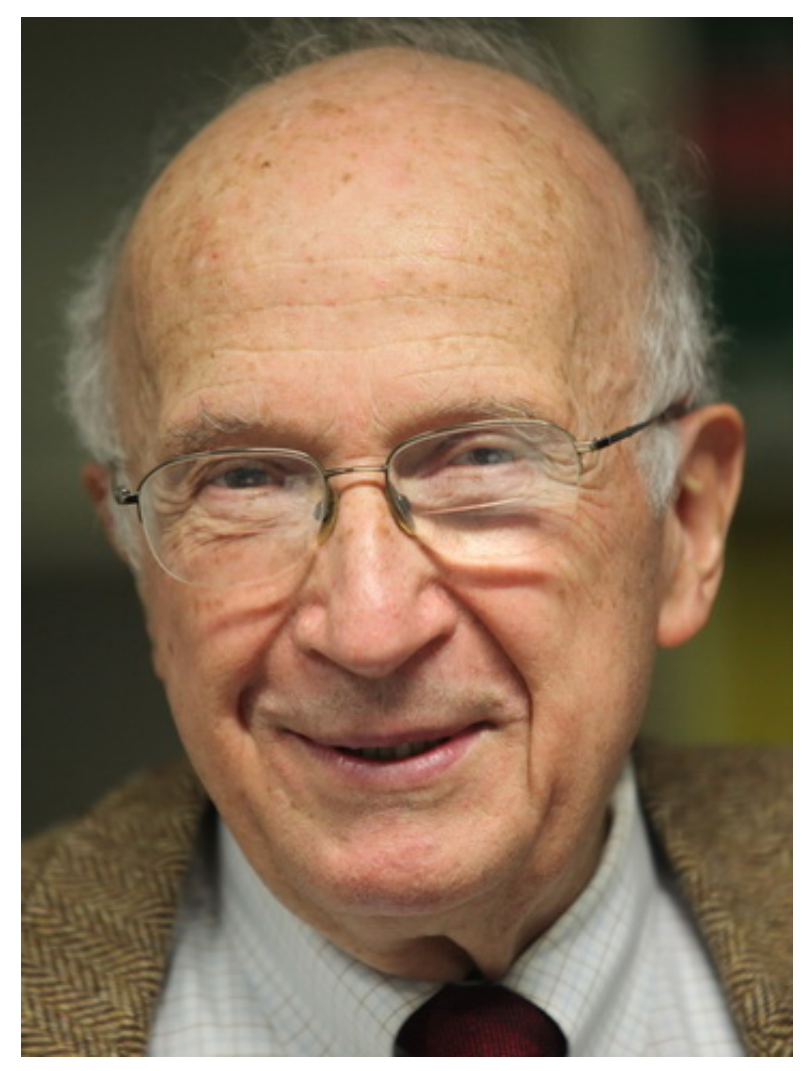

THE CHEMICAL IMAGINATION AT WORK IN VERY TIGHT PLACES

\section{Professor Roald Hoffmann}

The Nobel Prize in Chemistry 1981, Emeritus, Cornell University, USA

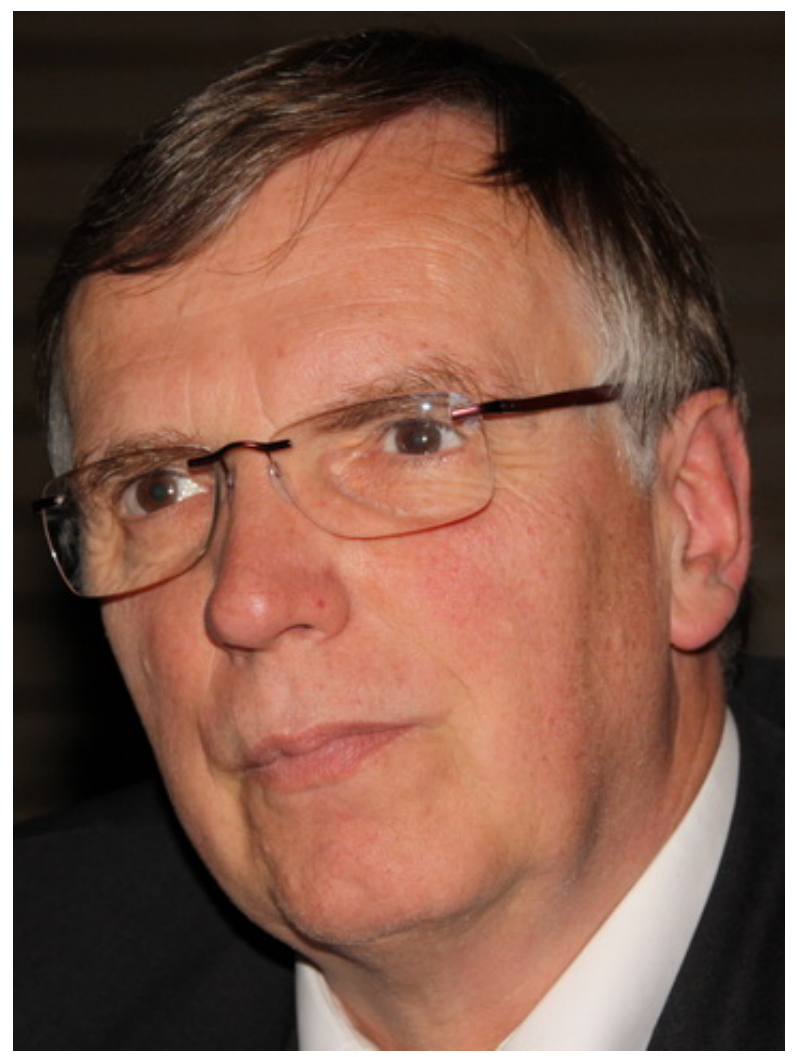

POLYMER PROPERTIES TO COMPLY WITH REQUIREMENTS FROM MEDICAL DEVICES

Professor Jörg Vienken

Former President of International Federation of Artificial Organs (IFAO),

Technical University Mittelhessen, Germany 

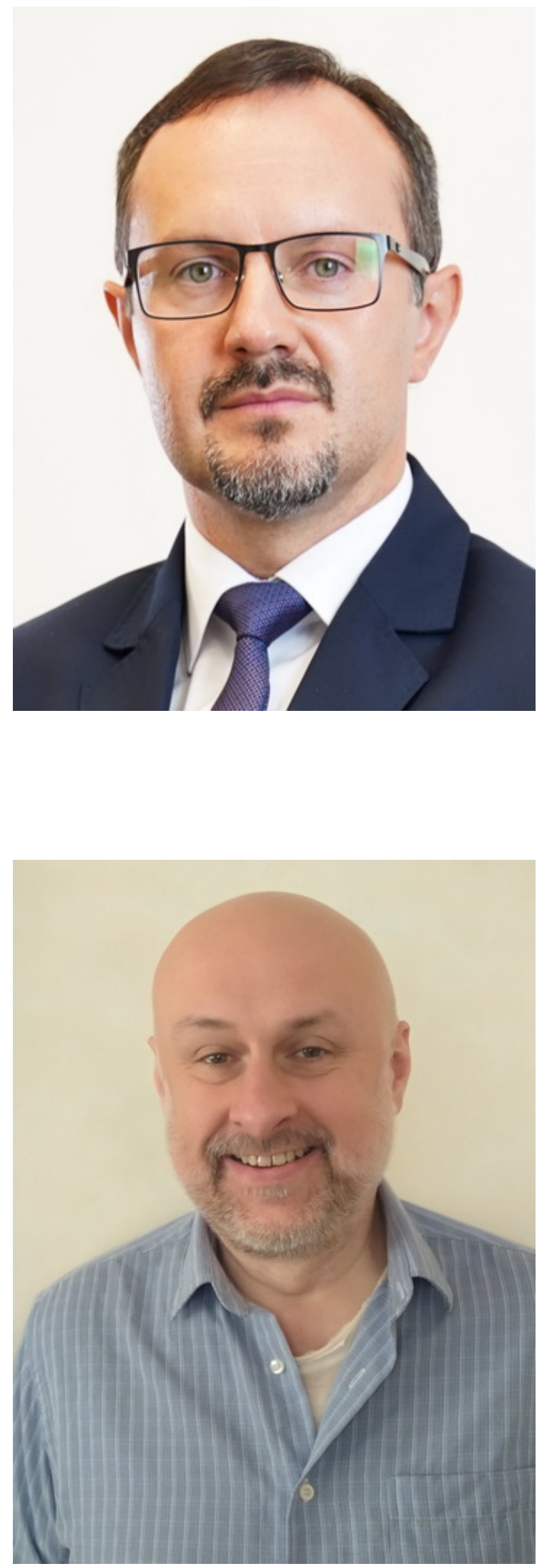

INNOVATIVE COSMETIC RAW

MATERIALS AND BIOLOGICALLY ACTIVE COMPOUNDS IN COSMETICS CHEMISTRY

Doctor Sebastian Grzyb

Rector of Warsaw College of Engineering and Health, Poland

\section{POLYPYRAZOLYLBORATE COMPLEXES OF THE LANTHANIDES: STRUCTURE, OPTICS AND MATERIALS SCIENCE \\ Doctor Roman Kresinski}

Senior Lecturer of the Materials Research Group, School of Life Sciences, Pharmacy and Chemistry, Kingston University, United Kingdom 


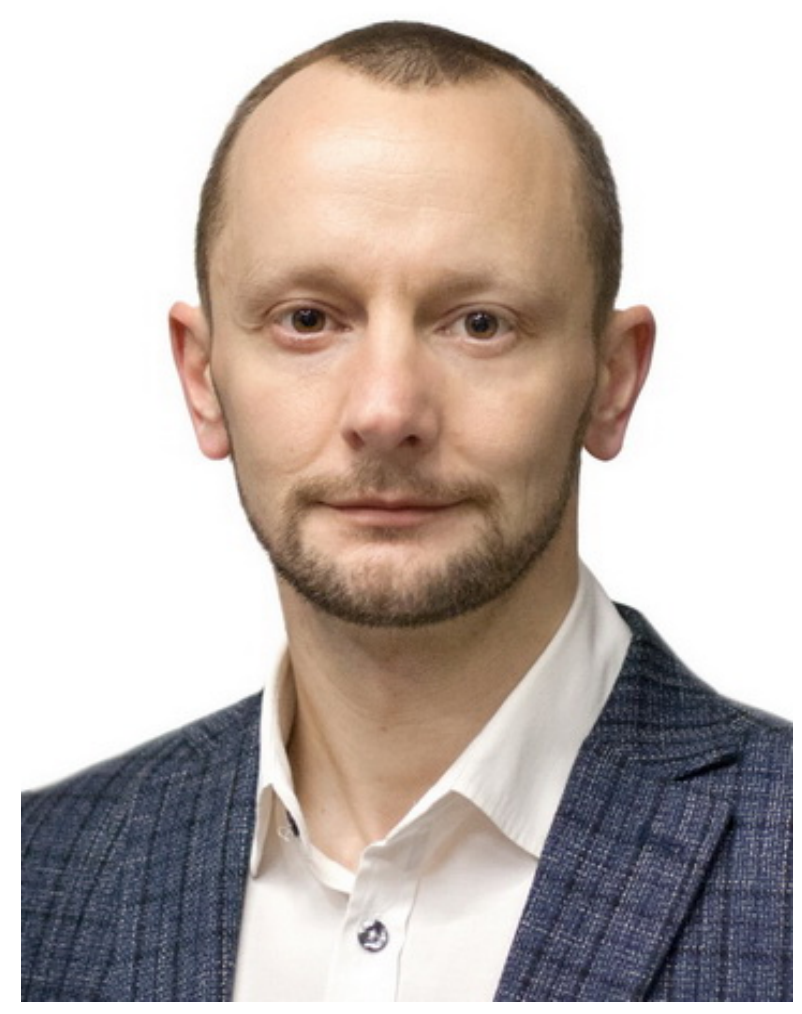

\section{SE-DRIVEN MICROGEL CATALYSTS FOR OXIDATION PROCESSES}

\section{Doctor Roman Nebesnyi}

Head of Research and Development

Department, Lviv Polytechnic

National University, Ukraine

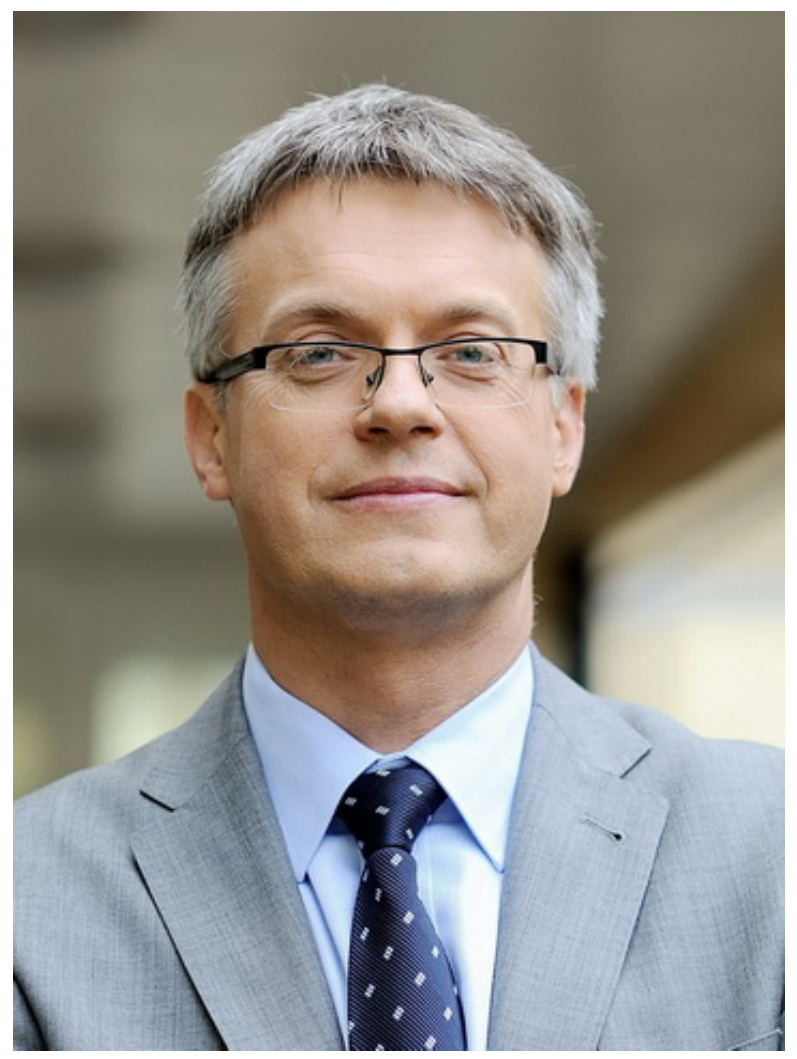

\section{LIQUID ATOMIZATION PROCESS IN} MEDICAL APPLICATIONS

\section{Professor Tomasz Sosnowski}

Vice-Dean for Scientific Research of the Faculty of Chemical and Process Engineering,

Warsaw University of Technology, Poland 


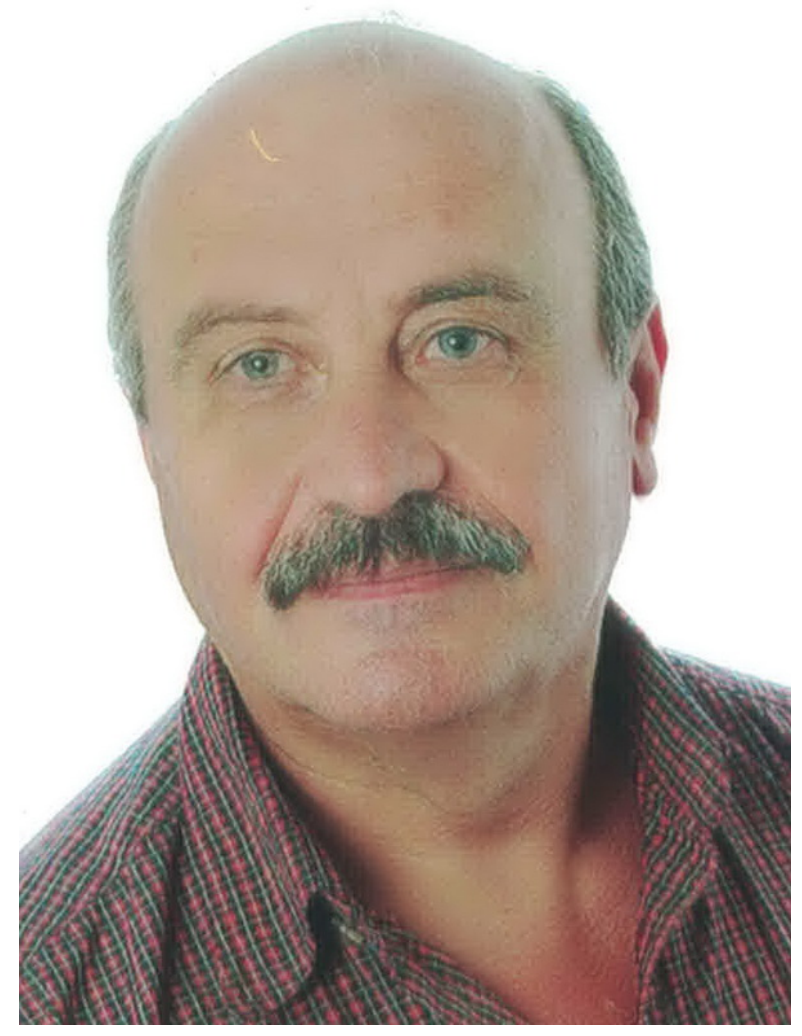

THE POLYURETHANE RECYCLING Applied Professor Wolodymyr Suprun Project Leader, Institute of Chemical Technology, University of Halle, Germany

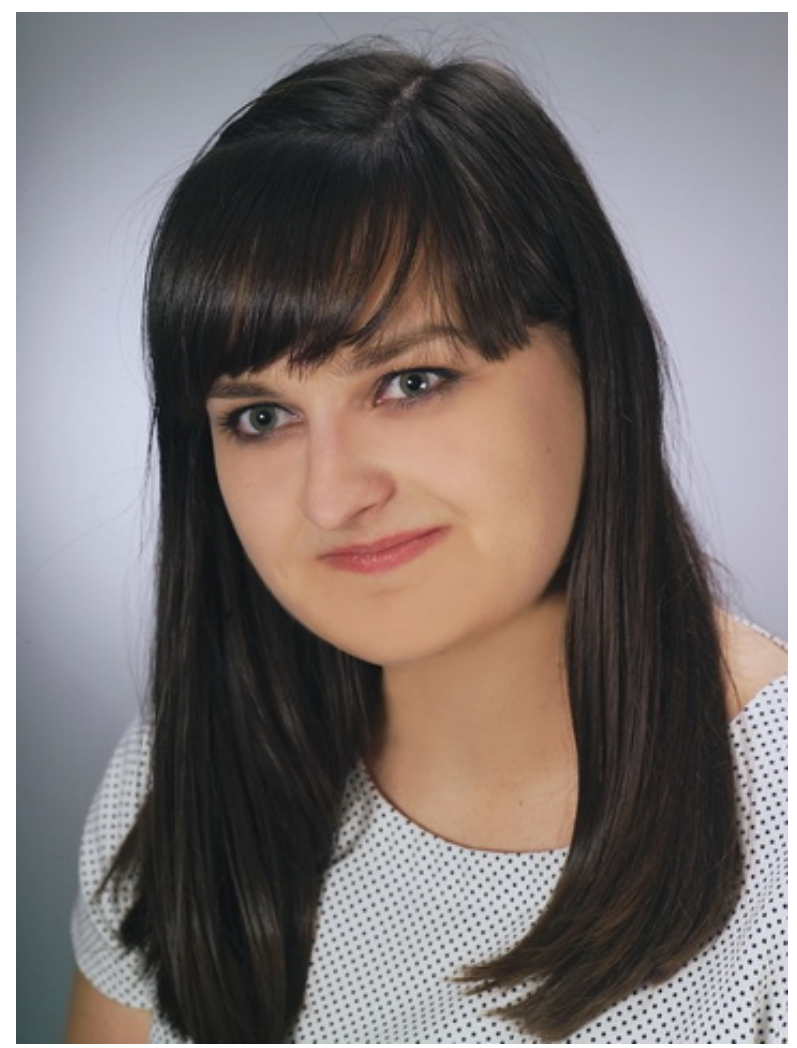

\section{SUPERCRITICAL CO2 EXTRACTION AS GREEN WASTE-FREE TECHNOLOGY - APPLICATIONS AND PERSPECTIVES}

\section{Doctor Katarzyna Tyśkiewicz}

Head of Supercritical Extraction Department, Łukasiewicz Research Network - New Chemical Syntheses Institute, Poland 


\section{YOUNG CHEMIST'S SCHOOL PRESENTATIONS}



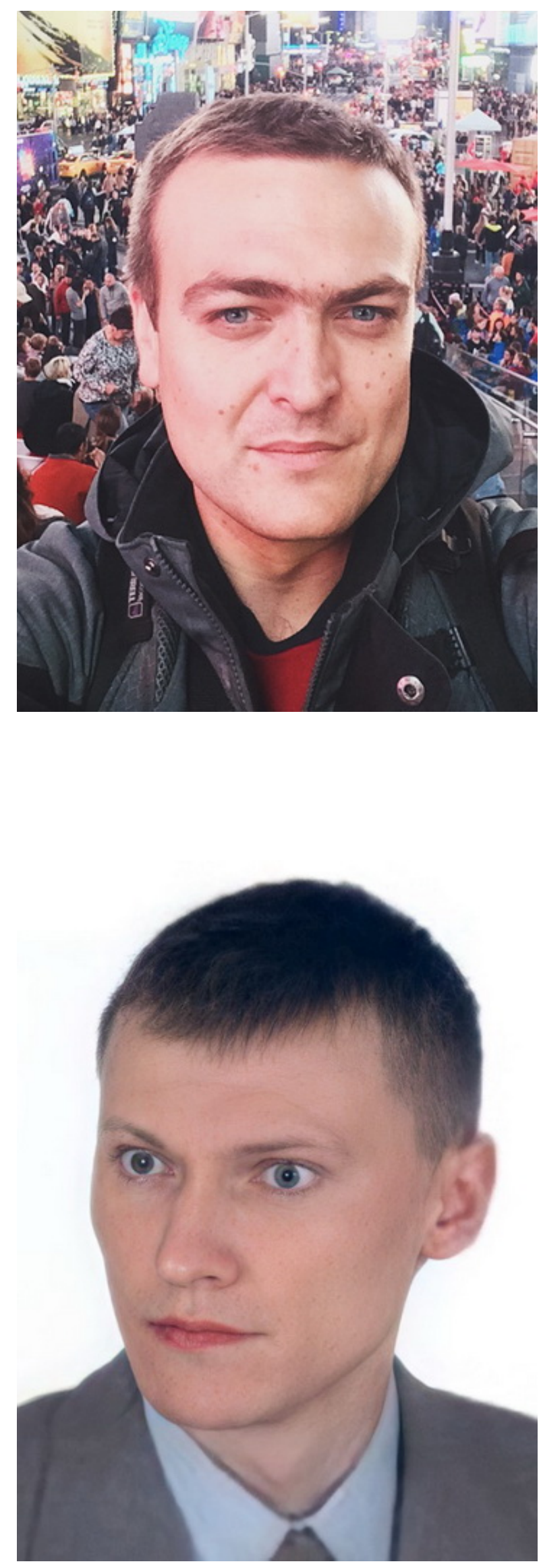

OPEN SCIENCE FOR EARLYCAREER RESEARCHERS

\section{Doctor Oleksandr Berezko}

General Board Member at Eurodoc, Lviv Polytechnic National University, Ukraine

\section{LAW AS A GUARANTOR OF HEALTH SAFETY IN THE CONTEXT OF THE APPLICATION OF INNOVATIVE TECHNOLOGIES IN THE CHEMICAL AND FOOD INDUSTRY}

\section{Professor Wojciech Lis}

Faculty of Law, Canon Law and Administration, John Paul II Catholic University of Lublin, Poland 


\section{THE CONFERENCE'S ORGANIZERS}



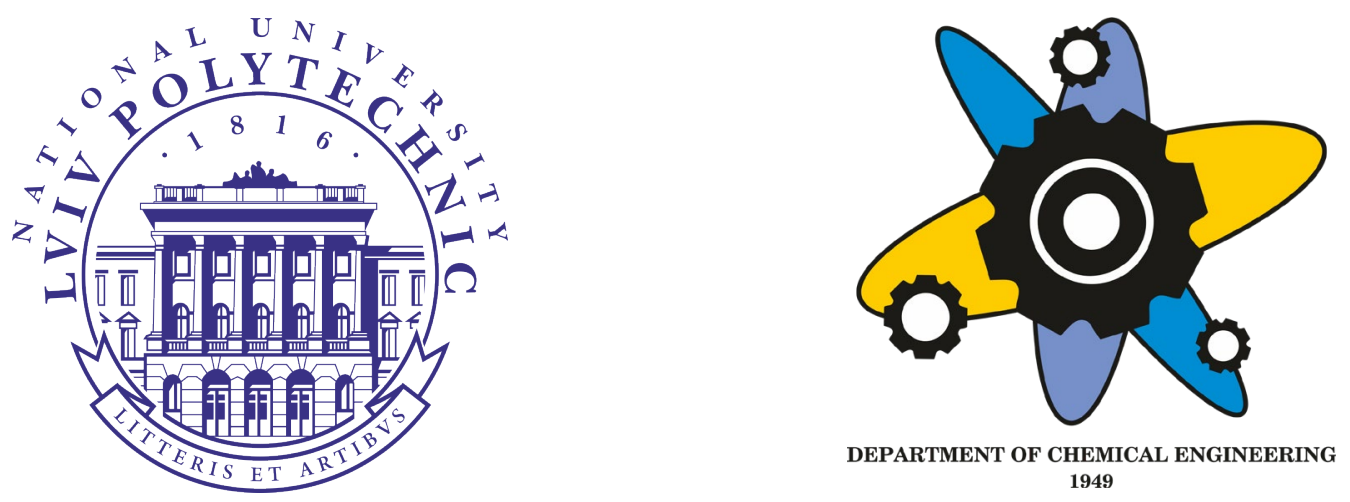

\section{Lviv Polytechnic National University}

\section{The Department of Chemical Engineering}

79013, Ukraine, Lviv, St.Yura sqr., 9/108, $9^{\text {th }}$ academic building of Lviv Polytechnic National University

E-mail: khi.dept@1pnu.ua

Tel: +38 (032) 258-26-57

www.Ipnu.ua

www.Ipce.Iviv.ua

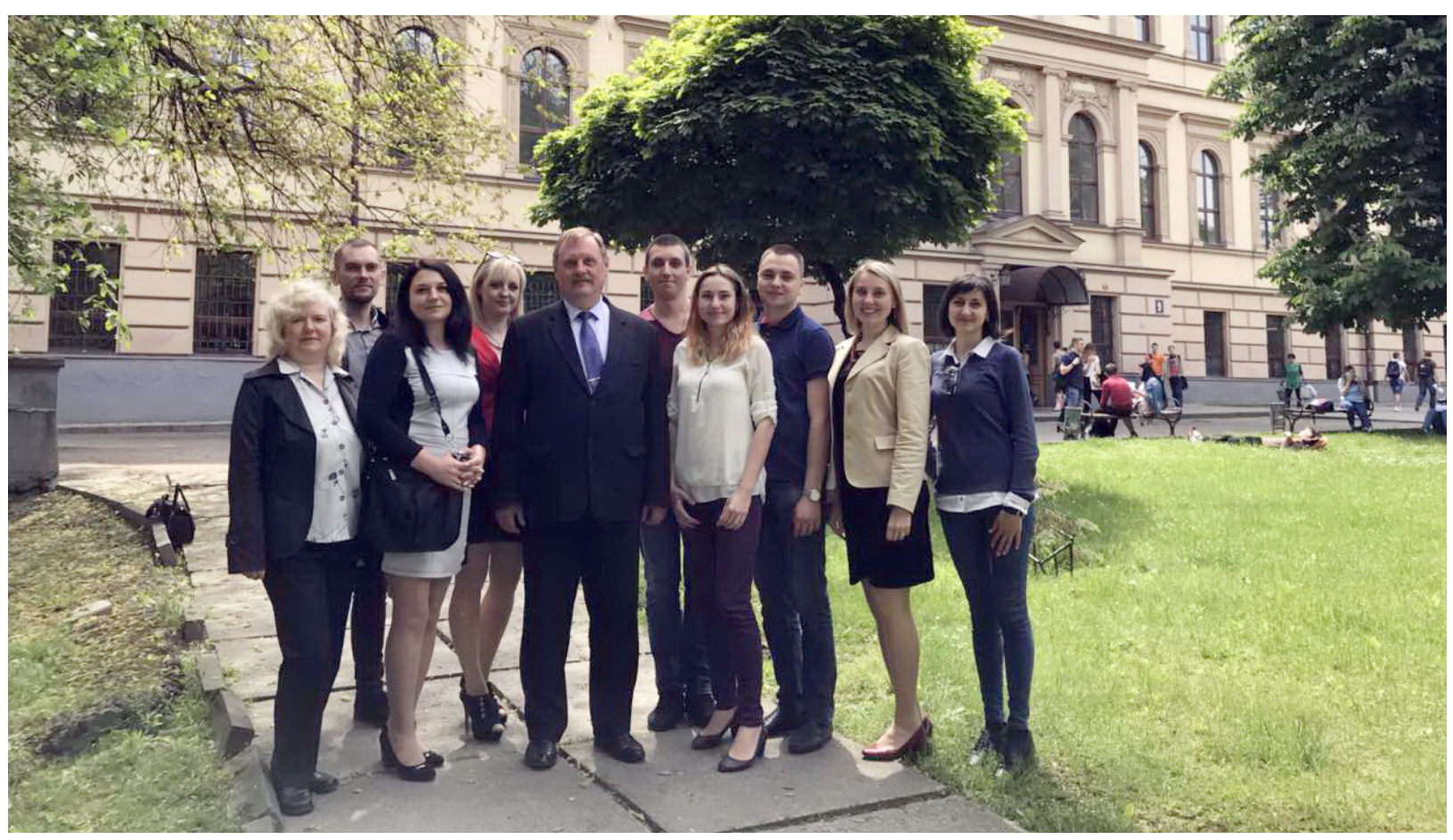

Department of Chemical Engineering of Lviv Polytechnic National University originates from 1949. Research of the Department of Chemical Engineering have been formed into a scientific school of mass transfer in systems with solid and liquid phases, study of the treatment processes of gas and liquid environments of solid impurities, mathematical and computer modeling of the basic processes of chemical technology. 
The Department provides training of the specialists in «Equipment of chemical industries and enterprises of building materials», «Processes and equipment of chemical plants» and «Computerical chemical engineering».

In recent years the Department has been actively developing a new line of work that is associated with numerical modeling of the chemical technology processes. Using advanced software for CFD-modeling, the Department prepares solid 3D-models of the objects with visualization of the research results in the form of change of the field of experimental values, trajectory of phase flows, graphs, tables etc.

CFD simulation covers the full range of tasks that arise in the design, modernization and analyze of the equipment of chemical, food, pharmaceutical industries and the industry of the building materials production.

\section{Areas of research projects}

- $\quad$ solid materials drying

- filtration drying of the porous and dispersed materials

- $\quad$ spray drying of solutions, suspensions and pastes

- cleaning of gas emissions of dust and the gas separation of heterogeneous systems

- processing of dispersed materials in swirling flows (drying, annealing, chemical treatment)

- optimization of heat in the industrial processes

- optimization of hydrodynamics and heat transfer in industrial installations - designing of the technology systems (software simulation: SOLIDWORKS, ANSYS FLUENT)

- $\quad$ CFD-modeling 


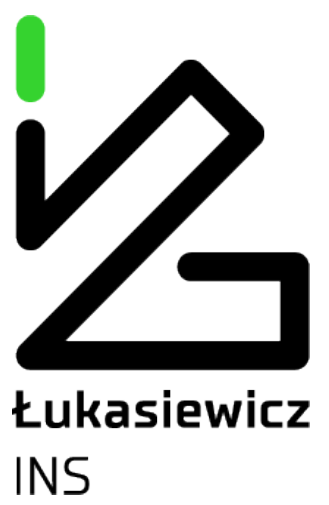

\section{Lukasiewicz Research Network - New Chemical Syntheses Institute}

24-110, Poland, Pulawy, Tysiaclecia Panstwa Polskiego av.13A

E-mail: sekretariat@ins.pulawy.pl

Tel.: +48 814731400

Fax.: +48 814731410

www.ins.lukasiewicz.gov.pl

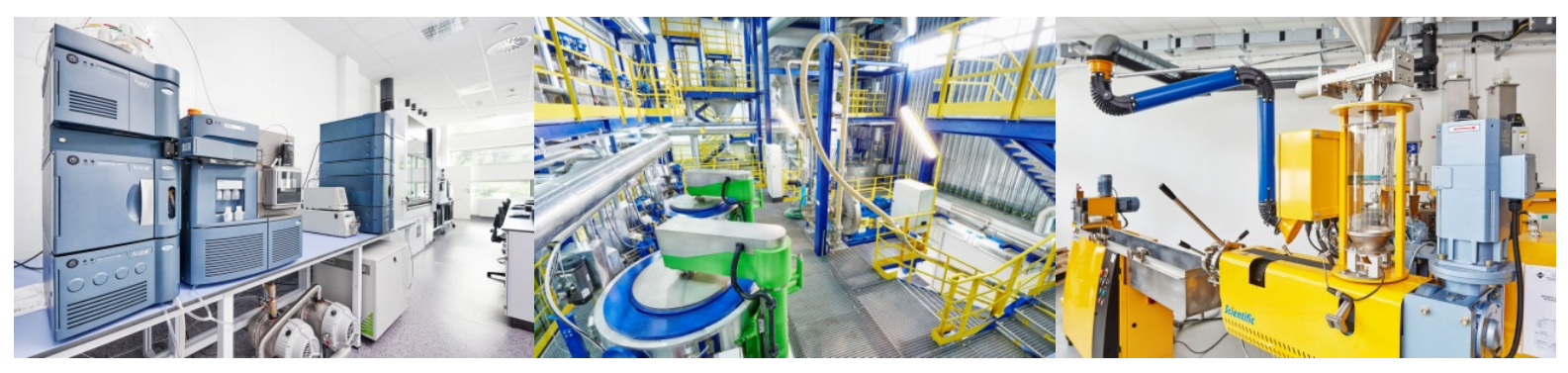

Łukasiewicz Research Network - New Chemical Syntheses Institute (Sieć Badawcza Łukasiewicz - Instytut Nowych Syntez Chemicznych) seated in Puławy, Poland is a state research institute with a long lasting tradition, good reputation and well known trade mark. Since 2019, it has been incorporated into the Polish Łukasiewicz Research Network - Europe's third largest research network integrating 32 research institutes located in 12 cities in Poland.

The principal aim of the Institute is work for chemical industry, mainly its fertilizer and inorganic branches, which leads to making innovations and higher competitiveness of companies operating in chemistry and chemical technology areas. Łukasiewicz - INS carries out research and development work in close partnership with industry employing high qualified staff and maintaining the highest standards applying to research methods and procedures. It has the unique advantage of carrying research works in pilot plants and directly on industrial plants. The Institute co-operates with all fertilizer producers in Poland and many abroad. This fruitful cooperation resulted in numerous licenses sold i.e. to Russia, Germany, Bulgaria, Czech Republic, Croatia, Ukraine, Belarus, and Hungary. Our catalysts are purchased worldwide by 18 countries, including Columbia, Chile, and USA.

In recent years, Łukasiewicz - New Chemical Syntheses Institute has developed 'green' studies in the field of bioeconomy such as supercritical extraction of plant raw materials using supercritical carbon dioxide, biodegradable polymers or environmentally friendly smart fertilizers. 


\section{Research and development}

- $\quad$ production and purification technologies of syngas, $\mathrm{H}_{2}, \mathrm{CO}_{2}$

- $\quad$ chemical technologies regarding ammonia, nitric acid and its salts

- reductions in emissions of nitrogen oxides, $\mathrm{NO}_{\mathrm{x}}$ and $\mathrm{N}_{2} \mathrm{O}$

- $\quad$ mineral fertilizers and mineral-organic fertilizers

- $\quad$ catalysts, sorbent and inert materials

- $\quad$ supercritical extraction of natural raw materials

- unit operations: granulation, absorption, adsorption, crystallization, filtration

- thermal efficiency optimization of industrial processes

- technologies for recovering useful substances from solid waste, sewage and technologies for disposal of industrial waste

- biodegradable plastics

- $\quad$ additives for synthetic materials including flame retardants and intumescent materials

- $\quad$ phosphate, polyphosphates, phosphoric acid and polyphosphoric acid technologies

- $\quad$ inorganic sodium salts technologies and peroxide compounds technologies

\section{Research services}

- technical assessment of industrial plants

- $\quad$ chemical process design

- $\quad$ expert opinions (fertilizer and inorganic industries)

- micronization

- chemical analyses, environmental research

\section{Experimental production}

- $\quad$ catalysts and sorbents

- $\quad$ hop pellets and hop extracts

- $\quad$ bioactive extracts from plants

- $\quad$ high pressure research apparatus

- $\quad$ chemicals for fertilizer conditioning, impregnation (fire retardants), steel degreasing and steel phosphating 

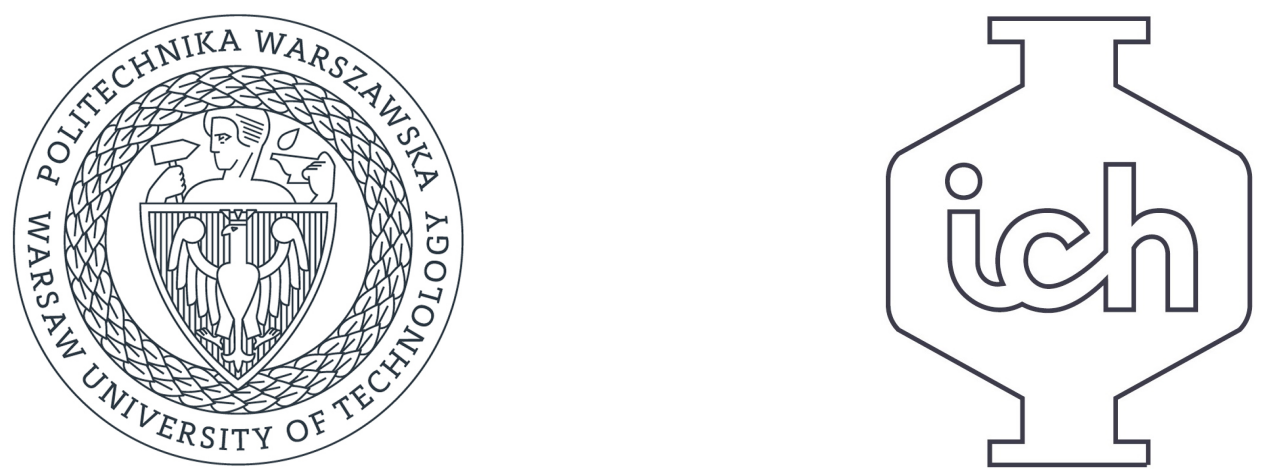

\section{Warsaw University of Technology}

Faculty of Chemical and Process Engineering

00-645, Poland, Warsaw, Waryńskiego str. 1

E-mail: sekretariat@ichip.pw.edu.pl

Tel.: +48222346453

\section{www.ichip.pw.edu.pl}

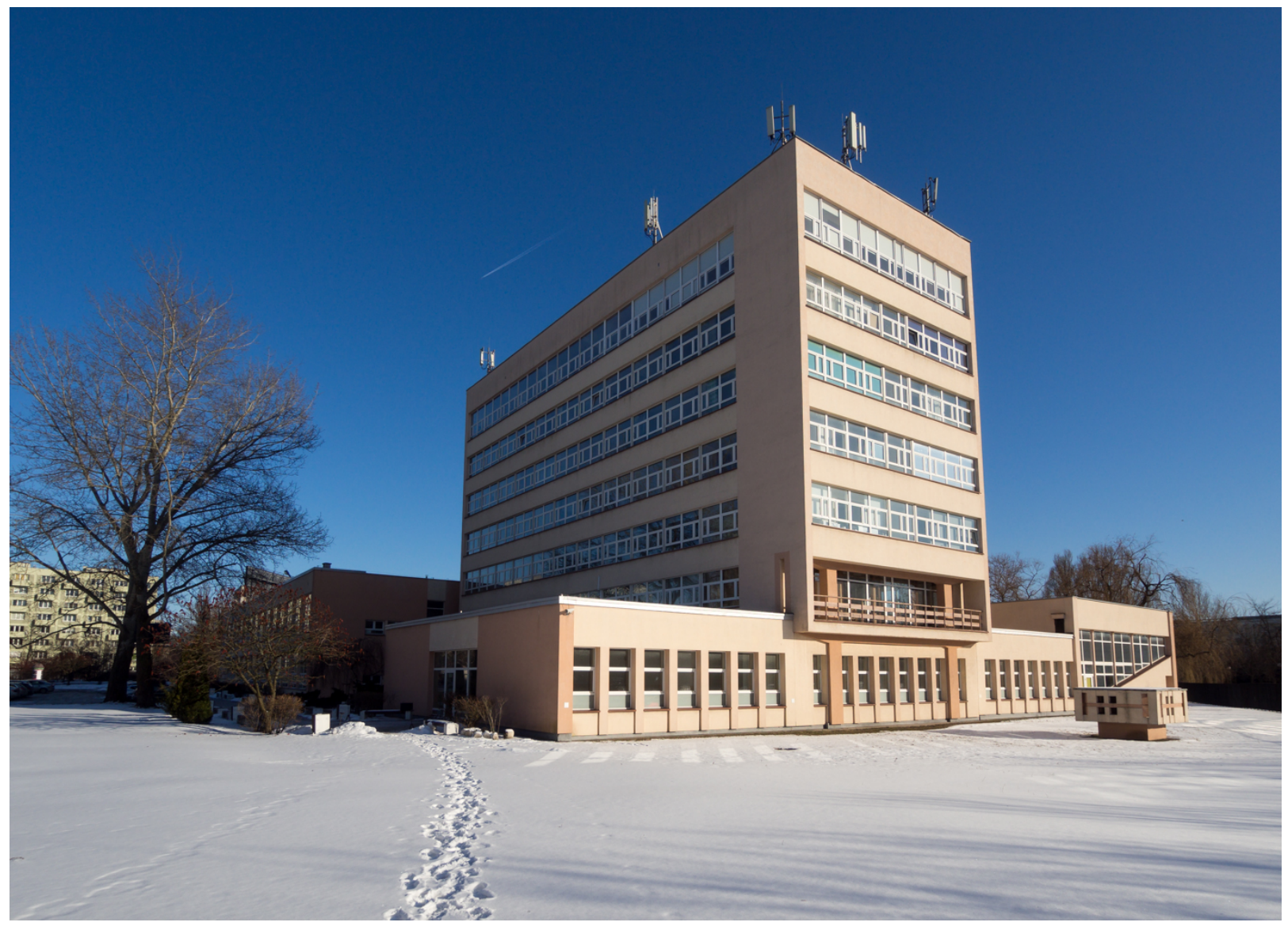

The Faculty of Chemical and Process Engineering, Warsaw University of Technology (FCPE WUT) is the leading academic entity in chemical engineering in Poland, known for high quality in scientific research and student education (B.Sc.Eng., M.Sc., and Ph.D.). In 2021, following the national academic evaluation process (PKA), the Faculty was nominated for the distinction "The Excellence in Academic Education". 
The Faculty celebrated the $50^{\text {th }}$ jubilee in 2020 , commemorated by the monograph "Chemical and Process Engineering for Environment and Health" (ISBN: 978-83-7789-629-7) with contributions from several partner scientific groups from Poland and abroad.

The academic staff of FCPE WUT is formed by 46 persons, with 7 full professors and 10 university professors. Five professors are members of the European Federation of Chemical Engineering (EFCE), and seven professors are members of the Committee of Chemical and Process Engineering of the Polish Academy of Sciences. The Dean of the Faculty in 2020-2024 is prof. Marek Henczka.

The Faculty structure contains one chair (Chair of Integrated Process Engineering) and four departments of: (i) Chemical Reactors Engineering and Dynamics, (ii) Separation Processes, (iii) Process Kinetics and Thermodynamics, and (iv) Biotechnology and Bioprocess Engineering.

\section{Several specialized laboratories are operating within the FCPE WUT:}

- $\quad$ Aerosol Filtration Laboratory (AEROFIL, led by dr Anna Jackiewicz-Zagórska)

- $\quad$ Laboratory of Medical Aerosols and Inhalers (RESPI-LAB: prof. Tomasz Sosnowski)

- $\quad$ Biomedical Engineering Laboratory (BIOMED-LAB: prof. Tomasz Ciach);

- $\quad$ Laboratory of Multifunctional Emulsion Systems (prof. Ewa Dłuska)

- $\quad$ Product Engineering Laboratory, including the Graphene Lab (prof. Łukasz Makowski)

- $\quad$ High Pressure Processing Laboratory (prof. Marek Henczka)

- Membrane Technology Laboratory (prof. Maciej Szwast)

\section{Scientific activities of the Faculty are also related to:}

- nanotechnology and functional materials,

- process intensification (supercritical technology, microwave-assisted processes, high-performance dispersion and mixing, etc.),

- $\quad$ processes for the environment and sustainability,

- experiments and computer simulations of fluid flows, heat and mass transfer, chemical reactors and bioreactors, and other fundamental and technological problems. 


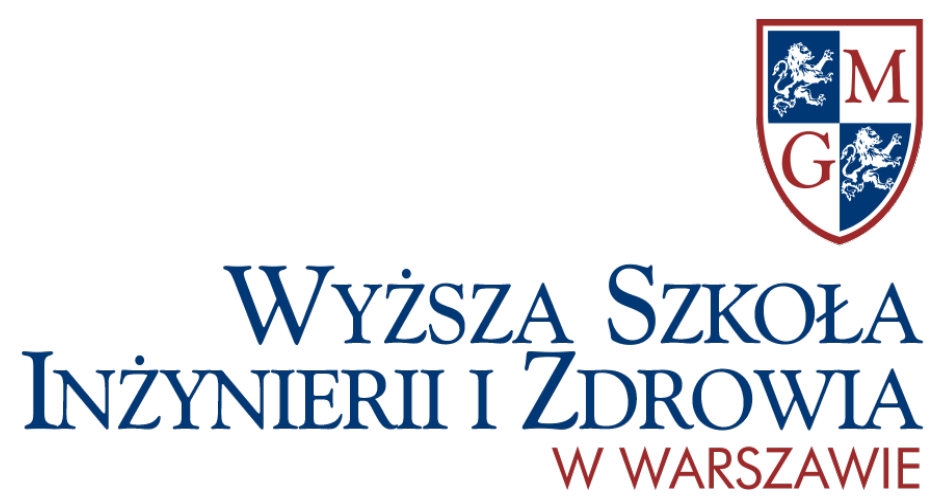

Warsaw College of Engineering and Health

02-366, Poland, Warsaw, Bitwy Warszawskiej 1920 r. str. 18

E-mail: biuro@wsiiz.p1

Tel.: +48226678290

www.wsiiz.pl

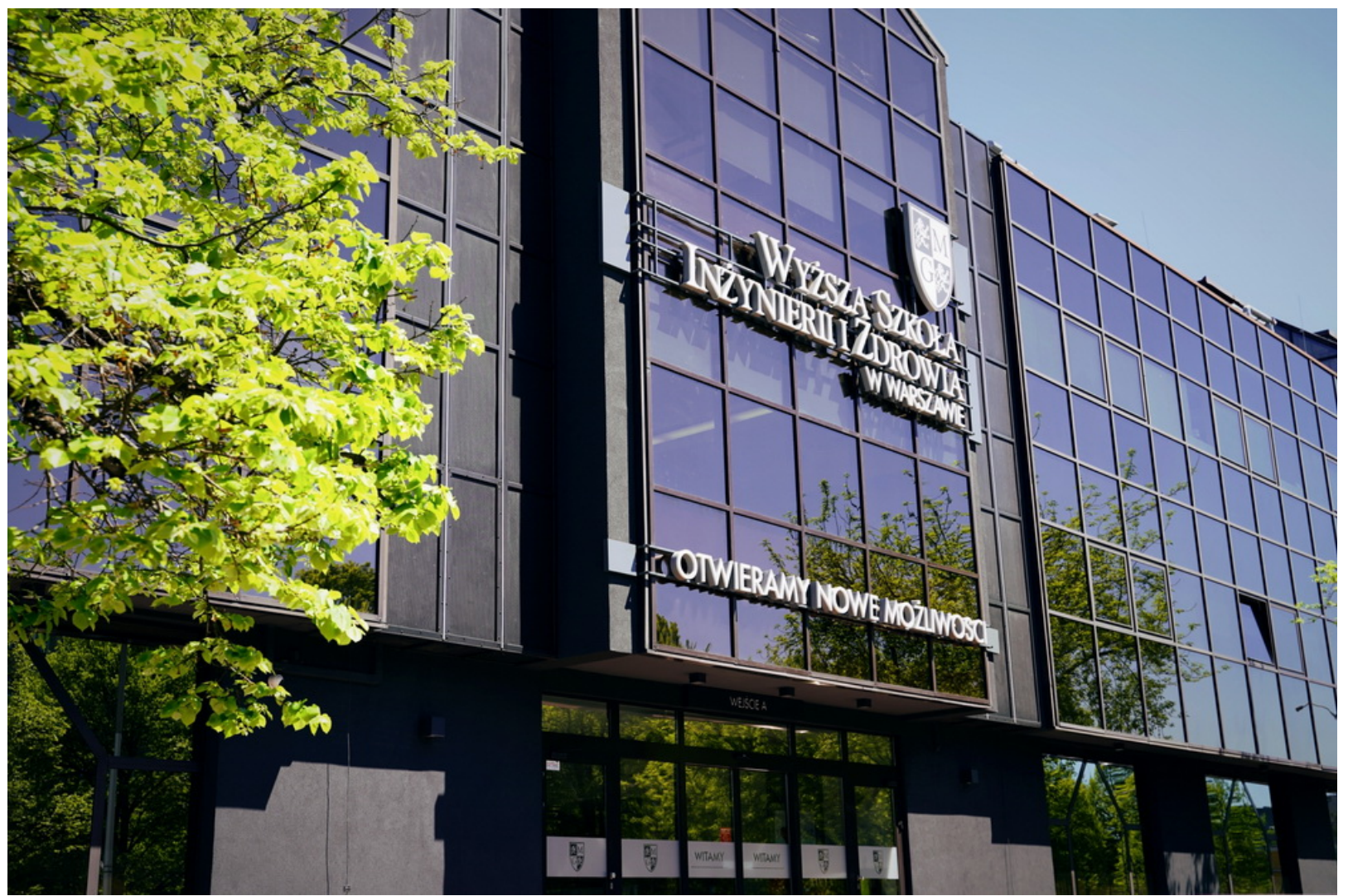

Warsaw College of Engineering and Health is a private higher education institution, existing since 2003, educating at undergraduate, engineering, master and postgraduate studies. The mission of the school is professional training of highly qualified staff in accordance with the needs of the developing economy of the country and uniting Europe. We create a university that:

- creates material and intellectual conditions for development and education of qualifications that meet the needs of the market

- gives graduates preparation and support to find a good job

- creates satisfactory working and development conditions as well as support for the 
implementation of scientific research

- serves the region's community through active participation in the development of the region, science and culture

In addition, the University is working on the organization of guest lectures of academic teachers from partner universities. The topics of the lectures will focus on the exchange of experiences as well as learning the specificity of teaching in other European countries.

In the context of the development of international cooperation, the University is aware of the necessity to launch mechanisms supporting activities aimed at increasing the attractiveness of studying foreign students in Warsaw College of Engineering and Health and facilitating international exchange of students and university staff. The program of these activities is constantly modified. 

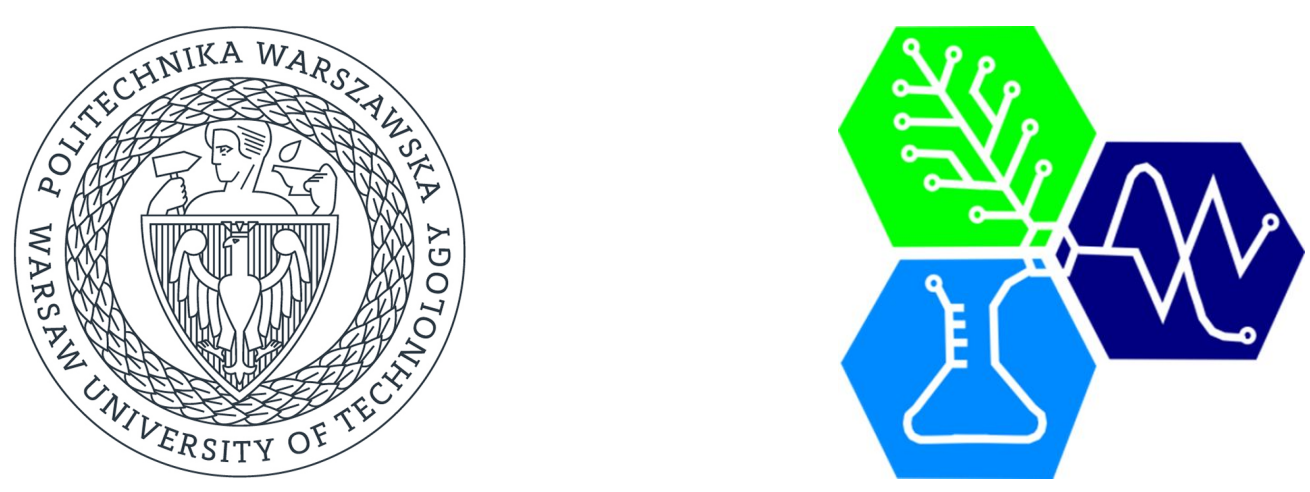

\title{
Warsaw University of Technology
}

\section{Department of Informatics and Environment Quality Research}

\author{
00-653, Poland, Warsaw, Nowowiejska str. 20 \\ E-mail: artur.badyda@pw.edu.pl \\ Tel: +48222345950
}

The Department was established in 2007, as a result of a change in the organizational structure of the Faculty of Environmental Engineering of the Warsaw University of Technology, by merging the Department of the Application of Mathematical Methods and Department of Environmental Chemistry. Currently the activities of the Department are carried out in three main areas around which there are teams concentrated at:

1. Environmental Informatics and Environmental Protection Management

a. Environmental Informatics deals with the research and development of methods for creating, transmitting, storing, processing, modeling, interpretation, presentation and dissemination of data and information for solving environmental problems in the process of investment preparation and implementation. Environmental Information Technology is also used to support environmental management in industrial activities, including the impact of rational use of energy, water, raw materials, waste management and emission control in the production process on the competitiveness of the product on the market;

b. Environmental Protection Management is conducted both at the level of management in the processes of infrastructure development, management in enterprises, as well as management in local governments units, with particular emphasis on urban agglomerations. It includes the preparation of Strategic Environmental Assessments for policies, plans and programs as well as Environmental Impact Assessments for different projects. The activities of the Department are also related to the nature of social conflicts resulting from the development of infrastructure, design and implementation of social consultancy programs accompanying the procedures of preparation of investments implementation, as well as protection of residents against various nuisances of the urban environment.

2. Statistics and Remote Research of the Environment 
a. Statistics and Geostatistics are modern methods of classical and spatial statistics used to solve various problems related to environmental research, including those regarding cost reduction and rationalization of these surveys. The research area of the Team is exploratory analysis of environmental data: studies of variability and spatial correlation, methods of estimation and simulation of spatial distributions, optimization of measurement networks, resource estimation, uncertainty assessment. In particular, the Team's interests include the issue of spatial integration of various environmental data;

b. Remote Research of the Environment uses various types of satellite images from different types of satellites to observe the Earth's surface, for example, soil moisture or changes in the forest cover. Remote tests are used for quick monitoring of large areas, which would be almost impossible to test using classical measurement methods.

3. Environmental Chemistry

a. Water and Wastewater research include chemical tests of waters, sewage and sludge in the scope of basic pollution indicators, research on methods of removing hard-todecomposable, toxic, anthropogenic organic pollutants from sewage, based on highly efficient oxidation processes and electrooxidation;

b. Metals Research in the Environment includes determination and speciation of metals in water, sewage, bottom sediments, soil and atmospheric air, testing of metal migration in all elements of the environment, including penetration of metals into plants;

c. Research on Organic Micropollutants includes determination of microgram, anthropogenic, water pollution, sewage, sediments and soils (petroleum hydrocarbons, PAHs, polychlorinated biphenyls and organotin compounds).

There are currently 20 people working at the Department. The academic staff include 1 full professor, 2 associate professors, 7 assistant professors and 2 assistants. In addition the Department employs 4 senior lecturers and 4 administrative and technical employees. 


\section{COMPUTER SIMULATION IN THE CHEMICAL TECHNOLOGY AND ENGINEERING}




\title{
The use of a porous medium method for modeling fixed-bed reactors with a low tube-to-particle diameter ratio
}

\author{
Tymoteusz Świeboda, Renata Krzyżyńska, Anna Bryszewska-Mazurek, \\ Wojciech Mazurek
}

Faculty of Environmental Engineering, Wroclaw University of Science and Technology, POLAND, Wrocław, 27 Wybrzeze Wyspianskiego St., E-mail: tymoteusz.swieboda@pwr.edu.pl

\begin{abstract}
The paper presents a method of modeling fixed-bed reactors based on the porous medium with an anisotropic thermal conductivity coefficient. The calculation results of the pressure drop and heat transfer of the simplified models were compared to the reference models results. As a comparative criterion, it was proposed to use area-weighted average pressure and mass-weighted average temperature.
\end{abstract}

Keywords - fixed-bed reactor, porous media, anisotropic thermal conductivity coefficient.

\section{Introduction}

Fixed-bed reactors are used in a wide range of technological processes, such as separation, purification, and chemical reactors. Among them, a special place is occupied by the devices with a low tube-to-particle diameter ratio $(N<10)$. While creating a computational mesh based on geometries special attention should be paid to the areas in the vicinity of the contact points of the bed elements $[1,2]$.

The porous medium seems to be an appropriate tool for modeling the fixed-bed reactors in engineering applications. This work presents a method to compensate for the impact of wall effects and local back-flows, which, at devices with small values of the tube-to-particle-diameter ratio $(N)$, severely affect the heat flow.

\section{Methods}

The starting point for the described procedure was the reactor described in [3], in the shape of a cylinder in $20 \mathrm{~mm}$ in diameter filled with glass spheres $\left(\lambda=1.1 \mathrm{~W} \cdot \mathrm{K}^{-1} \cdot \mathrm{m}^{-1}\right)$. The outer walls of the reactor were heated up to $400^{\circ} \mathrm{C}$ and its inlet was fed from the top with air at $60^{\circ} \mathrm{C}$.

a)

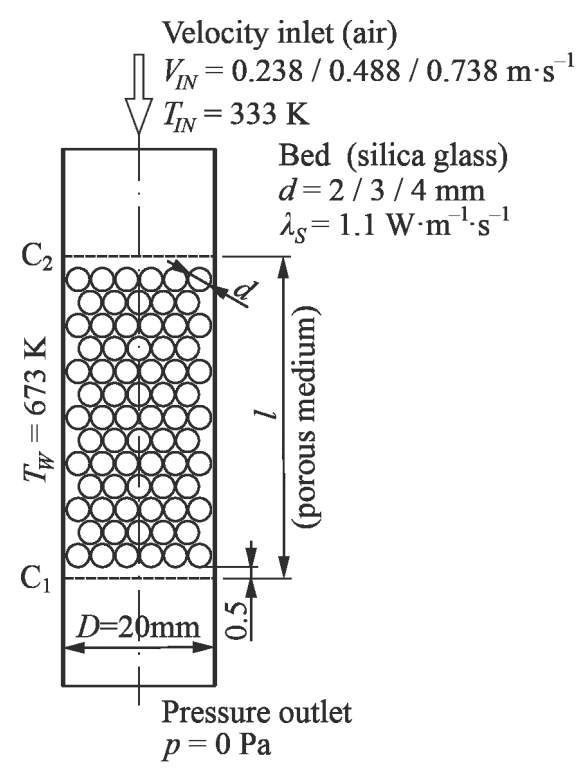

b)

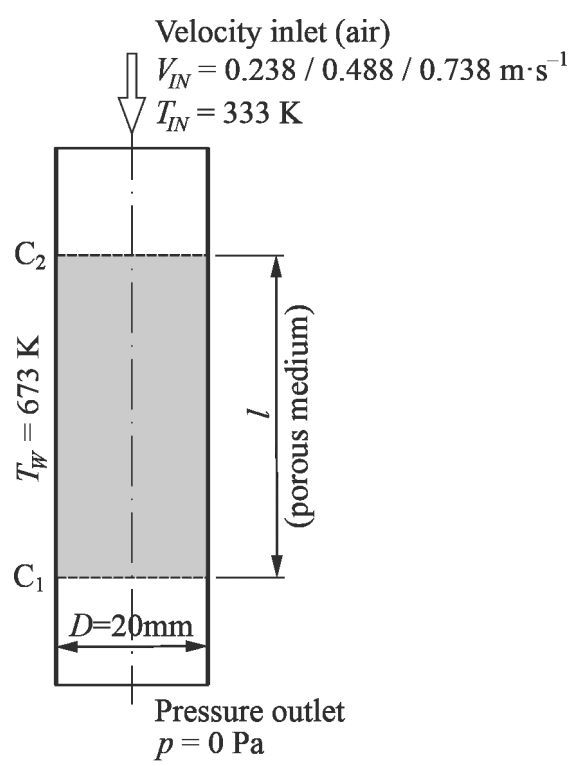

Fig. 1. Schematic of modeled fixed-bed reactor: a) reference model, b) simplified model 
Two sets of geometries were prepared for simulations. The first one consisted of nine variants of detailed bed geometries to use as reference models. The variants differed in the diameters of the filling spheres $(\mathrm{d}=2,3$ and $4 \mathrm{~mm})$ and the number of layers of the spheres $(5,9$ and 13) details in Fig. 1a. The second set contained nine variants of simplified geometries in which zones were dedicated to the porous medium. The length of each zone corresponded to the bed height in the reference model (see Fig 1b).

The area-weighted average (AWA) pressure and mass-weighted average (MWA) temperature were defined to enable the comparison of results from both model sets in planes $\mathrm{C}_{1}$ and $\mathrm{C}_{2}$.

$$
\begin{aligned}
& A W A(\phi)=\frac{1}{A} \int \phi d A=\frac{1}{A} \sum_{i=1}^{n} \phi_{i}\left|A_{i}\right| \\
& M W A(\phi)=\frac{\int \phi \varrho|\vec{v} \cdot d \vec{A}|}{\int e|\vec{v} \cdot d \vec{A}|}=\frac{\sum_{i=1}^{n} \phi_{i} e_{i}\left|\vec{v}_{i} \cdot \vec{A}_{i}\right|}{\sum_{i=1}^{n} e_{i}\left|\vec{v}_{i} \cdot \vec{A}_{i}\right|}
\end{aligned}
$$

\section{Results and discussion}

In the first stage, a series of simulations were performed to obtain the distribution of pressure and temperature within the reference model of the bed. For each geometry variant, three simulations were carried out at different inlet air velocities $(0.238,0.488$, and $0.738 \mathrm{~m} / \mathrm{s})$. Obtained pressure drops and air temperature increases calculated between cross-sections $\mathrm{C}_{1}$ and $\mathrm{C}_{2}$ were later used to determine the parameters of the porous medium (internal resistance, viscous resistance).

In the second stage, a series of analogous simulations were performed using simplified models with a standard porous medium. Thus, the second set of AWA pressure drop values and MWA temperature increase values was obtained. Comparing them with the values from reference models showed a satisfactory agreement of the obtained pressure drops (the discrepancies did not exceed $20 \%$ - in most cases below 13\%). It was different in the case of the air temperature increase values within the bed: simplified models gave results up to $200 \%$ higher than the corresponding reference models. Most likely these differences were caused by the inhomogeneous flow field within the bed including anomalies such as channelling, wall effects, local back-flows that occurred in the vicinity of the heated walls of the reactor.

a)

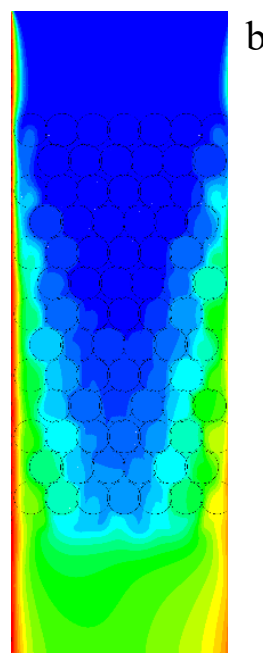

b)

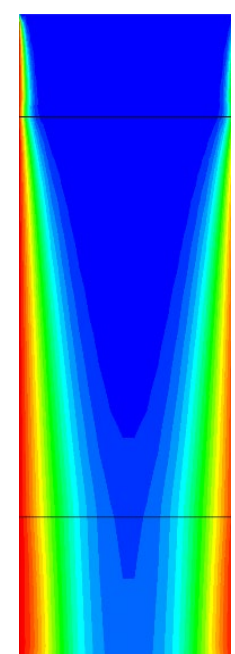

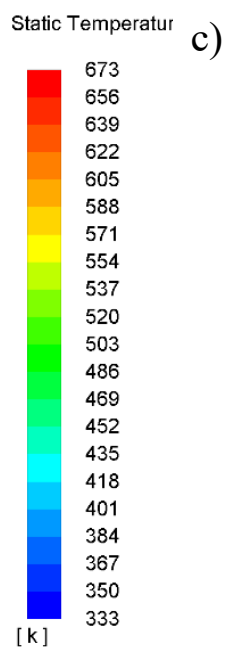

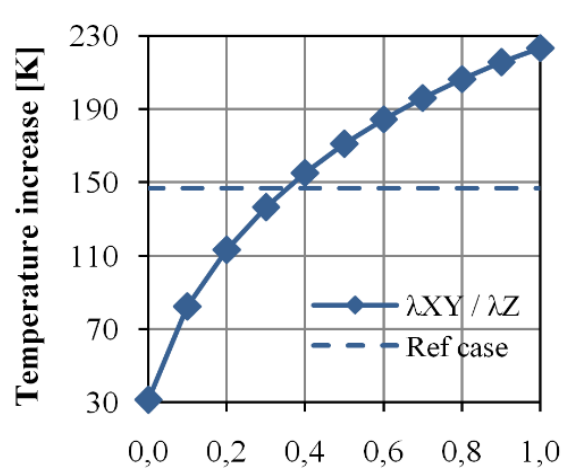

Relative thermal conductivity (in direction normal to flow)

Fig. 2. Comparison of exemplary temperature field simulation results: a) reference and b) simplified model temperature field, c) $\mathrm{C}_{1}-\mathrm{C}_{2}$ temperature increase error

Taking into account the nature of the anomalies described, the simplified models incorrectly reproduced the heat exchange in the direction perpendicular to the general direction 
of the fluid flow. Therefore, it was proposed to introduce into the porous medium an anisotropic thermal conductivity coefficient. Reducing the value of its perpendicular components (relative values in range $0.12-0.28$ of the nominal value of the component in the flow direction - Fig. 2) made it possible in each case under consideration to obtain full compliance of the MWA temperature increase in the simplified model with the results of the reference model. The detailed results comparison is shown in Fig. $3 \mathrm{a}-\mathrm{c}$.

a)

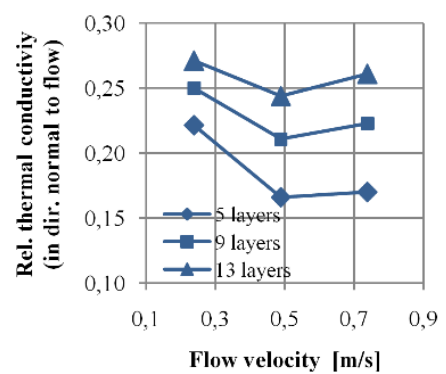

b)

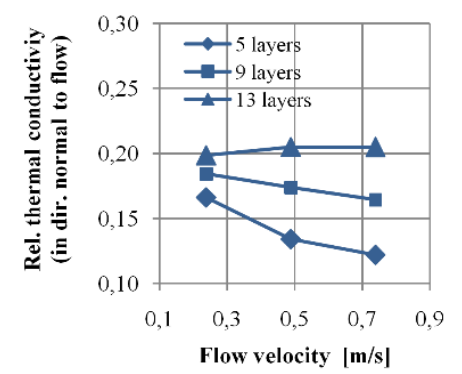

c)

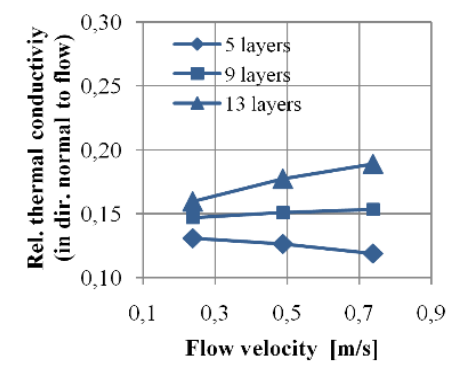

Fig. 3. Relative transverse thermal conductivity of porous medium as a function of air flow velocityfor a bed containing balls with a diameter of: a) $2 \mathrm{~mm}$, b) $3 \mathrm{~mm}$, c) $4 \mathrm{~mm}$

\section{Conclusion}

Models of fixed-bed reactors based on the standard porous medium method allow obtaining satisfactory consistency of results concerning pressure losses. Significant improvement of accuracy of determination of average outlet temperature can be obtained by using the proposed in this paper anisotropic thermal conductivity method. For model validation, the areaweighted average pressure and mass-weighted average temperature were chosen as comparison parameters.

\section{Acknowledgments}

This work was financed from project WND-POWR.03.02.00-00-I003/16-01 "InterDok Interdisciplinary Doctoral Studies Programs at the Wroclaw University of Science and Technology"

\section{References}

[1] Rebughini, S., Cuoci, A., Maestri, M. (2016). Handling contact points in reactive CFD simulations of heterogeneous catalytic fixed bed reactors. Chemical Engineering Science, 141, 240-249. https://doi.org/10.1016/j.ces.2015.11.013

[2] Dixon, A. G., Nijemeisland, M., Stitt, E. H. (2013). Systematic mesh development for 3d CFD simulation of fixed beds: Contact points study. Computers Chemical Engineering, 48, 135-153. https://doi.org/10.1016/j.compchemeng.2010.12.006

[3] Dong Y., Sosna B., Kroup O., Rosowski F., Horn R. (2017). Investigation of radial heat transfer in a fixed-bed reactor: CFD simulations and profile measurements. Chemical Engineering Journal, 317, 204-214. https://doi.org/10.1016/j.cej.2017.02.063 


\section{Computer prediction of biological activity of 1,2,4-triazole derivatives of 1,4-naphthoquinone}

Nataliia Polish, Oleksii Kurylo, Andriy Karkhut, Lesya Zhurakhivska, Nataliia Marintsova

Department of Technology of Biologically Active Compounds, Pharmacy and Biotechnology, Lviv PolytechnicNational University, UKRAINE, Lviv, S. Bandery st., 12, E-mail: polishn@ukr.net

Abstract - Promising directions of experimental research of 1,2,4-triazole-containing 1,4naphthoquinone derivatives biological activity using preliminary computer prediction with the PASS Online and GUSAR programs were found.

Keywords - 1,2,4-triazole-containing derivatives of 1,4-naphthoquinone, biological activity, toxicity, PASS Online, GUSAR.

\section{Introduction}

Today, the use of computer prediction methods is an important step in the initial stage of searching for biologically active compounds. Thus, in silico methods make possible to plan experimental biological research, chemical synthesis and accelerate the search and development of new drugs.

It is known that 1,4-naphthoquinones and 1,2,4-triazole derivatives are potential biologically active compounds with a broad spectrum of action [1]. That is why research on the synthesis of compounds containing both 1,2,4-triazine or 1,2,4-triazole moiety and quinoid linkage system is of great interest, and the use of PASS Online and GUSAR programs will help to achieve the most effective results in a short period of time.

\section{Discussion of results}

The following 1,2,4-triazole-containing derivatives of 1,4-naphthoquinone were selected asresearch objects:

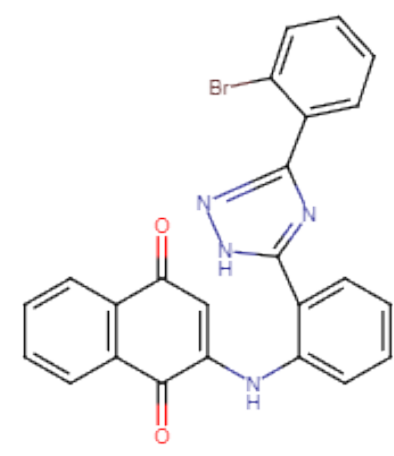

1a

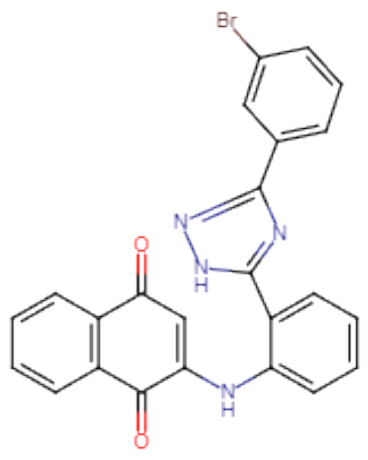

$1 b$

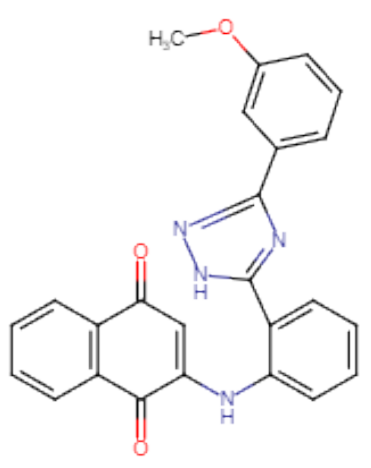

$1 \mathrm{c}$

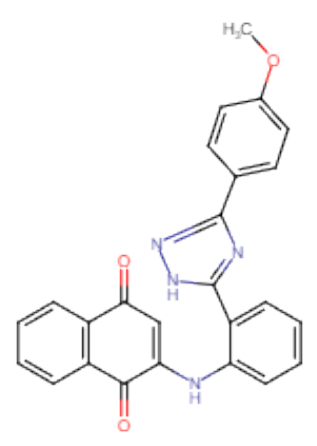

1d<smiles>O=C1C=C(Nc2ccccc2-c2nc(-c3ccccc3Cl)n[nH]2)C(=O)c2ccccc21</smiles>

$1 \mathrm{e}$ 
To plan the direction of experimental studies of the 1,2,4-triazole-containing derivatives of 1,4- naphthoquinone biological activity, we used prediction with the computer program PASS (Prediction of Activity Spectra for Substances) [2], which provides simultaneous prediction of many types of biologicalactivity based on the structure of organic compounds. As a result of screening, it was found that all ourcompounds (1a-e), with a probability of $\mathrm{Pa}>0.7$, have anticancer activity, and therefore are promising objects for further research. Also 1,2,4-triazole-containing naphthoquinone derivatives (1a-e) with a probability of $\mathrm{Pa}>0.8$ are inhibitors of histidine kinase and can be promising antimicrobial drugs.

Using the free web service (http://www.pharmaexpert.ru/GUSAR/AcuToxPredict/) we conducted acute rodent toxicity modeling QSAR, implemented in GUSAR software [3]. The LD $_{50}$ value is one of theimportant characteristics of acute toxicity, which corresponds to a dose that causes $50 \%$ mortality within 24 hours after administration of the substance. Acute toxicity determined by external, oral or inhalation administration is an important parameter for assessing the overall toxicological risk, while acute toxicity by intraperitoneal and intravenous administration is an important parameter for drug development.

It was found that 1,2,4-triazole-containing naphthoquinone derivatives (1a-e) probably belong to low-toxic drugs (toxicity class 4,5 ). Compounds (substances) $1 \mathrm{a}$ and $1 \mathrm{~b}$ by the intraperitoneal route of administration proved to be probably non-toxic. The obtained results testify to the high expediency of searching for new antitumor drugs among the studied naphthoquinone derivatives (1a-e).

Table 1

Predicted acute toxicity of synthesized 1,2,4-triazine containing 1,4-naphthoquinone derivatives to rats

\begin{tabular}{|c|c|c|c|c|c|c|c|c|}
\hline \multirow{2}{*}{ 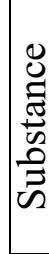 } & \multicolumn{2}{|c|}{$\begin{array}{l}\text { Intraperitoneal route of } \\
\text { administration }\end{array}$} & \multicolumn{2}{|c|}{$\begin{array}{l}\text { Intravenous route of } \\
\text { administration }\end{array}$} & \multicolumn{2}{|c|}{$\begin{array}{l}\text { Oral route of } \\
\text { administration }\end{array}$} & \multicolumn{2}{|c|}{$\begin{array}{c}\text { Subcutaneous route of } \\
\text { administration }\end{array}$} \\
\hline & $\begin{array}{c}\mathrm{LD}_{50} \\
(\mathrm{mg} / \mathrm{kg})\end{array}$ & $\begin{array}{l}\text { Classification } \\
\text { of toxicity of } \\
\text { substances* }\end{array}$ & \begin{tabular}{|c|}
$\mathrm{LD}_{50}$ \\
$(\mathrm{mg} / \mathrm{kg})$
\end{tabular} & $\begin{array}{l}\text { Classification } \\
\text { of toxicity of } \\
\text { substances* }\end{array}$ & $\begin{array}{c}\mathrm{LD}_{50} \\
(\mathrm{mg} / \mathrm{kg})\end{array}$ & $\begin{array}{l}\text { Classification } \\
\text { of toxicity of } \\
\text { substances* }\end{array}$ & $\begin{array}{c}\mathrm{LD}_{50} \\
(\mathrm{mg} / \mathrm{kg})\end{array}$ & $\begin{array}{l}\text { Classification } \\
\text { of toxicity of } \\
\text { substances* }\end{array}$ \\
\hline $1 \mathrm{a}$ & 1536,000 & Non Toxic & 120,400 & & 3213,000 & \begin{tabular}{|l|} 
Class 5 \\
\end{tabular} & 1909,000 & \begin{tabular}{|l|} 
Class 5 \\
\end{tabular} \\
\hline $1 b$ & 1579,000 & Non Toxic & 131,000 & Class 4 & 2783,000 & Class 5 & 2263,000 & Class 5 \\
\hline $1 \mathrm{c}$ & 861,700 & Class 5 & \begin{tabular}{|l|}
115,300 \\
\end{tabular} & Class 4 & 1664,000 & Class 4 & 1821,000 & Class 5 \\
\hline $1 d$ & 811,100 & Class 5 & 145,500 & Class 4 & 3306,000 & Class 5 & 1691,000 & Class 5 \\
\hline $1 \mathrm{e}$ & 985,300 & Class 5 & 118,900 & Class 4 & 2579,000 & Class 5 & 1200,000 & Class 5 \\
\hline
\end{tabular}

Note: * Classification of acute toxicity to rodents according to the OECD project

(Organization forEconomic Cooperation and Development).

\section{Conclusion}

Promising areas of experimental biological studies of 1,2,4-triazole-containing naphthoquinone derivatives (1a-e), based on the results of biological activity screening with use of a computer systemPASS and toxicity were found.

\section{References}

[1] Polish, N.V., Marintsova, N.G., Karkhut, A.I., Kovalenko, S.I., Novikov, V.P. (2020). Synthesis of new 1,2,4-triazine- and 1,2,4-triazole-containing 1,4-naphthoquinone derivatives and the study of their biological activity. Voprosy Khimii $i$ Khimicheskoi 
Tekhnologii, 5(132), 73-80. http://dx.doi.org/10.32434/0321-4095-2020-132-5-73-80

[2] Filimonov, D. A., Lagunin, A. A., Gloriozova, T. A., Rudik, A. V., Druzhilovskii, D. S., Pogodin, P. V., \& Poroikov, V. V. (2014). Prediction of the biological activity spectra of organic compounds using the PASS online web resource. Chemistry of Heterocyclic Compounds, 3(50), 444-457. https://doi.org/10.1007/s10593-014-1496-1

[3] Lagunin, A., Zakharov, A., Filimonov, D., \& Poroikov, V. (2011). QSAR modelling of rat acute toxicity on the basis of PASS prediction. Molecular informatics, 30(2-3), 241-250. https://doi.org/10.1002/minf.201000151 


\title{
The Use of Case-Based Reasoning for the Choice of Methods for Cleaning Exhaust Gases from Sulfur and Nitrogen Oxides
}

\author{
$\underline{\text { Yurii Beznosyk }}^{1}$, Liudmyla Bugaieva² \\ 1. The Department of Technical and Software automation, National Technical University of Ukraine "Igor Sikorsky \\ Kyiv Polytechnic Institute”, UKRAINE, Kyiv, 37 Peremohy Ave, E-mail: yu_beznosyk@ukr.net \\ 2. The Department of Technical and Software automation, National Technical University of Ukraine "Igor Sikorsky \\ Kyiv Polytechnic Institute”, UKRAINE, Kyiv, 37 Peremohy Ave, E-mail: bugaeva_1@ukr.net \\ Abstract - At present, artificial intelligence methods are implemented in many computer programs. One \\ such intelligent technique is Case-Based Reasoning (CBR). This approach is proposed by the authors \\ for use in an intelligent system to choose cleaning methods for exhaust gases from nitrogen and sulfur \\ oxides.
}

Keywords - case-based reasoning, case, exhaust gases, intelligent system, indexing, metric.

\section{Introduction}

Case-Based Reasoning (CBR) is an approach that allows to solve a new, unknown problem, using or adapting the solution of an already known problem, ie. using the experience already accumulated in solving such problems. The main concept in CBR is precedent (example, case) - a structured representation of experience in the form of data and knowledge, which provides its further automated processing by specialized software systems. The method of inference on precedents or CBR is considered as one of the approaches of artificial intelligence or data mining.

\section{Case-Based Reasoning}

Let's see how CBR works. The life cycle of a CBR is shown in Fig. 1. Often CBR is called the 4R method [1-3]:

1. Retrieving - search for precedents;

2. Reusing - reuse;

3. Revising - revision (adaptation) of the selected use case;

4. Retaining - approval and preservation of the decision.

As you can see in fig. 1, the life cycle in CBR-based systems consists of these main stages or phases.

The critical phase in CBR is the first phase, namely the search for the most suitable old solutions for adaptation (Retrieving). The tricky part is that it's not always obvious how relevant the old case is. CBR considers similar problems to have similar solutions. The formalization of the similarity significantly affects the quality and speed of the CBR system. Note that the similarity score depends on the subject area. When using complex structures to represent use cases, assessing similarity can be very time-consuming. Also, an increase the base of cases leads to a decrease in the efficiency of extraction, since more cases have to be analyzed. To solve this problem, the so-called indexing of cases is used. Indexing problem is one of the main ones in CBR. It includes questions such as: the type of indexes to use and how to organize the index search. A trivial solution to the problem is to use all the input characteristics of a case as indices.

Various attempts are being made to use CBR in combination with various machine learning techniques. It can be seen that a number of works have recently appeared, where it is proposed to combine CBR with artificial neural networks of different types [4, 5]. For example, authors [5] propose an approach called NOD-CC, which is a combination of convolutional neural networks and case-based reasoning (CBR). 


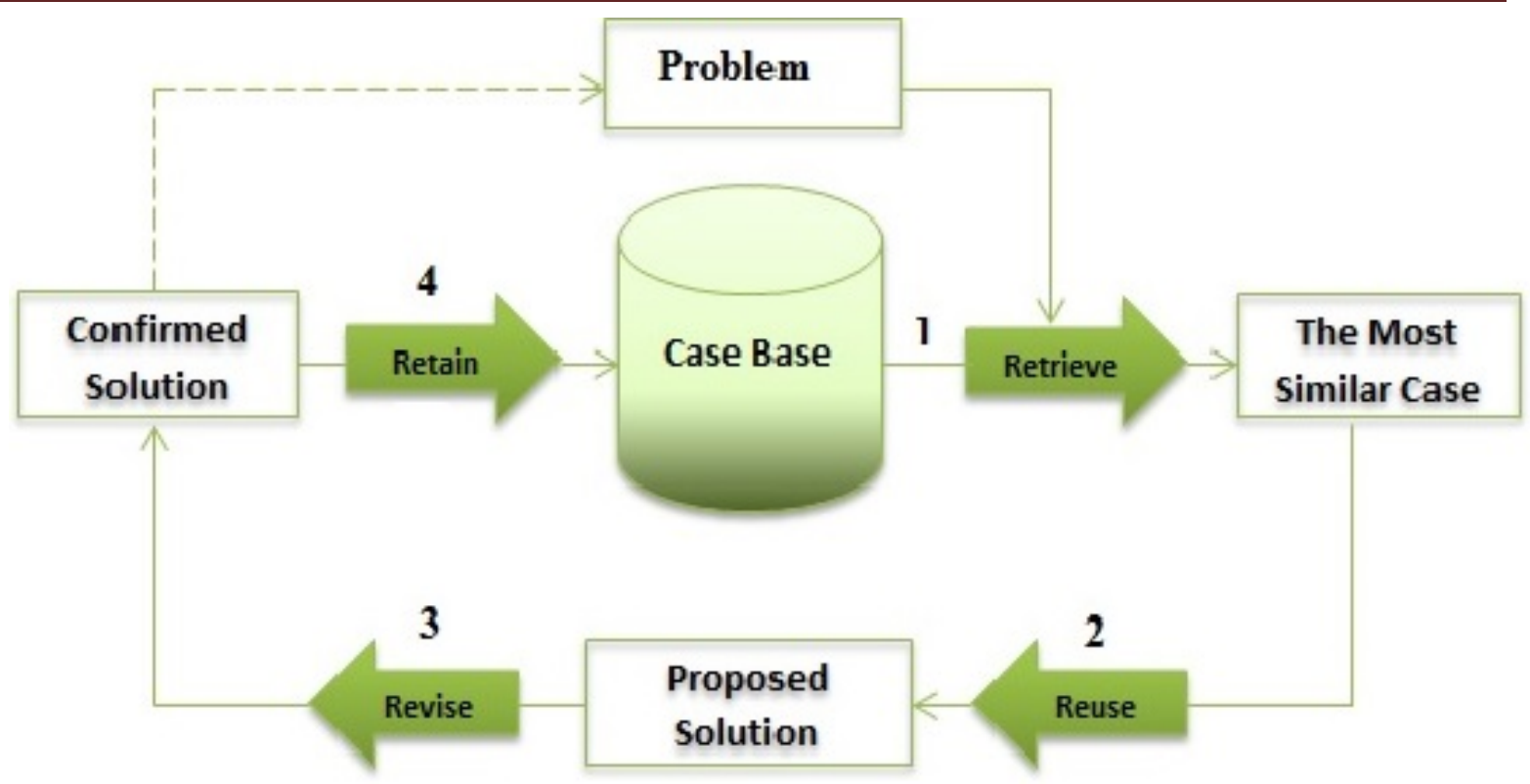

Fig.1. The life cycle of CBR.

A feature of the CBR approach and its implementation in software systems is its narrow specialization, that is, focus on solving specific problems in a limited subject area. As the analysis of the publication has shown, the applications based on the CBR approach for the tasks of chemical technology practically does not exist.

\section{Decision-making system for the choice of methods for cleaning exhaust gases from sulfur and nitrogen oxides}

This article shows the possibility of constructing an intelligent system using CBR to solve the urgent problem of chemical technology, namely, the choice of methods for cleaning exhaust gases from nitrogen and sulfur oxides. First of all, the collection of data for the formation of a base of precedents was carried out. The Case base keeps about 150 methods for cleaning exhaust gases from nitrogen and sulfur oxides that were formed by the specialists and the first version of the system was based on the rules [6]. However, the set of rules was not enough for searching relevant solution very often.

In the proposed system, it was possible to apply case characteristics as indices. The following characteristics of precedents were considered:

1. Degree of purification;

2. Initial concentration;

3. Temperature,

4. The presence of impurities;

5. Product;

6. Material consumption;

7. Energy consumption.

All these characteristics (attributes), except for the fourth and fifth, are given as numerical values with given units of measurement and can be easily normalized. The presence of impurities and the resulting product are categorical attributes with a certain set of values (classes).

The question now is, what metrics and method of similarity assessment will be appropriate to use in the developed system? The first two phases of the CBR lifecycle - Retrieving and Reusing - use the k-nearest neighbor method. There are many types of metrics that can be used to find close precedents - metrics like Heming, Mahalonobis, etc. The simpliest of them is 
Euclidean metric. It was used for estimating the distances between cases in the developed system.

During the third and fourth phases of CBR, the intervention of the decision maker is provided. The Revising phase - the adaptation of the relevant precedent is not necessarily automated procedure, rather it is a dialogue with an expert in a specific area. The process finished with the adoption of the found solution and the possible storage of this solution in the base of cases.

\section{Conclusion}

An intelligent decision-making system is proposed for the choice of methods for cleaning exhaust gases from sulfur and nitrogen oxides, based on the Case-Based Reasoning. The task was formalized: an indexing method and a metric for assessing similarity were selected. The work of the system was checked on test examples.

It is planned that the presented system will be a subsystem in the Decision Support System for the choice of methods for cleaning exhaust gases, which can use other decision-making methods [7]. The proposed CBR-based methodology, which has proven its effectiveness in making decisions on the choice of cleaning methods, can be extended to other technological problems, where enough solution options have been accumulated in the past. Of course, adapting old solutions is unlikely to lead to innovation, but finding solutions based on proven experience will always correspond to less uncertainty.

\section{References}

[1] Kolodner, J. (1993). Case-Based Reasoning. San Mateo: Morgan Kaufmann, 668.

[2] Kolodner, J. (2005). Retrieving events from case memory: A parallel implementation. In: Proceedings from the Case-based Reasoning Workshop, DARPA, Clearwater Beach, 233249.

[3] Aamodt, A. (1994). Explanation-driven case-based reasoning. // In: Wess, S., Althoff, K.D., Richter, M.M. (eds.) European Workshop on Case-Based Reasoning. Lecture Notes in Computer Science (Lecture Notes in Artificial Intelligence), 837, 274-288. https://doi.org/10.1007/3-540-58330-0_93.

[4] Turner, J.T., Floyd, M.W., Gupta, K. \& Oates, T. (2019). NOD-CC: A Hybrid CBR-CNN Architecture for Novel Object Discovery. In: Bach K., Marling C. (eds) Case-Based Reasoning Research and Development. Lecture Notes in Computer Science. Springer, Cham. ICCBR 2019,11680. https://doi.org/10.1007/978-3-030-29249-2_25.

[5] Amin, K., Kapetanakis, S., Althoff, K.D., Dengel, A. \& Petridis, M. (2018). Answering with cases: a CBR approach to deep learning. In: Cox, M.T., Funk, P., Begum, S. (eds.) Springer, Cham. ICCBR 2018. LNCS (LNAI), 11156, 15-27. https://doi.org/10.1007/9783-030-01081-2_2.

[6] Bugaeva, L.N., Beznosik, Yu.A., Statjukha, G.A. \& Kvitka, A.A. (1996). An application of expert system to choice, simulation and development of gases purification processes. Journal Computers \& Chemical Engineering, 20, S402-S406. https://doi.org/10.1016/0098-1354(96)00077-4.

[7] Bugaeva, L.N., Bojko, T.V. \& Beznosyk, Yu.A. (2017). System analysis of chemicaltechnological systems, Kyiv: Interservice. 253. 


\title{
Computational Fluid Dynamics Modeling of Mixing Process for Two- Components Mixture in the Large Scale Reactor
}

\author{
Roman Havryliv $^{1}$, Iryna Kostiv ${ }^{2}$, Sophia Vintoniak ${ }^{3}$ \\ 1. Department of Chemical Engineering, Lviv Polytechnic National University, UKRAINE, \\ Lviv, St.Yura square, 9, E-mail: havrilivroman@gmail.com \\ 2. Department of Chemical Engineering, Lviv Polytechnic National University, UKRAINE, \\ Lviv, St.Yura square, 9, E-mail: kostiv.irina@gmail.com \\ 3. Department of Chemical Engineering, Lviv Polytechnic National University, UKRAINE, \\ Lviv, St.Yura square, 9, E-mail: vintoniaksp8@gmail.com
}

\begin{abstract}
The CFD modeling of mixing process of the two-component reaction mixture in a large scale reactor was performed. The modeling results can be used in the following studies to develop real industrial designs of the apparatus.
\end{abstract}

Keywords - mixing process, large scale vessel, computational fluid dynamics, numerical modeling, mesh density.

\section{Introduction}

There are a lot of industrial processes in chemical engineering where mixing plays a critical role in different applications. Among them are homogenization, suspension, dispersion, heat and mass transfer, temperature uniformity, etc. The most common mixing process is the mechanical type provided by mechanical agitators with a different design.

For the chemical industry, the topic of mixing is especially of interest, since it is a common unit operation in many processes and empirical and semi-empirical correlations for predicting the hydrodynamic characteristics inside a batch mixing vessel do not consider the complete three-dimensional geometry of the vessel and impeller. This is important in processes such as crystallization, dissolution, compounding, and cellular production in bioreactors and others, and the obtained information can aid in the selection of the mixer geometry, the choice of mixing speed and for achieving comparable scale-up/down operation of laboratory and industrial mixing vessels.

Recently, Computational Fluid Dynamics (CFD) techniques have been widely used to reduce the investments and operating costs to analyze and optimize agitators' design and other equipment in chemical engineering. [1-3]. Simulations offer the possibility to obtain a deeper understanding of the evaluated process and can provide information that cannot be easily measured. Furthermore, CFD simulations consider the complete three-dimensional geometry as opposed to more basic correlations and various operational conditions and vessel/mixer geometries can be tested without the need for laboratory and large-scale operation.

In addition, CFD has been widely used to simulate mixing processes due to a lot of agitators configurations and its influence on the properties of the blend or on the process parameters that can be simulated in a short time.

In other words, using CFD requires consideration of many theoretical aspects of the mixing process. First of all, the computational mesh must fit all internal vessel elements, vessels wall contours and agitators blade. Next, the mathematical model should describe in detail the hydrodynamics and physical properties of fluid for a qualitative evaluation of the mixing process.

In this research, as the modeling object has been selected the large-type vessel to reflect the influence of different simulation parameters and their evaluation on the modeling results and the flow field behavior inside the vessels. 


\section{Results and Discussion}

The agitator which rotates in fluid volume provides fluid by energy, that creates complex circulation flows. The program complex of numerical simulation ANSYS Fluent 16 was used, as an instrument for simulating of the reaction mixture mixing process in the large-scale-reactor. The essence of such an approach, that implemented in ANSYS Fluent, lies in the numerical solution of the basic equations of hydro-dynamics, namely - the equation of continuity, the equation of conservation of the momentum, the energy conservation equation. These equations have expressed a base model of the flow and may be supplemented by equations for modeling turbulence, component transport, chemical reactions, and the like. The RANS approach has been used for turbulence modeling. The basic equations of the model were supplemented by k-w SST turbulence model to model the flow behaviour. The mixture of 2,3-dimethylbutadiene and methylmethacrylate was used to modeling this process.

The model of the large-scale-reactor was created by the means of 3D modeling ANSYS Design Modeler and is presented in Fig. 1.

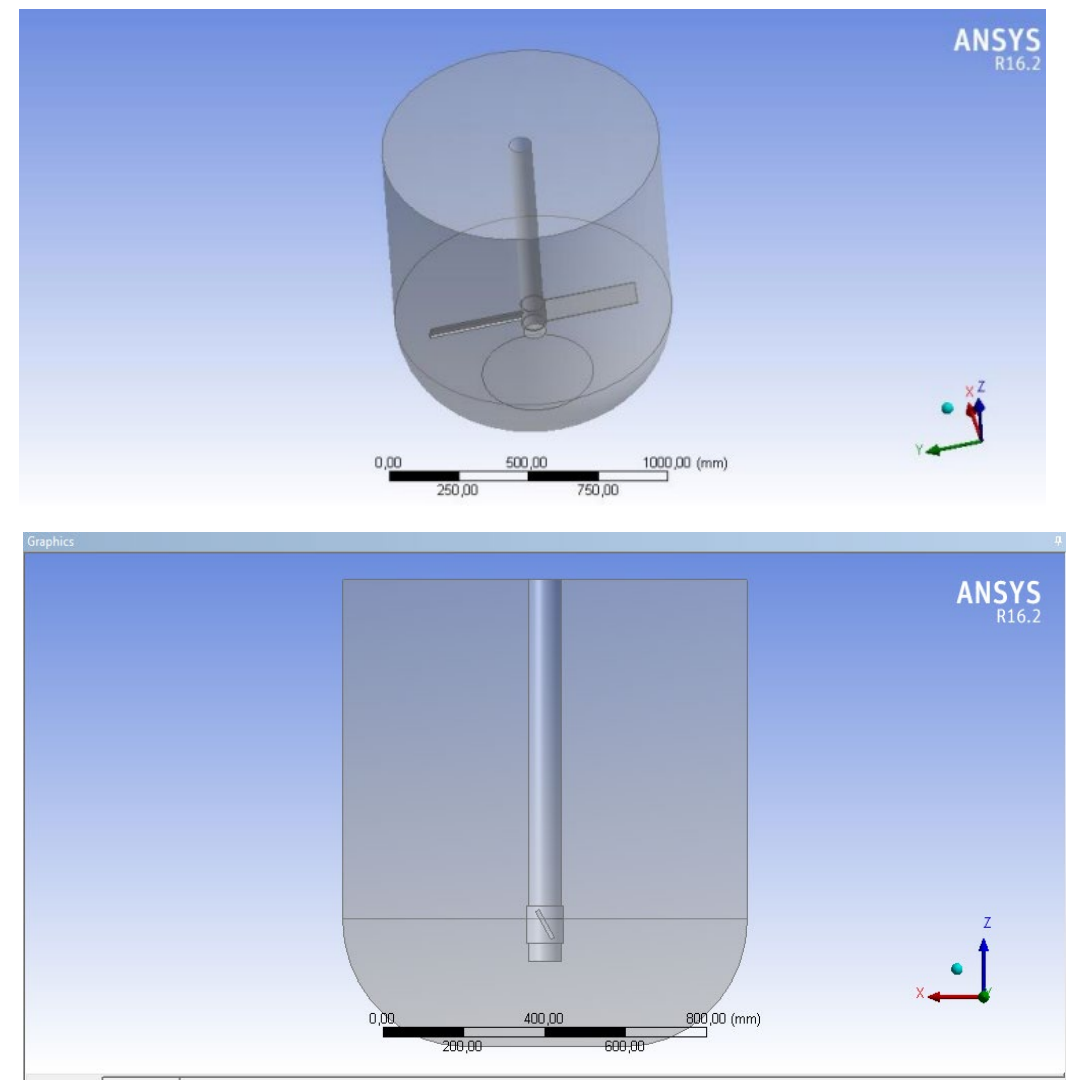

Fig. 1. The reactor geometry

The diameter of the reactor is $1000 \mathrm{~mm}$, the height is $1470 \mathrm{~mm}$. The reactor is equipped with a stirrer, the diameter of the stirrer is $520 \mathrm{~mm}$ the height is $933 \mathrm{~mm}$. The geometric dimensions of the stirrer sketch blade $76 / 10 \mathrm{~mm}$. The angle of the stirrer blades is 30 degrees. The distance from the bottom of the tank to the stirrer is $375 \mathrm{~mm}$

The mesh model, that was used for simulation, had created in the Mesh preprocessor, which contains approximately 645300 tetrahedral elements (fig.2). It should be noted, that the greatest density of the mesh is concentrated in the area of the blades, where the highest gradients of speed are observed. 


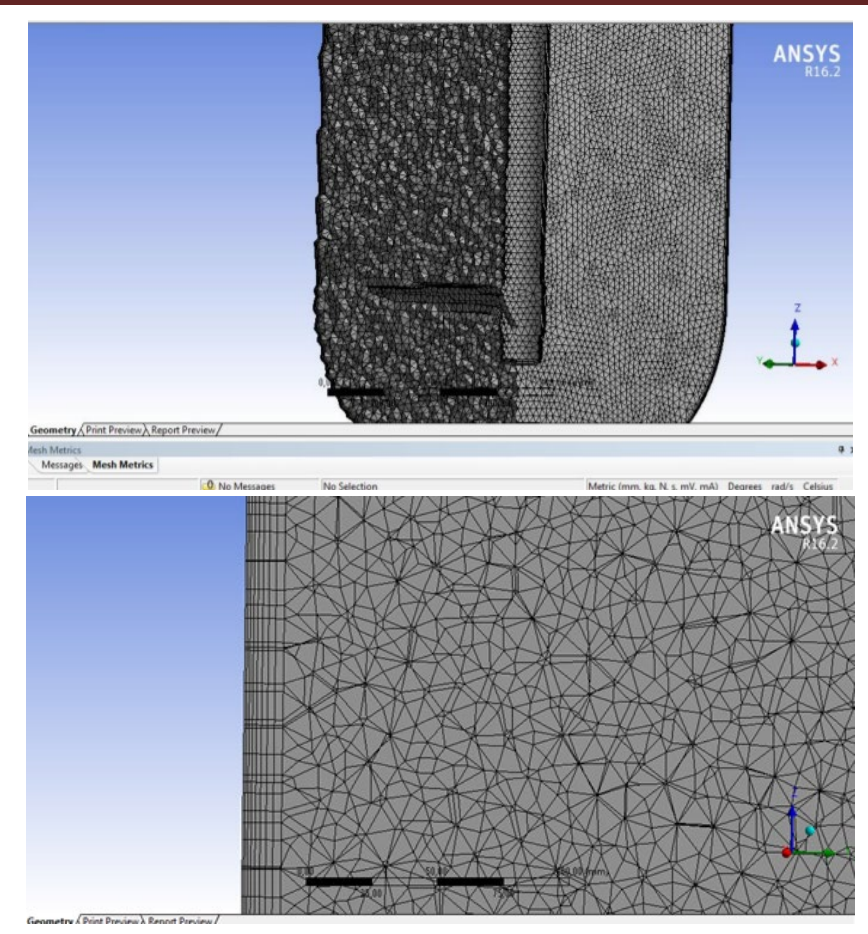

Fig. 2. The mesh of reactor

As results of simulation we obtained the contours of the velocity flow field in vertical cross-section of vessel domain and compared of velocity values in different points of the domain.

According to the presented results, it was installed, that the maximum flow rate is observed in the lower part of the reactor, where the agitator was located. Inside the flow domain there are small-scale local stagnation zones, where zones of zero flow have been formed. The fluid is moving in circular trajectories in the mixer zone. The circulatory flows that will have formed at the top of the reactor are causing an increase in the concentration of the solution in the lower part of the reactor. These observations have been clearly agreeing with the results of experimental research performed earlier.

\section{Conclusion}

The computer modeling of the hydrodynamics of the medium in a reactor with a stirrer was performed. A three-dimensional model of components mixture in a large-scale reactor has been developed using computational fluid dynamics techniques. The flow model takes into account the availability of two components mixture and their interactions have based on the the EulerEuler approach. The modeling results have given an opportunity to draw a conclusion, that the developed model will be using to evaluate the hydrodynamic picture, velocity field, turbulence intensity, determination of mixing power, efficiency of mixer design.

\section{References}

[1] Castro Gualdron, J. A., Abreu Moray, L. A., Díaz Mateus, F. A. (2013). CFD simulation of crude oil homogenization i pilot plant scale. Ciencia, Tecn y Futuro,5 (2), 19-30.

[2] $\mathrm{Wu}, \mathrm{B}$. (2012). Computational fluid dynamics study of largescale mixing systems with side-entering impellers. Eng Appl of Computational Fluids Mech, 6 (1), 123-133. https://doi.org/10.1080/19942060.2012.11015408

[3] Tsui, Y.Y., Hu, Y.C. (2011). Flow characteristics in mixers agitated by helical ribbon blade impeller. Engineering Applications of Computational Fluid Mechanics,5 (3), 416429. https://doi.org/10.1080/19942060.2011.11015383 


\title{
Development of the CFD model to the high viscosity fluid mixing modeling
}

\author{
$\underline{\text { Roman Havryliv }^{1}}$, Łukasz Radosiński ${ }^{2}$, Maciej Szudarek ${ }^{3}$, Sylwia Oleś ${ }^{4}$ \\ 1. Department of Chemical Engineering, Lviv Polytechnic National University, UKRAINE, Lviv, St.Yura square, 9, \\ E-mail: havrilivroman@gmail.com \\ 2. Novasell Ltd., POLAND, Wrocław, ul. Stablowicka 147, E-mail: lukasz.radosinski@novasell.pl \\ 3. Institute of Metrology and Biomedical Engineering, Warsaw University of Technology, POLAND, Warszawa, ul. \\ Św. Andrzeja Boboli 8, E-mail: maciej.szudarek@pw.edu.pl \\ 4. Department of Process Engineering and Chemical Technology, Gdańsk University of Technology, POLAND, \\ Gdańsk, Gabriela Narutowicza 11/12, E-mail: poczta.sylwia.oles@gmail.com
}

\begin{abstract}
The computational fluid dynamics (CFD) model has been developed in order to describe the mixing behavior of the liquid components and scale up the dissolver construction to industrial application. The Sliding Mesh approach has been selected for simulating rotating. For the numerical calculation of multiphase flow VOF multiphase model based on the Euler-Euler approach has been used.
\end{abstract}

Keywords - mixing, Non-Newtonian fluids, numerical simulation, free surface, Doughnut effect.

\section{Introduction}

Mechanical mixing processes are widely used in many industries such as chemical, pharmaceutical, food production, building materials production, etc. Among them, a special place is occupied by the high viscosity or non-Newtonian fluids mixing. These fluids have complex rheological properties, that create some difficult problems to provide an effective industrial mixing $[1,2]$.

Fire-resistant paint production is a special case of liquid and solid components mixing. The industrial paint mixer machines are used to combine and disperse the solids pigments and fluid components. The best mixing results can be obtained when the geometry of the mixer vessel, the dissolver disc diameter, the velocity magnitude, and the height of the dissolver disc above the bottom of the vessel as well as the rheological liquid properties are matched to one another.

From the hydrodynamic point of view, the mixing efficiency can be determined by the Doughnut effect as a signal that the maximum mechanical power possible is being transferred into the liquid phase and furthermore that the liquid is being agitated so that all the agglomerates will eventually reach the dissolver disc [3].

Taking these aspects into account, testing and optimizing the mixing process with high viscosity fluids in industrial conditions is extremely expensive and time-consuming.

Recently, CFD simulations have been used to optimize and scale up the laboratory results. The CFD modeling techniques make it possible to evaluate the hydrodynamics of mixing, the efficiency of mixer design, mechanical power, efficiency, and determines the time necessary to reach the optimum dispersion result $[4,5]$.

In this regard, the development of an appropriate CFD model is a key task for the use of modern engineering approaches for high viscosity fluids mixing.

\section{Results and Discussion}

To develop and validate the CFD model the laboratory $10 \mathrm{~L}$ dissolver was used. The 3D model of the dissolver $(10 \mathrm{~L})$ is presented in Fig. 1a and fully complied with the laboratory installation. The dissolver disc diameter of $70 \mathrm{~mm}$ was located at the center of the vessel, and 97 $\mathrm{mm}$ from the bottom and was driven by a variable-speed motor that could operate in the range of 
50-3000 rpm. The height of the fluid in the vessel was set at $155 \mathrm{~mm}$. This is $57 \mathrm{~mm}$ above the dissolver disc.

The sliding mesh approach was selected to simulate the mixing process inside the computational domain. In accordance with this approach, the fluid domain was divided into two different domain zones (the moving located around the dissolver disc and stationary zones for the rest of the domain).

The unstructured polyhedral mesh was used for the meshing of the domain (Fig. 1b). To reduce the computational effort, only $1 / 16$ (one blade passage) of the overall domain was modeled and periodic conditions were applied to the boundaries. The final mesh was about 30181 elements.

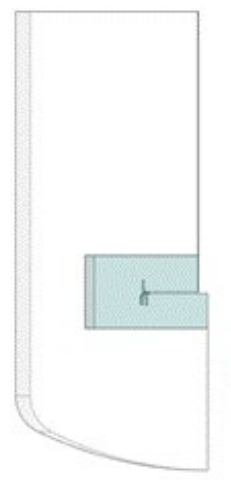

a)

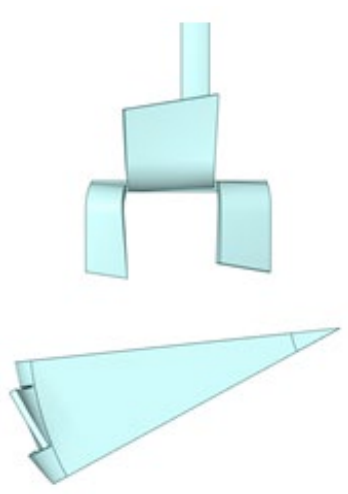

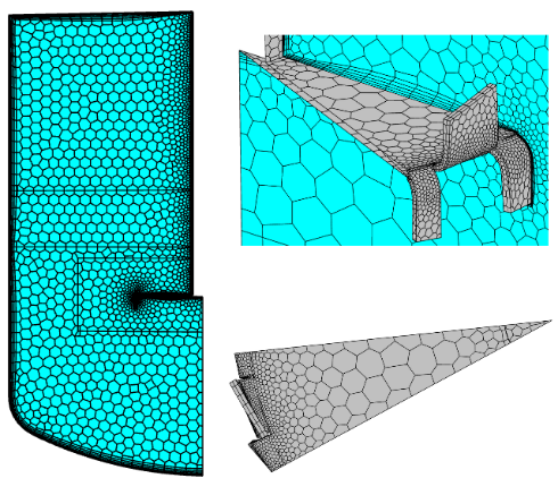

b)

Fig.1. Geometry and mesh.

ANSYS Fluent software version 2020R2 was used to simulate the fluid behavior inside the dissolver vessel. An Eulerian Multi-Fluid VOF multiphase model had to be used since a free surface between the fluids mixture (mill-base and let-down) and air existed.

To hydrodynamic modeling, in addition to governing equations (continuity and momentum), the Reynolds-Averaged Navier-Stokes (RANS) formulation has been used in the simulations to solve the flow field that requires an additional turbulence model for closure. In this study, the two-equation k- $\omega$ SST turbulence model was chosen to simulate the hydrodynamic performance in the mixing system.

No-slip wall condition was applied to the vessel wall, bottom, cover and to the shaft and the dissolver disc.

The computations were carried out with 24 parallel processors using a $2.6 \mathrm{GHz}$ Intel Xeon CPU E5-2690 v3 with 128 GB RAM. The simulation is converged when the residuals reach a plateau, as in the steady-state simulations.

In the first stage of the modeling, the mill-base and let-down mixture in 78/22\% vol. was used as a mixing highly viscous fluid. The mill-base has a non-Newtonian behavior and ranges from 550 to $1500 \mathrm{mPa} \cdot \mathrm{s}$ in shear condition. The rheological properties of the mixture, as well as the viscosity of each component, were determined by a rotational controlled stress rheometer (DV3TRV), equipped with a cone small sample adapter. The viscosity of the liquid mixture was in the range of 500 to $600 \mathrm{mPa} \cdot \mathrm{s}$.

Power consumption and velocity field are probably the most common approach to validate CFD models of stirred vessels. But in the case of the high viscous fluids mixing the hydrodynamic effect described before can be used as an additional tool.

CFD modeling results in Fig. 2 show the velocity field in vector forms Fig.2a and phases distribution profile Fig. $2 b$ in vertical cross-section for rotational frequency $n=3000 \mathrm{rpm}$. 


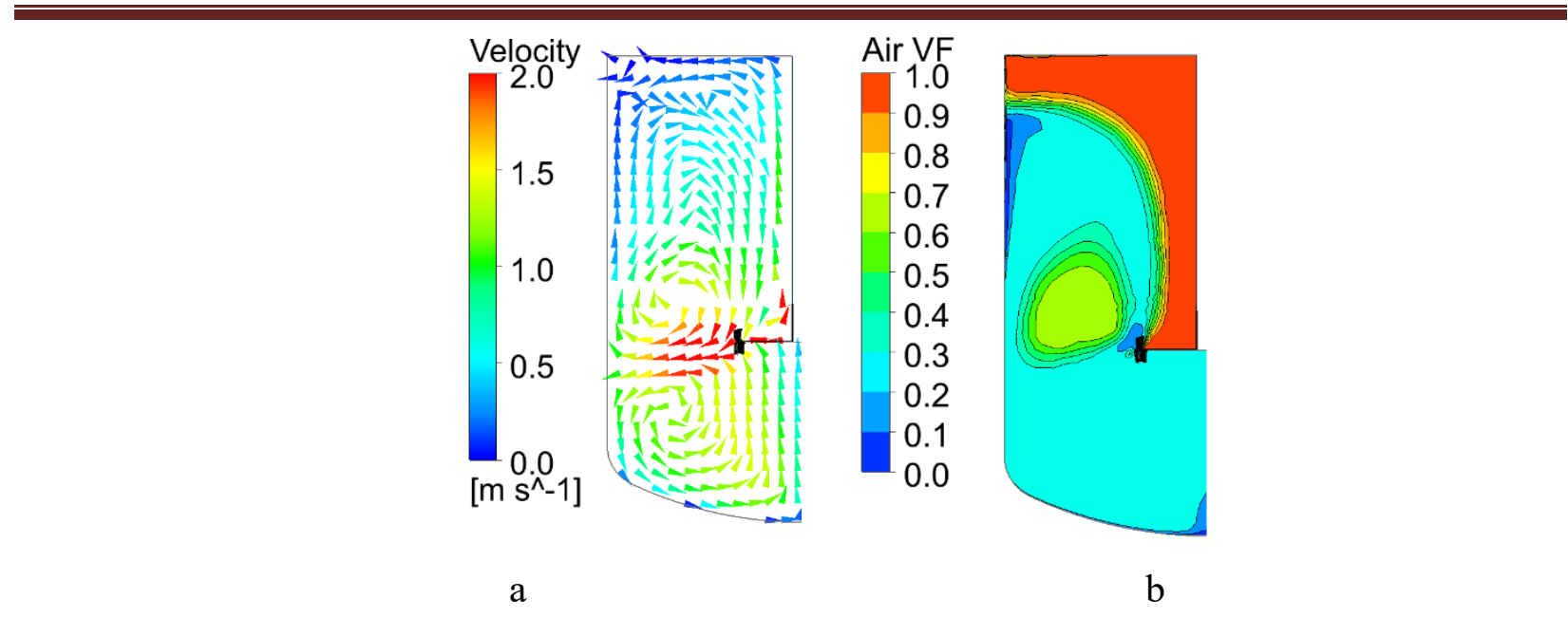

Fig.2. CFD modeling results. (a) Velocity field vectors; (b) Contours of air volume fraction

The results show that the stream is divided into two parts. The one going downwards flows back to the middle of the dissolver disc along the bottom of the vessel and rises up to hit the disc once again. The second part flowing upwards has the same circular path, which is limited by the force of gravity and the rheological properties of the liquid mixture. As was noted before, the best dispersion results are obtained when the Doughnut flow pattern is maintained, which is visible in both figures.

\section{Conclusion}

The purpose of the study was to develop a CFD model to predict different features of the high viscous fluid mixing process. The CFD model included the mixing process, the sheardependent viscosity, and the free surface problem. The numerically predicted velocities field and flow with a free surface (the Doughnut effect) are show good agreement to the experimental measurements. The CFD also predicts the location and magnitude of the vortex formed due to the Doughnut effect and disk location. The proposed CFD model can be used to scale up the real mixing processes in industrial applications.

\section{Acknowledgments}

The work has been funded and realized within NCBiR European Funds project POIR.01.01.01-00-0218/19 „Development of an innovative system for fire protection of steel structures."

\section{References}

[1] Arratia, P.E., Kukura, J., Lacombe, J., Muzzio, F.J., 2006. Mixing of shear-thinning fluids with yield stress in stirred tanks. AICHE J. 52, 2310-2322

[2] Zhu, H., Kim, Y., de Kee, D., 2005. Non-Newtonian fluids with a yield stress. J. NonNewtonian Fluid Mech. 129, 177-181

[3] Kazemzadeh, A., Ein-Mozaffari, F., Lohi, A., Pakzad, L., 2016. Effect of the rheological properties on the mixing of Herschel-Bulkley fluids with coaxial mixers: applications of tomography, CFD, and response surface methodology. Can. J. Chem. Eng. 9999, 1-13

[4] Cortada-Garcia, M., Dore, V., Mazzei, L., Angeli, P., 2017. Experimental and CFD studies of power consumption in the agitation of highly viscous shear thinning fluids. Chem. Eng. Res. Des. 119, 171-182

[5] Adams, L., Barigou, M., 2007. CFD analysis of caverns and pseudo caverns developed during mixing of non-Newtonian Fluids. Chem. Eng. Res. Des. 85, 598-604 


\title{
Effects caused by vacancies in carbon nanocluster $\mathbf{C}_{96}$ and polyaromatic molecule $\mathrm{C}_{96} \mathrm{H}_{24}$
}

\author{
O.S. Karpenko \\ Chuiko Institute of Surface Chemistry NAS of Ukraine, UKRAINE, Kyiv, 17 General Naumov Str., \\ E-mail: karpenkooksana@ukr.net
}

\begin{abstract}
The equilibrium spatial and electronic structure of hexagon-shaped carbon nanocluster (CNC) $C_{96}$ limited to six zigzag edges, analogical polyaromatic molecule (PAM) $\mathrm{C}_{96} \mathrm{H}_{24}$ and CNCs, $P A M s$ with defects (monovacancies, divacancies) have been calculated within the density functional theory method (DFT) with the exchange-correlation potential B3LYP and the basis set 6-31G+(d,p).
\end{abstract}

Keywords - density functional theory (DFT), graphene, carbon nanoclusters, monovacancies in graphene, divacancies in graphene.

\section{Introduction}

The ideal graphene consist of $\mathrm{sp}^{2}$-hybridized carbon atoms [1, 2]. The structure of edges in CNCs samples is important for the chemistry of graphene, but an analysis of literature has shown that a lot of quantum chemical studies of graphene with zigzag edges have not been fully clarified yet.

\section{Results and discussion}

CNC $\mathrm{C}_{96}$ (Fig. 1a) has six zigzag edges, each of which has four doubly coordinated carbon atoms $\left(\mathrm{C}^{(2)}\right)$. PAM $\mathrm{C}_{96} \mathrm{H}_{24}$ was built from related $\mathrm{CNC}$ by attaching hydrogen atoms to the peripheral doubly coordinated carbon atoms $\mathrm{C}^{(2)}($ Fig. $1 b)$.
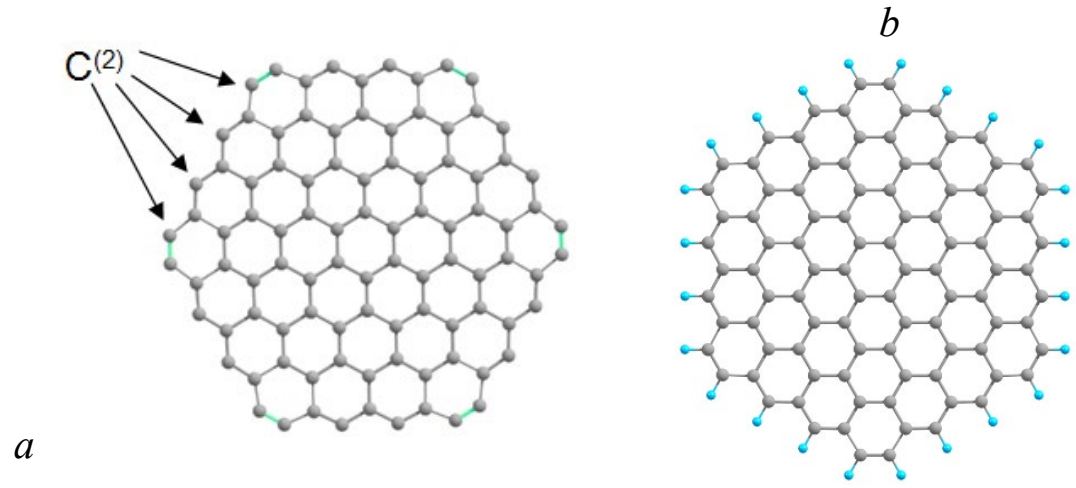

Fig.1. Carbon nanocluster $\mathrm{C}_{96}$ with doubly coordinated carbon atoms $(a)$, polyaromatic molecule $\mathrm{C}_{96} \mathrm{H}_{24}(b)$.

The structures with vacancies (Fig. 2) have been obtained from $\mathrm{C}_{96}$ and $\mathrm{C}_{96} \mathrm{H}_{24}$ by removing one carbon atom $\left(\mathrm{C}_{96-1(1)}\right.$ and $\left.\mathrm{C}_{96-1(1)} \mathrm{H}_{24}\right)$, two non-adjacent carbon atoms ( $\mathrm{C}_{96-2(1)}$ and $\left.\mathrm{C}_{96-2(1)} \mathrm{H}_{24}\right)$, two adjacent carbon atoms $\left(\mathrm{C}_{96-1(2)}\right)$ or two pairs of adjacent carbon atoms (C96-2(2)).

It have been established that the ground electronic state of $\mathrm{CNCs}_{96}, \mathrm{C}_{96-1(1)}$, $\mathrm{C}_{96-2(1)}$ and $\mathrm{C}_{96-1(2)}$, PAMs $\mathrm{C}_{96} \mathrm{H}_{24}, \mathrm{C}_{96-1(1)} \mathrm{H}_{24}, \mathrm{C}_{96-2(1)} \mathrm{H}_{24}$, despite its have even amount of electrons, is not singlet.

The equilibrium spatial structure of $\mathrm{CNC}_{96}$ is such that the $2 \mathrm{pz}$ atomic orbitals of the outer edge cyclic chain form a conjugate system loosely-coupled with $\pi$-system of the central part of the CNC. This suggests that the outer edge chain is relatively isolated and does not participate in the formation of a common conjugate $\pi$-system, delocalized throughout the CNC. The degree of separation of the outer edge chain increases from $\mathrm{CNC}_{96}$ to defect-containing 
CNCs $\mathrm{C}_{96-1(1)}$ and $\mathrm{C}_{96-2(1)}$. For systems $\mathrm{C}_{96-1(1)} \mathrm{H}_{24}$ and $\mathrm{C}_{96-2(1)} \mathrm{H}_{24}$, obtained from PAM $\mathrm{C}_{96} \mathrm{H}_{24}$, the formation of one or two monovacancies does not violate a single conjugate system.

The spectrum of single-electron energy levels of CNCs $\mathrm{C}_{96}, \mathrm{C}_{96-1(1)}$ and $\mathrm{C}_{96-2(1)}$ exhibits that some MOs distributed over outer cyclic chain remain vacant but theirs energies fall into the energy intervals of the highest occupied MOs.

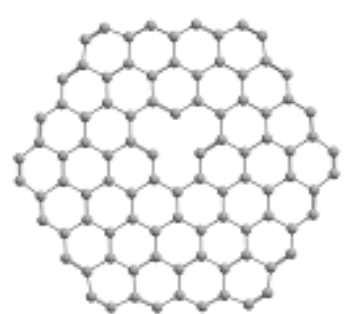

$\mathrm{C}_{96-1(1)}$

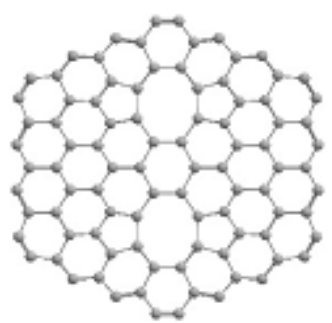

$\mathrm{C}_{96-2(2)}$

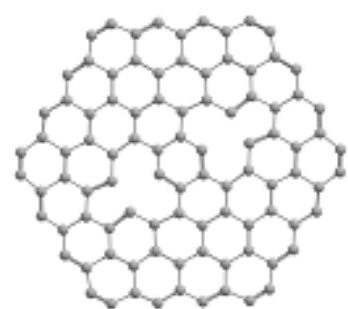

$\mathrm{C}_{96-2(1)}$

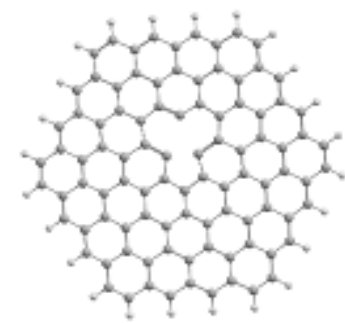

C96-1(1) $\mathrm{H}_{24}$
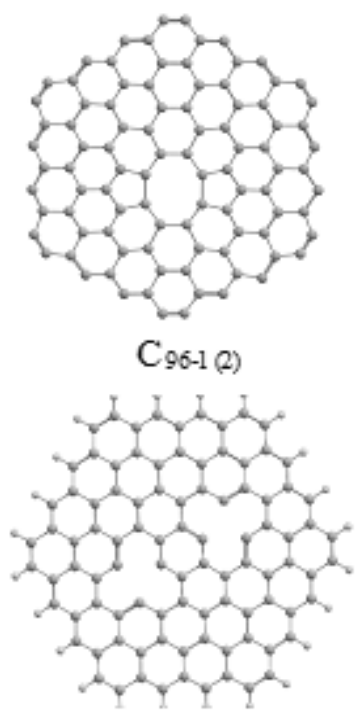

$\mathrm{C}_{96-2(1)} \mathrm{H}_{24}$

Fig.2. CNCs and PAMs with defects (monovacancies and divacancies)

The calculated energies of formation of one and two monovacancies in $\mathrm{CNC}_{96}$ indicate «loosening» of the structure during the transition from $\mathrm{C}_{96}$ to $\mathrm{C}_{96-1(1)}$, while for PAM $\mathrm{C}_{96} \mathrm{H}_{24}$ the introduction of vacancies «seals» the structure.

The formation of divacancies in the $\mathrm{CNC} \mathrm{C}_{96}$ (removing the $\mathrm{C}^{(2)}$ molecule from it) is more favourible energetically in comparison with the sequential removal of two adjacent carbon atoms.

The spectra of one-electron density states of CNC in the binding-energy scale of carbon $1 \mathrm{~s}$ $(\mathrm{C} 1 s)$ core-level allow to identification the different types of carbon atoms depending on the degree of hybridization of their atomic orbitals, the availability of vacancies and their position in the CNC.

\section{Conclusion}

Modeling of CNCs structures and properties as PAMs (when carbon atoms $\mathrm{C}^{(2)}$ saturated with hydrogen atoms) is not correctly both for defect-free and defect-containing hexagon-shaped CNCs.

\section{Acknowledgments}

This work was supported by the National Research Foundation of Ukraine (grant 2020.02/0050).

\section{References}

[1] Novoselov, K.S., Geim, A.K., Morozov, S.V., Jiang, D., Zhang, Y., Dubonos, S.V., Grigorieva, I.V., Firsov, A.A. (2004). Electric field effect in atomically thin carbon films. Science, 306(5696), 666-669. https://doi.org/10.1126/science.1102896

[2] Novoselov, K.S., Geim, A.K., Morozov, S.V. et al. Two-dimension gas of massless Dirac fermions in graphene. (2005). Nature, 438, 197-200. https://doi.org/10.1038/nature04233 


\title{
Improving computer simulation of vacuum pumping process of the plasma sputtering system
}

\author{
Roman Sheremeta \\ IMIT, Lviv Polytechnic National University, UKRAINE, Lviv, 12 Bandera street, \\ E-mail: r1sheremeta@gmail.com
}

- Abstract - The aim of the research is to improve mathematical model of the computer simulation of the vacuum pumping process. This is implemented by introducing additional blocks of operators, using of which allows to achieve optimum modes of carrying out the technological process of vacuum sputtering of $\mathrm{SiO}_{2}$ on polymeric surfaces.

- Keywords - sputtering, vacuum sputtering, silicon dioxide, vacuum system, mathematical model, calculation, computer simulation.

\section{Introduction}

Modern packaging standards require the use of the latest technologies to improve the quality of transportation and long-term storage of bulk products and beverages. One of the ways to solve this problem is to spray thin protective coatings on the inner surface of the plastic container. In particular, the technology of vacuum plasma coating with silicon dioxide on the inner surface of PET containers has been developed. Taking into account the repeatability of the process, there is a need to ensure that fastest possible pumping out of the vacuum plasma sputtering system is achieved. As well as to determine that the optimal amount of activating gas mixture is injected to create the required partial pressure in the working chamber.

\section{Research Description}

In the publication [1], a multifactor mathematical model describing the process of vacuum pumping of gases from closed systems was created. In the publication [2], this model became universalized, which allowed to present a wide range of design features of real vacuum systems. This paper also proposes computer simulation for calculating the parameters of pumping out vacuum systems in the Simulink environment from the Matlab software package. Example of vacuum pumping process of the plasma sputtering system simulation is shown in Fig. 1.

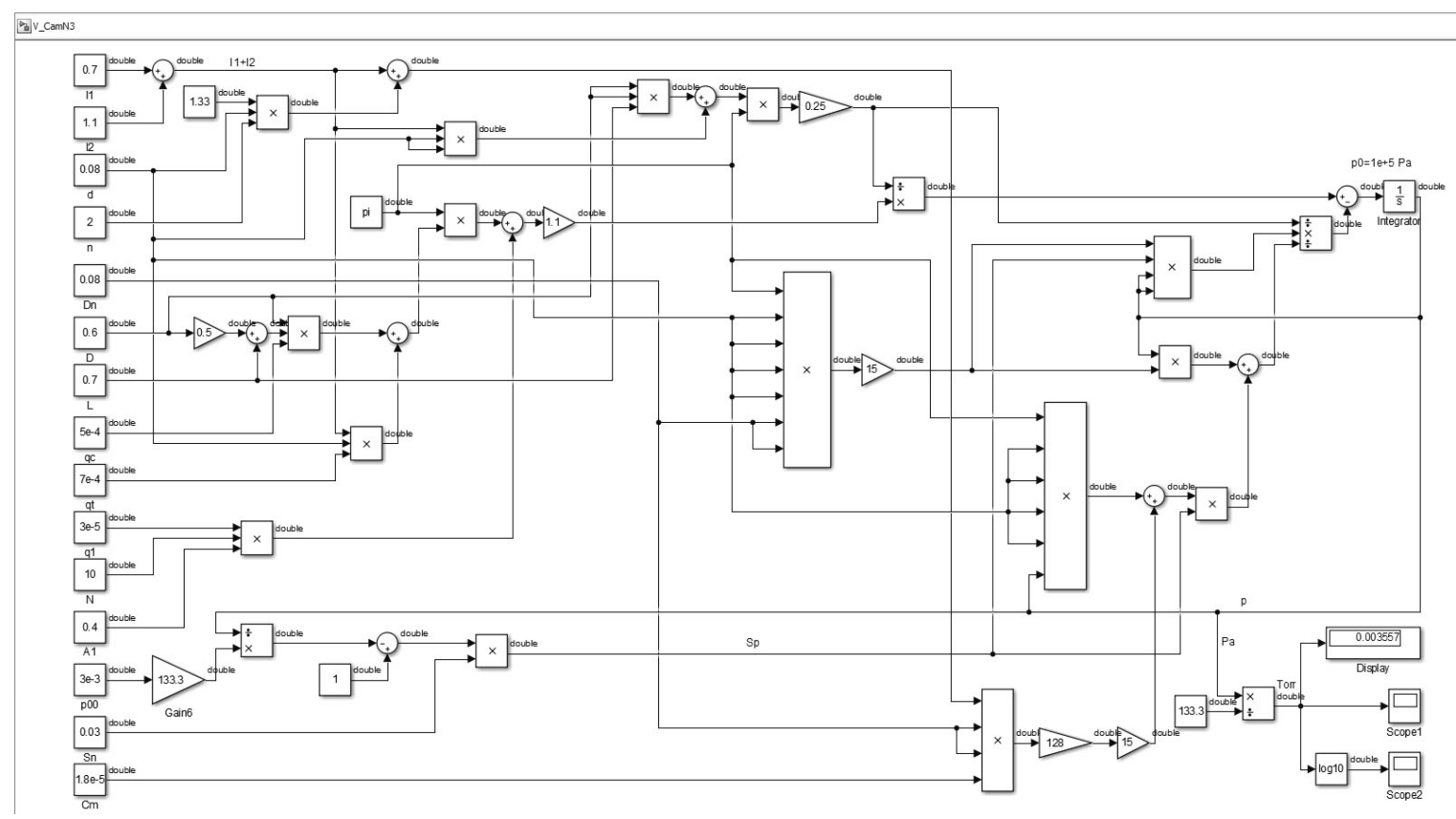

Fig. 1. Example vacuum pumping process of the plasma sputtering system simulation 
The proposed simulation allows to analyze the gas state in any structural element of the vacuum system during its operation. The graphical dependence of the pressure change in the working chamber of the system during the achievement of a given vacuum is shown in Fig. 2 .

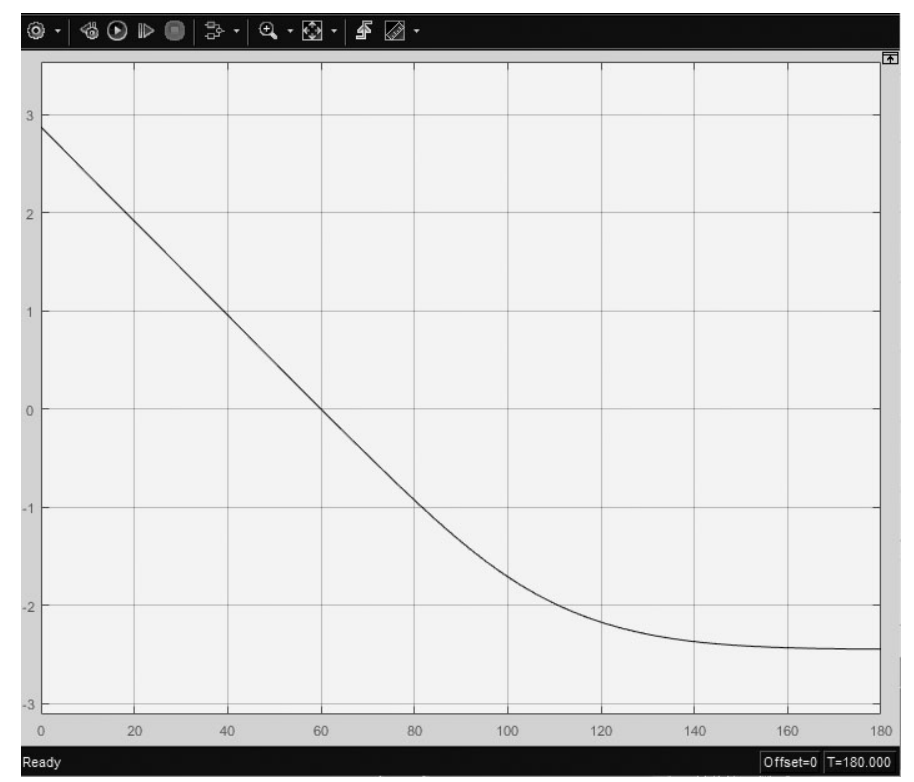

Fig. 2. Change of pressure in the working chamber of the system while achieving operational state

In order to automate calculation of the optimal pumping time, the simulation has been improved. To do this, a programmable timer and a comparator were introduced into the general simulation. With this innovation, when simulating the process of pumping out vacuum system a comparison of the running gas pressure in the working chamber is compared with the specified. In case of equality of these values timer indication is being fixed while signaling the moment of achieving of the working pressure in the vacuum system. The results of the computer simulation of the pumping out process showed sufficient accuracy compared to the experimentally obtained results.

\section{Conclusions}

Mathematical modeling and computer simulation of the pumping process allows to make optimal cyclograms of the individual elements of the vacuum system of technological installations. One of the results of the study is the creation of automated system that allows calculation of the parameters of the pumping process of vacuum systems, which should be used in the design and operation of this equipment.

\section{References}

[1] Sheremeta, R.M. (2001). Calculation of the kinetics of the process of forvacuum pumping of the vacuum system. Publication of IX Ukrainian - Polish Conference on "CAD in Machinery Design. Implementation and Educational Problems”. Warsaw, Poland, 131136.

[2] Sheremeta, R.M., Stotsko, Z.A., Plaska, S. (2008). Automated Calculation of Process Bailing of Vacuum Systems. Publication of the XVI Ukrainian - Polish Conference on "CAD in Machinery Design. Implementation and Educational Problems". Lviv, Ukraine.

[3] Sheremeta, R.M. (2011). Computer simulation of the vacuum systems pumping technological process. Lviv Polytechnic National University bulletin №713 "Optimization of production processes and technical control in mechanical engineering and instrument making", 132-137. 


\title{
Modeling Heat and Mass Transfer During Evaporation in the Film Apparatus with Cross Movement Phases
}

\author{
Lukashov V.K. ${ }^{1}$, Kostiuchenko Y.V. ${ }^{1,2}$, Timofeev S.V. ${ }^{1}$ \\ 1.Shostka Institute of Sumy State University, UKRAINE, Shostka, 1 Haharina Str., 41100, \\ E-mail: khtms@ishostka.sumdu.edu.ua \\ 2.Sumy State University, UKRAINE, Sumy, 2 Rymskogo-Korsakova Str., 40007, \\ E-mail: y.kostiuchenko@pohnp.sumdu.edu.ua
}

\begin{abstract}
A mathematical model has been developed for heat and mass transfer in a solution film flowing down a heated surface under conditions of evaporation into a cross flow of a neutral (inert) gas. An experimental setup has been created and the coefficients of heat and mass transfer for an aqueous solution of glycerol, which are the parameters of the model, have been determined. Modeling heat and mass transfer made it possible to establish the regularities of changes in the temperature and concentration of the solution along the length of the film.
\end{abstract}

Keywords - heat and mass transfer, evaporation, falling film, cross flow, neutral gas.

\section{Introduction}

Apparatus with gravitational film flow of liquid are widely used in industry for various technological processes. In many cases, this flow is accompanied by evaporation from the free surface of the film. The presence of a neutral (inert) gas over the film has a significant effect on heat and mass transfer in this system [1]. For its direct and countercurrent movement, heat and mass transfer during evaporation from a liquid film has been well studied. For the cross interaction of these flows, there is almost no information about the study, which makes it difficult to calculate and model. At the same time, from the viewpoint of increasing the efficiency of technological devices, the cross interaction of flows is of interest [2]. The aim of the work was to establish the regularities of heat and mass transfer during evaporation in film devices with cross-phase movement.

\section{Mathematical Model}

Mathematical modeling in this case is reduced to solving a system that includes the equations: fluid motion in the film; film continuity; mass transfer from the free surface of the film to the gas phase; material balance of the gas phase for the evaporated substance; the relative content of the evaporated substance in the gas phase; Dalton's law; heat transfer in the film; heat transfer in the gas phase; material balance of the film in terms of the evaporated substance.

To solve this system of equations, the numerical method of the explicit Euler scheme was used. As a result, recurrent formulas were obtained for calculating the change in the temperature of the solution film, air temperature, and water concentration in the solution along the length of the film. The calculations took into account the dependence of the solution characteristics (density, specific heat capacity, viscosity) on these values. The coefficients of heat transfer from the heated surface to the film and from the film to the gas phase required for calculations, as well as the coefficient of mass transfer of evaporated water into the gas phase, were determined from the results of an experimental study.

\section{Research Methodology}

The experimental study of heat and mass transfer was carried out on the setup, which is a model of the working element of the film apparatus [2]. The main unit of the setup was a 
rectangular container, the outer surface of one of the vertical walls (working surface) of which, $0.8 \times 0.01 \mathrm{~m}$ in size served for the solution film to flow down. A high-temperature liquid coolant circulated through the container, which was in contact with the inner surface of this wall. A boundary wall is placed at a distance of $18 \mathrm{~mm}$ from this surface. Air was supplied to the space between this wall and the working surface, uniformly in height and perpendicular to the movement of the film. An aqueous solution of glycerin was used as a liquid. The setup is equipped with systems for regulating and measuring the flow rate and temperature of the solution entering from above and flowing down from the bottom of the working surface, the temperature of the coolant in the tank, the flow rate and temperature of the air entering and leaving the space between the working surface and the boundary wall. The concentration values of glycerol in the initial solution and the solution flowing down from the bottom of the working surface were determined by its density.

\section{Results and Discussion}

The simulation results are presented as graphs of temperature variation of the solution and the solute concentration in the film in the direction of its movement for different parameters of the evaporation process. As an example, graphs (fig. 1) of changes in solution temperature and glycerol concentration therein in the direction of film movement are given for different values of the initial solution consumption.
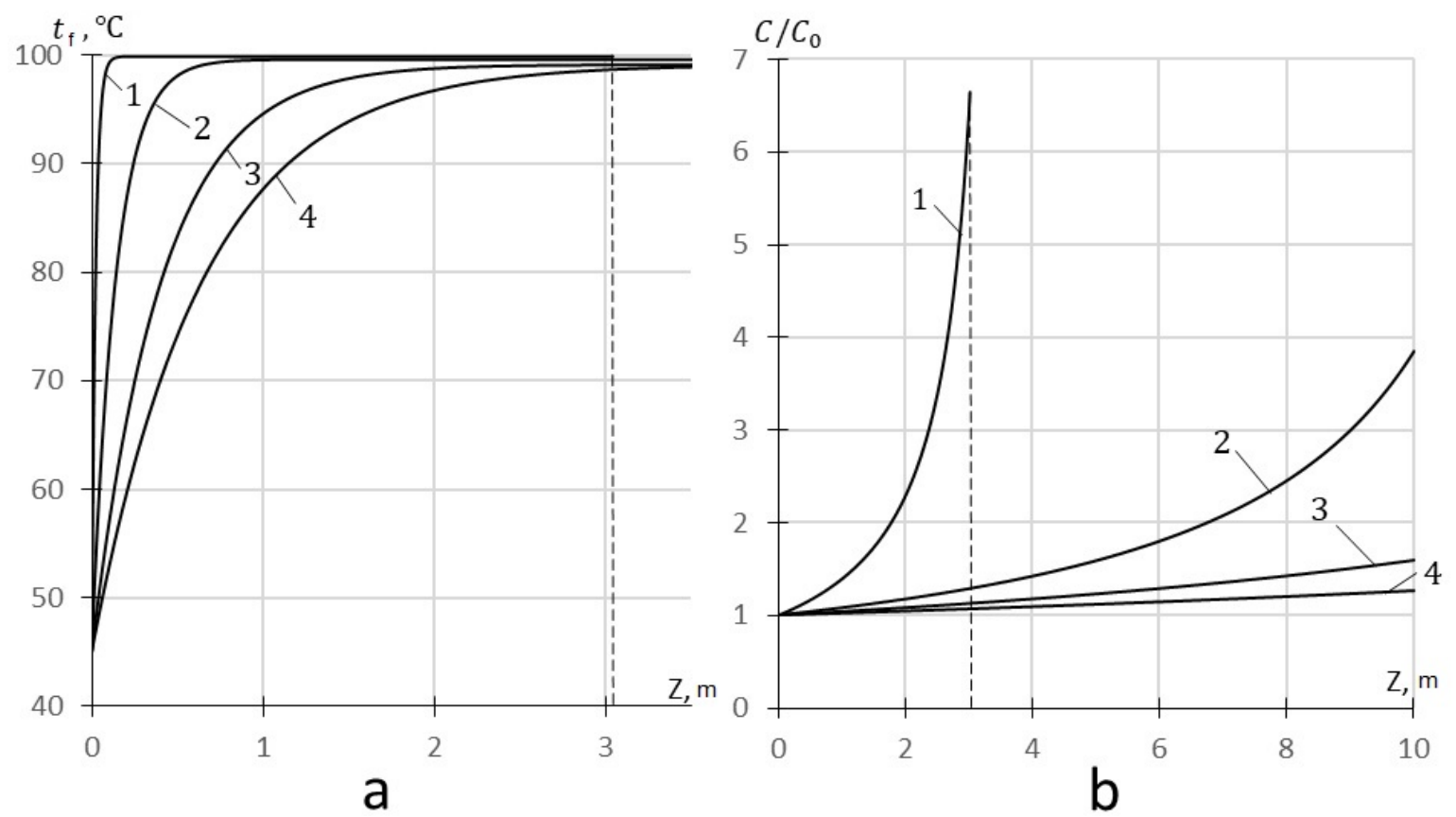

Fig. 1. - Change in temperature (a) and concentration of glycerol (b) in its aqueous solution along the length of the film at different initial flow rates of the solution:

$$
1-\mathrm{L}_{0}=0.00186 \mathrm{~kg} / \mathrm{s} ; 2-0,00485 \mathrm{~kg} / \mathrm{s} ; 3-0,00632 \mathrm{~kg} / \mathrm{s} ; 4-0,0102 \mathrm{~kg} / \mathrm{s}
$$

It follows from these graphs that the temperature of the solution in the film (fig. 1a) increases along its length and at a certain distance from the beginning reaches an equilibrium value, which remains constant until the water completely evaporates (curve 1 in fig. 1a). The intensity of the temperature rise along the length of the film increases with a decrease in the initial consumption of the solution.

The change in the glycerol concentration in the solution (fig. 1b) at the beginning of the film is close to linear, then it sharply rises until the complete evaporation of water (curve 1 in fig. 1b). Comparison of these curves with the solution temperature distributions in the film suggests 
that their linear character at the beginning of the film is associated with the temperature reaching steady-state values. After reaching the steady-state temperature, an increase in the concentration of the solution along the length of the film is observed.

Also temperature changes of the solution and the concentration of glycerol in it along the length of the film from the initial temperature of the solution, the air velocity in the space above the film, its initial temperature and surface temperature along which film flows were established.

\section{Conclusions}

On the basis of the developed mathematical model and the performed experimental studies, the regularities of heat and mass transfer in a solution film flowing down a heated surface under the conditions of evaporation into a cross flow of a neutral gas were established. An example of changes in temperature and concentration of an aqueous solution of glycerol shows their growth in the direction of film movement. At a certain distance from the initial section of the film, the temperature reaches an equilibrium value, which increases with an increase in the flow rate of the solution. Changing the concentration at the beginning of the film is close to linear character, then when the temperature reaches an equilibrium value, it occurs a sharp rise, which lasts until complete evaporation of the water.

\section{References}

[1] Serafimov, L.A., \& Frolkova, A.V. (2008). Konovalov's first law validity in reactive distillation processes with inert. Fine Chemical Technologies, 3(2), 47-54.

[2] Lukashov, V.K., Romanko, S.M., Kostiuchenko, Y.V. (2019). Apparatus for concentrating a solution of sulfuric acid (UA. Patent No. 134162). State Enterprise "Ukrainian Intellectual Property Institute". 


\title{
Mathematical modeling of sorption and desorption dynamics in adsorption
}

\section{systems}

\author{
Natalia Sorokova $^{1}$, Julia Kolchyk ${ }^{2}$, Rodion Sorokovoi ${ }^{3}$ \\ 1. National Technical University of Ukraine "KPI named after Igor Sikorsky", UKRAINE, Kyiv, 02000, \\ Polytechnic Street, 6, E-mail: n.sorokova@ukr.net
}

2. Kyiv National University of Construction and Architecture, UKRAINE, Kyiv, 03680, Povitroflotsky Avenue, 31, E-mail: yulia@orblink.kiev.ua

3. Institute of Engineering Thermophysics of the National Academy of Sciences of Ukraine, UKRAINE, Kyiv, 03164, Bulakhovsky street, 2, E-mail: emo4ka69@gmail.com

\begin{abstract}
A mathematical model and the results of calculating the dynamics of heat and mass transfer and phase transformations in the processes of sorption and desorption in solid porous sorbents in adsorption systems are presented. The calculation results indicate the adequacy of the mathematical model and the effectiveness of the calculation method.
\end{abstract}

Keywords - adsorption, desorption, adsorbent, adsorbate, mathematical modeling, intensity of phase transitions, mathematical modeling, dynamics of heat and mass transfer.

\section{Introduction}

Heat and mass transfer processes of sorption and desorption are an integral part of many production technologies of energy, chemical, construction and other industries. Their passage in heterogeneous porous systems is accompanied by phase transitions and possible deformation of the solid phase. The optimal organization of sorption and desorption ensures the preservation of the adsorption properties of sorbents and energy efficiency of production. Differences in the known mathematical models $[1,2]$ used to describe the dynamics of these processes are due to differences in the type and number of the main required functions and ways of closing the initial transfer equations. The methods of finding the intensity of phase transitions in them are quite approximate. Activation processes, the intensity of which significantly depends on temperature, have a significant effect on the dynamics of evaporation, condensation and diffusion transfer. The dynamics of sorption and desorption is characterized by the intensity of two competing processes: condensation of adsorbent molecules on the surface of the adsorbate layer covering the inner and outer surfaces of the porous body and evaporating molecules that are located near the free surface of the adsorbate layer and have reached the activation energy.

\section{Results and discussion}

The intensity of the phase transition on the outer surface of the body is found by the formula [3]

$$
I=\gamma_{\mathrm{c}}\left\{\bar{\delta}(2-\bar{\delta})\left[\exp \left(A /\left.R T\right|_{\mathrm{v}=0}\right)-1\right]^{-1}-\varphi_{\mathrm{e} . \mathrm{m} .}\left[\exp \left(A / R T_{\mathrm{e} . \mathrm{m} .}\right)-1\right]^{-1}\right\}, \quad \gamma_{\mathrm{c}}=\varepsilon \rho_{\mathrm{fl}} \delta * / 4
$$

where $\varepsilon$ is the radiation coefficient; $\rho_{\mathrm{fl}}$ is the density of the liquid; $\delta^{*}$ is the thickness of the condensate layer in which the evaporation process takes place; the value $\bar{\delta}=\delta / \delta^{*}$ is found from the conditions: for $0<\delta<\delta^{*}$ and $\bar{\delta}=1$ with $\delta>\delta^{*}, \delta$ the thickness of the condensate layer; $A$ is the activation energy; $R$ is the universal gas constant; $\varphi_{\mathrm{en}}$ relative humidity of the medium, $\varphi_{\text {e.m. }}=P_{\mathrm{v}} / P_{\mathrm{S}}, P_{\mathrm{v}}$ water vapor partial pressure, $P_{\mathrm{s}}$ saturation pressure; $T$ is temperature; $v$ is normal to the body surface. The first term in parentheses characterizes the intensity of evaporation of the adsorbate, and the second - the intensity of condensation of the sorbent. When the first term exceeds the second - the resultant process is the desorption of liquid, otherwise the adsorption of steam. 
The intensity of phase transformations $I_{V}$ in a unit volume of a porous body is the product of the intensity of phase transition I on the liquid surface on the walls of partially filled capillaries and the total area $S$ of the contact surface of liquid and gas phases $I_{V}=I S$. To determine the function $\mathrm{S}$ obtained formula [3]

$$
S=\frac{2 \sqrt{1-\varphi_{\mathrm{b}}}}{\rho_{\mathrm{fl}} \delta^{*}} \frac{\partial U_{\mathrm{fl}}}{\partial \varphi_{\mathrm{b}}}, \quad\left(S_{\min } \leq S \leq S_{\mathrm{max}}\right),
$$

where $\varphi_{b}$ is the adsorption humidity of the body, equal to the relative humidity of the gas, which according to the sorption-desorption isotherm corresponds to the volume concentration of the liquid $U_{\mathrm{fl}}$ at a given moment in time at a given point of the porous body; the derivative $\partial U_{\mathrm{f}} / \partial \varphi \mathrm{b}$ is found from the sorption isotherm equation.

Under the condition of local thermodynamic equilibrium, when $\left.T\right|_{\nu=0}=T_{\text {i.m. }}$, from (1) and (2) follows the expression for the intensity of phase transformations in the pores of the body

$$
I_{V}=\gamma_{\mathrm{c}} \frac{2 \sqrt{1-\varphi_{\mathrm{b}}}}{\rho_{\mathrm{fl}} \delta^{*}} \frac{\partial U_{\mathrm{fl}}}{\partial \varphi_{\mathrm{b}}}\left[\exp \left(\frac{A}{R T}\right)-1\right]^{-1}\left(\varphi_{\mathrm{b}}-\varphi\right),
$$

Where $\varphi=U_{\mathrm{v}} /\left[\Psi_{\mathrm{v}} P_{\mathrm{S}}(T)\right]$ is the relative humidity of the vapor-gas mixture in the capillaries $U_{\mathrm{v}}$ is volumetric concentrations of vapor phase; $\Psi_{\mathrm{v}}$ is volume fraction of the vapor in the porous body.

The thickness of the condensate layer is determined by the formula Nikitenko N.I. [4]

$$
\delta=\delta * \bar{\delta}=\delta *\left(1-\sqrt{1-P_{\mathrm{v}} / P_{\mathrm{eq}}}\right)=\delta *(1-\sqrt{1-\varphi}) .
$$

In accordance with (4), for given values of $T$ and $\varphi$ the thickness of the condensate layer on the walls of the pores is the same and equal to $\delta$ for capillaries of radius $r>\delta$, and the capillaries of radius $r \leq \delta$ are completely filled with liquid.

If the capillary-porous body is an adsorbent, in the process of sorption on its surface a monomolecular layer of condensate is formed, the molecules of which are most strongly bound to the adsorbent. Subsequent layers of bound liquid are held less tightly, and their properties approach the properties of the free liquid as they move away from the solid surface. To identify the nature and quantify the degree of influence of additional forces of interaction of a liquid particle with a solid body on the activation energy, it is convenient to use the potential of Sutherland, it describing the interaction of solid spheres with diameter $\sigma: \Phi(r)=\infty$ when $r \leq \sigma$ and $\Phi(r)=-B^{\prime} r^{-\gamma^{\prime}}$ when $r>\sigma$, where $\mathrm{B}^{\prime}$ and $\gamma^{\prime}$ are positive constants, $r$ is the distance between the spheres. Given the interaction of the liquid particle with the solid, the expression for the activation energy $A_{\text {ad }}$ can be written in the form $A_{a d}=A+\Delta A=A+B r^{-\gamma}$ where $\Delta A$ is the additional activation energy of the adsorbate molecules.

Wetting of the sorbent is carried out by supplying moist steam to its outer surface. The spent sorbent is dried by supplying it with energy from an external coolant.Transfer in capillaryporous bodies is carried out as a result of realization of several mechanisms: molecular (diffuse) and convective (filtration) transfer and transfer owing to phase transformations. In adsorption apparatuses, the processes of humidification and regeneration of sorbents are carried out at pressures lower than atmospheric. Therefore, the content of inert gases in the pores can be neglected. The movement of moisture in the material occurs in the form of liquid and vapor. Mathematical model of diffusion-filtration heat and mass transfer in a capillary-porous body, describing the processes of sorption and desorption includes the energy equation for the system as a whole and the equation of mass transfer of liquid and vapor 


$$
\begin{gathered}
c_{\mathrm{ef}}\left(\partial T / \partial t+w_{\mathrm{ef}} \nabla T\right)=\nabla\left(\lambda_{\mathrm{ef}} \nabla T\right)-L I_{V}, \\
\partial U_{\mathrm{fl}} / \partial t+\nabla\left(w_{\mathrm{fl}} U_{\mathrm{fl}}\right)=\nabla\left[D_{\mathrm{fl}}\left(\nabla U_{\mathrm{fl}}+\delta_{\mathrm{fl}}^{T} \nabla T\right)\right]-I_{V}, \\
\partial U_{\mathrm{v}} / \partial t+\nabla\left(w_{\mathrm{v}} U_{\mathrm{v}}\right)=\nabla\left[D_{\mathrm{v}}\left(\nabla U_{\mathrm{v}}+\delta_{\mathrm{v}}^{T} \nabla T\right)\right]+I_{V} .
\end{gathered}
$$

Here $U_{\mathrm{fl}}, U_{\mathrm{v}}$ - volumetric concentrations of liquid and vapor phases; $T$ - temperature; $t$ - time; $c_{\text {ef }}-$ effective heat capacity, $c_{\mathrm{ef}}=c_{\mathrm{s}} \rho_{\mathrm{s}}(1-\Pi)+c_{\mathrm{fl}} U_{\mathrm{fl}}+c_{\mathrm{v}} U_{\mathrm{v}} ; \Pi-$ the porosity of the adsorbent; $\lambda_{\mathrm{ef}}-$ effective thermal conductivity, $\lambda_{\mathrm{ef}}=\lambda_{\mathrm{s}}(1-\Pi)+\lambda_{\mathrm{fl}} U_{\mathrm{fl}} / \rho_{\mathrm{fl}}+\lambda_{\mathrm{v}} U_{\mathrm{v}} / \rho_{\mathrm{v}} ; \nabla$ is the Hamilton operator; $w_{\mathrm{ef}}-$ effective filtration rate, $w_{\mathrm{ef}}=\left(w_{\mathrm{fl}} c_{\mathrm{fl}} U_{\mathrm{fl}}+w_{\mathrm{v}} c_{\mathrm{v}} U_{\mathrm{v}}\right) / c_{\mathrm{ef}} ; w_{\mathrm{fl}}, \mathrm{w}_{\mathrm{v}}-$ are the velocity vectors of the filtration motion of the liquid and vapor phases, which, according to the Darcy law $w_{\chi}=-K_{0} K_{\chi} / \eta_{\chi} \nabla P_{\chi}(\chi=\mathrm{fl}, \mathrm{v})$ are proportional to gradient the phases $\nabla P_{\mathrm{fl}}$ and $\nabla P_{\mathrm{v}} ; L$ is the heati of phase transformation; $I_{V}$ specific intensity of phase transformations in the pores of the body; $D_{\mathrm{fl}}, \quad D_{\mathrm{v}}-$ are the effective diffusion coefficients of the liquid and the vapor, $D_{\mathrm{fl}}=\gamma_{D}\left[\exp \left(A_{D} / R T\right)-1\right]^{-1}$ (the formula is Nikitenko N.I. [4]), $D_{\mathrm{v}}=\gamma_{\mathrm{v}} T^{3 / 2} / P_{\mathrm{v}}$ (from the kinetic theory of gases), here $A_{D}$ is the activation energy of the liquid molecules for the diffusion process; $\gamma_{D}, \gamma_{\mathrm{v}}=$ const.

The pressures $P_{\mathrm{fl}}$ and $P_{\mathrm{v}}$ are calculated through the functions $U_{\mathrm{fl}}, U_{\mathrm{v}}$ and $T$ according to the following algorithm: volume fractions of the skeleton $\Psi_{\mathrm{s}}$, liquid $\Psi_{\mathrm{fl}}$ and vapor $\Psi_{\mathrm{v}}$ in the porous body: $\Psi_{\mathrm{s}}=1-\Pi, \Psi_{\mathrm{fl}}=U_{\mathrm{fl}} / \rho_{\mathrm{fl}}, \Psi_{\mathrm{v}}=1-\Psi_{\mathrm{s}}-\Psi_{\mathrm{fl}}$, partial densitie and pressure of vapor $\rho_{\mathrm{v}}=U_{\mathrm{v}} / \Psi_{\mathrm{g}}$, $P_{\mathrm{\Pi}}=\rho_{\Pi} R_{\mathrm{y}} T / \mu_{\mathrm{m}}$. The pressure of liquid phase: $P_{\mathrm{fl}}=P_{\mathrm{g}}+P_{\mathrm{c}}$, where capillary pressure $P_{\mathrm{c}}$ [5]

$$
P_{\mathrm{c}}=2 \sigma(T) \int_{r_{\min }}^{r_{\max }} \frac{\theta(r)}{r} f(r) d r / \int_{r_{\min }}^{r_{\max }} \theta(r) f(r) d r=\frac{2 \sigma(T)}{r^{*}}, \quad r_{\min }<r^{*}<r_{\max } .
$$

Here, $\theta(r)$ is the volume fraction of the capillary filled with liquid; $f(r)$ is the differential function of pore size distribution; $\sigma(T)$ is the coefficient of surface tension; $r^{*}$ is the characteristic parameter of the dispersion of pore sizes; $r_{\min }$ and $r_{\max }$ are the minimum and maximum pore radii in a unit volume.

The boundary conditions of the heat-mass transfer of the third kind for the processes of wetting and drying of the sorbents are presented as follows:

$$
\begin{aligned}
& \left.\lambda_{\mathrm{ef}} \frac{\partial T}{\partial v}\right|_{\nu=0}=\alpha\left(T_{\mathrm{e} . \mathrm{m} .}-\left.T\right|_{\nu=0}\right)-L I,(9) ; \quad D_{\mathrm{fl}}\left(\left.\frac{\partial U_{\mathrm{fl}}}{\partial v}\right|_{\nu=0}+\left.\delta_{\mathrm{fl}}^{T} \frac{\partial T}{\partial v}\right|_{\nu=0}\right)+\left.\nabla\left(w_{\mathrm{fl}} U_{\mathrm{fl}}\right)\right|_{\nu=0}= \pm I,(10) ; \\
& D_{\mathrm{v}}\left(\left.\frac{\partial U_{\mathrm{v}}}{\partial v}\right|_{v=0}+\left.\delta_{\mathrm{v}}^{T} \frac{\partial T}{\partial v}\right|_{v=0}\right)+\left.\nabla\left(w_{\mathrm{v}} U_{\mathrm{v}}\right)\right|_{v=0}=\gamma_{\mathrm{v} \text { e.m. }}\left(\left.U_{\mathrm{v}}\right|_{v=0} \mp \rho_{\mathrm{v}} \text { e.m. } \psi_{\mathrm{v}}\right) \text {. }
\end{aligned}
$$

The process of sorbents regeneration in sorption apparatuses often occurs during conductive energy supply. At the interface of the heat exchange surface with the adsorbent, the conditions of the fourth kind are set

$$
\left.\lambda \frac{\partial T}{\partial v}\right|_{\nu=-0}=\left.\lambda_{\text {ef }} \frac{\partial T}{\partial v}\right|_{\nu=+0} .
$$

The solution of the system (3) -- (6) under certain boundary conditions (9) -- (12) makes it possible to determine the values at each point of the body at each instant of time of temperature, volumetric concentrations of the liquid, vapor and air phases and other parameters, as well as the completion time of adsorption or desorption processes. For this, a grid method has been developed, which is based on an explicit three-layer recalculating difference scheme Nikitenko N.I. [5] and a computer program for the calculation has been compiled. 
The results of dynamics of moisture content and temperature change in a layer of silicagel during its moistened and regenerationare shown in Fig. 1,2.
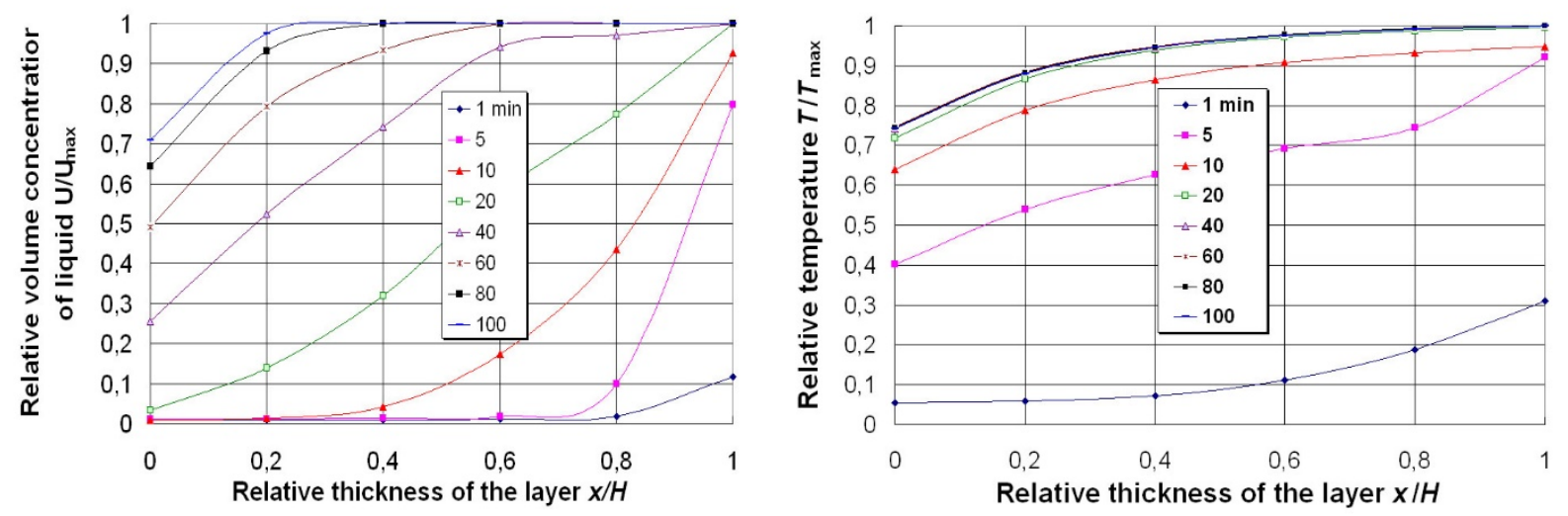

Fig. 1 The relative volumetric concentration of the liquid $\bar{U}_{\mathrm{fl}}=U_{\mathrm{fl}}(x) / U_{\mathrm{eq}}$ and the temperature $\bar{T}(x)=T(x) / T_{\max }$ in the silicagel layer at different times during adsorption. Parameters of vapor medium: $\varphi_{\mathrm{en}}=100 \%, T_{\mathrm{en}}=10^{\circ} \mathrm{C}$, body parameters: $T_{0}=10^{\circ} \mathrm{C}, T_{\text {мax }}=195^{\circ} \mathrm{C}$.
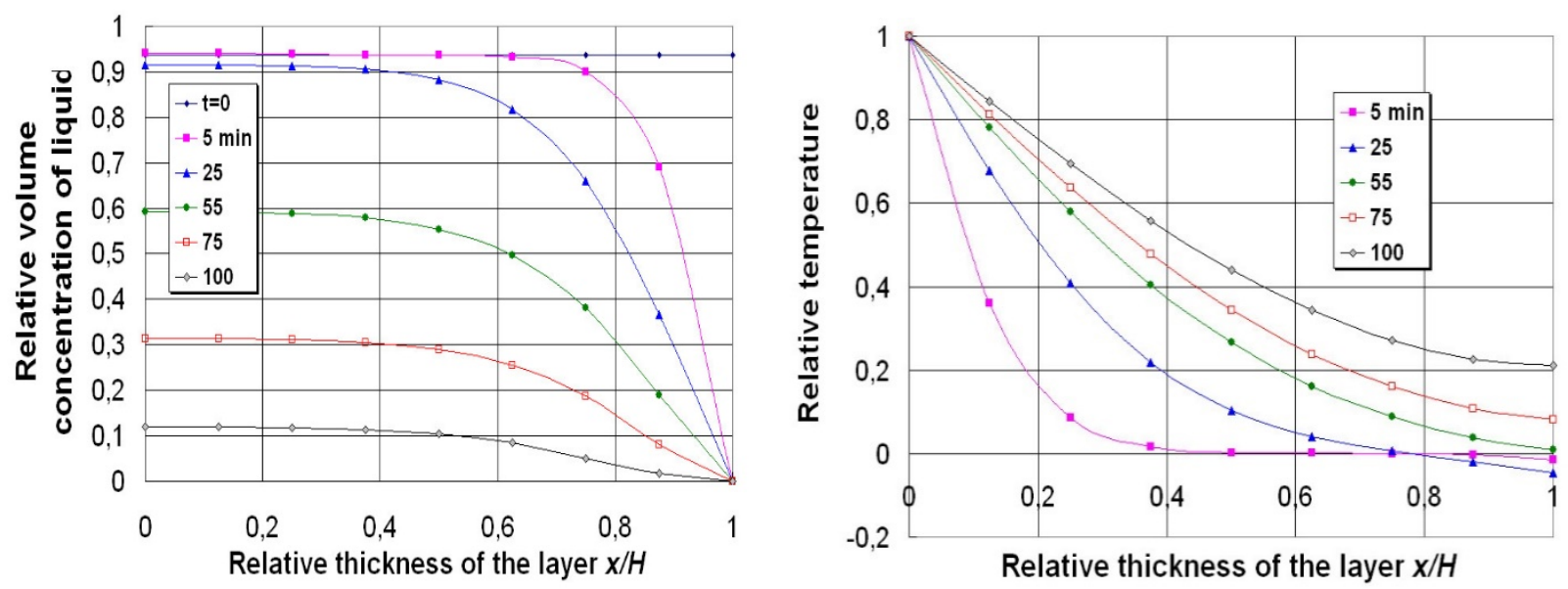

Fig.2 Relative values of volumetric liquid concentration $\bar{U}_{\mathrm{fl}}=\left(U_{\mathrm{fl}}(x)-U_{\mathrm{eq}}\right) / U_{\mathrm{fl} 0}$ and the temperature $\bar{T}(x)=\left(T(x)-T_{0}\right) /\left(T_{\text {h.s. }}-T_{0}\right)$ of the silicagel at different times of drying with a conductive method of supplying heat. $T_{0}=20^{\circ} \mathrm{C}, T_{\mathrm{h} . \mathrm{s}}=150^{\circ} \mathrm{C}$.

\section{Conclusion}

The results of comparing the calculated and experimental data on the kinetics of humidification and regeneration of different sorbents [5] indicate the adequacy of the mathematical model and the effectiveness of the calculation method.

\section{References}

[1] Keltsev, N.V. (1984) Fundamentals of adsorption technology. (2 th ed.). M.: Khimiya. 590 p. https://www.twirpx.com/file/1054811/.

[2] Zhang, L.Z. (2000). A three- dimensional non-equlibrium model for an intermittent adsorption cooling system. Solar energy, 69(1), 27-35. . http://dx.doi.org/ 10.1016/S0038092X(00)00010-4.

[3] Nikitenko, N.I., Snezhkin, Yu.F., Sorokovaya, N.N. (2010). Development of the theory and methods for calculating the dynamics of sorption and desorption. Journal of Engineering Physics and Thermophysics, 83 (4), 832-842. DOI: 10.1007/s10891-0100399-y

[4] Nikitenko, N.I. ( 2002) Investigation of the Dynamics of Evaporation of Condensed Bodies on the Basis of the Law of Spectral-Radiation Intensity of Particles. Journal of 


\section{Engineering Physics and Thermophysics, 75(3), 684-692.} https://doi.org/10.1023/A:1016813711896

[5] Nikitenko, N.I., Snezhkin, Yu.F., Sorokovaya, N.N., Kolchik, Yu.N. (2014). Molecular radiation theory and methods for calculating heat and mass transfer. Kiev: Naukova Dumka, 744 p. http://ittf.kiev.ua/wp-content/uploads/2016/12/nikitenko.pdf 


\title{
Multiple linear regression of C9 fraction inverced emulsion oligomerization
}

\author{
Roman Subtelnyi, Dariia Kichura, Yevhenii Zhuravskyi, Bohdan Dzinyak \\ Department of Technology of organic products, Lviv Polytechnic National University, UKRAINE, \\ Lviv, S. Bandery street 12, E-mail: roman.o.subtelnyi@lpnu.ua
}

\begin{abstract}
The production of hydrocarbon resins by low-temperature oligomerization in an emulsion of the 2nd kind is considered. Correlation dependences between yield, resin characteristics and process conditions are established. Statistical analysis of the yield and physicochemical characteristics of hydrocarbon resins was performed.
\end{abstract}

Keywords - petroleum resin, emulsion oligomerization, fraction C9, correlation, multiple linear regression.

\section{Introduction}

In the process of synthesis of ethylene/propylene by pyrolysis, a significant number of liquid by-products (about 30\%) are obtained. C9 fraction, containing unsaturated aromatics (styrenes and indenes), to produce aromatic oligomers. Aromatic oligomers (so-called petroleum or hydrocarbon resins) have a wide range of applications as film-forming agents in lacquer-paint and anticorrosive coatings [1,2].

We propose to use the emulsion method of oligomerization of unsaturated hydrocarbon of C9 fraction of diesel pyrolysis liquid by-products. This method can significantly reduce the process temperature and reaction time compared to the industrial methods of oligomers (hydrocarbon resins) synthesis [3].

Emulsifiers of the second kind form an emulsion of the "water-in-oil" type. Characterized by the value of hydrophilic-lipophilic balance (HLB) from 3 to 6 . The use of emulsifiers of the second kind (water-in-oil emulsion) allows for reducing the amount of water in the reaction mixture. This increases the productivity of the reaction equipment and reduces energy costs.

\section{Experimental results and discussion}

Composition of the reaction mixture of 2 nd kind emulsion oligomerization:

- $\quad$ the dispersion medium - liquid pirolisis by-products fraction C9 (density - $936 \mathrm{~kg} / \mathrm{m}^{3}$; bromine number - $68 \mathrm{~g} \mathrm{Br}_{2} / 100 \mathrm{~g}$, molecular weight - 102, the content of unsaturated compounds to $45 \%$ wt. especially: styrene - $17,85 \%$ viniltoluene $-6,99 \%$, dicyclopentadiene - 18,00\%, indene 1,25\%.);

- $\quad$ the disperse phase - water;

- $\quad$ emulsifier - used 2nd kind emulsifiers (Polyglycerol polyricinoleate - HLB $=6$; Ester A (a mixture of mono- and di-glycerides of oleic acid) HLB $=3$ )

- the initiator is soluble in the disperse phase (2nd kind emulsion) - Benzoyl Peroxide $1.0 \%$ wt. (in terms of fraction $\mathrm{C} 9$ ).

The $\mathrm{pH}$ of the reaction mixture is 2.8 . The study was performed at a reaction time of 180 min. The main studied process parameters:

- $\quad$ the reaction temperature was $303-353 \mathrm{~K}$,

- $\quad$ the emulsifier concentration $-0.6-1.0 \%$ (in terms of water),

- $\quad$ mixing intensity $(\mathrm{Re}=6870-10120)$,

- $\quad$ the volume ratio fraction C9: water - [1:1] - [1:5].

Microsoft Excel was used for the correlation index calculations. As confirmed by the average correlation indices (per module), the emulsion oligomerization temperature has the least 
effect on the process. The most significant effect $(0.81)$ on the yield of oligomers has the reaction duration. The results are shown in Table. 1.

Table 1

Correlation of petroleum resins characteristics and reaction conditions

\begin{tabular}{|c|c|c|c|c|c|}
\hline \multirow[b]{2}{*}{ Characteristic } & \multicolumn{5}{|c|}{ Correlation index } \\
\hline & $\begin{array}{c}\text { reactio } \\
\mathrm{n} \\
\text { duratio } \\
\mathrm{n}\end{array}$ & $\begin{array}{c}\text { temperatur } \\
\mathrm{e}\end{array}$ & $\begin{array}{c}\text { emulsifier } \\
\text { concentration }\end{array}$ & $\begin{array}{l}\text { phase } \\
\text { ratio }\end{array}$ & $\begin{array}{l}\text { mixing } \\
\text { intensity }\end{array}$ \\
\hline Yield & 0,81 & 0,30 & 0,03 & 0,51 & 0,51 \\
\hline Bromine number & $-0,83$ & $-0,27$ & 0,08 & $-0,57$ & $-0,06$ \\
\hline $\begin{array}{l}\text { Molecular } \\
\text { weight }\end{array}$ & $-0,28$ & 0,02 & 0,59 & 0,24 & 0,05 \\
\hline Softening point & 0,11 & 0,15 & 0,31 & 0,23 & $-0,05$ \\
\hline Color index & 0,54 & 0,45 & $-0,52$ & 0,05 & $-0,26$ \\
\hline
\end{tabular}

Multiple linear regression is suggested (Eq. 1). For it's construction, the parameters that have the most significant impact on the course of the oligomerization reaction are selected.

Table 2

Factors identified multiple linear regression

\begin{tabular}{|c|c|c|c|}
\hline $\begin{array}{c}\text { mixing intensity (M) } \\
\text { b3 }\end{array}$ & $\begin{array}{c}\text { the volume ratio of the phases (R) } \\
\text { b2 }\end{array}$ & $\begin{array}{c}\text { reaction duration (D) } \\
\text { b1 }\end{array}$ & b0 \\
\hline 0,0046 & 0,0924 & 0,0603 & $-8,9825$ \\
\hline
\end{tabular}

The dependence of the oligomer yield (Y) on the considered parameters (multiple linear regression) is described by the equation:

$$
Y=-8,9825+\mathrm{D} * 0,0603+\mathrm{R} * 0,0924+\mathrm{M} * 0,0046
$$

The calculated Fisher criterion is 95,593 . It's indicates the high adequacy of the proposed multiple linear regression [4].

\section{Conclusion}

The main correlations of the yield and petroleum resins characteristics to the reaction conditions are established. It is confirmed that the product yield depends on all process conditions. Multiple linear regression is suggested.

\section{References}

[1] Zohuriaan-Mehr, M. J., \& Omidian, H. (2000). Petroleum resins: an overview. Journal of Macromolecular Science, Part C: Polymer Reviews, 40(1), 23-49.

[2] Mildenberg, R., Zander, M., \& Collin, G. (2008). Hydrocarbon resins. John Wiley \& Sons.

[3] Fuch, U. V., Dzinyak, B. O., \& Subtelnyy, R. O. (2015). Study of emulsifier nature effect on the process of hydrocarbon fraction cooligomerization in the emulsion. EasternEuropean Journal of Enterprise Technologies, 4(6(76), 54-57.

[4] Mansouri, M., Sheriff, M. Z., Baklouti, R., Nounou, M., Nounou, H., Hamida, A. B., \& Karim, N. (2016). Statistical fault detection of chemical process-comparative studies. Journal of Chemical Engineering \& Process Technology, 7(1), 282-291. 


\section{DEVELOPMENT, ENERGY AND RESOURCE SAVING IN THE CHEMICAL AND FOOD TECHNOLOGIES}




\title{
Slag of thermal power plants as an attractive raw material for porous fillers production
}

\author{
Diana Kindzera $^{1}$, Ihor Mitin ${ }^{2}$, Volodymyr Atamanyuk ${ }^{3}$, Roman Hosovskyi ${ }^{4}$
}

1. Department of Chemical Engineering, Lviv Polytechnic National University, UKRAINE, Lviv,12 S. Bandery Str., E-mail: kindzera74@ukr.net

2. Department of Chemical Engineering, Lviv Polytechnic National University, UKRAINE, Lviv, 12 S. Bandery Str., E-mail: ihor.mitin.mxt.2020@lpnu.ua

3. Department of Chemical Engineering, Lviv Polytechnic National University, UKRAINE, Lviv,12 S. Bandery Str., E-mail: atamanyuk@ukr.net

4. Department of Chemical Engineering, Lviv Polytechnic National University, UKRAINE, Lviv, 12 S. Bandery Str., E-mail: roma5477@meta.ua

\begin{abstract}
The possibility of using TPP slag as the raw material for the production of porous filler has been proved. This approach increases the savings of natural resources, reduces the cost of finished product and reduces the level of environmental pollution. Insignificant values of the pressure drop confirm the application feasibility of the filtration drying as an energy-saving method of the drying of slag and clay for the preparation of the charge for porous filler production. Obtained results on kinetics are useful for the organization and intensification of the filtration drying process of slag and clay as the preliminary stage at the porous fillers production line. The qualitative new porous filler with the bulk density of $230 \mathrm{~kg} / \mathrm{m}^{3}$, the specific heat of $0,82 \mathrm{~kJ} / \mathrm{kg} \cdot \mathrm{K}$, the thermal conductivity of 0,067 $\mathrm{W} / \mathrm{m}^{2} \cdot \mathrm{K}$ and with a compressive strength of $27,7 \mathrm{MPa}$ has been obtained which can be used for the production of lightweight concretes.
\end{abstract}

Keywords - thermal power plant (TPP), ash and slag wastes, utilization, porous filler, filtration drying, lightweight concrete.

\section{Introduction}

In recent years, the growing demand for electricity and heat has increased the number of worldwide thermal power plants (TPP). The operation of power plants leads to air pollution and the accumulation of significant amount of solid wastes such as slag and ash which are formed as a result of the solid fuel combustion, especially coal, and are stored in ash slag dumps. Most of the ash and slag dumps of Ukrainian thermal power plants are practically already filled, and there is no possibility to expand them due to lack of territory. Therefore, environmental management of ash slag is essential for individual thermal energy companies and Ukraine as a whole and finding the methods of waste utilization is an essential task.

One of the rational method of slag and fly ash utilization is to involve them in the production process, which corresponds to current trends in technology in industrialized countries. In order to develop cost-effective organizational and technical solutions for the management with the solid wastes of TPP, the experience of developed countries was taken into account and separate extraction of ash and slag was introduced at some TPPs of Ukraine. This technical solution allows to use dry ash as an additive for concrete, mortar, cement, as well as to use it for production of silicate products, glass ceramics and road construction $[1,2]$.

One of the most efficient methods to reduce the slag volume is to transform it into potential resources. However, its humidity is very high caused by hydraulic method of removal and transportation to the dumps. Therefore, only a small amount of slag is used for industrial purposes.

Slag, which is formed in large quantities in coal-fired thermal power plants, is considered an attractive material for cost-effective porous fillers production creating new market opportunities. Reserves of well-bloating clay rocks as the raw materials for artificial porous 
fillers production are decreasing with every year. Therefore, the use of slags of TPP in the production of artificial porous fillers becomes actual [3].

Slag and clay, as the raw materials for industrial purposes, should be dried in view of it high moisture content. Since the cost of drying is a significant, finding alternative drying methods with designing new constructions of dryers is an urgent task. Therefore, to implement the drying process of slag and clay, we propose the filtration drying method which gives an opportunity to intensify mass and heat transfer processes and to reduce the drying agent amount, drying time and energy loss through outlet drying agent [4].

\section{Results and Discussions}

Comparing the chemical composition of clay and slag, we can observe that they are close to the main chemical components. Thus, to preserve the formulary capacity of the filler samples, part of the raw clay material can be replaced with slag. Furthermore, there is a greater amount of $\mathrm{Fe}_{2} \mathrm{O}_{3}$ in the slag $(20,6 \%)$ than in the clay $(6,5 \%)$, as well as sufficient amount of $\mathrm{Na}_{2} \mathrm{O}+\mathrm{K}_{2} \mathrm{O}$ $(1,5+0,7 \%)$ in the slag that plays a big role in bloating under the influence of high temperatures. Thus, the possibility of using TPP slag as the raw material for the production of porous filler is proved.

Investigation of the hydrodynamics and kinetics of the filtration drying process of slag and clay was performed by using experimental plant. Insignificant values of the pressure drop confirm the application feasibility of the filtration drying as an energy-saving method of the drying of slag and clay. The influence of the drying agent temperature on the kinetic during filtration drying of slag and clay was investigated. Results in the form of graphs are represented in Fig. 1.
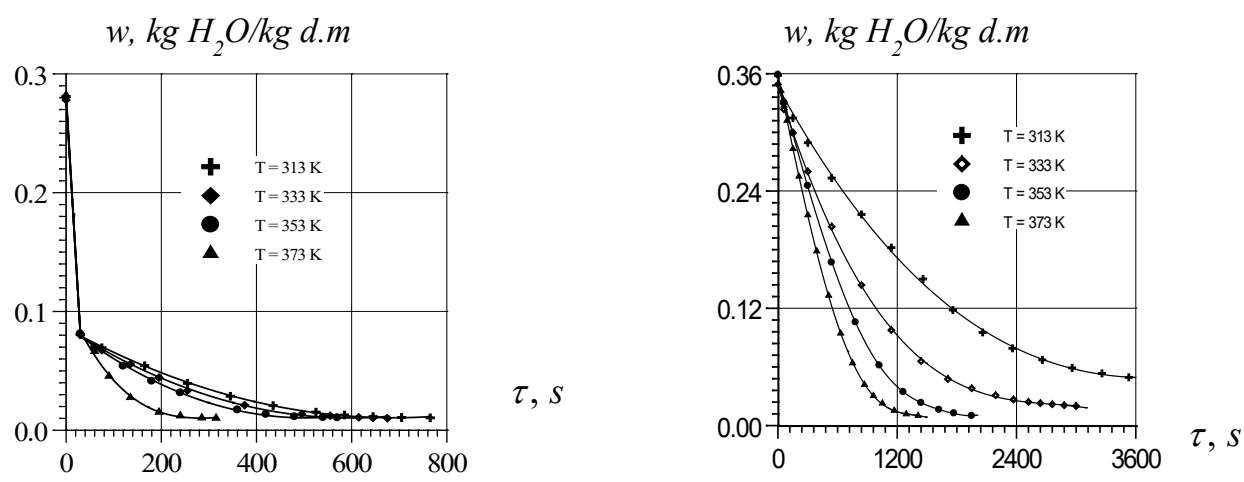

Fig. 1. The influence of the drying agent temperature on the kinetics during filtration drying of slag and clay: $\left(v_{0}=1,33 \mathrm{~m} / \mathrm{s}, H=0,12 \mathrm{~m}\right)$.

Obtained results (Fig. 1) are useful for the organization and intensification of the filtration drying process of slag and clay as the preliminary stage at the porous fillers production line.

Raw granules (samples of porous filler) were prepared in the form of cubes with size $15 \times 15 \times 15 \mathrm{~mm}$ by using a dispersed charge which includes clay 55\%, slag TPP $35 \%$, burning additives (sawdust and coal) 5\%, binding and gas-forming additives 5\%. The physicalmechanical properties of the filler prepared on base of TPP slag are shown in Table 1.

Table 1

Physical-mechanical parameters of the filler prepared on base of TPP slag

\begin{tabular}{|c|c|}
\hline Bulk density & $230 \mathrm{~kg} / \mathrm{m}^{3}$ \\
\hline Specific heat & $0,82 \mathrm{~kJ} /(\mathrm{kg} \cdot \mathrm{K})$ \\
\hline Thermal conductivity & $0,067 \mathrm{~W} /\left(\mathrm{m}^{2} \cdot \mathrm{K}\right)$ \\
\hline Compressive strength & $27,7 \mathrm{MPa}$ \\
\hline
\end{tabular}


The physical-mechanical properties of the porous filler obtained from TPS slag correspond to the requirements of DSTU B B.2.6-189: 2013 "Methods of selection of thermal insulation material for building insulation" and obtained filler can be recommended for the production of lightweight concretes.

\section{Conclusion}

The possibility of using TPP slag as the raw material for the production of porous filler has been proved. The main benefits of using such wastes in the production process are environmental protection, conservation of raw resources for the production of finished products.

Insignificant values of the pressure drop confirm the application feasibility of the filtration drying as an energy-saving method of the drying of slag and clay for the preparation of the charge for porous filler production and results of the kinetics investigation are useful for the organization and intensification of the filtration drying process of slag and clay as the preliminary stage at the porous fillers production line.

The qualitative new lightweight filler with the bulk density of $230 \mathrm{~kg} / \mathrm{m}^{3}$, the specific heat of $0,82 \mathrm{~kJ} / \mathrm{kg} \cdot \mathrm{K}$, the thermal conductivity of $0,067 \mathrm{~W} / \mathrm{m}^{2} \cdot \mathrm{K}$ and with a compressive strength of $27,7 \mathrm{MPa}$ has been obtained which can be used for the production of lightweight concretes.

\section{References}

[1] Cheng, T.W., Chen, Y.S. (2004). Characterisation of glass ceramics made from incinerator fly ash. Ceramics International, 30, 343-349. https://doi.org/10.1016/S02728842(03)00106-8

[2] Ahmaruzzaman, M., (2010). A review on the utilization of fly ash, Progress in Energy and Combustion Science, 36, 327-363. https://doi.org/10.1016/j.pecs.2009.11.003

[3] Mammadov, H., Suleymanova, I. (2010). An artificial porous gravel based on slags of thermal power stations. International Journal of Recent Scientific Research v. 9, Issue, 11(C), 29645-29649. http://dx.doi.org/10.24327/ijrsr.2018.0911.2899 .

[4] Hosovskyi, R., Kindzera, D., Atamanyuk, V. (2016). Diffusive mass transfer during drying of grinded sunflower stalks. Chemistry \& Chemical Technology, 10(4), 459-464. https://doi.org/10.23939/cte2019.01.105 


\title{
Installation for research of hydrogen sulfide chemisorption from gases by a quinhydrone absorbing solution under pressure
}

\author{
Andriy Slyuzar, Zenoviy Znak, Yaroslav Kalymon \\ Department of Chemistry and Technology of Inorganic Substances, Lviv Polytechnic National University, \\ UKRAINE, Lviv, 12 S. Bandery str. E-mail: Andrii.V.Sliuzar@lpnu.ua
}

\begin{abstract}
Theoretical bases for the development of an experimental installation of hydrogen sulfide chemisorption from oxygen-free gases by the quinhydrone method under a pressure of up to $10 \mathrm{MPa}$ are described. As a source of hydrogen sulfide-containing gas, it is proposed to use a mixture of industrial compressed nitrogen from cylinders and hydrogen sulfide from its liquefaction installation.
\end{abstract}

Keywords - hydrogen sulfide, liquefaction, chemisorption, pressure, experimental installation, quinhydrone absorbing solution.

\section{Introduction}

Natural and process gases are often under high pressure $(0.5 \ldots 10 \mathrm{MPa})$. It is advisable to carry out the stage of hydrogen sulfide chemisorption under pressure in the quinhydrone method of gas purification from hydrogen sulfide [1-3]. In the literature, studies of the processes of hydrogen sulfide chemisorption by quinhydrone absorbing solution under pressure are not presented. Therefore, there is a need for such studies.

The main difficulty in creating an experimental installation was to provide a source of hydrogen sulfide. There are methods of obtaining it (in the gaseous state at some excess pressure) from sodium or aluminum sulfide solution by acid decomposition with sulfuric or other acids [4]. The industry does not produce compressed hydrogen sulfide in cylinders. Only the use of hydrogen sulfide in low-volume cylinders compressed to low pressure ( $3 \mathrm{~atm})$ is known [5]. Therefore, the question arose of obtaining a mixture of hydrogen sulfide in the laboratory under high pressure and ensuring a constant gas pressure for some time with a stable flow rate.

The work aimed to develop the theoretical basis for the creation of an experimental installation for the study of hydrogen sulfide chemisorption from gases by a quinhydrone absorbing solution at a pressure of up to $10 \mathrm{MPa}$.

\section{Results and discussion}

The solution to the problem of obtaining a source of hydrogen sulfide under pressure, we found in the statement about the conditionality of the separation of the substances into gases and liquids. Gases have very low critical temperatures and therefore cannot be in a liquid state at room temperature. Instead, substances classified as liquids have high critical temperatures. Any gas can be converted into a liquid, but it is necessary to pre-cool the gas to a temperature below critical. For example, carbon dioxide can liquefy at room temperature because its critical temperature is $31.1{ }^{\circ} \mathrm{C}$ and above room temperature. The same applies to gases such as ammonia $\left(132.25^{\circ} \mathrm{C}\right)$ or chlorine $\left(143.75^{\circ} \mathrm{C}\right)$. But some gases cannot be liquefied at room temperature. These include air (nitrogen, oxygen, and argon), as well as hydrogen and helium, in which critical temperatures are much lower than room temperature. Such gases have wide practical use as refrigerants. To liquefy them, they must be pre-cooled to a temperature below the critical temperature, and then - compressed.

Two methods are usually used in industry for cooling and liquefying gases. The first method of gas liquefaction is associated with the phenomenon of changes in gas temperature during its adiabatic expansion by throttling from one constant pressure to another. The second method of gas liquefaction is carried out by cooling the gas during adiabatic expansion in the 
expanders and the implementation of external work. The method of adiabatic cooling by throttling is simpler. It does not cause the problem of lubrication of moving parts of devices operating at low temperatures.

Consider the properties of liquid hydrogen sulfide. According to [6], the critical constants of hydrogen sulfide $\mathrm{t}_{\mathrm{cr}}=100.4{ }^{\circ} \mathrm{C} ; \mathrm{P}_{\mathrm{cr}}=88.9 \mathrm{~atm}$. The dependence of the pressure $(\mathrm{P}$, atm $)$ of saturated vapor on the temperature in the range from boiling point to critical $(T, K)$ is described by the equation

$$
\lg P=4.441-\frac{930.5}{T} .
$$

The density $\left(\rho, \mathrm{g} / \mathrm{cm}^{3}\right)$ of liquefied hydrogen sulfide at temperatures $(\mathrm{t})$ from -82 to $-63{ }^{\circ} \mathrm{C}$ is described by the equation

$$
\rho=0.866-1.63 \times 10^{-3} \text {. }
$$

The boiling point or sublimation of hydrogen sulfide at different pressures are presented in table 1 [7].

Table 1

Boiling point or sublimation of hydrogen sulfide at different pressures [7]

\begin{tabular}{|c|c|c|c|c|c|}
\hline $\mathrm{P}, \mathrm{mm} \mathrm{Hg}$ & $\mathrm{t}_{\text {boil }},{ }^{\circ} \mathrm{C}$ & $\mathrm{P}$, atm & $\mathrm{t}_{\text {boill }},{ }^{\circ} \mathrm{C}$ & $\mathrm{P}$, atm & $\mathrm{t}_{\text {boill }},{ }^{\circ} \mathrm{C}$ \\
\hline 0,1 & $-153,6$ (solid) & 1 & $-60,2$ & 20 & 25,5 \\
\hline 1 & $-134,6$ (solid) & 2 & $-45,9$ & 40 & 55,8 \\
\hline 10 & $-116,5$ (solid) & 5 & $-22,3$ & 50 & 66,7 \\
\hline 100 & $-92,4$ (solid) & 10 & $-0,4$ & 60 & 76,3 \\
\hline
\end{tabular}

As you can see, at a temperature of $25{ }^{\circ} \mathrm{C}$ and a pressure of more than 20 atm concentrated $(100 \%)$ hydrogen sulfide will be in a liquid state. The critical temperature of hydrogen sulfide indicates that its liquefaction can be easily achieved by conventional cooling. At a pressure of 1 atm, it can be liquefied at a temperature of $-60.2{ }^{\circ} \mathrm{C}$ or less.

In the laboratory, cooling mixtures and refrigerants are used to cool and liquefy gases. These are usually various liquefied gases that are boiling. One of the effective and available refrigerants is nitrogen, the boiling point of which is $-195.75^{\circ} \mathrm{C}$.

Analysis of the above dependences made it possible to propose hydrogen sulfide in the liquefied state to create a hydrogen sulfide-containing gas mixture under pressure. As a carrier of hydrogen sulfide, which will ensure the flow of gas under pressure, we proposed to use industrial gas nitrogen from cylinders. Mixing nitrogen with hydrogen sulfide vapors will make it possible to obtain a hydrogen sulfide-containing gas mixture of a certain composition with a stable flow rate and pressure. An additional parameter for regulating the composition of the gas mixture may be a change in the temperature of the liquefied hydrogen sulfide.

To implement this method, we have developed a special design of a container (cylinder) for obtaining and storing liquefied hydrogen sulfide and a method of its filling, and also proposed the design of a bubble-type absorber for studies of hydrogen sulfide chemisorption under pressure by quinhydrone absorbing solution. Assistance in the design and manufacture of equipment was provided by specialists of Karpatnaftochim LTD (Kalush, Ivano-Frankivsk region).

Particular attention in the design of the installation for research was paid to the selection of materials for the manufacture of both the apparatus for storing hydrogen sulfide (cylinder) and other components of the installation. Hydrogen sulfide-containing gases under pressure in the presence of moisture are extremely corrosive. The problem of sulfide cracking of welded 
pipelines and equipment is especially acute in the gas industry due to the development of fields with significant impurities of hydrogen sulfide and other harmful substances [5]. The destruction of the metal in some cases can be very intense, which causes a great danger of production. As the partial pressure of hydrogen sulfide increases, the flooding of steel and the rate of its corrosion increase.

The initial data for the selection of structural material for the capacity of liquefied hydrogen sulfide (cylinder) were: operating temperature limits $-190 \ldots+70{ }^{\circ} \mathrm{C}$, the design pressure of $16 \mathrm{MPa}$. The construction material - steel 10X17H13M2T was chosen, the corresponding calculations were carried out and the cylindrical vertical device with the welded hemispherical bottom and a flat cover with two unions on a special carving is made. Fastening of a cover to the case - flange on 8 hairpins of $\mathrm{M} 30 \times 170$, a face type of "tongue-groove" with a paronite gasket. The main dimensions of the device: inner diameter $\mathrm{D}=0.1020 \mathrm{~m}$, thickness of the shell and bottom $\mathrm{S}=\mathrm{S}_{\mathrm{b}}=14 \mathrm{~mm}$, flat cover $\mathrm{S}_{\mathrm{c}}=32 \mathrm{~mm}$. Volume $\mathrm{V}=2 \mathrm{dm}^{3}$.

Initially, the cylinder was filled with hydrogen sulfide. The scheme of installation for filling is presented in figure 1.

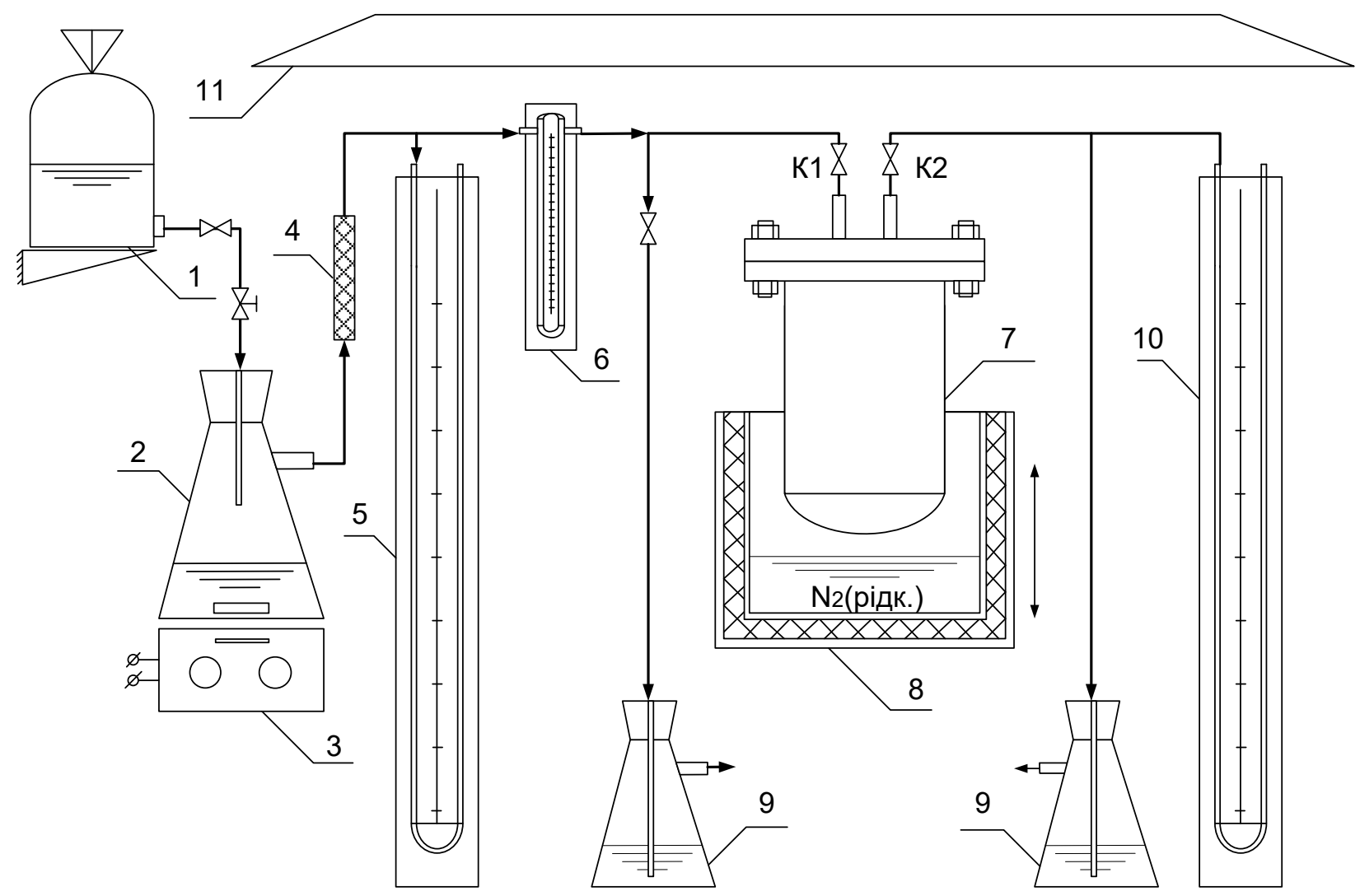

Fig.1 The scheme of installation of a cylinder filling with hydrogen sulfide.

The production of liquefied hydrogen sulfide is due to its production in the gaseous state. To do this, a solution of sodium sulfide was decomposed with a solution of sulfuric acid (1:4 wt.) in tank 2. Sulfuric acid was fed from vessel 1 under hydraulic pressure. Mixing of the reagents was performed using a magnetic stirrer 3 . The resulting hydrogen sulfide gas was purified in an absorber 4 . The pressure and gas flow were controlled by a manometer 5 and a rheometer 6 . First, all the hydrogen sulfide (unstable flow rate) was sent for sanitation in absorber 9, filled with an acidified solution of potassium permanganate. Gas with a stable flow rate has already flowed into cylinder 7. Liquid nitrogen (from JSC "Lviv Chemical Plant") was poured into a thermostated tank 8 from the Dewar tank. Due to the decrease in temperature, the gas liquefied 
and a vacuum was formed in cylinder 7. The pressure stability in the system is ensured by regulating the acid supply to tank 2 and regulating the liquid nitrogen level in tank 8 . The pressure was monitored using U-shaped manometers 5 and 10 filled with mineral oil. Uncondensed gases were supplied for sanitation to tank 9.

Due to such repetitive operations (7-10), it was possible to obtain $0.5 \ldots 0.6 \mathrm{dm}^{3}$ of liquefied hydrogen sulfide. With the help of taps K1 and K2 carried out the overlap of gas flows into and out of cylinder 7.

The research of hydrogen sulfide chemisorption under pressure was carried out on the installation, the scheme of which is shown in Figure 2. This experimental installation was mounted at LLC "Lviv Experimental Mechanical Plant” (Lviv).

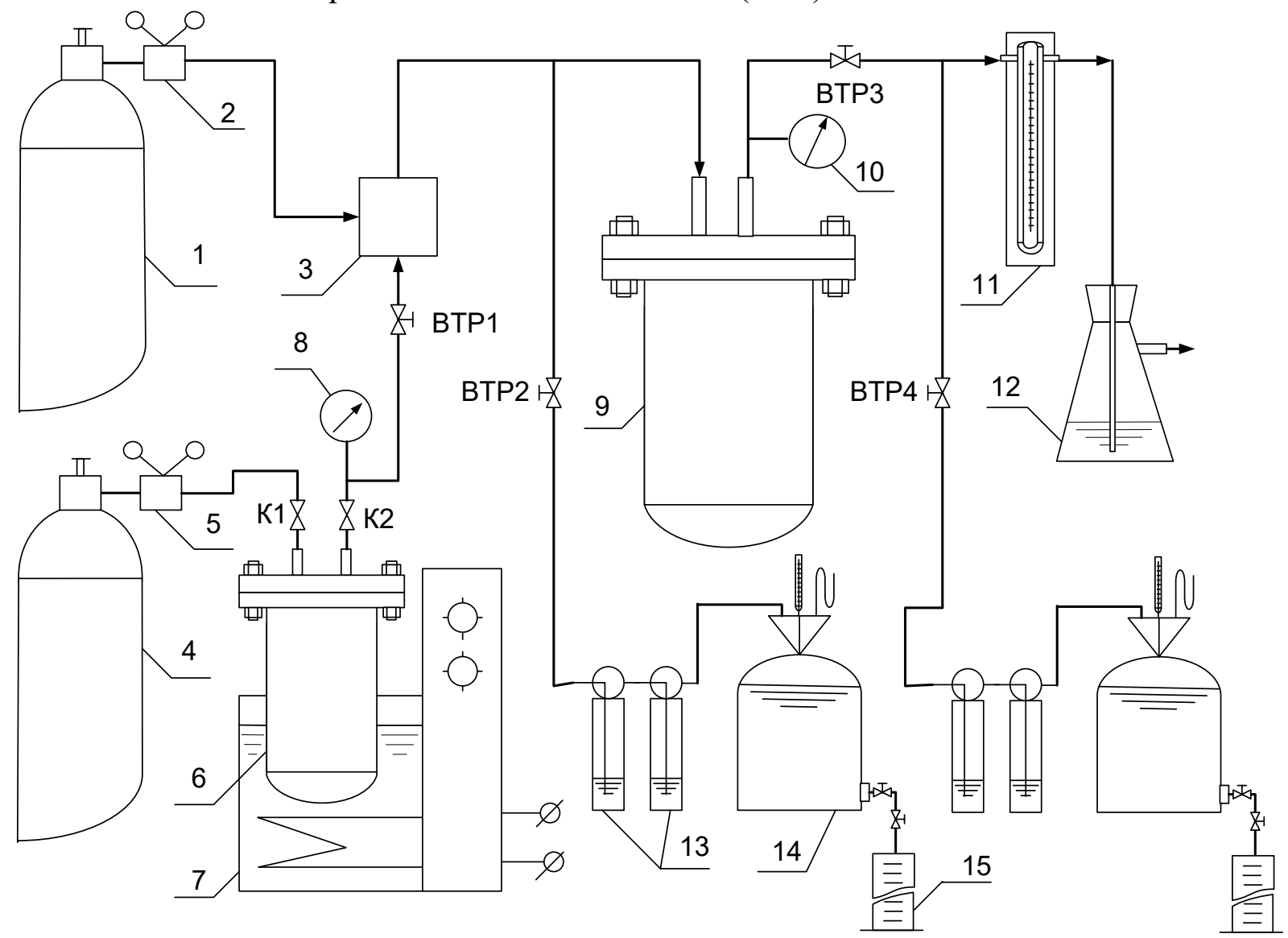

Fig.2 Scheme of installation for research of hydrogen sulfide chemisorption under pressure

Industrial nitrogen for the production of nitrogen-hydrogen sulfide mixture was used from cylinder 1 (from JSC "Lviv Chemical Plant"). The gas was fed into the gas mixer 3. The $\mathrm{H}_{2} \mathrm{~S}$ supply to the gas mixture was regulated by the BTP-1 valve (fine control valve). To compress ("blow out") $\mathrm{H}_{2} \mathrm{~S}$ from cylinder 6 , nitrogen supply was provided under slightly higher pressure from cylinder 4 . The pressure and nitrogen supply were regulated using a reducer 5 . The use of thermostat 7 also made it possible (by heating and increasing pressure) to increase the partial pressure of hydrogen sulfide in the gas mixture.

After mixer 3, the gas mixture was sent to absorber 9 for chemisorption of $\mathrm{H}_{2} \mathrm{~S}$ with quinhydrone absorbing solution in bubbling mode. The pressure in absorber 9 was monitored by a manometer 10 .

The initial data for the selection of structural material for the absorber were as follows: operating temperatures $+15 \ldots+45{ }^{\circ} \mathrm{C}$, design pressure $16 \mathrm{MPa}$. The construction material was chosen - steel 20 , the appropriate calculations were performed and a cylindrical vertical device 
with a welded hemispherical bottom and a flat cover with two fittings for special threads was made. Fastening of a cover to the case - flange on 8 hairpins of M30×170, a face type of "tongue-groove" with a paronite gasket. The main dimensions of the absorber: inner diameter D $=0.105 \mathrm{~m}$; the height of the inner cylindrical part $\mathrm{H}=0.5 \mathrm{~m}$, the thickness of the shell and bottom $\mathrm{S}=\mathrm{S}_{\mathrm{b}}=14 \mathrm{~mm}$, the thickness of the flat cover $\mathrm{S}_{\mathrm{c}}=34.0 \mathrm{~mm}$, the volume of the apparatus $\mathrm{V}=4.5 \mathrm{dm}^{3}$.

Valves BTP-2 and BTP-4 (before and after the absorber, respectively) in the installation were provided for gas sampling for hydrogen sulfide content. After hydrogen sulfide chemisorption in the absorber, the gas through the valve BTP-3 was fed for sanitation in a container 12, and released into the atmosphere.

After each series of studies, the pressure in the absorber was vented by releasing gas through the neutralization system 12. To regenerate the absorption solution after a series of studies, the air was supplied to the absorber using a compressor (not shown in figure 2).

The developed installation allows studying the influence of gas pressure and initial concentration of sodium carbonate in quinhydrone absorption solution on the degree of hydrogen sulfide chemisorption from a gas mixture.

\section{Conclusion}

1. Theoretical principles of obtaining a nitrogen - hydrogen sulfide gas mixture under pressure have been developed. The source of hydrogen sulfide is liquefied gas.

2. An experimental setup for the study of $\mathrm{H}_{2} \mathrm{~S}$ chemisorption from gases under pressure up to 10 MPa by a quinhydrone absorbing solution was developed and fabricated.

\section{References}

[1] Lobojko, A.Ya. (Ad.) (1993). Kataliticheskie i massoobmennye processy pod davleniem v tekhnologii neorganicheskih veshchestv. [Catalytic and mass transfer processes under pressure in the technology of inorganic substances]. Har'kov: Osnova. (in Russian)

[2] Slyuzar, A., Kalymon, Ya, Znak, Z., \& Helesh, A. (2020). Investigating equilibrium in the system of a hydrogen sulfide-quinhydrone absorbing solution. Eastern-European Journal of Enterprise Technologies, 5, 6(107), 76-82. https://doi.org/10.15587/17294061.2020.214425.

[3] Kohl, A.L., \& Nielsen, R.B. (1997). Gas Purification. (5-th ed.), Houston: Gulf Publishing Company.

[4] Karyakin, Yu.V., \& Angelov I.I. (1974). Chistye himicheskie veshchestva. [Pure chemicals] (4-th ed.). Moskva: Himiya. (in Russian)

[5] Pokhmurskii, V.I., \& Khoma, M.S. (2008). Koroziina vtoma metaliv ta splaviv. [Corrosion fatigue of metals and alloys]. Lviv: SPOLOM. (in Ukrainian).

[6] Kratkij spravochnik himika. [A brief guide to the chemist] (1964). Moskva-Leningrad: Himiya. (in Russian)

[7] Mel'nik, B.D. (1975). Inzhenernyj spravochnik po tekhnologii neorganicheskih veshchestv. Grafiki $i$ nomogrammy. [Engiering Handbook of Inorganic Substances Technology. Graphs and nomograms]. Moskva: Himiya. (in Russian) 


\title{
Autonomous catalytic hydrogen generator based on bioethanol steam reforming
}

\author{
L.Y. Dolgikh, A.I. Trypolskyi, I.L. Stolyarchuk, Y.I. Pyatnitsky, P.E. Strizhak
}

L.V. Pisarzhevskii Institute of Physical Chemistry of National Academy of Sciences of Ukraine, UKRAINE, Kyiv, Prospekt Nauki, 31, E-mail:atripolski@gmail.com

- Abstract-The generator is based on bioethanol steam reforming over the developed ferrite catalyst. The generator admits the utilization of thermal energy of the reaction mixture for vaporization and heating the input water-alcohol mixture. The generator is characterized by a simple single-stage design without a stage for hydrogen purification.

- Keywords - hydrogen, catalytic generator, bioethanol, steam reforming.

\section{Introduction}

The process of ethanol steam reforming (ESR) is a promising way for hydrogen production from liquid bio-materials: $\mathrm{C}_{2} \mathrm{H}_{5} \mathrm{OH}+3 \mathrm{H}_{2} \mathrm{O} \rightarrow 6 \mathrm{H}_{2}+2 \mathrm{CO}_{2}$. Theoretically, it allows obtaining $50 \%$ of hydrogen from ethanol and $50 \%$ of hydrogen from water. Hydrogen production from bioethanol by ESR does not affect the concentration of carbon dioxide in the atmosphere. Hydrogen produced via steam reforming from the renewable feed may be efficiently utilized for electric energy production, particularly, for small-scale electricity supply. Coupling the steam reforming with a fuel cell establishes a new kind of technology for power generation. Using portable power systems based on fuel cell application simultaneously resolves the two issues of hydrogen use, particularly, safe hydrogen storage and its transportation [1]. Using diluted bioethanol significantly reduces the energy cost compared to pure ethanol reforming. In the catalytic ESR process, the choice of the appropriate catalyst is a key factor for ethanol conversion and high hydrogen selectivity.

\section{The testing activity of ferrite catalysts for the ESR reaction}

Many solid catalysts have been explored for the ESR reaction, in the overwhelming majority, they were supported metals, including $\mathrm{Ni}, \mathrm{Co}, \mathrm{Cu}, \mathrm{Rh}, \mathrm{Ru}, \mathrm{Pd}$, Ir, and Pt [2]. An only a limited number of other types of catalysts have been employed for this reaction, among them, simple and complex oxides [3]. The comparative study of the ferrites $\mathrm{MFe}_{2} \mathrm{O}_{4}(\mathrm{M}=\mathrm{Mg}, \mathrm{Mn}, \mathrm{Fe}$, $\mathrm{Co}, \mathrm{Ni}, \mathrm{Cu}, \mathrm{Zn})$ as the catalysts for the ethanol steam reforming reaction has been performed. The nanoparticles of ferrites $\mathrm{MFe}_{2} \mathrm{O}_{4}$ were synthesized by two different procedures: by solvothermal decomposition of heteronuclear complexes $\left[\mathrm{MFe}_{2} \mathrm{O}\left(\mathrm{CH}_{3} \mathrm{COO}\right)_{6}\left(\mathrm{H}_{2} \mathrm{O}\right)_{3}\right] \cdot 2 \mathrm{H}_{2} \mathrm{O}(\mathrm{M}=$ $\mathrm{Mn}, \mathrm{Co}, \mathrm{Ni})$; by chemical co-precipitation method $(\mathrm{M}=\mathrm{Mg}, \mathrm{Mn}, \mathrm{Fe}, \mathrm{Cu}, \mathrm{Zn})$. The catalytic properties of ferrites were investigated at $250-700{ }^{\circ} \mathrm{C}$.

The nanosize ferrites $\mathrm{MFe}_{2} \mathrm{O}_{4}(\mathrm{M}=\mathrm{Mg}, \mathrm{Mn}, \mathrm{Fe}, \mathrm{Co}, \mathrm{Ni}, \mathrm{Cu}, \mathrm{Zn})$ are catalytically active in the process of steam reforming of ethanol. The X-ray diffraction data of the ferrites before and after catalysis indicates that the crystal structure of $\mathrm{MnFe}_{2} \mathrm{O}_{4}$, as distinct from nickel, cobalt, and copper ferrites, remains completely unchanged; it was observed only agglomeration of the $\mathrm{MnFe}_{2} \mathrm{O}_{4}$ crystallites and appearance of a negligible amount of complex oxide $\mathrm{FeO} / \mathrm{MnO}$ as result of partial reduction of manganese ferrite. According to XRD and electron diffraction data of other investigated ferrites obtained by the co-precipitation method, the crystalline phases of ferrites $\mathrm{FeFe}_{2} \mathrm{O}_{4}, \mathrm{MnFe}_{2} \mathrm{O}_{4}, \mathrm{MgFe}_{2} \mathrm{O}_{4}$, and $\mathrm{ZnFe}_{2} \mathrm{O}_{4}$ with a lattice of the spinel type were identified. The stability of $\mathrm{MFe}_{2} \mathrm{O}_{4}$ ferrites depends on a reducing ability of $\mathrm{M}^{2+}$ cations in the conditions of the ESR where hydrogen is a reducing agent. 
Ethanol is converted on the studied ferrites into acetaldehyde and/or acetone, followed by acetaldehyde/acetone steam reforming to hydrogen and $\mathrm{CO}_{2}$; no $\mathrm{CO}$ was found out in the reaction products up to $500{ }^{\circ} \mathrm{C}$ for all explored ferrites. At higher temperatures, $\mathrm{CO}$ was found for $\mathrm{MnFe}_{2} \mathrm{O}_{4}$ only at $700{ }^{\circ} \mathrm{C}$, for $\mathrm{NiFe}_{2} \mathrm{O}_{4}$ and $\mathrm{CoFe}_{2} \mathrm{O}_{4}$ at $550-700{ }^{\circ} \mathrm{C}$ and $600-700{ }^{\circ} \mathrm{C}$, respectively. The maximum hydrogen yield decreases in order: $\mathrm{MnFe}_{2} \mathrm{O}_{4}>\mathrm{MgFe}_{2} \mathrm{O}_{4}>\mathrm{FeFe}_{2} \mathrm{O}_{4}$ $>\mathrm{CuFe}_{2} \mathrm{O}_{4}>\mathrm{CoFe}_{2} \mathrm{O}_{4}>\mathrm{ZnFe}_{2} \mathrm{O}_{4}>\mathrm{NiFe}_{2} \mathrm{O}_{4}$.

During ESR over $\mathrm{MnFe}_{2} \mathrm{O}_{4}-\mathrm{CP}$ catalyst prepared by co-precipitation method, almost $100 \%$ ethanol conversion is achieved in the temperature range between $500{ }^{\circ} \mathrm{C}$ and $600{ }^{\circ} \mathrm{C}$. Selectivity toward hydrogen reaches the maximum $\mathrm{S}_{\mathrm{H} 2}=84.3 \%$ at $550{ }^{\circ} \mathrm{C}$. The main reaction products are hydrogen and carbon dioxide. No detectable amount of carbon monoxide was found among the reaction products at $500-600{ }^{\circ} \mathrm{C}$. However, at $650{ }^{\circ} \mathrm{C}$ carbon monoxide formation was detected due to the reverse water-gas shift reaction. The ethanol conversion over the $\mathrm{MnFe}_{2} \mathrm{O}_{4}-\mathrm{HP}$ catalyst prepared by the solvothermal method is $90-100 \%$ in the temperature range of $500-650{ }^{\circ} \mathrm{C}$. This catalyst demonstrates higher selectivity toward hydrogen at $600-$ $650{ }^{\circ} \mathrm{C}$. The selectivity reaches $94.6 \%$. The formation of the carbon monoxide on the $\mathrm{MnFe}_{2} \mathrm{O}_{4}-$ $\mathrm{HP}$ catalyst is observed at $700{ }^{\circ} \mathrm{C}$. $\mathrm{MnFe}_{2} \mathrm{O}_{4}-\mathrm{CP}$ catalyst exhibits higher hydrogen yield in the temperature range between $450{ }^{\circ} \mathrm{C}$ and $550{ }^{\circ} \mathrm{C}$ compared to $\mathrm{MnFe}_{2} \mathrm{O}_{4}-\mathrm{HP}$ catalyst. In contrast, the higher hydrogen yield is observed on the $\mathrm{MnFe}_{2} \mathrm{O}_{4}-\mathrm{HP}$ catalyst for $\mathrm{T}>600{ }^{\circ} \mathrm{C}$.

\section{Technological design of the catalytic hydrogen generator}

The catalyst introduced in the present paper may be used for a portable autonomous hydrogen generator. That requires a simple technological scheme allowing one to easily operate. The autonomous catalytic hydrogen generator was developed under ISO 16110 Hydrogen generators using fuel processing technologies and IEC 62282-5-100 Portable fuel cell power systems requirements. The essential parts of a portable hydrogen generator are a fuel processing system, fuel cell module, fuel supply system, onboard energy storage system, and water treatment system. The fuel processing system provides fuel conversion into hydrogen. In the fuel cell module, hydrogen is converted into electric energy and heat in an electrochemical way. The obtained heat and electricity are further integrated into the energy generation system. Small power plants are typically based on proton-exchange membrane fuel cells (PEMFC) and solid oxide fuel cells (SOFC). We used the PEMFC. It works at low temperature $\left(<80^{\circ} \mathrm{C}\right)$ and does not sensitive to hydrogen purity, e.g., $\mathrm{CO}_{2}$ additives. For the calculations of the generator efficiency, we use the characteristics of the commercially available PEMFC produced by Horizon Fuel Cell Technologies Company.

According to the overall ESR reaction scheme, the stoichiometric molar ratio water/alcohol equals 3 , which corresponds to $46 \%$ of alcohol by weight. For a three-column scheme of the bioethanol synthesis, the grout distillate with an average alcohol content of approximately $40 \%$ (vol.) is obtained at the first column. This alcohol content is equivalent to the water/alcohol molar ratio of 3.5. We propose an approach to carry out ESR reaction in a single fixed bed reactor using the patented catalyst. A principal scheme of the hydrogen generator is shown in the figure. The applicability of a single-reactor scheme is governed by the developed $\mathrm{MnFe}_{2} \mathrm{O}_{4}-\mathrm{HP}$ catalyst that gives almost $100 \%$ of bioethanol conversion at $650^{\circ} \mathrm{C}$. Exceedingly small amounts of the reaction byproducts, e.g., oxygenates and $\mathrm{CO}$, are obtained. The amount of $\mathrm{CO}$ is only 50 - $60 \mathrm{ppm}$, which is suitable for PEMFC stable functioning. The unreacted bioethanol and reaction byproducts (oxygenates) do not affect the PEMFC operation. Carbon dioxide does not poise the Pt-Ru catalyst in the fuel cell, whereas water is required for stable fuel cell functioning. 


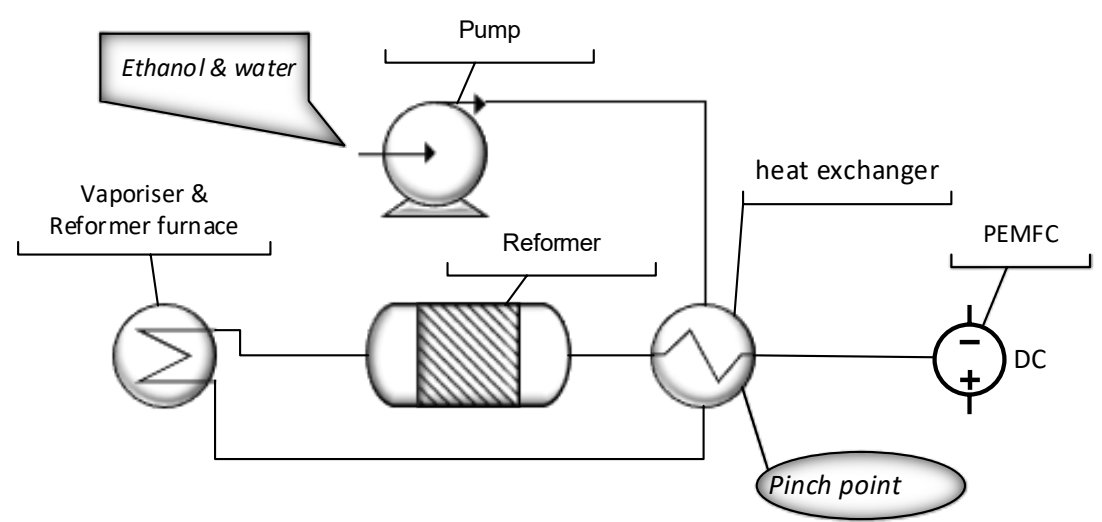

The presented scheme admits the utilization of thermal energy of the reaction mixture for vaporization and heating the input water-alcohol mixture. According to the scheme, the heat exchanger is placed between the reactor and fuel cell module and serves as a pinch zone. The pinch zone provides the flexibility of the water/alcohol ratio in the input mixture. The role of the water/alcohol ratio is crucial because this ratio significantly affects the alcohol conversion, hydrogen yield, as well as catalyst lifetime.

\section{Conclusion}

Hydrogen may be produced from renewable feedstock, e.g., bioethanol derived from biomass, using steam reforming. In this case, hydrogen yield significantly depends on the catalyst used and process conditions. Steam reforming is performed over the $\mathrm{MnFe}_{2} \mathrm{O}_{4}$ catalyst with spinel structure. Using this catalyst $98-100 \%$ ethanol conversion is achieved in the temperature range between 500 and $650^{\circ} \mathrm{C}$, whereas hydrogen yield reaches more than $90 \%$. Hydrogen obtained by steam reforming may be converted into electricity via the application of the fuel cells. Existing hydrogen power plants are inappropriate for small-scale electricity production. To this end, a single-stage autonomous catalytic hydrogen generator is developed. The developed generator does not contain hydrogen purification equipment and utilizes the heat of the reaction products. The energy conversion efficiency toward ethanol equals $44 \%$.

\section{Acknowledgments}

This research is partially supported by the Target Program of the National Academy of Sciences of Ukraine "Development of scientific grounds for hydrogen production, storage, and use in autonomous energy supply systems".

\section{References}

[1] Ni, M., Leung, D. Y. C., Leung, M. K. H. (2007). A review on reforming bio-ethanol for hydrogen production, Int. J. Hydrogen Energy, 32(15), 3238-3247. https://doi.org/10.1016/j.ijhydene.2007.04.038.

[2] Contreras, J. L., Salmones, J., Colín-Luna, J. A., Nuño, L., Quintana, B., Córdova, I., Zeifert, B., Tapia, C., Fuentes, G.A. (2014). Catalysts for $\mathrm{H}_{2}$ production using the ethanol steam reforming. Int. J. Hydrogen Energy 39(33), 18835-18853. https://doi.org/10.1016/j.ijhydene.2014.08.072.

[3] Dolgikh, L.Y., Pyatnitsky, Y.I., Strizhak, P.E. (2018). Hydrogen production from bioethanol on mixed oxide catalysts. In M. Brenzo, Bioethanol and Beyond: Advances in Production Process and Future Directions. Nova Science Publishers, Inc. https://novapublishers.com/shop/bioethanol-and-beyond-advances-in-production-processand-future-directions. 


\section{Study of diffusion processes in carrot particles}

Iryna Huzova, Volodymyr Atamanyuk

Department of Chemical Engineering, Lviv Polytechnic National University, UKRAINE, Lviv, 12 Bandera street, E-mail: iryna.o.huzova@lpnu.ua

Abstract - Internal porosity of the carrot particle, the value of which determines the coefficient of mass transfer have been determined. On the basis of the experiments we derived the dependence, allowing to determine the mass transfer coefficients for sucrose molecules in blanched carrot fruits within the temperatures corresponding to the quality of the finished product.

Keywords - diffusion, temperature, internal surface, carrot fruit, sucrose, mass transfer coefficient

\section{Introduction}

Candied fruits is a capillary-porous matter with a complex structure, saturated with sugar. That is why the value of the coefficients of sucrose diffusion in the plant material and proceeding of the diffusion process on the whole will be influenced by the temperature of the sugar syrup, as well as the shape, size and internal structure of the raw material.

\section{Materials and methods}

The carrots were cut into cylinders $12 \mathrm{~mm}$ in diameter and $4 \mathrm{~mm}$ in height. After the fruit was blanched for 10 minutes. The slice was taken from the middle of the cylinder (the part between the core and the bark). A slice of carrot with a thickness of 500 microns was analyzed under a electronic microscope. Eyeglass - 10, increase - 400.

\section{Results of experimental studies}

The general view of raw and blanched carrot cells is shown in Figs. 1a and $1 \mathrm{~b}$, respectively. Raw carrot cells are almost rectangular, pores are clearly defined. After blanching the pumpkin cells are almost round and the pores are much wider, which will contribute to a better diffusion of sucrose molecules to the middle of the carrot particle.

From the picture of blanched carrot (Fig. 1b), the average diameter of the pores between the carrot cells $(\mathrm{d}=3 \mu \mathrm{m})$ and the average cross-sectional area of carrot cell $(620 \mu \mathrm{m} 2)$ were determined.

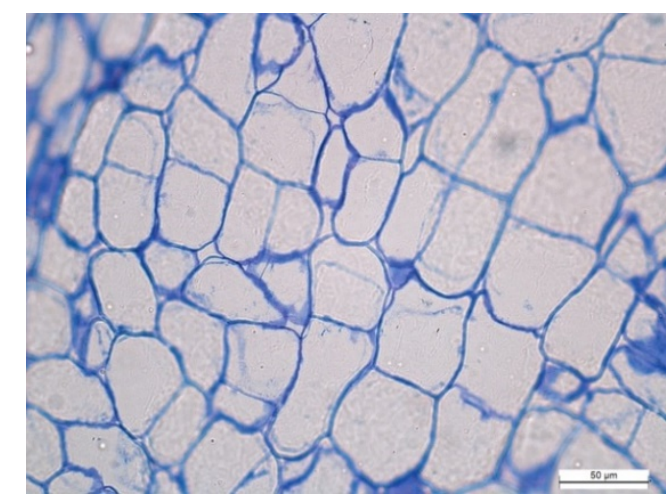

a)

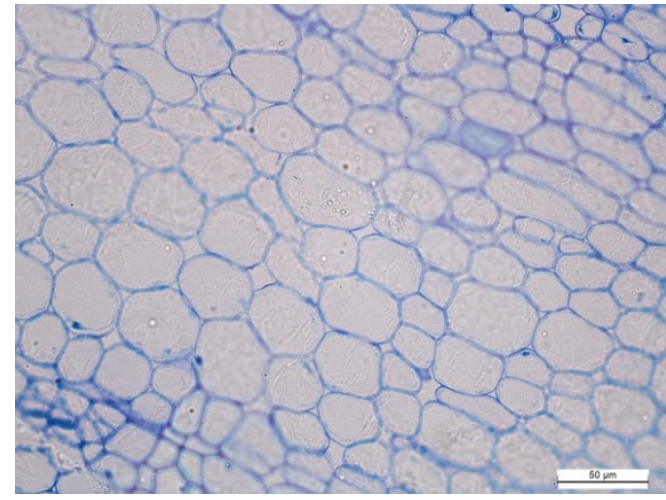

b)

Fig. 1. Photos of the raw (a) and blanched (b) carrot cells

The diffusion coefficient depends on the temperature, nature and shape of the particle. Well-known Einstein's eq. (1) determines the diffusion coefficient of large circular molecules in a liquid [1]: 


$$
D_{c}=\frac{k \cdot T}{6 \cdot \pi \cdot \mu \cdot r}
$$

where $\mathrm{k}$ is Boltzmann constant, $\mathrm{J} / \mathrm{K} ; \mathrm{T}$ is an absolute temperature, $\mathrm{K} ; \mathrm{r}$ is the radius of diffusing particles, $\mathrm{m} ; \mu$ is the viscosity of the liquid medium, $\mathrm{Pa} \cdot \mathrm{sec}$

The radius of diffusing particles is the radius of the sucrose molecule. Taking into account that $\mathrm{D}_{\mathrm{c}}$ is the coefficient of isothermal diffusion in a liquid continuum, in porous bodies, a coefficient of mass transfer $D_{m}$ is used instead of $D_{c}$.

As a rule, the coefficient $D_{m}$ is less than the diffusion coefficient $D_{c}$. The mass transfer area is less compared with that for free diffusion. The ratio of these areas is equal to the matter porosity $\mathrm{m}$.

Thus, the mass transfer coefficient will be equal to

$$
D_{m}=m \cdot D_{c}
$$

where $m$ is the porosity $\mathrm{m}^{2} / \mathrm{m}^{2}$

The porosity is determined from the photograph of the sample slice (Fig. 1b), $\mathrm{m}=0.3$ $\mathrm{m}^{2} / \mathrm{m}^{2}$.

Fig. 2 shows the dependence of the mass transfer coefficient determined from equation (2) on the experimental temperature of the medium. The obtained points were approximated by exponential dependence. As a result of the approximation, the equation (3) is obtained:

$$
D_{m_{T}}=6.62 \cdot 10^{-4} \cdot D_{m_{293}} \cdot e^{0.02 \cdot T}
$$

The values of the coefficients in Eq. (3) depend only on the fruit kind and its internal structure.

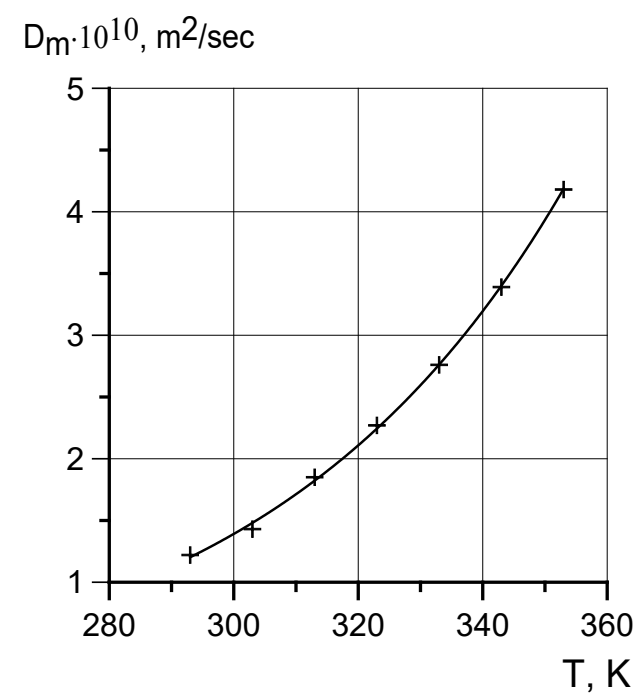

Fig. 2. Dependence of the mass transfer coefficient of sucrose molecules in blanched carrot fruits on the medium temperature.

\section{Conclusion}

Eq. (3) allows to determine the mass transfer coefficients of sucrose molecules in blanched carrot fruits at the temperature corresponding to the quality of the finished product.

\section{References}

[1] Atamanyuk, V., Huzova, I., Gnativ, Z. (2017). Study of diffusion processes in pumpkin particles during candied fruits production. Food Science and Technology, 11(4), 21-28. doi.org/10.15673/fst.v11i4.727 


\section{Research of the soybean oil extraction using polar solvents}

$\underline{\text { Anna Hlukhaniuk }}^{1}$, Oleksandr Ivashchuk ${ }^{1}$, Yevgen Semenyshyn ${ }^{1}$, Roman Chyzhovych $^{1}$, Tetiana Kuzminchuk ${ }^{1}$, Semen Khomyak ${ }^{2}$

1. Department of Chemical Engineering, Lviv Polytechnic National University, UKRAINE, Lviv, 12 Bandery str., E-mail: anna.hlukhaniuk.mnxt.2019@lpnu.ua

2. Department of Technology of Biologically Active Substances, Pharmacy and Biotechnology, Lviv Polytechnic National University, UKRAINE, Lviv, 12 Bandery str.

Abstract - The article considers the peculiarities of the process of vegetable oil extraction using polar solvents. It is shown that the efficiency of using polar solvents for the extraction of soybean oil depends on the nature and physicochemical properties of the solvent.

Keywords - extraction, polar solvents, vegetable oil, soybean oil, extraction efficiency

\section{Introduction}

The main traditional oilseeds are soybeans, rapeseed, and sunflower. The industrial removal of oil from vegetable raw materials is realized by pressing and extraction [1]. The main disadvantage of existing technologies is the high content of residual oil in the semi-fat meal (about 20\%). Therefore, there is a need to find more effective methods of extracting oil from raw materials [2].

There are various factors influencing the quantitative parameters of the efficiency of the extraction process, but along with investigation of increasing the efficiency it is necessary to investigate in detail the qualitative parameters of the obtained target component, both to determine the influence of the nature of the extractant on the chemical state of oils and for further planning the purification stages according to technological requirements [3].

\section{Research basics}

The extraction method is widely used in world industry due to the high efficiency of extraction of oils not only from raw materials with a high content of the target component but also those where the concentration of the latter does not exceed $5 \%[2,4]$.

The technical design and operating conditions of the extraction process are determined by the properties of the selected solvent. Comparative experimental studies have shown that polar solvents are more effective in dissolving vegetable oils [5].

Due to the fact that the extraction of oil from vegetable raw materials includes both intramolecular transfer of components to the phase contact surface and external diffusion from the phase contact surface to the bulk of the solvent, the effect of grinding on the extraction efficiency was investigated. The obtained data indicate a direct effect of grinding on the intensification of the extraction of the target component [5].

It is important to control the quality and composition of the extracted oil too. The main indicators that determine the properties and quality of oil are the number of saponification, iodine, acid and ester numbers. Also for quality control of oil raw materials are used methods of refractometry and various types of spectroscopic analysis.

\section{Experimental}

Soybean raw material was grinded and distributed by sieve fractionation with different particle sizes of $0.2 \mathrm{~mm}, 0.5 \mathrm{~mm}, 1.0 \mathrm{~mm}$ and an average mixture of crushed fractions, and dried to a moisture content of 2-5\%. Polar solvents were used: dichloromethane, ethanol, isopropanol, n-propanol. The extraction of soybean vegetable oil using polar solvents was carried out in the 
Soxhlet apparatus for 8 hours at a solvent's boiling temperature. Sampling was performed every 2 hours.

Among the important controlled parameters according to the current standards, during the experimental studies were determined chemical constants (acid number, iodine number, ester number, saponification number, etc.) according to the methods [6], as well as optical and spectral properties by refractometry and UV-Vis -spectroscopy and IR spectroscopy, the latter in particular to confirm the presence of major functional groups and to detect abnormalities.

Determination of the refractive index of the oil was performed according to the method [7]. Ultraviolet spectroscopy (UV-Vis) data, obtained on a spectrophotometer, model ULAB 108UV Spectrophotometer, operating in the range of $190-1100 \mathrm{~nm}$.

IR spectroscopic examination was performed on a spectrophotometer SPECORD M80 (Carl Zeiss Jena) in thin films, range $4000-400 \mathrm{~cm}^{-1}$.

\section{Results and discussion}

The results of quantitative analysis of extraction are given in the form of graphical scales of oil concentration in selected signs from time $C=f(t)($ Fig. 1, 2) for each fraction.

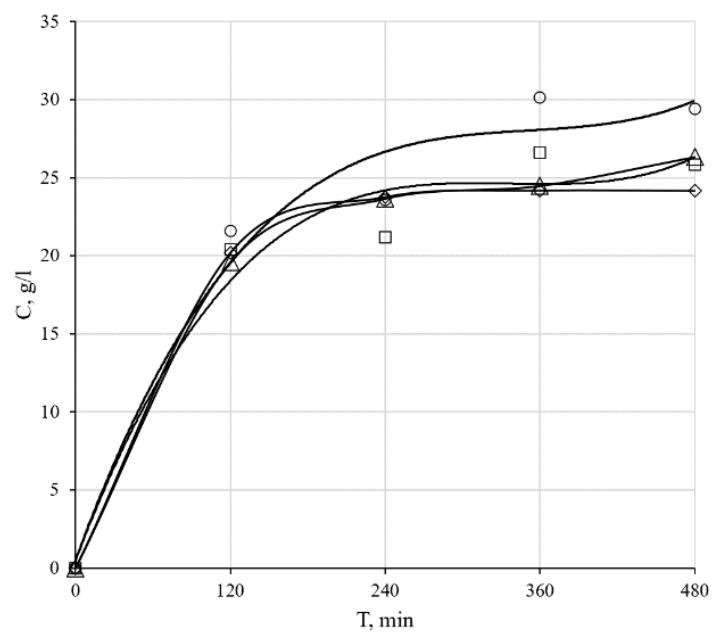

Fig. 1. Graphical dependences $\mathrm{C}=\mathrm{f}(\mathrm{t})$ of soybean oil extraction with dichloromethane

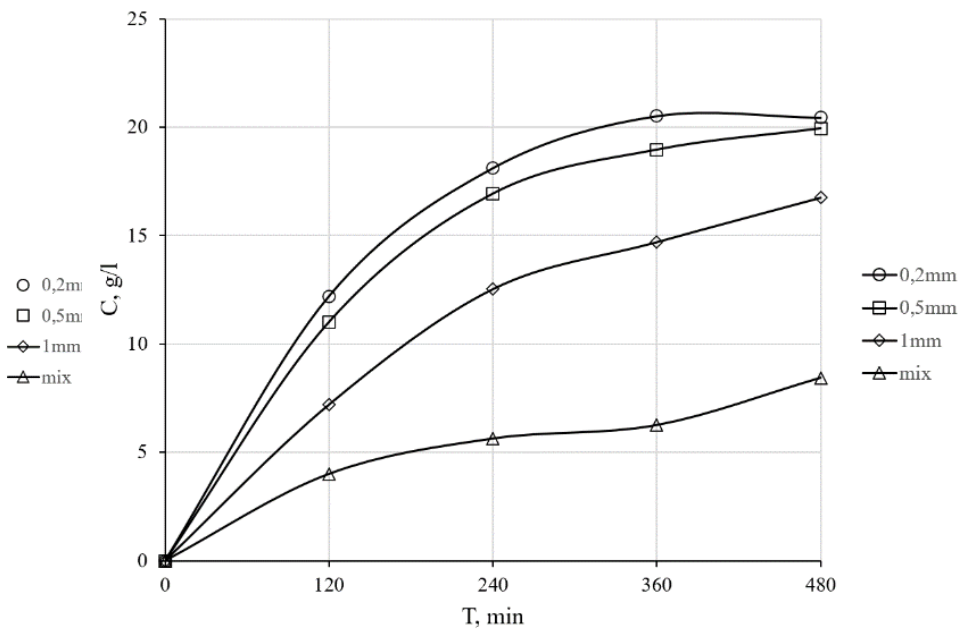

Fig. 2. Graphical dependences $\mathrm{C}=\mathrm{f}(\mathrm{t})$ of soybean oil extraction with ethanol

The results of experimental studies show that for each selected solvent the accumulation of the target product increases over time (Fig. 1, 2). Graphical dependences of vegetable oil yield on time $\mathrm{C}=\mathrm{f}(\mathrm{t})$ indicate that the main oil extraction occurs during the first $360 \mathrm{~min}$ of the experiment. Comparing the results for both solvents, it is obvious that the use of dichloromethane and increasing the level of grinding has a positive effect on the oil extraction process.

From Fig.1 it is obvious that a greater degree of grinding contributes to the efficiency of extraction when using dichloromethane, at the same time as for ethanol such an effect is not observed. Therefore, in the case of dichloromethane, the grinding of the raw material has a greater effect on the final oil yield by increasing the contact area of the phases.

Also, to compare the efficiency of extraction with the investigated solvents, additional studies of two more polar solvents - isopropanol and n-propanol.

The results of changes in oil concentration in samples over time and the final yield of soybean oils are shown in graphical form in Fig. 3. The increase in the rate of accumulation of the target product increases in a number: ET $<\mathrm{P}<\mathrm{IP}<\mathrm{DCM}$. 
The results of changes in oil concentration in samples over time and the final yield of soybean oils are shown in graphical form in Fig. 3. The increase in the rate of accumulation of the target product increases in a number: $\mathrm{ET}<\mathrm{P}<\mathrm{IP}<\mathrm{DCM}$.

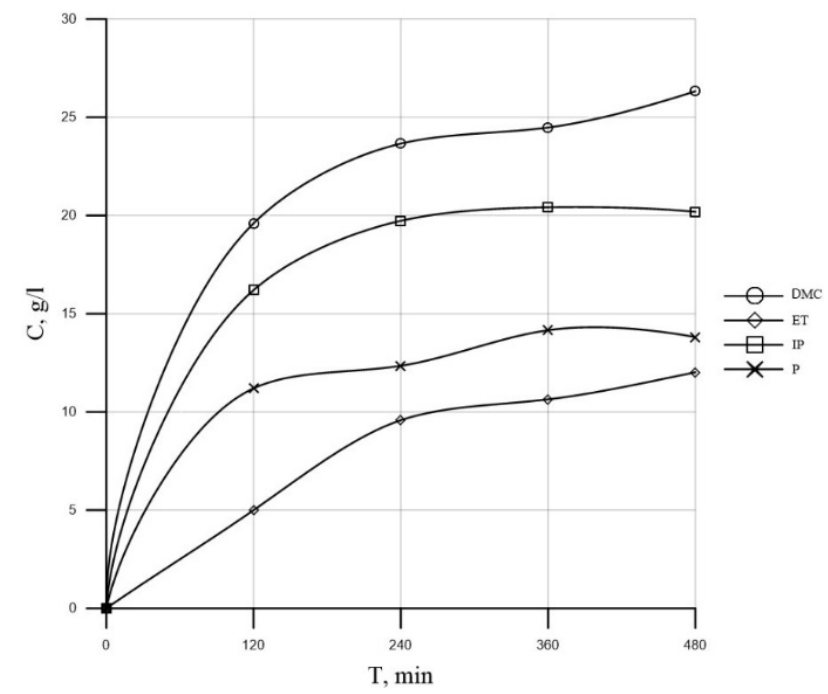

Fig.3. Graphic dependences $\mathrm{C}=\mathrm{f}(\mathrm{t})$ for the rate of accumulation of soybean oil by extraction with polar solvents.

The results of changes in oil concentration in samples over time and the final yield of soybean oils are shown in graphical form in Fig. 3. The increase in the rate of accumulation of the target product increases in a number: $\mathrm{ET}<\mathrm{P}<\mathrm{IP}<\mathrm{DCM}$.

The results of the analyzes to determine the chemical constants and refractive index of soybean oil for different fractions extracted with dichloromethane are given in Table 1.

Table 1

Qualitative analysis results of soybean oil obtained from fractions of different grinding (extractant - dichloromethane)

\begin{tabular}{|c|c|c|c|c|c|}
\hline \multirow{2}{*}{ Parameter } & \multicolumn{4}{|c|}{ Fraction size } & \multirow{2}{\text{Standart}}{$\begin{array}{c}4534: 2006 \\
\text { (Ukraine), unrefined }\end{array}$} \\
\cline { 2 - 5 } & $0,2 \mathrm{~mm}$ & $0,5 \mathrm{~mm}$ & $1 \mathrm{~mm}$ & mix & $0,922-0,934$ \\
\hline Density, kg/m3 & 0,91 & 0,92 & 0,94 & 0,91 & $\leq 100$ \\
\hline Iodide number & 124,33 & 94,73 & 95,51 & 119,87 & $\leq 4,0$ \\
\hline Acid nubmer & 6,39 & 4,37 & 2,86 & 3,94 & - \\
\hline Ester number & 196,06 & 179,62 & 148,47 & 204,97 & $186-195$ \\
\hline Saponification number & 202,45 & 183,99 & 151,33 & 208,90 & $1,468 \pm 0,07$ \\
\hline Refractive index & 1,4765 & 1,4753 & 1,4787 & 1,4761 & \\
\hline
\end{tabular}

Indicators of IN, AN, EN and saponification number for the obtained soybean oil samples increase with decreasing degree of grinding of raw materials (Table 1). The closest to the standard are the indicators for the sample obtained from the fraction of average diameter $\mathrm{d}=0.5$ $\mathrm{mm}$.

Fig.4 presents the data of ultraviolet spectroscopy (UV-Vis) obtained for samples of soybean oil, presented as the dependence of absorption on the wavelength $\alpha=f(\lambda)$. The obtained spectra of oils are characteristic and do not differ from the UV spectra of pure vegetable oils.

The results of spectral IR analysis of the studied oil samples are presented below in the form of graphs of spectral absorption in Fig.5. 


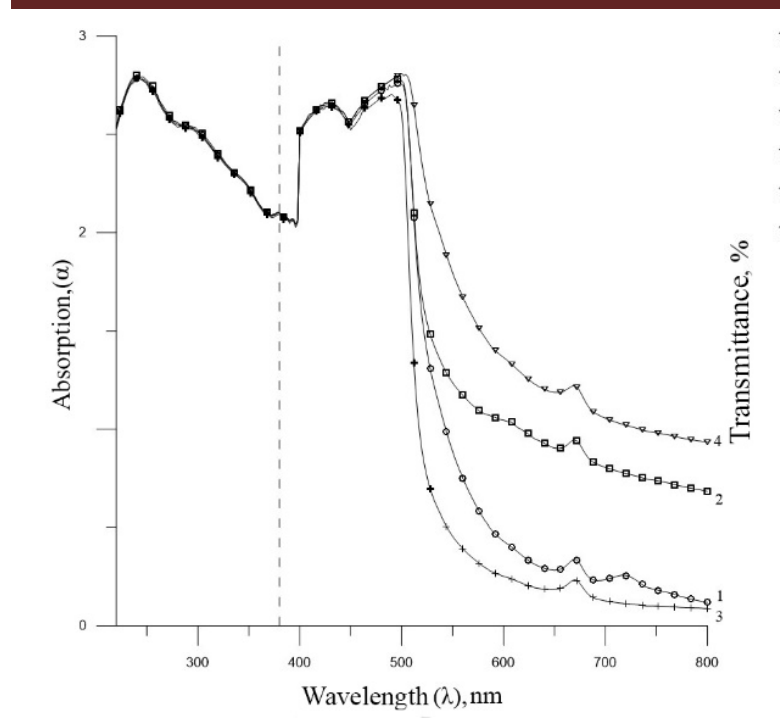

Fig.4. Normalized UV-visible absorption spectrum of samples of soybean oil (1 mixture; 2 - $0.5 \mathrm{~mm} ; 3-0.2 \mathrm{~mm} ; 4-1.0 \mathrm{~mm})$.

The obtained IR spectra showed the presence of alkyl residues of triglycerides (the main components of vegetable oils), as evidenced by peaks with a wave number close to $2900 \mathrm{~cm}^{-1}$. However, there are also slight differences in absorption for the groups $-\mathrm{C}=\mathrm{O}\left(1700 \mathrm{~cm}^{-1}\right)$ and $\mathrm{C}-\mathrm{O}\left(1200 \mathrm{~cm}^{-1}\right)$. This may mean that the test samples contain different amounts of compounds with these functional groups.

\section{Conclusions}

The analysis of the results of research on the process of extraction of oil from different fractions of crushed raw materials indicates that one of the most influential factors in the intensification of extraction is grinding. In the case of dichloromethane, extraction of oil from the crushed mixture is economically feasible, the oil yield reaches the average value between the investigated separated fractions at the level of the average equivalent particle size of $0.5 \mathrm{~mm}$, in industrial conditions it will reduce energy costs. The qualitative analysis slightly deviates from standardized values, so the nature of the causes of these differences should be investigated in more detail.

\section{References}

[1] Kovalchuk, S.Ia. (2010). Rozvytok motyvatsiinykh mekhanizmiv vyrobnytstva biolohichnykh vydiv palyva. Zbirnyk naukovykh prats Vinnytskoho derzhavnoho ahrarnoho universytetu, 42(1), 125-130.

[2] Harish, N., Anil Kumar, K., D. Srinivas \&amp; Sivala Kumar. (2017). Review on Oil Extraction Techniques. International Journal of Agricultural Science and Research (IJASR), 567-576

[3] Syrotiuk, S.V. (2000). Mekhanizatsiia pererobky ta zberihannia produktsii roslynnytstva: Kurs lektsii, 2, Lviv: LDAU, 249.

[4] Semenyshyn, Ye., Atamanyuk, A., Rymar, T. et al. (2020). Mass transfer in the solidliquid system: mechanism and kinetics of the extraction. Chemistry and Chemical Technology, 14 (1), 121-128.

[5] Ivashchuk, O., Hlukhaniuk, A., Semenyshyn, Ye., Chyzhovych, R., Kuzminchuk, T., Khomyak, S. (2021). Influence of extraction conditions on qualitative composition of vegetable oils. Chemistry \& Chemical Technology, 15(2), 233-238. https://doi.org/10.23939/chcht15.02.233 
[6] Ivashchuk,O., Atamanyuk, V., Semenyshyn, Ye., Hlukhaniuk, A., Chyzhovych,R., Kuzminchuk T. (2020). The research of the rapeseed oil extraction for the biodiesel production. Chemical and Process Engineering for Environment and Health. Monography, 49-56. ISBN978-83-7789-629-7.

[7] Ioffe, B.V. (1974). Refraktometricheskie metody' khimii. L.: Khimiya, Leningr., 174. 


\title{
Thermal stability of materials of vegetable origin
}

\author{
Tetiana Korinchevska, Viacheslav Mykhailyk
}

\begin{abstract}
Department of Heat and Mass Transfer in Heat Technologies, Institute of Engineering Thermophysics of
\end{abstract} NAS of Ukraine, UKRAINE, Kyiv, 2 Academician Bulakhovsky Str., E-mail: tvkorin@gmail.com

\begin{abstract}
The behavior of vegetable samples at programmed heating up to $270{ }^{\circ} \mathrm{C}$ was studied by the method of thermal analysis. The stage of water removal is considered. Moisture, average rate and conditional thermal effect of water removal are calculated. The temperature of the beginning of thermal destruction of materials is determined.
\end{abstract}

Keywords - thermal analysis, thermal stability, destruction, vegetables, dehydration.

\section{Introduction}

Vegetables are an important component in the production of various foods. Since they are high-moisture products, they can quickly lose their natural value during storage. Preserving by drying is one of the reliable and effective ways to protect vegetables from spoilage. Qualitative characteristics of dried products depend on the choice of dehydration mode. The temperature of the material during drying is one of the main mode parameters which provides high quality of the product, nutritional value and preservation of the whole complex of biologically active substances. Therefore, it is important to know the temperature after which the process of thermal destruction begins. This temperature determines the thermal stability of materials.

\section{Materials and methods}

Samples of vegetable products (Table 1) were selected as the most available and widely used in the Ukrainian market. The thermal stability of the samples was determined by the method of thermal analysis on the derivatograph "Q-1000", modernized in the IET of NAS of Ukraine.

For research, the samples were crushed to ensure the homogeneity of the structure. The mass of the samples was 187.0 - 202.4 mg. Prepared samples were placed in a conical platinum crucible from the device kit. $\mathrm{Al}_{2} \mathrm{O}_{3}$ was used as an inert substance. The obtained samples were subjected to programmed heating at a rate of $3.6 \mathrm{~K} / \mathrm{min}$ in the range of $20-270{ }^{\circ} \mathrm{C}$. The collection and processing of information from the channels of measurement was performed using the applied computer program "Derivatograph". The temperature deviation did not exceed $\pm 0.5 \mathrm{~K}$. The change in temperature and mass of the sample, the rate of change in mass, and the thermal effect were registered during the experiment.

\section{Results}

Structural-mechanical and physico-chemical changes in the material occur during heating. Since all the studied materials are high-moisture products, their heating is accompanied by the removal of water. The endothermic effect is registered in the range from ambient temperature to $164-210{ }^{\circ} \mathrm{C}$ depending on the type of product (Table 1). The determined moisture of the samples varies from $61.51 \%$ for garlic to $92.45 \%$ for white cabbage.

The rate of dehydration of the studied vegetables increases with increasing temperature and reaches a maximum at $117-128^{\circ} \mathrm{C}$ and further decreases to almos to zero. The average rate of dehydration of the samples is defined in the range from 1.36 to $2.00 \% / \mathrm{min}$. Moreover, for potatoes and garlic, the rate is the lowest and is 1.36 and $1.42 \% / \mathrm{min}$ in accordance. White cabbage, onion, roots of parsley and celery have the maximum water removal rate (1.97 $2.00 \% / \mathrm{min}$ ). It can be noted that the average rate of dehydration directly depends on the initial moisture of the product (Table 1). 
The results of processing the obtained data of thermal analysis of vegetables

\begin{tabular}{|c|c|c|c|c|c|c|c|}
\hline \multirow[b]{2}{*}{ № } & \multirow[b]{2}{*}{ Material } & \multicolumn{5}{|c|}{ Water removal } & \multirow[b]{2}{*}{$\begin{array}{c}\text { The } \\
\text { beginning } \\
\text { of thermal } \\
\text { destruction, } \\
{ }^{\circ} \mathrm{C}\end{array}$} \\
\hline & & $\begin{array}{c}\text { Temperature } \\
\text { interval, } \\
{ }^{\circ} \mathrm{C}\end{array}$ & $\begin{array}{c}\text { Maximum } \\
\text { of rate, } \\
{ }^{\circ} \mathrm{C}\end{array}$ & $\begin{array}{l}\text { Mois- } \\
\text { ture, \% }\end{array}$ & $\begin{array}{l}\text { Average } \\
\text { rate, } \\
\% / \mathrm{min}\end{array}$ & $\begin{array}{l}\text { Condi- } \\
\text { tional } \\
\text { thermal } \\
\text { effect, } \\
\mathrm{mV} \cdot \mathrm{s} / \mathrm{mg}\end{array}$ & \\
\hline 1 & Potato & $24-210$ & 122 & 72,29 & 1,36 & 91,20 & 210 \\
\hline 2 & Carrots & $22-179$ & 117 & 86,84 & 1,93 & 95,13 & 179 \\
\hline 3 & Beetroot & $25-179$ & 121 & 82,44 & 1,83 & 103,30 & 179 \\
\hline 4 & Pumpkin & $22-184$ & 125 & 84,11 & 1,85 & 93,37 & 184 \\
\hline 5 & $\begin{array}{l}\text { White } \\
\text { cabbage }\end{array}$ & $24-186$ & 123 & 92,45 & 2,00 & 97,42 & 186 \\
\hline 6 & $\begin{array}{l}\text { Parsley } \\
\text { root }\end{array}$ & $21-164$ & 121 & 82,79 & 1,97 & 97,77 & 164 \\
\hline 7 & $\begin{array}{l}\text { Celery } \\
\text { root }\end{array}$ & $23-181$ & 128 & 90,14 & 1,98 & 96,13 & 181 \\
\hline 8 & Onion & $22-179$ & 123 & 88,93 & 1,98 & 99,37 & 179 \\
\hline 9 & Garlic & $23-172$ & 126 & 61,51 & 1,42 & 97,83 & 172 \\
\hline
\end{tabular}

Gradual mass loss is registered after complete removal of water, which indicates the thermal destruction of certain components of the material. The change in mass is accompanied by a noticeable release of heat in the studied temperature interval for all samples except potatoes and cabbage. However, this study does not allow to establish which component decomposes. The temperature of the beginning of thermal destruction is in the range from $164{ }^{\circ} \mathrm{C}$ for parsley root to $210{ }^{\circ} \mathrm{C}$ for potatoes.

The conditional thermal effect was determined to compare the heat consumption for water removal. The results (Table 1) show that the most heat is expended during dehydration of beetroot, and the least - potatoes. This may be due to the different ratio of free and bound water in the samples [1].

\section{Conclusion}

The results of thermal analysis of samples of vegetable raw materials allowed to determine their moisture, thermal stability, average rate of dehydration and to estimate heat consumption for dehydration using the conditional thermal effect.

\section{References}

[1] Mykhailyk, V. A., Dmitrenko, N. V., \& Mykhailyk T. A. (2007) Vliyanie termicheskogo vozdeystviya na sostoyanie vodyi v rastitelnyih tkanyah. Promyishlennaya teplotehnika. 29(7),212-217. 


\title{
State of water during dehydration of sugar beet tissue
}

\author{
Viacheslav Mykhailyk, Tetiana Korinchevska \\ Department of Heat and Mass Transfer in Heat Technologies, Institute of Engineering Thermophysics of National \\ Academy of Sciences of Ukraine, UKRAINE, Kyiv, 2 Academician Bulakhovsky Str., \\ E-mail:mhlk45@gmail.com
}

Abstract - The DSC method was used to study the state of water in the process of dehydration of fresh, after long-term storage and de-sugared tissues of sugar beet root. It has been detected that the waterretaining properties of tissues are mainly determined by the hydration of sucrose. It has been shown that the specific content of bound water in a fresh root is $\sim 2.3$ times higher than a root after long-term storage.

Keywords - differential scanning calorimetry, sugar beet, free and bound water, hydration, sucrose

\section{Introduction}

Water plays an important role in plants during the growing season and in fruits during storage and processing. The state of water in plant raw materials and products of its processing is of great importance for the optimization of technological modes. The processes that take place at the root of sugar beet during storage are extremely complex, and the factors on which they depend are numerous. During storage, the root remains a living organism with its inherent complex of complicated processes of transformation of substances. The reasons, as a result of which the root loses its inherent stability and ability to be stored for a long time, are associated with a change in the state of the water in it. The loss of water by the cells causes profound physiological changes in the root and a marked activation of enzymes, which leads to the loss of sucrose. The water-holding capacity of cells is determined by the integral value of intermolecular forces and depends on the general physiological state of the plant. The rupture of hydrogen bonds during dehydration causes the destruction of the structure of plant tissues. Two states of water are noted in biological objects of plant origin. First state is similar to the state of pure water (free water). The other state arises as a result of beneficial energetic interactions with biopolymer macromolecules, molecules and ions of cell sap (bound water) [1].

The aim of this study was to investigate the changes in the state of water during dehydration of fresh, after long-term storage and de-sugared sugar beet root tissues.

\section{Materials and methods}

In this work, the method of differential scanning calorimetry (DSC) and the technique described in [2] were applied. Measurements were performed in a DSM-2M differential scanning microcalorimeter using the Water-5 software application. The object of the study were tissues of fresh and after storage for 8 months of sugar beet roots. Plates 1.5-2 mm thick were cut out in the middle part of the root perpendicular to its vertical axis, from which samples with a diameter of $5 \mathrm{~mm}$ were made. De-sugared tissues were obtained by triple extraction of sucrose with distilled water at $85{ }^{\circ} \mathrm{C}$. The completeness of the extraction of sucrose was controlled by the refractometric method. Samples with different humidity were obtained by drying the original tissues with air at a temperature of $\sim 50^{\circ} \mathrm{C}$.

\section{Results}

Analysis of the obtained data shows that with a decrease in tissue moisture, the fractional composition of water is redistributed towards bound water (Fig. 1). The content of bound water in fresh beets is significantly higher than in beets after long-term storage at equal initial moisture values. This difference persists with dehydration. However, the difference in values decreases 
with decreasing moisture. In the fresh root, the ratio of the mass of bound to free water is $\sim 1: 3$, after storage is $\sim 1: 7$. This dependence is also observed in de-sugared tissues, but the content of bound water in them is somewhat higher than in beet tissues after storage.

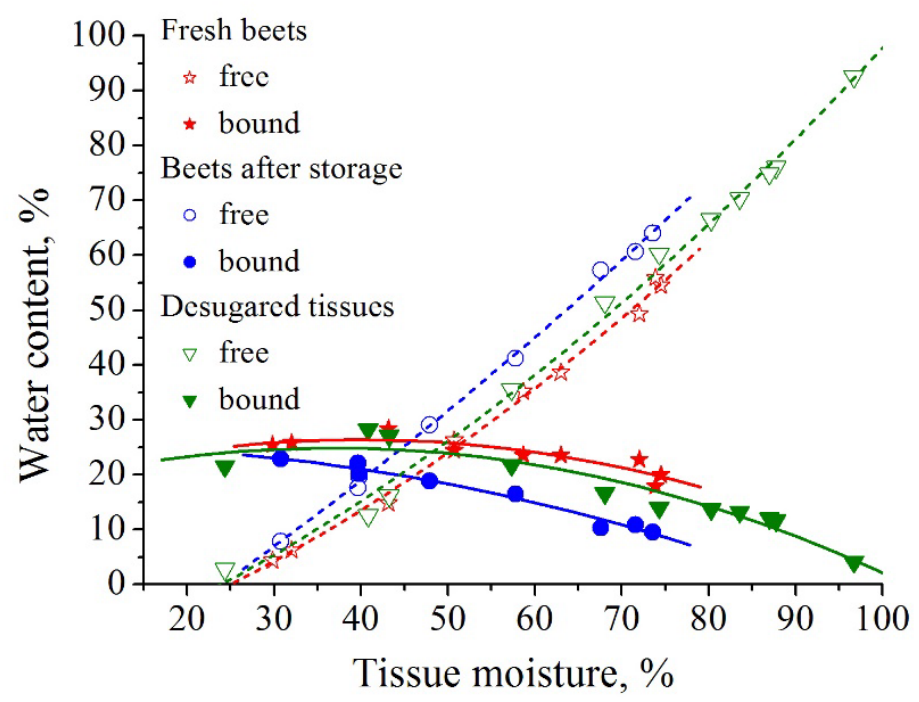

Fig. 1. Change in the content of free and bound water in fresh, after long-term storage and de-sugared tissues of the sugar beet root during dehydration.

Dependencies become more interesting if we represent the mass of bound water referred to the mass of dry matter (Fig. 2). It can be seen that in the process of dehydration, simultaneously with a decrease in the content of free water, the specific content of bound water (water retention) decreases. The observed phenomenon is a consequence of a decrease in the number of hydrophilic active centers with which water molecules can form hydrogen bonds.

The most significant component of sugar beet dry matter is sucrose, the hydration of which depends on the water content [3]. A quantitative assessment showed that in the tissues of fresh beets, about $90 \%$ of the bound water is retained by sucrose.

With dehydration, the amount of water bound by non-sugars also decreases. The reason for the loss of water-holding capacity is a change in the structure of biopolymers as a result of tissue shrinkage during dehydration. In the case of de-sugared tissues, the higher values of water retention can be explained by the freshness of the original tissues, as well as by the reaction of biopolymers to thermal effects in the water environment.

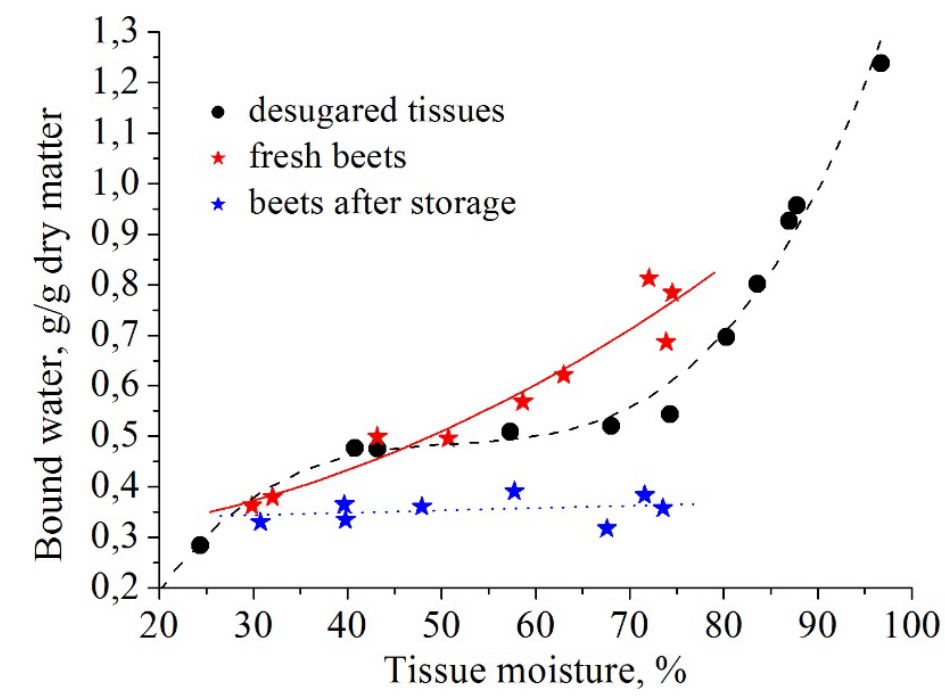

Fig. 2. Dependence of the specific content of bound water in fresh, after long-term storage and de-sugared tissues of the sugar beet root on moisture. 


\section{Conclusion}

From the above, it follows that sucrose plays a decisive role in the water retention of parenchymal tissues of the root of fresh sugar beet. In the process of dehydration, the specific content of bound water in tissues decreases symbatically with a change in the hydration capacity of sucrose.

The general decrease in water retention by parenchymal tissues after storage is a consequence of biochemical processes that have occurred at the root. First of all, the change in the nature of water retention is explained by a decrease in the content of sucrose during storage. In addition, the destruction of biopolymers is accompanied by a weakening of their waterretaining capacity.

Received as a result of calorimetric research information about the state of water in the tissues of fresh root and root after long-term storage, confirms the possibility of changing the water-holding capacity to judge the degree of stability of plant cells.

\section{References}

[1] Franks, F. (1985). The properties of aqueous solutions at temperatures below zero. In: F. Franks (Ed.), Water and Water Solutions at Temperatures below $0^{\circ} \mathrm{C}$ (pp. 176-276). Kiev: Naukova Dumka

[2] Mykhailyk, V. A., Snezhkin, Yu. F., \& Dmitrenko, N. V. (2015). Investigation of the state of water in energy trees in the process of drying by differential scanning calorimetry. Journal of Engineering Physics and Thermophysics, 88(5), 1093-1099. https://doi.org/10.1007/s10891-015-1288-1

[3] Mykhailyk, V.A. (2006). Eksperimentalnoe issledovanie gidratatsii saharozyi. Odes $k a$ nacional'na akademiya xarchovy’x texnologij. Naukovi praci, 28(2), 370-373. 


\title{
Obtaining bitumen from paraffinic-base crude via joint oxidation of tar and different products of oil processing
}

\author{
Andriy Nagurskyy $^{1}$, Bohdan Korchak ${ }^{2}$ \\ 1. Department of Chemical Engineering, Lviv Polytechnic National University, UKRAINE, Lviv, \\ S. Bandery street 12, E-mail: andrii.o.nahurskyi@lpnu.ua \\ 2. Department of Civil Safety, Lviv Polytechnic National University, UKRAINE, \\ Lviv, S. Bandery street 12, E-mail: kor4ak93@gmail.com
}

\begin{abstract}
Petroleum bitumen has been obtained via oxidation of tar produced from paraffin-base crude and via joint oxidation of tar and dark petroleum resin, pyrolysis heavy resin and neutralized acid tar.
\end{abstract}

Keywords - tar, paraffin-base crude, bitumen, oxidation, modification.

\section{Introduction}

Petroleum bitumen production is one of the priority directions of oil refining. Recently the more strict demands for the quality of petroleum bitumen are made especially for their mechanical and deformational properties, thermooxidative resistance, etc [1]. The bad quality of crude, namely the residuals of paraffin-base crude, is the main problem of bitumen production. It is the especially urgent problem for bitumen producers in Ukraine because the main part of oil produced in this country is the paraffinic-base crude [2].

The aim of this work was to examine the production of high-quality petroleum bitumen on the basis of parrafinic oil residuals and study the joint oxidation of residuals with different additives.

\section{Experimental}

The tar obtained while West-Ukrainian paraffinic crude processing was used as a raw material. Its characteristic is given in Table 1. The initial material has a high content of oil components and paraffinic hydrocarbons and refers to the colloidal structure of "gel" type characterized by insufficient content of resins and polycyclic aromatics. It is considered as bad crude for bitumen production.

Table 1

Characteristics of the initial tar and oxidated bitumen

\begin{tabular}{|l|c|c|}
\hline \multicolumn{1}{|c|}{ Index } & Tar & Oxidated bitumen \\
\hline Softening temperature, ${ }^{\circ} \mathrm{C}$ & 42 & 46 \\
\hline Penetration at $25^{\circ} \mathrm{C}, 0.1 \mathrm{~mm}$ & 245 & 163 \\
\hline Ductility at $25^{\circ} \mathrm{C}, \mathrm{cm}$ & 13 & 14 \\
\hline Group composition, $\mathrm{wt} \%:$ & & \\
asphaltenes & 19.60 & 22.37 \\
resins & 24.38 & 24.63 \\
oils & 56.02 & 53.00 \\
including paraffines & 5.42 & 5.36 \\
\hline
\end{tabular}

The investigations were carried out by two directions: the initial tar oxidation and joint oxidation of the initial tar with other components. The main regularities of the oxidated bitumen obtaining have been studied. The following indexes were determined for the obtained product: softening temperature, ductility and penetration. Table 1 contains the characteristics of bitumen obtained via paraffinic tar oxidation at $250{ }^{\circ} \mathrm{C}$, air consumption of $2.5 \mathrm{~min}^{-1}$ for $6 \mathrm{~h}$.

The obtained oxidated bitumen is characterized by low ductility and high penetration that is irregular for commercial bitumen. Such results are explained by inadequate group composition 
of obtained bitumen. Moreover, the obtained bitumen is characterized by high content of paraffinic hydrocarbons which are inert while oxidation, worsen the ductility, decrease the plasticity temperature interval and worsen the bitumen strength and adhesion.

To intensify the bitumen obtaining we studied the main regularities of joint oxidation of tar obtained from paraffinic-base crude and different products of oil processing. The following products were studied as additives for the raw material:

- dark petroleum resin (DPR) - dark-brown substance obtained via thermal oligomerization of pyrolysis heavy resin;

- pyrolysis heavy resin (PHR) - by-product of hydrocarbon crude pyrolysis;

- acid tar - by-product of sulfuric acid refining.

The results of joint oxidation under optimum conditions are presented in Table 2.

Table 2

Effect of initial tar additives on the obtaining of petroleum bitumen

\begin{tabular}{|c|c|c|c|c|c|}
\hline \multicolumn{3}{|c|}{ Joint oxidation conditions } & \multicolumn{3}{|c|}{ Petroleum bitumen characteristics } \\
\hline $\begin{array}{l}\text { Time, } \\
\mathrm{h}\end{array}$ & $\begin{array}{l}\text { Air } \\
\text { consumption, } \\
\min ^{-1}\end{array}$ & $\begin{array}{l}\text { Temperature, } \\
{ }^{\circ} \mathrm{C}\end{array}$ & $\begin{array}{l}\text { Softening } \\
\text { temperature, }{ }^{\circ} \mathrm{C}\end{array}$ & $\begin{array}{l}\text { Penetration at } \\
25^{\circ} \mathrm{C}, 0.1 \mathrm{~mm}\end{array}$ & $\begin{array}{l}\text { Ductility at } \\
25^{\circ} \mathrm{C}, \mathrm{cm}\end{array}$ \\
\hline \multicolumn{6}{|c|}{ Additive - DPR in amount of $7.5 \mathrm{wt} \%$} \\
\hline 6 & 2.5 & 250 & 55 & 59 & 21 \\
\hline \multicolumn{6}{|c|}{ Additive - PHR in amount of $5 \mathrm{wt} \%$} \\
\hline 9 & 2.5 & 250 & 49 & 102 & 35 \\
\hline \multicolumn{6}{|c|}{ Additive - neutralized acid tar in amount of $20 \mathrm{wt} \%$} \\
\hline 6 & 2.5 & 250 & 52 & 97 & 9 \\
\hline
\end{tabular}

The addition of DPR increases the softening temperature and ductility and decreases penetration. Moreover, the DPR introduction intensifies oxidation process and reduces oxidation time. While using PHR it is possible to increase the degree of crude "aromatization" and oxidation intensity. The paraffinic hydrocarbons which are inert ones are oxidized in a higher degree in the presence of aromatics. Bitumen obtained using PHR are characterized by higher hardness, refractoriness and plasticity compared with bitumen on the basis of only paraffinic tar.

The addition of neutralized acid tar allows to increase the softening temperature and decrease the bitumen penetration. It is important that acid tar, which is a large-tonnage waste product, may be ably utilized.

\section{Conclusion}

Bitumen obtained via oxidation of tar produced from Ukrainian paraffin-base crude has operational properties which do not fulfill requirements for road bitumen. While using petroleum resin or pyrolysis heavy resin in amount of $5-7.5 \mathrm{wt} \%$ for joint oxidation with paraffinic tar it is possible to intensify oxidation, reduce oxidation time, increase bitumen hardness and refractoriness and improve plasticity.

\section{References}

[1] Fryder, I., Pysh'yev, S., Grynyshyn, O. (2013). Gas condensate residual usage for oxidated bitumen production. Chemistry \& Chemical Technology, Vol.7, №1, 105-108. https://doi.org/10.23939/chcht07.01.105

[2] Nagurskyy, A., Khlibyshyn, Y., Grynyshyn, O., Kochubei, V. (2020). Rubber crumb modified bitumen produced from residuals of crude oils of ukrainian deposits. Chemistry \& Chemical Technology, Vol.14, №3, 420-425. https://doi.org/10.23939/chcht14.03.420 


\title{
Research of valuable substances extraction from alcohol distillery stillage
}

\author{
Oleksandr Ivashchuk $^{1}$, Tetiana Kuzminchuk ${ }^{1}$, Roman Chyzhovych ${ }^{1}$, Semen Khomyak ${ }^{2}$, \\ Yevgen Semenyshyn ${ }^{1}$, Sofiia Kiiaieva ${ }^{1}$, Roman Zherebetskyi ${ }^{3}$ \\ 1. Department of Chemical Engineering, Lviv Polytechnic National University, UKRAINE, Lviv, 12 Bandery str., \\ E-mail: oleksandr.s.ivashchuk@lpnu.ua \\ 2. Department of Technology of Biologically Active Substances, Pharmacy and Biotechnology, \\ Lviv Polytechnic National University, UKRAINE, Lviv, 12 Bandery str. \\ 3. Department of Organic Products Technology, Lviv Polytechnic National University, \\ UKRAINE, Lviv, 12 Bandery str.
}

\begin{abstract}
The purpose of research was to study possibility of extraction of valuable components from waste of alcohol production - alcohol distillery stillage. The influence of raw material moisture on the extraction process was investigated. The study of the optical properties of the obtained extracts by infrared spectroscopy was carried out.
\end{abstract}

Keywords - alcohol distillery stillage, secondary raw materials, extraction, polar solvents, infrared spectroscopy.

\section{Introduction}

Recently scientists have begun to pay more and more attention to environmental problems solving, the rational use of natural resources of the regions, the development of secondary raw materials recycling. For Ukraine the problem of waste disposal and reusing is extremely relevant, as the country is a leader in Europe in the amount of waste per capita [1].

The alcohol industry, producing ethanol from food raw materials, has a problem of accumulation of waste from the production of alcohol - distillery stillage. Due to the high chemical and biochemical consumption of oxygen, suspended solids, specific color and odor, low $\mathrm{pH}$ value purification of such waste in the filtration fields or its discharge into environmental water is impossible [2].

According to various literature data, the dry matter content in alcohol distillery stillage from different raw materials is about $10 \%$. In terms of dry matter, it contains: protein - 13.9$37.25 \%$, fat $-3.7-10.7 \%$, fiber $-6.2-11.25 \%$, various substances and micronutrients: calcium 0.13-0.24\%, phosphorus - 0.29-0.69\%, amino acids: lysine, methionine, cystine, tryptophan, nitrogen-free extractives, as well as vitamins (A, D, E, B vitamins, folic acid), biotin $(\mathrm{H})$, carotenoids, etc. [3].

\section{Experimental}

The aim of the research was to study the possibility of obtaining valuable components from the corn distillery stillage by extraction in the system «solid - liquid». The extraction process was done in a Soxhlet apparatus according to the method described in [4].

As a solvent, a polar substance was chosen - methylene chloride, that has positively proven itself in previous studies [4, 5]. Methylene chloride has a low boiling point at $39.6{ }^{\circ} \mathrm{C}$. It is stable in working conditions, does not mix with water and it is easily removed from a product with low energy consumption [5].

The research was conducted with two types of raw materials. The first type - alcohol distillery stillage after the centrifugation process, obtained on the production line of SE «Vuzlove distillery» (Vuzlove, Lviv region, Ukraine), with a humidity of $70.98 \%$. The second type is the same raw material, pre-dried by filtration drying, with a moisture content of $6.67 \%$. 
A spectral study in the infrared region, for the obtained extracts, was performed on a spectrophotometer SPECORD M80 (Carl Zeiss Jena).

\section{Results and discussion}

The results of experimental studies of the extraction process from the alcohol distillery stillage are shown in Table 1.

Table 1

Extracts' concentrations of the alcohol distillery stillage extraction with methylene chloride.

\begin{tabular}{|c|c|c|}
\hline \multirow{2}{*}{ Time, $\min$} & \multicolumn{2}{|c|}{ C, g/1 } \\
\cline { 2 - 3 } & Dry & Wet \\
\hline 120 & 6,40 & 1,20 \\
\hline 240 & 7,20 & 0,99 \\
\hline 360 & 6,97 & 1,11 \\
\hline 480 & 6,95 & 1,44 \\
\hline Yield, \% & 6,06 & 1,22 \\
\hline
\end{tabular}

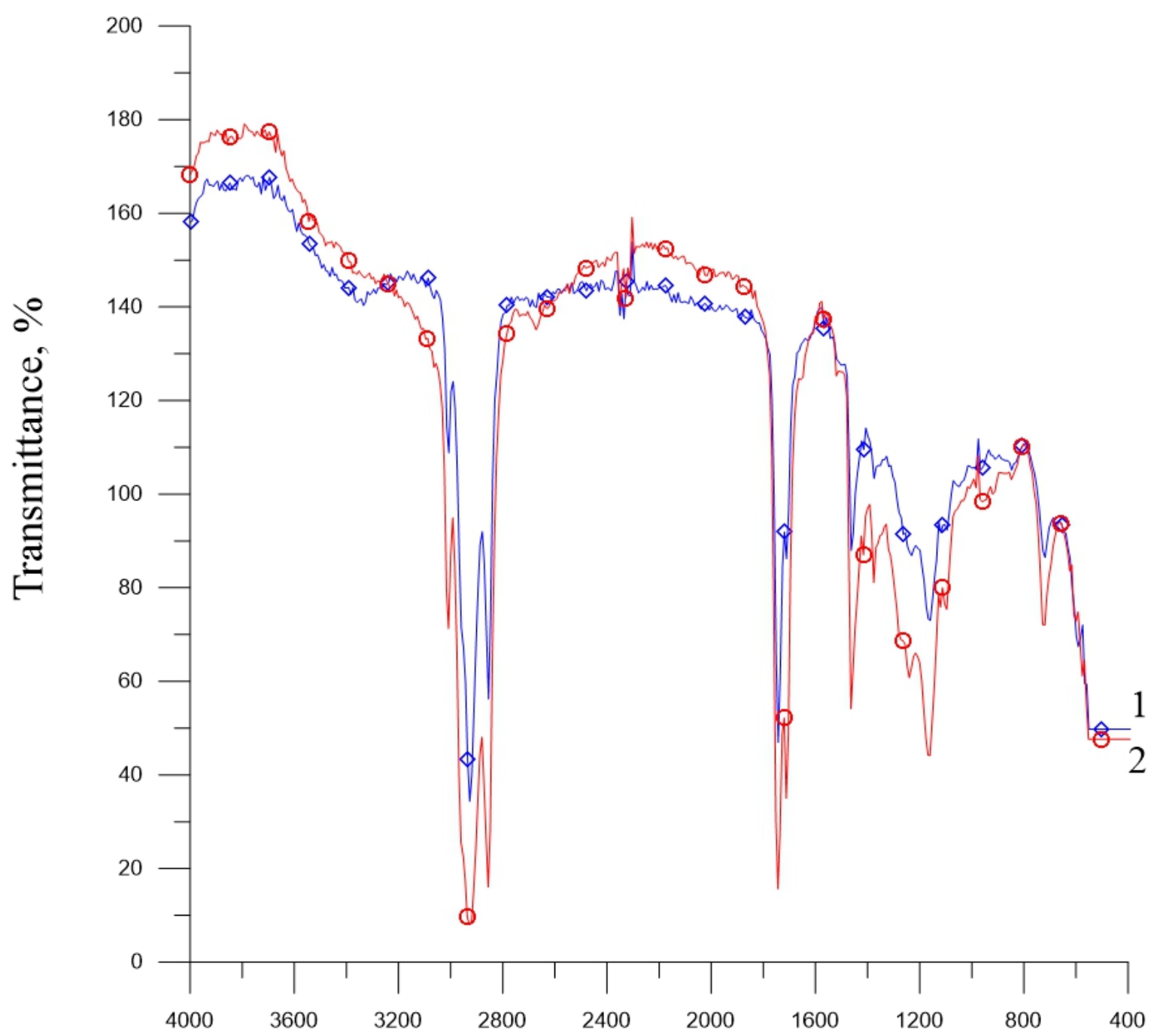

\section{Wavenumber $(\lambda), \mathrm{cm}^{-1}$}

Fig. 1. IR spectra of samples of distillery stillage extracts: 1 - pre-dried distillery stillage; 2 - distillery stillage obtained at the factory.s 
The results clearly show the positive effect of pre-drying the alcohol distillery stillage on the efficiency of the extraction process. However, such a reduction in the moisture content of the raw material requires more energy consumption for drying.

Infrared spectrophotometry of the obtained samples of extracts was also performed. The results are shown as the dependence of the transmission on the wavenumber (Fig. 1).

Analysis of the obtained data in the infrared region of the spectrum $\left(400-4000 \mathrm{~cm}^{-1}\right)$ showed the repetition of the main peaks in the spectra of both samples (Fig. 1). This indicates an insignificant effect of distillery stillage moisture on the quality of the product. The peaks on the IR spectrum are characteristic for substances found in vegetable oils [6]. This fact is expected because polar solvents are effective exactly for the extraction of vegetable oils $[5,6]$. However, in the range of $3000-3300 \mathrm{~cm}^{-1}$ there is a difference, its explanation requires additional research.

\section{Conclusions}

Analysis of the results of studies of the distillery stillage extraction with different humidities shows that humidity is a factor that significantly affects the quantitative indicator of product yield. The use of pre-dried raw materials shows a positive effect on the concentration of the extract in the solvent. Due to the preliminary drying of the raw material from a humidity of $70.98 \%$ to $6.57 \%$, the product yield increased from $1.22 \%$ from wet material to $6.06 \%$ from dry one. However, on the other hand, spectral analysis indicates insignificant differences in the qualitative composition of the obtained extracts of distillery stillage with different humidities.

Thus, the extraction process allows the use of valuable components from the alcohol distillery stillage. Detailed identification of substances in the extracts requires additional research and analysis.

\section{References}

[1] Kryvenko, S.V. (2014). Suchasni pidxody do rozvytku recyklingu vtorynnykh materialnykh resursiv v konteksti «zelenoyi» industriyi. Naukovyj visnyk Poltavskogo universytetu ekonomiky $i$ torgivli, 4(66), 83-89.

[2] Golub, N. B. (2018). Suchasni metody pererobky j utylizaciyi zernovoyi pislyaspyrtovoyi bardy. Innovative Biosystems and Bioengineering: international scientific e-journal, 2(2), 125-134.

[3] Hizhnjak, M.I. \& Cion', N.I. (2010). Spirtova barda jak cinna kormova dobavka j organichne dobrivo u sil's'komu gospodarstvi. Ribogospodars 'ka nauka Ukrajiny, 2, 122130.

[4] Ivashchuk, O., Hlukhaniuk, A., Semenyshyn, Ye., Chyzhovych, R., Kuzminchuk, T. \& Khomyak, S. (2021). Influence of extraction conditions on qualitative composition of vegetable oils. Chemistry \& Chemical Technology, 15(2), 233-238.

[5] Hlukhaniuk, A.R., Kuzminchuk, T.A., Chyzhovych, R.A., Semenyshyn, Ye.M. \& Ivashchuk, O.S. (2020). Research of grinding degree influence and polar solvents nature on the efficiency of oil withdrawal from vegetable raw material using extraction method. Chemistry, Technology and Application of Substances, 3(1), 161-168.

[6] Chyzhovych R.A., Ivashchuk O.S., Khomyak S.V., Semenyshyn Ye.M., Kuzminchuk T.A., Hlukhaniuk A.R., Zherebetskyi R. (2021). Research of rapeseed oil qualitative characteristics with IR spectroscopy. Monograph of the $9^{\text {th }}$ edition of the European Young Engineers Conference: Warsaw, Poland, 163. 


\section{Features of Aging of Road Bitumen}

$\underline{\text { Myroslava Donchenko }}^{1}$, Oleg Grynyshyn ${ }^{2}$, Yuriy Khlibyshyn ${ }^{3}$

1. Department of Chemical Technology of Oil and Gas Processing, Lviv Polytechnic National University,

UKRAINE, Lviv, 12 Bandera street, E-mail: myroslava.i.donchenko@lpnu.ua

2. Department of Chemical Technology of Oil and Gas Processing, Lviv Polytechnic National University, UKRAINE, Lviv, 12 Bandera street, E-mail: oleg.b.grynyshyn@lpnu.ua

3. Department of Organic Products Technology, Lviv Polytechnic National University, UKRAINE, Lviv, 12 Bandera street, E-mail: yurii.y.khlibyshyn@lpnu.ua

Abstract - The aging process of oxidized and residual oil bitumens was carried out in a thin film at the temperature of $163^{\circ} \mathrm{C}$ for 5 and 10 hours. By comparing the main characteristics of aged and original bitumen samples it was possible to investigate the changes that occur during aging.

Keywords - bitumen, bitumen aging, tar oxidation, oxidized bitumen, residual bitumen, pavement.

\section{Introduction}

Today, the aging of the binder is one of the main reasons for the loss of bitumen properties. In accordance to thus, the deterioration of the main bonding component of the asphalt mixture leads to deformation and destruction of the entire pavement. The reason for such negative changes is the effect of atmospheric oxygen, solar radiation, water, mechanical loads and high technological temperatures on the thin bituminous film.

Until recently it was believed that the effect of light and ultraviolet radiation can be ignored, but nowadays this claim was found to be false. Water also has a significant negative impact on the service life of the pavement. In the regions with increased humidity, when the roads are sometimes flooded, the processes that accelerate the loss of the pavement strength will certainly occur. In addition, water impairs the distribution of road load, causing surface breaking and loss of fine-grained fractions. Moisture leaches asphalt concrete, dissolves and washes away its components, which contributes to the intensity of bitumen oxidation.

Thus, bitumen constantly undergoes aging due to weather and climatic factors on the one hand, but also undergoes changes due to the processes within its structure. It is important to note that oxygen absorption, which is the reason of bitumen aging, depends on the diffusion rate, bitumen viscosity and the film thickness [1].

So, in this paper we studied the processes occurred on the stationary film during binder aging due to air and high temperature. The samples of residual and oxidized bitumen produced in Ukraine were compared.

\section{Experimental}

To simulate the thermal oxidative aging of bitumen samples, artificial aging was performed according to the method that is slightly modified compared to the standard one and allows to obtain a binder after heating at $163^{\circ} \mathrm{C}$ in a $2 \mathrm{~mm}$ thin film for 5 and $10 \mathrm{~h}$ [18]. As can be seen, the film thickness was changed (cf. $4 \mathrm{~mm}$ according to the standard). However, in this case, the surface of the test sample will be oxidized primarily, whereas the changes in volume will depend on the viscosity [2].

To study we used oxidized bitumen of BND 60/90 brand produced by PJSC "Ukrtatnafta" (Kremenchuk, Ukraine) and residual bitumen of BD 130/200 brand, obtained after refining of Orkhovitska oil at JSC "Ukrgazvydobuvannya" (Lviv, Ukraine).

The weight loss of the samples after aging and the softening temperature changes were determined according to EN 1427:2007. The main indices before and after 5 and $10 \mathrm{~h}$ of aging 
were determined according to the standard methods, including penetration (EN 1426:2000) and ductility (EN 13589:2008). The brittleness temperature $\left(\mathrm{Tb},{ }^{\circ} \mathrm{C}\right)$ was determined by the formula: $\mathrm{Tb}=\mathrm{Ts}-7 \cdot(10-\mathrm{PI})$, where Ts is the softening temperature, ${ }^{\circ} \mathrm{C}$ and $\mathrm{PI}$ is the penetration index. The plasticity interval of the samples was calculated as the sum of the softening temperature and the brittleness temperature [3]. Group analysis was performed by the Marcusson method.

\section{Results}

The data show a rapid deterioration of the bitumen properties due to aging process. We observed a sharp decrease in the penetration value (by $55.5 \%$ for the oxidized sample and by 26 $\%$ for the residual one), as well as an increase in the softening temperature by $22.5 \%$ and $24.5 \%$ for the oxidized and residual bitumen, respectively. The plastic properties of the oxidized bitumen, the ductility of which is reduced by more than $90 \%$, deteriorate sharply. On the other hand, the plasticity of the residual sample remains at a very high level even after $10 \mathrm{~h}$ of aging. The plastic range of both samples also varies in different ways, namely the temperature range, which is desirable for pavement maintenance and within which the binder remains in the viscoplastic state. In this case, there is a decrease of the value by $9^{\circ} \mathrm{C}$ for the oxidized sample and an increase by $8^{\circ} \mathrm{C}$ for the residual bitumen. Another negative consequence of aging for the oxidized bitumen is the loss of frost resistance (the brittleness temperature increases by almost $20^{\circ} \mathrm{C}$ ). The penetration index is higher for residual bitumen, i.e. this bitumen has better heat resistance [4]. The described characteristics demonstrate that the aging processes that occur in the residual bitumen are less intense to compare with the oxidized sample; however, both bitumen samples after a few hours of aging lose their commercial characteristics.

The data of structural group analysis also confirm the significant impact of aging processes on both samples of bitumen.

\section{Conclusion}

Comparing the aging peculiarities of residual and oxidized bitumen, it can be argued that changes in oxidized bitumen occur with greater intensity. This is especially noticeable due to the analysis of its structure. And, as the result of aging, the structure of the oxidized bitumen becomes similar to the structure of the residual one.

Thus, the aging process leads to a significant deterioration of the binding properties of both samples, but the residual bitumen is more stable. At the same time, even a slight decrease in operational temperature during oxidized bitumen production or certain changes in production technology can significantly improve bitumen properties.

\section{References}

[1] Donchenko, M. I., Grynyshyn, O. B., Kochubey, V. V., Khlibyshyn, Yu. Ya. (2020). Characteristics Of Aging Of Oxidized Oil Bitumen BND 60/90 PJSC "Ukrtatnafta". Chemistry, Technology and Application of Substances, Vol. 3, No. 1, 83-89. https://doi.org/10.23939/ctas2020.01.083.

[2] Pechenyi, B. G., Kurbatov, V. L., Losev, V. P. (2019). On The Mechanism Of Bitumen Aging And Methods Of Their Testing. Universitetskaja nauka, № 2 (8), 28-32.

[3] Kopylov, V. E., Burenina, O. N. (2019). Influence Of Bitumen Plasticity Interval On Asphalt Concrete Thermal Stability. Roads and Bridges, 190-196.

[4] Peide, C., Mingjing, F., Zongwu, Ch., Mingwei, Y. (2018). Residual Fatigue Properties of Asphalt Pavement after Long-Term Field Service. Materials, 11(6), 892-904. https://doi.org/10.3390/ma1 1060892 


\title{
The improved evaluation of the duration of the fouled membrane modules regeneration
}

\author{
Serhii Huliienko, Ihor Tereshenko
}

Department of Machines and Apparatus of Chemical and Oil Refinery Productions, National Technical University of Ukraine "Igor Sikorsky Kyiv Polytechnic Institute", UKRAINE, Kyiv, Prosp. Peremohy, 37, 03056, E-mail: sergii.guliienko@gmail.com

- Abstract - The calculations of the duration of the membrane modules regeneration using the corrected dimensionless equation were carried out. It was defined that proposed equation allows avoiding the overestimation of regeneration time. The results show that assumption about the negligible influence of the concentration change in the cleaning solution is reliable.

- Keywords - fouling, membrane, regeneration, dimensionless equation, calculation, cleaning solution, mass transfer coefficient.

\section{Introduction}

Membrane fouling is one of the main problems during the exploitation of membrane equipment, which determines the necessity of periodic membrane regeneration [1]. In previous work, the method of the spiral wound membrane modules regeneration with using of vacuuming was developed. The mathematical model of this process, which allows calculating the regeneration process duration, also was proposed [2]. However, in that work the dimensionless equation was used, which was obtained with several assumptions that lead to the overestimation of the mass transfer coefficient. This equation was corrected in work [3]. The current work aims to carry out the improved evaluation of the regeneration time taking into account the corrected dimensionless equation. Also, in work [2] the influence of the changes in cleaning solution concentration wasn't taken into account, therefore, the improved evaluation has also aimed to verify the reliability of that assumption.

\section{Materials and methods}

The process of mass removal from the membrane surface is described by the equation [2]:

$$
\frac{d M}{d \tau}=K\left(C^{p}-C_{0}-\frac{M_{\Pi}}{V}\left(1-\frac{M_{\Pi}-M}{M_{\Pi}}\right)\right) F
$$

The starting conditions are: $M=0$ for $\tau=0$.

The determination of mass transfer coefficient $K$, unlike work [2], in the current research the following dimensionless equation was used [3]:

$$
\mathrm{Sh}=0.00045 \operatorname{Re}^{0.8} \mathrm{Sc}^{0.33}\left(d_{e} / l\right)
$$

The solving was carried out by the Runge-Kutta, the calculations were done using the program written in the programming language Python in two variants (with and without taking into account the concentration change in cleaning solution).

\section{Results and discussion}

The calculations were carried out for the case of the fouling which consists of $\mathrm{FeCl} 3$ (this material used as model foulant in experimental researches) with an initial mass of $0.002 \mathrm{~kg}$, and an operating temperature of $25^{\circ} \mathrm{C}$. The mass flow rate of the cleaning solution in a range of $0.001-0.025 \mathrm{~kg} / \mathrm{s}$. which correspond to the real working condition of the regeneration setup. The results of the calculation are represented in table 1. 
Table 1

The results of calculations

\begin{tabular}{|c|c|c|c|c|}
\hline $\begin{array}{c}\text { The mass } \\
\text { flow rate of } \\
\text { the cleaning } \\
\text { solution, } \\
G, \mathrm{~kg} / \mathrm{s}\end{array}$ & $\begin{array}{c}\text { With taking into account the } \\
\text { concentration change in cleaning } \\
\text { solution }\end{array}$ & \multicolumn{2}{c|}{$\begin{array}{c}\text { Without taking into account the } \\
\text { concentration change in cleaning } \\
\text { solution }\end{array}$} \\
\cline { 2 - 5 } & $\begin{array}{c}\text { Reynolds } \\
\text { number, Re }\end{array}$ & $\begin{array}{c}\text { The time of } \\
\text { complete cake layer } \\
\text { removal, } \tau, \mathrm{s}\end{array}$ & $\begin{array}{c}\text { Reynolds } \\
\text { number, Re }\end{array}$ & $\begin{array}{c}\text { The time of complete } \\
\text { cake layer removal, } \tau, \\
\text { sm }\end{array}$ \\
\hline 0,0010 & 2,163 & 141000 & 2,163 & 141119 \\
\hline 0,0025 & 5,407 & 67740 & 5,410 & 67801 \\
\hline 0,0050 & 10,814 & 38910 & 10,814 & 38942 \\
\hline 0,0075 & 16,221 & 28130 & 16,221 & 28154 \\
\hline 0,0100 & 21,628 & 22350 & 21,628 & 22366 \\
\hline 0,0125 & 27,035 & 18700 & 27,035 & 18710 \\
\hline 0,0150 & 32,442 & 16160 & 32,442 & 142917 \\
\hline 0,0175 & 37,849 & 14290 & 37,849 & 12846 \\
\hline 0,0200 & 43,256 & 12840 & 43,256 & 11691 \\
\hline 0,0225 & 48,663 & 11690 & 48,663 & 10746 \\
\hline 0,0250 & 54,070 & 10740 & 54,070 & \\
\hline
\end{tabular}

As it can be seen from table 1, the difference in the time of complete cake layer removal for the calculation with and without taking into account the concentration change in the cleaning solution is negligible, therefore, the assumption made in work [2] is reasonable. At the same time, the duration of the regeneration differs significantly. In work [3] it was pointed out that previous mass transfer correlation was obtained with overestimated values of diffusivities. The results of improved calculation show that this led to the overestimation of the regeneration duration in 4-5 times, therefore, for the practical calculation the corrected dimensionless equation should be used.

\section{Conclusion}

The use of the corrected dimensionless equation allows predicting the duration of the membrane modules regeneration with higher accuracy. Moreover, the assumption about the negligible impact of the concentration change in the cleaning solution on the mass transfer coefficient value appears to be reasonable.

\section{References}

[1] Jafari M., D'haese A., Zlopasa J., Cornelissen E.R., Vrouwenvelder J.S., Verbeken K., Verliefde A., van Loosdrecht M.C.M., Picioreanu C. (2020). A comparison between chemical cleaning efficiency in lab-scale and full-scale reverse osmosis membranes: Role of extracellular polymeric substances (EPS). Journal of Membrane Science, 609, 118189, https://doi.org/10.1016/j.memsci.2020.118189

[2] Korniyenko Y., Guliienko S., Lialka M. (2015). Mathematical simulation of fouled membrane modules regeneration. Ukrainian Food Journal, 4. (3), 481-493

[3] Huliienko S. V., Korniienko Y. M., Metlina M. S., Tereshenko I. Y., Kaminskyi V. S. (2020). The correction of the dimensionless equation for the mass transfer coefficient estimation during the membrane modules regeneration. Journal of Engineering Sciences, 7(2), 24-29, https://doi.org/10.21272/jes.2020.7(2).f4 


\title{
Establishment of energy-saving modes of dispersion and fractionation of pectin-containing powder
}

\author{
$\underline{\text { Raisa Shapar }}^{1}$, Olena Husarova ${ }^{2}$ \\ 1. Department of Mass Transfer in Heat Technologies, Institute of Engineering Thermophysics of the National \\ Academy of Sciences of Ukraine, UKRAINE, Kyiv, 2a, Marii Kapnist Str., 03057, \\ E-mail: r.sh@ukr.net
}

2. Department of Mass Transfer in Heat Technologies, Institute of Engineering Thermophysics of the National Academy of Sciences of Ukraine, UKRAINE, Kyiv, 2a, Marii Kapnist Str., 03057,

E-mail: o.v.husarova@nas.gov.ua

\begin{abstract}
The research of dispersion and fractionation of pectin-containing powder is carried out in the work. Energy-saving modes of dispersion and fractionation processes are also determined.
\end{abstract}

Keywords - dispersion, fractionation, pectin-containing powder, energy-saving, rotor speed, dispersion of beet powder.

\section{Introduction}

The most convenient form for storage and use of dried fruits and vegetables is a powder form. The aggregate state of powders, their high moisture absorption capacity promotes to increase the speed of biochemical and diffusion processes by increasing the contact surface and interaction with other ingredients and provides maximum extraction of pectin, carotene, dyes and other biologically active substances, thus excluding the use of synthetic dyes and fillers in food products [1-4].

The main indicator that determines the scope of application of food powders is the degree of dispersion (grinding). The dispersion process is characterized by high energy costs, which are determined primarily by the properties of dried vegetable raw materials [5].

\section{Purpose and task of the research}

The purpose of the work is to conduct research on the dispersion and fractionation of dried plant materials and to determine the energy-saving regimes of these processes.

The task of the research is to develop optimal modes of dispersion of dried plant materials; to determine the dependence of the micromill performance and power consumption on the rotation speed of the dispersant rotor; to establish the influence of the load on the sieve and the scattering time on the fractionation process.

\section{Objects, equipment and research methods}

Dried beets with residual humidity $W_{\mathrm{r}}=6 \ldots 8 \%$ were used as objects of research. Studies of the dispersion process were performed on an $8 \mathrm{MM}$ micromill, the coarse part was ground on a DESI disintegrator, the study of the dispersed composition of powders was carried out on the device 029 [5].

\section{Results of investigations}

The analysis of the existing methods of grinding and mills for its carrying out showed that the mills of a shock mode of action are the most suitable for dispersion of the dried vegetable raw materials. It is experimentally proven that increasing the speed of the disperser rotor from 20 to $70 \mathrm{~m} / \mathrm{s}$ leads to a decrease in the equivalent diameter of the crushed particles and increase the powder dispersion by $35 \%$. The optimal rotor operating speed is $50 \mathrm{~m} / \mathrm{s}$. At this speed, energy consumption for grinding dried materials is minimal. 
Figure 1 shows the results of the influence of the rotor speed of the dispersant on the dispersion of beet powder in the form of integral and differential distribution curves by fractions.

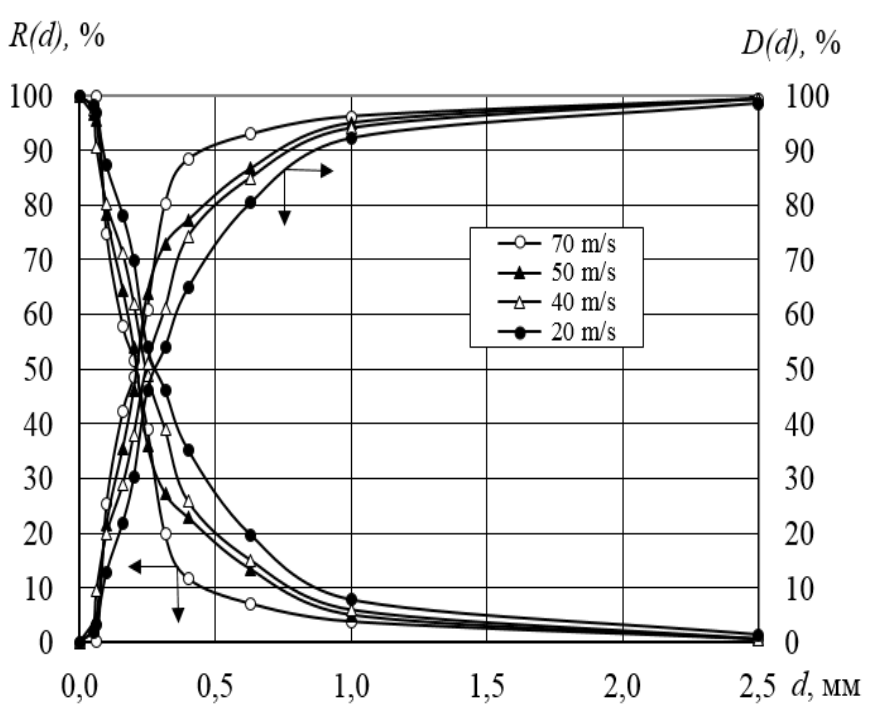

a)

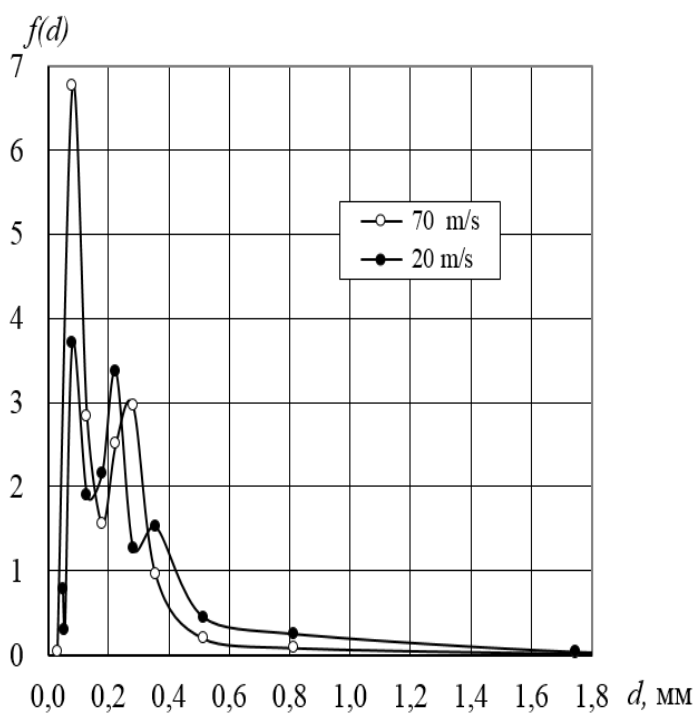

b)

Fig.1. The influence of the rotor speed of the dispersant on the dispersion of beet powder in the form of integral (a) and differential (b) distribution curves by fractions.

One can see that beet powder, regardless of the rotor speed, has a clear maximum, which corresponds to the most probable diameter of the particles. As the rotor speed of the dispersant increases, the mass distribution function corresponding to the most probable distribution increases, i.e., the grinding of the particles is more uniform. Its maximum value corresponds to a rotor speed of $70 \mathrm{~m} / \mathrm{s}$, the minimum $-20 \mathrm{~m} / \mathrm{s}$; the maximum distribution is $0.08 \mathrm{~mm}$. The distribution function curves at rotor speeds of 40 and $50 \mathrm{~m} / \mathrm{s}$ are so similar that they are not provided in the graphic illustration for better clarity.

It is established that food powders from vegetable raw materials, including beet, consist of a mixture of particles of different sizes and shapes, which determine their physicochemical and technological properties. Our experience has shown that the particle sizes of powders used in food production should not exceed $0.25 \mathrm{~mm}$. The results of experimental studies on fractionation depending on the load on the sieve and the scattering time show that the yield of the fine fraction of beet powder is more influenced by the scattering time, while the load on the sieve does not significantly affect the particle size distribution.

Figure 2 presents the integral and differential distribution curves of beet powder depending on the scattering time. As the scattering time increases, a larger mass of fine powder falls on the lower sieves and on the integral curves the median moves towards a smaller diameter. However, it is impractical to increase the process duration by more than 3 minutes, because if the scattering time is increased from 2 to 4 minutes, the mass of the fine fraction will increase by only $2 \ldots 5 \%$ (the residue on the 0.25 sieve decreases from 34 to $29 \%$ ).

On differential curves with increasing scattering time, the maximum of the function $f(d)$ moves to smaller $d$ values. There is a bright maximum of the function $f(d)$, which is the particle size $d=0.1 \mathrm{~mm}$, which confirms the data shown in Fig. 1. The yield of the fine fraction of beet powder according to the optimal modes of dispersion and fractionation is $62 \ldots 65 \%$.

Analyzing the results of fractionation depending on the duration of scattering and other food powders (in particular apple, carrot, pumpkin), it is proved that the regularity of the influence of the process duration on the particle size distribution is similar. 


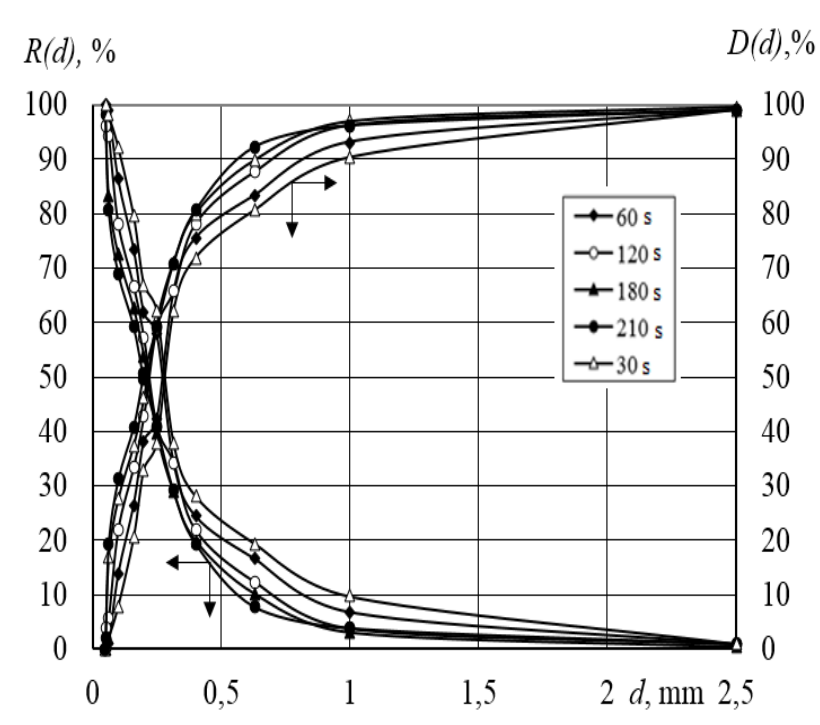

a)

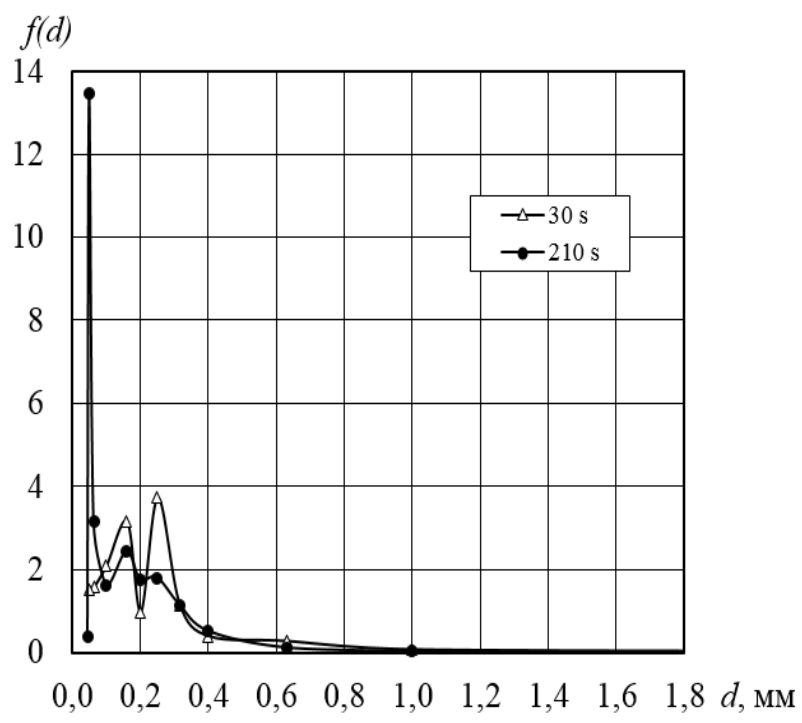

b)

Fig. 2. The integral (a) and differential (b) distribution curves of beet powder depending on the scattering time.

\section{Conclusion}

According to the results of the research, the optimal dispersion regimes, the dependence of micromill productivity and power consumption on the dispersant rotor speed, as well as the effect of load on the sieve and scattering time of beet powders on the fractionation process are determined.

On the basis of the conducted researches, energy-saving conditions of processes of dispersion and fractionation of pectin-containing powders and proper work of the corresponding equipment are defined.

\section{References}

[1] Sniezhkin, Yu.F., Shapar, R.O., Khavin, O.O. \& Chalaiev, D.Y. (2002). Dosvid vykorystannia naturalnykh poroshkiv z roslynnoi syrovyny u molochnykh produktakh. Industrial heating technology, application, 4. 57 - 59.

[2] Shapar, R.O. \& Husarova, O.V. (2020). Naturalni dobavky iz roslynnoi syrovyny. Materials int. scientific-practical conf. "Health foods and dietary supplements: technology, quality and safety". (Ukraine, Kyiv, November 19-20, 2020), Kyiv: NUFT,14 - 16.

[3] Van Muorik, S.V. (2004). Sovremennyie tendentsii razvitiya promyishlennosti pischevyih dobavok i ingridientov. Food ingredients - raw materials and additives, 1, 20 - 22.

[4] Shapar, R.O., Sorokova, N.M. \& Husarova, O.V. (2020). Resurso- ta enerhozberezhennia u pereroblenni termolabilnykh roslynnykh materialiv na susheni produkty. Scientific notes of TNU named after VI Vernadsky. Series: technical sciences, 31 (70). part 2. no 3, $79-84$. DOI: https://doi.org/10.32838/TNU-2663-5941/2020.3-2/14.

[5] Baudelaire, E.D. (2013). Grinding for food powder production. Handbook of Food Powders: Processes and Properties Woodhead Publishing Series in Food Science, Technology and Nutrition. Woodhead Publishing, 132 - 149. ISBN 9780857095138. DOI: https://doi.org/10.1533/9780857098672.1.132. 


\title{
Changes in the properties of semi-synthetic motor oil Castrol 10W-40 during its use in the diesel engine of commercial vehicles
}

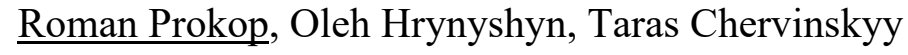 \\ Lviv Polytechnic National University, 12, Bandery St., 79013 Lviv, Ukraine, E-mail: ogrynyshyn@ukr.net
}

\begin{abstract}
The changes in operational and physico-chemical properties of original and used semisynthetic motor oil Castrol 10W-40 before and after its use in a diesel engine have been investigated. Derivatographic studies were carried out to examine a thermal stability; IR spectroscopy was used to confirm the presence of oil aging products. The composition of the inorganic part of the studied semisynthetic oils was established by X-ray fluorescence analysis.
\end{abstract}

Keywords: semi-synthetic motor oil, used oil, thermal decomposition, oil aging, X-ray fluorescence analysis, IR spectroscopy.

The main consumers of lubricating oils are machine-building and automobile industries; automobile, railway, aviation and sea transport; fuel and energy complex, etc. The traditional basis of these products is mineral oils, the amount of which varies within 96-98\%. However, despite a low cost of mineral lubricating oils, they have a number of negative properties, in particular, low biodegradability, relatively high toxicity, limited shelf life and so on.

Nowadays, at the time of rapid development, renewal and improvement of many sectors of the economy, the task of creating and improving highly biodegradable lubricating materials is becoming increasingly important. One of the ways to produce environmentally friendly lubricants is to create new and improve existing formulations of semi-synthetic and synthetic motor oils with a long service life due to the addition of synthetic and polymeric materials. This solution to the long-term problem allows to release a significant part of the mineral base of lubricating oils, increase their service life in internal combustion engines (ICE) and significantly increase the service life of ICE [1].

During operation in ICE the motor oils undergo significant changes: water flooding, contamination with mechanical impurities and residues of unburned fuel, changes in chemical composition, etc. The composition of used motor oils includes pollutants, decomposition products of additives, heavy metals and acids, products of oil thermal decomposition, products of various chemical transformations of oil hydrocarbon part, etc. The toxicity of used oils (UO) is increased with the increase of molecular weight, acid value (AI), as well as the content of arenes, asphalt-resinous substances and sulfur compounds. More than 140 carcinogenic compounds have been identified in UO, in particular, benzo $(\alpha)$ pyrene, fenatren, etc. The amount of these hazardous compounds increases with increasing service life of engine oil in ICE and negatively affects the environment and public health. The combination of the processes, which leads to the deterioration of the operationl properties of motor oil, is called the oil aging. However, despite numerous studies the essence of this phenomenon remains controversial and not fully understood [2].

To date, semi-synthetic motor oils are one of the most popular groups of oils used in diesel engines of regional and international vehicles (commercial class). Due to the lack of attention paid to the study of aging processes of such motor oils, they were selected as the object of research. The study on changes in their properties after using in ICE will establish the probable causes and mechanism of oil aging. At the same time, the obtained results will be used to select the optimal regeneration technology for used semi-synthetic motor oils (USSO). 
So, the purpose of this work is to study the change in performance of original and used semi-synthetic motor oil Castrol 10W-40, their thermal stability, changes in the inorganic part, search and confirmation of the presence of primary aging products in the used oil.

The densities of the above oils were determined by the pycnometric method, the viscosity - by the viscometric method; the refractive index was determined using a refractometer, and the flash point - using an open cup device.

To determine the elemental composition of oils the X-ray fluorescence spectral analysis was performed on a mobile precision analyzer EXPERT 3L, designed to determine the mass fraction of chemical elements in homogeneous monolithic and powdery objects. Oil samples for the analysis were burned at $723 \mathrm{~K}$ for $4 \mathrm{~h}$, cooled in a desiccator and ground to a powder.

It was found (Table 1) that used semi-synthetic motor oil is characterized by lower viscosity and viscosity index, compared with those values of original oil. This change is explained by the fact that during the diesel engine operation in different modes under various mechanical and thermal loads a certain amount of diesel fuel, which has not burned in the engine, passes into the motor oil and dilutes it. This is confirmed by a decrease in the oil flash point due to the presence of diesel residues. Moreover, the group hydrocarbon composition of USSO is changed, which is confirmed by changes in the refractive index. At the same time, the used oil Castrol 10W-40 is characterized by a higher value of water content and mechanical impurities than original oil, which indicates the wear of the cylinder-piston group parts during ICE operation under different thermal loads. The coking ability of the oil increases, which is obviously also the result of changes in group composition. However, the most important defective indicator of oil aging is the value of the acid number, which increases as well. As a result, the oil acquires aggressive properties to metal parts of the engine, which will lead to chemical destruction of their surface.

Table 1

Physico-chemical characteristics of original and used Castrol 10W-40

\begin{tabular}{|l|c|c|}
\hline \multicolumn{1}{|c|}{ Index } & Original oil & Used oil \\
\hline Viscosity, $\mathrm{mm}^{2} / \mathrm{s}:$ & & \\
$-\quad \quad$ at $323 \mathrm{~K}, v_{50}$ & 62.61 & 84.86 \\
$-\quad$ at $373 \mathrm{~K}, v_{100}$ & 12.46 & 11.97 \\
$-\quad v_{50} / v_{100}$ & 5.00 & 7.09 \\
\hline Viscosity index & 120 & 60 \\
\hline Density, $\mathrm{kg} / \mathrm{m}^{3}$ & 863.0 & 879.7 \\
\hline Water content, \% & 0.06 & 0.15 \\
\hline Mechanical impurities & 0.63 & 1.24 \\
content, \% & 0.73 & 1.55 \\
\hline Coking ability, \% & 1.4692 & 1.4806 \\
\hline Refractive index, $\mathrm{n}_{\mathrm{D}}{ }^{20}$ & $<253$ & 253.5 \\
\hline Freezing point, $\mathrm{K}$ & 490 & 474 \\
\hline Flash point $($ open cup), $\mathrm{K}$ & 1.54 & 2.25 \\
\hline Acid number, $\mathrm{mg} \mathrm{KOH} / \mathrm{g}$ & & \\
\hline
\end{tabular}

Today, car manufacturers, namely Detroit Diesel, Caterpillar, Cummins and others, strictly regulate the metal content in motor oils. Thus, the above car manufacturers recommend to replace the engine oil with a new one when the content of such metals as iron, chromium, lead, copper, tin, aluminum, sodium, potassium and non-metals (silicon, boron) in the working oil 
exceeds the allowable one (15-150 ppm). Excessive increase in the content of metals is one of the reasons for motor oil replacement.

The experimental results are presented in Table 2.

Table 2

Elemental composition of the inorganic part of the semi-synthetic motor oil Castrol 10W-40

\begin{tabular}{|c|c|c|}
\hline \multirow{2}{*}{ Element } & \multicolumn{2}{|c|}{ Content, \% } \\
\cline { 2 - 3 } & Original oil & Used oil \\
\hline $\mathrm{Si}$ & $0.950 \pm 0.029$ & $1.141 \pm 0.032$ \\
\hline $\mathrm{P}$ & $4.428 \pm 0.022$ & $4.834 \pm 0.023$ \\
\hline $\mathrm{S}$ & $3.959 \pm 0.018$ & $4.193 \pm 0.017$ \\
\hline $\mathrm{Ca}$ & $41.800 \pm 0.091$ & $36.694 \pm 0.098$ \\
\hline $\mathrm{Cr}$ & - & $0.058 \pm 0.011$ \\
\hline $\mathrm{Fe}$ & $0.106 \pm 0.006$ & $0.544 \pm 0.010$ \\
\hline $\mathrm{Cu}$ & $0.011 \pm 0.004$ & $0.223 \pm 0.005$ \\
\hline $\mathrm{Zn}$ & $14.626 \pm 0.053$ & $18.582 \pm 0.059$ \\
\hline $\mathrm{Mo}$ & $0.719 \pm 0.005$ & $0.240 \pm 0.003$ \\
\hline $\mathrm{Pb}$ & - & $0.035 \pm 0.002$ \\
\hline
\end{tabular}

Analyzing the obtained results (Table 2) we can state the following: phosphorus, sulfur, and zinc indicate the presence of antioxidant and anti-wear additives in the oil (for example, DF11, LANI-317, Anti Wear, ZDDP, etc.); calcium, chromium, iron and copper reveal the presence of detergent-dispersing additives (for example, SC-3); molybdenum and lead characterize the presence of friction additives (for example, $\mathrm{MoS}_{2}$, lead naphthenate), as well as corrosion inhibitors and remetallizers.

The change in the content of above-mentioned metals indicates the presence of wear elements of the ICE cylinder-piston group, as well as the ingress of unwanted mechanical contaminants into the oil. The above-identified metals (iron, molybdenum, lead) contained in USSO, are mandatory components of metal alloys of parts of any engine. During its operation, microscopic metal particles are erased from the work surfaces and get into the engine oil. Thus, iron is the main structural material of the most important parts: cylinder block, cylinder head, valves, crankshafts and camshafts, connecting rods, piston pins, oil pump. The increased content of iron in the used oil usually indicates wear of one or more engine components. Titanium, which is characterized by its strength, is the main element of the alloy used for turbines, springs and valves manufacture. Molybdenum, as a wear-resistant metal, is most commonly found in piston rings and rolling bearings. Lead is often used for babbit based coatings, as well as for doping alloys used for connecting rods and bearing pad of crankshaft. The lead content in the used oil indicates the wear of the crankshaft bearings, etc. The decrease in calcium content in USSO indicates the depletion of detergent-dispersing additives or corrosion inhibitors. Phosphorus and sulfur in small quantities allow the surfaces of metal parts to be chemically inert. The increase in their content indicates the wear of the metal surfaces.

Another reason for the increase in inorganic components content is the addition of a new portion of oil between its changes. Typically, this is done for engines with significant mileage (approaching the repair period) in order to compensate the oil losses from burning and leakage. 
In this case, only the organic part of the oil burns out, and inorganic components accumulate in the oil, which circulates in the lubrication system of ICE.

\section{References}

[1] Hrynyshyn, O., Korchak, B., Chervinskyy, T., Kochubei, V. (2017). Chem. Chem. Technol., 11, 387. https://doi.org/10.23939/chcht11.03.387

[2] Korchak, B., Hrynyshyn, O., Chervinskyy, T., Polyuzhin, I. (2018). Chem. Chem. Technol.,12, 365. https://doi.org/10.23939/chcht12.03.365 


\title{
Complex processing of liquid pyrolysis products
}

\author{
Dariia Kichura, Roman Subtelnyi, Bohdan Dzinyak \\ Institute of chemistry and chemical technology, Lviv Polytechnic National University, \\ UKRAINE, Lviv, St. Banderu str., E-mail: dariia.b.kichura@1pnu.ua
}

\begin{abstract}
The processing of oil fractions or natural gas produces a significant amount of liquid products of pyrolysis (LPP) or cracking of hydrocarbons. Due to the increase in the capacity of pyrolysis plants, a large number of LPPs are formed, the qualified use of which is a necessary condition for ensuring the profitability and waste-freeness of ethylene. The yield of LPP, depending on the raw material and the mode of the pyrolysis process, is $20 \ldots 40 \%$. The use of LPP for the production of petroleum resins can significantly improve the technical and economic performance of ethylene plants and reduce the cost of ethylene by 20 ... 30\%. LPP fractions and their combinations are mainly used to obtain petroleum resins (PRs).
\end{abstract}

Keywords - liquid pyrolysis products and cracking, heavy pyrolysis resin, hydrocarbons, dienes wine.

\section{Introduction}

Given the constant rise in prices for traditional hydrocarbons and all types of energy efficiency, the question of a natural or natural approach to assessing the energy efficiency of petrochemical and refining industries, along with conventional industries. It is known that any hydrocarbon obtained by refining oil, natural gas or coal is a potential raw material for chemical processes or a primary energy source. Prices for such energy and raw hydrocarbons in international markets depend on many factors: economic, social, political, and so on. Therefore, value comparisons in the choice of chemical processing of raw materials do not always give a positive result, so increasing the energy efficiency and waste-freeness of such industries does not lose its relevance.

In the pyrolysis of lower olefins by thermal pyrolysis of hydrocarbons, liquid pyrolysis products (LPPs) with a boiling point of $28-450{ }^{\circ} \mathrm{C}$ and above are formed. Pyrolysis of straightrun gasoline per 1 ton of ethylene yields 1.0 to 1.1 tons of LPP. On modern ethylene complexes LPP is divided into light pyrolysis resin (LPR) $\left(28-200{ }^{\circ} \mathrm{C}\right)$ and heavy pyrolysis resin (HPR) boiling point $200{ }^{\circ} \mathrm{C}$. LPPs and LPR obtained on ethylene plants contain valuable active, alkenyl-, vinyl aromatic and other hydrocarbons. This is, in particular, the fraction $\mathrm{C}_{5}(30-70$ $\left.{ }^{\circ} \mathrm{C}\right)$, containing isoprene, cyclopentadiene (CPD), piperylene; fraction $\mathrm{C}_{8-9}\left(130-190{ }^{\circ} \mathrm{C}\right)-$ styrene, inden, dicyclopentadiene (DCPD), vinyltoluene.

Fraction $\mathrm{C}_{5}$ in its composition contains a significant amount of valuable new monomers, \% wt $: 2025$ isoprene, 20 - $25 \mathrm{CPD}, 10-15$ piperylene. In the pyrolysis of gaseous hydrocarbons $\mathrm{C}_{2}-\mathrm{C}_{4}$ at a temperature of $790-800{ }^{\circ} \mathrm{C}$, the contact time of $1.5 \mathrm{~s}$, the yield of the fraction $\mathrm{C}_{5}-$ the beginning of boiling $-70{ }^{\circ} \mathrm{C}$, is $2.5-3.5 \mathrm{wt} \%$. From raw materials (density $0.65-0.73 \mathrm{~g} /$ $\mathrm{cm} 3$, bromine number $100-180 \mathrm{~g} \mathrm{Br}_{2} / 100 \mathrm{~g}$, diene content $35-60 \%$ of the mass. The fraction $\mathrm{C}_{5}$ of pyrolysis of a mixture of gaseous hydrocarbons and gasoline contains 0.26 to $0.54 \%$ of the mass. Codimers DCPD with isoprene and pentadienes, isoprene 9.48 - 13.7\% wt., CPD 7.6 $11.5 \%$ wt., DCPD 1.92 - 4.29\% wt. In addition, it may contain several percent oxygencontaining compounds.

The composition of the fraction $\mathrm{C}_{5}$ of atmospheric gas oil $\left(180-360{ }^{\circ} \mathrm{C}\right)$ differs little from the composition of the fraction $\mathrm{C}_{5}$ pyrolysis of gasoline, only a small content of compounds with sulfur and nitrogen. This fraction has a diene content of about $40-60 \%$ of the mass. and a very low flash point $\left(-25^{\circ} \mathrm{C}\right)$. Fraction $\mathrm{C}_{8-9}$, boiling in the range of $120-200^{\circ} \mathrm{C}$, contains mainly 
alkenylaromatic hydrocarbons and cerebral palsy. In the case of pyrrole from gaseous hydrocarbons or mixed raw materials (gaseous hydrocarbons and gasoline), the fraction is characterized by a high degree of aromatization and the content of non-aromatic hydrocarbons in it is $2-5 \%$ of the mass.

The composition of the fraction $\mathrm{C}_{8-9}$ pyrolysis of gasoline with increasing temperature of pyrolysis from $770-780^{\circ} \mathrm{C}$ to $825-840^{\circ} \mathrm{C}$ increases the content of alkenylaromatic hydrocarbons. Fraction $\mathrm{C}_{8-9}$ of pyrolysis of atmospheric gas oil $\left(810{ }^{\circ} \mathrm{C}\right.$, sulfur content $0,2 \mathrm{wt}$.) Has a high content, \% wt .: indene 17 - 23, styrene 15 - 19, alkyl benzene 25 - 33. Heavier raw materials yield of dienes $\mathrm{C}_{6-9}$, styrene, vinyl styrene decreases, and diene $\mathrm{C}_{5}$ is virtually unchanged. The fraction $\mathrm{C}_{9}\left(150-190^{\circ} \mathrm{C}\right)$ pyrocondensate of the propylene mode of pyrolysis of gasoline in industrial plants contains $50 \%$ of the mass. reactive alkenylaromatic hydrocarbons and cerebral palsy, with increasing stiffness, the number of these compounds decreases by $9 \%$ of the mass. Fraction $\mathrm{C}_{6-7}\left(70-130^{\circ} \mathrm{C}\right)$ LPPs contains a small amount of dienes, usually $3-5 \%$ wt., mostly aliphatic in nature and has no industrial interest.

The heavy pyrolysis resin (HPR) contains up to $20-25 \%$ of the mass. naphthalene and its alkyl homologues. Developed and prepared hydrogenations on the technology of the process of obtaining naphthalene from the Air Force, which will purify pyrolysis naphthalene from impurities of unsaturated and saturated hydrocarbons, which provides the possibility of separation of naphthalene from the hydrogenate by distillation with high yield from its potential content (up to 90\%) energy-intensive operations, such as crystallization, pressing.

\section{Experimental results and discussion}

Hydrogenation processes of HPR fractions using catalysts based on: Pd, Ni, Mo, Co, W will offer a number of processes for the production of tetralin, dimethylnaphthalene, acenaphthene, fluorene and other important products. An HPR recycling scheme has been developed, which will fully meet the needs for naphthalene, dark PR, raw materials for coke and carbon black. It is expedient to expand the range of marketable products made of pyrocondensate, LPR and HPR, to improve the complex scheme of their qualified processing.

\begin{tabular}{|c|c|c|c|c|}
\hline & & & $\rightarrow$ & in the dark PRs \\
\hline & $\rightarrow$ & dark PRs & & naphthalene \\
\hline & & coking & $\rightarrow$ & coke \\
\hline & $\rightarrow$ & & $\rightarrow$ & peck \\
\hline HPR & & & & carbon black \\
\hline & & distillation & $\rightarrow$ & associated gases \\
\hline & $\rightarrow$ & & $\rightarrow$ & \\
\hline
\end{tabular}

\begin{tabular}{|l|l|l|l|}
\hline & & $\rightarrow$ & naphthalene, tetralin \\
\hline & & $\rightarrow$ & alkylnaphthalenes \\
\hline & & $\rightarrow$ & acenaphthene, fluorine \\
\hline & & $\rightarrow$ & motor fuel \\
\hline & $\rightarrow$ & $\rightarrow$ & raw material for carbon black \\
\hline & & $\rightarrow$ & raw materials for electrode coke \\
\hline & & $\rightarrow$ & raw materials for electrode pitch \\
\hline & & $\rightarrow$ & raw materials for needle coke \\
\hline & & $\rightarrow$ & dark PRs \\
\hline
\end{tabular}




\section{Conclusion}

Such complex processing of liquid pyrolysis products allows to significantly reduce the amount of waste products of oil refining and its fractions and increase the efficiency of production. Introduction into production of the offered products will allow to receive valuable substances from secondary raw materials.

\section{References}

[1] Zohuriaan-Mehr, M. J., \& Omidian, H. (2000). Petroleum resins: an overview. Journal of Macromolecular Science, Part C: Polymer Reviews, 40(1), 23-49.

[2] Mildenberg, R., Zander, M., \& Collin, G. (2008). Hydrocarbon resins. John Wiley \& Sons. 


\section{THE INNOVATIVE TECHNOLOGIES IN THE CHEMICAL AND FOOD INDUSTRIES}




\title{
Se-driven microgel catalysts for oxidation processes
}

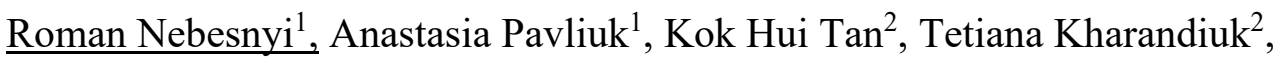 \\ Volodymyr Ivasiv ${ }^{1}$, Andrij Pich ${ }^{2}$
}

1. Lviv Polytechnic National University, S. Bandery st. 12, Lviv, Ukraine;

2. DWI - Leibniz Institute for Interactive Materials, Forckenbeckstr. 50, Aachen, Germany

\begin{abstract}
New highly efficient colloidal Se-modified microgel catalyst was synthesised. It shows exceptional catalytic performance in heterophase aldehyde oxidation reaction with green hydrogen peroxide oxidant at mild reaction temperature.
\end{abstract}

Keywords - microgel, oxidation, heterophase reaction, catalysis, acrolein, acrylic acid.

\section{Introduction}

Reactions in heterophase (water/oil) conditions attract more attention due to more environmentally friendly conditions - reactions are performed in aqueous media, easier product separation and purification. But organic reactants usually are not soluble in water. Surfactants are often used to facilitate reactions but it can be problematic to separate surfactant from product and catalyst is still needed for the reaction. Good solution for these issues would be heterogeneous catalyst with surfactant ability. Microgels are soft multifunctional crosslinked polymer colloids with tuneable chemical composition, functionality and particle architecture, that can be swollen in water or other solvents. Previously we reported synthesis and characterization of Selenium modified microgels and their high catalytic activity in homogeneous oxidation process of acrolein with hydrogen peroxide as green oxidant [1]. Here we report the study of Se-modified microgel in heterophase oxidation reaction of benzaldehyde to benzoic acid as model reaction.

\section{Methods}

Poly(N-vinylcaprolactam) (PVCL) microgel modified with diselenide functional groups (diselenide crosslinker, $2 \%$ mol.) was synthesized by precipitation polymerization in aqueous/DMSO media at $70^{\circ} \mathrm{C}$ along with conventional crosslinker N,N'Methylenebis(acrylamide) (1.5\%) according to the reported procedure [1]. Diselenide bonds inside the microgel were cleaved through oxidation by $\mathrm{H}_{2} \mathrm{O}_{2}$ and converted to catalytically active seleninic peracid whilst maintaining the microgel microstructure intact. Catalytic performance of Se-modified microgel $(\mathrm{Se}-\mu \mathrm{G})$ was evaluated in benzaldehyde oxidation reaction with $\mathrm{H}_{2} \mathrm{O}_{2}$ (60\%wt.) as oxidant (benzaldehyde: $\mathrm{H}_{2} \mathrm{O}_{2}$ ratio - 1:1.3) judged by the yield of benzoic acid.

\section{Results and discussion}

Two heterophase systems were used: "water in oil" (toluene:water ratio - 4:1) and "oil in water" (toluene:water ratio - 1:4). Catalytic performance of Se-modified microgels was compared to $\mathrm{H}_{2} \mathrm{SeO}_{3}$ and diphenyl diselenide (DPDS) - highly active catalysts in oxidation reaction [2] and diselenide crosslinker (X-linker) that don't have surfactant properties (Fig. 1). When reaction was performed in medium with large excess of water ("oil in water"), benzoic acid yield was quite low (Fig. 1a). This phenomenon can be explained by inhibitory effect of water on the oxidation reactions as has been reported before [2]. On the other hand, previous studies of microgel colloidal properties in "water in oil" and "oil in water" systems shown that there are droplets of water formed in oil regardless the proportion of oil and water phases [3]. In the emulsion system "oil in water" reactant (benzaldehyde) is concentrated in toluene phase, which are surrounded by microgel while oxidant (hydrogen peroxide) is concentrated mainly in 
water part and the reaction occurs at the "oil/water" interface in the microgel. In this case, at the interface we have proportion of reactant:oxidant $=4: 1$, but in the system "water in oil" we have opposite proportion - reactant:oxidant $=1: 4$. Such excess of oxidant might promote oxidation and therefore cause much higher yield of the product.

Furthermore, if we compare results of $\mathrm{H}_{2} \mathrm{SeO}_{3}$ that has no surfactant activity with Semodified microgel in both "oil in water" and "water in oil" we can see that both catalyst shown higher catalytic performance in "water in toluene" system (Fig. 1a). Se- $\mu$ G has higher catalytic activity in both systems due to reaction occurring inside the micrgel particles where reactants from both liquid phases can freely interact with catalytic Se groups, so the microgels can be considered as catalytic microreactors.
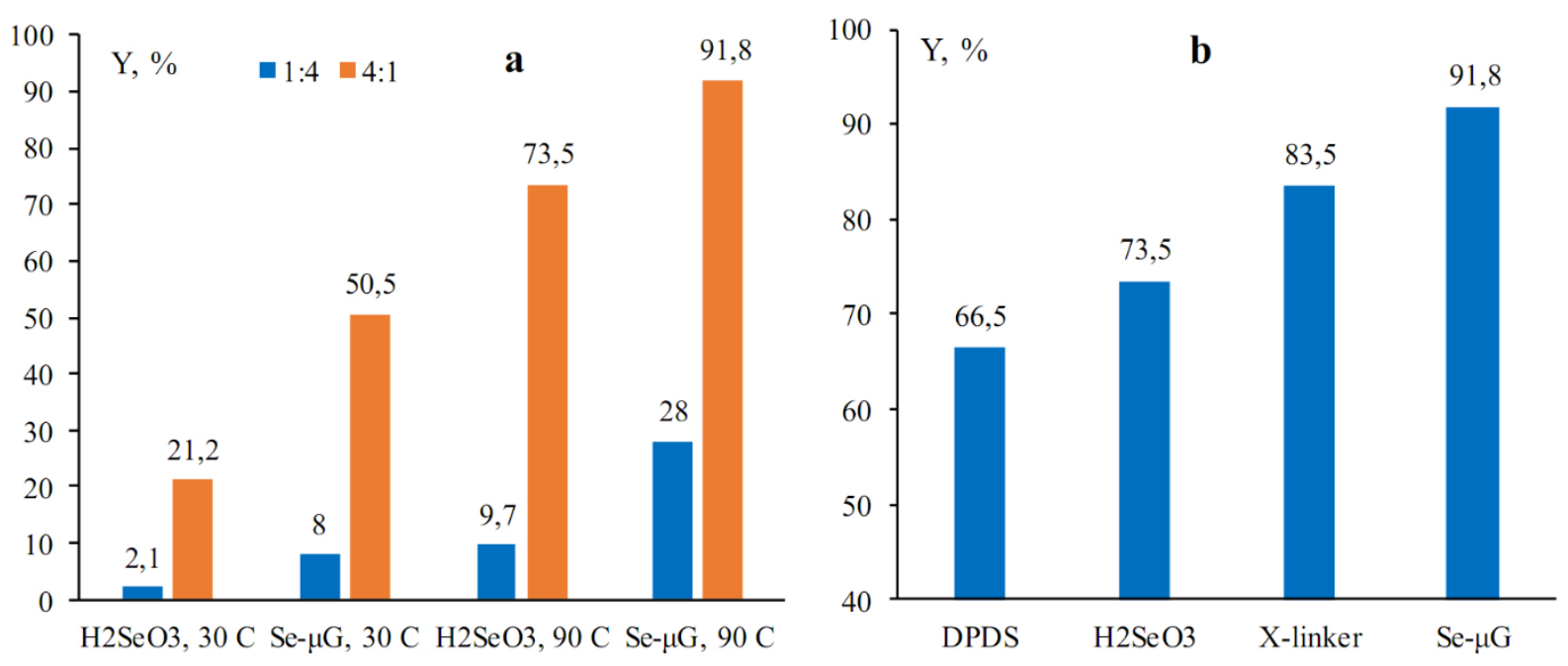

Fig.1. (a) Effect of toluene:water ratio, catalyst and reaction temperature on the yield of benzoic acid (Y), reaction time $-8 \mathrm{~h}$. (b) Effect of catalyst on the yield of benzoic acid (Y), toluene:water ratio $=4: 1$, reaction temperature $-90^{\circ} \mathrm{C}$, reaction time $-8 \mathrm{~h}$.

Catalytic performance of Se- $\mu \mathrm{G}$ was compared with other Se-containing catalysts (Fig. 1b). Se-modified microgel shown the highest catalytic activity among studied catalysts and allows to achieve $91.8 \%$ yield of benzoic acid already after $8 \mathrm{~h}$ of the reaction.

\section{Conclusions}

Newly synthesised Se-modified microgel is highly efficient colloidal catalyst at heterophase reaction conditions. It shows exceptional catalytic performance in aldehyde oxidation reaction with green oxidant hydrogen peroxide. Even at mild reaction temperature (30 $\left.{ }^{\circ} \mathrm{C}\right) \mathrm{Se}-\mu \mathrm{G}$ proved to be highly active catalyst.

\section{References}

[1] Tan, K.H., Xu, W., Stefka, S., Demco, D.E., Kharandiuk, T., Ivasiv, V., Nebesnyi, R., Petrovskii, V.S., Potemkin, I.I., Pich, A. (2019). Selenium-Modified Microgels as BioInspired Oxidation Catalysts. Angewandte Chemie - International Edition, 58 (29), 97919796. https://doi.org/10.1002/anie.201901161

[2] Nebesnyi, R., Ivasiv, V., Pikh, Z., Kharandiuk, T., Shpyrka, I., Voronchak, T., Shatan, A.B. (2019). Low temperature acrolein to acrylic acid oxidation with hydrogen peroxide on se-organic catalysts. Chemistry and Chemical Technology, 13 (1), 38-45. https://doi.org/10.23939/chcht13.01.038 
[3] Li, Z., Ming, T., Wang, J., Ngai, T. (2009). High internal phase emulsions stabilized solely by microgel particles. Angewandte Chemie - International Edition, 48 (45), 8490-8493. https://doi.org/10.1002/anie.200902103 


\title{
Polypyrazolylborate complexes of the lanthanides: structure, optics and materials
}

\author{
Seema S. S. Pillai, Roman Kresinski, Emil Bojarski, Peter J. S. Foot \\ Department of Materials Science, School of Pharmacy and Chemistry, Kingston University, UK, Kingston-upon- \\ Thames, Penrhyn Road, E-mail: r.kresinski@kingston.ac.uk
}

\begin{abstract}
We report the synthesis and characterisation of monomeric [ $\left.\mathrm{LnTp}_{2}\left(\mathrm{O}_{2} \mathrm{CCH}=\mathrm{CHCH}\right)\right](\mathrm{Ln}=$ Ce-Ho, except Pm) and dimeric $\left[\mathrm{LnTp}\left(\mathrm{O}_{2} \mathrm{CCH}=\mathrm{CHR}\right)_{2}\right]_{2}\left(\mathrm{R}=\mathrm{CH}_{3}, \mathrm{Ln}=\mathrm{Ho}-\mathrm{Lu} ; \mathrm{R}=\mathrm{C}_{6} \mathrm{H}_{5}, \mathrm{Ln}=\mathrm{Ce}\right.$ $Y$ b, except Pm), along with their co-polymerisations with styrene and methyl methacrylate. The structures and some optical properties of the lanthanide complexes and co-polymers are presented.
\end{abstract}

Keywords - lanthanide, lanthanon, polypyrazolylborate, polystyrene, polymethylmethacrylate, copolymer, luminescence.

\section{Introduction}

The inclusion of $\left(\mathrm{Ln}^{3+}\right)$ ions into polymers has the potential of the production of processible materials with magnetism, or optical properties. We sought to make polymeric species in which lanthanide ions were separated, so as to avoid quenching of magnetism or optical emission. In order to achieve this, we initially pursued the synthesis of heteroleptic hydrotrispyrazolylborate-crotonate and cinnamate complexes $\left[\mathrm{LnTp}_{2}\left(\mathrm{O}_{2} \mathrm{CCH}=\mathrm{CHCH}_{3}\right)\right](\mathrm{Ln}=$ Ce-Ho, except Pm $)$ and $\left[\mathrm{LnTp}\left(\mathrm{O}_{2} \mathrm{CCH}=\mathrm{CHR}\right)_{2}\right]_{2}\left(\mathrm{R}=\mathrm{CH}_{3}, \mathrm{Ln}=\mathrm{Ho}-\mathrm{Lu} ; \mathrm{R}=\mathrm{C}_{6} \mathrm{H}_{5}, \mathrm{Ln}=\mathrm{Ce}-\mathrm{Yb}\right.$, except $\mathrm{Pm}$ ), as potential copolymerisation monomers. Firstly, these species are resistant to ligand redistribution reactions[1], which makes the stoichiometry of lanthanide to double bond a reliable 1:1 or 1:2 ratio, simplifying any understanding of kinetics. Secondly, the lanthanide ion is encapsulated within an environment, for which it has a greater affinity than a non-polar one. It was thus our anticipation that the lanthanide ions would remain in predictably-distant 'island' points in any product polymer, wherefrom they would migrate only under great stress.

\section{Initial Findings}

The $\left[\mathrm{LnTp}_{2}\left(\mathrm{O}_{2} \mathrm{CCH}=\mathrm{CHCH}_{3}\right)\right](\mathrm{Ln}=\mathrm{Ce}-\mathrm{Ho}$, except $\mathrm{Pm})$ and $\left[\mathrm{LnTp}\left(\mathrm{O}_{2} \mathrm{CCH}=\mathrm{CHR}\right)_{2}\right]_{2}(\mathrm{R}$ $=\mathrm{CH}_{3}, \mathrm{Ln}=\mathrm{Ho}-\mathrm{Lu} ; \mathrm{R}=\mathrm{C}_{6} \mathrm{H}_{5}, \mathrm{Ln}=\mathrm{Ce}-\mathrm{Yb}$, except $\mathrm{Pm}$ ) complexes, fully characterised by infrared spectroscopy and mass spectrometry, and representative examples were characterised by single-crystal X-ray means. Copolymers of the above classes were synthesised and studied optically, by both emissive and absorptive means. Some of them showed productive energy transfer to, and re-emission from, the lanthanide ion.

\section{Conclusion}

Selected lanthanide species were copolymerised with styrene and methylmethacrylate, and some of the resulting materials showed promise as processible materials showing promise in materials applications.

\section{References}

[1] Moss, M.A.J., Jones, C.J., Edwards, A.J. (1989). Dalton Trans., 1393. 


\section{Supported transition metals oxides and N-hydroxyphthalimide in catalysis of the liquid-phase oxidation of cumene}

Suprun Wolodymyr ${ }^{1}$, Sheparovych Roman ${ }^{2}$, Hrynda Yurii ${ }^{2}$, Khavunko Oksana ${ }^{2}$, Opeida Iosyp $^{2}$

1. Institute of Chemical Technology, Martin-Luther-Universität Halle-Wittenberg, , Universitätsplatz 10, 06108 Halle, GERMANY, E-mail: wladimir.suprun@chemie.uni-halle.de

2. Department of Physical Chemistry of Fossil Fuels InPOCC, National Academy of Sciences of Ukraine, Naukova str/3a, 79060 Lviv, UKRAINE, E-mail: opeida_i@yahoo.co.uk

- Abstract - The heterogeneous catalysts based on single active component such as $\mathrm{V}_{2} \mathrm{O}_{5}, \mathrm{MnO}_{\mathbf{x}}$ and $\mathrm{CuO}_{\mathrm{x}}$ and bi-components $\mathrm{V}_{2} \mathrm{O}_{5}-\mathrm{MoO}_{3} \mathrm{~V}_{2} \mathrm{O}_{5}-\mathrm{WO}_{3}$ and $\mathrm{V}_{2} \mathrm{O}_{5}-\mathrm{SbO}_{x}$ supported onto $\mathrm{TiO}_{2}, \mathrm{TiO}_{2}-\mathrm{SiO}_{2}$ and $\mathrm{Al}_{2} \mathrm{O}_{3}-\mathrm{SiO}_{2}$ was prepared, characterized and their cataalitic activities measured.

- Keywords - cumene, liquid-phase oxidation, catalysts, transition metal oxide, $\mathrm{N}$ hydroxyphthalimide

\section{Introduction}

Based on the principles of ,green chemistry“, molecular oxygen is the most preferable oxidant for production of hydroperoxide compounds via liquid-phase oxidation of hydrocarbons. However, utilizing of molecular $\mathrm{O}_{2}$ in oxidation processes requires application of efficient catalysts in order to achieve high yields of the target products at sufficient reaction rates. Most often various salts of transition metals (TM) were used as homogeneous catalysts of oxidation with molecular oxygen. In this work, we report on the synthesis and characterization of series of heterogeneous catalysts comprising the $\mathrm{Mn}, \mathrm{Cu}$ and $\mathrm{V}$ oxides supported on $\mathrm{TiO} 2, \mathrm{TiO}_{2}-\mathrm{SiO}_{2}$ and $\mathrm{SiO}_{2}-\mathrm{Al}_{2} \mathrm{O}_{3}$ (as a commonly used industrial support materials), their catalytic effect on the rates of liquid-phase cumene oxidation with molecular oxygen in the presence of radical catalyst Nhydroxyphthalimide (NHPI).

\section{Catalysts preparation}

The oxide catalysts such as $\mathrm{V}_{2} \mathrm{O}_{5}-\mathrm{TiO}_{2}(6$ wt. $\% \mathrm{~V}), \mathrm{V}_{2} \mathrm{O}_{5}-\mathrm{MoO}_{3} / \mathrm{TiO}_{2}(4.5 \% \mathrm{~V}$ and $9.2 \mathrm{wt}$. $\% \mathrm{Mo}$ ) and $\mathrm{V}_{2} \mathrm{O}_{5}-\mathrm{SbO}_{2} / \mathrm{TiO}_{2}(4 \mathrm{wt} . \% \mathrm{~V}$ and $9.7 \mathrm{wt} . \% \mathrm{Sb}$ ) were prepared by spray-drying method. $\mathrm{Cu}$ and $\mathrm{Mn}$ containing catalysts supported on TiO2 modified with silica were prepared by wet-ness impregnation of support materials with aqueous solution of manganese nitrate or copper nitrate respectively. $\mathrm{V}_{2} \mathrm{O}_{5} / \mathrm{TiO}_{2}-\mathrm{WO}_{3}$ catalysts, containing 0.2 or 2.2 wt.- $\%$ of $\mathrm{V}$ are industrial $\mathrm{TiO}_{2}-\mathrm{WO}_{3}$ samples and were provided by Ebinger Katalysorservice Ltd.

Table 1

Composition, textural and physico-chemical properties of heterogeneous catalysts based on transition metal oxide supported on $\mathrm{TiO}_{2}, \mathrm{TiO}_{2}-\mathrm{SiO}_{2}$ or $\gamma-\mathrm{Al}_{2} \mathrm{O}_{3}-\mathrm{SiO}_{2}$.

\begin{tabular}{|c|c|c|c|c|c|c|c|}
\hline & Abbr. & $\begin{array}{c}\text { Catalyst } \\
\text { composition }\end{array}$ & $\begin{array}{c}\text { Content of TM/ } \\
\text { wt. } \%{ }^{\text {a) }}\end{array}$ & $\begin{array}{l}\mathrm{A}_{\mathrm{BET} /} \\
\mathrm{m}^{2} \mathrm{~g}^{-1} \\
\mathrm{~b})\end{array}$ & $\begin{array}{l}\mathrm{PD} / \\
\mathrm{nm}^{\mathrm{c}}\end{array}$ & $\begin{array}{c}\mathrm{TA} / \\
\mathrm{mmol} \mathrm{g}^{-1 \mathrm{~d})}\end{array}$ & $\begin{array}{c}\mathrm{H}_{2}{ }^{\text {cons/ }} \\
\left.\mu \mathrm{mol} \mathrm{g}^{-1} \mathrm{e}\right)\end{array}$ \\
\hline 1 & $\mathrm{TiO}_{2}$ & & 0.00 & 105 & 10,0 & 0.12 & 225 \\
\hline 2 & $\mathrm{Mn} / \mathrm{Ti}-\mathrm{Si}$ & $\mathrm{MnO}_{\mathrm{x}} / \mathrm{TiO}_{2}-\mathrm{SiO}_{2}$ & Mn: 17.0 & 141 & 10,5 & 5.6 & 2178 \\
\hline 3 & $\mathrm{Cu} / \mathrm{Al}-\mathrm{Si}$ & $\mathrm{CuO}_{\mathrm{x}} / \mathrm{Al}_{2} \mathrm{O}_{3}-\mathrm{SiO}_{2}$ & $\mathrm{Cu}: 15.0$ & 246 & 6,5 & 3.1 & 1670 \\
\hline 4 & $\mathrm{~V} / \mathrm{Ti}$ & $\mathrm{V}_{2} \mathrm{O}_{5} / \mathrm{TiO}_{2}$ & $\mathrm{~V}: 6.0$ & 92 & 9.3 & 4.45 & 2180 \\
\hline 5 & $\mathrm{~V}-\mathrm{Mo} / \mathrm{Ti}$ & $\mathrm{V}_{2} \mathrm{O}_{5}-\mathrm{MoO}_{3} / \mathrm{TiO}_{2}$ & V: 4.5; Mo: 9.2 & 86 & 9.8 & 0.53 & 3750 \\
\hline 6 & $\mathrm{~V}-\mathrm{Sb} / \mathrm{Ti}$ & $\mathrm{VO}_{\mathrm{x}}-\mathrm{SbO} / \mathrm{TiO}_{2}$ & V: 4.0: Sb: 9.7 & 83 & 10.5 & 0.49 & 3920 \\
\hline 7 & $0.2 \mathrm{VWTi}$ & $\mathrm{V}_{2} \mathrm{O}_{5}-\mathrm{WO}_{3} / \mathrm{TiO}_{2}$ & $\mathrm{~V}: 0.2 ; \mathrm{W}: 5.8$ & 69 & 20.1 & 0.16 & 285 \\
\hline 8 & 2.2VWTi & $\mathrm{V}_{2} \mathrm{O}_{5}-\mathrm{WO}_{3} / \mathrm{TiO}_{2}$ & $\mathrm{~V}: 2.2 ; \mathrm{W}: 5.5$ & 68 & 19.1 & 0.29 & 970 \\
\hline
\end{tabular}


Content of TM (a) was determined by RFA analysis; b) the specific surface area (ABET) and the average pore diameter $(\mathrm{PD})^{\mathrm{c})}$, determined by $\mathrm{N}_{2}$ adsorption/desorption method; d) the total number of acidic sites (TA) determined by TPD of ammonia; e) total hydrogen consumption determined by TPR experiment with hydrogen at the temperature range between 100 and $700{ }^{\circ} \mathrm{C}$.

\section{Catalytic activity experiments}

Catalytic activity test of liquid-phase cumene oxidation in the presence of NHPI and heterogeneous catalyst was carried out at atmospheric pressure in a manometric homemade closed temperature-controlled gasometric device. The oxidation experiments were conducted using pure oxygen in a glass microreactor $(\mathrm{V}=5 \mathrm{~mL})$ equipped with magnetic stirring. The catalyst content was incrementally varied between 0.01 and $0.04 \mathrm{~g} \mathrm{~mL}-1$ of the charged cumene ( $1 \mathrm{~mL}$ of $\mathrm{RH})$. Solvent in all experiments was acetonitrile, the volume ratio of oxidized mixture : solvent 1:1. Oxidation was carried out under constant pressure of oxygen of $0,101 \mathrm{Mpa}$.

\section{The effect of TMO on reaction rate of oxidation}

Two groups of supported transition metal oxides were studied as catalysts: one active component $\mathrm{V}_{2} \mathrm{O}_{5} / \mathrm{TiO}_{2}, \mathrm{MnO}_{\mathrm{x}} / \mathrm{TiO}_{2}-\mathrm{SiO}_{2}, \mathrm{CuO}_{\mathrm{x}} / \mathrm{Al}_{2} \mathrm{O}_{3}-\mathrm{SiO}_{2}$ and binary mixtures of $\mathrm{TMO}$ containing e.g. $\mathrm{V}_{2} \mathrm{O}_{5}-\mathrm{MoO}_{3}, \mathrm{~V}_{2} \mathrm{O}_{3}-\mathrm{SbO}$ or $\mathrm{V}_{2} \mathrm{O}_{5}-\mathrm{WO}_{3}$ supported on titanium dioxide. In our preliminary tests it was found that oxidation of pure cumene with molecular oxygen at $70^{\circ} \mathrm{C}$ and oxygen pressure of $0,101 \mathrm{MPa}$ in the absence of the catalyst or the initiator was not observed for a time of more than $2 \mathrm{~h}$. It was also found that in the presence of solely one catalyst $\left(0.04 \mathrm{~g} \mathrm{~mL}^{-}\right.$ ${ }^{1}$ ) in cumene oxygen uptake at temperature $70^{\circ} \mathrm{C}$ occurs with pretty low reaction rates. In all cases the rate was less than $1 \times 10^{-6} \mathrm{M} \mathrm{s}^{-1}$ and only in the case of the most active magnesium oxide it was about $2 \times 10^{-6} \mathrm{M} \mathrm{s}^{-1}$. It allows us to conclude, that under the conditions of our experiments, the reaction rate of cumene $\mathrm{C}-\mathrm{H}$ bond activation and the free radicals formation are very small.

The calculated initial reaction rates of the oxygen consumption for catalytic oxidation of cumene for the first 800 second reaction time at the constant reaction condition are presented in Fig.1

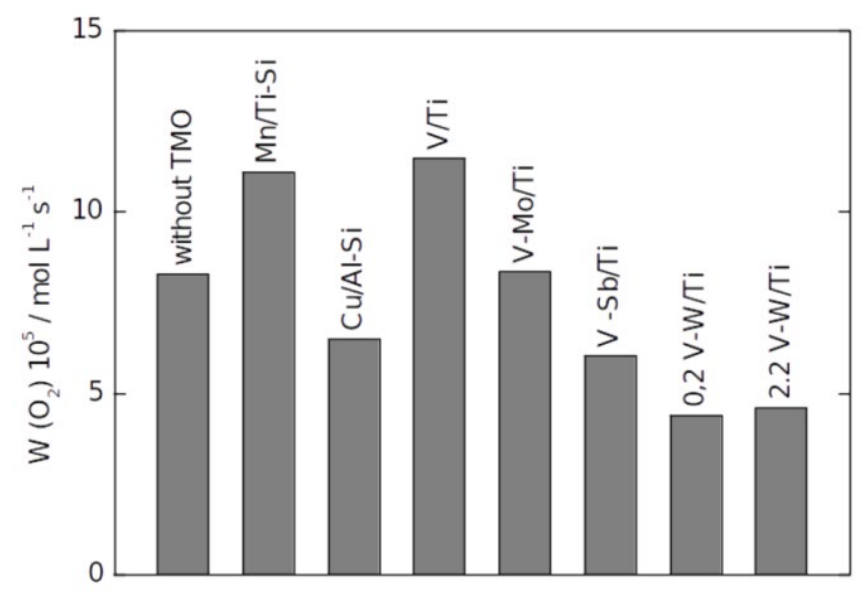

Fig.1. Comparison of the initial reaction rate of oxidation in the presence of AIBN, NHPI and different TMO loaded on various support materials.

\section{Conclusion}

In the oxidation of cumene, the most catalytically active are systems containing manganese and vanadium oxides, where in the presence of NHPI a significant synergistic effect is observed. 


\title{
Silicates as fillers for polymer composites
}

\author{
Oleksandra Dzeikala $^{1}$, Mirosława Prochoń $^{2}$ \\ 1. Institute of Polymer and Dye Technology, University of \\ Technology, POLAND, Lodz, Stefanowskiego 12/16, 90-924, E-mail: Dzeikala.sandra@gmail.com \\ 2. Institute of Polymer and Dye Technology, University of \\ Technology, POLAND, Lodz, Stefanowskiego 12/16, 90-924,, E-mail: miroslawa.prochon@p.lodz.pl
}

\begin{abstract}
Polyethylene is widely used in the packaging industry and is characterized by high mechanical strength and high chemical resistance. New properties can be obtained through the use of fillers such as layered silicate. In this study, a filler was added to the composite with a size of an hour ontice ranging from $63 \mu \mathrm{m}$ to $125 \mu \mathrm{m}$.
\end{abstract}

Keywords - Polyolefins, polyethylene, filler, mineral fillers, vermiculite, packaging

\section{Modification of polyethylene}

Polyethylene is characterized by high elasticity of $\mathrm{C}-\mathrm{C}$ bonds, and in combination with low intermolecular interaction of chains, this polymer has a relatively low melting point. Depending on the preparation method, the polymer can have a linear or highly branched structure. The main products obtained from various types of polyethylene are packaging materials, and due to good biocompatibility and chemical inactivity, it is widely used in medical devices: filters, bottles and disposable ampoules. [1]

Polyolefins, including polypropylene, are a group of polymers used in mass production areas, and due to their average physicochemical properties (mainly low melting point and not very high tensile strength), they are not used as construction materials. [1]

However, the list of fillers modifying the properties of the material is surprisingly extensive. It includes both the simplest inorganic fillers and polyhedral oligomeric silesquioxanes (POSS). Among the fillers, the following are distinguished: calcium carbonate; talc; silica; glass flour; nanocellulose; cellulose fillers.

Regardless of the application, plastics require special protection against the risk of fire. Almost most plastics are not very resistant to heat and direct fire, including polymers from the group of polyolefins: polyethylene or polypropylene. Some types of plastics, during their thermal decomposition, emit poisonous, irritating or extremely harmful chemical compounds, including epichlorhydrin, vinyl chloride, $\mathrm{HCl}$ or hydrogen cyanide. [2]

Analyzing the research conducted so far, it turns out that vermiculite can be a filler that works effectively as a flame retardant. Its presence in the polymer matrix causes that the combustion process is less rapid compared to the reference, unfilled samples. It also turns out that in situ expanded vermiculin can compete with its flame retardant properties with commercially available inorganic fillers - sepiolite or smectite.

\section{References}

[1] Moosavi, A. N. (2003). Fusion-Bonded Epoxy (FBE): A Foundation for Pipeline Corrosion Protection. Corrosion, 59, 12.

[2] Riegert D. (2013). The ability to modification the properties of flammable plastics (7th ed.). BADANIA I ROZWÓJ, 30(2), https://panel.sft.cnbop.pl/storage/91dad163-497e-49409078-f3538e291666 


\section{Hydrodynamics of cotton filtration drying}

Volodymyr Atamanyuk $^{1}$, Zoriana Gnativ ${ }^{1}$ Dauren Dzhanabaiev ${ }^{2}$, Alisher Khusanov ${ }^{2}$

1. Department of Chemical Engineering, Lviv Polytechnic National University, UKRAINE, Lviv, 9 St. Yura square, Building 9, E-mail: atamanyuk@ukr.net

2. Department of Production machines and equipment, Auezov South Kazakhstan State University, KAZAKHSTAN, Shymkent, Tauke khan avenue, 5, E-mail: husanov_a@mail.ru

Abstract - The movement of the gas flow through the porous structure of the material is a problem of hydrodynamics. The intensity of heat and mass transfer during the drying process determines the rate of thermal agent movement relatively to the elements of the porous layer. In this paper, the experimental results regarding the pressure loss in a layer of cotton fiber during filtration drying are presented. Under the action of pressure difference the effect of the cotton fiber layer height on the porosity, equivalent diameter, through which the thermal agent is filtered, the specific surface area and the pressure loss was analytically determined.).

Keywords - cotton fiber, hydrodynamics, filtration drying, criterion dependencies.

\section{Introduction}

It is known [1-4] that cotton, namely cotton fiber, is widely used in various industries: chemical, automotive, aviation, for the production of wool and materials for industrial and household use. Cotton fiber is also used as new, non-traditional material, such as reinforcing composites, geotextiles, individual absorbents, etc. [5]. Since the 1940s, the world consumption of cotton has been steadily increasing by $2 \%$ per year [6]. Approximately 20 million tonnes of raw cotton is produced worldwide each year. As a result, approximately 6,5-7 million tonnes of cotton fiber is produced. When processing raw cotton in order to obtain more efficient and high quality fiber, its moisture content should be within $8-9 \%$, and this demand requires drying of freshly picked cotton [7]. Therefore, modernization of cotton processing is extremely important for the development of Kazakhstan's economy.

According to its structure, raw cotton is a heterogeneous material, which consists of three main components - the cotton fiber itself, the peel and the seed kernel. Cotton seeds are used to produce oils, lubricants, soaps, glycerin, stearin, ethyl and methyl alcohols, citric and acetic acids and many other products [8]. In general, raw cotton is a colloidal capillary-porous material containing all kinds of moisture $[9,10]$, the removal of which consumes a considerable amount of energy.

Cotton fiber is a thermolabile material and contains mainly bound moisture. It is important to choose the optimum drying mode to prevent fiber break and reduction of fiber length [11]. The analysis of literature data [9-12] makes it possible to conclude that there is no comprehensive and systematic approach to intensify the drying processes of wet cotton fiber.

The object of the experimental studies was freshly harvested cotton fiber. The chemical composition is: $95-98 \%$ of cellulose, about $1 \%$ of minerals, the rest is natural waxes, fats and proteins. JSM-6490LV raster electron microscope was used to determine the average size of cotton villi.

More than 100 samples of randomly selected cotton fibers were analyzed. The cotton fiber under study (Fig. 1) consists of thin villi with a length of $25-45 \mathrm{~mm}$, an average width of 24.8 $\mu \mathrm{m}(170 \mathrm{mtex})$ and an average thickness of $4.51 \mu \mathrm{m}$. The cotton fiber density is $1520 \mathrm{~kg} / \mathrm{m} 3$. 

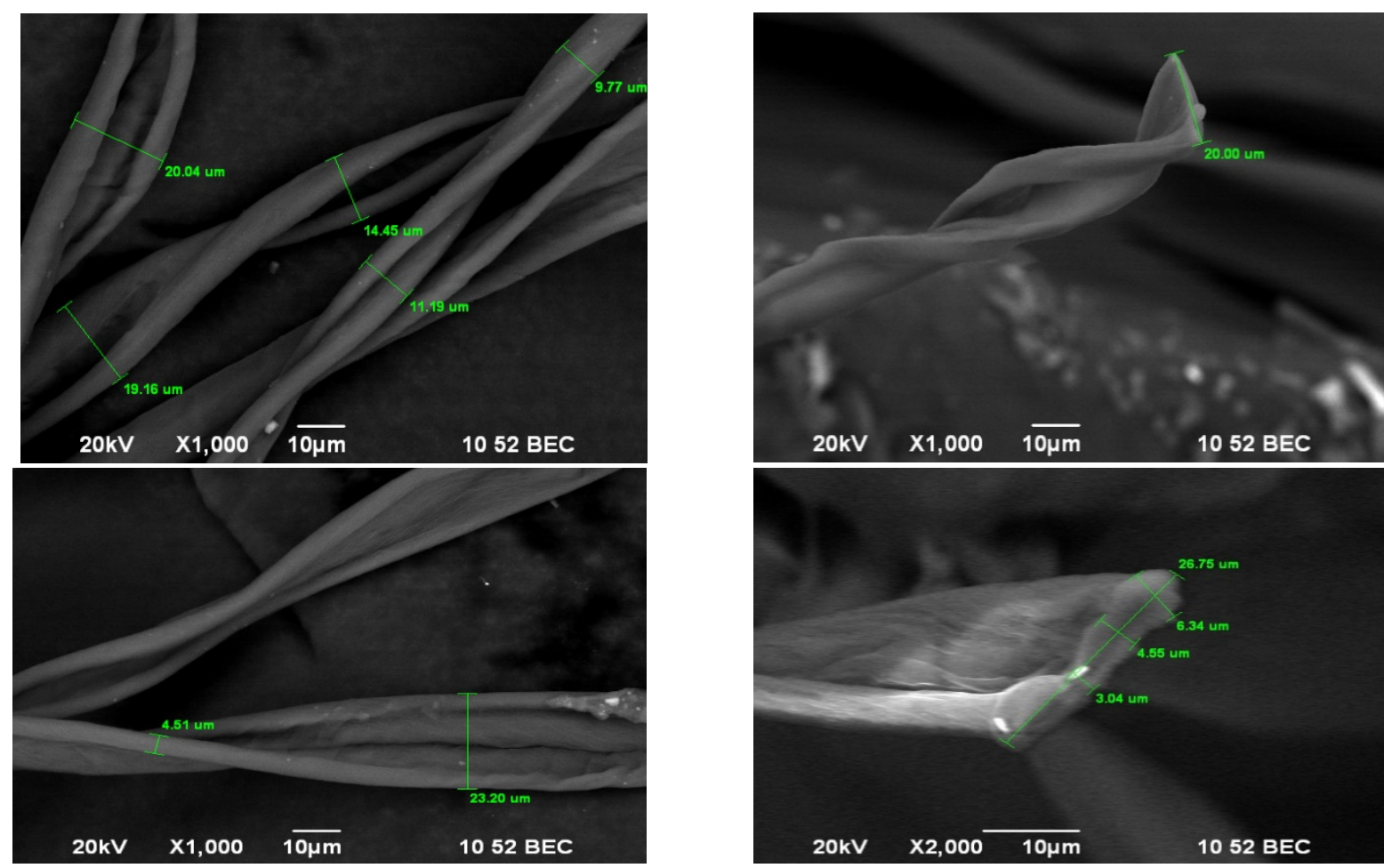

Fig. 1. Images of individual villi of cotton fiber (x1000)

\section{The experimental part.}

All experiments were performed with corresponding aliquots of cotton fiber. Taking into account that the moisture content of natural cotton fiber is negligible $(0.08-0.12 \mathrm{~kg} \mathrm{H} 2 \mathrm{O} / \mathrm{kg}$ dry.mat. ) and the moisture is mainly bound one, for the gas flow temperature $\mathrm{T}=293 \mathrm{~K}$ and relative humidity $\varphi=60 \%$ its evaporation will also be negligible (the time of the experiment was $90-120 \mathrm{~s}$, the weight loss of the sample during the experiment was less than $0.2 \%$ ). So, the influence of moisture evaporation on the pressure loss was neglected.

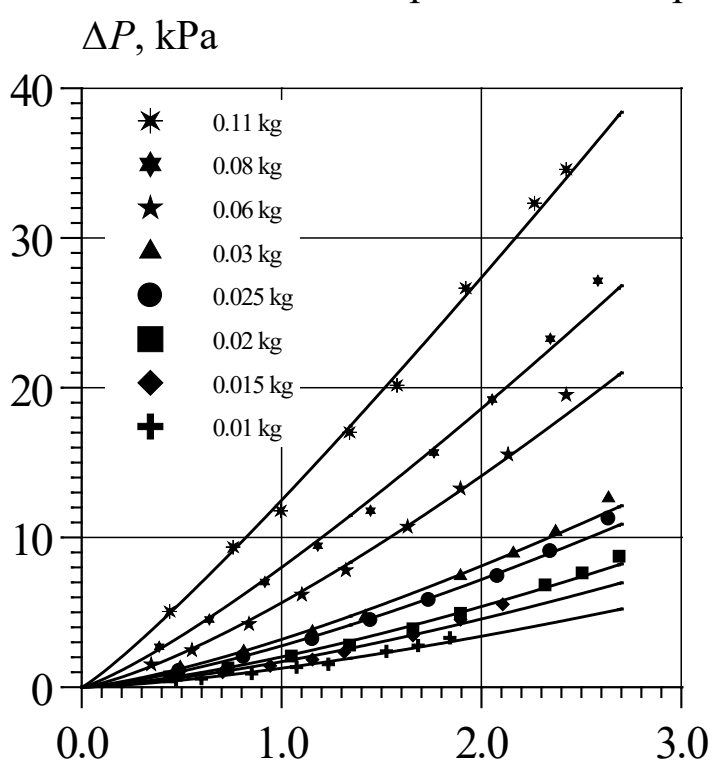

$v_{0}, \mathrm{~m} / \mathrm{s}$

Fig. 2. The dependence of the pressure loss in the cotton fiber layer on the fictitious filtration rate of the thermal agent at different weight of the samples $\varepsilon, \mathrm{m}^{3} / \mathrm{m}^{3}$

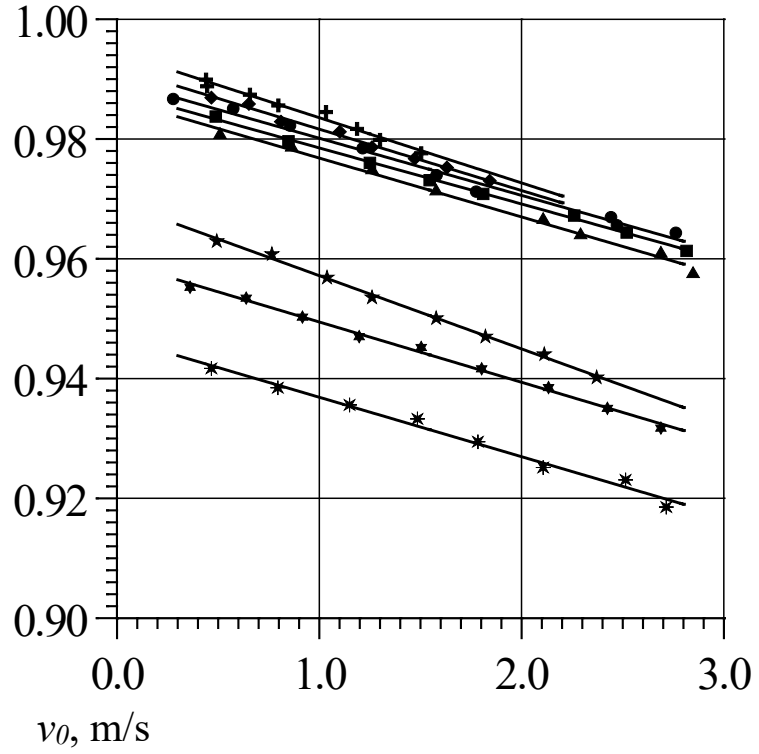

Fig. 3. The dependence of the cotton fiber layer porosity on the fictitious filtration rate of the thermal agent (symbols are the same as for Fig. 2) 
Experimental results of the thermal agent filtration through a layer of cotton fiber of different weights are presented in the form of functional dependence $\Delta P=f\left(v_{0}\right)$ and are shown in Fig. 2.

The analysis of Fig. 2 shows that the curves are parabolic, that is, the pressure loss in the cotton fiber layer is affected by both viscous and inertial components. The change in the layer porosity depending on the fictitious filtration rate of the thermal agent $\varepsilon=f\left(v_{0}\right)$ is shown in Fig. 3.

\section{Conclusion.}

Obtained dimensionless dependence allows to predict the energy costs necessary to create the pressure difference (under the same hydrodynamic conditions); it is suitable during the design of new drying equipment. The dependence can be used when technological parameters need to be changed, for example, the height of the cotton fiber layer or the filtration rate of the thermal agent. The error between theoretically calculated values and experimental data does not exceed $14.2 \%$, which is quite acceptable for the design of new drying equipment.

\section{References}

[1] Kale, R., Bansal, P. and Gorade, V. (2017). Extraction of Microcrystalline Cellulose from Cotton Sliver and Its Comparison with Commercial Microcrystalline Cellulose. Journal of Polymers and the Environment, 26(1), 355-364.

[2] Zeng, L., Zhao, S. and He, M. (2018). Macroscale porous carbonized polydopaminemodified cotton textile for application as electrode in microbial fuel cells. Journal of Power Sources, 376, 33-40.

[3] Wedin, H., Niit, E., Mansoor, Z., Kristinsdottir, A., de la Motte, H., Jönsson, C., Östlund, A. and Lindgren, C. (2018). Preparation of Viscose Fibres Stripped of Reactive Dyes and Wrinkle-Free Crosslinked Cotton Textile Finish. Journal of Polymers and the Environment, 26(9), 3603-3612.

[4] Cui, L., Shi, S., Hou, W., Yan, Z. and Dan, J. (2018). Hydrolysis and carbonization mechanism of cotton fibers in subcritical water. New Carbon Materials, 33(3), 245-251.

[5] L.H.C.D., S. (2000). Estudo da Secagem de Materiais Texteis. Ph.D. Maringaa.

[6] Azhimetova, G. (2011). Mirovoy opyt i obzor razvitiya khlopkovodstva v Kazakhstane. Sovremennyye problemy nauki i obrazovaniya, 1, 53-58.

[7] Shaykhov, E. and Normukhamedov, N. (1990). Pakhtachilik. Tashkent: Mekhnat, 284.

[8] Lv, N., Wang, X., Peng, S., Luo, L. and Zhou, R. (2018). Superhydrophobic/superoleophilic cotton-oil absorbent: preparation and its application in oil/water separation. RSC Advances, 8(53), 30257-30264.

[9] Ibrogimov, K., Alimardonov, K., Zul'fanov, S. and Badalov, A. (2007). Termodinamicheskiye kharakteristiki protsessa degidratatsii khlopka-syrtsa. Tekhnologiya tekstil'noy promyshlennosti, 4, 19-22.

[10] Boltaboyev, S. and Parpiyev, A. (1980). Sushka khlopka-syrtsa. Tashkent: Ukituvchi.

[11] Egamberdiyev, A., Ibragimov, S. and Amanturdiyev, A. (2009). Ġŭza selektsiyasi, urugchiligi va biologiyasi. Tashkent: Nauka, 128.

[12] Azhimetova, G. (2011). Mirovoy opyt i obzor razvitiya khlopkovodstva v Kazakhstane. Sovremennyye problemy nauki i obrazovaniya, 1, 53-58. 


\section{Hydrodynamics of cotton stalks filtration drying}

\section{Zagira Kobeyeva $^{1}$, Alisher Khusanov ${ }^{1}$, Zoriana Gnativ ${ }^{2}$, Volodymyr Atamanyuk ${ }^{2}$, Dauren Dzhanabaiev $^{1}$}

1. Department of Production machines and equipment, Auezov South Kazakhstan State University, KAZAKHSTAN, Shymkent, Tauke khan avenue, 5, E-mail: husanov_a @ mail.ru

2. Department of Chemical Engineering, Lviv Polytechnic National University, UKRAINE, Lviv, 9 St. Yura square, Building 9, E-mail: atamanyuk@ukr.net

- Abstract - Waste from agriculture and industry can serve as a renewable source of raw materials for the production of building materials suitable for use in building structures, as fillers for composite wood-plastic panels and for the production of biofuel pellets. Increasing their usage will not only provide the industry with additional raw materials and expand the range of building materials and products, but also contribute to the preservation and rational use of natural materials, which is an important environmental task.

- Keywords - cotton stalks (guza-pie), filtration drying, hydrodynamics, composite materials.

\section{Introduction}

Every year the world generates a large amount of plant waste after processing cereals and cotton, in particular from 500 thousand tons of cotton stalks about $70 \%$ is used inefficiently. At the same time, cotton stalks (guza-pie) can be used for the production of fuel briquettes, as a filler for energy-saving heat-insulating building materials, in particular arbolite composite products, etc.

Given that the cotton stalks after the annual harvest of cotton are stored in open areas, their humidity can reach more than $40 \%$. Therefore, to use cotton stalks as an organic cellulosecontaining raw material for the production of various products, they must be dried and grinded. Grinded cotton stalks are characterized by a large variety of physical and mechanical properties, including initial moisture content, amount of free and bound moisture, internal structural structure of particles, pore size and capillaries containing moisture, polydispersity and porosity of the stationary layer, which determine energy costs for drying. The processes of heat exchange between wet material and heat agent are limited by the low thermal conductivity of organic material, and mass transfer is limited by the intensity of moisture transfer from cells into the intercellular space and through micro and macropores into the heat agent. Thus, study of the laws of filtration drying of dispersed materials with plant origin will outline the optimal conditions and create a technology for preparing plant raw materials for use in wood-plastic panels and building materials, products and structures.

Abroad, wood is widely used as a substitute for filling composite wood-plastic materials and boards, flax stalks, pruning vines, hemp, kenaf and various types of straw. Currently, planches of plant residues are produced in Poland, France and several other countries. Planches from bagasse, sugar cane waste, are obtained in Cuba, the Philippines, Argentina, India, Brazil, Mexico, South Africa and other countries.

In this aspect, the development and production of composite wood-plastic board materials based on fillers from cotton stalks (guza-pie) and their implementation into production are of particular importance. The need for wood-plastic materials and boards at the expense of internal resources is provided that will allow to save valuable wood raw materials which have important ecological value. 
Existing theoretical and experimental studies of filtration drying patterns: hydrodynamics, external and internal heat transfer, are insufficient to build clear theoretical dependences of process parameters on the physicochemical properties of guza-pie, so the aim is to develop energy-saving technology for production alternative composite materials from plant raw materials and its industrial implementation.

The aim of the work is a theoretical analysis and experimental study of the hydrodynamics of filtration of a heat agent through a stationary layer of guza-pie and presentation of the results of experimental studies in dimensionless form.

\section{Experimental part}

The first stage of the study of the filtration drying process is an experimental study of the hydrodynamics of heat agent filtration through the porous structure of the stationary layer of the guza-pie due to the pressure drop. The values of heat and mass transfer coefficients, as well as the thickness of hydrodynamic, heat and diffusion boundary layers, which in turn affect on the intensity of heat and mass transfer during filtration drying, depend on the filtration rate of the gas flow through the stationary layer of dispersed material.

The hydrodynamics of the stationary layer of the guza-pie was experimentally investigated according to the standard method. Changes in pressure losses were investigated in the layer of the guza-pie with a height of $60-160 \cdot 10^{-3} \mathrm{~m}$. The results of experimental studies of pressure losses as a function of the fictitious rate of filtration of the heat agent through the stationary layer of the guza-pie are shown in Fig. 1.

$$
\Delta \mathrm{P}, \mathrm{Pa}
$$

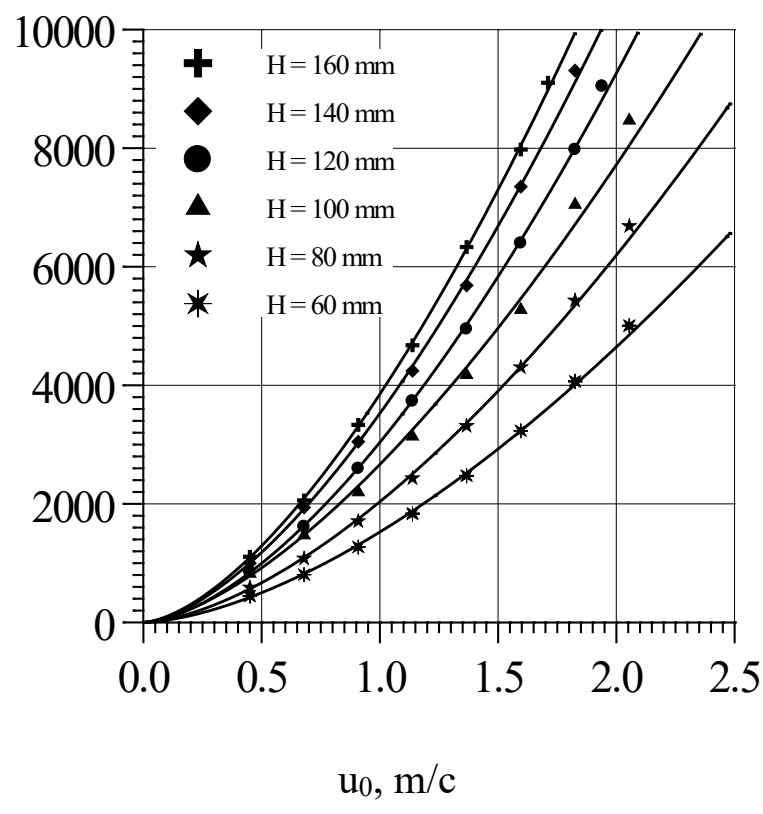

Fig.1 Dependence of pressure losses $\Delta \mathrm{P}$ in the stationary layer of the guza-pie on the fictitious rate $\mathrm{u}_{0}$ for different heights of the layer $\mathrm{H}$

$$
\frac{\Delta P}{H \times u_{\mathrm{n}}}, \frac{\mathrm{Pa} \times \mathrm{c}}{m^{2}}
$$

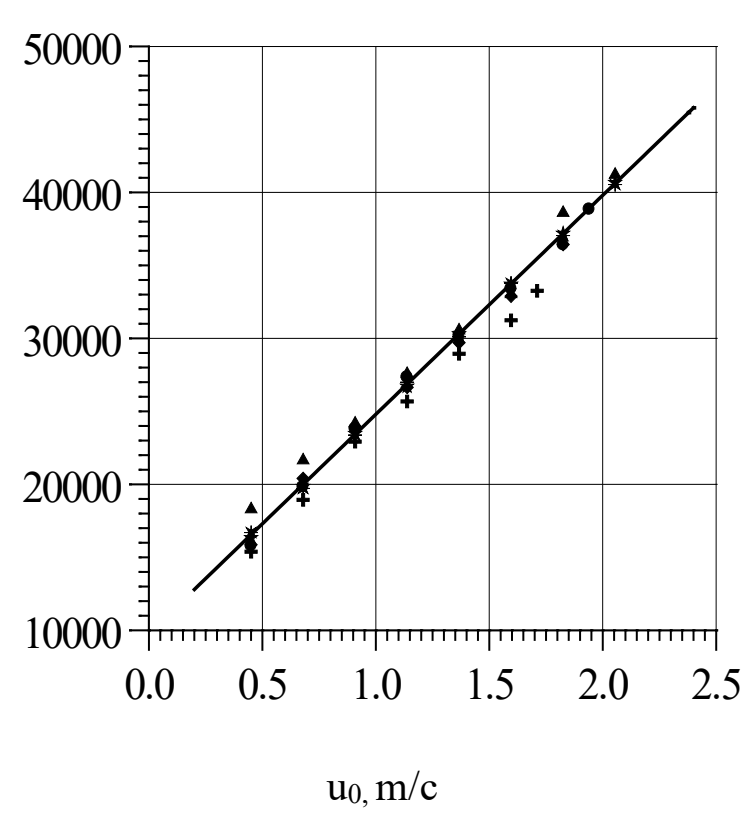

Fig. 2. Graphic dependence $\frac{\Delta P}{H \cdot u_{n}}=f\left(u_{0}\right)$ to determine the unknown coefficients $\mathrm{A}^{*} \mathrm{i} \mathrm{B}^{*}$ in the layer 
As can be seen from fig. 1, with increasing height of the guza-pie layer the hydraulic resistance increases, and its value is relatively small, which is positive for the organization of the process of drying the guza-pie by the filtration method. It also should be noted that the dependence of pressure losses on the fictitious rate is parabolic, so the process is influenced by both inertial and viscous components.

To predict the pressure losses in the stationary layer of material in the technical literature is used a modified two-term Ergan equation, which is linearized relatively to the fictitious filtration rate of the gas flow in the form:

$$
\frac{\Delta P}{H u_{\mathrm{n}}}=A^{*}+B^{*} * u_{0}
$$

To determine the unknown coefficients $\mathrm{A} *$ and $\mathrm{B} *$, the obtained experimental results of pressure losses in the guza-pie layer were presented in the form of the functional dependence $\Delta \mathrm{P}$ $/\left(\mathrm{H} \mathrm{u}_{0}\right)$, shown in fig. 2.

From the graphical dependence (fig. 2), the coefficient A* was determined by the segment intersecting the line on the ordinate axis, and the coefficient $\mathrm{B} *$ was determined by the tangent of the angle of inclination of the line to the abscissa axis. Therefore, having determined the unknown coefficients, equation (1) can be presented as follows for the dry layer of the guza-pie:

$$
\frac{\Delta P}{H u_{\mathrm{n}}}=9800+15000 \cdot u_{0}
$$

\section{Conclusion}

Thorough study of the physicochemical properties of grinded guza-pie and determination of optimal conditions for its preparation when used as fillers for composite wood-plastic materials and planches is an urgent task. The use of plant waste or the use of cheap plant raw materials will undoubtedly have a significant economic effect, supported by an effective method of filtration drying, which involves the usage in the technological scheme. The hydrodynamics of gas flow filtration through the stationary layer of the guza-pie was investigated and the unknown coefficients of the modified Ergan equation were determined. 


\title{
Complex hydrogels based on aquasol and polyacrylamide
}

\author{
Chobit M., Kalin D., Tokarev V. \\ Institute of Chemistry and Chemical Technologies, Lviv Polytechnic National University, UKRAINE, \\ Lviv, 3/4 pl. Sviatoho Yura, e-mail: maksym.r.chobit@lpnu.ua
}

\begin{abstract}
The aim of the work is to obtain hydrogel composites, a crosslinked structure based on polyacrylamide and aquazole; to study the swelling kinetics of the obtained hydrogels and to study the thermomechanical properties of the obtained material.
\end{abstract}

Keywords - polymers, hydrogels, polymerization, aquazole, swelling.

\section{Introduction}

In recent years, the development of chemical technologies has made it possible to obtain a large number of different polymers. One of the rapidly developing areas in this area is associated with polymeric hydrophilic gels (hydrogels). This type of polymer gels has a very high, compared to other materials, the ability to adsorb water, aqueous solutions, and other substances. They are biologically inactive, very similar to natural tissues due to the high water content. Due to these properties of polymer gels, they are actively used as fillers in diapers, surgical wipes, soft insoles. They are widely used in the chemical industry in the drainage of gases used in agriculture to obtain moisture-retaining soil. In medicine, hydrogels are used for the manufacture of contact lenses, for the treatment of wounds and skin burns, and are also considered promising for the use of polymer gels to create new generation implants. Hydrogels are also used in cosmetics to prevent wrinkles, namely hydrogel masks, which moisturize and fill skin cells with nutrients. Recently, the availability of hydrogels has increased significantly, and today, for example, hydrogel balls can be bought in almost any flower shop.

The chemistry of synthetic polymers opens up new possibilities for obtaining new types of hydrophilic polymers, architectures or combinations to improve their properties and future promising applications, in particular in the form of hydrogels. This class of materials has various interesting properties, individual shape and size, which is of great interest for biomedical, cosmetic use, biotechnology and other areas of human activity.

The aim of the work is to obtain hydrogel composites, a crosslinked structure based on polyacrylamide and aquazole (poly-2-ethyl-2-oxazoline) [1]; to study the swelling kinetics of the obtained hydrogels and to study the thermomechanical properties of the obtained material.

Based on the conducted studies, hydrogel composite materials based on crosslinked structures of polyacrylamide and aquazole were obtained. Aquazol has demonstrated excellent crosslinking properties of polymer materials. The degrees of swelling are calculated and thermomechanical properties are determined.

The degrees of swelling are calculated and thermomechanical properties are determined. The resulting hydrogel composites have high rates of swelling and are capable of long-term storage in an aqueous environment while maintaining elastic properties.

By grafted polymerization of hydrophilic functional monomers in an aqueous medium, spatially crosslinked polymer hydrogels containing chemically conjugated aquazole were obtained.

The process was performed in an aqueous solution of monomers (acrylamide (AAm) and acrylic acid (AA)) in the presence of the initiator $\mathrm{K}_{2} \mathrm{~S}_{2} \mathrm{O}_{8}$. A mixture of aquazole and an aqueous solution of monomers $(0.5 \mathrm{ml}$ in volume) was intensively mixed using a magnetic stirrer. 
After achieving homogenization, the reaction mixture was heated at $80^{\circ} \mathrm{C}$ for 5 hours. Polymerization was initiated by decomposition of the initiator $\mathrm{K}_{2} \mathrm{~S}_{2} \mathrm{O}_{8}$.
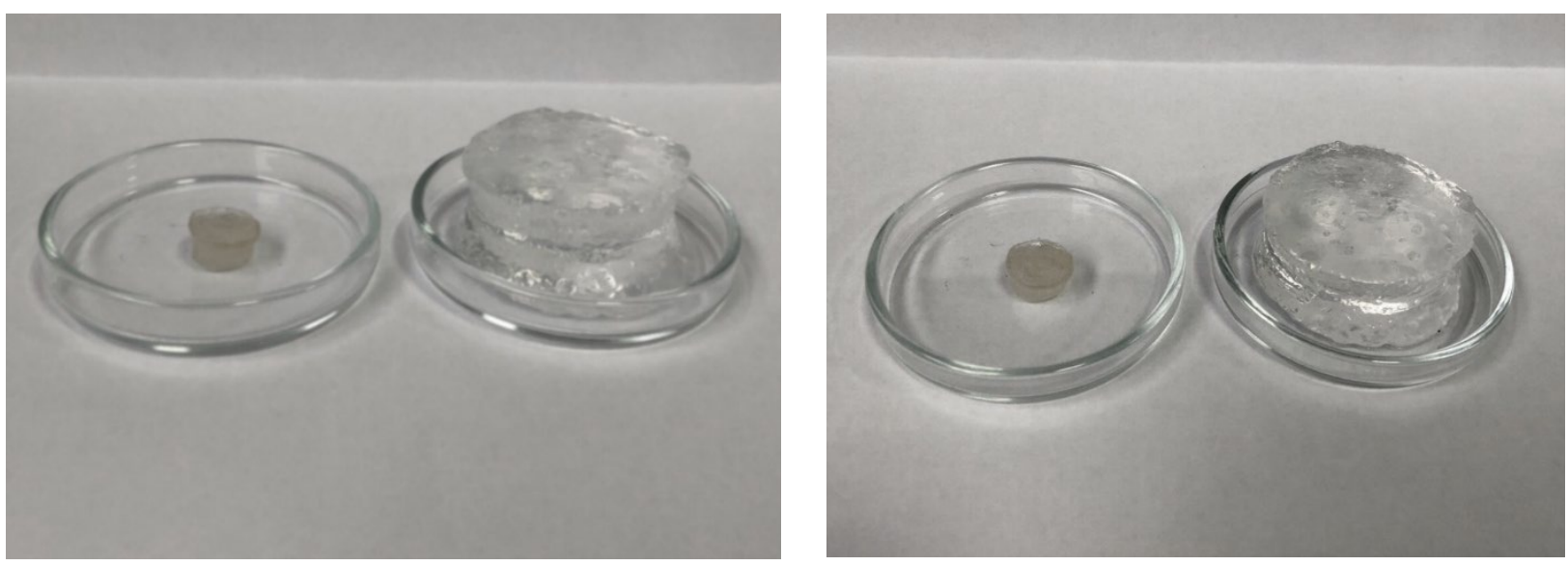

Fig.1. Hydrogels before and after prolonged exposure to water (copolymer composition, wt $\%$ : Aquazol $=20, \mathrm{AAm}=40, \mathrm{AA} .=40)$.

\section{Conclusion}

New hydrogel composites based on polyacrylamide and copolymers of acrylamide and acrylic acid grafted with poly-2-ethyl-oxazoline were synthesized. Such composites show good absorbent properties, the degree of their swelling can reach more than $26,000 \%$ by weight. The study of the swelling kinetics of the obtained hydrogel samples showed that with an increase in the content of Aquazol 50, the degree of their swelling increases, and with an increase in the content of Aquazol 500, it decreases. Composites with Aquazol 500 show better absorbent properties compared to Aquazol 50 and are able to maintain their shape in an aqueous environment for a longer time. The dependences of swelling on the composition of the hydrogel composite indicate that when acrylic acid links are introduced into the hydrogel structure, the absorption capacity increases by half an order of magnitude. The kinetics of relative changes in the size of hydrogel composites during swelling was studied, which confirmed the main patterns obtained in the study of the kinetics of their swelling. The longest preservation of shape and size was observed for samples of Aquazol 500-based hydrogel composites containing acrylic acid links, apparently due to the fact that these composites have a stronger crosslinked structure compared to others. Thermomechanical studies of the obtained polymer materials were carried out and the temperature of their heat resistance was determined. It was found that with an increase in the content of Aquazoles, a natural decrease in the temperature of heat resistance is observed, and in the case of Aquazol 50 it is sharper. The introduction of AA links does not significantly affect the temperature of heat resistance of composites. From the conducted thermomechanical researches it is possible to draw a conclusion that composites have thermoplastic properties with rather low temperatures of heat resistance thanks to what it will be possible to process them easily into certain products.

\section{References}

[1] Pizzi, D., Humphries, J., Morrow, J. P., Fletcher, N.L., Bell, C.A., Thurecht, K.J., Kempe,K. (2019). Poly(2-oxazoline) macromonomers as building blocks for functional and biocompatible polymer architectures. European Polymer Journal, 109258, 121. 


\title{
The interaction regularities of acetic and oleic acids esters and triethanolamine
}

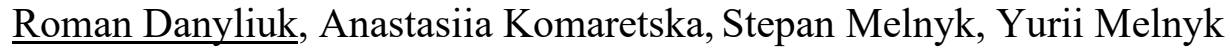 \\ Department of Organic Products Technology, Lviv Polytechnic National University, UKRAINE, Lviv, \\ S. Bandera str., 12, E-mail: roman.v.danyliuk@lpnu.ua
}

\begin{abstract}
The interaction regularities of ethyl and butyl esters of acetic, propionic, and oleic acids and triethanolamine have been studied. The influence of the ester type and catalyst on the process technological parameters was determined. It was found that under the same reaction conditions, oleic acid esters have higher reactivity than esters of lower aliphatic acids.
\end{abstract}

Keywords - transesterification, ammonolysis, ester, triethanolamine, catalyst.

\section{Introduction}

Ethanolamides and amino esters of fatty acids are an important class of organic compounds that function as nonionic surfactants. They have found their application as lubricants, detergents, cosmetics, paper coatings, mold removers, additives to polyethylene films, water repellents for textiles, and as additives to printing ink [1,2]. Ethanolamides and amino esters of aliphatic acids can be synthesized from ethanolamines and acyl donor molecules. Such donors are free fatty acids [3-5], fatty acid chlorides [6], vegetable oils [7] and fatty acid esters [8]. The usage of fatty acid chlorides is characterized by high process intensity. However, this method has a number of disadvantages. In particular, the synthesis is relatively expensive, and acid chlorides are corrosive and toxic substances. Their toxicity can affect the biological activity of ethanolamides in the first place. The main disadvantage of the free fatty acids usage is the formation of ionic pairs of ethanolamine and free fatty acids [9]. Due to the insoluble salt formation, the reaction becomes less efficient. Therefore, the use of fatty acid esters as acyl donors is more promising compared to other donors.

\section{Results and discussion}

This study aimed to investigate the interaction of fatty acid esters (ethyl oleate, butyl oleate, butyl propionate, and butyl acetate) with triethanolamine (grade B, ethanolamine content was $21 \mathrm{wt} . \%$ ) in the presence of catalysts cation exchange resin KU-2-8, p-toluenesulfonic acid, anion exchange resin $\mathrm{AB}-17-8$, potassium hydroxide.

The regularities of esters interaction with ethanolamines have been studied by the distillation of ethanol or butanol, formed as a result of ammonolysis and transesterification reactions. The reaction was carried out in the round bottom reactor, equipped with Dean-Stark trap and a reflux condenser. The average reaction temperature was maintained within $135 \pm 5{ }^{\circ} \mathrm{C}$. The reaction intensity was determined by the ethanol or butanol accumulation and by an amine value change of the reaction mixture. The content of alcohols was determined chromatographically. The amine value change was determined by reaction mixture titration with the sulfuric acid solution $\left(\mathrm{C}\left(1 / 2 \mathrm{H}_{2} \mathrm{SO}_{4}\right)=0,1 \mathrm{~mol} / \mathrm{dm}^{3}\right)$.

It was established that the investigated reaction mixtures have a relatively low conversion rate. In particular, under the reaction conditions of butyl propionate with ethanolamines at a molar ratio $(1,2-4,2): 1$ for a time of $140-340 \mathrm{~min}$ in the presence of $1-3,4 \mathrm{wt}$ \% of cation exchange resin KU-2-8 ester conversion is only $2,8-21,7 \%$. The feature of this reaction system (also for butyl acetate) is the presence of two liquid phases of the reagents due to ester and ethanolamines limited solubility. The presence of a heterogeneous catalyst is an additional reason for the low reaction rate. The accumulation of lower aliphatic alcohol in sufficient 
concentration homogenizes the reaction system, but afterwards the reaction slows down. It should also be noted that even though the reaction temperature is higher than the boiling point of butanol, the accumulation of this alcohol in the Dean-Stark trap is very slow. A possible reason for this is the hydroxyl groups high content in the reaction mixture and, accordingly, a significant amount of hydrogen bonds between alcohols. The type of catalyst also affects the reaction intensity. The least active catalysts are p-toluenesulfonic acid and anion exchange resin AB-178. The regularities of ethyl oleate and ethanolamines interaction were studied at a molar ratio of $1: 0,9-2$ and the content of KU-2-8 cation exchange resin in the reaction mixture of $1-3 \%$ by weight of loaded reagents. It was found that the use of a double excess of triethanolamine provides $53.6 \%$ conversion of ethyl oleate in $270 \mathrm{~min}$ of reaction. The higher degree of ester conversion can be explained by the formation of a stable emulsion between ethanolamines and oleic acid esters, which promotes better contact between the reagents.

\section{Conclusion}

It has been determined that the reaction between triethanolamine and oleic acid esters occurs more efficiently than reaction with propionic and acetic acid esters.

\section{References}

[1] Liu, K. J., Nag, A., Shaw, J. F. (2001). Lipase-catalyzed synthesis of fatty acid diethanolamides. J. Agric. Food Chem., 49, 5761-5764. doi:10.1021/jf0107858

[2] Feairheller, S., Bistline, R., Bilyk, A., Dudley, R., Kozempel, M., Haas, M. (1994). A novel technique for the preparation of secondary fatty amides. J. Am. Oil Chem. Soc., 71, 863-866. doi:10.1007/BF02540463

[3] Wang, X., Wang, X., Wang, T. (2012). Synthesis of oleoylethanolamide using lipase. J. Agric. Food Chem., 60, 451-457. doi:10.1021/jf203629w

[4] Plastina, P., Meijerink, J., Vincken, J. P., Gruppen, H., Witkamp, R., Gabriele, B. (2009). Selective synthesis of unsaturated $\mathrm{N}$-acylethanolamines by lipase-catalyzed $\mathrm{N}$-acylation of ethanolamine with unsaturated fatty acids. Lett. Org. Chem., 6, 444-447. doi: $10.2174 / 157017809789124885$

[5] Maag, H. Fatty acid derivatives: important surfactants for household, cosmetic and industrial purposes (1984). J. Am. Oil Chem. Soc., 61, 259-267. doi:10.1007/BF02678778

[6] Kolancilar, H. (2004). Preparation of laurel oil alkanolamide from laurel oil. J. Am. Oil Chem. Soc., 81, 597-598. doi: 10.1007/s11746-006-0947-y

[7] Wang, X., Wang, T., Wang, X. (2012). An improved method for synthesis of N-stearoyl and N-palmitoylethanolamine. J. Am. Oil Chem. Soc., 89, 1305-1313. doi:10.1007/s11746012-2017-y

[8] Khanmohammadi, M., Kojidi, M. H., Garmarudi, A. B., Ashuri, A., Soleymani, M. (2009). Quantitative monitoring of the amidation reaction between coconut oil and diethanolamine by attenuated total reflectance fourier transform infrared spectrometry. J. Surfact. Deterg., 12, 37-41. doi:10.1007/s11743-008-1101-7

[9] Tufvesson, P., Annerling, A., Hatti-Kaul, R., Adler-Creutz, D. (2007). Solvent-free enzymatic synthesis of fatty alkanolamides. Biotechnol. Bioeng., 97, 447-453. doi: $10.1002 /$ bit.21258 


\title{
Determination of pressure drop in a fixed bed catalytic reactor during ammonia oxidation on nanostructured catalyst
}

\author{
Oksana Dobrovetska $^{1}$, Diana Kindzera ${ }^{2}$, Roram Hosovskyi ${ }^{3}$, Volodymyr Atamanyuk $^{4}$
}

1. Department of Chemical Engineering, Lviv Polytechnic National University, UKRAINE, Lviv, 12 S. Bandery Str, E-mail: oksanadobrovetska@gmail.com

2. Department of Chemical Engineering, Lviv Polytechnic National University, UKRAINE, Lviv, 12 S. Bandery Str., E-mail: kindzera74@ukr.net

3. Department of Chemical Engineering, Lviv Polytechnic National University, UKRAINE, Lviv, 12 S. Bandery Str., E-mail: roma5477@meta.ua

4. Department of Chemical Engineering, Lviv Polytechnic National University, UKRAINE, Lviv, 12 S. Bandery Str., E-mail: atamanyuk@ukr.net

\begin{abstract}
The effect of the increasing gas velocity on the pressure drop in the fixed beds with a length of $3510^{-3}, 4510^{-3}, 5510^{-3}, 6510^{-3}$ and $75 \cdot 10^{-3} \mathrm{~m}$ which were generated in the downflow reactor has been established by experimental method. Ergan and Darcy-Weisbach equations have been used as the numerical methods to calculate the pressure drops within the Reynolds number range of $312 \leq R e \leq$ 1177. The difference between experimental and calculated values of pressure drops was found to be increased with the increase of the Reynolds number. Maximal relative error between experimental and theoretical values does not exceed $\pm 3 \%$.
\end{abstract}

Keywords - nanostructured catalyst, fixed bed reactor, low-temperature ammonia oxidation process

\section{Introduction}

Nowadays, ammonia and methanol synthesis, methane reforming with carbon (IV) oxide, the ethane, hydrochloric acid and sulfur (IV) oxide oxidation, as well as production of hydrogen by the rich combustion of heavy fuel oil and waste treatment are carried out in fixed bed catalytic reactors, also called packed bed catalytic reactors [1-3]. These reactors are the most commonly used in large-scale production of chemicals. In the reactors the continuous phase is a fluid or gas and the porous phase consists of catalytic granules which can be loaded into the reactor as single bed units, multi-bed units, and multi-tube units [4]. Oxidation of ammonia $\left(\mathrm{NH}_{3}\right)$ in the presence of catalysts takes place with the formation $\mathrm{N}_{2}, \mathrm{~N}_{2} \mathrm{O}$ and $\mathrm{NO}$ and the resulting product depends on the process conditions and the catalyst nature [5]. The catalytic oxidation of ammonia to nitrous oxide $\left(\mathrm{N}_{2} \mathrm{O}\right)$ at low temperatures is an efficient technique and it can be intensified by the application of new selective catalysts [6].

High activity at low-temperature ammonia oxidation and high selectivity for $\mathrm{N}_{2} \mathrm{O}$ are shown by Pt-based catalysts [7]. The technology of obtaining nanostructured catalysts attracts the special attention of researchers due to the high activity of the catalyts [8]. Therefore, nanostructured platinum catalysts obtained by electrochemical method are promising and their application will provide the intensification of the ammonia oxidation process in the fixed bed reactor.

\section{Results and discussion}

The pressure drops were measured for fixed beds with length of $35 \cdot 10^{-3}, 45 \cdot 10^{-3}, 55 \cdot 10^{-3}$, $65 \cdot 10^{-3}, 75 \cdot 10^{-3} \mathrm{~m}$ and experimental curves are presented in Fig. 1. 


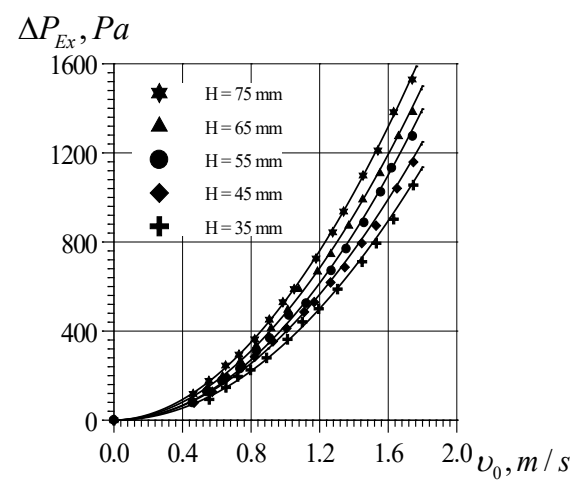

Fig. 1. The pressure drop in fixed beds of different length vs. gas superficial velocity.

In general, Fig. 1 demonstrates that the increase in the gas superficial velocity increases the pressure drop in fixed beds. The effect of fixed beds' length on the pressure drop is significant and, as the example, it is evident, that at the actual velocity of $1.78 \mathrm{~m} / \mathrm{s}$ the pressure drop is changing from $985 \mathrm{~Pa}$ for the length of the fixed bed $\mathrm{H}=35 \cdot 10^{-3} \mathrm{~m}$ to $1530 \mathrm{~Pa}$ for the length of the fixed bed $\mathrm{H}=75 \cdot 10^{-3} \mathrm{~m}$.

To determine the pressure drop in the fixed beds of different length when passing the gas flow through them, the Ergan equation (1) and Darcy-Weisbach equation (2) were used.

$$
\begin{gathered}
\frac{\Delta P}{H}=150 \frac{\mu \cdot(1-\varepsilon)^{2} \cdot}{d_{p}^{2} \cdot \varepsilon^{3}} v_{0}+1,75 \frac{\rho \cdot(1-\varepsilon)}{d_{p} \cdot \varepsilon^{3}} v_{0}^{2} \\
\Delta P=\lambda \cdot \frac{H_{e}}{d_{e}} \cdot \frac{\rho \cdot v_{0}^{2}}{2}(2)
\end{gathered}
$$

So, Ergan equation allows to predict accurately the pressure drop in the fixed bed up to Reynolds number of 850 , but with the increasing of Reynolds number above 850, the error between experimental and calculated values increases due to increased gas turbulence in the channels between particles of the catalyst, when the effect of inertial component increases and the effect of the viscous component decreases.

Since the Euler number includes the velue of the pressure drop, the equation may be represented as:

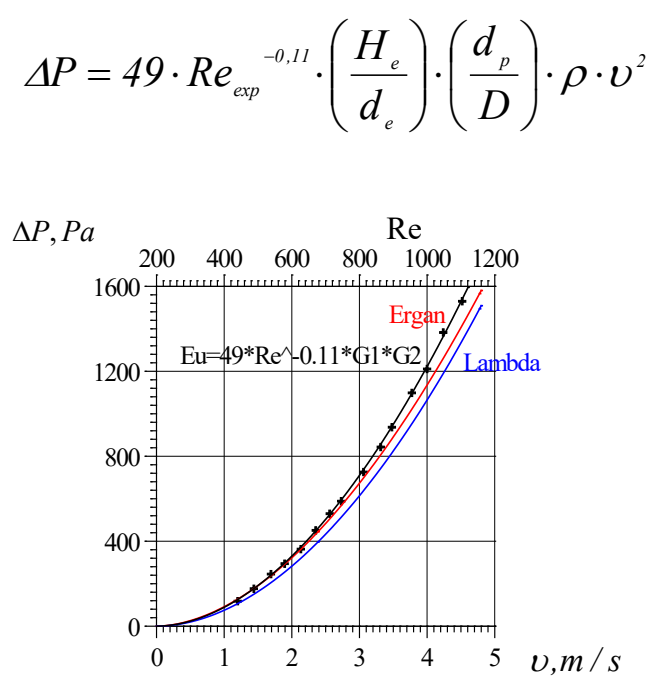

Fig. 2. Pressure drops in the fixed bed of the length $H=75 \cdot 10^{-3} \mathrm{~m}$ versus actual gas velocities within the Reynolds number range of $312 \leq \mathrm{Re} \leq 1177$ 
Graphic dependencies in Fig. 2 show that values of the pressure drop obtained by using Eq. (3) accurately describe the experimental data.The maximal relative error between experimental and theoretical values does not exceed $\pm 3 \%$. Therefore, the proposed equation (3) allows us to calculate theoretically with high accuracy the pressure drop in the downflow fixed bed reactor within Reynolds number range of $312 \leq \mathrm{Re}_{\exp } \leq 1177$.

\section{Conclusion}

The effect of the increasing gas velocity on the pressure drop in the fixed beds of nanostructured platinum catalyst with the length of $35 \cdot 10^{-3}, 45 \cdot 10^{-3}, 55 \cdot 10^{-3}, 65 \cdot 10^{-3}$ and $75 \cdot 10^{-3} \mathrm{~m}$ which were generated in the downflow fixed bed reactor has been established by experimental method. Ergan and Darcy-Weisbach equations have been used as the numerical methods to calculate the pressure drops and the graphic dependencies have been plotted to compare the results with experimental data. The error between values of pressure drops was found to be increased at Reynolds number above 850.

Generalizing the experimental results, the equation $\Delta P=49 \cdot \operatorname{Re}_{\exp }{ }^{-0,11} \cdot\left(H / d_{e}\right) \cdot\left(d_{p} / D\right) \cdot \rho \cdot v^{2}$ has been proposed which allows to calculate theoretically with high accuracy the pressure drop in the downflow fixed bed reactor with new catalyst within Reynolds number range of $312 \leq \operatorname{Re}_{\exp } \leq 1177$. The maximal relative error between experimental and theoretical values does not exceed $\pm 3 \%$.

\section{References}

[1] Sandeep, K. C., Mohan, S., Mandal, D., Mahajani, S. (2019). Determination of gas film mass transfer coefficient in a packed bed reactor for the catalytic combustion of hydrogen. Chemical Engineering Science, 202, 508-518. https://doi.org/10.1016/j.ces.2019.02.042

[2] Sun, Z., West, D. H., Balakotaiah, V. (2019). Bifurcation analysis of catalytic partial oxidations in laboratory-scale packed-bed reactors with heat exchange. Chemical Engineering Science, 377, 1197651. https://doi.org/10.1016/j.cej.2018.08.151

[3] Gómez, J., Mmbaga, J.P., Hayes R.E., Toledo, M., Gracia, F. (2018) Modeling hydrogen production in a catalytic-inert packed bed reactor by rich combustion of heavy fuel oil. International Journal of Hydrogen Energy, 43, 2677-2688. https://doi.org/10.1016/j.ijhydene.2017.12.056

[4] Bazmi, M., Hashemabadi, S.H., Bayat, M. (2011). Modification of Ergun equation for application in trickle bed reactors randomly packed with trilobe particles using computational fluid dynamics technique. Korean Journal of Chemical Engineering, 28, 1340-1346. https://doi.org/10.1007/s11814-010-0525-8

[5] Manna, M.V., Sabia, P., Ragucci, R., Joannon, M. (2020). Oxidation and pyrolysis of ammonia mixtures in model reactors. Fuel, 264, 116768, https://doi.org/10.1016/j.fuel.2019.116768

[6] Masalitina, N.Yu. (2017). Ph.D. Thesis, National Technical "Kharkiv Polytechnic Institute", Ukraine, Kharkiv

[7] Ma, H., Schneider., W. F. (2020). DFT and microkinetic comparison of Pt, Pd and Rhcatalyzed ammonia oxidation. Journal of Catalysis, 383, 322-330. https://doi.org/10.1016/j.jcat.2020.01.029

[8] Saldan, I., Girella, A., Milanese, C., Fratini, F., Dobrovetska, O., Levchuk, I., Kuntyi, I. (2018). Size and distribution of palladium nanoparticles electrodeposited on graphite. Functional Materials, 25. 82-87, doi:https://doi.org/10.15407/fm25.01.082 


\title{
Development of new functional food products based on spreads
}

\author{
Chobit M., Vasylyev V., Panchenko Yu., Usiichuk M. \\ Institute of Chemistry and Chemical Technologies, Lviv Polytechnic National University, UKRAINE, \\ Lviv, 3/4 pl. Sviatoho Yura, E-mail: maksym.r.chobit@lpnu.ua
}

\begin{abstract}
The aim of this work was to determine the types of butter as a raw material for the development of new formulations of spreads using vegetable oils and the creation of new functional products. As a result, we obtained an improved functional food product with improved quality characteristics and developed a method for its production.
\end{abstract}

Keywords - butter, spreads, flax oil, linen cake extract, functional products.

The concept of "spreads" came into circulation recently. Spreads are safer in terms of nutrition compared to butter and other animal fats. They meet the requirements of a healthy diet, as they have a balanced content of fatty acid residues and are enriched with vitamins. The production of spreads is young, so there are many issues that need to be addressed, ranging from improving the regulatory framework and ending with the consumer sphere. Currently, the cause of all the typical problems of modern nutrition is excessive consumption of high-calorie foods, persistent deficiency of vital components, as well as unbalanced diet.

Our diet is too high in fat, salt, sugar and very little fresh vegetables and fruits. The definition of "healthy eating" means the use of a variety of products, mainly of plant origin in the optimal ratio to provide the body with all necessary nutrients. In this context, emulsion fat products, which include spreads, deserve special attention. They contain a small amount of saturated fats, which are a risk factor for health and no cholesterol; they contain the necessary vitamins, minerals, dietary fibre, antioxidants. Providing the population with high-quality food is the most important economic and social problem. The leading role in its implementation belongs to the dairy and oil and fat industry.

The aim of this work was to determine the types of butter as a raw material for the development of new formulations of spreads using vegetable oils and the creation of new functional products. As a result, we obtained an improved functional food product with improved quality characteristics and developed a method for its production.

To create new functional products, we chose linseed oil, which has a high content of unsaturated fatty acids: 44-61\% $\alpha$-linolenic (Omega-3), 15-30\% linoleic (Omega-6), 13-29\% oleic -9). The content of saturated acids is $9-11 \%$. Flaxseed oil is obtained by cold pressing, so this product does not undergo heat treatment and does not lose its properties due to the destruction of useful elements at high temperatures.

The effect of temperature on the consistency of two types of butter with a fat content of $63 \%$ and $72.5 \%$ was studied. As a result of the experiments, it was found that the optimal temperature is $30^{\circ} \mathrm{C}$, and the optimal time for melting butter is 30 minutes.

In order to form a variety of tastes in the spreads and create new functional products, we have developed sweet cream spreads with a fat content of $69.2 \%, 73 \%$ and $78 \%$. The raw materials for their production were sweet cream butter "Sandwich" with a fat content of $63 \%$, linseed oil (vegetable component), for which the optimal amount was determined, milk powder (to normalize fat content) and water.

In the studies we used the flaxseed extract (ELM) obtained by us, the feature of which is the content of lignans. These are phenolic compounds that have estrogenic properties. In addition, flaxseed meal is rich in vitamins $\mathrm{B}, \mathrm{E}$ and folic acid, very useful for the digestive system. It contains $30-35 \%$ protein, more than $30 \%$ nitrogen-free extractives and $8-9 \%$ fiber. 
Appearance of spreads based on sweet butter with fat content $72,5 \%$

\begin{tabular}{|c|c|c|c|}
\hline $\begin{array}{c}\text { Font } \\
\text { Quality }\end{array}$ & $\mathbf{8 0 \%}$ & $\mathbf{8 2 , 5 \%}$ & $\mathbf{8 5 \%}$ \\
\hline $\begin{array}{c}\text { Appearance at } \\
\text { temperature } \\
5-7^{\circ} \mathrm{C}\end{array}$ & & & \\
\hline $\begin{array}{c}\text { Appearance on the cut } \\
\text { Appearance at room } \\
\text { temperature (for } 15 \\
\text { minutes) }\end{array}$ & & \\
\hline
\end{tabular}

Flax mucus soothes the gastric mucosa, relieves inflammation, and fiber promotes the excretion of toxins. The cake also contains iron, magnesium, potassium and other trace elements. The extracted components acted as a food additive with the potential functions of filler, stabilizer and emulsifier. The determined optimal amount of ELM partially weakens the yellow colour of the spread. The consistency of the finished product becomes more plastic, at room temperature the spread slowly melts and is easily spread on bread. ELM enhances the smell of flax in spreads and does not affect the taste.

In the studies we used the flaxseed extract (FE) obtained by us, the feature of which is the content of lignans. These are phenolic compounds that have estrogenic properties. In addition, flaxseed meal is rich in vitamins $\mathrm{B}, \mathrm{E}$ and folic acid, very useful for the digestive system. It contains $30-35 \%$ protein, more than 30\% nitrogen-free extractives and $8-9 \%$ fiber. Flax mucus soothes the gastric mucosa, relieves inflammation, and fiber promotes the excretion of toxins. The cake also contains iron, magnesium, potassium and other trace elements. The extracted components acted as a food additive with the potential functions of filler, stabilizer and emulsifier. The determined optimal amount of FE partially weakens the yellow color of the spread. The consistency of the finished product becomes more plastic, at room temperature the spread slowly melts and is easily spread on bread. FE enhances the smell of flax in spreads and does not affect the taste.

\section{Conclusion}

Thus, as a result of research, a method of obtaining new functional products - spreads with improved quality characteristics, which contain unsaturated fatty acids, a complex of vitamins, easily absorbed by the human body and can be used for healthy eating. The composition of ingredients for different types of butter as raw materials for spreads is optimized. Flaxseed oil with valuable useful properties as a component of vegetable fat in the received functional products is applied. The use of flaxseed extract as a food additive with the potential properties of a stabilizer, emulsifier and useful filler is proposed. The complex of researches of physicochemical and organoleptic properties and the constructed profilograms testify to the conformity of the obtained DSTU products and allowed to determine their best formulations. 


\title{
The degree of complexity of the subsolidus structure of three-component systems $\mathrm{MgO}-\mathrm{Al}_{2} \mathrm{O}_{3}-\mathrm{FeO}, \mathrm{MgO}-\mathrm{Al}_{2} \mathrm{O}_{3}-\mathrm{TiO}_{2}, \mathrm{MgO}_{2} \mathrm{TiO}_{2}-\mathrm{FeO}, \mathrm{Al}_{2} \mathrm{O}_{3}-\mathrm{TiO}_{2}-\mathrm{FeO}$
}

\author{
$\underline{\text { Oksana Borysenko }}^{1}$, Sergey Logvinkov ${ }^{2}$, Galina Shabanova ${ }^{1}$, Andrii Ivashura ${ }^{2}$ \\ 1. Department of Ceramics, Refractory Materials, Glass and Enamels Technology, National Technical University \\ "Kharkiv Polytechnic Institute", UKRAINE, Kharkiv, 2 Kyrpychova str., E-mail: onborisenko@ukr.net \\ 2. Department of Technologies and Safety of Vital Activity, Simon Kuznets Kharkov National University of \\ Economics, UKRAINE, Kharkiv, 9-a pr-t Nauki
}

\begin{abstract}
The results of calculations of the subsolidus structure's complexity of three-component systems are presented. It has been found that for carrying out a research of the subsolidus structure of $\mathrm{MgO}-\mathrm{Al}_{2} \mathrm{O}_{3}-\mathrm{FeO}$ system it is necessary to analyze 1 model solid-phase exchange reaction, for $\mathrm{MgO}$ $\mathrm{Al}_{2} \mathrm{O}_{3}-\mathrm{TiO}_{2}-25$, for $\mathrm{MgO}-\mathrm{TiO}_{2}-\mathrm{FeO}-36$ and for $\mathrm{Al}_{2} \mathrm{O}_{3}-\mathrm{TiO}_{2}-\mathrm{FeO}-25$.
\end{abstract}

Keywords - the three-component system, subsolidus structure, connode, double compounds, phase composition.

\section{Introduction}

Three-component systems with different combinations of oxides form the physical and chemical basis of composite materials. The study of the structure of state diagrams of such systems gives technologists an opportunity to forecast the phase composition of materials based on them. However, the research on the state diagrams of three-component systems is the most knowledge-intensive task of materials science. To solve this problem, thermodynamic prognosis and modeling of all variants of solid-phase exchange reactions between compounds of the system are used. This is not difficult to achieve, when there are no triple compounds in the system and double compounds are in one or two subsystems. If double compounds are included in all subsystems and are not equally spread, as well as the presence of triple compounds, it makes this procedure much more difficult.

$\mathrm{MgO}-\mathrm{Al}_{2} \mathrm{O}_{3}-\mathrm{FeO}, \quad \mathrm{MgO}-\mathrm{Al}_{2} \mathrm{O}_{3}-\mathrm{TiO}_{2}, \quad \mathrm{MgO}-\mathrm{TiO}_{2}-\mathrm{FeO}, \mathrm{Al}_{2} \mathrm{O}_{3}-\mathrm{TiO}_{2}-\mathrm{FeO}$ systems are important for producing refractory materials, such as heat-resistant spinel-containing, modified magnesia, corundum-reinforced and others. They can also be contained in other more complex systems. In particular, they are part of the four-component $\mathrm{MgO}-\mathrm{Al}_{2} \mathrm{O}_{3}-\mathrm{FeO}-\mathrm{TiO}_{2}$ system, which is the basis for production of periclase-spinel refractories for rotary furnaces of cement industry and mine furnaces of different purposes. The subsolidus structure of the considered threecomponent systems allows predicting not only the phase composition of the ready-made product, but also its behavior during exploitation. Thus, the estimation of the subsolidus structure's complexity of three-component systems, which in the future will be the basis for a more complex research of these systems' structures, is an innovative and relevant task.

\section{Results and Discussion}

The work considers the results of estimations of the complexity of $\mathrm{MgO}-\mathrm{Al}_{2} \mathrm{O}_{3}-\mathrm{FeO}, \mathrm{MgO}-$ $\mathrm{Al}_{2} \mathrm{O}_{3}-\mathrm{TiO}_{2}, \mathrm{MgO}-\mathrm{TiO}_{2}-\mathrm{FeO}, \mathrm{Al}_{2} \mathrm{O}_{3}-\mathrm{TiO}_{2}-\mathrm{FeO}$ systems, which were carried out according to the methods of this work [1].

Subsolidus structure of $\mathrm{MgO}-\mathrm{Al}_{2} \mathrm{O}_{3}-\mathrm{FeO}$ system is simpler, compared with other threecomponent systems, as in this system two compounds are stable: in subsystem $\mathrm{MgO}-\mathrm{Al}_{2} \mathrm{O}_{3}[2]-$ 1, in subsystem $\mathrm{Al}_{2} \mathrm{O}_{3}-\mathrm{FeO}$ [3] - 1. The subsolidus structure of $\mathrm{MgO}-\mathrm{Al}_{2} \mathrm{O}_{3}-\mathrm{TiO}_{2}, \mathrm{MgO}-\mathrm{TiO}_{2}-$ $\mathrm{FeO}, \mathrm{Al}_{2} \mathrm{O}_{3}-\mathrm{TiO}_{2}-\mathrm{FeO}$ systems is more complicated because of not only presence of three or more stable binary compounds, but also due to the increase of their number with rising the temperature. In other words, the subsolidus structure of these systems becomes more 
complicated as the temperature goes up. Fig. 1 shows the analyzed systems above the temperature of $1537 \mathrm{~K}$.
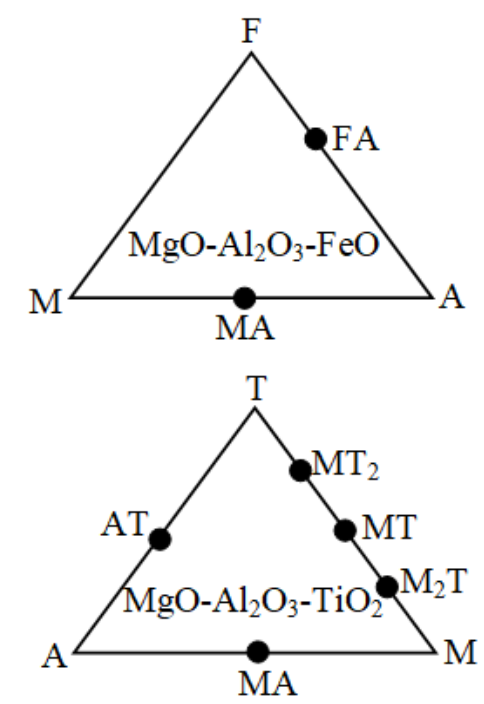
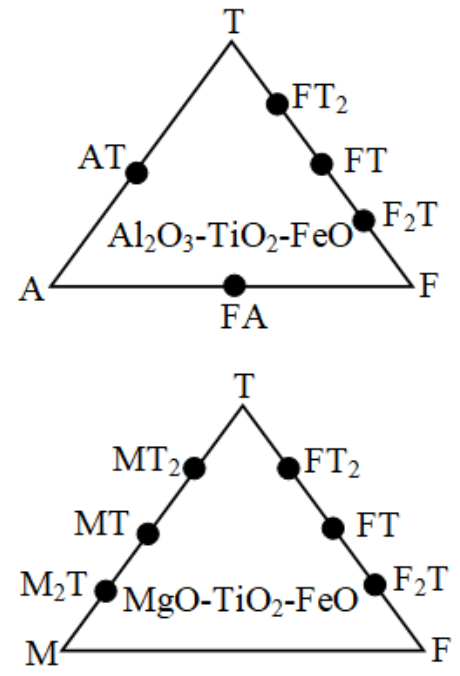

Fig.1. Composition points of binary compounds as initial information for establishing the subsolidus structure of systems above the temperature of $1537 \mathrm{~K}$.

According to Fig. 1 in the $\mathrm{MgO}-\mathrm{Al}_{2} \mathrm{O}_{3}-\mathrm{FeO}$ system has two stable compounds, in $\mathrm{Al}_{2} \mathrm{O}_{3}-$ $\mathrm{TiO}_{2}-\mathrm{FeO}$ - five, in $\mathrm{MgO}-\mathrm{Al}_{2} \mathrm{O}_{3}-\mathrm{TiO}_{2}$ there are five, in $\mathrm{MgO}-\mathrm{TiO}_{2}-\mathrm{FeO}-$ six. In the $\mathrm{MgO}-$ $\mathrm{Al}_{2} \mathrm{O}_{3}-\mathrm{FeO}\left(\mathrm{V}_{1}=1, \mathrm{~V}_{2}=1\right)$ and $\mathrm{MgO}-\mathrm{TiO}_{2}-\mathrm{FeO}\left(\mathrm{V}_{1}=3, \mathrm{~V}_{2}=3\right)$ systems the compounds are equally divided into two subsystems. The $\mathrm{Al}_{2} \mathrm{O}_{3}-\mathrm{TiO}_{2}-\mathrm{FeO}\left(\mathrm{V}_{1}=1, \mathrm{~V}_{2}=1, \mathrm{~V}_{3}=3\right)$ and $\mathrm{MgO}-$ $\mathrm{Al}_{2} \mathrm{O}_{3}-\mathrm{TiO}_{2}\left(\mathrm{~V}_{1}=1, \mathrm{~V}_{2}=1, \mathrm{~V}_{3}=3\right)$ systems are almost similar - there are three compounds in one subsystem and one in two.

According to [1] for $\mathrm{MgO}-\mathrm{Al}_{2} \mathrm{O}_{3}-\mathrm{FeO}$ system we have determined: the number of compounds in the system $\mathrm{d}=2$, the number of possible connodes $\mathrm{k}=3$ and the number of intersection points of connodes $\mathrm{P}=1$; for $\mathrm{MgO}_{-} \mathrm{TiO}_{2}-\mathrm{FeO}-\mathrm{d}=6, \mathrm{k}=15$ and $\mathrm{P}=36$; for $\mathrm{Al}_{2} \mathrm{O}_{3}$ $\mathrm{TiO}_{2}-\mathrm{FeO}-\mathrm{d}=5, \mathrm{k}=12$ and $\mathrm{P}=25$; for $\mathrm{MgO}-\mathrm{Al}_{2} \mathrm{O}_{3}-\mathrm{TiO}_{2}-\mathrm{d}=5, \mathrm{k}=12$ and $\mathrm{P}=25$.

\section{Conclusion}

Therefore, the evaluation of the complexity of the systems boils down to the calculating the number of intersection points of all possible line segments between the points of compositions, this means that it allows defining all possible model solid-phase exchange reactions, and consequently the subsolidus structure of the systems.

\section{References}

[1] Logvinkov, S. M., Borisenko, O. M., Tsapko N. S., Shabanova, G. N., Korohodska, A. N., Shumejko, V. N., Gaponova, O. O. (2020). Calculation evaluation of the degree of subsolidus structure complexity of the physico-chemical three-component systems. Bulletin of the National Technical University "KhPI". Series: Chemistry, Chemical Technology and Ecology, 2(4), 57-67. https://doi.org/10.20998/2079-0821.2020.02.08

[2] Hallstedt, B. (1992). Thermodynamic Assessment of the System $\mathrm{MgO}-\mathrm{Al}_{2} \mathrm{O}_{3}$. Journal of the American Ceramic Society, 75(6), 1497-1507. https://doi.org/10.1111/j.11512916.1992.tb04216.x

[3] Dreval, L., Zienert, T., Fabrichnaya, O. (2016). Calculated phase diagrams and thermodynamic properties of the $\mathrm{Al}_{2} \mathrm{O}_{3}-\mathrm{Fe}_{2} \mathrm{O}_{3}-\mathrm{FeO}$ system. Journal of Alloys and Compounds, 657, 192-214. https://doi.org/10.1016/j.jallcom.2015.10.017 


\title{
Modified polylactide composites
}

Nataliya Semenyuk, Khrystyna Kysil, Galyna Dudok, Volodymyr Skorokhoda

Lviv Polytechnic National University, UKRAINE, Lviv, S. Bandery st., 12, 79013,

E-mail: nataliia.b.semeniuk@lpnu.ua

\begin{abstract}
The basic technological principles of obtaining modified polylactide materials in the films form and porous matrices for special application are investigated. Modification of polylactides with glycerol, polyvinylpyrrolidone, and heat treatment has been committed. The influence of synthesis conditions, composition composition on structure, morphology and properties of modified polylactide materials are revealed.
\end{abstract}

Keywords - polylactide, modified films, composites, porous polymer matrices, polyvinylpirrolidone.

Aggravation of the problems related to the plastic waste utilization has prompted to the searching and developing of technology to obtain biodegradable polymers which are able for decomposition in environment in a relatively short time. One of the most perspectives of this group of polymers is polylactide (PLA), which is biodegradable, biocompatible, thermoplastic polymer. It is capable to be processed into products from both melt and solution. PLA is applied in medicine, pharmacy, agriculture as well as in textile industry, packaging industry, paper lamination and food industry, etc. [1,2].

Polylactides modification can significantly expand the areas of its application also improve their properties [3,4]. Therefore, the research on the creation of modified PLA is relevant.

In the work the fundamentals of derivation technology of the modified polylactide materials with adjustable properties of the special purpose are developed.

The research was conducted in two directions: 1 - creation of modified PLA film materials for the packaging industry and paper lamination; 2- new porous modified PLA matrices development for application in medicine, in particular for osteoplasty.

To directly influence on the properties of PLA materials, its structure and morphology the polylactides were modified with glycerol and polyvinylpyrrolidone as well as by physical action, in particular, heat treatment.

At the first stage, the peculiarities of film formation on the basis of molified PLA by watering from the solution were researched. The given method made it possible to combine the process of film formation with subsequent modification of the properties of the initial polymers in the system. To improve the elasticity of the forming films the plasticizers, in particular glycerol, were added into the polymer solution. The selection of optimal solvent for the film formation by watering, namely chloroform was conducted. Concentration, temperature and time modes of the formation of modified PLA films are substantiated.

The influence of the solvent nature on viscosity characteristics of PLA solutions has been studied. Chloroform affects the crystallinity of films owing to conformational changes. Based on the conducted viscosity studies the molecular weight of PLA of the different brands, which are being applied for film formation, was determined.

The structure of films depends on the velocity and time of the solvent evaporation. The kinetics of solvent evaporation at the different temperature and time conditions has been studied. At a temperature of $50{ }^{\circ} \mathrm{C}$ there is a rapid evaporation of chloroform from the solution. Right away after 15 minutes from the beginning of evaporation the solvent almost does not remain. Evaporation of chloroform from PLA solutions and PLA blends with glycerol occurs at almost the same velocity.

By the SEM studies it is confirmed that the surface morphology of composite films with PLA is being determined via many factors, in particular, the nature of the polymer, the content and nature of the

$3^{\text {rd }}$ INTERNATIONAL SCIENTIFIC CONFERENCE “CHEMICAL TECHNOLOGY AND ENGINEERING”, JUNE 21-24 ${ }^{\mathrm{TH}}, 2021$, LVIV, UKRAINE 
plasticizer, the temperature of the molding modes. Through the changing of mentioned factors, it is possible to influence on the structure of composites and their properties.

Infrared spectroscopic studies of PLA films, which are modified as well as heat-treated were performed that was confirmed an existence of absorption bands which are typical for PLA. The film's spectra based on PLA and glycerol blends confirm the presence of -OH group on the absorption spectrum.

According to thermal analysis, it was found that samples based on PLA and PLA with glycerol blends are characterized by high heat resistance and thermal resistance. The beginning of intensive mass loss of the samples caused by deep destructive and thermo-oxidative processes shifted to the diapason of high temperatures $\left(265^{\circ} \mathrm{C}\right.$ and above).

Influence of the conditions of film formation, glycerol amount, nature of PLA on physicalmechanical and elastic-deformation properties of modified PLA materials has been researched. The most strength films were formed applying the Luminy LX175 PLA.

An important modern direction of PLA composites usage is medicine. The features of porous matrices formation based on PLA in the presence of polyvinylpyrrolidone have been studied. The total porosity of the obtained composites is $70 \ldots 80 \%$, the total pore diameter is $280 \ldots 1000 \mu \mathrm{m}$. Since PLA composites do not satisfy the requirements concerning fungibactericidal properties, therefore in the given work it was modified with polyvinylpyrrolidone which can be used as a reducing agent during silver nanoparticles derivation in the composites [5-7].

A comparative analysis of the bactericidal and fungicidal properties of composites containing silver nanoparticles obtained by the PVP reduction reaction and non-silver-containing composites showed that composites containing silver nanoparticles block the growth of bacteria and fungi, demonstrating the fungibactericidal ability.

\section{References}

[1] Muller, J., González-Martínez, Ch., Chiralt, A. (2017). Combination of Poly(lactic) Acid and Starch for Biodegradable Food Packaging. Materials, 10(8), 952-974. doi: 10.3390/ma10080952.

[2] Malinconico, M., Vink, E., Cain, A. (2018). Industrial Applications of Poly(lactic acid). Cham: Springer International Publishing AG.

[3] Semenyuk, N., Kostiv, U., Suberlyak, O., Skorokhoda, V. (2013). Peculiarities of Filled Porous Hydrogels Production and Properties. Chemistry and Chemical Technology, 7(1), 95-99. doi: 10.23939/chcht07.01.095.

[4] Wei, L., Luo, S., McDonald, A. G., Agarwal, U. P., Hirth, K. C. et al. (2017). Preparation and Characterization of the Nanocomposites from Chemically Modified Nanocellulose and Poly(lactic acid). Journal of Renewable. Materials, 5(5), 410-422. doi:10.7569/JRM.2017.634144.

[5] Skorokhoda, V., Semenyuk, N., Dziaman, I., Suberlyak, O. (2016). Mineral Filled Porous Composites Based on Polyvinylpyrrolidone Copolymers with Bactericidal Properties. Chemistry and Chemical Technology, 10(2), 187-192. doi: 10.23939/chcht10.02.187.

[6] Suberlyak, O. Skorokhoda, V., Kozlova, N., Melnyk, Yu., Semenyuk, N., Chopyk, N. (2014). The Polyvinylpyrrolidone Graft Copolymers and Soft Contact Lenses on Their Basis. Science Rise, 5(3/5), 52-57. doi: 10.15587/2313-8416.2014.33235.

[7] Skorokhoda, V., Dziaman, I., Dudok, G., Skorokhoda, T., Bratychak, M., \& Semenyuk, N. (2019). The Ultrasonic Effect on Obtaining and Properties of Osteoplastic Porous Composites. Chemistry and Chemical Technology,13(4), 429-435. doi: 10.23939/chcht13.04.429. 


\title{
Comparison of the adsorption capacity of methylene blue nanostructured composites based on $\mathrm{CoMnO}_{2}$ and $\mathrm{CuO}$
}

\author{
Olena Makido, Galyna Khovanets', Natalya Koretska \\ Department of PhChFF InPOCC NAS of Ukraine, UKRAINE, Lviv, Naukova Str., 3a, \\ E-mail: khovanets_galyna@ukr.net
}

\begin{abstract}
The adsorption kinetics of methylene blue dye from aqueous solutions of various concentrations on the surface of nanostructured magnetosensitive catalysts based on CoMnO2 and $\mathrm{CuO}$ have been studied. The kinetic parameters of the process have been investigated. The adsorption process is presented as a quasi-chemical process of displacement of solvent molecules by dye molecules from the adsorption layer. The equilibrium state is described by the Langmuir equation. The limiting adsorption of methylene blue was determined.
\end{abstract}

Keywords - "core-shell" type catalyst, methylene blue, Fenton system, kinetics, adsorption.

\section{Introduction}

One of the effective methods of wastewater treatment from organic pollutants is their catalytic oxidation by the Fenton process. The use of heterogeneous catalytic systems in the Fenton process, on the one hand, does not limit the access of reagents to the active centers, because the transition metal atoms are on the surface of the catalyst. On the other hand simplifies the process of removing the catalyst at the end of the process.

The composition of the nanostructured catalysts of the "core-shell" type developed by us based on transition metals includes a magnetically sensitive core of cobalt ferrite $\left(\mathrm{CoFe}_{2} \mathrm{O}_{4}\right)$ and a protective layer of porous $\mathrm{SiO}_{2}$. On the $\mathrm{SiO}_{2}$ surface, there are clusters of cobalt and manganese oxides $\left(\mathrm{CoMnO}_{2}\right)$ and copper oxide $(\mathrm{CuO})$, which play the role of catalytic centers. The presence of a layer of highly porous $\mathrm{SiO}_{2}$ due to its adsorption properties should lead to an increase in the concentration of reagents around the catalytic centers, which can increase the efficiency of the Fenton process.

This work presents the results of the study of the adsorption capacity of the synthesized catalysts $\mathrm{CoFe}_{2} \mathrm{O}_{4} / \mathrm{SiO}_{2} / \mathrm{CoMnO}_{2}$ and $\mathrm{CoFe}_{2} \mathrm{O}_{4} / \mathrm{SiO}_{2} / \mathrm{CuO}$ by the example of the adsorption of methylene blue (MB) dye from an aqueous solution.

\section{Results and discussion}

The kinetics and equilibrium state of adsorption of methylene blue by the composite were investigated using a spectrophotometer Spekol 11 under the following conditions: up to $5 \mathrm{ml}$ of a model solution with a defined initial concentration of MB $\left(2 \cdot 10^{-5}-5 \cdot 10^{-5} \mathrm{~mol} / \mathrm{L}\right)$ was added $10 \mathrm{mg}$ of catalyst as sorbent.

The obtained kinetic adsorption curves are Langmuir isotherms, which made it possible to calculate the main parameters of the MB adsorption process on the catalyst surface (Fig. 1). The optimal contact time, during which the saturation of adsorption centers with dye molecules occurs, is 50-60 minutes. The difference in the behavior of composites is primarily associated with the composition of the catalytic layer. The nature of the dependence of the adsorption efficiency for different adsorbate concentrations is similar for both samples, however, the adsorption efficiency is higher for the catalyst based on $\mathrm{CuO}$. This indicates its greater affinity for the selected dye. The adsorption kinetics parameters for this composite correspond to the proposed model of the pseudo-first order (Table 1). The adsorption process is presented as a pseudochemical equilibrium reaction of the displacement of solvent molecules by molecules of adsorbate from adsorption centers on the adsorbent surface [1]. 

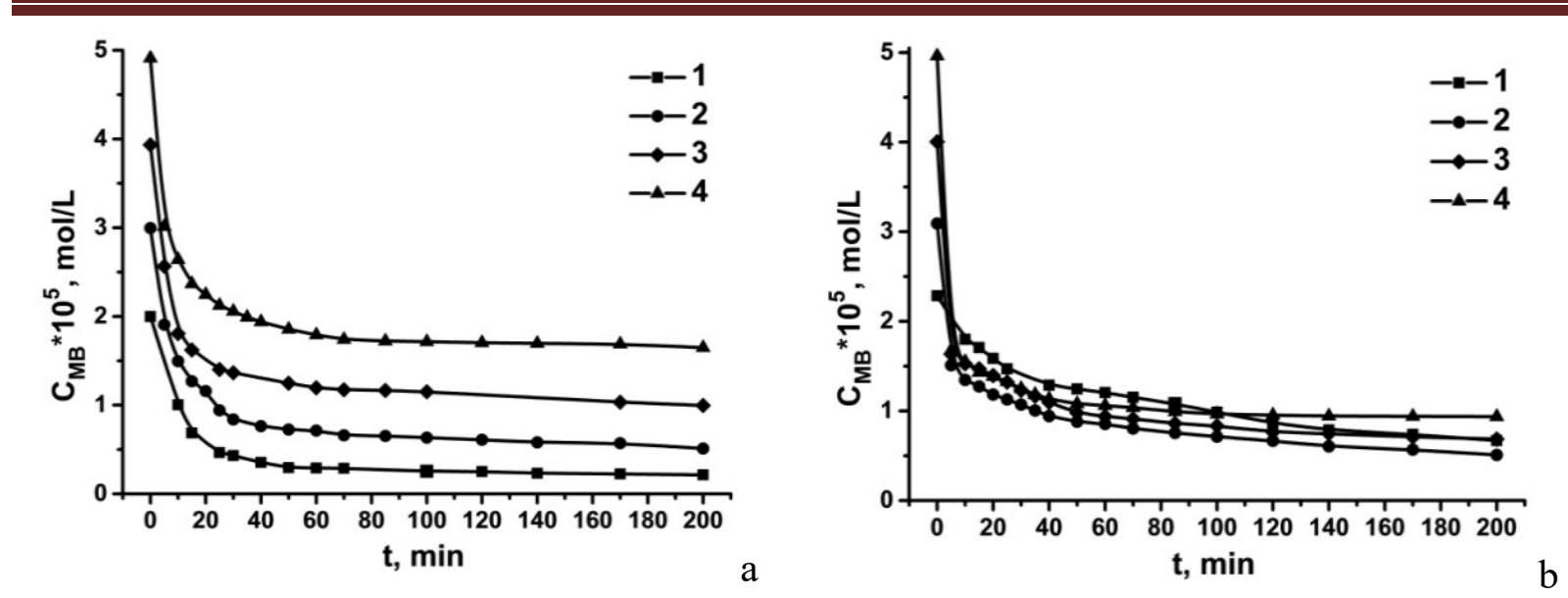

Fig. 1. Kinetic curves of the adsorption of methylene blue on the surface of the catalyst $\mathrm{CoFe}_{2} \mathrm{O}_{4} / \mathrm{SiO}_{2} / \mathrm{CoMnO}_{2}$ (a) and $\mathrm{CoFe}_{2} \mathrm{O}_{4} / \mathrm{SiO}_{2} / \mathrm{CuO}$ (b) at different initial concentrations of the dye $\mathrm{C}_{\mathrm{MB}}, \mathrm{mol} / \mathrm{L}: 1-2 \cdot 10^{-5} ; 2-3 \cdot 10^{-5} ; 3-4 \cdot 10^{-5} ; 4-5 \cdot 10^{-5}$.

Table 1

Kinetic parameters of MB adsorption on the surface of catalysts

\begin{tabular}{|c|c|c|c|c|c|c|c|c|c|c|c|}
\hline \multirow[b]{2}{*}{ No } & \multirow{2}{*}{$\begin{array}{r}\mathrm{C}_{0} \times 10 \\
\mathrm{~mol} / \mathrm{L}\end{array}$} & \multicolumn{5}{|c|}{$\mathrm{CoFe}_{2} \mathrm{O}_{4} / \mathrm{SiO}_{2} / \mathrm{CoMnO}_{2}$} & \multicolumn{5}{|c|}{$\mathrm{CoFe}_{2} \mathrm{O}_{4} / \mathrm{SiO}_{2} / \mathrm{CuO}$} \\
\hline & & $\begin{array}{l}\mathrm{k} \times 10^{-3} \\
\min ^{-1}\end{array}$ & $\ln \frac{a+C_{0}}{C_{0}}$ & $\begin{array}{l}\mathrm{a} \times 10^{5}, \\
\mathrm{~mol} / \mathrm{L}\end{array}$ & $\begin{array}{c}\mathrm{A} \times 10^{-4}, \\
\mathrm{~L} / \mathrm{mol}\end{array}$ & $\mathrm{R}^{2}$ & $\begin{array}{c}\mathrm{k} \times 10^{-3}, \\
\min ^{-1}\end{array}$ & $\ln \frac{a+C_{0}}{C_{0}}$ & $\begin{array}{l}\mathrm{a} \times 10^{5}, \\
\mathrm{~mol} / \mathrm{L}\end{array}$ & $\begin{array}{c}\mathrm{A} \times 10^{-4} \\
\mathrm{~L} / \mathrm{mol}\end{array}$ & $\mathrm{R}^{2}$ \\
\hline 1 & 2 & 1,09 & 1,12 & 3,80 & 1,7 & 0,98 & 3,0 & 0,85 & 2,9 & 2,0 & 0,96 \\
\hline 2 & 3 & 1,08 & 0,59 & 2,50 & 1,8 & 0,98 & 3,3 & 0,81 & 2,5 & 1,8 & 0,99 \\
\hline 3 & 4 & 1,05 & 0,36 & 1,55 & 1,8 & 0,96 & 3,4 & 0,71 & 2,1 & 1,6 & 0,99 \\
\hline 4 & 5 & 1,03 & 0,13 & 0,60 & 1,8 & 0,93 & 3,4 & 0,54 & 1,6 & 1,5 & 0,98 \\
\hline
\end{tabular}

The equilibrium data were analyzed using the Langmuir model. It provides for the adsorption of a monolayer on the surface, which contains a finite number of adsorption centers with homogeneous energies without adsorbate movement in the surface plane [1].

The plots constructed from the experimental

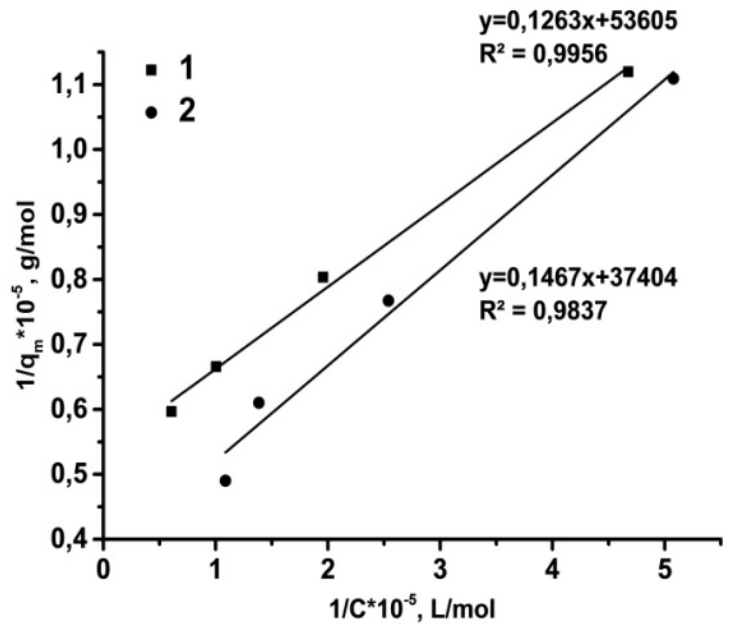

Fig. 2. Linearized Langmuir adsorption isotherms: $\mathrm{CoFe}_{2} \mathrm{O}_{4} / \mathrm{SiO}_{2} / \mathrm{CoMnO}_{2}(1)$ and $\mathrm{CoFe}_{2} \mathrm{O}_{4} / \mathrm{SiO}_{2} / \mathrm{CuO}(2)$ data for both samples (Fig. 2) demonstrated that the adsorption isotherms of methylene blue on the catalyst surface within a certain concentration range are well described by the proposed equation $\left(\mathrm{R}^{2}=0,99\right)$.

Carrying out investigations showed that with 30 minutes of adsorption before adding the oxidizing agent to the reactor, the completeness of the dye destruction increases by $13 \%$.

\section{Conclusion}

It has been determined that the adsorption of a dye from an aqueous solution can be represented as a pseudochemical reaction of the displacement of solvent molecules by adsorbate molecules from adsorption centers on the 
adsorbent surface. The results are described by the proposed pseudo-first order equation. The investigated adsorption properties of catalysts have a positive effect on the process of oxidative destruction of MB.

\section{References}

[1] Makido, O.Yu., Medvedevskikh, Yu.G., Khovanets', G.I. (2020). Investigation into the adsorption of methylene blue on the surface of a «core-shell» type catalyst for the Fenton system. Voprosy khimii $i$ khimicheskoi tekhnologii, 6 (133), 91-98. http://dx.doi.org/10.32434/0321-4095-2020-133-6-91-98 


\title{
Activity of Magnetically Separable Catalyst $\mathrm{Fe}_{3} \mathrm{O}_{4}$ in Fenton Type Reaction during Methyl Violet Discoloration
}

\author{
Sheparovych Roman, Opeida Lubov
}

\begin{abstract}
Department of Physical Chemistry of Fossil Fuels InPOCC, National Academy of Sciences of Ukraine, Naukova str/3a, 79060 Lviv, UKRAINE, E-mail: sheparomko@ukr.net, li.opeida@gmail.com
\end{abstract}

\begin{abstract}
The efficiency of the magnetoseparable $\mathrm{Fe}_{3} \mathrm{O}_{4}$ catalyst in a Fenton-type reaction of methylene violet discoloration has been studied. It was shown that reaction process consists of two stages: rapid-adsorption of the dye on the $\mathrm{Fe}_{3} \mathrm{O}_{4}$ and slower - its oxidation with $\mathrm{H}_{2} \mathrm{O}_{2}$.
\end{abstract}

Keywords - magnetoseparable catalyst, methylene violet, hydrogen peroxide, Fenton-type reaction.

\section{Introduction}

Finding ways to treat wastewater from organic pollutants and products of their transformation in natural conditions remains an urgent problem. Among the purification methods, one can be distinguish destructive approach based on the deep redox transformations initiated by various oxidants $\left(\mathrm{O}_{2}, \mathrm{O}_{3}, \mathrm{H}_{2} \mathrm{O}_{2}\right)$. Fenton's reagent $\mathrm{Fe}$ (II) and hydrogen peroxide in aqueous solution has long been known for its oxidizing properties. Fenton system is widely used in wastewater treatment and recovery in various industries. However, most these techniques suffer from irreversible loss of its valuable components used in the process. Therefore, the search for advanced and economically efficient methods, that would allow contaminant removal and regeneration of its components, is one of the areas of development of wastewater treatment technology. Promising in this direction is the use of magnetically separable catalysts, which can be easily separated from the purified medium and reused.

\section{Results and discussion}

Magnetically separable catalyst $-\mathrm{Fe}_{3} \mathrm{O}_{4}$, was synthesized by coprecipitation of salts of $\mathrm{Fe}^{2+}$ and $\mathrm{Fe}^{3+}$ with sodium hydroxide in aqueous medium, $\left[\mathrm{Fe}^{2+}\right]:\left[\mathrm{Fe}^{3+}\right]=1: 2$. The activity of the obtained catalyst was studied by the kinetic method. under Fenton-type reaction conditions. The destruction of the dye - methyl violet (MV), was monitored by photocolorimetric determination of the change in optical density (D) of the band with a wavelength $(\lambda)$ of $540 \mathrm{~nm}$ in quartz cuvettes with a thickness of (1) $5 \mathrm{~mm}$. The studies were performed in the concentration range, where no deviations from the Bouguer-Lambert-Ber law were observed.

The effects of various parameters on the oxidation reaction of the dye were investigated: $\mathrm{pH}$, temperature, stirring rate, catalyst deposition rate on the magnet, initial concentrations of $\mathrm{Fe}_{3} \mathrm{O}_{4}, \mathrm{H}_{2} \mathrm{O}_{2}$ and methyl violet. The optimal conditions for the process were determined: $\mathrm{pH}=7$, $[\mathrm{MV}]=5.8 \times 10-5 \mathrm{~mol} / 1,\left[\mathrm{H}_{2} \mathrm{O}_{2}\right]=1.05 \times 10^{-2} \mathrm{M}, \mathrm{Fe}_{3} \mathrm{O}_{4}=0.075 \mathrm{~g}, 25^{0} \mathrm{C}$.

A sharp drop in the optical density of the reaction mixture in the first minutes of the Fenton-type reaction (when mixing a methyl violet dye with a $\mathrm{Fe}_{3} \mathrm{O}_{4} / \mathrm{H}_{2} \mathrm{O}_{2}$ reagent) is shown, which is difficult to quantify. Discoloration of the dye solution with a catalyst without hydrogen peroxide also occurs with a significant decrease in the optical density of the methyl violet solution in the first minutes after the addition of $\mathrm{Fe}_{3} \mathrm{O}_{4}$, which can be explained by the adsorption of part of the dye on the catalyst (Fig. 1).

The obtained kinetic data allow distinguishing the contribution of dye adsorption on the catalyst (Fig. 1, a) and the contribution of the Fenton-type reaction (Fig. 1, b) to the methylene violet discoloration. 


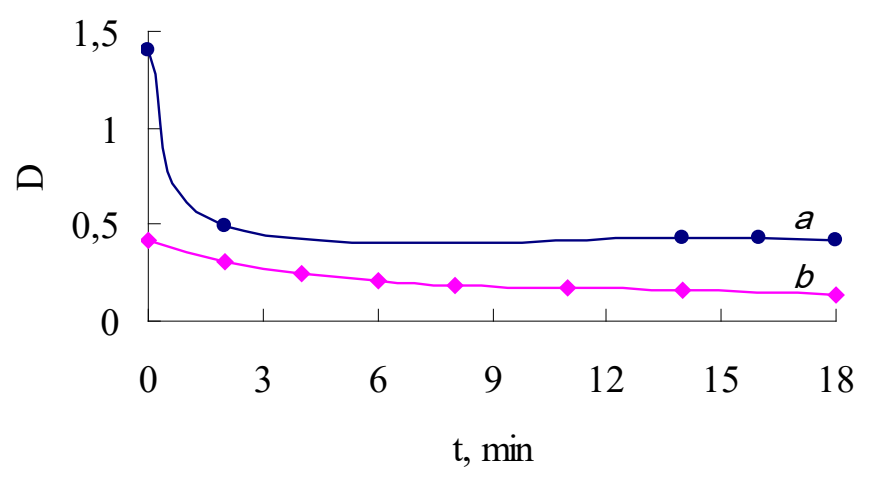

Fig.1. The changes in the optical density of the MV solution (D) after the addition of $\mathrm{Fe}_{3} \mathrm{O}_{4}$ due to adsorption (a) and in the reaction $\mathrm{Fe}_{3} \mathrm{O}_{4}$ with $\mathrm{H}_{2} \mathrm{O}_{2}$ (b). $[\mathrm{MV}]=5.8 \cdot 10^{-5} \mathrm{M}, \quad\left[\mathrm{H}_{2} \mathrm{O}_{2}\right]=$

$$
1.05 \cdot 10^{-2} \mathrm{M}, \mathrm{Fe}_{3} \mathrm{O}_{4}=0.075 \mathrm{~g} . \lambda=540 \mathrm{~nm}, 1=5 \mathrm{~mm}, 25{ }^{\circ} \mathrm{C}
$$

Table 1

Dependence $\left(\mathrm{D}_{\mathrm{o}}-\mathrm{D}_{\mathrm{ads}}\right)$ in the absence of $\mathrm{H}_{2} \mathrm{O}_{2}$ and the initial rate of discoloration of $\mathrm{MV}$, $\left(\mathrm{W}_{0}\right)$. Reduced to Dads in the discoloration of the dye in the system $\mathrm{Fe}_{3} \mathrm{O}_{4}+\mathrm{H}_{2} \mathrm{O}_{2}$, on the content of $\mathrm{Fe}_{3} \mathrm{O}_{4}$ in the solution $[\mathrm{MV}]=5.8 \cdot 10^{-5} \mathrm{M}$, where $\mathrm{D}_{\text {ads }}$ - optical density of the MV solution after its adsorption on the catalyst, $\mathrm{D}_{0}$ - optical density of the initial solution MV.

\begin{tabular}{|c|c|c|}
\hline$\left(\mathrm{Fe}_{3} \mathrm{O}_{4}\right), \mathrm{g}$ & $\mathrm{D}_{\mathrm{o}}-\mathrm{D}_{\text {ads }}$ & $\mathrm{W}_{0 .} / \mathrm{D}_{\text {ads }}$ \\
\hline & {$\left[\mathrm{H}_{2} \mathrm{O}_{2}\right]=0 \mathrm{M}$} & {$\left[\mathrm{H}_{2} \mathrm{O}_{2}\right]=1.05 \cdot 10^{-2} \mathrm{M}$} \\
\hline 0.005 & 0.20 & 0.050 \\
\hline 0.01 & 0.30 & 0.059 \\
\hline 0.02 & 0.45 & 0.072 \\
\hline 0.05 & 0.72 & 0.102 \\
\hline 0.075 & 0.93 & 0.131 \\
\hline
\end{tabular}

The data presented in Table 1 show that there is a linear relationship of the decrease in the optical density of MV ( $\left.D_{o}-D_{\text {ads }}\right)$, ie the amount of adsorbed dye, and the amount of catalyst in the absence of hydrogen peroxide

$$
\mathrm{D}_{\mathrm{o}}-\mathrm{D}_{\mathrm{ads}}=10.071 \times\left[\mathrm{Fe}_{3} \mathrm{O}_{4}\right]+0.1977, \mathrm{R}^{2}=0.9841
$$

This dependence allows us to estimate the contribution of the reaction of hydrogen peroxide with MV. According to the experimentally obtained kinetic data, the initial rate of MV oxidation was determined, and it was calculated on the initial linear section of the kinetic curve. The dependence of the initial discoloration rate of $\mathrm{MV}$ divided by $\mathrm{D}_{\mathrm{o}}$ on the catalyst content is well described by the linear dependence with coefficient $\approx 1$ at $\left[\mathrm{Fe}_{3} \mathrm{O}_{4}\right]$

$$
\mathrm{W}_{0 .} / \mathrm{D}_{\text {ads }}=1.1197 \times\left[\mathrm{Fe}_{3} \mathrm{O}_{4}\right]+0.047, \quad \mathrm{R}^{2}=0.9963
$$

This indicates the first order reaction on the MV dye in the catalytic process of it oxidation.

\section{Conclusion}

The high efficiency of the magnetoseparable $\mathrm{Fe}_{3} \mathrm{O}_{4}$ catalyst in a Fenton-type reaction has been established. Studies of the kinetics of methylene violet discoloration in reaction with $\mathrm{Fe}_{3} \mathrm{O}_{4}$ and $\mathrm{H}_{2} \mathrm{O}_{2}$ show that the process consists of two stages: rapid - adsorption of the dye on the catalyst and oxidation of the dye with hydrogen peroxide under the action of a heterogeneous catalyst. 


\section{Biosynthesis of silver nanoparticles using extracts of medicinal plants}

Kateryna Yatskiv, Diana Zahorodnia, Romana Petrina, Semen Khomyak, Viktoriya Havryliak

Lviv Polytechnic National University, UKRAINE, Lviv 79013, E-mail: kateryna.yatskiv.mbt.2020@lpnu.ua

Abstract - Synthesized silver nanoparticles using extracts of Calendula officinalis and Arnica montana callus biomass. It is shown that the rate of nanoparticle formation is influenced by plant cultivation conditions. It was found that in the presence of an extract obtained from callus, the process of nanoparticle formation occurs rapidly. The synthesized silver nanoparticles were studied by spectroscopy.

Keywords - nanoparticle, csllus biomass, Calendula officinalis, Arnica montana, extract, polyphenols.

\section{Introduction}

Nanoparticle (NPs) biosynthesis is environmentally friendly, without the use of harmful chemicals, has a low cost, has no by-products and contaminants. Plant extracts are an interesting medium for NPs synthesis because they contain many biologically active compounds, such as flavonoids, alkaloids, saponins, steroids, terpenoids, which act as reducing agents and stabilizers. With this method you can get a woofer of controlled size and shape, which is important for further use in medicine and cosmetology. We used medicinal plant extract, which contains high levels of polyphenols.

The aim of study is to obtain silver nanoparticles (AgNPs) in the medium of an aqueous extract of Calendula officinalis and Arnica montana callus biomass.

\section{Results}

The ability of calluss biomass to accumulate secondary metabolites opens the possibility of using it for extracts. For all the studied plants, the conditions were selected and the nutrient medium was optimized under which the maximum amount of biomass was formed.

The methodology of biotechnological research is based on conventional classical methods of working with the culture of isolated tissues of plants. Cultivation was carried out on various modifications of Murashige-Scoog (MS) medium with the addition of phytohormones. The cultivation was carried out with a light of $2000 \mathrm{~lx}$, a photoperiod of 16 hours, a temperature of $20-26^{\circ} \mathrm{C}$, humidity of $60-70 \%$.

The synthesis was carried out in an aqueous extract of $C$. officinalis and A. montana callus biomass. $250 \mathrm{ml}$ of bidistilled water and $10 \mathrm{~g}$ of biomass of plant were used, the solution was boiled for $10 \mathrm{~min}$, filtered and added to $1 \mathrm{mM} \mathrm{AgNO} 3$ solution $(1: 10, \mathrm{~V} / \mathrm{V})$, stirred at $35^{\circ} \mathrm{C}$ on a magnetic stirrer. The solution was incubated at $60{ }^{\circ} \mathrm{C}$ for 24 hours in the dark. AgNPs were investigated by spectroscopy.

The color of the extract changes from light yellow to brown after about 15 minutes of stirring, indicating the formation of AgNP. Absorption in the UV spectrum was not observed for AgNO3 solution. The absorption peak of the aqueous extract of $C$. officinalis and A. montana was detected at $325 \mathrm{~nm}$. Absorption of a solution containing leaf extract and AgNP was determined after 5, 10, 15 and 20 minutes. The peak absorption of the solution was observed at $420 \mathrm{~nm}$ after 15 minutes, indicating the presence of AgNP.

\section{Conclusion}

Biosynthesis of AgNPs in C. officinalis and A. montana callus biomass extract was performed. The presence of AgNPs was confirmed visually and by spectrophotometry. The process of nanoparticle formation depending on the cultivation conditions was also studied and their antimicrobial activity was studied. 


\title{
Improving the Technology of Bitter Tinctures
}

\author{
Iryna Sokolovska, Roman Zherebetskyi, Oksana Orobchuk, Roman Subtelnyi
}

Department, of Technology of Organic Products, Lviv Polytechnic National University, UKRAINE, Lviv, S. Bandery street 12, E-mail: oksana.m.orobchuk@lpnu.ua, iryna.sokolovska.mxr.2020@lpnu.ua

\begin{abstract}
Improving the technology of bitter tinctures have been investigated. The new recipe for the drink have been proposed. In order to improve the traditional scheme of extraction of aromatic raw materials, the use of the extractor with a rotary pulsation pump have been proposed.
\end{abstract}

Keywords - extraction, bitter tincture, rotary-pulsation extractor, ethanol, technology, juniper, thorns, echinacea.

\section{Introduction}

One of the main stages in the manufacture of tinctures is extraction. Extraction is the process of extracting substances from raw materials using an extractant, the process is based on the difference in the coefficients of distribution of extractives between the phases of liquid and solid [1]

Good solvent are methanol, ethanol, acetone, water and ethyl acetate. But when choosing an extractant for the production of bitter tincture, it must meet the requirements: the extractant must not mix with the extraction raw material, well dissolve the target compounds and do not dissolve impurities, no toxicity to humans. Given all the above requirements, ethanol is used as an extractant, because it is a universal solvent, due to its molecular structure is able to dissolve polar hydrophilic and non-polar hydrophobic compounds [2].

A complex extraction process is a combination of a number of processes: wetting, swelling, dissolution, chemical interaction, adsorption, desorption, diffusion, dialysis. There are three main stages:

- impregnation of vegetable raw materials with extractant is carried out due to capillary forces;

- $\quad$ swelling and dissolution of plant cell components;

- mass transfer is the process of transition of a substance from one phase to another [3].

The extraction process can be accelerated by increasing the contact area of the phases, the porosity of the extractive layer, creating the optimal ratio of extractant and extractive raw materials, increasing the temperature, ensuring the dynamic movement of the extractant.

In the process of making extracts for tinctures usually use the method of classical maceration. The essence of which is that the extraction raw material is poured into a container, filled with extractant and infused for 5 - 10 days. Obtaining the extract by this method requires a significant amount of time and the resulting extract is low in concentration. That is why other extraction methods have started to be used in the industry, namely: extraction with the use of ball mills, extraction with the use of rotary pulsation devices, extraction with liquefied gases, filtration extraction, etc. [4].

The use of a rotary pulsation extractor and a new formulation of the drink is proposed in order to improve the process of making bitter tincture.

The search and characterization of new methods of improving the process of making bitter tinctures, development of new recipes for bitter tinctures using local raw materials was the aim of research. 


\section{Results and Discussion}

Bitter tinctures are an alcoholic beverage obtained by extracting spicy-aromatic raw materials with alcohol or water. A significant number of modern brands of bitter tinctures have been created as medicines. But due to their spicy bitter-sweet and harmonious taste, they began to be often used in cocktails and as aperitifs [5].

After analyzing the existing recipes for bitter tinctures, a new recipe for the drink is proposed, which will include components of local origin, namely juniper, thorns, echinacea, apple and pear leaves. This raw material has not only good spicy-aromatic properties, but also contains a significant number of useful elements, especially ascorbic acid.

In order to improve the traditional scheme of extraction of spicy-aromatic raw materials, it was decided to use an extractor with a rotary pulsation pump, which will ensure the constant movement of the extractant through the extractive layer. Aromatic raw materials are loaded into the extractor through the upper hatch, then the extractant (ethanol) is fed. The extraction process is carried out by continuously pumping the extractant from the bottom of the extractor to the top. Thus the maximum degree of release of aromatic substances from vegetable raw materials in a short time is reached.

This method allows you to get the finished extract in two days, not 5 - 10. Accelerated extraction allows you to more efficiently use the resources of the entire production equipment.

\section{Conclusion}

An improved scheme for the production of bitter tinctures is proposed and the cost coefficients per 1 dal of drink are calculated. Selected innovations allow to reduce the extraction time and, in turn, the production time of the finished drink from 250 to 175 days. Due to the intensification of all processes, the cost of wages to employees is reduced and it is possible for the company to produce a wider range of products. Local raw materials are cheaper and more affordable, which has a positive effect on the cost of the finished drink. Selected innovations reduce the extraction time and, in turn, the time off.

\section{References}

[1] Diachok, V.V. (2010). Scientifically are theoretical bases of extracting from a medical vegetal raw material. Thesis for a doctor of technical sciences degre. Kyiv, $41 \mathrm{p}$.

[2] Zubrick, J.W. (2014). The organic chem lab survival manual: a student's guide to techniques. Hoboken: John Wiley \& Sons, 346 p. ISBN 9781118083390.

[3] Kazarynov, M.O., Kabachna, A.V. (2015). Praktykum z promyslovoi tekhnolohii likarskykh zasobiv. NFaU, 374 p.

[4] Handa, S.S., Khanuja, S.P.S., Longo, G., Rakesh, D.D. (2008). Extraction Technologies for Medicinal and Aromatic Plants. International centre for science and hightechnology. Trieste, $266 \mathrm{p}$.

[1] Ramalakshmi, K., Raghavan, B. (1999). Caffeine in Coffee: Its Removal. Why and How? Critical Reviews in Food Science and Nutrition, 39 (5), 441-456. doi:10.1080/10408699991279231. ISSN 1040-8398. 


\title{
Application of the method od discrete input pulse energy for energy-efficient production of chelidonium majus extract
}

\author{
$\underline{\text { Liubov Gozhenko }}^{1}$, Georgii Ivanitskyi ${ }^{1 ; 2}$, Bogdan Tselen ${ }^{1}$, \\ Natalia Radchenko ${ }^{1}$, Anna Nedbailo ${ }^{1}$ \\ ${ }^{1}$ Department of Heat and Mass Transfer in Dispersed Systems, Institute of Engineering Thermophysics of \\ the National Academy of Sciences of Ukraine, UKRAINE, Kyiv, 2a, Maria Kapnist Str, E-mai: ittf_tds@ukr.net \\ ${ }^{2}$ Department of Machines and Apparatus of Chemical and Oil Refinery Productions, National Technical University \\ of Ukraine "Igor Sikorsky Kyiv Polytechnic Institute", UKRAINE, Kyiv, 39, Politekhnichna Str., \\ E-mai: gergey4@gmail.com
}

\begin{abstract}
The paper is devoted to the application of the method of discrete input pulse energy (DIPE), which today is one of the most effective ways to achieve high energy performance in food and chemical technologies. The results of experimental studies of aqueous extraction of chelidonium majus using the method of DIPE are presented. Physico-chemical parameters of the aqueous extract of chelidonium majus depending on the temperature of treatment are given.
\end{abstract}

Keywords - the method of discrete input pulse energy, cavitation, extraction, chelidonium majus.

\section{Introduction}

The main task of developing energy efficient technologies is to increase the technical and economic indicators of raw material processing. In particular, increasing the productivity of equipment and reducing energy consumption for technological operations involves the creation and implementation of efficient devices with low specific energy and material consumption, a high degree of impact on the processed substances. Economic, rational, resource-saving and energy-efficient production of biologically active components of natural origin for further use in various industries always remains an urgent problem. The work is devoted to a comprehensive study of technological modes of obtaining biologically active components on the example of chelidonium majus, as its aqueous extract has simultaneous antimicrobial, phagocytic, mitotic and antioxidant activity and is widely used. Experimental studies of the chelidoniun majus extraction process were performed on an apparatus using the method of DIPE developed at the Institute of Engineering Thermophysics of the National Academy of Sciences of Ukraine. This device is one of the modifications of pulsation devices with an active membrane, which has been tested as the energy-efficient cavitation pulsation-type reactor.

\section{Research results}

The extraction process using only intensive mixing of the medium provides a condition for increasing the convective diffusion coefficient to infinity, ie convective mass transfer is instantaneous, and the mass transfer coefficient is determined only by the diffusion coefficient in the pores of vegetable raw materials. Initiation of the cavitation mechanism during processing in the reactor leads to a significant acceleration of the process at its slowest stage, ie allows to influence the internal diffusion coefficient. Due to the intense oscillation of the particles of the system "solid - liquid" in places of friction there is a local increase in temperature, a decrease in the viscosity of the extractant, and hence an increase in the internal diffusion coefficient. Since the study was performed using an apparatus in which the processes of dispersion and extraction are implemented simultaneously, to obtain an uncontaminated extract of celandine grass raw material was loaded crushed to the optimal size $l=3 \div 5 \mathrm{~cm}$. In the course of research it was found that with less fine grinding the number of ruptured cells increases sharply. This causes the leaching of concomitant substances that contaminate the water system (proteins, mucus, pectin

$3^{\text {rd }}$ INTERNATIONAL SCIENTIFIC CONFERENCE “CHEMICAL TECHNOLOGY AND ENGINEERING”, JUNE 21-24 ${ }^{\mathrm{TH}}, 2021$, LVIV, UKRAINE 
and other macromolecular compounds), which is visually observed during processing. As the result of the conducted experimental researches water systems not turbid which are easily filtered are received. Based on the analysis of economic and technological aspects of testing the process of extraction of celandine grass were carried out at temperatures of $6{ }^{\circ} \mathrm{C}$ and $27{ }^{\circ} \mathrm{C}$ and hydromodule 1:8. Samples of the water system were taken during treatment with a five-minute interval for further determination of physicochemical properties using the measuring complex EZODO PCT-407. In all selected samples, the value of the hydrogen index was within $\mathrm{pH}=6,5 \div 6,78$.

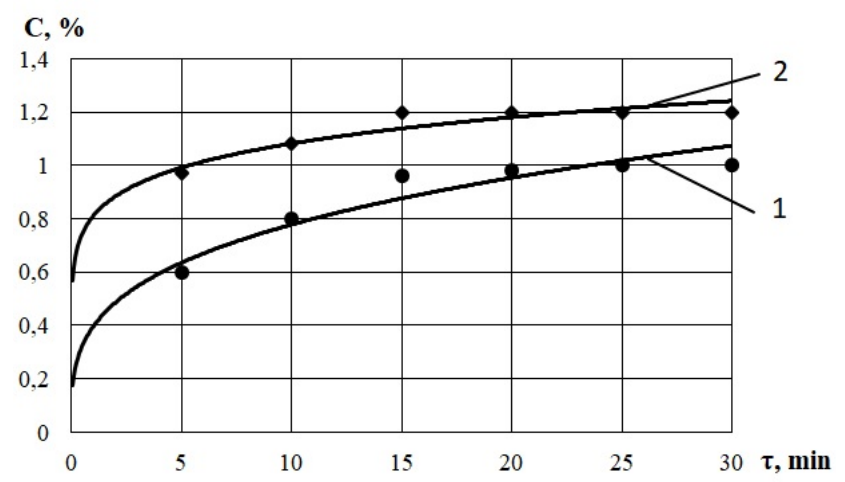

a)

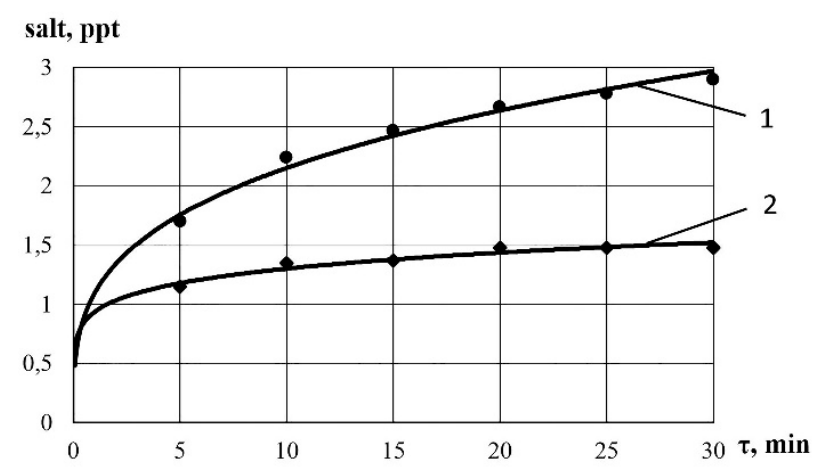

b)

Fig. 1. Dependence of the amount of dry matter (a) and salt content (b) in the aqueous extract of chelidonium majus from the duration of processing at temperatures: $1-6^{\circ} \mathrm{C} ; 2-$ $27{ }^{\circ} \mathrm{C}$.

Determination of the amount of dry matter in the obtained samples was performed in accordance with GOST 28561-90. The obtained results are shown in fig 1 a. The presented dependences show that $15 \mathrm{~min}$ treatment in a cavitation reactor provides equilibrium of concentrations of target substances in the raw material and extract at a temperature of $6{ }^{\circ} \mathrm{C}$ and $27^{\circ} \mathrm{C}$. However, the value of salt content in fig. $1 \mathrm{~b}$ at an extraction temperature of $27^{\circ} \mathrm{C}$ are more stable than in the samples obtained at $6^{\circ} \mathrm{C}$. This can be explained by the unsaturation of the solution at a temperature of $6^{\circ} \mathrm{C}$, because during the extraction process there is a significant local increase in temperature and, accordingly, an increase in the internal diffusion coefficient. At a temperature of $27^{\circ} \mathrm{C}$ of the medium, a moderate local increase in temperature was observed. However, in both cases the medium was heated due to the use of the method of DIPE and the implementation of its most powerful cavitation mechanism.

Note that during the research, the temperature of $27^{\circ} \mathrm{C}$ was maintained throughout the processing period, which is, accordingly, additional energy consumption. Instead, the temperature of $6^{\circ} \mathrm{C}$ did not have to be maintained. It was a constant temperature of the water system at room temperature. However, a relatively maximum yield of dry matter $(1,2 \%)$ can be achieved at a constant ambient temperature of $27^{\circ} \mathrm{C}$.

So, comparing fig. $1 \mathrm{a}$ and fig. $1 \mathrm{~b}$, it is possible to substantiate the obtained indicators of physicochemical parameters against the background of the quantitative composition of the target substances in the system depending on the duration of processing in the cavitation reactor pulsation type. The difference is obtained $\Delta C=\left(C_{2}-C_{1}\right), \%$ is an inversely proportional value corresponding to the differences in fig. $1 \mathrm{~b}$, which indicates a more intense course of redox reactions in the system using a cavitation mechanism at $6{ }^{\circ} \mathrm{C}$ than when maintaining a temperature of $27^{\circ} \mathrm{C}$. The measured values of the redox potential (ORP) differ by an order of magnitude depending on the temperature effect on the medium when initiating the cavitation mechanism. However, to describe the quality of the resulting aqueous system, saturated with 
target substances, it is necessary to have data on biological and chemical parameters in oxidative reactions. It is well known that the oxygen content in water is inverse with respect to temperature, ie with its increase always decreases. Local temperature increase due to the implementation of the cavitation mechanism in the system leads to the release of oxygen. A decrease in ORP indicates an increase in renewable substances in the system, and its growth oxidative. Accordingly, it is possible to influence the relaxation of the ORP through cavitation treatment. Due to the cavitation effect on the environment, the decrease in the value of ORP is proportional to the decrease in pressure pulses.

\section{Conclusion}

The dynamic effects of hydrodynamic cavitation, which are inherent in the pulsation type reactor, have different effects on water systems during the extraction process depending on the duration of processing and temperature regimes. The obtained values of physico-chemical parameters allow to evaluate the efficiency of the extraction process using the cavitation mechanism. The $\mathrm{pH}$ value of the aqueous extract of celandine for $30 \mathrm{~min}$ meal at temperatures of $6{ }^{\circ} \mathrm{C}$ and $27^{\circ} \mathrm{C}$ were in the range of $\mathrm{pH}=6.5 \div 6.78$. At a temperature of $6{ }^{\circ} \mathrm{C}$ there was an increase of about 1,5 times. Determining the amount of dry matter yield from the duration of treatment showed that 15 min cavitation effect on the medium during the extraction of celandine provides a balance of mass concentrations of the system "solid - liquid", which reduces the duration of the extraction of target substances without additional heating to boiling point.

The technology of obtaining plant extracts at room temperature is important for the extraction of thermolabile substances, which ensures the optimal use of cavitation mechanisms in mass transfer devices.

\section{References}

[1] Dolinskyi, A. A., Ivanitskyi, G. K. (2008). Teplomassoobmen i hidrodinamika v parozhidkostnykh dispersnykh sistemakh. Teplofizicheskie osnovy diskretno-impulsnoho vvoda enerhii [Heat and mass transfer and hydrodynamics in vapour-liquid disperse systems], Naukova dumka, Kyiv, Ukraine, 381 .

[2] Ivanitskyi, G. K., Gozhenko, L. P. (2014). Analiticheskoe issledovanie usloviy vozniknovenia kavitatsii $v$ trube pulsatsionnoho disperhatora udarnoho tipa [The analytical study of the conditions for cavitation in the tube of a pulsating dispersant of impact type]. Prom. teplotekhnika [Industrial heat engineering]. Kyiv: 36 (6), 5 - 12.

[3] Ivanitskyi, G. K., Chayka, O. I., Gozhenko, L. P. (2015). Zastosuvannia kavitatsiynoho reaktora pulsatsionnoho typu dlia ekstrahuvannia $z$ roslynnoi syrovyny [The use of pulsating cavitation reactor type for extraction of plant raw material]. Naukovi pratsi ONAKHT [Scientific Works]. Odesa: 2 (47), 138 - 142.

[4] Vitenko, T. M. (2009). Hidrodynamichna kavitatsia u masoobminnykh, chimichnykh $i$ biolohichnykh protsessakh [The hydrodynamic cavitation in mass transfer, chemical and biological processes]. Ternopil Ivan Puliuy National Technical University, Ternopil, Ukraine, 220.

[5] Basok, B. I., Novitskaia, M. P., Chayka, O. I. (2014). Hidrodynamika i teploobmen pri pnevmopulsatsionnom vozdeystvii na zhydkie sistemy [Hydrodynamics and heat transfer in case of pneumatic pulsation action on liquid systems], Kalyta, Kyiv, 140 . 


\title{
Hydrogels membranes obtained by modification in the volume
}

\author{
Nataliia Baran, Oleh Suberlyak, Oleksandr Grytsenko \\ Department of Plastic Engineering, Lviv Polytechnic National University, Ukraine, Lviv, 12, St. Bandera str., \\ E-mail: natabmk@ukr.net
}

\begin{abstract}
Synthesized composite hydrogel membranes based on copolymers of 2-hydroxyethyl methacrylate with polyvinylpyrrolidone, with simultaneous modification in volume with a solution of a mixture of polyamide-6 with polyvinylpyrrolidone, at different concentration of mass. The influence of water quantity on physical and mechanical properties and water absorption of the obtained membranes is investigated.
\end{abstract}

Keywords - hydrogel, hybrid, modification in the volume, 2-hydroxyethyl methacrylate, polyvinylpyrrolidone, polycaproamide.

\section{Introduction}

Due to the high water content and biocompatibility, nowadays the hydrogels attract a lot of attention and achieved a significant progress during the designing, synthesis and utilizing those materials for biological and biomedical application. The current studies include the development and synthesis of new hydrogels for their application in the tissue engineering, drug delivery and biotechnology [1].

2-hydroxyethyl methacrylate (HEMA) belongs to the basic raw materials for the hydrogels' formation. The high water content, biocompatibility and mechanical properties similar to the natural fabrics make the hydrogels especially attractive for the tissue engineering.

\section{Results and Discussion}

The composite membrane modification can be achieved in the surface layer and in the volume.

The membranes synthesized in the surface layer exhibit the improved strength, however, their obtaining method is toilful.

The forming of the homogeneous structure material is the most appealing method. The strengthening approach of the PVP/2-HEMA copolymeric matrix hydrogel by incorporating the PA-6/PVP polymeric matrix solution, which is characterized by the high strength, in the volume has been proposed.

The effect of the water amount in the initial reaction mixture on the physical mechanical properties and water content of the modified hydrid membranes, formed in the volume has been investigated.

\section{Conclusions}

It was defined that the deformation strengthening properties and water content of the synthesized hybrid membranes modified in the volume show the different physical mechanical properties, depend on the water amount in the initial composition. Additionally, in the majority cases those properties are higher than in the primary HEMA-PVP hydrogel films. It has been shown that the tension during the modified polymeric membranes pulling diminishes with the increase of the water amount in the reaction mixture, however, their elongation and water content rise.

\section{References}

[1]. Peppas, N. A., Hilt, J. Z., Khademhosseini, A., Langer, R. (2006). Hydrogels in biology and medicine: from molecular principles to bionanotechnology. Advanced Materials, 1(11), 13451360. doi: 10.1002/adma.20050161 


\title{
Kinetics of adsorption of iron ions (III) by natural zeolite
}

\author{
Vira Sabadash, Jaroslaw Gumnitsky \\ Department of Ecology and Sustainable Environmental Management, Lviv Polytechnic National University, \\ UKRAINE, Lviv, 12, S.Bandery St., 79013, E-mail: virasabadash@gmail.com
}

\begin{abstract}
- Abstract - The natural zeolite was used as adsorbent for Fe(III) removal from aqueous solution. The maximum adsorption capacity was $309.5 \mathrm{mg} \mathrm{Fe} / \mathrm{g}$ zeolite. The kinetic data were fitted to homogeneous micropore model and found that the mass transfer coefficient and diffusivity of the Fe ${ }^{2+}$ are directly affected by the kinetic parameters.
\end{abstract}

- Keywords - adsorption, masstransfer, kinetis, heavy metals, zeolite

\section{Introduction}

In the present work, application of natural zeolite was investigated for removal of heavy metals from water. Particularly for removal of iron ions from aqueous solution as a major contaminant that enters water by corrosion of household plumbing systems. The adsorption capacity of zeolite relative to heavy metal ions depends on the radius of the ion and its charge in the order $\mathrm{Pb}$ (II) $>\mathrm{Cr}(\mathrm{VI})>\mathrm{Cu}$ (II) $>\mathrm{Cr}$ (III) $>\mathrm{Zn}$ (II). Atom radii: $\mathrm{Pb}$ (II) $147 \mathrm{pm}(120 \mathrm{pm})>\mathrm{Cu}$ (II) $138 \mathrm{pm}(96 \mathrm{pm})>\mathrm{Zn}$ (II) $131 \mathrm{pm}(74 \mathrm{pm})>\mathrm{Cr} 127 \mathrm{pm}$ (III) $(65 \mathrm{pm})>\mathrm{Cr}$ (VI) (52 pm) ) and electronegativity by Pauling: $\mathrm{Pb}$ (II) (2.33)> Cu (II) (1.9)> Cr (VI)> (1.66) $\mathrm{Cr}$ (III) (1.66) $\mathrm{Zn}$ (II) (1.65). Thus, the adsorption capacity of zeolite relative to heavy metal ions depends on the ion radius and valence of the metal in the corresponding compound. Multicharged ions are best absorbed. The effects of adsorption kinetic parameters were tested in order to obtain the optimum kinetic parameter for minimizing the rate of adsorption of iron.

\section{Experimental}

Aqueous solutions of iron chloride of initial concentrations ranging from 10 to $500 \mathrm{mg} / \mathrm{dm}^{3}$ were prepared. Batch adsorption isotherms were performed for fixed particle size of zeolite $(<3 \mathrm{~mm})$. Using two sets of stopper bottles, equal weights of $0.1 \mathrm{~g}$ of the produced zeolite were added to $0.1 \mathrm{dm}^{3}$ of $\mathrm{Fe}^{3+}$ solution. Then the zeolite/ $\mathrm{Fe}^{3+}$ mixtures were placed in an isothermal shaker $\left(20 \pm 1^{\circ} \mathrm{C}\right)$ for 2 days to allow complete equilibration. Based on different nature of acidity of the produced zeolite, $\mathrm{pH}$ was adjusted by adding few drops of $\mathrm{NaOH}$ or $\mathrm{HCl}$. Batch adsorption kinetic studies were performed in a $1 \mathrm{dm}^{3}$ beaker with Plexiglas cover. This cover is attached with 4 Plexiglas baffles spaced around the circumference at $90^{\circ}$ to ensure smooth mixing without stagnant areas and vortex formation. Mixing was carried out using a two-blade stainless steel impeller driven by a variable speed motor. The experiments were established by adding a fixed weight of the produced zeolite into $0.5 \mathrm{dm}^{3}$ of known $\mathrm{Fe}^{3+}$ solution, and kept agitated for $180 \mathrm{~min}$. All experiments were carried out at ambient temperature $\left(20 \pm 1{ }^{\circ} \mathrm{C}\right)$ unless otherwise stated. Effect of stirring speed (200, 400 and $800 \mathrm{rpm})$ was also considered in the kinetic experiments. Samples were withdrawn at time interval of 0.5, 1, 2, 3, 5, 10, 20, 30 and 60 min using a fritted glass tube then centrifuged to remove the suspended particles. The resulting samples were analyzed using Thermo Element Atomic Absorption Spectrophotometer.

A graphical interpretation of the experimental data on the adsorption of iron with natural zeolite by the Langmuir isotherm for the area of initial concentrations up to $500 \mathrm{mg} / \mathrm{dm}^{3}$ is presented on Fig. 1. 


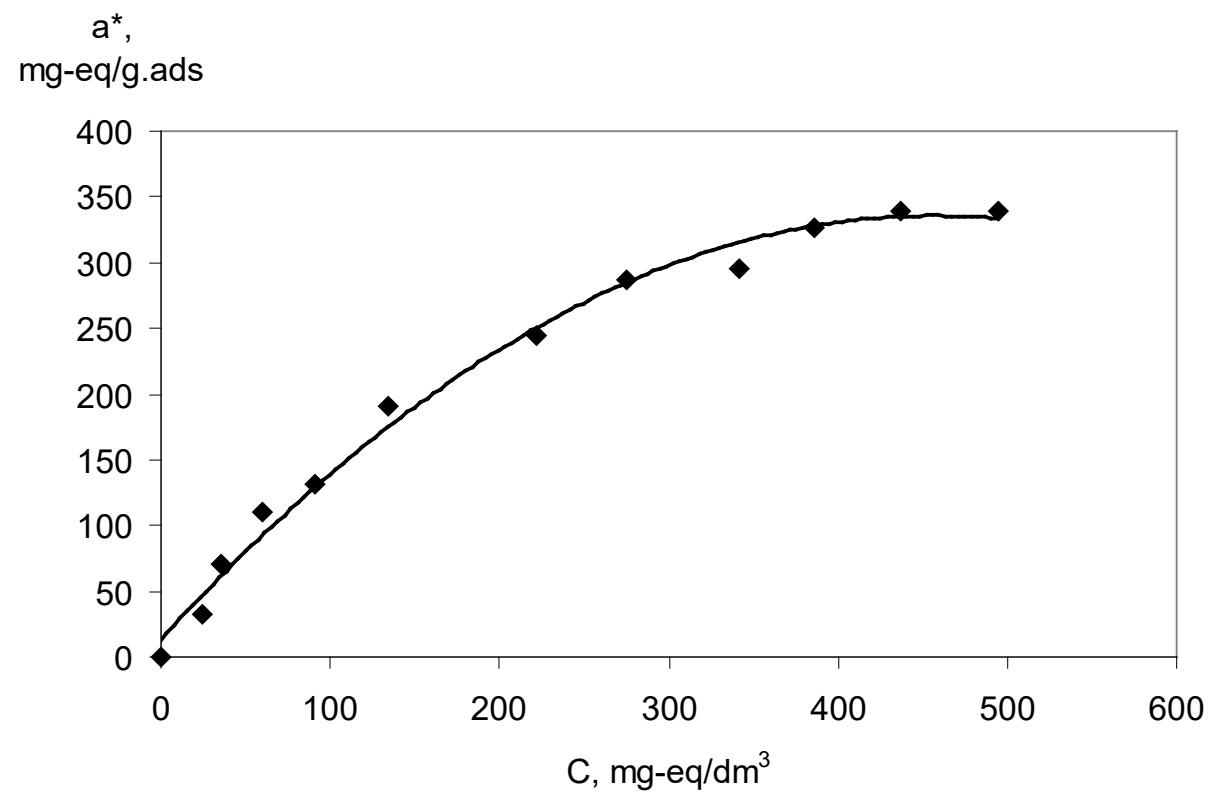

Fig. 1 - Isotherm for adsorption of Fe(III) by natural zeolite

For the experimental conditions, a diagram of the distribution of concentrations of the products of the interaction of iron chloride with aluminosilicate was ploted (Fig. 2). To obtain the calculated dependences, it was taken into account that the studied zeolite contains $\mathrm{Al}_{2} \mathrm{O}_{3}$ and $\mathrm{SiO}_{2}$ in a ratio of $1: 6$.

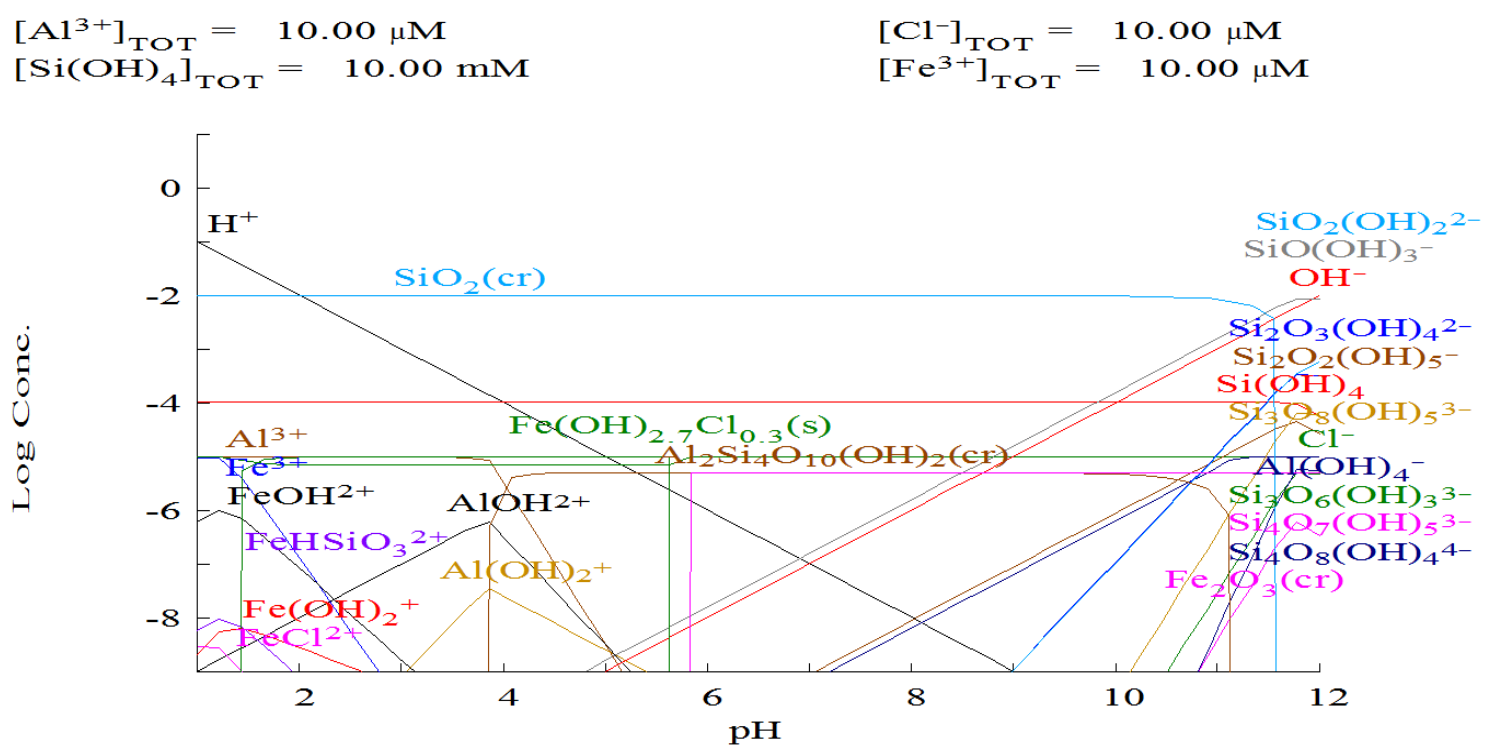

Fig. 2 - The approximate composition of the products of the interaction of $\mathrm{FeCl}_{3}$ with zeolite depending on the $\mathrm{pH}$

Therefore, in addition to ion exchange in the adsorption system is quite an incredible phenomenon of chemisorptions. The results of the study of adsorption kinetics are presented in Fig. 3. Agitation speeds were carried out at 200, 400, 600 and $800 \mathrm{rpm}$.

It appears that the increase in speed of agitation decreased the time required for iron to equilibrate. This increase in agitation speed decreased the boundary layer resistance to mass transfer, increased the diffusion rate of Fe(III) from the bulk into zeolite particles and hence increased in the rate of iron uptake. Moreover, the number of collisions between Fe(III) ions 
inside the micropores will increase leading to the increase in diffusion coefficient which increase the rate of adsorption.

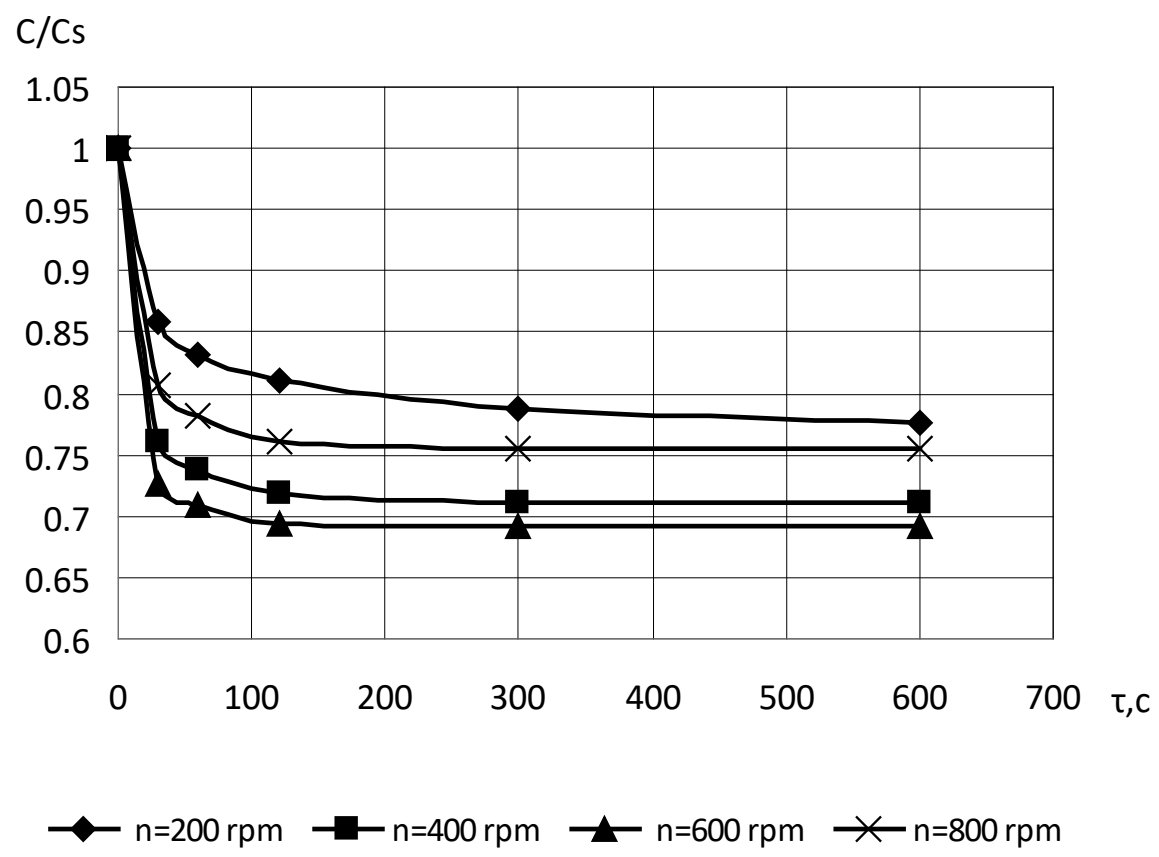

Fig. 3 - Effect of agitation speed on the adsorption kinetics Fe(III) of by natural zeolite

Table 1

Adsorption kinetic parameters for removal of $\mathrm{Fe}(\mathrm{III})$ from aqueous solution.

\begin{tabular}{|c|c|c|}
\hline Mixing speed,rpm & Values $\beta(\mathrm{cm} / \mathrm{s})$ & Deff $\left(\mathrm{cm}^{2} / \mathrm{s}\right)$ \\
\hline 200 & 0.001 & $4.01 \times 10-6$ \\
400 & 0.005 & $5.77 \times 10-6$ \\
600 & 0.0057 & $7.01 \times 10-6$ \\
800 & 0.0063 & $9.05 \times 10-6$ \\
\hline
\end{tabular}

\section{Conclusion}

The adsorption isotherm and kinetics data obtained for the removal of copper ions from aqueous solution would be perfectly attained by the natural zeolite of Sokyrnytsia deposit. The adsorption is affected by the concentration of Fe(III) where an increase in adsorption capacity is cleared with the increase in initial concentration. The kinetic parameters showed that the rate of adsorption is well enhanced with agitation speed. The provided model best fitted to the experimental data and predicted the variation of particles porosity on the removal efficiency. The given adsorbent is not expensive, widely available and solve an environmental issue.

\section{References}

[1] Sabadash, V., Mylanyk, O., Matsuska, O., \& Gumnitsky, J. (2017). Kinetic regularities of copper ions adsorption by natural zeolite. Chemistry \& Chemical Technology, 4 (11), 2017, 11(4), 459-462.

[2] Hyvlud, A., Sabadash, V., Gumnitsky, J., \& Ripak, N. (2019). Statics and kinetics of albumin adsorption by natural zeolite. Chemistry \& Chemical Technology, 1 (13), 2019, (1), 95-100. 


\title{
Activation of polyethylene granules
}

\author{
$\underline{\text { Anastasiya Kucherenko }}^{1}$, Olena Nikitchuk ${ }^{1}$, Ludmila Dulebova ${ }^{2}$, Volodymyr Moravskyi $^{1}$ \\ 1. Department of Chemical Technology of Plastics Processing, Lviv Polytechnic National University, UKRAINE, \\ Lviv, 12 Bandera str., E-mail: anastasiia.m.kucherenko@lpnu.ua
}

2. Department of Mechanical Engineering Technologies and Materials, Technical University of Kosice, SLOVAKIA, Kosice, 74 Mäsiarska str., E-mail: ludmila.dulebova@tuke.sk

\begin{abstract}
The possibility to obtain an active raw polymer suitable for its next metallization in solutions of chemical reduction was observed. The results of experimental researches of mechanical activation of polyethylene granules by small-dispersive zinc in bullet mill features were produced.
\end{abstract}

Keywords - activation, granules, polyethylene, zinc, bullet mill.

\section{Introduction}

Composite materials filled by metals are used in different spheres of the industry for its complex of valuable properties, the first and foremost is the high strength, chemical stableness, increased heat and electric conductivity, ability to recycle into complex conformation products at the high productivity equipment, exploitation reliability. The main problem of the composite materials obtainment is the creation of simple and effective methods to combinate filler and polymer matrix. One of the methods of the combination of metals and polymers is metallization. The metallization allows to combinate the high polymer manufacturability, low cost of the production with operating metal characteristics. That is why the polymer metallization is widely used for high technological products and decorative coverings in the undustry. So it is suggested to use the process of the metallization for obtaining polymer composites filled by metals by us.

\section{Experimental}

The activation process before chemical metallization of the polymer surface is important for obtaining a necessary qualitative product. The method of the surface polymer activation is used in that paper, which uncludes combined processing of the polymer granules in the bullet mill in the presence of small-dispersive metal - activator. The result of that processing is a high metal fixation. Determinating of the high qualitative active raw materials was our purpose, which can be used for metallization in the future. The main indicator of the activation efficiency was a metal quantity on the polymer granules after its activation, which was rated as a mass difference between active polyethylene granules before acid etching and after it. Acid treatment was performed to dissolve the metal that was attached to the polymer surface during activation. Our studies allow to establish that the main reason which influences on activation efficiency of the polyethylene grains is the rotation speed, index of mill loading by polymer and metal, polymer and metal ratio, durance of the activation. It is established there is not essential activation rise above limited ratio between polymer and metal. Such ration depends on rotation speed of the bullet mill and it is $5-10 \%$ of the mass.

\section{Conclusion}

Obtained results allow to affirm that during the process of mechanical activation of the polyethylene granules it is possible to receive an active raw polymer suitable for its next coppering in the solutions of chemical reduction. 


\title{
Influence of polymer additives on rheological properties of heavy high- viscosity oil
}

\author{
P. Topilnytskyy ${ }^{1}$, V.Romanchuk ${ }^{2}, \underline{\text { T.Yarmola }}^{3}$
}

1. Department of Chemistry and Technology of Petroleum, Lviv Polytechnic National University, Str. St. Bandery, 12, Lviv, 79013, UKRAINE, E-mail: topoil@polynet.lviv.ua

2. Department of Chemistry and Technology of Petroleum, Lviv Polytechnic National University, Str. St. Bandery, 12, Lviv, 79013, UKRAINE, E-mail: vikarom318@gmail.com

3. Department of Chemistry and Technology of Petroleum, Lviv Polytechnic National University, Str. St. Bandery, 12, Lviv, UKRAINE, 79013, E-mail: yarmolatetana@gmail.com

\begin{abstract}
The rheological properties of high-viscosity oils from 2 wells of the Yablunivske field (Poltava region, Ukraine). To improve the rheological properties of the oil, polymer additives were added and the dynamic viscosity and shear stress. The addition of polymer additives has been found to improve the rheological properties of heavy oils and reduce kinematic viscosity, which is of practical importance for facilitating their extraction and transportation.
\end{abstract}

Keywords - heavy oil, polymer additives, oil transportation, rheological properties of oil.

\section{Introduction}

To date, due to the steady reserves depletion of light, low-viscosity oils, there is an urgent necessity to introduce into operation the fields of heavy reserves, such as high-viscosity oils and natural bitumen. Oil fields of this type are usually characterized by high concentration of metals and sulfur compounds, high values of density, viscosity and coking ability due to the high content of asphaltenes and resins [1]. Rheological properties are important parameters of oil field products. The study of rheological properties allows to substantiate and implement effective complex technologies to increase oil recovery during the operation of certain facilities. The peculiarity of the rheological properties of heavy oils is the variability of their dynamic viscosity, which depends on the applied shear stress and flow rate. According to the experts, the largest reserves of heavy high-viscosity oil are located in Canada, Venezuela, the Russian Federation. Approximately $2 \%$ of the world's reserves of high-viscosity oil are concentrated in Ukraine.The largest of Dnieper-Donetsk basin - Yablunivske gas condensate field. The difficulties of operation of the Yablunivsky gas condensate field - is located in Poltava region, require its rational development, and for the extraction and transportation of reserves it is necessary to determine the rheological properties of oil. There are many ways to process oil to reduce its viscosity. And one of them is the addition of polymer additives. [2].Chemical reagents used to reduce the oil viscosity provide the conditions that prevent the formation of collective colloidal structures, reduce gravity between colloidal particles and preserve the colloidal component in the form of single particles. The introduced synthetic polymer products are able to change oil viscosity and shear stress. Usually esters, alcohols and various polymers are used [3].

The aim of research: to determine the effect of polymer additives on the rheological properties of heavy highly resinous oil, to reduce the oil viscosity and to find ways of heavy oil processing.

\section{Experimental}

To study the rheological properties we used the high-viscosity oil of Yablunivske field from two wells:sample 1 - oil with a density of $977 \mathrm{~kg} / \mathrm{m}^{3}$ at $20{ }^{\circ} \mathrm{C}$ from well 88 , sample 2 - oil with a density of $972 \mathrm{~kg} / \mathrm{m}^{3}$ at $20{ }^{\circ} \mathrm{C}$ from well 337.

To improve the rheological properties, polyethylene glycol (PEG, molecular weight 400, density $\mathrm{d}_{20}=1130 \mathrm{~kg} / \mathrm{m}^{3}$ ), polypropylene glycol (PPG, molecular weight 400 , density $\mathrm{d}_{20}=1010$ 
$\mathrm{kg} / \mathrm{m}^{3}$ ) and demulsifier of PM brand (content of ethylene and propylene oxides copolymer is $70 \%$, density $1000 \mathrm{~kg} / \mathrm{m}^{3}$ ) were added separately in the amount of $3 \%$ per sample. Before adding the oil was heated to $50{ }^{\circ} \mathrm{C}$. The dynamic viscosity and shear stress of samples from both wells were investigated at 20,30, and $40{ }^{\circ} \mathrm{C}$. After addition of polymer additives the measurements were carried out again. The most important physico-chemical properties of oils are presented in Table 1.

Table 1

Physico-chemical properties of oil

\begin{tabular}{|l|c|c|}
\hline \multicolumn{1}{|c|}{ Property } & Sample 1 & Sample 2 \\
\hline Density at $20{ }^{\circ} \mathrm{C}, \mathrm{kg} / \mathrm{m}^{3}$ & 977 & 972 \\
\hline Kinematic viscosity at $50{ }^{\circ} \mathrm{C}, \mathrm{mm}^{2} / \mathrm{s}$ & 326 & 386 \\
\hline Coking ability, \% & 9.8 & 7.3 \\
\hline Pour point, ${ }^{\circ} \mathrm{C}$ & 14 & 8 \\
\hline Content of water, \% & 4.9 & 5.6 \\
\hline Content of chlorides, $\mathrm{mg} / \mathrm{dm}^{3}$ & 2900 & 6280 \\
\hline Content of sulfurous resins, vol \% & 16.9 & 14.8 \\
\hline
\end{tabular}

The addition of polymer additives significantly affects the rheological properties of oils. The shear stress of the sample 1 at 20,30 and $40{ }^{\circ} \mathrm{C}$ is $1338.40,564.03$ and $261.94 \mathrm{~Pa}$, respectively. When polypropylene glycol is added, the shear stress is $1070.7,398.33$ and 229.44 PA, respectively. The addition of polyethylene glycol reduces the shear stress to 873.13, 481.18 and $2176.69 \mathrm{~Pa}$, respectively. And the addition of the PM demulsifier to the sample 1 reduces the shear stress to $924.11 \mathrm{~Pa}$ at $20{ }^{\circ} \mathrm{C}$, and to 200.76 and $97.19 \mathrm{~Pa}$ at higher temperatures, respectively.

The addition of polymer additives to sample 2 also significantly affects the shear stress. For this sample, the addition of polypropylene glycol shows slightly better results. The shear stress at the above mentioned temperatures decreases to 4397.5, 1937.45 and $828.52 \mathrm{~Pa}$, respectively. The addition of polyethylene glycol and PM demulsifier also reduces the shear stress. The addition of polymer additives to high-viscosity oils also has a significant effect on reducing the dynamic viscosity. Thus, the dynamic viscosity of sample 1 at the temperatures of 20, 30 and $40^{\circ} \mathrm{C}$ is $2.961,1.248$ and $0.579 \mathrm{~Pa} \cdot \mathrm{s}$, respectively. When adding PPG, PEG and PM demulsifier the value decreases by $20-35 \%$ at a shear rate of $452 \mathrm{~s}^{-1}$. For sample 2, the dynamic viscosity is 13.666, 5.781 and $2.51 \mathrm{~Pa} \cdot \mathrm{s}$, respectively. When PPG and PEG are added, the dynamic viscosity decreases insignificantly, but the addition of PM demulsifier reduces this value by $25 \%$.

\section{Conclusions}

The addition of polymer additives PEG, PPG, copolymers of ethylene oxide and propylene to high-viscosity oils significantly reduces the viscosity, shear stress and will help to reduce energy consumption in oil production and transportation.

\section{References}

[1] Topilnytskyy, P., Paiuk, S., Stebelska, H., Romanchuk, V., \& Yarmola, T. (2019). Technological features of high-sulfur heavy crude oils processing. Chemistry \& Chemical Technology, 4 (13), 2019, (4), 503-509.

[2] Pyshyev, S., Gunka, V., Grytsenko, Y., Shved, M., \& Kochubei, V. (2017). Oil and gas processing products to obtain polymers modified bitumen. International Journal of Pavement Research and Technology, 10(4), 289-296. 
[3] Topilnytskyy, P., Romanchuk, V., Boichenko, S., \& Golych, Y. (2014). Physico-chemical properties and efficiency of demulsifiers based on block copolymers of ethylene and propylene oxides. Chemistry \& Chemical Technology, 8(2), 211-218. 


\title{
Obtaining of modified polyamide from the solution
}

\author{
Natalia Chopyk, Victoria Zemke, Iryna Dovga \\ Department of Chemical Technology Plastics Processing, Lviv Polytechnic National University, 12 Bandery str., \\ Lviv, UKRAINE. E-mail: viktoriia.m.zemke@lpnu.ua
}

Abstract - the features of modified polyamide-6 derivation from the solution. The optimal conditions for obtaining polymer nanocomposites based on organoclay and polyamide have been studied and determined.

Keywords - polyamide, montmorillonite, solvent, polyvinylpyrrolidone, precipitation.

\section{Introduction}

At the end of twentieth century, a group of scientists have obtained nanocomposites based on polyamide and layered silicates which has positively effected on the properties of PA-6 and significantly expanded areas of this polymer application. Obtaining of polymer nanocomposite is possible by the next methods: in solution, in the melt, in the process of polymer synthesis as well as the use of sol-gel process. The most interesting is the method of obtaining a polymer nanocomposite from the solution.

\section{Research results}

Polyamide, by its properties, is practically insoluble in ordinary solvents except the water (polar solvent). During the research we refused to apply the water due to its impact on the structure of the obtained complex.

Polyamide is soluble in formic acid in the range of concentrations from $77 \%$ to $90 \%$, but $85 \%$ showed itself the best.

It has been researched that for $85 \%$ of concentrated formic acid in a volume of $100 \mathrm{ml}$, $15 \%$ of mass PA-6 is optimally dissolved. The process of complete dissolution of PA-6 in formic acid continues for $2 \ldots 3$ hours.

The next stage was adding of MPS complex into the composition (a mixture of montmorillonite with polyvinylpyrrolidone in the ratio MMT: PVP $=1: 5$ in the form of a fine powder) in amount of 5, 10, $20 \mathrm{wt} \%$. relatively to the mass of PA-6. Applying acetone as a solvent made it possible to precipitate the PA-6 complex with the MPS but a large consumption of it was found. To reduce the consumption of acetone other possible solvents were analyzed and their optimal ratio was experimentally determined. Therefore, benzene was used as a co-solvent. The obtained mixture was precipitated with a solution of acetone and benzene (ratio of components 1: $1 \mathrm{rpm}$ ). At the initial stage of precipitation $200 \mathrm{ml}$ of solution was applied. The obtained mixture was holded to settle for 15 minutes, followed by draining of the surface layer. Next step was re-precipitation via the solvents mixture in an amount of $100 \mathrm{ml}$. The precipitate formed was filtered off with a water pump and dried in a vacuum oven at $80{ }^{\circ} \mathrm{C}$ for 8 hours with further raising the temperature to $105^{\circ} \mathrm{C}$.

\section{Conclusion}

Consequently, the conducted studies made it possible to obtain a nanocomposite based on PA-6 and MPS from the solution which determined positive effect on the properties of PA-6. The developed composites are characterized by the manufacturability inherent in thermoplastics as well as may be respective for the manufacture of structural products by injection molding. 


\title{
Transesterification of vegetable oil by ethanol in the presence of heterogeneous catalysts
}

\author{
$\underline{\text { Yurii Melnyk }}^{1}$, Stepan Melnyk ${ }^{2}$, Halyna Mahorivska ${ }^{3}$ \\ 1. Department of Organic Products Technology, Lviv Polytechnic National University, UKRAINE, Lviv, S. \\ Bandera str., 12, E-mail: yurii.r.melnyk@lpnu.ua \\ 2. Department of Organic Products Technology, Lviv Polytechnic National University, UKRAINE, Lviv, S. \\ Bandera str., 12, E-mail: stepan.r.melnyk@lpnu.ua
}

3. Department of Chemical Technology of Silicate Materials, Lviv Polytechnic National University, UKRAINE, Lviv, S. Bandera str., 12, E-mail: halyna.y.mahorivska@lpnu.ua

\begin{abstract}
Transesterification of vegetable oil by ethanol in the presence of heterogeneous catalysts has been investigated. Zinc and nickel(II) oxides and cation exchange resin $\mathrm{CU}-2-8$ with immobilized $\mathrm{Sn}^{2+}$ and $\mathrm{Zn}^{2+}$ ions were shown to have the highest catalytic activity among an investigated catalysts. The optimal concentration of catalysts and optimal molar ratio triglycerides : alcohol have been established.
\end{abstract}

Keywords - transesterification, triglycerides, oxides of metals, cation exchange resin CU-2-8, ethanol.

\section{Introduction}

Acid and basic homogeneous and heterogeneous catalysts are used for the transesterification process of vegetable oils triglycerides (TG) by aliphatic alcohols [1, 2]. Heterogeneous catalysts can be easily separated from the reaction mixture and further used many times in the process. When using heterogeneous catalysts, it is easier to realize a continuous process [2-4]. The amount of heterogeneous catalysts using in transesterification process is quite limited. The aim of research is to investigate a metal oxides and cation exchange resin CU-2-8 with immobilized cations as a transesterification reaction catalyst of vegetable oils triglycerides by ethyl alcohol.

\section{Results and discussion}

Sunflower, rapeseed and linseed oils were used as the TG raw sources. Anhydrous ethanol was used as an ethyl alcohol raw source. Fine powders of the metal oxides $\mathrm{ZnO}, \mathrm{NiO}, \mathrm{MgO}$, $\mathrm{SnO}_{2}, \mathrm{MnO}, \mathrm{PbO}, \mathrm{Al}_{2} \mathrm{O}_{3}, \mathrm{Cr}_{2} \mathrm{O}_{3}$ (all were analytical grade) were used as the catalysts. The cation exchange resin CU-2-8 in $\mathrm{H}^{+}$-form and the cation exchange resin CU-2-8 with an immobilized ions of $\mathrm{Co}^{2+}, \mathrm{Zn}^{2+}, \mathrm{Ni}^{2+}, \mathrm{Sn}^{2+}, \mathrm{Cu}^{2+}$ were used as the catalysts. Transesterification of $\mathrm{TG}$ was carried out with anhydrous ethanol at $75^{\circ} \mathrm{C}$ and ethanol : TG molar ratio of $(3.6-8,0): 1$. The amounts of TG were recalculated to glycerol trioleate. The content of the metal oxides was from $0.13 \mathrm{wt} \%$ to $0.50 \mathrm{wt} \%$ and the content of cation exchange resin was from $0,5 \mathrm{wt} \%$ to $4,0 \mathrm{wt} \%$. The effect of the catalyst content was studied using zinc oxide. Its content was varied in the range from $0.13 \mathrm{wt} \%$ to $0.50 \mathrm{wt} \%$ in the reaction mixture. The transesterification reaction was carried out during 150-180 minutes.

The transesterification of TG by ethanol in the presence of heterogeneous catalysts was carried out in a glass three-necked flask equipped with a reflux condenser under intensive stirring. The samples were taken after each 30 minutes. The ethanol content was determined by chromatography, the acid number - by titrimetry after end of the reaction.

Chromatographic analysis of the reaction mixture was performed using a gas-liquid chromatograph LHM-80 with a thermal conductivity detector under the conditions given in [5]. The acid number was determined by alkalimetric titration [6]. 
It was shown high catalytic activity of fine metal oxides as transesterification catalysts of TG by anhydrous ethanol. Zinc and nickel (II) oxides were found to be the most active catalysts among the studied metal oxides. It was established that the increase in ethanol : TG molar ratio to 4,1: 1 and more results an almost complete conversion of sunflower oil TG. It was also found that in the presence of zinc and nickel (II) oxides an esterification reaction of FFA present in the vegetable raw material takes place.

It was established that the activity of transesterification reaction catalysts based on the cation exchange resin with immobilized metal ions depends on the cation type. It was shown that the cation exchange resin with immobilized ions of $\mathrm{Sn}^{2+}$ and the cation exchange resin in $\mathrm{H}^{+}$form have the highest activity in the transesterification reaction of TG by ethyl alcohol. In the presence of the examined catalysts conversion of TG decreases with an increase in the alcohol chain length. It was established that optimal molar ratio of ethanol : TG is (4-5):1.

Extreme dependence of the initial rate of the transesterification reaction and triglycerides conversion on the content of the heterogeneous catalysts was established. It was established that optimal content of cation exchange resin with immobilized metal ions is $2 \mathrm{wt} \%$ and optimal content of metal oxides is $0.25-0.30 \mathrm{wt} \%$.

\section{Conclusion}

Thus it can be assume that the examined catalysts demonstrate high activity in the transesterification reaction of TG by ethyl alcohol. The catalysts make it possible to achieve high transaction rate of raw materials. The obtained results indicate the applying feasibility of catalysts based on the cation exchange resin with immobilized metal ions or metal oxides in the transesterification reaction of TG by ethanol.

\section{References}

[1] Van Gerpen, J. (2005). Biodiesel processing and production. Fuel Process. Technol., 86 1097-1107. https://doi.org/10.1016/j.fuproc.2004.11.005.

[2] Leung, D. Y., Wu, X., Leung, H. M. (2010). A review on biodiesel production using catalyzed transesterification. Appl. Energ., 87, 1083-1095. https://doi.org/10.1016/j.apenergy.2009.10.006.

[3] Shibasaki-Kitakawa, N., Honda, H., Kuri-bayashi, H., Toda, T., Fukumura, T. \& Yonemoto, T. (2007). Biodiesel production using anionic ion-exchange resin as heterogeneous catalyst. Bioresource Technology, 98(2), 416-421. https://doi.org/10.1016/j.biortech.2005.12.010.

[4] Yan, S., DiMaggio, C., Mohan, S., Kim, M., \& Salley, S. O. (2010). Advancements in heterogeneous catalysis for biodiesel synthesis. Topics Catal., 53(11-12), 721-736. https://doi.org/10.1007/s11244-010-9460-5.

[5] Melnyk, Yu., Starchevskyi, R., \& Melnyk, S. (2019) Transesterification of triglycerides by ethanol in the presence of metal oxides. Bulletin of NTU "KhPI". Series: New solutions in modern technologies, 5(1330), 132-138. https://doi.org/10.20998/2413-4295.2019.05.17.

[6] Biocyclopedia.com. Methodology for Lipids. Retrieved February 13, 2021, from http://www.biocyclopedia.com/index/plant_protocols/lipids/Estimation_of_free_fatty_acid s.php 


\title{
The process of catalytic hydration of acetylene compounds using a homogeneous catalyst based on gold (I) complex with water-soluble organophosphorus ligands
}

\author{
$\underline{\text { Ivan Kokhan }}^{1}$, Sergiy Kudryavtsev ${ }^{2}$ \\ 1. Faculty of Engineering, Volodymyr Dahl East Ukrainian National University, UKRAINE, Sievierodonetsk, \\ Tsentralny Ave., 59a, E-mail: ivan.v.kokhan@gmail.com \\ 2. Faculty of Engineering, Volodymyr Dahl East Ukrainian National University, UKRAINE, Sievierodonetsk, \\ Tsentralny Ave., 59a, E-mail: sergeykudryavtsevsnu@gmail.com
}

\begin{abstract}
The work provides the description of one of the realizations of the process of catalytic hydration of acetylenic compounds using a homogeneous catalyst based on the gold (I) complex with water-soluble organophosphorus ligands. In particular, we are to present the process of catalytic hydration of acetylene. The reactor unit consists of a gas-liquid reactor and a column for the separation of the reaction product, acetaldehyde, is also is used. When developing the process, attention was paid to the peculiarities of using a homogeneous catalyst and preventing its entrainment from the reaction unit along with the reaction product.
\end{abstract}

Keywords - acetaldehyde, acetylene compounds, acetylene, homogeneous catalyst, gold complexes, catalytic hydration, organophosphorus ligands, gas-liquid reactor, product separation column.

\section{Introduction}

The last decades in the field of chemical engineering were marked by an active search for ways to use homogeneous metal complex catalysis in the processes of basic organic synthesis. There are several reasons for this, in particular, homogeneous metal complex catalysis can significantly increase the conversion level, process selectivity, while reducing energy consumption. The last of these factors is of particular interest, since the use of this type of catalysis allows the processes to be carried out at atmospheric or close to atmospheric pressure and at low temperatures. It is also worth noting that in many processes using homogeneous metal complex catalysis, with the correct selection of the ligand, it is possible to achieve the solubility of the catalyst in water, which in some cases makes it possible to abandon the use of organic solvents, or to reduce their use to a minimum. The above advantages are also largely characteristic of the process we are considering, the catalytic hydration of acetylene using catalyst based on the gold (I) complex. During a long time, industrial processes for the catalytic hydration of acetylenic compounds were based on the Kucherov reaction, in which mercury salts were used as a catalyst, which caused a number of problems associated with their toxicity. It should also be noted the need for a large amount of catalyst and the complexity of its regeneration, characteristic of the processes based on the Kucherov reaction. In connection with the above, the processes of hydration of acetylene compounds based on the Kucherov reaction are currently not used in the basic organic synthesis. These disadvantages of the above process were undertaken to search for new homogeneous metal complex catalysts, on the one hand, tested in preparative practice [1], on the other hand, those that can be used in the industrial process of catalytic hydration of acetylene. As a result of this research, the process described below has been developed.

\section{The process description}

The proposed process uses a homogeneous catalyst based on the gold (I) complex. The sodium triphenylphosphine trisulfonate (TPPTS) is used as a ligand. The counter ion is chlorine. 
The choice of the TPPTS as a ligand is due to the need to ensure the solubility of the catalyst in a water.

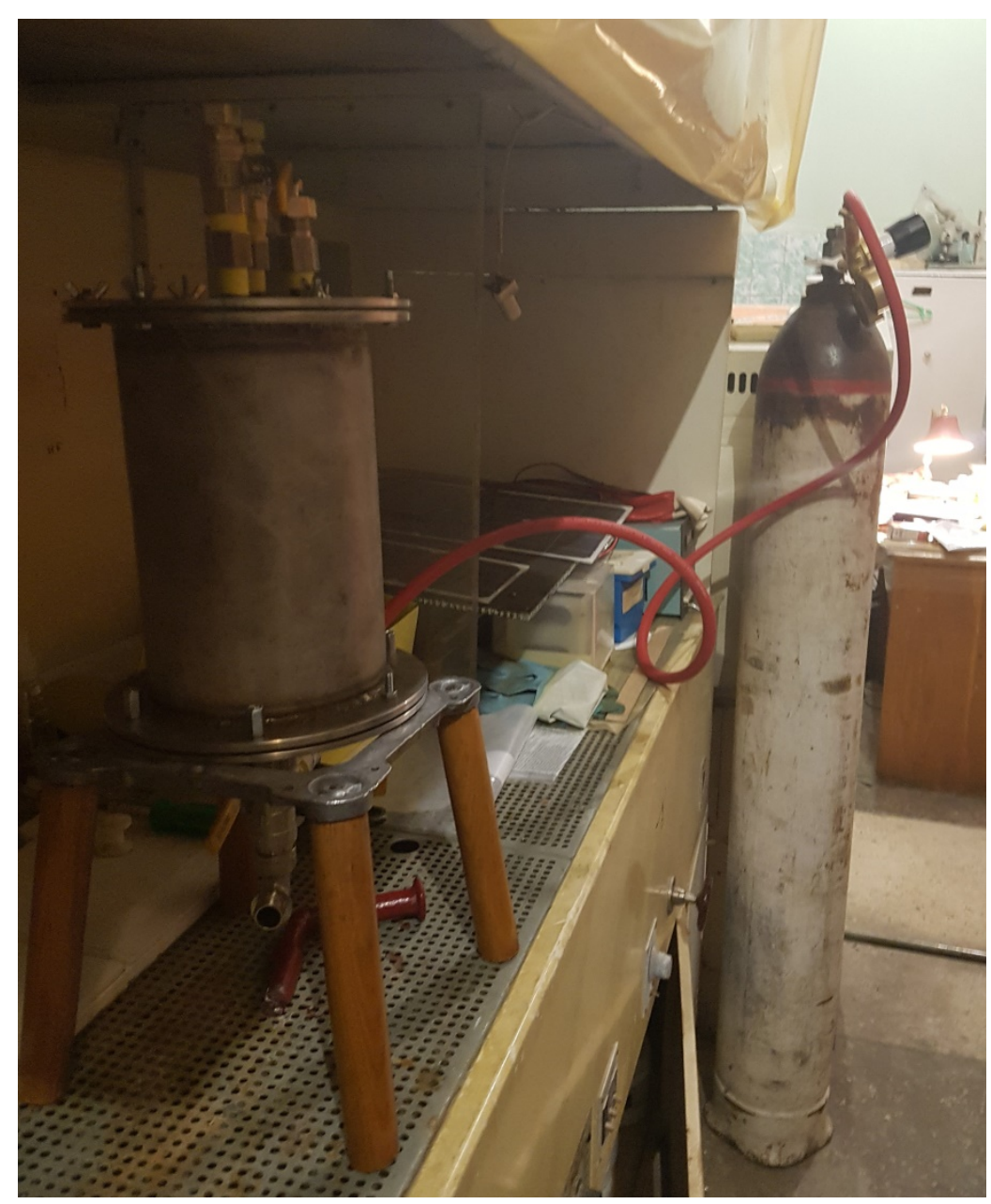

Fig.1. The pilot-laboratory installation for research the process of catalytic hydration of acetylene.

The reaction of catalytic hydration of acetylene is carried out in a gas-liquid reactor [2]. The reactor is filling of the water, which is both a solvent and a hydration reagent. The catalyst in an amount of about $0.2 \mathrm{~mol} \%$ is soluble in water. A small amount of sulfuric acid is used as a co-catalyst. Further, the liquid phase in the reactor is heated to a temperature of $65^{\circ} \mathrm{C}$, at which the reaction can already proceed. Upon reaching the temperature indicated above, acetylene start supplys in the reactor and bubble through the liquid phase. It should be noted that the reaction is carried out at atmospheric pressure, which greatly simplifies the design of the reactor unit.

The acetaldehyde formed during bubbling has a boiling point of $20.2^{\circ} \mathrm{C}$, due to which the reaction product evaporates from the reaction mass, the temperature of which is $65^{\circ} \mathrm{C}$. Thus, acetaldehyde, together with the unreacted part of the acetylene, is removed in gaseous form from the upper part of the reactor and enters the column for separating the reaction product. The column is partially filled with circulating ice water, which, absorbing acetaldehyde, goes to rectification, as a result of which the reaction product, acetaldehyde, is released. At the same time, unreacted acetylene is bubbled through the water in the column and is recycled. The water remaining after rectification is cooled and fed to the recirculation column for the separation of the reaction product.

Separately, it should be noted that the homogeneous catalyst in the reactor is solubled in water, and at a temperature of $65^{\circ} \mathrm{C}$ is not carried away along with the reaction product, but 
remains in the reactor. In this case, there is no need to separate the catalyst and return it to the reaction mass.

The proposed process is designed as a pilot-laboratory installation [3]. The process has several advantages. The reaction is doing at a low temperature and atmospheric pressure. There is no transfer of the catalyst along with the reaction product. Both the catalyst and the co-catalyst are present in the reaction mass in small amounts. No organic solvents are used in the process, and unreacted reagents are recycled, which makes the process accordingly with a principles of Green Chemistry.

Among the disadvantages of the process, it should be noted the need to ensure not only the heating of the reaction mixture to $65^{\circ} \mathrm{C}$, but also the need to cool the absorbing water to $5^{\circ} \mathrm{C}$.

\section{Conclusion}

The reaction of catalytic hydration of acetylene used in the described process using a metal complex catalyst based on gold (I) complex was researched using the reaction of catalytic hydration of phenylacetylene, as a result of which acetophenone was resieved. The conversion of $99 \%$ and higher was achieved. The conversion level was determined from the intensity of the peaks in the ${ }^{1} \mathrm{H}$ NMR Spectra.

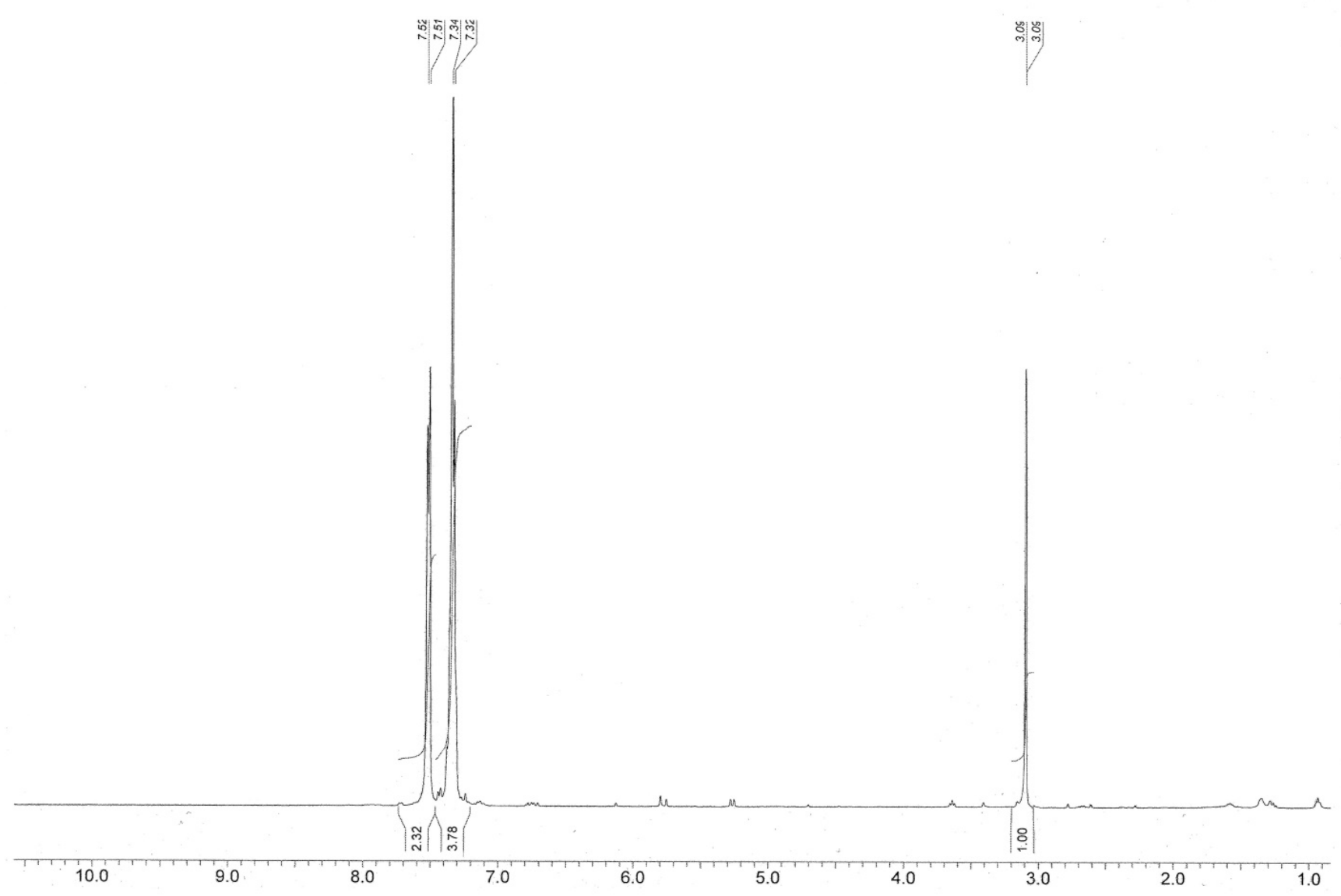

Fig. 2. ${ }^{1} \mathrm{H}$ NMR Spectra of the reaction mixture at the start of the reaction.

To additional catalytic research the pilot-laboratory installation [3] is used, it is contained a gas-liquid reactor [2] and product separation column. Using this installation authors doing kinetic research the process described above. The presented process has a great perspectives for further research and industrial implementation. 


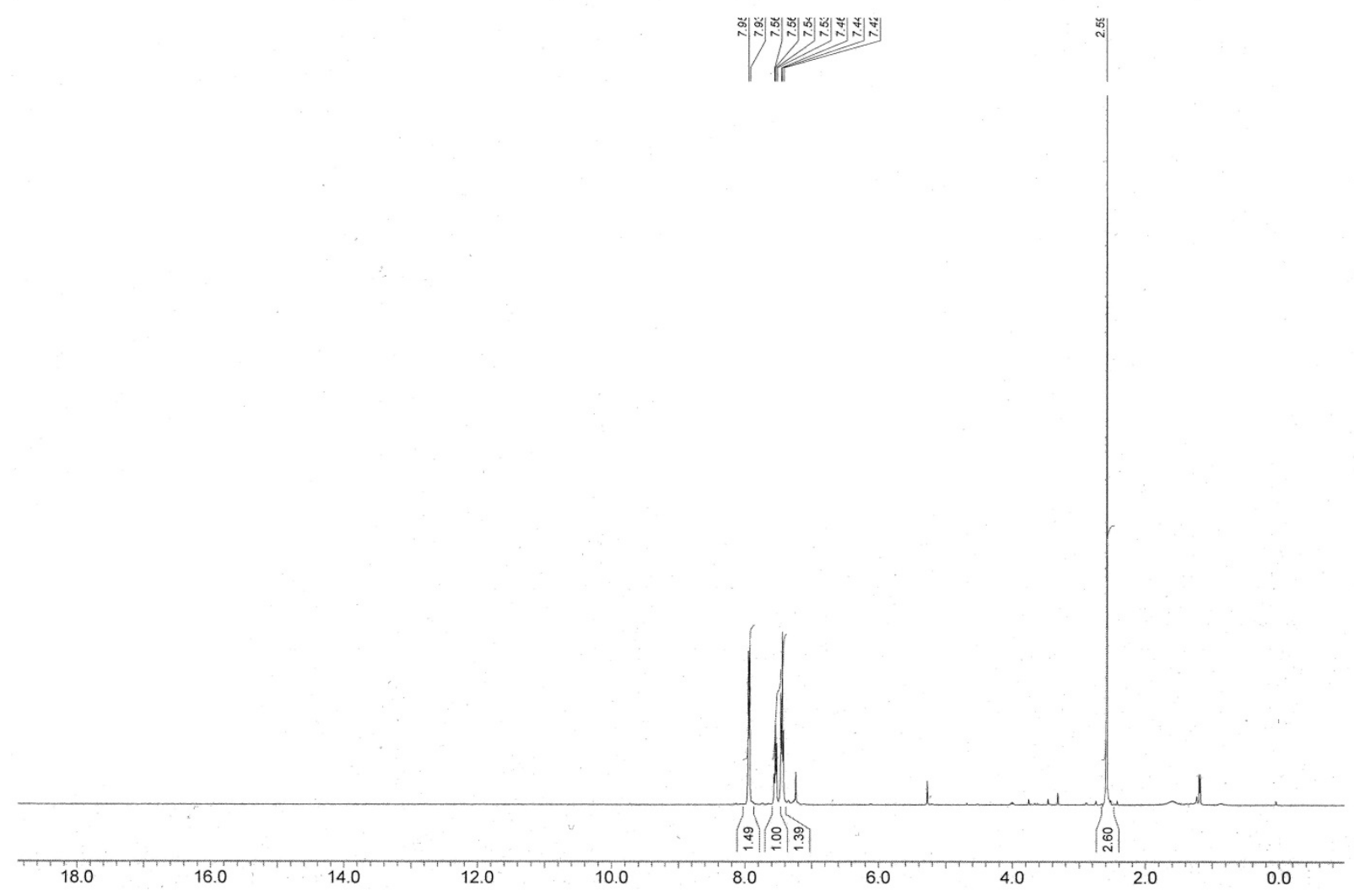

Fig.3. ${ }^{1} \mathrm{H}$ NMR Spectra of the reaction mixture at the end of the reaction.

\section{References}

[1] Sanz, S., Jones L.A., Mohr, F., Laguna, M. (2007). Homogenous Catalysis with Gold: Efficient Hydration of Phenylacetylene in Aqueous Media. Organometallics, 26, 952-957, https://doi.org/10.1021/om060821y

[2] Kokhan, I.V. (2019). Gas-liquid reactor for processes using homogeneous metal complex catalysts. Technology-2019, The materials of the XXII International Scientific and Technical Conference, Sievierodonetsk, 1, 21-22.

[3] Kokhan, I.V. (2020). The pilot-laboratory installation for the research of catalytic hydration of acetylene using a homogeneous metal complex catalyst. Technology-2020. The materials of the XXIII International Scientific and Technical Conference, Sievierodonetsk, 1, 10-11.

[4] Green, D.W., Southard, M.Z. (2019). Perry's Chemical Engineers' Handbook (9th ed). New York, N.Y.: McGraw-Hill Education.

[5] Poling, B.E., Prausnitz, J.M., O’Connell J.P. (2001). The Properties Of Gases And Liquids (5th ed). New York, N.Y.: Mc Graw Hill. 


\section{OPTIMIZATION OF BIOCHEMICAL PROCESSES AND BIOENGINEERING}




\title{
Polymer properties to comply with requirements for medical devices
}

\author{
Jorg Vienken
}

Technical University Mittelhessen, Giessen. GERMANY, E-mail: vienken.usingen@gmail.com

\begin{abstract}
Polymers applied for medical devices need to be tested in depth before considering them suitable, during production of devices and in clinical application when being part of the final device. Both performance and stability, as well as blood compatibility, release of extractables and surface activity are keywords to be considered.
\end{abstract}

Keywords - Polymer performance, medical devices, blood compatibility, extractables, device approval

\section{Introduction}

Polymers used for the application in medical devices have to undergo harsh assessments and characterization. This involves in vitro and in vivo biocompatibility testing, qualification for purity. In addition, long-term stability of implanted medical devices under conditions of a possibly corrosive human environment is of paramount importance, whilst individual patient profiles, such as e.g., underlying diseases, like diabetes do further complicate polymer assessment and application.

\section{Physico-chemical stability}

Medical devices and composing polymers must show stability features already during production and sterilization processes. Thus, stability against acids, bases and solvents as well as the glass transition temperature in case of steam sterilization, are important properties.

\section{Blood compatibility}

Due to its peculiar composition, human and animal blood is able to wet any type of polymer, irrespective of its polymer formula. Based on its content of water, electrolytes, fat, carbohydrates and enzymes, blood allows for wetting the surface of both hydrophilic and hydrophobic, as well as the surface of polymers with domain structures. As a consequence, blood may provoke the release of leachables and induce subsequent adverse reactions. Examples for this notion are plasticizers and leachable members of the bis-phenol family, which show endocrine effects in patients. Thus, polymer purity or in case of polymer blends, careful action has to be taken in order to avoid or at least reduce leachable material. A careful assessment of blood compatibility and stability by the bioengineer already in the early phases of device development is recommended.

\section{Reproducibility and performance}

Protein adsorption to material surfaces may interfere with long-term performance due to a secondary layer formation. E.g., fibrinogen adsorption may lead to platelet adhesion and clot formation. Functional groups, such as OH-groups, stimulate the plasmatic immune system (complement activation) and net negative charges on polymer surfaces may induce blood pressure drop.

\section{Summary}

Selection of polymers intended for the use in medical devices has to be precisely prepared and assessed. Surface properties of polymers need to be considered already in the early phase of development. Knowledge of polymer properties and on their stability under the condition of the human corrosive environment is a "must" for bioengineers. Under the current new Medical Device Regulations (MDR) in Europe, approving authorities, such as the European Medical Agency (EMA) in Amsterdam/NL, require polymer testing and characterization, both at the beginning of device development and during subsequent clinical use. 


\title{
Innovative cosmetic raw materials and biologically active compounds in cosmetics chemistry
}

\author{
Sebastian Grzyb \\ Warsaw College of Engineering and Health, POLAND, ul. Bitwy Warszawskiej 1920 r. nr 18, 02-366 Warszawa, \\ E-mail: sgrzyb@wsiiz.pl
}

\begin{abstract}
Innovative, safe and effective cosmetic raw materials and biologically active compounds are the fundament of sound cosmetic products. The cosmetics industry is one of the fastest to develop, in worldwide. Recently, this development focuses also on scientific research in the field of effective cosmetic ingredients and biologically active compounds, innovative forms and technologies, so as to meet the expectations of both producers and, above all, increasingly demanding customers-consumers who on a daily basis use varied and plenty cosmetic products.
\end{abstract}

Keywords - cosmetic raw materials, biologically active compounds, biomimetic peptides

\section{Introduction}

Cosmetic raw materials and biologically active compounds are the fundament of many cosmetic products. We used natural compounds such as plant polyphenols, flavonoids, anthocyanins, proteins, polysaccharides as plant extracts, peptides, growth factors, cytokines, and stem cells and synthetic raw materials such as biomimetic peptides [1]. Biomimetic peptides are synthetic peptides that are lab-crafted to mimic naturally-occurring peptides. In skin care, biomimetic peptides can be found in targeted treatments like facial serums and antiaging cosmetics products. These compounds help reduce the appearance of skin aging $[2,3]$.

\section{Biomimetic peptides}

Peptide synthesis has become accessible, and advances in peptide engineering, sequencing technologies, and structural bioinformatics have resulted in the rational designing of novel peptides. All these advancements would lead to the more prominent roles of peptides in many areas [4]. The cosmetics industry requires effective chemical compounds which can be synthesized cheaply and quickly. Many cosmetics products is effective cosmetic ingredients and biologically active compounds, innovative forms and technologies, so as to meet the expectations of both producers and, above all, increasingly demanding customers-consumers who on a daily basis use varied and plenty cosmetic products. Biomimetic peptides are syntetic compounds which produces biochemical, chemical, physical or physicochemical effects on the physiology and function of the skin, mucous membranes and their appendages, including hair and teeth [5]. These peptides, which can either be synthesized in a laboratory or extracted from plants, are truly revolutionizing the world of cosmetics. They are relatively inexpensive, they can easily permeate the skin thanks to their small size and the effective conjugation with carriers such as liposomes and nanosomes. They therefore effectively mimic the activity of natural proteins, physiologically affecting aging in a non-aggressive or irritating manner. As our knowledge on skin physiology and on the mechanisms of aging progress, new peptides are being identified and used to compensate for cutaneous deficiencies. Chemical compounds of the type proteins (peptides, amino acids) may be enzymes (inhibitors, catalysts), antioxidants, growth factors and regulators of skin metabolism. They take part in numerous biochemical processes taking place in the skin [6]. Production of modified peptides consisting of specially selected amino acids with a size and/or functions gives possibility to penetration the dermis (natural ones are too large often to penetrate the stratum corneum). 
Biomimetic peptides are most often obtained from plant extracts (e.g. soybeans, rice) or chemical synthesis. We known carrier, signaling, neurotransmitter and enzyme modulating peptides [7]. Carrier peptides are transporting active substances deep into the skin. They attach to another component and make it easier for it to get to the target site of its activity. The first peptides were used in preparations for accelerating wound healing, and later in rejuvenating cosmetics. Signaling peptides stimulate protein synthesis and activity of fibroblasts for the production of skin support fibers, collagen and elastin, contributing to the reduction of wrinkles and skin rejuvenation. The most popular signaling peptide is palmitoyl pentapeptide-4, which stimulates the production of collagen I, III and IV type (Fig. 1).

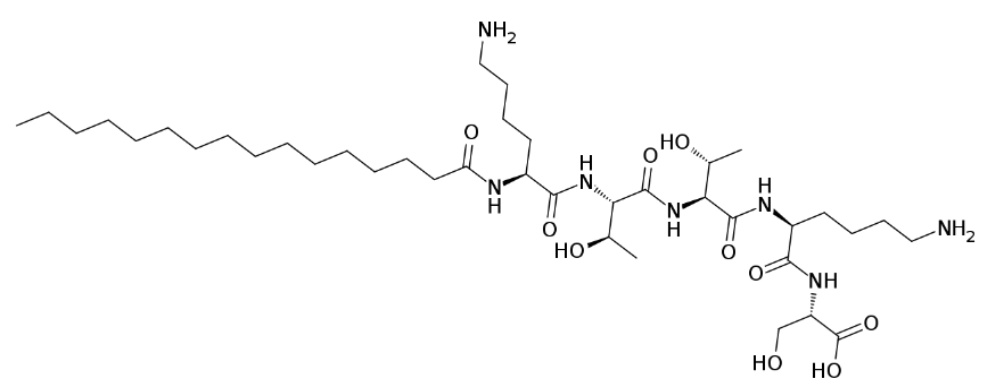

Fig.1. Palmitoyl pentapeptide-4.

Neurotransmitter peptides relax the muscles responsible for the formation of mimic wrinkles and counteract the constant tension and stress of the skin. Enzyme modulating peptides inhibit the action of enzymes in metabolic processes. Intelligent peptides (peptides with an attached chain of fatty acid, e.g. palmitic acid) facilitates the passage of the complex through the epidermis and penetration into the dermis. Other known biomimetic peptides it e.g. myristoyl pentapeptide-17 (Fig. 2) and palmitoyl tripeptide-38 (Fig. 3).

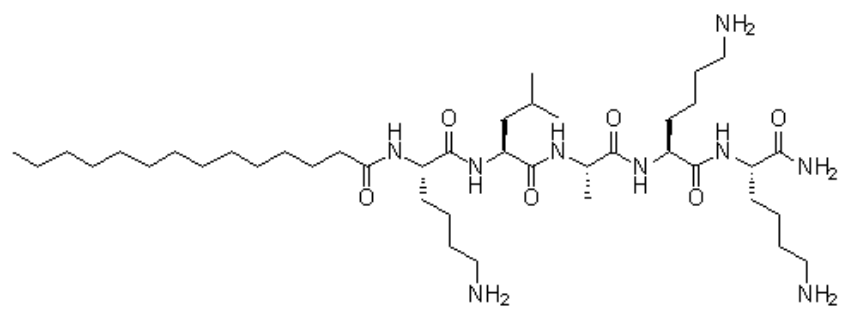

Fig. 2. Myristoyl pentapeptide-17

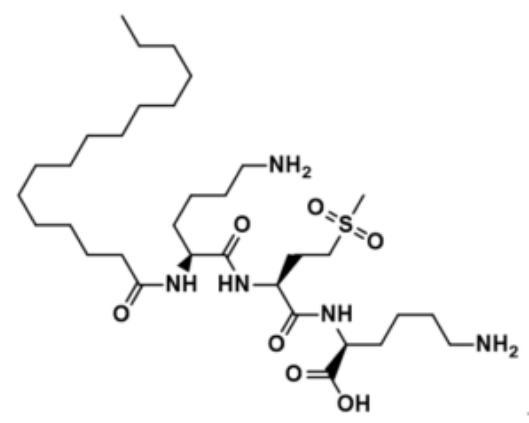

Fig. 3. Palmitoyl tripeptide-38 
Biomimetic peptydes are structurally similar to natural peptides naturally occuring in the human body. The amino acids sequence in biomimetics peptides is similar to natural peptides. Peptides may aid in cell communication between the epidermis, the outer protective layer of skin, and the dermis, the very active middle layer of skin. This could help make the skin's repair process more effective, which, in turn, may help to reduce the appearance of many of the common signs of aging such as fine lines, wrinkles and discoloration. These compounds stimulate the renewal of skin cells, increasing skin density, improving its elasticity and reducing the depth of wrinkles, stimulating the production of elastin, glucosaminoglycans (including hyaluronic acid) and collagen.

\section{Conclusion}

Peptides offer a very high biological potency and the spectrum in the fields of cosmetics is continuously growing. Biomimetic peptides are components of many new generation cosmetic products. These are substances imitate the mechanism of action of their natural counterparts. They are used in cosmetics as innovative and effective cosmetic raw materials.

\section{References}

[1] Malerich, S., \& Berson, D. (2014). Next generation cosmeceuticals: the latest in peptides, growth factors, cytokines, and stem cells. Dermatologic clinics, 32(1), 13-21. https://doi.org/10.1016/j.det.2013.09.003

[2] Gazitaeva, Z. I., Drobintseva, A. O., Chung, Y., Polyakova, V. O., \& Kvetnoy, I. M. (2017). Cosmeceutical product consisting of biomimetic peptides: antiaging effects in vivo and in vitro. Clinical, cosmetic and investigational dermatology, 10, 11-16. https://doi.org/10.2147/CCID.S97573

[3] Sanz, M. T., Campos, C., Milani, M., Foyaca, M., Lamy, A., Kurdian, K., \& Trullas, C. (2016). Biorevitalizing effect of a novel facial serum containing apple stem cell extract, pro-collagen lipopeptide, creatine, and urea on skin aging signs. Journal of cosmetic dermatology, 15(1), 24-30. https://doi.org/10.1111/jocd.12173

[4] Negahdaripour, M., Owji, H., Eslami, M., Zamani, M., Vakili, B., Sabetian, S., Nezafat, N., \& Ghasemi, Y. (2019). Selected application of peptide molecules as pharmaceutical agents and in cosmeceuticals. Expert opinion on biological therapy, 19(12), 1275-1287. https://doi.org/10.1080/14712598.2019.1652592

[5] Lima, T. N., \& Pedriali Moraes, C.A. (2018). Bioactive Peptides: Applications and $\begin{array}{llll}\text { Relevance for } & \text { Cosmeceuticals. }\end{array}$ https://doi.org/10.3390/cosmetics5010021

[6] Gorouhi, F., Maibach, H. I. (2009). Role of topical peptides in preventing or treating aged skin. International Journal of Cosmetic Science, 31(5), 327-345. https://doi.org/10.1111/j.1468-2494.2009.00490.x

[7] Lupo, M. P., \& Cole, A. L. (2007). Cosmeceutical peptides. Dermatologic therapy, 20(5), 343-349. https://doi.org/10.1111/j.1529-8019.2007.00148.x 


\title{
Liquid atomization process in medical applications
}

\author{
Tomasz R. Sosnowski, Katarzyna Dobrowolska
}

Faculty of Chemical and Process Engineering, Warsaw University of Technology, POLAND, Warsaw,

Waryńskiego 1, E-mail: Tomasz.Sosnowski@pw.edu.pl

\begin{abstract}
Aerosols are used as carriers of drugs delivered to the lungs by inhalation. One of the common methods of aerosol generation for this purpose is the atomization of liquid medicines in nebulizers. In this work, we present the most important engineering aspects of this process which create a challenge for the efficient and safe administration of pharmaceutics to patients of different ages and health conditions.
\end{abstract}

Keywords - aerosol generation, droplets, nebulization, inhalation, drug delivery.

\section{Introduction}

Drug delivery by inhalation is the most convenient way of therapy for the lung diseases such as asthma, COPD, and others. The treatment requires a simple intake of air with aerosol particles composed of a pharmaceutical agent. Since aerosols are unstable, they must be formed just before the inhalation, and this process is accomplished by inhalers of the various operation principles. If the medicine is available as a liquid, the aerosol can be obtained with the atomization process atomized done in devices known as nebulizers.

Nebulizers produce droplets with the most desirable size (typically smaller than $5 \mu \mathrm{m}$ ) that assures their penetration to the diseased regions of the lungs. Pneumatic (or: jet) nebulizers use compressed air for aerodynamic spraying the liquid into droplets of various sizes. Only the smallest droplets are emitted via the attached mouthpiece or mask, while the larger ones are separated and drain to the bulk liquid. Ultrasonic nebulizers (UN) use the energy of fast acoustic vibrations. The classic UNs atomize liquids via the creation of surface waves (frequency of $\sim 2$ $\mathrm{MHz}$ ) and are not recommended for viscous fluids and suspensions. The so-called vibrating mesh nebulizers eject aerosols from the surface of the porous membrane oscillating with the frequency of 100-200 kHz. Here, the aerosol is less polydisperse, but the droplet size distribution strongly depends on the properties of the mesh and the liquid.

The main advantage of nebulizers is their use during spontaneous breathing, which is very convenient for all groups of patients, including infants or people with disabilities. They may also be used for ventilated patients by attaching the nebulizer into the ventilation circuit.

\section{Selected technical issues of drug atomization in nebulizers}

The problem of reproducible generation of aerosol with the properties optimal for inhalation requires addressing several technical issues:

1) the influence of physicochemical properties of atomized liquid on the aerosol mass output rate and droplet size distribution;

2) the influence of actual inhalation conditions during nebulizer use, i.e., the aerosol flow rate and dilution with the auxiliary air, nebulizer position (angle), the role of attached elements (mouthpiece, inhalation mask, ventilation tubings, inhalation chamber, etc.);

3 ) the influence of technical characteristics of the nebulizer on the aerosol quality (e.g., the droplet size and velocity at the outflow from the device), which determine drug delivery to the defined regions of the respiratory system.

\section{The available experimental techniques}

As mentioned earlier, the most important characteristic of the aerosol produced by nebulizers is the droplet size distribution (DSD). Since aerosol concentration in the emitted cloud 
is very high, the application of typical methods of aerosol characterization (such as optical particle counting) is limited. High dilution of the nebulized mists with clean air required in the counters usually results in partial evaporation of droplets. Therefore, the recorded DSD shows significantly smaller droplets than initially emitted from the nebulizer. The evaporation as the effect of a high thermal capacity of the metal device also limits the use of cascade impactors, although they are typically recommended for the characterization of pharmaceutical aerosols. Some researchers suggested that impactors should be cooled to eliminate the problem, but it makes the measurements more problematic and time-consuming.

From the above, it seems that laser diffraction offers the most convenient method of DSD determination. The optical signal is scattered on the whole concentrated aerosol cloud, which can be measured directly at the nebulizer outflow (i.e., without dilution). Either the Fraunhofer or Mie theory allows determining the volume-based DSD, taking into account the refraction index of droplets and the gas phase (air). The method available in our lab uses the Spraytec ${ }^{\circledR}$ spectrometer (Malvern, UK). The atomization output rate can be obtained from the gravimetric analysis, i.e., from weighing the nebulizing vessel at the given time intervals. The essential physicochemical properties of atomized liquids are determined in our studies as follows:

a) rheologic characteristics: MCR 102 rheometer (Anton Paar, Austria),

b) the surface tension (equilibrium/dynamic values): pendant/oscillating drop tensiometer PAT-1M (Sinterface, Germany),

c) zeta-potential and crystal size (in liquid suspensions): Nanosizer ZS (Malvern, UK),

d) liquid suspension stability: Genesys 10S spectrophotometer (Thermo Scientific, USA).

Aerosol velocity profile at the nebulizer outflow can be measured by several methods, including particle image velocimetry (PIV) or laser doppler anemometry (LDA). Both techniques require sophisticated equipment, so they are not often used for nebulizer characterization. In our laboratory, we have an opportunity to use 2D LDA system (Dantec, Denmark) for this purpose [1].

\section{Conclusion}

In this communication, we indicate selected technical challenges during the assessment of the atomization process in medical nebulizers. The physiochemical characteristics of liquids and the specific properties of the nebulizing device should be analyzed simultaneously to obtain crucial information on the therapeutic potential of the emitted aerosol. We suggest that chemical engineering offers valuable scientific tools to optimize nebulizer use in clinical practice.

\section{Acknowledgments}

Work done within the NCN project No. 2018/29/B/ST8/00273.

\section{References}

[1] Dobrowolska, K., Sosnowski, T. R. (2020). Evolution of droplet size distribution in selected nebulizers. Physicochem. Probl. Miner. Processing 56(6), 32-40. https://doi.org/ 10.37190/ppmp/126312. 


\title{
Atomization of oxygen nanodispersions in isotonic saline for applications in aerosol therapy.
}

\author{
Marcin Odziomek, Katarzyna Dobrowolska, Karol Ulatowski, Paweł Sobieszuk, \\ Tomasz R. Sosnowski
}

\begin{abstract}
Faculty of Chemical and Process Engineering, Warsaw University of Technology, POLAND, Warsaw, Waryńskiego 1 Street, 00-645 Warsaw, E-mail: marcin.odziomek@pw.edu.pl
\end{abstract}

\begin{abstract}
We tested the possibility of using dispersions of oxygen nanobubbles as new carriers for inhalation drugs delivered from medical nebulizers. Their successful application may become attractive in the treatment of lung diseases, giving the possibility of simultaneous delivery of the drug and improve the oxygen supply. The results show that after atomization nanobubbles are preserved in aerosol droplets. Simultaneously, the aerosol size distribution and output rate do not change.
\end{abstract}

Keywords - nanobubbles, aerosol therapy, oxygen therapy, inhalation, nebulization, nebulizer, droplet size distribution, volume median diameter.

\section{Introduction}

Nebulization is the aerosolization method of liquid drugs delivered to the respiratory system via inhalation. It is preferentially used for patients in severe health conditions (e.g., patients under mechanical ventilation support) and often accompanies oxygen therapy [1]. The high efficiency of inhalable treatment demands micrometer-sized aerosol produced from solutions or suspensions of the active pharmaceutical active ingredient (API) in special medical devices called nebulizers. According to a mode of action: jet nebulizers, vibrating mesh nebulizers, and ultrasonic nebulizers can be distinguished.

In this work, we tested the possibility of using dispersions of oxygen nanobubbles (DONs) as an alternative liquid carrier for APIs aerosolized in different kinds of nebulizers. Nanobubbles are nanoscale gas spheres suspended in liquids with numerous characteristics distinguishing them from their macroscale counterparts [2, 3]. Excellent stability, high internal pressure, the enormous surface-to-volume ratio, and the high gas dissolution rate are essential features of NBs, leading to many promising applications in various fields of advanced science and technology [4, 5]. As stated, the nanobubbles dispersions influence the proliferation of cells and even wholeorganism growth $[6,7]$. Additionally, they can assist in treating numerous diseases, including local hypoxia, e.g., ischemic foot $[8,9]$. The successful application of DONs in the role of the carrier in aerosol therapy would have potentially an additional advantage of introducing much more oxygen - along with the aerosolized drug - to the surface of the respiratory system. This may improve the oxygen supply, especially in the respiratory diseases associated with hypoxia.

\section{Methodology}

The generation of nanobubbles was performed using the membrane method and setup with flat membrane and mechanical stirrer (originally designed by our research team). Generation processes were carried out in $0.9 \% \mathrm{NaCl}$ (physiological saline, B.Braun, Germany). The dispersions were atomized using four medical nebulizers with a different mode of action: jet nebulizer (Pari Boy SX, PARI Pharma GmbH, Germany), two vibrating mesh nebulizers - VMN (Aerogen Solo, Aerogen, USA and Intec Mesh Twister, Intec Medical, Poland) and ultrasonic nebulizer (Thomex MBU, Medbryt, Poland). 
The output rate of aerosol released from nebulizers was measured gravimetrically, and the volumetric droplet size distribution was measured using a laser diffractometer (Spraytec, Malvern Panalytical, UK). The emitted aerosols were also collected in a glass vessel that allowed to convert them to liquid again. Dispersions at each stage were analyzed using Dynamic Light Scattering (Zetasizer NanoZS, Malvern Panalytical, UK) for number-averaged densities of the size distribution of nanobubbles.

\section{Results}

The results show that after atomization, nanobubbles are still present in the liquid collected from condensing aerosol. Simultaneously, there are noticeable differences in size distributions of oxygen nanobubbles present in dispersions based on the isotonic solution before and after atomization with different nebulizers. It can be seen that their average size decreases in the case of ultrasonic and jet nebulizers and increases in both devices with vibrating mesh. (Fig. 1).

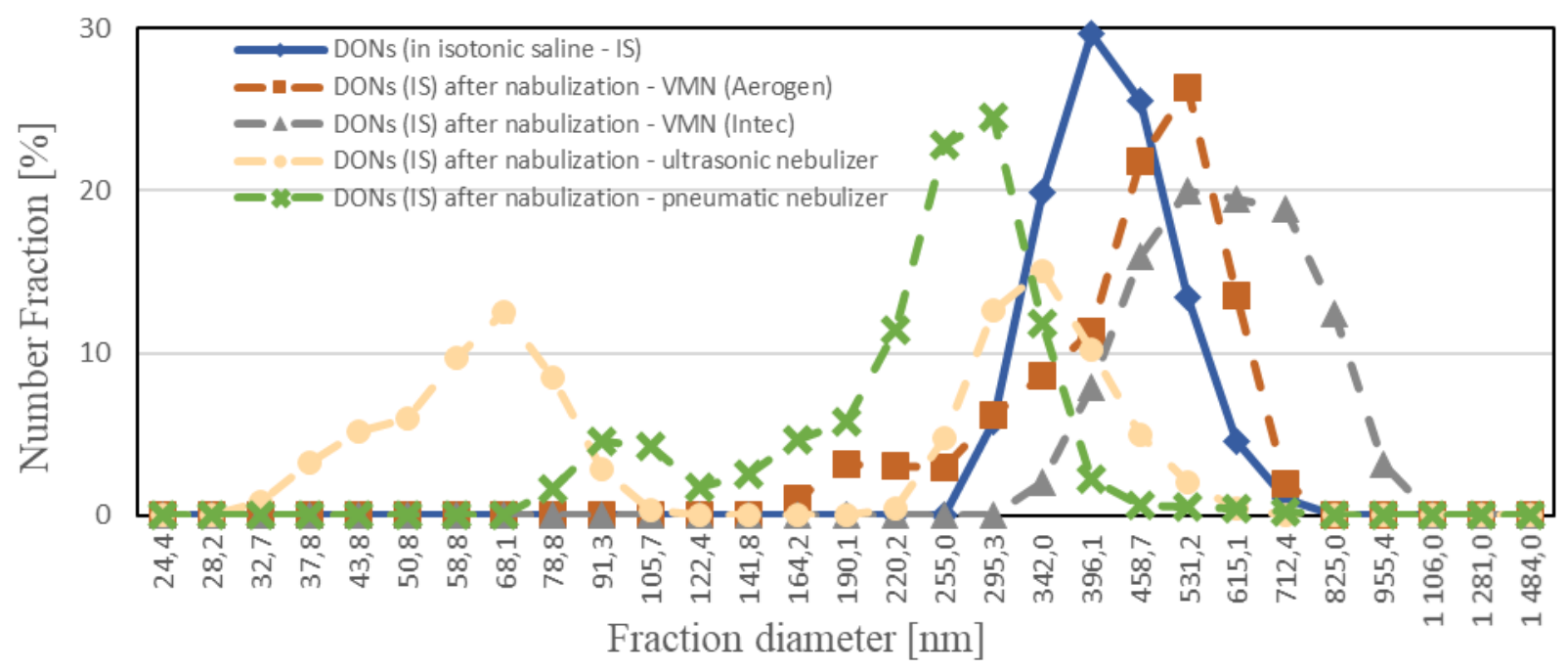

Fig. 1. The size distribution of nanoobjects in dispersions based on isotonic saline before and after atomization in different nebulizers.

The comparison of aerosol generated from liquids with and without (w/out) nanobubbles shows that the size of droplets and output rate are similar (Fig. 2, Fig. 3).

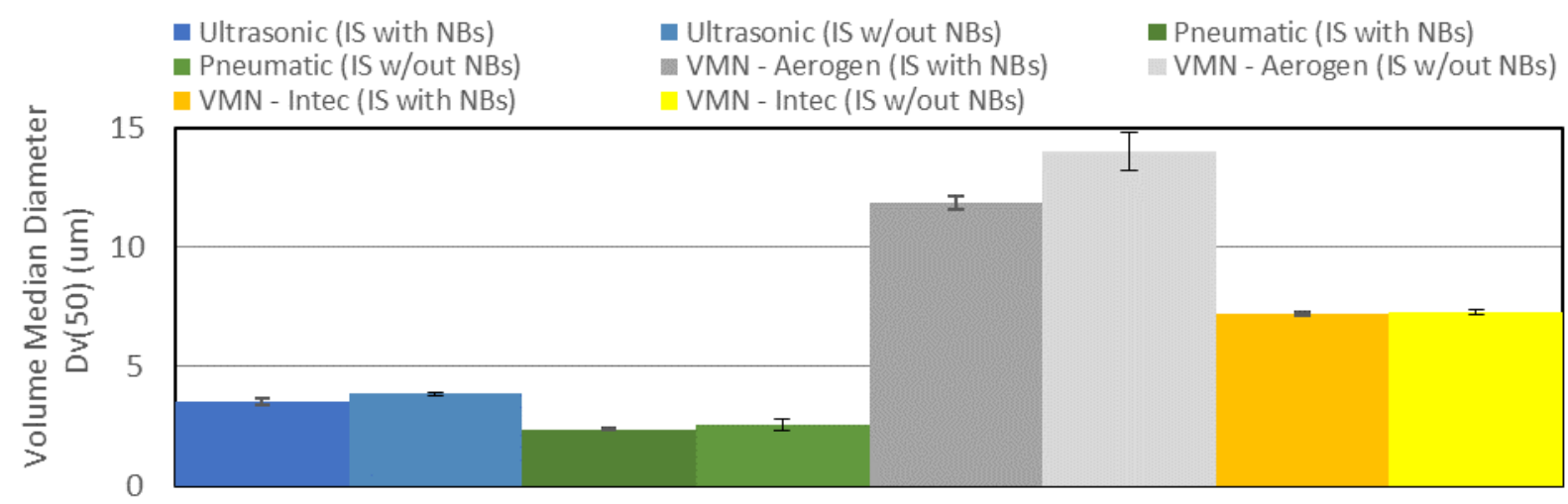

Fig. 2. Volume median diameter of aerosols dispersed by different medical nebulizers from isotonic saline and DONs in isotonic saline. 


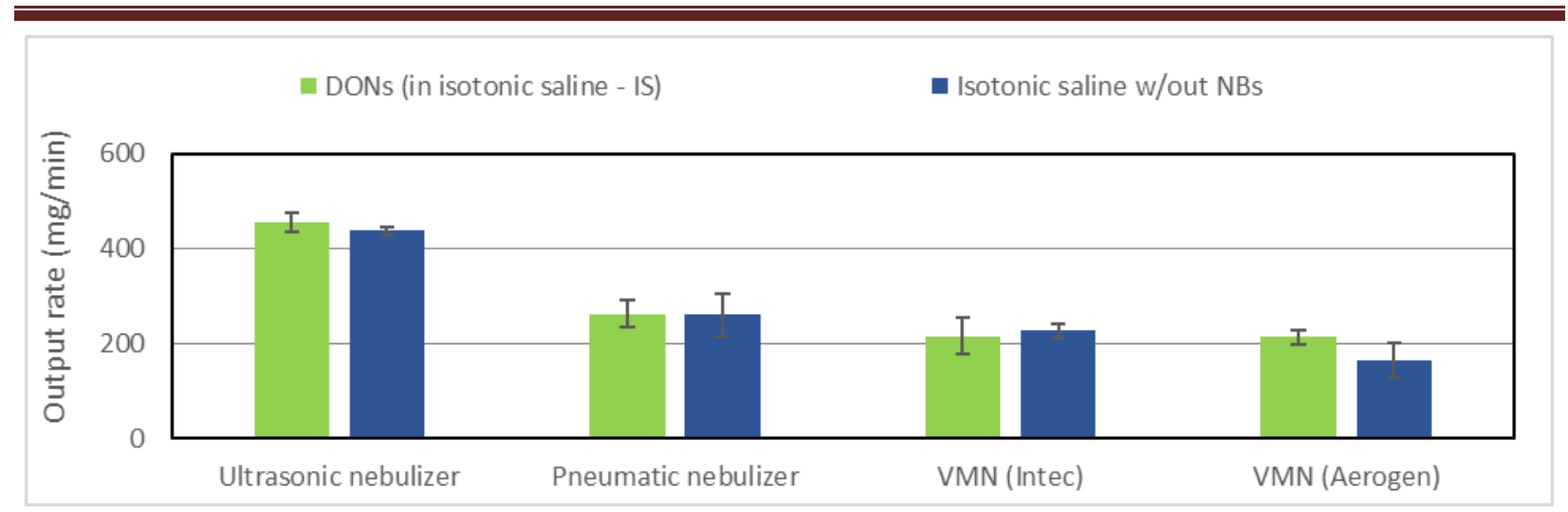

Fig. 3. Output rate of aerosols dispersed by different medical nebulizers from isotonic saline and DONs in isotonic saline.

\section{Conclusion}

The addition of nanobubbles to a nebulized solution does not require changing the construction of commercially available nebulizers or other parameters of the atomization process to obtain fine droplets with a huge potential in aerosol therapy. Simultaneously, initial results indicate that the aerosol generation process in medicinal nebulizers does not change the stability of DONs.

\section{Acknowledgments}

Work supported/Studies were funded by BIOTECHMED-1 project granted by Warsaw University of Technology under the program Excellence Initiative: Research University (ID-UB).

\section{References}

[1] Dhanani, J., Fraser, J. F., Chan, H. K., Rello, J., Cohen, J., Roberts, J. A. (2016). Fundamentals of aerosol therapy in critical care. Critical care (London, England), 20(1), 269. https://doi.org/10.1186/s13054-016-1448-5

[2] Azevedo, A., Oliveira, H., Rubio, J. (2019) Bulk nanobubbles in the mineral and environmental areas: Updating research and applications. Adv Colloid Interface Sci 271:101992. doi: 10.1016/j.cis.2019.101992

[3] Alheshibri, M., Qian, J., Jehannin, M., Craig, V.S.J. (2016) A History of Nanobubbles. Langmuir 32:11086-11100. doi: 10.1021/acs.langmuir.6b02489

[4] Ulatowski, K., Sobieszuk, P., Mróz, A., Ciach, T. (2019) Stability of nanobubbles generated in water using porous membrane system. Chem Eng Process - Process Intensif 136:62-71. doi: 10.1016/j.cep.2018.12.010

[5] Wang, Q., Zhao, H., Qi, N., et al (2019) Generation and Stability of Size-Adjustable Bulk Nanobubbles Based on Periodic Pressure Change. Sci Rep 9:1-9. doi: 10.1038/s41598-01838066-5

[6] Park, J.S., Kurata, K. (2009) Application of microbubbles to hydroponics solution promotes lettuce growth. Horttechnology, 19:212-215

[7] Ebina, K., Shi, K., Hirao, M., et al (2013) Oxygen and Air Nanobubble Water Solution Promote the Growth of Plants, Fishes, and Mice. PLoS One 8:2-8. doi: 10.1371/journal.pone.0065339

[8] Sayadi, L.R., Banyard, D.A., Ziegler, M.E., et al (2018) Topical oxygen therapy \& micro / nanobubbles : a new modality for tissue oxygen delivery. 363-374. doi: 10.1111/iwj.12873

[9] Wang, S., Yin, C., Han, X., et al (2019) Improved Healing of Diabetic Foot Ulcer upon Oxygenation Therapeutics through Oxygen-Loading Nanoperfluorocarbon Triggered by Radial Extracorporeal Shock Wave. 


\title{
Proliferation of Rindera graeca transgenic roots in oscillatory rocked disposable bioreactor
}

\author{
$\underline{\text { Kamil Wierzchowski }}^{1}$, Mateusz Kawka ${ }^{2}$, Katarzyna Sykłowska-Baranek ${ }^{2}$, Maciej Pilarek ${ }^{1}$ \\ 1. Faculty of Chemical and Process Engineering, Warsaw University of Technology, POLAND, Warsaw, \\ Waryńskiego 1, E-mail: kamil.wierzchowski.dokt@pw.edu.pl (KW), maciej.pilarek@pw.edu.pl (MP) \\ 2. Faculty of Pharmacy, Medical University of Warsaw, POLAND, Warsaw, Banacha 1, \\ E-mail: mateusz.kawka@wum.edu.pl (MK), katarzyna.syklowska-baranek@wum.edu.pl (KS-B)
}

\begin{abstract}
- Abstract - Plant biomass is a commonly known source of pharmaceutically valuable compounds. The study aimed to investigate the influence of wave-type agitation conditions on the proliferation of Ringera graeca hairy roots in the disposable bioreactor. Transgenic roots morphology, fresh biomass increases, and yield of extracellularly secreted bioactive compounds have been recognized.
\end{abstract}

- Keywords - disposable (single-use) bioreactor, wave-assisted agitation, transgenic (hairy) roots, aeration, bioprocess intensification

\section{Introduction}

Plant biomass is a commonly known source of pharmaceutically valuable compounds exhibiting a range of biological activities [1]. In vitro cultures of plant biomass are mainly performed as small scale bioprocesses, e.g., in Erlenmeyer flasks, in which aeration of culture medium is far insufficient. A low level of oxygen dissolved in culture medium significantly limits biomass proliferation and might strongly impact on metabolic pathways [2]. Disposable (single-use) bioreactors are recognized as suitable systems for increasing and controlling level of aeration in cultures of isolated plant cells, tissues, or cultures. In such approaches, agitation is achieved by continuous horizontal oscillation movement of the whole disposable container fixed in a rocker unit. Under gentle conditions of continuous rocking, the interfacial area formed between the gas and culture medium is renewed by waving and therefore the bubble-free surface aeration of the liquid phase is successfully accomplished. Simultaneously, the generated waves induce agitation of large volumes of culture medium and facilitate the dispersion of medium components, enhancing the homogeneity of the culture microenvironment [3]. The aim of the study was to investigate the proliferation of Ringera graeca transgenic roots in the disposable bioreactor. The influence of basic operational parameters defining wave-assisted agitation, i.e., angle $(\alpha)$ and frequency $(\omega)$ of oscillations, on transgenic roots morphology, fresh biomass increase $(F B)$, and yield of extracellularly secreted secondary metabolites $\left(C_{\mathrm{NQ}}\right)$, has been recognized.

\section{Materials and methods}

ReadyToProcess WAVE 25 bioreactor system (WAVE 25) equipped with $2 \mathrm{dm}^{3}$ disposable bag-like container (Cellbag ${ }^{\mathrm{TM}} 2 \mathrm{~L}$ ), has been applied for bioprocessing of Rindera graeca hairy roots at the following ranges of the operational parameters: $\alpha=2-10^{\circ}$ and $\omega=10-40 \mathrm{~min}^{-1}$. Hairy roots of $R$. graeca were maintained for 28 days at $25{ }^{\circ} \mathrm{C}$, with harvesting samples of culture medium twice a week. Lyophilized and micronized hairy roots, as well as samples of culture medium, were extracted with organic solvent and the level of naphthoquinone-analogues secondary metabolites has been chromatographically analyzed. 


\section{Results}

The values of $F B$ and $C_{\mathrm{NQ}}$ noted for $R$. graeca hairy roots cultured in WAVE 25 at various conditions of continuously rocking resulted in wave-type agitation has been shown in Table 1 .

Table 1

The values of $F B$ and $C_{\mathrm{NQ}}$ noted for cultures of $R$. graeca hairy roots in the WAVE 25 system

\begin{tabular}{|c|c|c|c|}
\hline \multicolumn{2}{|c|}{ conditions of wave-type agitation } & \multirow{2}{*}{$\begin{array}{c}F B \\
{[-]}\end{array}$} & \multirow{2}{*}{$\begin{array}{l}C_{\mathrm{NQ}} \\
{[\mu \mathrm{g}]}\end{array}$} \\
\hline$\alpha\left[^{0}\right]$ & $\omega\left[\mathrm{min}^{-1}\right]$ & & \\
\hline \multirow{4}{*}{6} & 10 & 1.85 & 420.0 \\
\hline & 20 & 5.38 & 134.8 \\
\hline & 30 & 1.50 & 75.12 \\
\hline & 40 & \multicolumn{2}{|c|}{ disintegration of biomass } \\
\hline 2 & \multirow{5}{*}{20} & 8.14 & 384.8 \\
\hline 4 & & 6.22 & 228.2 \\
\hline 6 & & 5.38 & 134.8 \\
\hline 8 & & 3.84 & 85.93 \\
\hline 10 & & 1.78 & 40.68 \\
\hline
\end{tabular}

In the case of cultured transgenic roots morphology, two different morphological forms have been observed: highly ramified and compact structures. For cultures maintained at $\alpha \leq 6^{\circ}$ and $\omega \leq 20 \mathrm{~min}^{-1}$ the morphology was highly ramified, as for typical cultures performed in Erlenmeyer flask. But in other cultures, the hairy roots agglomerated into compact structures.

\section{Conclusion}

Morphology of transgenic roots strongly depended on conditions of wave-assisted agitation supported by the WAVE 25 bioreactor system. Hairy roots grew as typical highly ramified biomass at low sets of $\alpha$ and $\omega$. Intensified wave-assisted agitation resulted in the agglomeration of hairy roots into compact structures. The highest increase of $R$. graeca transgenic roots fresh biomass, i.e., over $800 \%$, has been observed for cultures performed at $\alpha=2^{0}$ and $\omega=20 \mathrm{~min}^{-1}$. In the case of secondary metabolites secretion, the highest level of naphthoquinone-analogues, i.e., $420.0 \mu \mathrm{g}$, has been observed for cultures performed at $\alpha=6^{0}$ and $\omega=10 \mathrm{~min}^{-1}$.

\section{Acknowledgements}

Research was funded by (POB Biotechnology and Biomedical Engineering) of Warsaw University of Technology within the Excellence Initiative: ResearchUniversity (IDUB) programme.

\section{References}

[1] Ochoa-Villarreal, M., Howat, S., Hong, S., Jang, M. O., Jin, Y.-W., Lee, E.-K., Loake, G. L. (2016). Plant cell cultures strategies for the production of natural products. BMB Reports, 49(3), 149-158. https://doi.org/10.5483/BMBRep.2016.49.3.264

[2] Nowak, B., Kawka, M., Wierzchowski, K., Sykłowska-Baranek, K., Pilarek, M. (2021). MTMS-Based Aerogel Constructs for Immobilization of Plant Hairy Roots: Effects on Proliferation of Rindera graeca Biomass and Extracellular Secretion of Naphthoquinones. Journal of Functional Biomaterials, 12, 19. https://doi.org/10.3390/jfb12010019

[3] Wierzchowski, K., Grabowska, I., Pilarek, M., (2020). Efficient propagation of suspended HL-60 cells in a disposable bioreactor supporting wave-induced agitation at various Reynolds number. Bioprocess and Biosystems Engineering, 43, 1973-1985. https://doi.org/10.1007/s00449-020-02386-6. 


\title{
Adaptation of the sensor method for the determination of mixing time in a rocking single-use bioreactor
}

\author{
Mateusz Bartczak, Kamil Wierzchowski, Maciej Pilarek \\ Faculty of Chemical and Process Engineering, Warsaw University of Technology, POLAND, Warsaw, \\ Waryńskiego 1, E-mail: mateusz.bartczak.dokt@pw.edu.pl (MB), kamil.wierzchowski.dokt@pw.edu.pl (KW), \\ maciej.pilarek@pw.edu.pl (MP)
}

\begin{abstract}
The aim of the study was to determine the characteristics of mixing time in a rocking singleuse bioreactor equipped with a 2-litre bag-like container by the sensor method. Results have shown that the frequency of rocking movement has the biggest influence on the values of mixing time.
\end{abstract}

Keywords - single-use bioreactor, wave-type agitation, rocking motion, mixing time, sensor method, design of experiments.

\section{Introduction}

Nowadays, single-use bioreactors (SUBs) have gained significant applicability across the whole bioprocess and biopharmaceutical industries. The distinctive feature of SUBs is the use of disposable bag-like containers, as vessels made from multi-layer plastics [1]. Many different SUBs are currently available on the market, with rocking bioreactors being the most popular [2]. The liquid phase inside a bag-like container is agitated by the oscillatory movement of the bioreactor platform - this motion results in wave propagation on the liquid surface. Rocking bioreactors are appreciated for their very gentle mixing mechanism, suitable for fragile biomass, e.g. shear-sensitive mammalian cells cultures and integrated forms of biomass, e.g. hairy roots, and bubble-free aeration without sparging equipment $[2,3]$.

Hydrodynamical properties of liquid flow inside rocking SUBs are not fully systematised. Hence, the aim of this study was to quantitatively determine the influence of operating parameters defining wave-assisted agitation on the values of mixing time reached in commercially available WAVE 25 bioreactor. Mixing time is a parameter that allows for easy assessment of mixing quality inside the system and is recognised as an important feature that affects the applicability of bioreactors in bioprocess engineering [4].

\section{Materials and methods}

ReadyToProcess WAVE 25 (GE Healthcare) bioreactor system was utilised. The bioreactor was equipped with Cellbag $2 \mathrm{~L}$ disposable bag-like container (Fig. 1).

The mixing time values were determined using the sensor method. A conventional $\mathrm{pH}$ electrode was used (EPP-1, Elmetron, Poland) to monitor $\mathrm{pH}$ values after injection of a tracer. Data acquisition was performed automatically via a universal meter (CX-401, Elmetron, Poland). The electrode was mounted on the upper side of the vessel (Fig. 2).

Mixing time was defined as the moment in which the value of homogeneity Ho entered the range of $100 \% \pm 5 \%$ for the last time (based on [4]). Ho was calculated from the following equation:

$$
H o(t)=\frac{p H(t)-p H_{0}}{p H_{\infty}-p H_{0}}
$$

In each experiment, $2.5 \mathrm{~mL} / \mathrm{L}$ of the tracer $(\mathrm{NaOH}$ solution, $0.5 \mathrm{~mol} / \mathrm{L})$ was added to an $\mathrm{HCl}$ solution of $\mathrm{pH}=3$. The measurement of $\mathrm{pH}$ changes was started at the timepoint of tracer injection. 


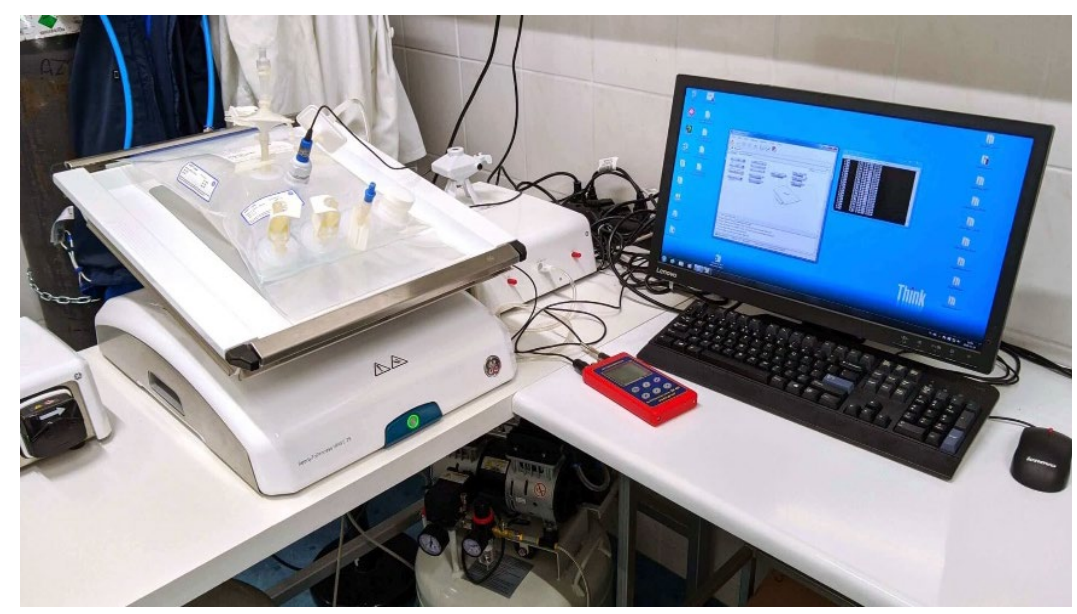

Fig. 1. Experimental setup: ReadyToProcess WAVE 25 bioreactor and the CX-401 meter connected to a computer.

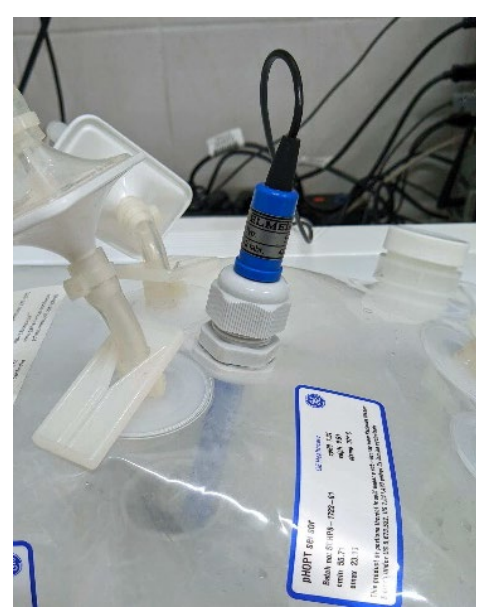

Fig. 2. pH electrode mounted on the Cellbag $2 \mathrm{~L}$ vessel.

Four bioreactor operating parameters were investigated with regards to their significant or insignificant influence on the values of mixing time: rocking angle, rocking frequency, volume of liquid inside the vessel and rocking acceleration. A design of experiments (DoE) approach was used to plan the experimental values of the parameters. With three selected values for each parameter, a full experimental plan consisted of 81 variants. In total, 243 measurements have been

performed.

\section{Results}

Average values of mixing time for the experimental values of operating parameters are presented in Table 1.

Table 1.

Average values of mixing time based on the experimental data.

\begin{tabular}{llr}
\hline $\begin{array}{l}\text { Operating } \\
\text { parameter }\end{array}$ & $\begin{array}{l}\text { Experimental } \\
\text { value }\end{array}$ & \multicolumn{2}{l}{$\begin{array}{l}\text { Average } \\
\text { mixing time } \\
(\mathrm{s})\end{array}$} \\
\hline Rocking & 2 & 451 \\
frequency & 21 & 36 \\
$\left(\right.$ min $\left.^{-1}\right)$ & 40 & 5 \\
\hline Rocking & 2 & 269 \\
angle $\left(^{\circ}\right)$ & 7 & 150 \\
& 12 & 73 \\
\hline
\end{tabular}

\begin{tabular}{llr}
\hline $\begin{array}{l}\text { Operating } \\
\text { parameter }\end{array}$ & $\begin{array}{l}\text { Experimental } \\
\text { value }\end{array}$ & \multicolumn{2}{l}{$\begin{array}{l}\text { Average } \\
\text { mixing time } \\
\text { (s) }\end{array}$} \\
\hline Volume of & 0.2 & 72 \\
liquid $\left(\mathrm{dm}^{3}\right)$ & 0.6 & 186 \\
& 1.0 & 235 \\
\hline Acceleration & 30 & 160 \\
$(\%)$ & 60 & 166 \\
& 90 & 167 \\
\hline
\end{tabular}

\section{Conclusions}

In the studied system, the measured values of mixing time ranged from 3 to $1800 \mathrm{~s}$. According to the acquired data, parameters that significantly influenced the mixing times in a rocking bioreactor are the rocking angle, rocking frequency, and liquid volume. The parameter which has the most substantial impact on the mixing time was the rocking frequency. The 
rocking acceleration parameter showed no significant influence on experimentally reached values of mixing time.

Performed adaptation of the sensor method proved to be an effective way of measuring mixing time in the studied system. The adaptation allows for the potential use of different sensors and could be applied in similar setups.

\section{Acknowledgments}

Research was funded by the Warsaw University of Technology, grant IChem-1.

\section{References}

[1] Vanhamel, S., \& Piton, C. (2019). Production of Disposable Bags - A Manufacturer's Report. In Single-Use Technology in Biopharmaceutical Manufacture (pp. 95-116). John Wiley \& Sons, Ltd. https://doi.org/10.1002/9781119477891.ch8

[2] Jossen, V., Eibl, R., \& Eibl, D. (2019). Single-Use Bioreactors - An Overview. In SingleUse Technology in Biopharmaceutical Manufacture (pp. 37-52). John Wiley \& Sons, Ltd. https://doi.org/10.1002/9781119477891.ch4

[3] Pilarek, M., Sobieszuk, P., Wierzchowski, K., \& Dąbkowska, K. (2018). Impact of operating parameters on values of a volumetric mass transfer coefficient in a single-use bioreactor with wave-induced agitation. Chemical Engineering Research and Design, 136, 1-10. https://doi.org/10.1016/j.cherd.2018.04.012

[4] Bauer, I., Dreher, T., Eibl, D., Glöckler, R., Husemann, U., John, G. T., Kaiser, S. C., Kampeis, P., Kauling, J., Kleebank, S., Kraume, M., Kuhlmann, W., Löffelholz, C., Meusel, W., Möller, J., Pörtner, R., Sieblist, C., Tscheschke, B., \& Werner, S. (2020). Recommendations for process engineering characterisation of single-use bioreactors and mixing systems by using experimental methods (2nd Edition). Dechema Biotechnologie. https://dechema.de/en/Single_Use_PE_Characterization-path-123211,124930.html 


\title{
Nanohybrid platform based on carbon material for glucose detection
}

\author{
$\underline{\text { Maria Kuznowicz }}{ }^{1}$, Artur Jędrzak ${ }^{2}$, Teofil Jesionowski ${ }^{3}$ \\ - $\quad$ 1. Institute of Chemical Technology and Engineering, Faculty of Chemical Technology, Poznan University \\ of Technology, POLAND, Poznań, Berdychowo 4, PL-60965, E-mail: maria.m.kuznowicz@doctorate.put.poznan.pl \\ - 2. Institute of Chemical Technology and Engineering, Faculty of Chemical Technology, Poznan University \\ of Technology, POLAND, Poznań, Berdychowo 4, PL-60965, E-mail: artur.jedrzak@put.poznan.pl \\ - 3. Institute of Chemical Technology and Engineering, Faculty of Chemical Technology, Poznan University of \\ Technology, POLAND, Poznań, Berdychowo 4, PL-60965, E-mail: teofil.jesionowski@put.poznan.pl

\begin{abstract}
The main goal of the activities was to create a hybrid nanoplatform decorated with copper oxide. The produced matrix was used for the non-enzymatic detection of glucose in model solutions and blood serum.
\end{abstract}

Keywords - sensor, non-enzymatic sensor, nanomaterials, hybrid material, glucose detection, amperometric sensor

\section{Introduction}

Sensors are becoming increasingly common in food and biomedical industries, as well as in clinical diagnostics, biological, and environmental applications. Glucose sensors, in particular, are critical for diabetes diagnosis and tracking food quality. Sensors are instruments made up of active sensing materials coupled with a transducer of a signal. These devices transmit the signal from a reaction shift or selective compound and generate a signal (such as electrical, thermal, or optical output signals) that is transformed for further processing into digital signals. Because of their outstanding electro-catalytic activity, selectivity, and sensitivity, amperometric glucose biosensors using glucose oxidase have been widely investigated for the detection of glucose levels in blood and food products [1].

Enzyme-based biosensors, on the other hand, have drawbacks such as unpredictable responses caused by changes in $\mathrm{pH}$, temperature, humidity, and the presence of interfering chemicals. Additional drawbacks include enzyme leaching, direct electron transfer between the active sites of enzymes (flavin adenine dinucleotide or FAD), and electrode replacement difficulties due to the redox centre of FAD being deeply embedded in enzyme molecules. An alternative strategy based on direct electro-oxidation with non-enzymatic glucose sensors has been proposed to address these challenges. The main aim was to find a suitable catalyst with direct electrochemical activity and to resolve the limitations of currently available enzymatic glucose sensors [2].

The majority of non-enzymatic glucose sensors investigated are focused on noble metal substrates such as platinum, gold, palladium, alloys of $\mathrm{Pt}, \mathrm{Pd}, \mathrm{Pb}$, and $\mathrm{Rh}$, metals such as copper, nickel, zinc, manganese, metal compounds, metal oxide composites, polymer-modified composites, carbon nanotubes, carbon nanofibers, graphene, and their composites, doped diamond-like materials, and nanodiamonds, as well as carbon nanotubes. Due to their high electrochemical activity, non-toxicity, low cost, and potential integration with other materials, metals/metal oxides, especially copper and its oxides, are promising for the preparation of nonenzymatic glucose sensors. Copper and copper oxide-based nanomaterials have been studied for their glucose sensing properties as well as for improving the catalytic activity of other nanomaterials used as support matrices [3]. 
In this work, a hybrid material was produced based on multi-wall carbon nanotubes and a polymer coating. The material was then decorated with copper(II) oxide using electrodeposition. The schematic steps of the process are presented in the Fig. 1.

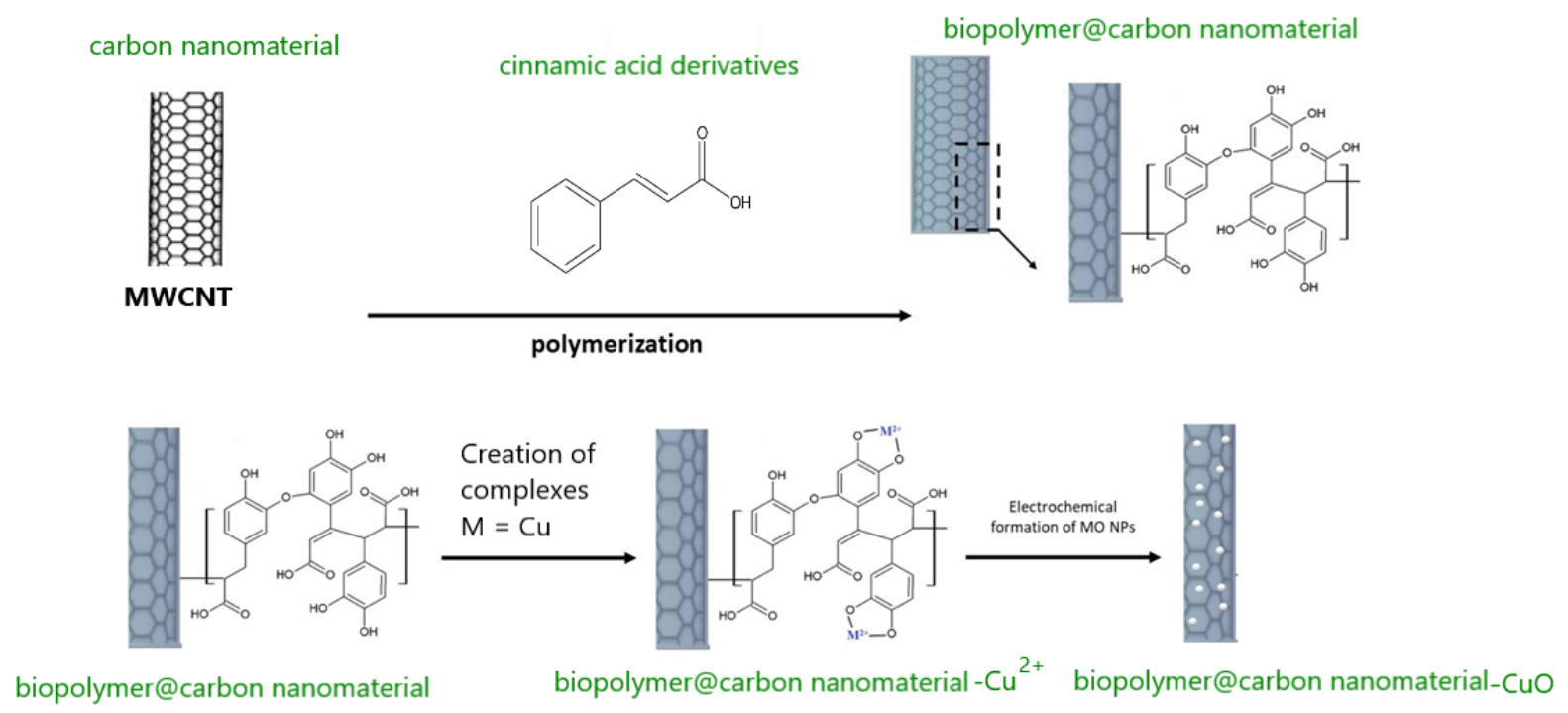

Fig.1. Schematic representation of the activities performed as part of the experiment

Besides, good accuracy and high precision have been demonstrated for quantifying glucose concentrations in human serum samples. Observed good features of the proposed sensor have great potential in creating sensitive and selective non-enzymatic glucose sensors.

\section{Conclusion}

In this work, the novel nanohybrid platform has been proposed. Copper(II) oxide was produced by the electrodeposition process on the matrix surface. This made it possible to use the matrix as a non-enzymatic glucose sensor. The proposed sensor was characterized by good analytical properties and was successfully used to detect glucose in blood serum.

\section{Acknowledgments}

This work was financed and prepared as part of a research project supported by the National Science Center Poland, no. 2017/27/B/ST8/01506.

\section{References}

[1] Sridara, T., Upan, J., Saianand, G., Tuantranont, A., Kuruwan, C., Jakmunee, J. (2020). Non-enzymatic amperometric glucose sensor based on carbon nanodots and copper oxide nanocomposites electrode, 20,808. doi: 10.3390/s20030808.

[2] Batool, R., Rhouati, A., Nawaz, M.H., Hayat, A., Marty, J.L (2019) A review of the constriction of nano-hybrids for electrochemical biosensing of glucose. Biosensors 9, 46, doi:10.3390/bios9010046

[3] Carbone, M., Tagliatesta, P. (2020) NiO grained-flowers and nanoparticles for ethanol sensing. Materials, 13,1880. doi:10.3390/ma13081880. 


\title{
Glucose detection in food real samples using an amperometric biosensor
}

\author{
$\underline{\text { Artur Jędrzak }}^{1}$, Maria Kuznowicz $^{2}$, Teofil Jesionowski ${ }^{3}$ \\ 1. Institute of Chemical Technology and Engineering, Faculty of Chemical Technology, Poznan University of \\ Technology, POLAND, Poznań, Berdychowo 4, PL-60965, E-mail:artur.jedrzak@put.poznan.pl \\ 2. Institute of Chemical Technology and Engineering, Faculty of Chemical Technology, Poznan University of \\ Technology, POLAND, Poznań, Berdychowo 4, PL-60965, E-mail: maria.m.kuznowicz@doctorate.put.poznan.pl \\ 3. Institute of Chemical Technology and Engineering, Faculty of Chemical Technology, Poznan University of \\ Technology, POLAND, Poznań, Berdychowo 4, PL-60965, E-mail: teofil.jesionowski@put.poznan.pl
}

- Abstract - The goal of the research was to construct an amperometric biosensor. The biosensor was constructed on a bioinspired nanomaterial and glucose oxidase as a bioreceptor. The biosensor was used to measure glucose in real solutions of various food products.

- Keywords - amperometric sensor, biosensor, glucose detection, food samples, glucose oxidase, hybrid materials, nanomaterials

\section{Introduction}

Blood plasma glucose levels rise as a result of dietary carbohydrate consumption. Larger and longer rises in blood sugar levels after meals can play a role in the development of vascular complications of diabetes. The high sugar content in today's diet has been linked to a variety of chronic health problems, including obesity, diabetes, cardiovascular disease, and fatty liver disease [1].

While several methods for glucose analysis are available, such as spectrophotometry, spectrofluorometry, conductometry, gas chromatography, mass spectrometry, colorimetry, reflectance photometry, and so on, the majority of these methods require complex procedures, low reproducibility, and instability. As a result, a simple, responsive, stable, accurate, microvolume, reproducible, and low-cost glucose analysis method must be developed as a viable alternative to existing methods [2].

Electrochemical methods are currently receiving a lot of attention because they are quick, responsive, fast, reliable, and cost-effective as compared to other methods. Enzyme-based electrodes, which combine enzyme specificity with the high sensitivity of electrochemical instruments, are now widely used in clinical diagnostics and food analysis. Biosensor systems with higher materials sensitivity, stability, selectivity, and durability are appealing alternatives among biosensors for determining the level of glucose in various media such as commercial samples (drinks, glucose-based supplements juices, fruits) or body fluids (blood plasma, whole blood) [3].

The immobilization of the widely used glucose oxidase (GOx) onto the electrode surface is an important step in enzyme-based electrochemical glucose sensing, as it facilitates successful electron transfer at the enzyme electrode interface, which is difficult because the active core (FAD) of GOx is deeply buried within the enzyme [3].

The main goal of the research was to create a hybrid matrix. Then, glucose oxidase was immobilized on its surface. The obtained nanoplatform was characterized using physicochemical and biochemical techniques. Finally, a second-generation biosensor was constructed using an external mediator. Several electrochemical tests have been carried out to optimize its performance. Some glucose-containing compounds, as well as real solutions, were tested. The obtained results were compared with the spectrophotometric technique to more precisely check the effectiveness of the sensor. 


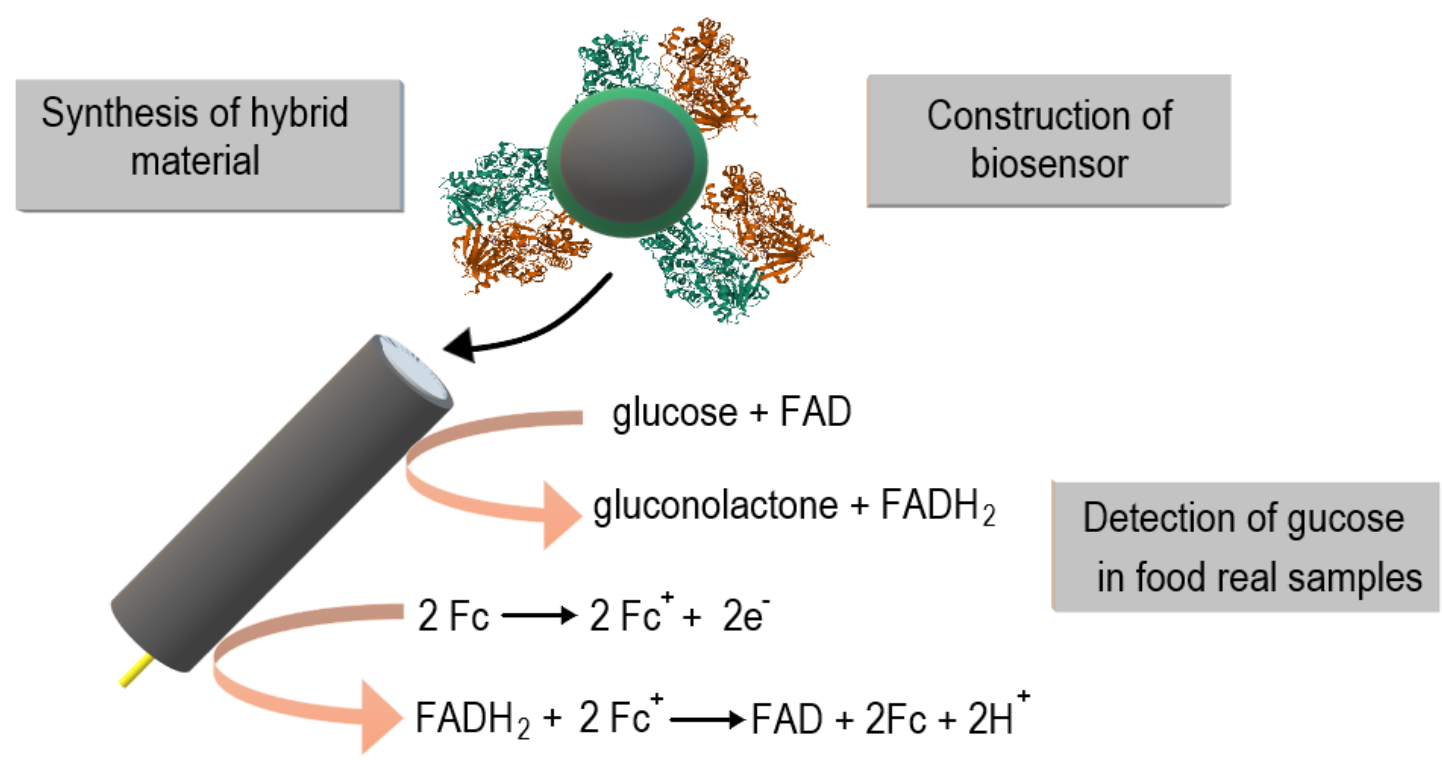

Fig.1. Schematic presentation of research work

The presented sensor was characterized by good selectivity, stability, and a wide range of linearity. The generated platform can serve as a matrix for the detection of other compounds in food when a different bioreceptor is used.

\section{Conclusion}

This paper presents an amperometric biosensor based on a hybrid material and glucose oxidase. The presented sensor was characterized by high sensitivity and selectivity. Besides, it was used with great efficiency to detect glucose in real solutions. Our proposed biosensors, which are based on hybrid micro and nanoplatforms, show promise as a biodetector in the food industry and diabetes care.

\section{Acknowledgments}

This work was financed and prepared as part of a research project supported by the National Science Center Poland, no. 2017/27/B/ST8/01506.

\section{References}

[1] Artigues, M., Abellà, J., Colominas, S. (2017). Analytical Parameters of an Amperometric GlucoseBiosensor for Fast Analysis in Food Samples. Sensors, 17, 2620, doi: $10.3390 /$ s17112620

[2] Jędrzak, A., Rębiś, T., Klapiszewski, Ł., Zdarta, J., Milczarek, G., Jesionowski, T. (2018) Carbon paste electrode based on functional GOx/silica-lignin system to prepare an amperometric glucose biosensor. Sensors Actuators B: Chem., 256, 176-185. doi: 10.1016/j.snb.2017.10.079

[3] Jayanthi Kalaivani, G., Suja, S.K (2019). Nanomolar level sensing of glucose in food samples using glucose oxidaseconfined MWCNT-Inulin- $\mathrm{TiO}_{2}$ bio-nanocomposite. Food Chemistry, 298, 124981, doi:10.1016/j.foodchem.2019.124981

[4] Jędrzak, A, Rębiś, T, Kuznowicz, M., Jesionowski, T (2019) Bio-inspired magnetite/lignin/polydopamine-glucose oxidase biosensing nanoplatform. From synthesis, via sensing assays to comparison with others glucose testing techniques. Int. J. Biol. Macromol. 127, 677-682 doi: 10.1016/j.ijbiomac.2019.02.008 


\section{GREEN CHEMISTRY}




\title{
Supercritical $\mathrm{CO}_{2}$ extraction as green and waste-free technology - applications and perspectives
}

\author{
Katarzyna Tyśkiewicz, Marcin Konkol, Agnieszka Dębczak \\ Supercritical Extraction Department, ŁUKASIEWICZ Research Network - New Chemical Syntheses Institute, al. \\ Tysiąclecia Państwa Polskiego 13A, 24-110 Puławy, POLAND, \\ E-mail: katarzyna.tyskiewicz@ins.lukasiewicz.gov.pl
}

\begin{abstract}
Supercritical $\mathrm{CO}_{2}$ extraction has attracted growing interest due to its unique properties such as high diffusivity, low surface tension, and ease of solvent removal at the end of the process. In addition, $\mathrm{scCO}_{2}$ is the most environmentally acceptable solvent possessing many advantages compared with the conventional aqueous and solvent-based processing.
\end{abstract}

Keywords - supercritical carbon dioxide, plant extract, scaling-up, separation, enrichment, fractionation, molecular distillation, supercritical solvent impregnation

\section{Introduction}

In recent years, the supercritical fluid extraction (SFE) of natural plant materials, with the most commonly used solvent being carbon dioxide, has been considered one of the most effective alternatives to conventional solvent extraction of bioactive compounds and enriched fractions [1]. In contrast to classical methods of the extraction of bioactive compounds from natural plant materials, such as maceration, distillation, liquid liquid extraction or Soxhlet extraction, supercritical fluid extraction is a green waste-free process. Since the SFE process eliminates the necessity of using large amounts of organic solvents, often toxic and harmful to environment, it perfectly fits into a definition of green chemistry as the one focused on the designing of products and processes that minimizes the use and generation of hazardous substances [2]. As far as the recovery of bioactive substances and their preservation in extract are concerned, moderate critical temperature $\left(31.2^{\circ} \mathrm{C}\right)$ is a crucial parameter. By changing the pressure and temperature of the fluid $\left(\mathrm{scCO}_{2}\right)$, the properties i.e. solvation power can be tuned to extract plant matrices with increased efficiency and selectivity with more selective product recovery. However, extraction of more polar phytochemicals incorporated in the cell walls structure requires the utilization of a polar co-solvent such as water or ethanol to overcome the problem of $\mathrm{CO}_{2}$ low polarity [3]. It is also noteworthy that, since $\mathrm{scCO}_{2}$ exhibits antibacterial properties, the obtained extracts are essentially sterile. Due to comprehensiveness of supercritical technology it has been recognised as an useful device allowing extraction of plant constituents exerting a wide range of nutritional, functional and biological activities. Hence, $\mathrm{scCO}_{2}$ extracts have been advantageously applied in the broad range of industrial branches including food, cosmetics, pharmaceutics, specialty lubricants and fine chemicals.

$\mathrm{SFE}$ is one of the most common non-conventional technique, particularly when it uses supercritical $\mathrm{CO}_{2}$ as a green solvent, that can be easily applicable at industrial scale. In large scale the fluid could be recycled which minimizes waste generation. For instance, the use of supercritical fluid extraction in food industry involves hop cones extraction and decaffeination of coffee resulting in obtaining pure caffeine, which may be further used in other industries [4].

When researching SFE technology, lab-scale studies are most often performed for different purposes using small volumes of feed material. It mainly intends to optimize extraction parameters for different materials and to maximise total extract yields and, recovery of target bioactive constituents or groups of them. For further development of scale-up procedures Response Surface Methodology (RSM) is being applied. Models based on Central Composite Design (CCD) were proved to be valid for a large volume extraction processes. It is worth noting

$3^{\text {rd }}$ INTERNATIONAL SCIENTIFIC CONFERENCE “CHEMICAL TECHNOLOGY AND ENGINEERING”, JUNE 21-24 ${ }^{\mathrm{TH}}, 2021$, LVIV, UKRAINE 
that most investigations $(60 \%)$ towards non-conventional extraction technology were performed with SFE [5]. In terms of cost effectiveness, time of processing is the crucial parameter affecting industrial SFE- $\mathrm{CO}_{2}$. It can result either with incomplete extraction or even bioactive compounds degradation when the extraction time is too short or too long, respectively [6].

The SFE is applied, for instance, in (1) impregnation, textile industry (Adidas china) DyeCoo ${ }^{\circledR}$ technology, which pressurises powder dye into polyester fabric using $\mathrm{CO} 2$, uses zero water and reduces energy and chemical use by $50 \%$ compared to traditional dyeing methods. The $\mathrm{CO}_{2}$ is even vacuumed out after use, allowing for $95 \%$ recovery and reuse, (2) material dyeing based on plant-derived dyes from different plant representatives, (3) by-products recovery (fruit and vegetable waste), (4) extraction of lignocellulosic materials, (5) deorodization of fats and oils, performed at relatively low temperature and critical pressure of the solvent (6) phospholipids separation, (7) aromas and flavors extraction. The SFE in a material industry in terms of aerogels drying is also worth mentioning. The aim of the process is to remove the organic solvent by placing the gel in a pressure vessel filled with liquid carbon dioxide which is then heated to reach its critical parameters. The significant point in drying aerogels is a gradual depressurization.

Current and future challenges in scaling-up extraction of bioactive compounds require a parallel development of suitable analytical methods to monitor the process and ensure high yield and quality.

\section{Conclusion}

Even though, the SFE has been widely studied, future researches should be focused towards utilization of a number of bioactive compounds derived from natural materials. Hence, the efforts should be made in terms of the isolation and identification of new compounds.

\section{References}

[1] da Silva, R. P. F. F., Rocha-Santos, T. A. P., Duarte, A. C. (2016). Supercritical fluid extraction of bioactive compounds. Trends in Analytical Chemistry, 76, 0.1016/j.trac.2015.11.013

[2] "Green Chemistry". (2006). United States Environmental Protection Agency.

[3] Khaw, K. I., Parat, M. I., Shaw, P. N. (2017). Solvent Supercritical Fluid Technologies to Extract Bioactive Compounds from Natural Sources: A Review. Molecules, 22, 10.3390/molecules22071186

[4] De Marco, I., Riemma, S., Iannone, R. (2017). Supercritical carbon dioxide decaffeination process: a life cycle assessment study. Chemical Engineering Transactions, 57, 10.1016/j.supflu.2017.11.005

[5] Belwal, T., Chemat., F., Venskutonis, P. R., Cravotto, G., Jaiswal, D. K., Bhatt, I. D., Devkota, H. P., Luo, Z. (2020). Recent advances in scaling-up of non-conventional extraction techniques: Learning from successes and failures. Trac. Trends Anal. Chem. 127, 10.1016/j.trac.2020.115895

[6] Uwineza, T. J., Waśkiewicz A. (2020). Recent advances in supercritical fluid extraction of natural bioactive compounds from natural plant materials. Molecules, 25, $10.3390 /$ molecules 25173847 


\section{Preparation and characterization of thermoplastic starch/polylactide blends with palmitic acid}

$\underline{\text { Justyna Ostrowska }^{1}, \text { Magdalena Paluch }^{2}, \text { Karolina Sołtan }^{3}, \text { Waldemar Sadurski }}{ }^{4}$, Piotr Tyński ${ }^{5}$

1. Organic Technologies Department, Łukasiewicz Research Network - New Chemical Syntheses Institute, POLAND, 24-110 Puławy, Al. Tysiąclecia Państwa Polskiego 13A,

E-mail: justyna.ostrowska@ins.lukasiewicz.gov.pl

2. Organic Technologies Department, Łukasiewicz Research Network - New Chemical Syntheses Institute, POLAND, 24-110 Puławy, Al. Tysiąclecia Państwa Polskiego 13A,

E-mail: magdalena.paluch@ins.lukasiewicz.gov.pl

3. Organic Technologies Department, Łukasiewicz Research Network - New Chemical Syntheses Institute, POLAND, 24-110 Puławy, Al. Tysiąclecia Państwa Polskiego 13A,

E-mail: karolina.soltan@ins.lukasiewicz.gov.pl

4. Organic Technologies Department, Łukasiewicz Research Network - New Chemical Syntheses Institute, POLAND, 24-110 Puławy, Al. Tysiąclecia Państwa Polskiego 13A,

E-mail: waldemar.sadurski@ins.lukasiewicz.gov.pl

5. Organic Technologies Department, Łukasiewicz Research Network - New Chemical Syntheses Institute, POLAND, 24-110 Puławy, Al. Tysiąclecia Państwa Polskiego 13A, E-mail: piotr.tynski@ins.lukasiewicz.gov.pl

- Absstract - The effect of palmitic acid on the thermoplastic starch (TPS)/polylactide (PLA) blends was presented. TPS/PLA granulates were prepared during extrusion process. The TPS/PLA blends modified by fatty acid were analyzed by different methods to determine thermal, structural and rheological properties. The influence of acid on the blends plasticization was discussed.

- Keywords - thermoplastic starch, polylactide, palmitic acid, plasticization, rheological properties

\section{Introduction}

Synthetic polymers produced from petrochemicals dominate the packaging market due to their low production costs, a well-known technology and a wide range of applications. However, the environmental problems related to the fact that petrochemical polymer waste is not biodegradable and the growing concern about the consequence of using these materials have inspired the research development on biodegradable polymer materials [1,2].

Currently, the two most popular biodegradable polymers made from natural and renewable raw materials are thermoplastic starch (TPS) and polylactide (PLA).

Native starch is a glucose polymer in which the monosaccharide units are linked by the $1,4^{\prime}$ - $\alpha$-glycosidic bonds. Starch can be separated into two fractions: insoluble in cold water called amylose and a fraction that dissolves in cold water called amylopectin. Amylose is a linear polymer which constitutes about $20 \%$ by weight of starch. Amylopectin is a highly branched molecules constitutes the remaining $80 \%$ of starch by weight and exhibits 1,6'- $\alpha$-glycosidic branches in its structure. Their structures are shown in Figure 1 [3].

Semicrystalline starch can be transformed into a fully amorphous material in the extrusion process at the temperature higher than $70{ }^{\circ} \mathrm{C}$, under the influence of shear forces and in the presence of plasticizers. Thus, the produced material is known as thermoplastic starch (TPS). Unfortunately, thermoplastic starch - based products have high water vapor permeability and poor mechanical properties depending on changing humidity conditions. One of the known method regarding the improvement of the TPS properties is blending of thermoplastic starch with high-strength polyesters [4]. 

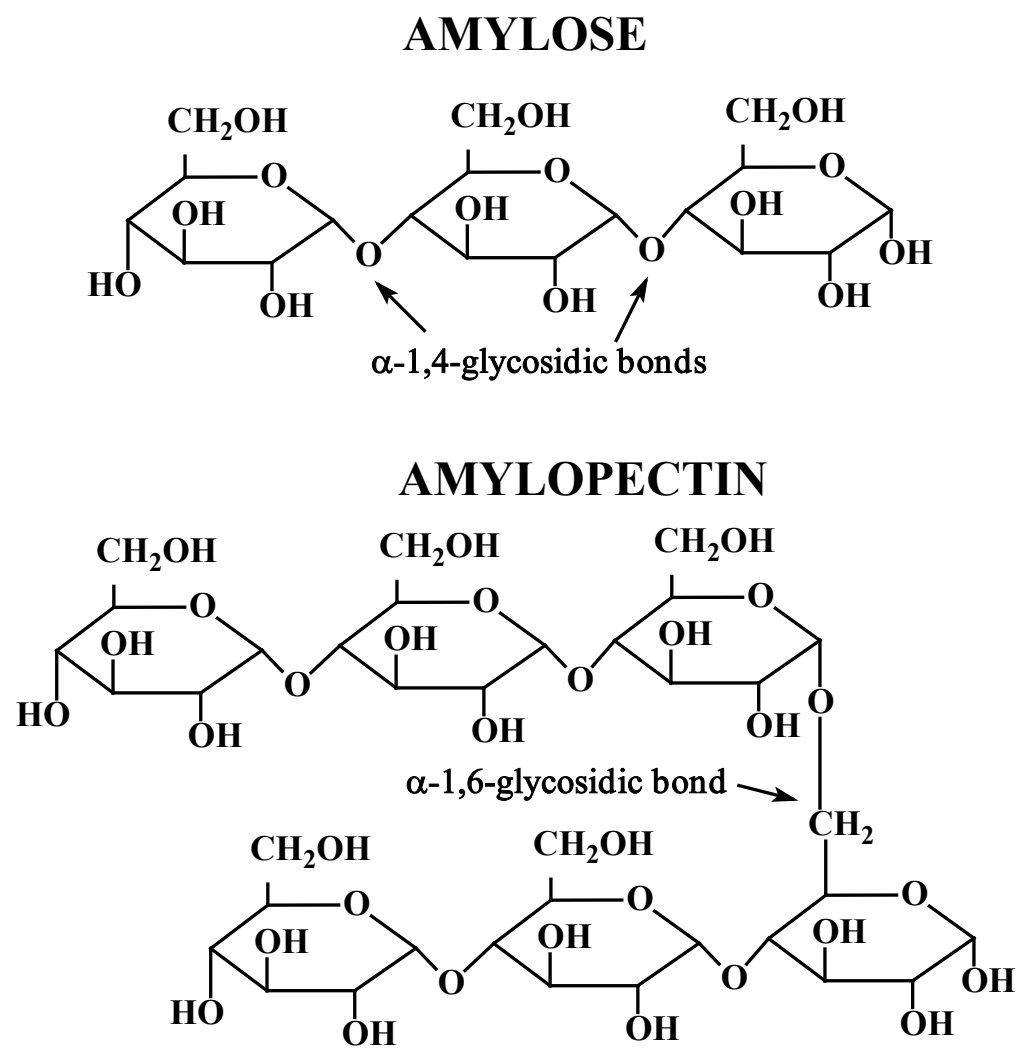

Fig.1. Structure of amylose and amylopectin.

Polylactide (Fig. 2) is a biodegradable aliphatic polyester obtained from L- and D-lactic acid. The PLA structure differs depending on the ratio of L- and D-lactide, offering different degrees of crystallinity, melting point as well as mechanical, rheological and barrier properties. PLA is a thermoplastic polymer in many ways similar to poly(ethylene terephthalate) (PET) and polystyrene (PS). It is highly transparent, rigid and brittle polymer. It has a relatively low rate of crystallization, which makes it a promising candidate for the fabrication of biaxially oriented films, thermoformed containers and stretch-blown bottles $[5,6]$.<smiles>CCOC(=O)C(C)O</smiles>

Fig.2. PLA structure.

The combination of TPS and PLA is an effective way to reduce the price of the final product and improve the usable properties of starch materials [7]. The strategy of producing TPS/PLA blends has been used to decrease the dependence on the relative humidity and increase mechanical properties. A difficulty encountered in the production TPS/PLA polymer compositions results from the incompatibility of the two polymers. PLA is a hydrophobic polyester and TPS is hydrophilic, respectively. To enhance the interfacial adhesion between two polymers, a compatibilizing agent, such as maleic anhydride, diisocyanates or organic acid, may be added in the reactive extrusion process. The esterification with fatty acids makes it possible to obtain more hydrophobic starch esters [8,9]. 
In this study, the effect of palmitic acid $\left[\mathrm{CH}_{3}\left(\mathrm{CH}_{2}\right)_{13} \mathrm{CH}_{2} \mathrm{COOH}\right]$ on the TPS/PLA (50/50) blend properties was determined. For this purpose, reactive extrusion with saturated fatty acid was carried out and its activity as a plasticizer and compatibilizer was discussed.

\section{Materials and methods}

\section{Materials}

Native potato starch was purchased from Przedsiębiorstwo Przemysłu Ziemniaczanego Niechlów (Poland). Polylactide (PLA Ingeo TM Biopolymer 2003D) was supplied by NatureWorks (USA). Glycerol (99,5\% purity) was purchased from Brentag (Poland). Palmitic acid ( $\geq 99 \%$ purity) was obtained from Sigma-Aldrich.

\section{TPS/PLA blends preparation}

The TPS/PLA blends were prepared in a two-step extrusion process. In the first stage, the thermoplastic starch (TPS) was obtained. The potato starch and glycerol were premixed using a high speed mixer (Labtech Engineering, Thailand). The concentration of glycerol as a main plasticizer was $30 \mathrm{wt} \%$ on starch dry weight. Palmitic acid (PA) was added to the starch/glycerol mixture and mixed again. The levels of palmitic acid in the mixture were 0.5 wt. $\%$, 1 wt. $\%$ and 3 wt.\%, respectively. Glycerol-starch mixture with fatty acid were processed using co-rotating twin-screw extruder (Labtech Engineering, Thailand) with screw diameter $\mathrm{D}=20 \mathrm{~mm}$ with $\mathrm{L}: \mathrm{D}$ ratio $48: 1$ using barrel temperature in the range $70{ }^{\circ} \mathrm{C}-150{ }^{\circ} \mathrm{C}$ and at $120 \mathrm{rpm}$ screw speed.

Then, the obtained thermoplastic starch pellets were hand mixed with polylactide in $50 \mathrm{wt} . \% / 50 \mathrm{wt} . \%$ ratio and extruded again in the second step in the temperature range of $160{ }^{\circ} \mathrm{C}$ $-180{ }^{\circ} \mathrm{C}$ to produce a blends in the granulate form. Additionally, pure polylactide with palmitic acid in amount of $0.5 \mathrm{wt} . \%$ and $3 \mathrm{wt} . \%$ were processed to compare the properties of PLA in blends.

\section{Infrared spectrum (IR)}

FTIR spectra in the range of $4000-700 \mathrm{~cm}^{-1}$ were recorded by attenuated total reflection (ATR) method on a Nicolet iS10 Spectrum Scanner (Thermo Scientific, USA) over 32 consecutive scans with a resolution of $4 \mathrm{~cm}^{-1}$ at room temperature.

\section{Differential Scanning Calorimetry (DSC)}

The DSC measurements were performed using a TA Instruments Model Q20. The samples were heated and cooled from $-90^{\circ} \mathrm{C}$ to $180{ }^{\circ} \mathrm{C}$ in a nitrogen atmosphere at a rate of $10{ }^{\circ} \mathrm{C} / \mathrm{min}$.

\section{Rheological properties}

Mass Flow Rate (MFR) and Melt Volume Rate (MVR) were measured using a plastometer CEAST MF20 (Instron Ceast, Italy). The measurements were carried out at $190{ }^{\circ} \mathrm{C}$ and $200{ }^{\circ} \mathrm{C}$ with a mass of $2.16 \mathrm{~kg}$ according to ISO 1133.

The twin-bore capillary rheometer (Smart Rheo 50, Instron Ceast, Italy) was used to the assessment of the rheological properties of the produced granules. The viscosity values were measured in the following points of shear rate: 100, 200, 300, 500, 700, 900, 1100, 1400, 1700, 2000,2500 and $3000 \mathrm{~s}^{-1}$. The preheating time was equal to $300 \mathrm{~s}$. The measurements were carried out at 160 and $170{ }^{\circ} \mathrm{C}$ and two capillary dies ( $\mathrm{L} / \mathrm{D}=30$ and 5) were used. The real values of shear rate, shear stress and viscosity were calculated by applying the Rabinowitsch and the Bagley corrections.

\section{Results and discussion}

\section{FTIR (ATR) Spectroscopy}


Fig. 3 shows the FTIR spectra of neat polylactide and TPS/PLA (50/50) blends with or without palmitic acid. PLA has a strong carboxyl stretching absorption at about $1750 \mathrm{~cm}^{-1}$. The band does not shift in TPS/PLA blends. Furthermore, there is no additional peaks exhibit when palmitic acid is included into the blend. However, some differences in the wavenumber ranges from $1000 \mathrm{~cm}^{-1}$ to $1150 \mathrm{~cm}^{-1}$ were observed. The peak at $1024 \mathrm{~cm}^{-1}$ in TPS/PLA blend is attributed to the stretching vibration of $\mathrm{C}-\mathrm{O}$ in $\mathrm{C}-\mathrm{O}-\mathrm{C}$ [10]. The intensity of this peak decreases as the PA content increases, suggesting that acid hydrolysis reaction of the glycosidic linkages has occurred. The interaction between palmitic acid and starch/glycerol mixture was observed during the preparation of thermoplastic starch (Fig. 4). The peak at $1700 \mathrm{~cm}^{-1}$ is attributed to the $\mathrm{C}=\mathrm{O}$ stretching vibration in carboxyl group of pure palmitic acid. A new absorption band occurring at about $1734 \mathrm{~cm}^{-1}$ could be result of an esterification reactions between palmitic acid and starch or glycerol which occurred during the reactive extrusion. Due to the presence of ester linkages in a similar range of wavenumber as for in PLA, these linkages can be overlapped, it is difficult to observe these new ester linkages in spectra of TPS/PLA compositions.

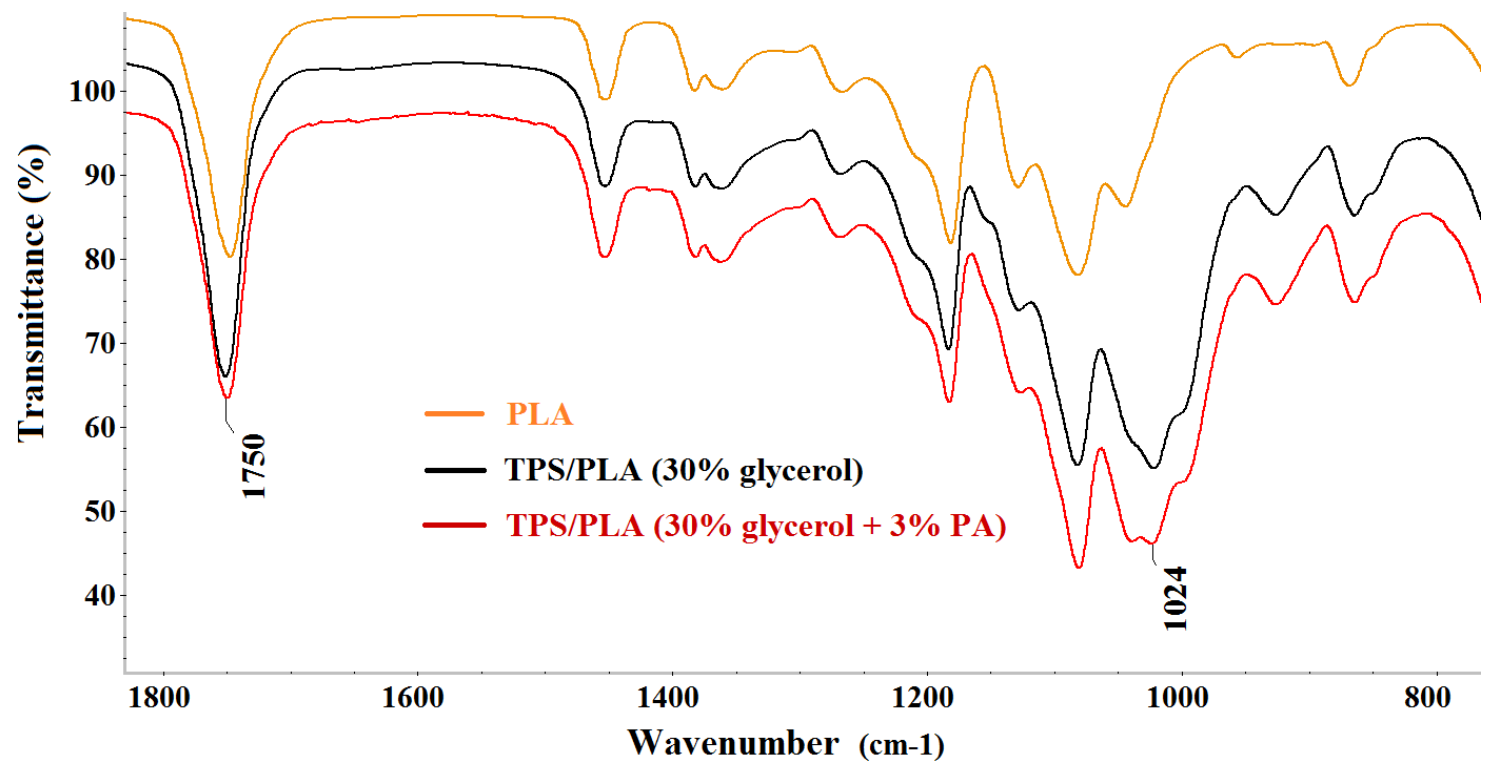

Fig.3. FTIR spectra of TPS/PLA blends.

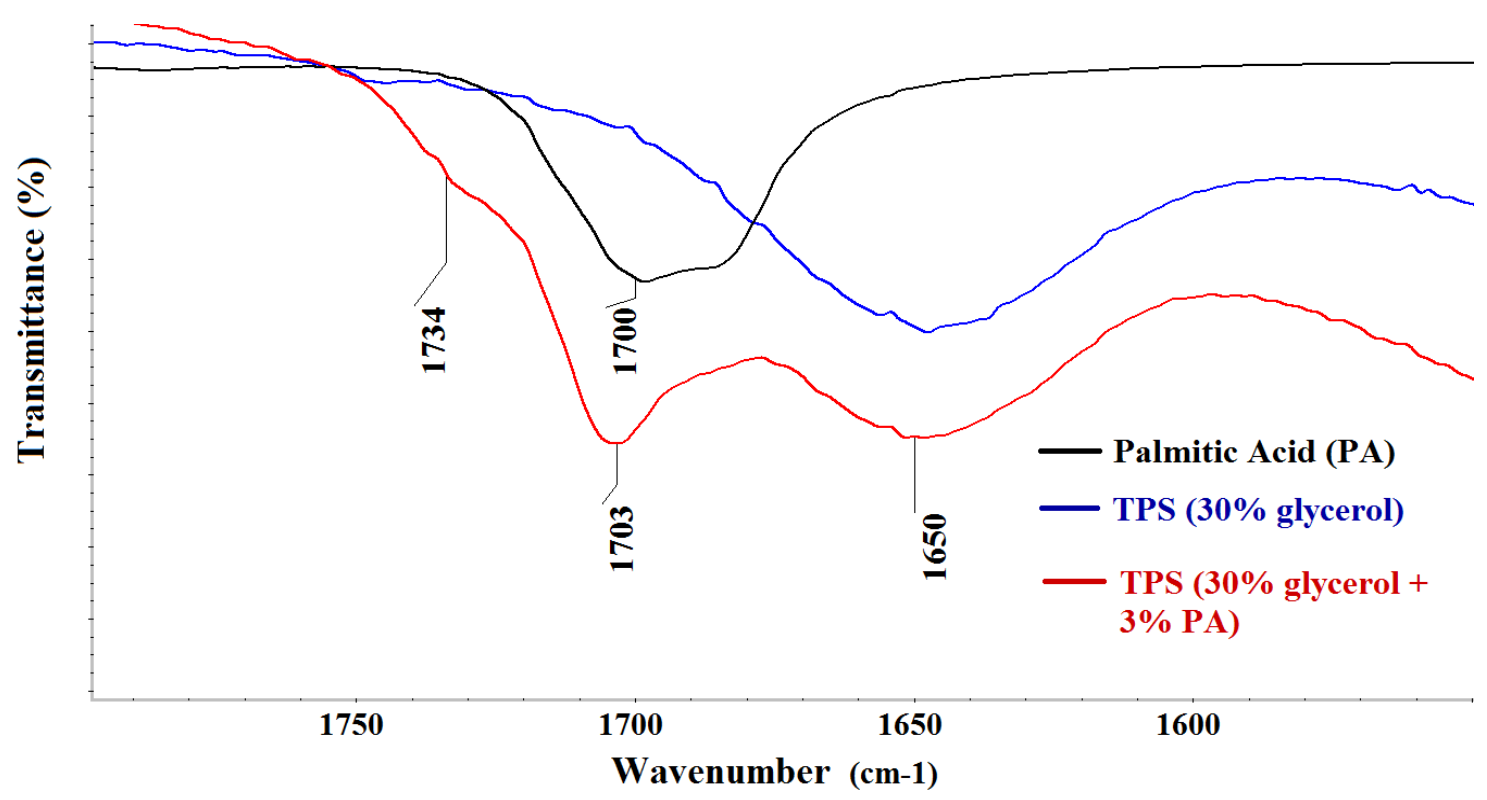

Fig.4. FTIR spectra $\left(1800 \mathrm{~cm}^{-1}-1500 \mathrm{~cm}^{-1}\right.$ range $)$ of thermoplastic starch with and without palmitic acid. 


\section{Thermal properties}

The DSC thermograms of PLA and PLA/TPS composites are shown in Figs. 5 and 6, respectively. The corresponding glass transition temperatures $\left(\mathrm{T}_{\mathrm{g}}\right)$, cold crystallization temperatures $\left(\mathrm{T}_{\mathrm{cc}}\right)$, and melting points $\left(\mathrm{T}_{\mathrm{m}}\right)$ of PLA compositions are reported in Table 1. After added the palmitic acid (PA) in amount $3 \mathrm{wt} . \%$, the $\mathrm{T}_{\mathrm{g}}$ of the TPS/PLA blends decreased by ca. $3^{\circ}$ and two obvious melting peaks of PLA was observed. The cold crystallization temperatures of the TPS/PLA blends decreased with a increasing an amount of PA. Changes in $T_{g}, T_{c c}$ and $T_{m}$ of PLA after adding fatty acid indicate interaction between the PLA chain and PA. These types of changes in thermograms are observed when the polymer plasticization process takes place.

Table 1

DSC data for neat PLA, PLA with palmitic acid and TPS/PLA blends

\begin{tabular}{|c|c|c|c|}
\hline PLA and its blends & $\mathbf{T}_{\mathbf{g}}\left[{ }^{\circ} \mathbf{C}\right]^{\mathbf{1})}$ & $\mathbf{T}_{\mathbf{c c}}\left[{ }^{\circ} \mathbf{C}^{\mathbf{2})}\right.$ & $\mathbf{T}_{\mathbf{m}}\left[{ }^{\circ} \mathbf{C}\right]^{\mathbf{3})}$ \\
\hline neat PLA & & & \\
\hline PLA + 0,5\% PA & 58 & 117 & 150 \\
\hline PLA + 3\% PA & 54 & 103 & 145,151 \\
\hline TPS/PLA & 58 & - & 148 \\
\hline TPS/PLA + 0,5\% PA & 59 & - & 148 \\
\hline TPS/PLA + 1\% PA & 60 & 113 & 147 \\
\hline TPS/PLA + 3\% PA & 56 & 108 & 145 \\
\hline
\end{tabular}

${ }^{1)} 2^{\text {nd }}$ heating cycle, ${ }^{2)} 1^{\text {st }}$ heating cycle, ${ }^{3)} 1^{\text {st }}$ heating cycle
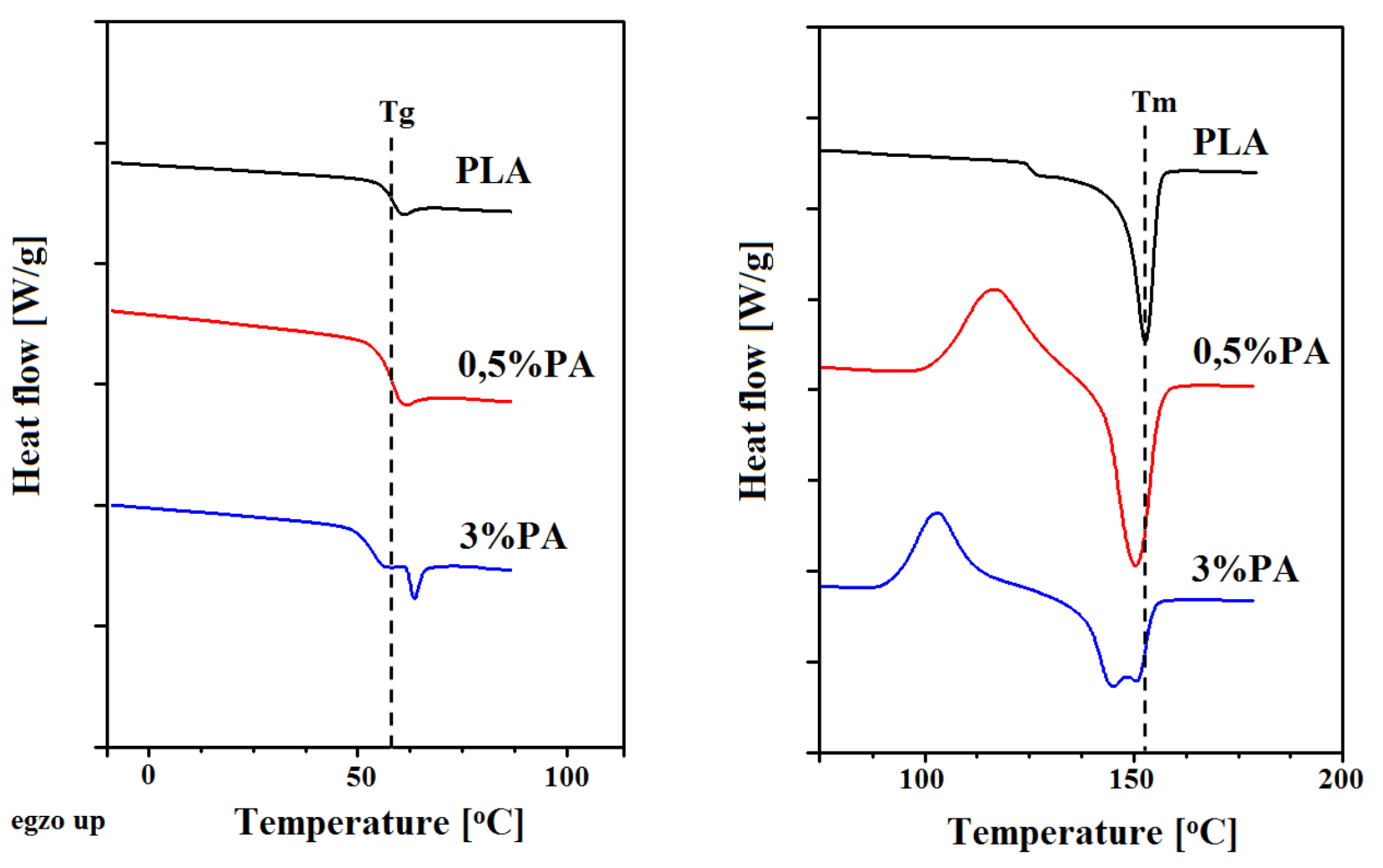

Fig.5. DSC thermograms of neat PLA and PLA modified palmitic acid in amount 0.5 wt.\% and 3 wt.\%. 

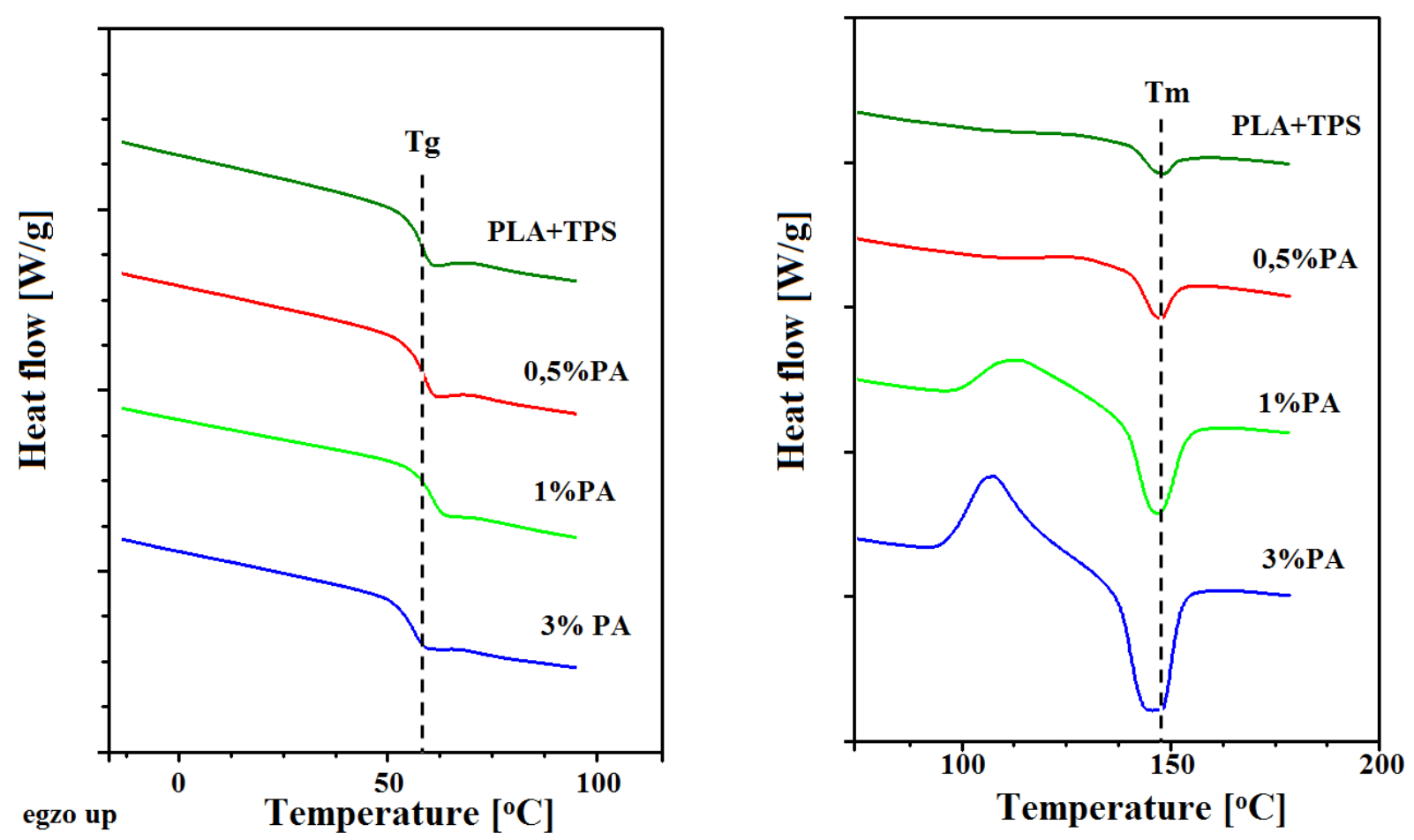

Fig.6. DSC thermograms of TPS/PLA (50/50) blends with different content of palmitic acid.

\section{Rheological properties}

TPS/PLA [50/50] blend itself had a MFR of $6.28 \mathrm{~g} / 10 \mathrm{~min}$ and a MVR of $5.22 \mathrm{~cm}^{3} / 10 \mathrm{~min}$. The use of palmitic acid in amount $0.5 \%$ and $1 \%$ in blend resulted in decreased of melt flow rate. A different situation was observed after adding $3 \%$ fatty acid to the blend. At that time, both index doubled (Table 2).

Table 2

Melt flow rate (MFR) and melt volume rate (MVR) of TPS/PLA blends modified by PA

\begin{tabular}{|c|c|c|c|c|}
\hline Temperature & \multicolumn{2}{|c|}{$\mathbf{1 9 0}^{\circ} \mathbf{C}$} & \multicolumn{2}{c|}{$\mathbf{2 1 0}^{\circ} \mathbf{C}$} \\
\hline Type of blend & $\begin{array}{c}\text { MFR, } \\
\mathrm{g} / 10 \mathrm{~min}\end{array}$ & $\begin{array}{c}\mathbf{M V R}, \\
\mathrm{cm}^{3} / 10 \mathrm{~min}\end{array}$ & $\begin{array}{c}\text { MFR, } \\
\mathrm{g} / 10 \mathrm{~min}\end{array}$ & $\begin{array}{c}\mathbf{M V R}, \\
\mathrm{cm}^{3} / 10 \mathrm{~min}\end{array}$ \\
\hline TPS/PLA (50/50) & 6,28 & 5,22 & 28,24 & 23,53 \\
\hline TPS/PLA (50/50)+ 0,5\% PA & 5,00 & 4,21 & 21,79 & 18,28 \\
\hline TPS/PLA (50/50)+1\% PA & 4,30 & 3,74 & 19,53 & 16,40 \\
\hline TPS/PLA (50/50)+3\% PA & 16,25 & 13,68 & 92,67 & 81,01 \\
\hline
\end{tabular}

Fig. 7 shows the viscosity curves of TPS/PLA (50/50) blends in the double logarithmic system. The TPS/PLA blends exhibit the properties of pseudoplastic fluids. The real viscosity of the TPS/PLA blends decrease with an increasing temperature. Palmitic acid in addition in $0.5 \mathrm{wt} \%$ and $1 \mathrm{wt} . \%$ content in TPS/PLA blends slightly changes the viscosity as compared to the polymer composition plasticized only by glycerol. Then, the viscosity slightly increase or decrease depending on shear rate change. Overall, palmitic acid in amout $3 \mathrm{wt} . \%$ in blend can effectively reduce the melt viscosity. The same property was occured during the MFR measurements. This could be the result of the plasticization of the polylactide and its partially degradation into macromolecules with lower molecular weights, as indicates by the reduction of 
the melting point of PLA under influence of acid. The low viscosity of the TPS/PLA blend is favorable for injection process.
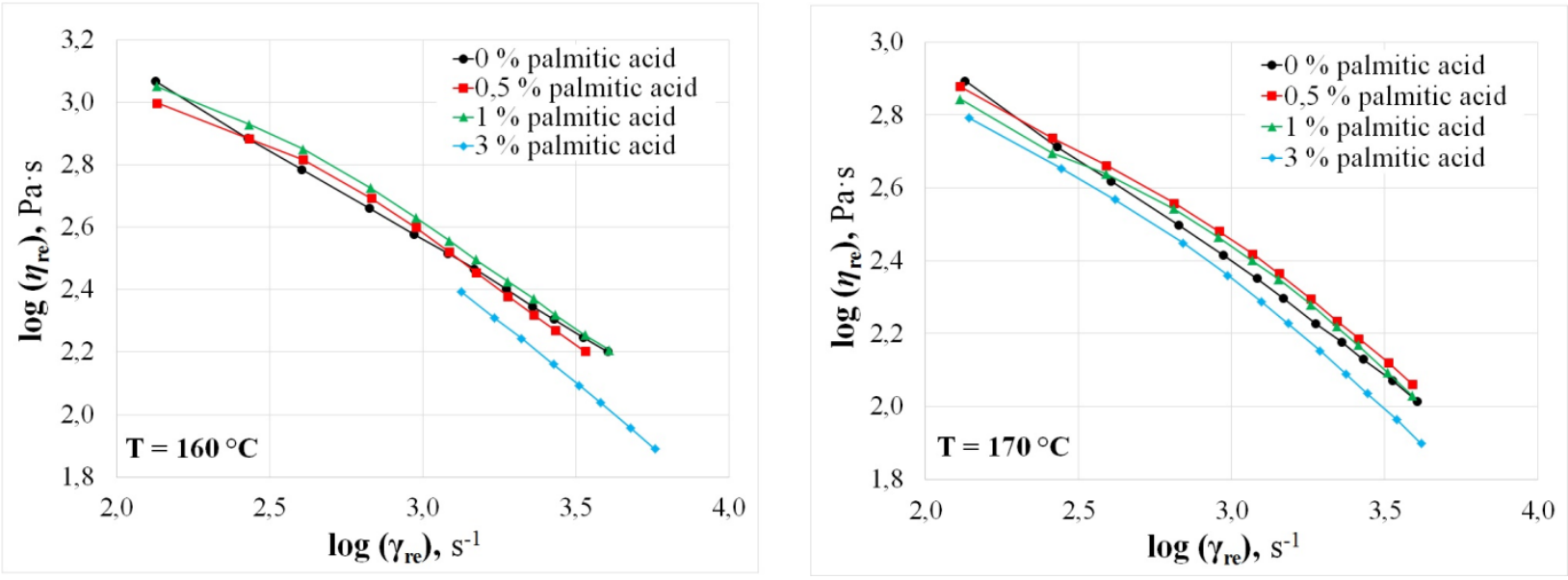

Fig.7. TPS/PLA composites capillary rheology test results.

\section{Conclusion}

TPS/PLA blends were produced by reactive extrusion with fatty acid as an additive. Fourier transform infrared spectroscopy (FTIR) suggests that palmitic acid partly reacts with hydroxyl group of the glycerol or starch by esterification reaction. The addition of palmitic acid to the TPS/PLA blend reduces the glass transition temperature of the polylactide and the melt viscosity. It can be concluded that palmitic acid has a plasticizing effect and at the same time facilitates processing as a lubricant. The viscosity results indicate that TPS/PLA composition can be further processed by extrusion and injection molding to obtain films or shapes.

\section{Acknowledgments}

This work was financially supported by The National Centre for Research and Development (LIDER X), grant number LIDER/36/0198/L-10/18/NCBR/2019 entitled: "The development of technology for obtaining the new biodegradable plastics based on thermoplastic starch for the films production".

\section{References}

[1] Averous, L. (2004). Biodegradable multiphase systems based on plasticized starch: a review. Journal of Macromolecular Science, Part C, 44(3), 231-274. https://doi.org/10.1081/MC-200029326

[2] Huneault, M. A., Li, H. (2012). Preparation and properties of extruded thermoplastic starch/polymer blends. Journal of Applied Polymer Science, 126(S1), 96-108. https://doi.org/10.1002/app.36724

[3] Perez, S. Bertof, E. (2010). The molecular structures of starch components and their contribution to the architecture of starch granules: A comprehensive review. Starch Starke, 62(8), 389-420. https://doi.org/10.1002/star.201000013

[4] Rodriguez-Gonzalez, F. J., Ramsay, B. A., Favis, B. A. (2004). Rheological and thermal properties of thermoplastic starch with high glycerol content. Carbohydrate Polymers, 58(2), 139-147. https://doi.org/10.1016/j.carbpol.2004.06.002

[5] Huneault, M. A., Li, H (2007). Morphology and properties of compatibilized polylactide/thermoplastic starch blends. Polymer, 48(1), 270-280. https://doi:10.1016/j.polymer.2006.11.02 
[6] Auras, R., Harte, B., Selke, S. (2004). An Overview of Polylactides as Packaging $\begin{array}{llll}\text { Materials. } & \text { Macromolecular } & \text { 835-864. }\end{array}$ https://doi.org/10.1002/mabi.200400043

[7] Kaseem, M., Hamad, K., Deri, F. (2012). Thermoplastic starch blends: A review of recent works. Polymer Science Series A, 54(2), 165-176. https://doi.org/10.1134/S0965545X1202006X

[8] Olivato, J. B., Muller, C. M. O., Carvalho, G. M., Yamashita, F., Grossmann, M. V. E. (2014). Physical and structural characterisation of starch/polyester blends with tartaric acid. Materials Science and Engineering:C, 39(1), 35-39. https://doi.org/10.1016/j.msec.2014.02.020

[9] Clasen, S. H., Muller, C. M. O., Pires, A. T. N. (2015). Maleic Anhydride as a Compatibilizer and Plasticizer in TPS/PLA Blends. Journal of the Brazilian Chemical Society, 26(8), 1583-1590. http://dx.doi.org/10.5935/0103-5053.20150126

[10] Shi, R., Zhang, Z., Liu, Q., Han, Y., Zhang, L., Chen, D., Tian, W. (2007). Characterization of citric acid/glycerol co-plasticized thermoplastic starch prepared by $\begin{array}{llll}\text { melt blending. } & \text { Carbohydrate } & \text { 748-755. }\end{array}$ http://dx.doi.org/10.1016/j.carbpol.2007.02.010 


\title{
Convenient and Efficient Suzuki Miyaura Coupling Reactions of Meso- Halogenated BODIPYs
}

\author{
Gökçe Hilal Taşan ${ }^{1}$, Raşit Fikret Yılmaz ${ }^{2}$, Yavuz Derin ${ }^{1}$, Büşra Albayrak Mısır ${ }^{1}, \underline{\text { Ahmet Tutar }^{1}}$ \\ 1. Faculty of Arts and Sciences,Department of Chemistry, Sakarya University, TURKEY, Sakarya 54187, \\ E-mail: gokce.tasan@ogr.sakarya.edu.tr; yavuzderin@sakarya.edu.tr; bursa.albayrak4@ogr.sakarya.edu.tr; \\ atutar@sakarya.edu.tr
}

2. Department of Fundamental Sciences, Turkish Naval Academy, National Defence University, TURKEY, İstanbul, 34940, E-mail: rfyilmaz@dho.edu.tr

\begin{abstract}
In this study, we synthesized new conjugated BODIPY compounds with potential fluorescence by treated the BODIPY compound containing bromine in the meso position with different boronic acids. BODIPY cores derived from meso position are used in interesting applications such as pH probe and redox sensors.
\end{abstract}

Keywords - BODIPY, halogenated BODIPY, Suzuki-Miyaura coupling reactions, boronic acids, photophysical and electrochemical properties.

\section{Introduction}

Boradiaza-s-indacene (boron dipyrrin or boron dipyrromethene, BODIPY) dyes have gained outstanding place for use in fluorescent materials, labels, and probes. Derivatization at the 8-position, or meso-position, is a preferred method for the construction of complex BODIPY fluorophores. The nature of the new substituent has strong influence on the spectral properties of the dyes [1]. Spectroscopic features can be easily accommodated by different synthetic strategies on BODIPY nucleus [2]. Halogenated BODIPYs are important precursors to synthesize a variety of substituted BODIPYs and potential sensitizers for photodynamic therapy (PDT). Halogenated systems can be derivatized by transition metal catalyzed cross-coupling reactions [3].

The palladium-catalyzed Suzuki cross-coupling reaction is one of the most efficient methods for the construction of $\mathrm{C}_{\text {aryl }}-\mathrm{C}_{\text {aryl }}$ bonds and has found widespread use in organic synthesis. Carboncarbon bond formation reactions are some of the most important processes in chemistry, that provide key steps in the building of more complex molecules from simple precursors [4].

\section{Conclusion}

In this study, 4,4-difluoro-8-(4-bromophenyl)-4-bora-3a,4a-diaza- $s$-indacene (BODIPY) was synthesized from reaction of pyrrole with 4-bromobenzaldehyde and complexation with $\mathrm{BF}_{3}$. $\mathrm{OEt}_{2}$. The synthesized BODIPY nucleus was treated with different boronic acids and new BODIPY compounds derived from the 8-position were obtained.

\section{Acknowledgments}

This study is supported by the the Scientific Research Projects Unit of Sakarya University (BAP-2020-7-24-54).

\section{References}

[1] Leen, V., Yuan, P., Wang, L., Boens, N., Dehaen, W. (2012). Synthesis of Meso-Halogenated BODIPYs and Access to Meso-Substituted Analogues. Organic Letters, 14 (24) 6150-6153. https://doi.org/10.1021/o13028225

[2] Derin, Y., Y1lmaz, R. F., Baydilek, I. H., Atalay, V. E., Ozdemir, A., Tutar,A. (2018). Synthesis Electrochemical/Photophysical Properties and Computational Investigation of 3,5- dialkyl BODIPY Fluorophores. Inorganica Chimica Acta, 482, 130-135. https://doi.org/10.1016/j.ica.2018.06.006

[3] Lakshmi, V., Ravikanth, M. (2012). Brominated Boron Dipyrrins. Synthesis, Structure, Spectral an Electrochemical Properties. Dalton Transactions, 41, 5903-5911. https://doi.org/10.1039/C2DT00019A

[4] Suzuki, A. (2002). Cross-coupling Reactions via Organoboranes. Journal of Organometallic Chemistry $653 \quad(1-2) \quad 83-90 . \quad$ https://doi.org/10.1016/S0022-328X(02)01269-X 


\title{
Biocidal preparations based on thiosulphonates and biosurfactants
}

\author{
$\underline{\text { Vira Lubenets }}^{1}$, Natalia Monka $^{1}$, Ihor Bobalo ${ }^{1}$, Tetyana Pokynbroda ${ }^{2}$, Alla Prokopalo ${ }^{2}$, \\ Olena Karpenko ${ }^{2}$
}

\begin{abstract}
1. Department of Technology of Biologically Active Substances, Pharmacy and Biotechnology, Lviv Polytechnic National University, UKRAINE, Lviv Bandera street, 12, E-mail: vlubenets@gmail.com
\end{abstract}

\begin{abstract}
2. Department of Physical Chemistry of Fossil Fuels of the Institute of Physical-Organic Chemistry and Coal Chemistry named after L. M. Lytvynenko of the National Academy of Sciences of Ukraine, UKRAINE, Lviv, Naukova str, 3a
\end{abstract}

\begin{abstract}
The deficit of effective biocides and disinfectants for medicine and veterinary determines the need to develop safe drugs, in particular, green synthesis products. Thiosulfoesters and biosurfactants of microbial origin, rhamnolipids, correspond these criteria. The presence of rhamnolipids in the compositions significantly reduces the effective concentrations of biocides, enhances the antimicrobial effect.
\end{abstract}

Keywords - rhamnolipids, thiosulfonates, biocides, antimicrobial activity, disinfectants.

\section{Introduction}

Intensive technologies for the production of livestock products are often accompanied by the spread of opportunistic and pathogenic microflora and the occurrence of various animal diseases. An important role here is played by disinfection measures to ensure the destruction of pathogenic microorganisms, including mycobacteria. Therefore, new, more effective methods are needed to ensure the stable veterinary welfare of livestock industries. Existing means for the prevention of tuberculosis and other diseases of farm animals are not effective and often contain toxic substances. Therefore, green chemical products are especially relevant. Sulfur-containing organic compounds are used as biologically active substances in pharmacy and agrochemistry, as well as reagents in organic synthesis [1]. The development of green methods for their synthesis is an urgent task for specialists in the chemical, pharmaceutical and other industries. Compounds with a disulfide bond (thiosulfonates), structural analogs of the unstable antibiotic garlic allicin, are of particular interest [2]. Thiosulfonates exhibit a wide spectrum of antimicrobial activity and are more stable than allicin. These compounds are already promising as preservatives, antimicrobial, insecticidal [3,4], antitumor [5], antithrombotic [6] substances.

A new method of green synthesis of S-alkyl-4-R-benzenethiosulfonates with biocidal action without organic solvents (in an aqueous medium) has been developed at the Department of Technology of Biologically Active Substances, Pharmacy and Biotechnology. However, thiosulfonates are low soluble in water, which limits their bioavailability and application. The ability of biosurfactants to disperse hydrophobic compounds and regulate the permeability of cell membranes can be used in disinfection compositions. The high efficiency of biosurfactants is due to the physicochemical properties and biological activity, as well as their biodegradability and low toxicity. In the compositions, a synergistic effect can be achieved, that is, the active concentrations of biocides can be reduced [7,8]. New biocidal preparations based on thiosulfonates (methyl thiosulfonate - MTS, ethyl thiosulfonate - ETS, allyl thiosulfonate - ATS) with biosurfactants (rhamnolipids of the Pseudomonas sp. PS-17 strain - RL), which active against the cultures Esherichia coli, Mycobacterium luteum, Staphylococcus aureus, Candida tenuis. The optimal ratio of the components was selected, their minimum inhibitory (MIC) and bactericidal (MBC) concentrations were determined (Table 1). 
It was shown that in the compositions of ETS with rhamnolipids, the MIC is reduced by 2 times in comparison with the biocide itself, and the composition ETS + RL (10: 1) was effective against test microorganisms.

Thus, the results indicate that the addition of biosurfactants to the composition with ETS contributed to a decrease in its minimum inhibitory and biocidal concentrations to the tested pathogens. This can be explained by the increase in the permeability of microorganisms cell membranes under the action of biosurfactants and their ability to solubilize low soluble biocides.

Table 1

Antimicrobial activity of compositions of ethylthiosulfonylate with rhamnolipids

\begin{tabular}{|c|c|c|c|c|c|}
\hline \multirow{2}{*}{ Compositions } & $\begin{array}{c}\text { Minimum } \\
\text { inhibitory and } \\
\text { bactericidal } \\
\text { concentrations, } \\
\mu \mathrm{g} / \mathrm{ml}\end{array}$ & $\begin{array}{c}\text { Esherichia } \\
\text { coli }\end{array}$ & $\begin{array}{c}\text { Mycobacterium } \\
\text { luteum }\end{array}$ & $\begin{array}{c}\text { Staphylococcus } \\
\text { aureus }\end{array}$ & $\begin{array}{c}\text { Candida } \\
\text { tenuis }\end{array}$ \\
\hline ETS+RL(1:1) & MIC & 62,5 & 7,8 & 7,8 & 0,9 \\
\cline { 2 - 6 } & MBC & 125,0 & 31,3 & 31,3 & 15,6 \\
\hline ETS+RL & MIC & $31,2: 3,1$ & $15,6: 1,6$ & $15,6: 1,6$ & $15,6: 1,6$ \\
\cline { 2 - 6 }$(10: 1)$ & MBC & $62,5: 6,2$ & $31,3: 3,1$ & $31,3: 3,1$ & $31,3: 3,1$ \\
\hline \multirow{2}{*}{$\begin{array}{c}\text { ETS+RL } \\
(20: 1)\end{array}$} & MIC & 15,$6 ; 0,8$ & $15,6: 0,8$ & $31,2: 3,15$ & $31,2: 3,15$ \\
\cline { 2 - 6 } & MBC & $31,3: 1,5$ & $31,3: 1,5$ & $62,5: 3,1$ & $62,5: 3,1$ \\
\hline ETS & MIC & 62,5 & 31,2 & 31,2 & 31,2 \\
\cline { 2 - 6 } & MBC & 12,5 & 6,2 & 6,2 & 62,5 \\
\hline RL & MIC & - & 15,6 & 15,6 & 62,5 \\
\cline { 2 - 6 } & MBC & - & 62,5 & 125,0 & - \\
\hline
\end{tabular}

The bactericidal effect of MTS and ATS at concentrations of $0.5 \%$ and exposure for 24 hours against atypical Mycobacterium fortuitum and the causative agents of tuberculosis $M$. bovis, $M$. avium was established. The results obtained indicate the advisability of using a composite disinfectant based on thiosulfonates and rhamnolipids for disinfection in the following modes: "MTS-ATS-RL" - 1\% - 48 hours (bactericidal effect); 1\% - 30 hours (inhibitory effect). So, the efficiency of the synthesized green substances of thiosulfonates for disinfectants against tuberculosis and other pathogens has been shown. The combination of biocides and biosurfactants makes it possible to significantly reduce their effective concentrations and increase antimicrobial activity.

\section{Conclusion}

It has been established that the use of thiosulfonates obtained by green synthesis is promising for the creation of new biocidal and disinfectants, including against tuberculosis pathogens and other pathogens. The combination of thiosulfonates with biosurfactants of microbial origin can significantly reduce the effective concentrations of biocides, enhance the antimicrobial effect, and has environmental and economic significance. The obtained results indicate the prospects of green chemistry products for the creation of safe and effective means for veterinary medicine. 


\section{References}

[1] Mampuys, P., McElroy, R., Clark, J., Orru, R., \& Maesa, B. (2019). Thiosulfonates as Emerging Reactants: Synthesis and Applications. Adv. Synth. Catal., 362, 3-64. https://doi.org/10.1002/adsc.201900864.

[2] Leontiev, R., Hohaus, N., Jacob, C., Martin, C. H. Gruhlke \& Alan J. Slusarenko A. (2018). Comparison of the Antibacterial and Antifungal Activities of Thiosulfinate Analogues of Allicin Scientific RePoRtS. 8:6763. DOI:10.1038/s41598-018-25154-9.

[3] Lubenets,V., Vasylyuk, S., Monka, N., Bolibrukh, K., Komarovska-Porokhnyavets, O., Baranovych, D., Musyanovych, R., Zaczynska, E., Czarny, A., Nawrot, U., Novikov, V. (2017). Synthesis and antimicrobial properties of 4-acylaminobenzenethiosulfoacid S$\begin{array}{lllll}\text { esters. Saudi Pharmaceutical Journal, } & 25, & 266 & 274 .\end{array}$ http://dx.doi.org/10.1016/j.jsps.2016.06.07

[4] Lubenets, V., Stadnytska, N., Baranovych, D., Vasylyuk, S., Karpenko, O.,Havryliak, V., Novikov V. (2019). Thiosulfonates: The Prospective Substances against Fungal Infections. In: Fungal Infection. Eds. Érico Silva de Loreto and JulianaSimoni Moraes Tondolo, IntechOpen, London DOI: 10.5772/intechopen.84436

[5] Dmitryjuk, M., Szczotko, M., Kubiak, K.,Trojanowicz, R., Parashchyn, Z., Khomitska, H., Lubenets, V. (2020). S-methyl-(2-methoxycarbonylamino-benzimidazole-5) thiosulfonate as a potential antiparasitic agent - its action on the development of ascaris suum eggs in vitro. Pharmaceuticals, 13(11), 1-11 doi: 10.3390/ph13110332.

[6] Lubenets, V.I. (2003). Thiosulfonates: synthesis and properties. Ukr. khim. Zhurn, 69(3), 114-121.

[7] Sotirova, A., Avramova, T., Lazarkevich, I., Lubenetz, V., Karpenko, O., Galabova, D. (2014). Antibacterial potential of novel synthetic derivatives of 1,4-naphthoquinone and their complexes with biosurfactants. Research Journal of Pharmaceutical, Biological and Chemical Sciences, 5, 530-541.

[8] Lubenets, V., Karpenko, O., Ponomarenko, M., Zahoriy, G., Krychkovska, A., Novikov, V. (2013). Development of new antimicrobial compositions of thiosulfonate structure. Chemistry and Chemical Technology, 7, 119-124 https://doi.org/10.23939/chcht07.02.119 


\title{
Chemical resistance of biopolymers based on the epoxy resin modified with epoxidised and cyclocarbonated soybean oils
}

\author{
Olha Purikova $^{1}$, Larisa Gorbach $^{2}$, Oleksandr Brovko $^{3}$ \\ 1. Department of Physical Chemistry of Polymers, Institute of Macromolecular Chemistry of the National \\ Academy of Sciences of Ukraine, UKRAINE, Kyiv, Kharkivske shosse 48, E-mail: olhapurikova@gmail.com \\ 2. Department of Physical Chemistry of Polymers, Institute of Macromolecular Chemistry of the National \\ Academy of Sciences of Ukraine, UKRAINE, Kyiv, Kharkivske shosse 48, E-mail: gorbachla@ukr.net \\ 3. Department of Physical Chemistry of Polymers, Institute of Macromolecular Chemistry of the National \\ Academy of Sciences of Ukraine, UKRAINE, Kyiv, Kharkivske shosse 48, E-mail: brovko@nas.gov.ua
}

\begin{abstract}
Environmentally friendly biocomposites based on ED-20 epoxy resin modified with reactive soybean oils functionalized with cyclocarbonate and epoxy groups were obtained with UP (mono(cyanoethyl) diethylene triamine) hardener. Influence of the curing mode on the water absorption and chemical resistance of the synthesized polymer materials was investigated.
\end{abstract}

Keywords - biocomposites; epoxy resin; epoxidized and cyclocarbonated soybean oil, chemical resistance, mechanical properties

\section{Introduction}

The attraction on the biocomposite materials (also known as green composites) due to the potential of being substitute to conventional materials has significantly increased nowadays because of awareness of environmental issues. Vegetable oils are typical sourses of biogenic modifiers; they are triacylglycerides and can be functionalised with reactive groups such as epoxy and cyclocarbonate and, hence, can be cross-linked to form rigid biocomposites [1-3]. Therefore, the objective of this work was to modify diglycidyl ether of bisphenol-A epoxy resin (ED-20) with functionalized SbO such as as cyclocarbonated soybean oils ( $\mathrm{SbOc}$ ) and mixture of epoxidized soybean oil and cyclocarbonated one (SbOm). The effect of modifier and curing mode on water sorption and chemical resistance of the synthesised samples has been studied and discussed.

\section{Experimental section}

Sample Preparation. Compositions of pristine as wel as modified ED-20 samples were synthesized with UP ((mono(cyanoethyl) diethylenetriamine)) hardener, its content for all samples was $20 \mathrm{wt} . \%$ according to the monomer(s). Functionalised soybean oils, such as SbOc and SbOm were supplied by the group of researchers headed by Grishchenko V.K. and used as modifiers [4]. SbOm is a mixture of soybean oil functionalized with epoxy (12.5 wt.\%) and cyclocarbonate (24.6 wt.\%) groups, while SbOc contains soybean oil functionalized only with cyclocarbonate (27.03 wt.\%) groups. Mass fraction of functionalized SbO for all biocomposite samples was $10 \mathrm{wt} . \%$. The homogenized reaction mixture was poured into molds and cured under three different temperature regimes. The curing mode I was performed at $25{ }^{\circ} \mathrm{C}$ for 4 hours; curing mode II - 2 hours at $80{ }^{\circ} \mathrm{C}, 7$ hours at $100{ }^{\circ} \mathrm{C}$; and curing mode III - 1 hour at 80 ${ }^{\circ} \mathrm{C}, 1$ hour at $100{ }^{\circ} \mathrm{C}, 3$ hours at $120^{\circ} \mathrm{C}$, and 2 hours at $160{ }^{\circ} \mathrm{C}$.

Characterization. Fourier transform infrared (FT-IR) spectra $\left(4000-400 \mathrm{~cm}^{-1}\right)$ of all synthesized materials were recorded on a TENSOR 37 spectrometer using $\mathrm{KBr}$ pellets. The chemical resistance of the synthesized samples to the action of aggressive media (water, $10 \mathrm{wt} . \%$ $\mathrm{H}_{2} \mathrm{SO}_{4}$ and 10 wt.\% $\mathrm{NaOH}$ ) was determined in accordance with water absorption tests by ASTM D-570 - 98(2018) "Standard Test Method for Water Absorption of Plastics" and ISO 175:2010 
"Plastics - Methods of test for the determination of the effects of immersion in liquid chemicals".

\section{Results and Discussion}

The chemical structures of the synthesizes samples were analyzed by FT-IR. It is observed that the characteristics peaks of both epoxy resin and functionalised SbO appear in all spectra of the initial reaction mixture. Characteristic bands of cyclocarbonates $\left(1798 \mathrm{~cm}^{-1}\right)$ and oxiran rings (913 and $830 \mathrm{~cm}^{-1}$ ) disappear after curing procedure. Biocomposite samples containing SbOc and $\mathrm{SbOm}$ revealed small band at $1713 \mathrm{~cm}^{-1}$ that corresponds to the $\mathrm{C}=\mathrm{O}$ group of hydroxyurethanes that confirm possible interaction between cyclocarbonate groups of $\mathrm{SbO}$ and amino-groups of UP hardener. This process can contribute to the grafting between epoxy matrix and soybean oil (Scheme 1) [5].

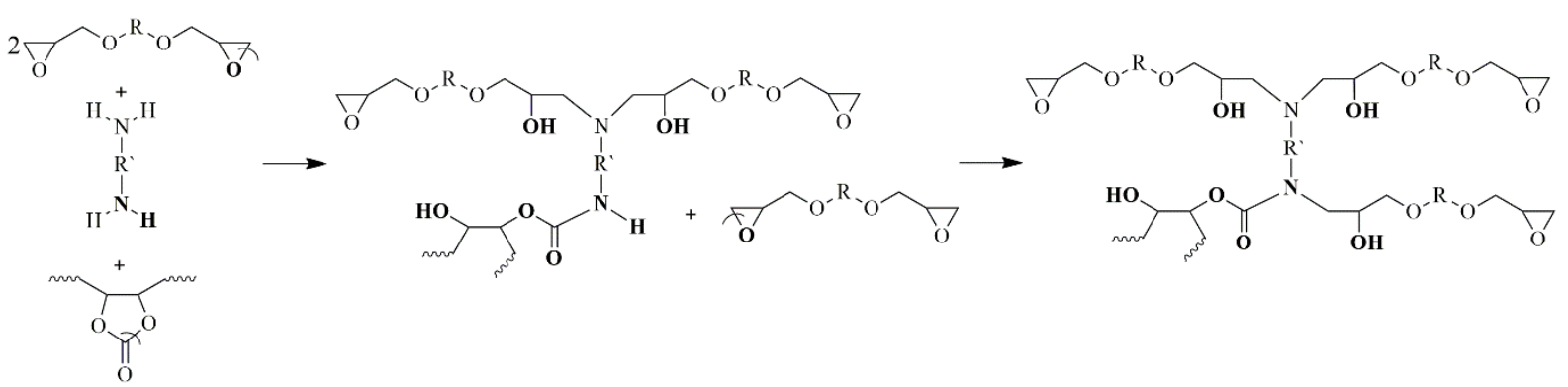

Scheme 1. Representation of interaction between epoxy resin, cyclocarbonate group of functionalized $\mathrm{SbO}$ and UP hardener as diamine

The character of the absorption curves indicates that all samples achieve sorption equilibrium without destruction in all aggressive media (Fig. 1). The water absorption degree in distilled water as well as in alkaline media of biocomposites increases negligibly compared to the corresponding samples of pristine ED-20 regardless of the type of modifier (Fig. 1.a and b). Thus, equilibrium water absorption $\left(W_{\max }\right)$ was in the range of $(1.0-1.8) \%$ for samples ED-20 with different curing mode, and $(2.0-2.8) \%$ and $(2.3-2.7) \%$ for samples ED-20/SbOc and ED-20/SbOm correspondently. It means that presense of functionalized $\mathrm{SbO}$ at the formation of epoxy network leads to slightly less dense netted structure formation. It should be noted that an increase in the curing temperature also has no significant effect on equilibrium water absorption in both water and alkaline medium for samples of pristine epoxy resin and biocomposites.
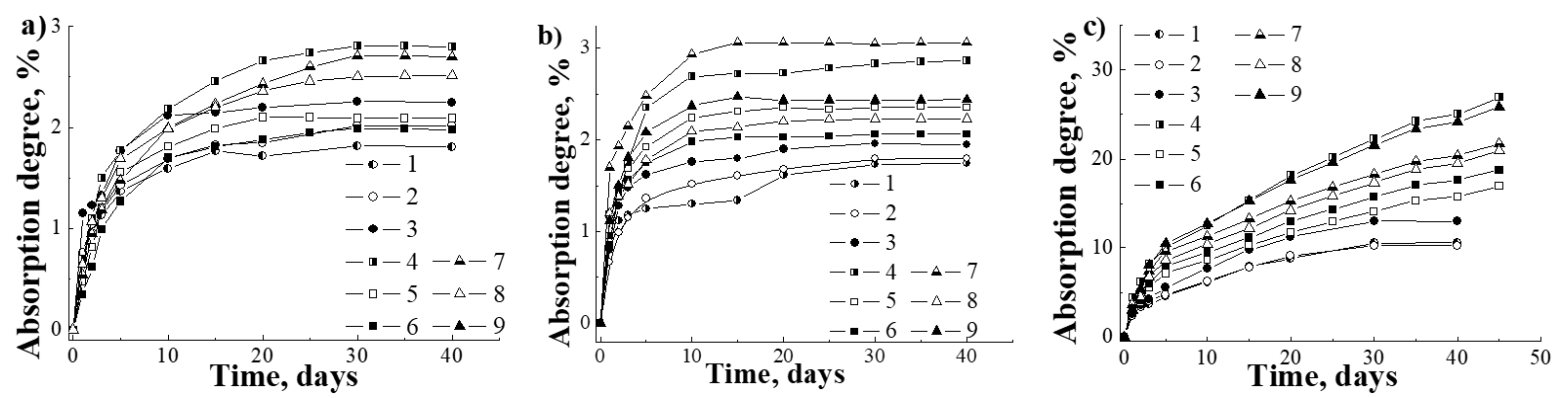

Fig.1. Water absorption curves (a) in distilled water, (b) in alkaline medium, (c) in acidic medium of epoxy polymers based on the ED-20 and their biocomposites made with UP

hardener: 1, 2, 3 - pristine ED-20; 4, 5, 6-ED-20/SbOc; 7, 8, 9 - ED-20/SbOm. 1, 4, 7 - curing mode I; 2, 5, 8 - curing mode II; 3, 6, 9 - curing mode III.

Investigation of chemical resistance in the acidic environment revealed that all samples had higher sorption capacity and thus lower chemical resistance (Fig. 1.c). For example, it increases 
by $\sim 6$ times for samples based on the pristine ED-20 and $\sim(7-9)$ times for biocomposites comparing to correspondent samples ' resistane in the alkaline media. Samples of biocomposites showed, that their chemical resistance to acidic media is lower by $\sim 2$ times comparing with pristine ED-20 samples of corresponding curing mode.

It should be notified, that all synthesized samples after exposure to aggressive media did not detect any defects in the film surface such as cracking, delamination, discoloration, weight loss. Therefore, it can be concluded that destruction of the synthesized samples did not proceed.

\section{Conclusion}

In conclusion, environmentally friendly biocomposites based on ED-20 epoxy resin modified with reactive soybean oils functionalized with cyclocarbonate and epoxy groups were obtained with UP (mono(cyanoethyl) diethylene triamine) hardener. Possible chemical interaction between reactive groups of SbO, epoxy resin and hardener was shown. Influence of the curing mode on the water absorption and chemical resistance of the synthesized polymer materials was investigated. Samples of biocomposites as well as unmodified samples revealed lower chemical resistance in acidic environment comparing to the water and alkali media. Addition of functionalized SbO to the epoxy matrix and chosen curing modes did not change chemical resistance to water and alkaline medium dramatically.

\section{References}

[1] Garipov, R. M., Sysoev, V. A., Mikheev, V. V., Zagidullin, A. I., Deberdeev, R. Y., Irzhak, V. I., \& Berlin, A. A. (2003). Reactivity of cyclocarbonate groups in modified epoxy-amine compositions. Doklady Physical Chemistry, 393 (1), 289-292. Kluwer Academic Publishers-Plenum Publishers.

[2] Gupta, A. P., Ahmad, S., \& Dev, A. (2011). Modification of novel bio-based resin-epoxidized soybean oil by conventional epoxy resin. Polymer Engineering \& Science, 51(6), 1087-1091. https://doi.org/10.1002/pen.21791

[3] Rokicki, G., \& Wojciechowski, C. (1990). Epoxy resin modified by aliphatic cyclic carbonates. Journal of applied polymer science, 41(3-4), 647-659. https://doi.org/10.1002/app.1990.070410315

[4] Barantsova A.V., Grishchenko V.K., Busko N.A., Falchenko Z.V., Shevchenko V.V. (2012). Synthesis and investigation of functionalized oils derivatives of different nature as biofuel raw materials, development of polymeric materials based on them. Catalysis and Petrochemistry, 21, 143-151. (In Ukr.)

[5] Cornille, A., Auvergne, R., Figovsky, O., Boutevin, B., \& Caillol, S. (2017). A perspective approach to sustainable routes for non-isocyanate polyurethanes. European Polymer Journal, 87, 535-552. https://doi.org/10.1016/j.eurpolymj.2016.11.027 


\title{
Synthesis and antibiofilm activity of substituted 1-deazapyrimido $[1,2,3-c d]$ purinium salts
}

\author{
$\underline{\text { Liubov Muzychka }}^{1}$, Oksana Muzychka $^{1}$, Oleg Smolii ${ }^{1}$, Iryna Boiko $^{2}$, Nataliia Hrynchuk ${ }^{2}$
}

1. Department of Chemistry of Natural Compounds, V.P. Kukhar Institute of Bioorganic Chemistry and Petrochemistry of the NAS of Ukraine, UKRAINE, Kyiv, 1, Murmanska st., E-mail: 1muzychka@rambler.ru

2. Laboratory of Pharmacology of Antimicrobial Agents, SI Institute of Pharmacology and Toxicology of the NAMS of Ukraine, UKRAINE, Kyiv, 14, Anton Tsedik st., E-mail: boikoir.ol@gmail.com

- Abstract - Two examples of new derivatives of 1-deazapyrimido[1,2,3-cd]purine were synthesized by intramolecular cyclization of 7-substituted 7H-pyrrolo[2,3-d]pyrimidine-6-carboxylates. The results of antimicrobial tests showed that 1-deazapyrimido[1,2,3-cd]purinium salts exhibited a pronounced effect against gram-positive and gram-negative bacteria biofilm.

- Keywords - pyrrolo[2,3- $d]$ pyrimidine, 1-deazapyrimido[1,2,3-cd]purine, quaternary salts, synthesis, antibiofilm activity.

\section{Introduction}

Quaternary ammonium salts are used in medicine and pharmacology as bactericides and antiseptics [1]. Their wide application caused the development of microbial resistance to these compounds. In recent years, much work has been devoted to the problem of preventing the formation of biofilms by bacteria [2]. Therefore, there is a need to synthesize new quaternary ammonium salts that can be used as effective disinfectants to combat both planktonic and biofilm forms of microorganisms. In addition, the antimicrobial properties of quaternary heterocyclic compounds, including 1-deazapyrimido[1,2,3-cd]purinium salts, remain poorly understood to date. Taking this into account, we synthesized a series of 1-deazapyrimido[1,2,3$c d$ ]purinium salts and evaluated their antimicrobial effect against biofilms formed by microorganisms.

\section{Results and discussion}

The synthesis of the target 5,6-dihydro-4H-1-deazapyrimido[1,2,3-cd]purine-7-ium salts 3, 6 was performed according to Scheme 1. For the synthesis of new derivatives of 1deazapyrimido[1,2,3-cd]purine, we used an approach based on the reaction of intramolecular cyclization of 7-substituted pyrrolo[2,3- $d$ ]pyrimidines [3]. The bromination of methyl 7-allyl-4(dimethylamino)-7H-pyrrolo[2,3- $d$ ]pyrimidine-6-carboxylate (1) produced 5-bromo-5,6-dihydro4H-1-deazapyrimido[1,2,3-cd] purine-7-ium bromide 3 . The interaction of pyrrolo[2,3d]pyrimidine-6-carboxylic acid $\mathbf{2}$ with iodine led to the formation of iodolactonization product 8(iodomethyl)pyrimido[5',4':4,5]pyrrolo[2,1-c][1,4] oxazine 4 . Treatment of oxazine 4 with sodium methylate resulted in the formation of methyl 7-(oxiran-2-ylmethyl)-7H-pyrrolo[2,3d]pyrimidine-6-carboxylate (5). The heating of compound 4 in acetonitrile in the presence of triethylammonium chloride gave 1-deazapyrimido[1,2,3-cd]purine-7-ium salt $\mathbf{6}$ after intramolecular cyclization.

The ability of 1-deazapyrimido[1,2,3-cd] purine derivatives in subinhibitory concentrations $10 \mu \mathrm{g} / \mathrm{mL}$ and $50 \mu \mathrm{g} / \mathrm{mL}$ to prevent bacteria from biofilm formation has been tested on polystyrene plates by gentianvioletum sorption on biofilm structures, followed by its desorption with organic solvent [4]. Antibacterial activity was investigated against clinical bacterial strains of gram-positive (Staphylococcus aureus 222 (MRSA)) and gram-negative (Escherichia coli 311, Pseudomonas aeruginosa 449) bacteria used in the study. 


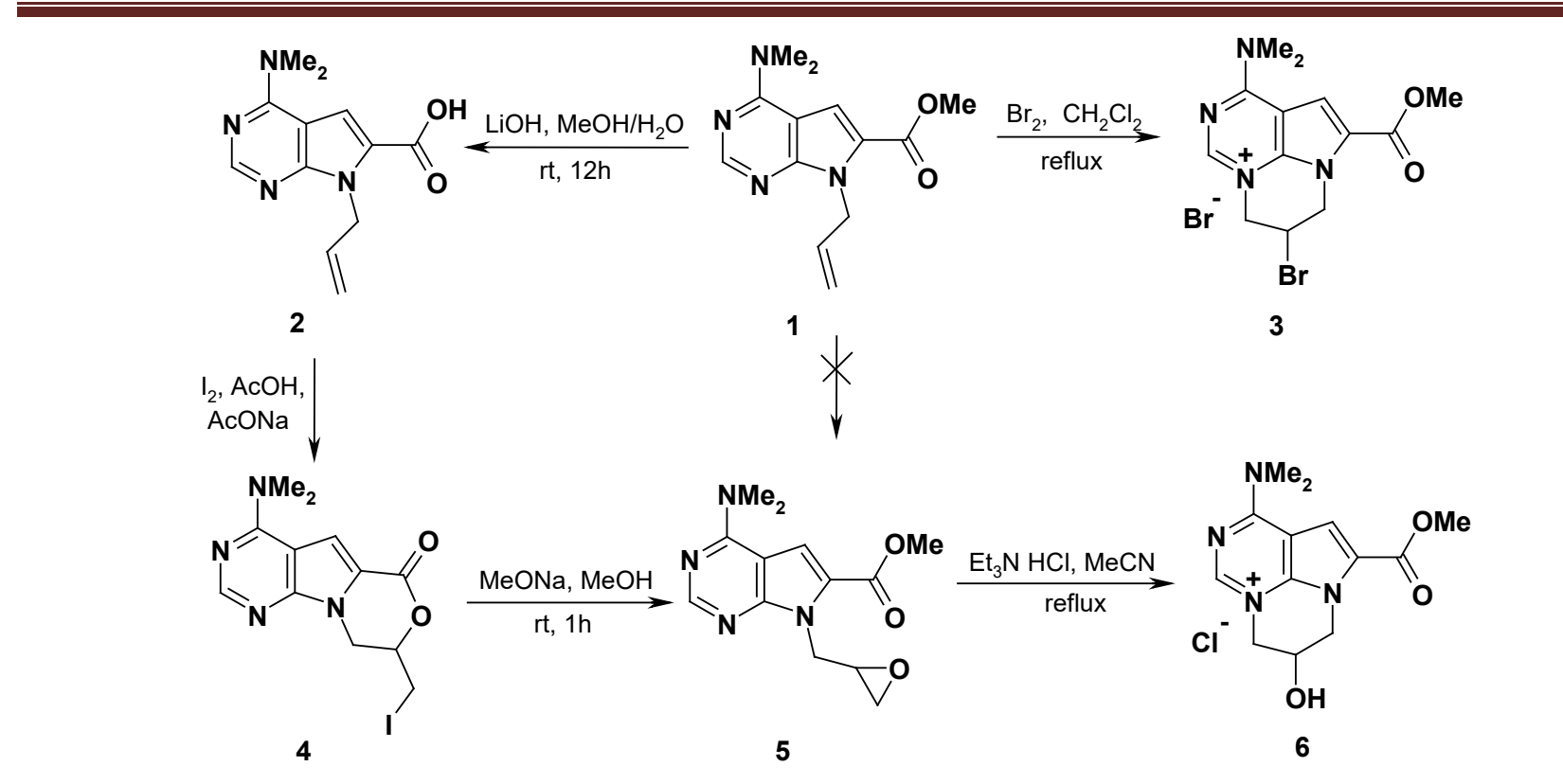

Scheme 1. Synthesis of 5,6-dihydro-4H-1-deazapyrimido[1,2,3-cd]purin-7-ium salts 3, 6.

Our results demonstrated that compounds $\mathbf{3}$ and $\mathbf{6}$ prevented $S$. aureus biofilm formation in a dose-dependent manner. The mass of MRSA 222 biofilm decreased by $81.2-85.0 \%$ at 50 $\mu \mathrm{g} / \mathrm{mL}$ and by $18.8-33.6 \%$ at $10 \mu \mathrm{g} / \mathrm{mL}$ when compared with untreated culture. The compound 6 inhibited E. coli and P. aeruginosa biofilms formation: the biomass decreased by $24.9 \%$ and $42.9 \%$ at concentration of $50 \mu \mathrm{g} / \mathrm{mL}$ and by $49.6 \%$ and $60.9 \%$ at concentration of $10 \mu \mathrm{g} / \mathrm{mL}$ respectively. Treatment of the gram-negative bacteria biofilm with compound $\mathbf{3}$ led to the reduction of the biomass by $31.5-38.4 \%$ (E. coli) and $12.9-18.7 \%$ (P. aeruginosa).

\section{Conclusion}

The synthesis of the two 1-deazapyrimido[1,2,3-cd]purine derivatives was developed on the basis of 7-substituted 7H-pyrrolo[2,3-d]pyrimidine-6-carboxylates. The results of antibiofilm activity showed that compounds specifically reduced the biofilm formation of S. aureus 222, E. coli 311 and P. aeruginosa 449.

\section{References}

[1] Kwaśniewska, D., Chen, Y.-L., \& Wieczorek, D. (2020). Biological activity of quaternary ammonium salts and their derivatives. Pathogens, 9(6), 459-471. https://doi:10.3390/pathogens9060459

[2] Obłąk, E., Futoma-Kołoch, B. \& Wieczyńska, A. (2021). Biological activity of quaternary ammonium salts and resistance of microorganisms to these compounds. World Journal Microbiology and Biotechnology, 37, 22. https://doi.org/10.1007/s11274-020-02978-0

[3] Muzychka, L. V., Yaremchuk, I. O., Verves, E. V., \& Smolii, O.B. (2019). Pyrrolo[2,3d]pyrimidine derivatives in the synthesis of a novel heterocyclic system $2 a, 5 a, 7-$ triazaacenaphthylene. Chemistry of Heterocyclic Compounds, 55(4-5), 397-400. https://doi:10.1007/s10593-019-02471-z

[4] O'Toole, G. A. (2011). Microtiter dish biofilm formation assay. Journal of Visualized Experiments, 47. pii: 2437. https://doi: 10.3791/2437 


\section{Waterborne polyurethane-polyacrylate dispersions of mixed type}

Tamara Travinskaya, Alexandra Brykova, Lyudmila Robota, and Yuri Savelyev

Department of heterochain polymers and interpenetrating networks, Institute of macromolecular chemistry, NAS of Ukraine, UKRAINE, Kyiv, Kharkivske sh., 48, E-mail: travinskaya-tamara@rambler.ru

Abstract - A series of waterborne, aggregatively stable PUI/PA dispersions has been obtained by combining in the mixture both type of polymers. The effects of component ratio on various properties of PUI/PA, such as particle size, surface tension, rheological behavior, physic-mechanical properties and thermodynamical compatibility have been investigated.

Keywords - waterborne polyurethane, polyacrylate, dispersion, mixture, compatibility, composition.

\section{Introduction}

In recent years, the production of dispersions, emulsions and latexes has been widely developed through the development and implementation of resource-saving and environmentally friendly technologies for their production. However, the growing demands on the complex of properties force to create new compositions. One of the way to solve this problem is to change the properties of polymers by modifying them with other polymers, including by mixing them. Among many dispersions and latexes polyurethane and polyacrylate in terms of their production and use occupy one of the leading places. Polyurethane ionomers (PUI) are extremely promising. The presence in their macrochain of ionic centers and water as a liquid phase, solves the problem of environmental protection. Polyacrylate aqueous dispersions (PA) are also widely used as film formers in various sectors of the economy. Obtaining dispersions of the mixed type has the advantage that opens the possibility of "combining" in the binary film of thermodynamically incompatible polymers and improving the characteristics of existing materials. The paper studies the properties of PUI/PA dispersions and based films, depending on the components' ratio.

\section{Materials}

PUI was obtained on the basis of POTMG (MM-1000), TDI (mixture of 2,4-2,6 isomers) in a ratio of 65:35. Isophthalic acid dihydrazide was used as chain extender, pyromelitic acid dianhydride - as the carrier of ionic groups. As the acrylate component was used an aqueous dispersion of a copolymer of ethylester of acrylic acid, nitrile of acrylic acid and methacrylic acid in the ratio $84: 13: 3$, respectively. PUI/PA dispersions of the mixed type were obtained by introducing of from 1 to $50 \mathrm{wt} \%$ PA into PUI latex.

\section{Results}

The properties of PUI, PA dispersions, PUI/PA mixtures and based films are shown in table 1.

Table 1

Properties of PUI, PA, PUI/PA and based films

\begin{tabular}{|c|c|c|c|c|c|r|c|}
\hline \multicolumn{2}{|c|}{$\begin{array}{c}\text { Compositio } \\
\mathrm{n}, \mathrm{wt} \%\end{array}$} & \multicolumn{3}{|c|}{ Properties of dispersions } & \multicolumn{3}{c|}{ Properties of films } \\
\hline $\begin{array}{c}\text { PU } \\
\mathrm{I}\end{array}$ & $\mathrm{PA}$ & $\mathrm{pH}$ & $\begin{array}{c}\mathrm{r}_{\mathrm{av}} \\
\mu \mathrm{km}\end{array}$ & $\begin{array}{c}\delta \\
\mathrm{mN} / \mathrm{m}\end{array}$ & $\begin{array}{r}\text { Water } \\
\mathrm{abs}, \%\end{array}$ & $\begin{array}{c}\sigma, \\
\mathrm{MPa}\end{array}$ & $\begin{array}{c}\mathrm{E}, \\
\%\end{array}$ \\
\hline 100 & 0 & 7,38 & 0,56 & 37,34 & 18,7 & 23 & 500 \\
\hline 95 & 5 & 7,06 & 0,43 & 36,32 & 19,3 & 25 & 600 \\
\hline 90 & 10 & 6,86 & 0,38 & 38,35 & 28,0 & 30 & 680 \\
\hline 80 & 20 & 6,65 & 0,41 & 36,32 & 20,1 & 28 & 630 \\
\hline 70 & 30 & 6,35 & 0,58 & 36,32 & 27,7 & 18 & 550 \\
\hline 50 & 50 & 6,02 & 0,64 & 36,83 & 24,7 & 15 & 500 \\
\hline 0 & 100 & 5,36 & 0,06 & 32,00 & 76,0 & 18 & 450 \\
\hline
\end{tabular}


The choice of the optimal amount of PA affects not only the stability of dispersions, but also the strength characteristics of the films and the value of their water absorption. It is advisable to obtain PUI/PA with a PA content of not more than $20 \%$, since an increase in the proportion of the acrylate component leads to a loss of strength. At $10 \%$ content of the acrylate component, the value of surface tension $(\delta)$ is greater than the individual components. The higher the surface tension of the mixture, the stronger the intermolecular interaction of the components. The increased tensile strength of the binary film of this composition is in agree with the obtained data. The average particle size $\left(\mathrm{r}_{\mathrm{av}}\right)$ of the mixtures almost does not change with the change of composition, which confirms the absence of aggregation processes. According to rheological studies, all studied mixtures belong to structured systems and are the non-Newton liquids with thixotropic properties. The effective viscosity exceeds the additive values up to almost $20 \%$ of the PA content. Within the same compositions, the tensile strength and relative elongation exceed the parameters of the original components. This may be due to the compatibility of the components in mixtures of these compositions. The calculated values of the free mixing energy showed that for mixtures in which the PA content does not exceed $20 \%$ are negative, which indicates the thermodynamic compatibility of the components within this concentration range. When the PA content increases by more than $20 \%$, the free mixing energy changes the sign to the opposite (positive), which corresponds to the two-phase state of the system. The reason for the compatibility in the studied polymer mixture is probably the formation of hydrogen bonds between the urethane group of PUI and the ester group of PA. However, compatibility also depends on the competition between the enthalpy and entropy of mixing. The micrographs of the original latexes and their mixtures $90 / 10$ presented in Fig. 1 indicate a more homogeneous structure of the binary PUI/PA (90/10) film. The average value of the particle size in this composition $\mathrm{r}_{\mathrm{av}}(90 / 10)$ is $0,38 \mu \mathrm{km}$, which is less than in other PUI/PA ratios.

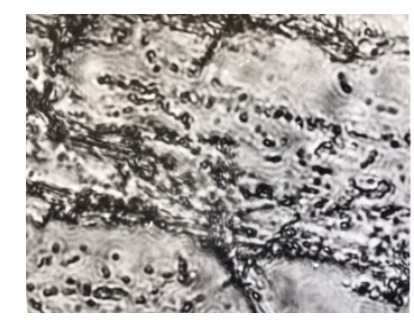

PUI

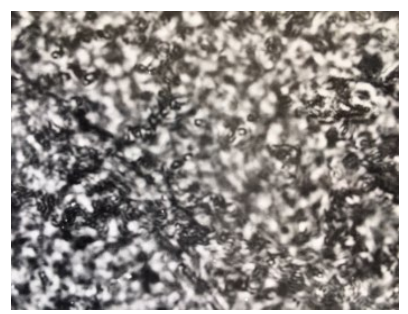

PUI/PA 90/10

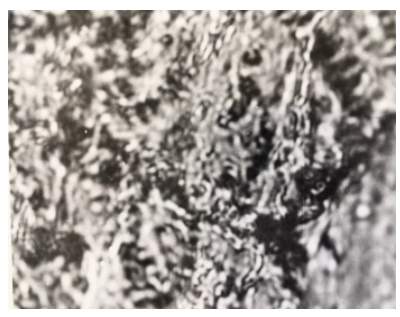

PA

Fig.1. Polarizing optical microscope images of combined PUI/PA dispersions

\section{Conclusions}

Aggregatively stable film-forming polyurethane-polyacrylate aqueous dispersions were obtained by mechanical combinig of different amounts of initial polyurethane and polyacrylate dispersions. It was found that the obtained colloidal mixtures retain the level of dispersion characteristic of individual components.

According to the data of rheological studies, polyurethane-polyacrylate mixtures are structured non-Newtonian systems in the entire studied range of compositions and are characterized by thixotropic properties.

The strength of binary films exceeds that of individual components, wherein the range of increased strength values coincides with the range of thermodynamic compatibility of the components.

Thus, the properties of the combined mixtures can be controlled by changing their quantitative composition. 


\section{ALTERNATIVE AND NON-CONVENTIONAL ENERGY SOURCES}




\title{
Processing of granules based on peat and sludge
}

\author{
Zhanna Petrova, Yuliia Novikova, Anton Petrov \\ Department of Heat and mass transfer in heat technologies, Institute of Engineering Thermophysics of \\ NAS of Ukraine, Ukraine, Kyiv, 2, Bulakhovsky 2 Str., E-mail: bergelzhanna@ukr.net
}

Abstract - The urgent task is to move from traditional energy sources to alternative ones. The purpose of the work is to study the creation and drying of granules based on sludge and peat. The kinetics of drying of granules depending on different compositions and proportions of components is investigated.

Keywords - peat, sludge, fuel, granulation, drying.

\section{Introduction}

An urgent problem in Ukraine is the increase in gas and oil prices. The transition from traditional fuels to alternative (renewable) fuels that help the country become energy independent and cover the shortage of traditional fuels. One of the cheap alternative fuels is peat.

On the overflow of sludge sites, activated sludge merges every year, which over the years turns into sludge, which leads to the deterioration of the ecology of Ukraine. These sites store sludge that are more than 30 years old with a low content of organic matter, so they are not suitable for fuel and fertilizers. To increase the organic component to the sludge should be added peat [1].

The purpose of the work is to study the creation and drying of granules based on sludge and peat.

\section{Discussion of results}

On the basis of sludge and peat created different compositions in 3 proportions. In compositions 1 and 2, sludge of $63.1 \%$, peat with a moisture content of $75.1 \%$ and $45.1 \%$, respectively, were added.

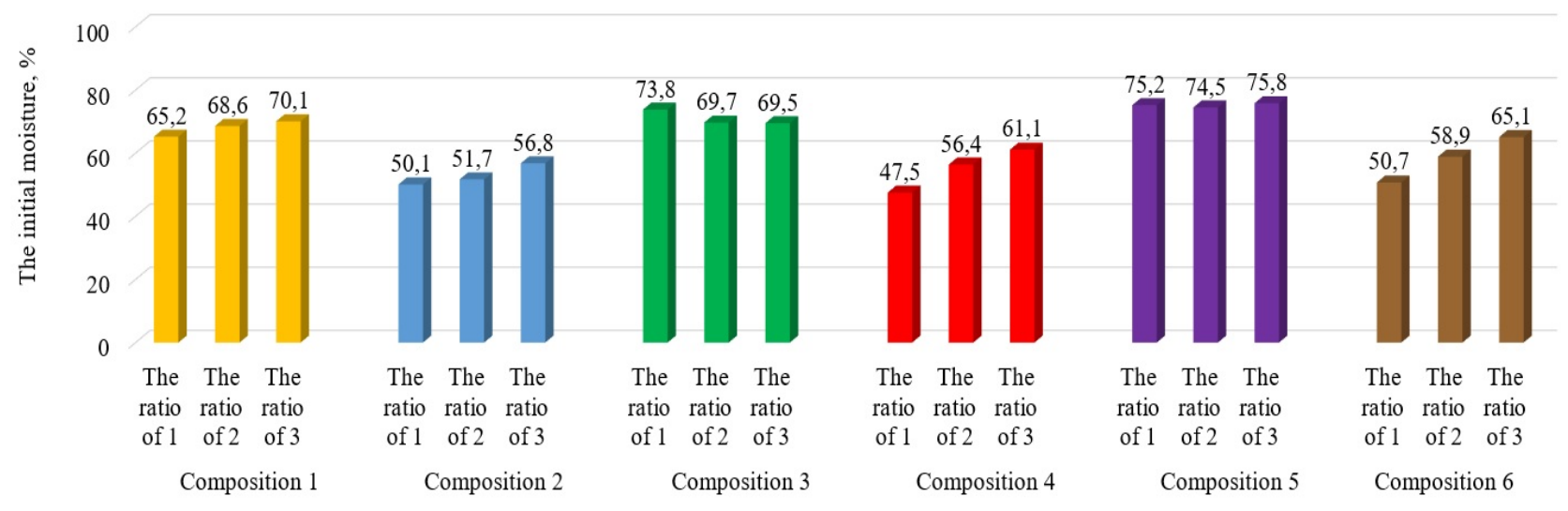

Fig. 1. Variable of initial moisture depending on the composition and the ratio of the composition of the granules.

For composition 3 and 4 - sludge with a moisture content of $70.1 \%$, peat with a moisture content of $75.1 \%$ and $45.1 \%$, respectively. To the composition 5,6 - sludge with a moisture content of $75.9 \%$, peat with a moisture content of $75.1 \%, 45.1 \%$, respectively. The formed granules with peat with a moisture content of $45.1 \%$ crumbled [2]. 


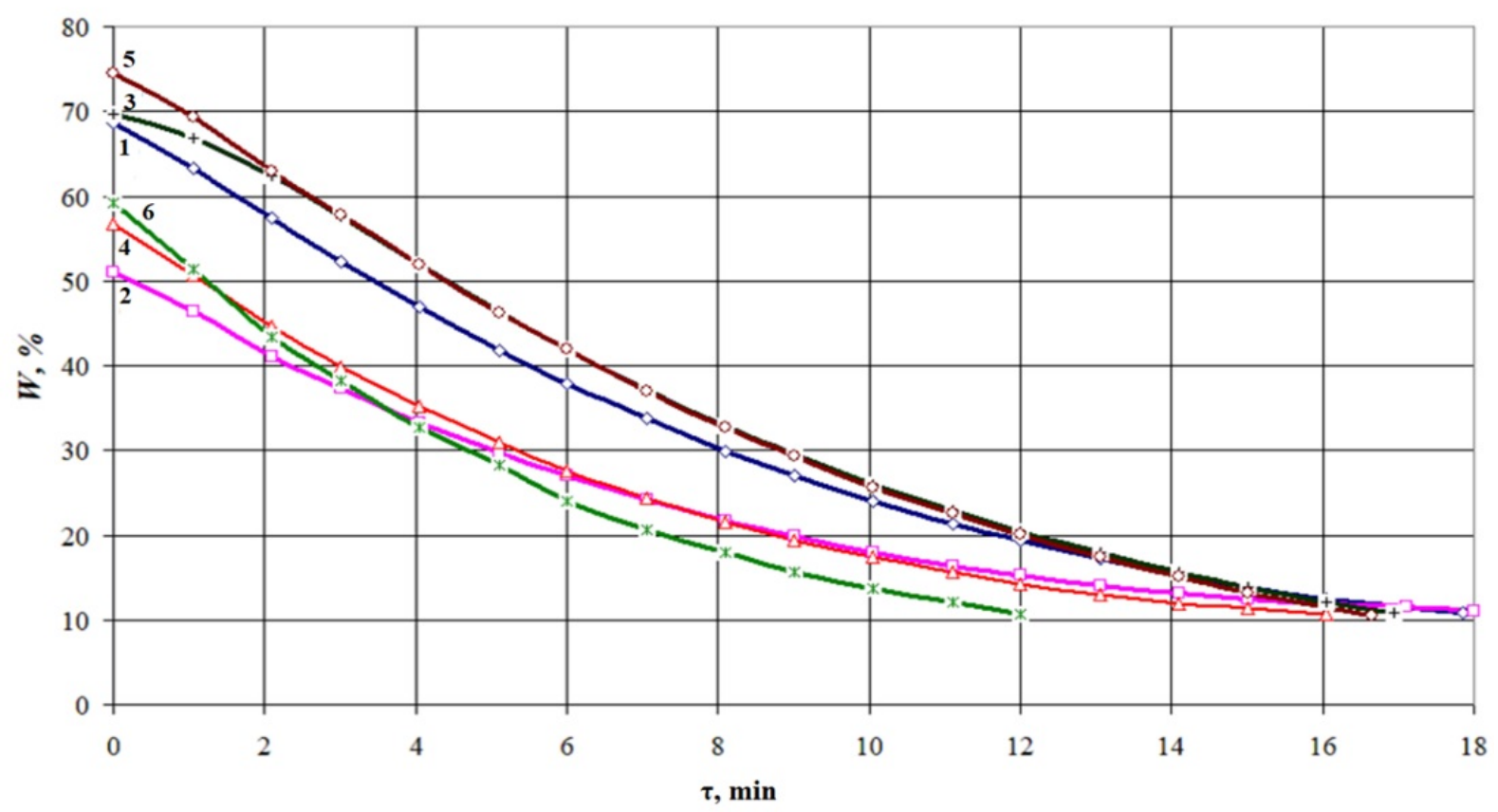

Fig. 2. The effect of the components of the compositions № $1-6$ on the duration of drying in the second ratio at $\mathrm{t}=120^{\circ} \mathrm{C}, \mathrm{V}=2 \mathrm{~m} / \mathrm{s}, \mathrm{d}=6 \mathrm{~mm}$

In fig. 2. the research of kinetics of drying process from compositions № 1 - 6 in the second ratio of components is represented. As can be seen from the figure, the shortest drying time in composition 6 , which is 1.5 times less than in composition 2. In General, the drying time of granules with a diameter of $6 \mathrm{~mm}$ in different compositions at different ratios is 16 to 18 minutes.

\section{Conclusion}

Granules with "burt" peat (moisture 45.1\%) in the ratio 6 has the lowest drying rate, but all the formed granules are brittle and crumble. Therefore, for further work it is advisable to choose the ratio of "fresh" peat (moisture $75.1 \%$ ).

\section{References}

[1] Petrova, Zh.O., Kremnov, V.O., Korbut, N.S., \& Novikova Yu.P. (2020). Granulation of mixtures of obsolete sludge and peat. Abstracts of papers XVIII Interenational scientific conference "Improvement of processes and equipment in food and chemical industries" (Oct. 12-16, 2020, Odessa). Odessa: Odessa National Academy of Food Technologies, 1416.

[2] Petrova, Zh., \& Novikova, Yu. (2021, March 17). Preparation of raw materials, creation of compositions and granulation from obsolete sludge, peat and biomass. Ceramics: Science and Life, 1(50), 14-18. https://doi.org/10.26909/csl.1.2021.2 


\title{
Pyrolysis of polymer waste is a source of motor fuels
}

\author{
$\underline{\text { Ksenya Hrynyshyn }}^{1}$, Volodymyr Skorokhoda ${ }^{2}$, Taras Chervinskyy ${ }^{3}$ \\ 1. Department of Chemical Technology of Plastics Processing, Lviv Polytechnic National University, UKRAINE, \\ Lviv, 12 Bandera street, E-mail: kseniia.o.hrynyshyn@lpnu.ua \\ 2. Department of Chemical Technology of Plastics Processing, Lviv Polytechnic National University, UKRAINE, \\ Lviv, 12 Bandera street, E-mail: volodymyr.yo.skorokhoda@lpnu.ua \\ 3. Department of Chemical Technology of Oil and Gas Processing, Lviv Polytechnic National University, \\ UKRAINE, Lviv, 12 Bandera street, E-mail: taras.i.chervinskyi@lpnu.ua
}

\begin{abstract}
The process of pyrolysis of half-dimensional waste is carried out and the composition and properties of the obtained products are analyzed.
\end{abstract}

Keywords - pyrolysis, pyrocondensate, pyrocarbon, polyethylene wastes, used tyres, recycling.

\section{Introduction}

Polymer wastes accumulated in huge quantities in landfills, scattered in forests and fields, floated on almost all water surfaces of our planet, significantly pollute the environment. Taking into account that wastes do not decompose, their quantity increases daily. This problem has already become a global one. In order to save the planet from catastrophic pollution by polymer waste, they must be utilized in a proper way. Known methods include incineration, recycling with reuse, and so on. The purpose of the work is to study the composition and properties of pyrocondensate pyrolysis of different types of polymer waste for their further use in the processes of obtaining commercial motor fuels.

\section{Results}

The basic properties of polyethylene pyrolysis pyrocondensate were studied. It was found that pyrocondensate and its narrow fractions do not contain sulfur but a significant amount of unsaturated (iodine number is $85.9 \mathrm{~g} \mathrm{I}_{2} / 100 \mathrm{~g}$ ) and paraffinic hydrocarbons, due to which they are characterized by unsatisfactory low-temperature properties (freezing point is $+4{ }^{\circ} \mathrm{C}$ ).

The basic properties of used tyres pyrolysis pyrocondensate and its narrow fractions were studied. A significant amount of unsaturated hydrocarbons (iodine number is $67.8 \mathrm{~g} \mathrm{I}_{2} / 100 \mathrm{~g}$ ) and sulfur $(1.59 \mathrm{wt} \%)$ were found in them.

It was established that both pyrocondensate and narrow fractions cannot be used as marketable products. It was proposed to use those narrow fractions as raw materials for the production of commercial gasoline and diesel fuels together with the corresponding fractions at refineries.

The main properties of pyrocarbon obtained in the process of used tyres pyrolysis were studied. It was proposed to be used as an adsorbent for the collection and localization of oil and petroleum products spills on solid and water surfaces. The specific consumption of pyrocarbon is $1.02-1.46 \mathrm{~g} / \mathrm{g}$ depending on the type of absorbed petroleum product.

The basics of the technology of polymer waste pyrolysis process were developed, in particular the basic technological scheme and process chart; the process material balance was calculated.

The main technical and economic indices of the pyrolysis installation for polymer wastes were calculated based on the example of used tyres pyrolysis. It is determined that the cost of pyrocondensate is $1565.55 \mathrm{UAH}$ per ton, and the payback period of the installation is 3 years. 


\section{Conclusion}

The main properties of pyrocondensate of pyrolysis of polyethylene and worn car tires are studied. It is established that pyrocondensate and narrow fractions isolated from it can be used to obtain marketable motor fuels. It is established that pyrocarbon obtained in the process of pyrolysis of worn car tires can be used as an adsorbent for the absorption of petroleum products. 


\title{
Research of the calorific value of dried alcohol distillery stillage
}

\author{
Oleksandr Ivashchuk ${ }^{1}$, Volodymyr Atamanyuk ${ }^{1}$, Roman Chyzhovych $^{1}$, Tetiana Kuzminchuk ${ }^{1}$, \\ Roman Zherebetskyi ${ }^{2}$, Sofiia Kiiaieva ${ }^{1}$ \\ 1.Department of Chemical Engineering, Lviv Polytechnic National University, \\ UKRAINE, Lviv, 12 Bandery str., E-mail: oleksandr.s.ivashchuk@lpnu.ua \\ 2.Department of Organic Products Technology, Lviv Polytechnic National University, \\ UKRAINE, Lviv, 12 Bandery str.
}

\begin{abstract}
The calorific value of dried corn alcohol distillery stillage was determined. The obtained data have shown a prospect for using distillery stillage as solid fuel.
\end{abstract}

Keywords - alcohol distillery stillage, secondary raw materials, calorific value, solid fuel briquettes.

\section{Introduction}

The main by-product in the production of ethyl alcohol is alcohol distillery stillage, which is formed during the fermentation of food raw materials. Depending on the technology, about 1015 liters of stillage are formed per 1 liter of ethanol $[1,2]$. The dry matter content in the product is only up to $10 \%$ - and it leads to quick deterioration. Excessive humidity complicates subsequent use of alcohol distillery stillage and limits the area of its application.

Given the above, alcohol distillery stillage can be determined as a waste product, reprocessing or utilization of which is an important industrial task - because in Ukraine there are more than 80 distilleries, which produce about 4 million $\mathrm{m}^{3}$ of molasses stillage and 3.6-3.8 mln $\mathrm{m}^{3}$ of grain distillery stillage [3].

Alcohol distillery stillage is valuable for its chemical composition. The main components are sugars, glycerin, cellulose, starch, hemicellulose. There are also proteins, amino acids, vitamins, micro- and macronutrients, and carbohydrates [4]. Given this, the dry distillery stillage is ahead of most feed products, so its using in animal husbandry is the most rational. Alcohol distillery stillage can also be used as a plasticizer for concrete mixtures [4, 5], for the biogas obtaining [6]. Need to be noted, all these ways require previous drying of the product as usually.

A promising method of using of secondary raw materials with natural fibers is the production of solid fuel briquettes. Fuel pellets are an environmentally friendly source of energy used in municipal energy for heating residential buildings and technical premises. The energy required to produce pellets is about $10 \%$ higher than the energy content in the pellets themselves, which is used for drying raw materials, and to produce pellets from dry raw materials consumes only $1-2 \%$ of the energy contained in them [7].

\section{Experimental}

The object of research was alcohol corn distillery stillage after the centrifugation process, obtained on the production line of SE «Vuzlove distillery» (Vuzlove, Lviv region, Ukraine) and dried by the filtration drying. The obtained material was analyzed to determine the residual moisture after filtration drying according to the method described in State Standard of Ukraine DSTU EN 14774-2: 2013. Solid biofuels. Determination of moisture content [8]. Determination of calorific value was done according to the requirements of State Standard of Ukraine DSTU EN 14918: 2016. Solid biofuels. Method for determining the calorific value [9].

\section{Results and discussion}

The dried sample of the corn distillery stillage was left for several days in room conditions, after that it was studied to determine the residual humidity according to the method from [8]. The 
research results showed an average humidity of $3.14 \pm 0.06 \%$ wt., which fully satisfies the industrial needs to increase the shelf life of the alcoholic distillery stillage and the possibility of its long-term storage and transportation.

The calorific value of the dried distillery stillage was experimentally determined according to [9]. The obtained value of the calorific value of alcoholic corn distillery stillage was 19545 $\mathrm{kJ} / \mathrm{kg}$ or $4672 \mathrm{kcal} / \mathrm{kg}$, and it is slightly higher than the calorific value of miscanthus and energy willow (Table 1), that are widely used for the solid fuel briquettes production $[7,10]$.

Table 1

The calorific value of dried distillery stillage and widely used plants for solid fuel production

\begin{tabular}{|c|c|c|c|}
\hline & $\begin{array}{c}\text { Dried corn distillery } \\
\text { stillage }\end{array}$ & Energy willow & Miscanthus \\
\hline $\begin{array}{c}\text { Calorific value, } \\
\mathrm{kJ} / \mathrm{kg}\end{array}$ & 19545 & $\approx 17600$ & $\approx 17500$ \\
\hline
\end{tabular}

Additionally, the obtained value satisfies the requirements of European standards for pellets among countries such as Germany, Austria, Sweden [7].

\section{Conclusions}

Thus, the measurements of calorific value showed the prospects for the use of dried alcoholic corn distillery stillage as a solid fuel briquette, that requires subsequent research.

\section{References}

[1] Beltran, F. J. et al. (2001). Treatment of high strength distillery wastewater (cherry stillage) by integrated aerobic biological oxidation and ozonation. Biotechnology Progress, 17(3), 462-467.

[2] Nataraj, S. K., Hosamani, K. M., \& Aminabhavi, T. M. (2006). Distillery wastewater treatment by the membrane-based nano-filtration and reverse osmosis processes, Water Research, 40(12), 2349-2356.

[3] Mazur, A.H., Tsikhanovska, V.M. \& Hontaruk, Ya.V. (2013). Perspektyvy vyrobnyctva biogazu na spyrtovykh zavodax Vinnyckoyi oblasti. Naukovi praci Institutu bioenergetichnih kul'tur i cukrovykh burjakiv: zb. nauk. prac, 19, 245-249.

[4] Hizhnjak, M.I. \& Cion', N.I. (2010). Spirtova barda yak cìnna kormova dobavka j organìchne dobrivo u sìl'skomu gospodarstvì. Ribogospodars'ka nauka Ukrajiny, 2, 122 130.

[5] Obodovych, A. \& Sydorenko, V. (2010). Barda spirtovyh zavodov - cennyj othod dlia proizvodstva kormovyh drozhzhej i betona. Keramika: Nauka I Zhittja, 4(29), 15-19. doi: 10.26909/csl.4.2015.2

[6] Golub, N.B. \& Potapova, M.V. (2018). Tehnologiya oderzhannya biogazu z pislyaspyrtovoyi bardy. Vidnovljuvana energetyka, 2, 70-77.

[7] Roik, M.V., Sinchenko, V.M., Fuchylo Ya.D. et al. (2015). Energetychna verba: tehnologiya vyroschuvannya ta vykorystannya. Vinnycya: Niland-LTD.

[8] DSTU EN 14774-2:2013 (2015). Tverde biopalivo. Viznachennja vmistu vologi. Kyiv: Minekonomrozvytku Ukrajiny.

[9] DSTU EN 14918:2016 (2016). Tverde biopalivo. Metod viznachennya teplotvornoyi zdatnosti. Kyiv: Minekonomrozvytku Ukrajiny.

[10] Khivrych, O.B., Kvak, V.M., Kas'kiv V.V., Mamajsur, V.V. \& Makarenko, A.S. (2011). Energetychni roslyny yak alternatyva tradycijnym vydam palyva. Agrobiologiya, 6, 153156. 


\section{ECOLOGY AND SUSTAINABLE DEVELOPMENT. ENVIRONMENTAL PROTECTION}




\title{
Usefulness of facial masks against COVID-19 transmission - an experimental
} evidence

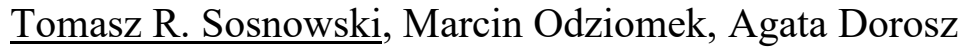 \\ Faculty of Chemical and Process Engineering, Warsaw University of Technology, POLAND, Warsaw, \\ Waryńskiego 1, E-mail: Tomasz.Sosnowski@pw.edu.pl
}

\begin{abstract}
The primary route of transmission of COVID-19 disease is associated with the inhalation of airborne SAR-CoV-2 coronavirus exhaled by infected persons. Therefore, the use of facemasks has been proposed as one of the basic means of protection. This study presents methods of the evaluation of the protective properties of the masks at various exhalation conditions. The preliminary results show that even high-quality masks (respirators) offer only a partial elimination of aerosol particles due to the tightness issues.
\end{abstract}

Keywords - air filtration, personal protective equipment, filtration facemasks, aerosol exhalation.

\section{Introduction}

COVID-19 pandemic changed our world in 2020-21. Social distancing, hand hygiene, and covering the face with air-filtering masks have become the main recommendations in preventing the spread of the disease [1]. The actual value of these recommendations has been disputed due to the lack of firm data that would justify them. However, despite the ongoing debate $[2,3]$, face coverings are mandatory in many countries as primary protection means against coronavirus transmission via the aerosol route. It is based on the evidence that asymptomatic and presymptomatic infected persons can exhale the virus. The pathogen in the aerosol form can be inhaled by bystanders leading to further infection [4]. Considering this scenario, filtering out the exhaled air by facemasks is equally important as the filtration of inhaled air. Air filtration during inhalation requires very efficient masks (respirators) since low-class facemasks do not offer enough protection. Respirators are expensive and non-comfortable (due to high resistance), so they are not commonly used. Instead, most of the population wears less sophisticated face covers, e.g., surgical masks or cloth masks. Despite their lower filtration efficiency during inhalation, they may have good barrier properties against exhalation of the virus in the form of droplets generated in the respiratory system [5]. The aim of this work is to test this function under realistic in vitro conditions.

\section{Experimental}

Five types of face masks have been used in the preliminary studies (Table 1). They have been tested using a manikin head adapted for fitting the masks and aerosol emission via either a mouth opening or nostrils (Fig. 1a)

Table 1.

The parameters of facemasks used in the studies

\begin{tabular}{|c|c|}
\hline Designation & Description \\
\hline SM & surgical mask \\
\hline F3 & FFP3 mask (respirator) without valve \\
\hline F2f & FFP2 mask (respirator) with the exhalation valve in the front \\
\hline F2s & FFP2 mask (respirator) with the exhalation valve on the side \\
\hline CLM & Cloth mask \\
\hline
\end{tabular}




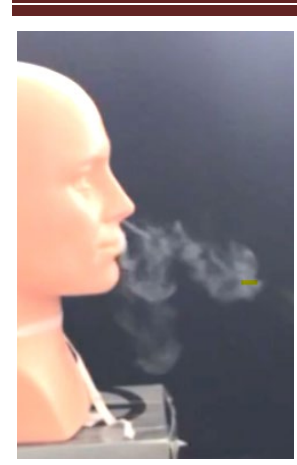

(a)

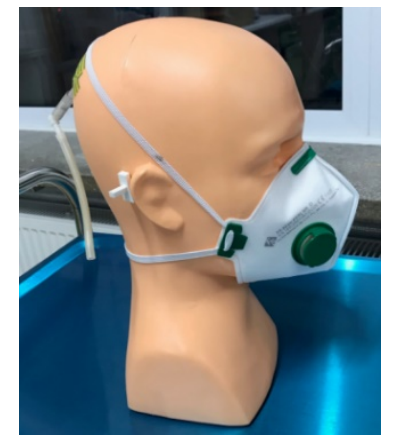

(b)

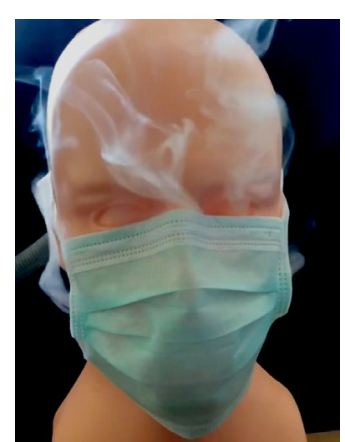

(c)

Fig.1. (a) Visualization of aerosol exhalation through the nostrils of the manikin; (b) the manikin wearing the F2vs mask; (c) visualization of aerosol penetration through the spaces of the inadequate fit of the surgical mask to the face surface.

Aerosol particles in the close vicinity of the manikin head were counted with the OPC-N3 laser spectrometer (Alphasense, Great Britain) that allowed to monitor the concentration of particles within the size range of $0.35-40 \mu \mathrm{m}$ which is representative for aerosols expelled from the respiratory system [5]. First trials with the wet aerosol generated from a medical nebulizer were unsuccessful due to the partial evaporation of droplets that made the results vague. Instead, we decided to generate the dry aerosol of gypsum powder using the pneumatic nebulizer (Sidestream, Philips Respironics, USA). This allowed suspending the aerosol in a $2 \mathrm{~L}$ glass chamber, from which the pulse of compressed air produced the puff of aerosol released through the manikin nostrils. Such a flow pattern was used to simulate realistic non-steady outflow conditions, that may be comparable, e.g., to a sneeze. The aerosol was blown into the particlefree atmosphere of purified sheath flow (Fig. 2), so the spectrometer could detect even a low number of particles penetrating the mask. The experimental setup (without the nebulizer) is schematically shown in Fig. 2. The airflow dynamics at the outflow from the manikin nostrils were determined in the independent measurement (with no aerosol in the system) with a digital airflow meter (model 3063, TSI Inc., USA).

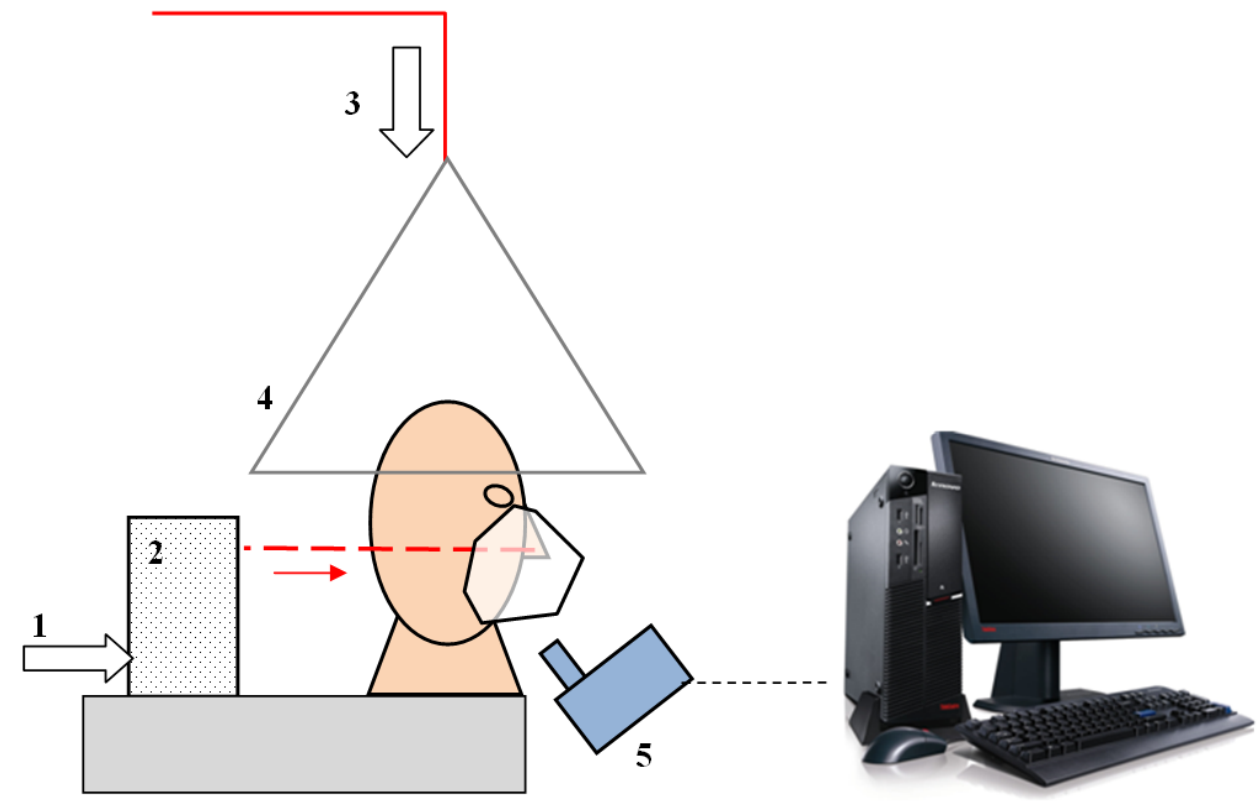

Fig.2. Experimental setup: 1 - pulse flows of the compressed air, 2 - aerosol chamber, 3 clean air (sheath flow), 4 - hood, 5 - aerosol spectrometer. 


\section{Results and discussion}

Fig. 3 shows the exhalation dynamics produced in the outflow of the manikin. It can be seen that the system allowed to generate short puffs with a duration of approximately $1.5 \mathrm{~s}$. They can be related to the cough or sneeze dynamics, although, in reality, the airflow rates are expected to be higher [6-8].

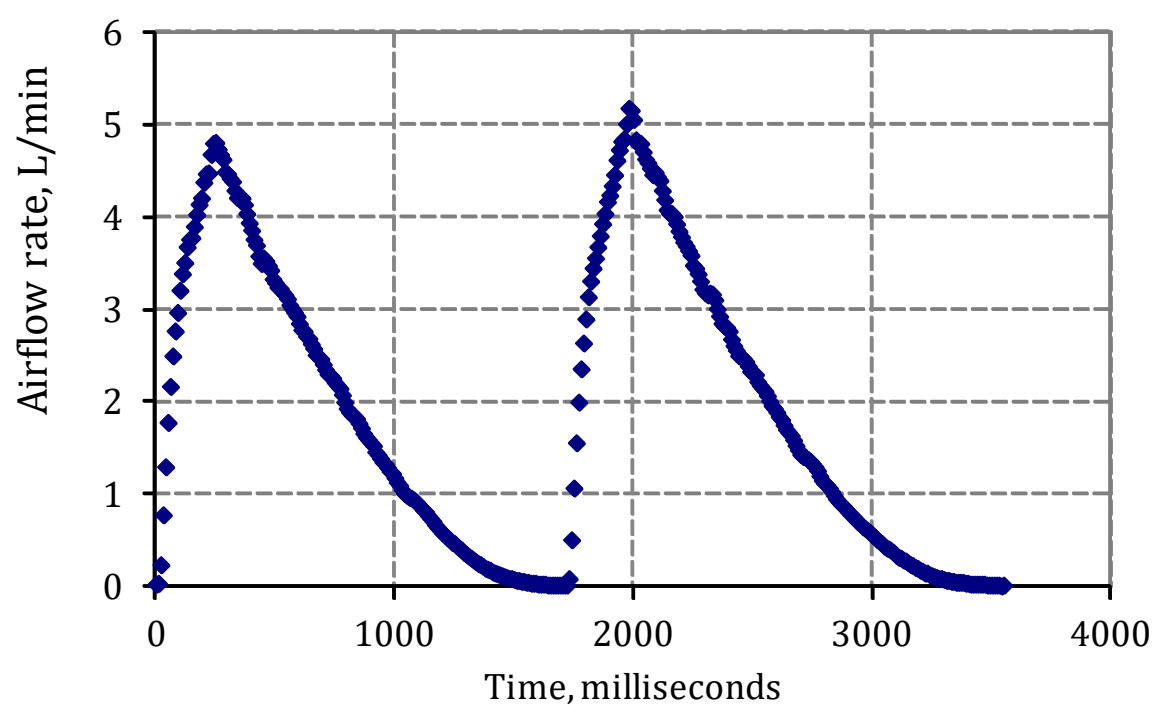

Fig.3. Air/aerosol flow dynamics generated in the system.

The overall efficiency of the five masks is compared in Fig.4. It is seen that even the most efficient F3 respirator allows for the escape of more than $40 \%$ of exhausted aerosol particles, whereas the results for less efficient facemasks are even worse. Interestingly, the side valve in the FFP2 mask (F2s) is responsible for a massive penetration of aerosol particles, which is comparable to the use of a simple surgical mask (SM). As expected, the masks (or respirators) designed mainly for the protection against inhaled aerosol particles, insufficiently filter out exhaled particles, especially under dynamic conditions. It can be attributed to a poor fitting of the mask to the face during exhalation, i.e., when the positive pressure builds up inside the mask.

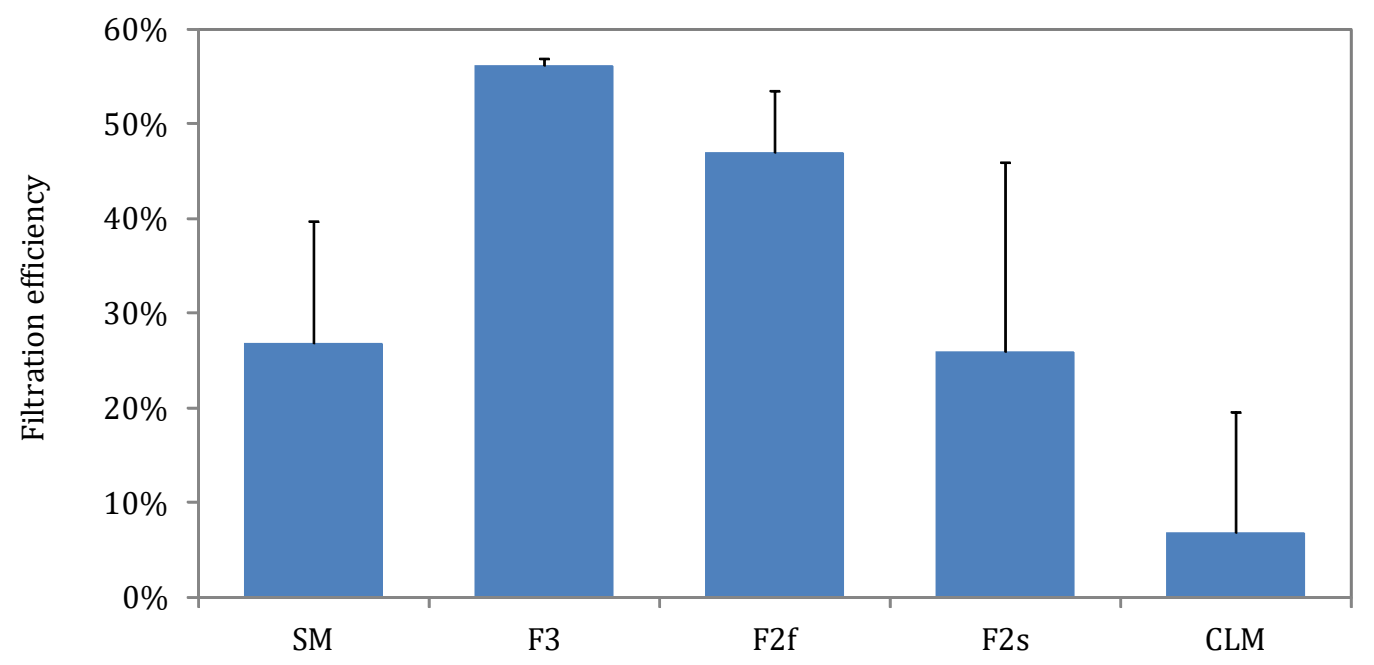

Fig.4. The efficiency of the respirators and masks regarding aerosol exhalation (error bars denote the standard deviation, $\mathrm{n}=3$ ). 
Dynamic events such as cough or sneeze can push the mask out from the face and facilitate aerosol emission. Also, the valves (if present) increasing the breathing comfort, become open during exhalation and allow the particles to escape outside the mask.

Fig. 5 shows the comparison of the particle size distribution in the aerosol penetrating the masks. The masks with a better filtration efficiency during exhalation remove mostly larger particles, so the cumulative size distribution is shifted towards smaller sizes comparing to the original aerosol ("no mask"). The mass median diameter values (d50) of the original and filtered aerosol are approximately 4 and $3 \mu \mathrm{m}$, respectively. The $\mathrm{d} 90$ ( $90^{\text {th }}$ centile) is reduced from approximately 9 to $6 \mu \mathrm{m}$. These numbers suggest that the largest particles are eliminated, probably due to the predominating inertial mechanism of particle deposition on the inner surface of the facemasks.

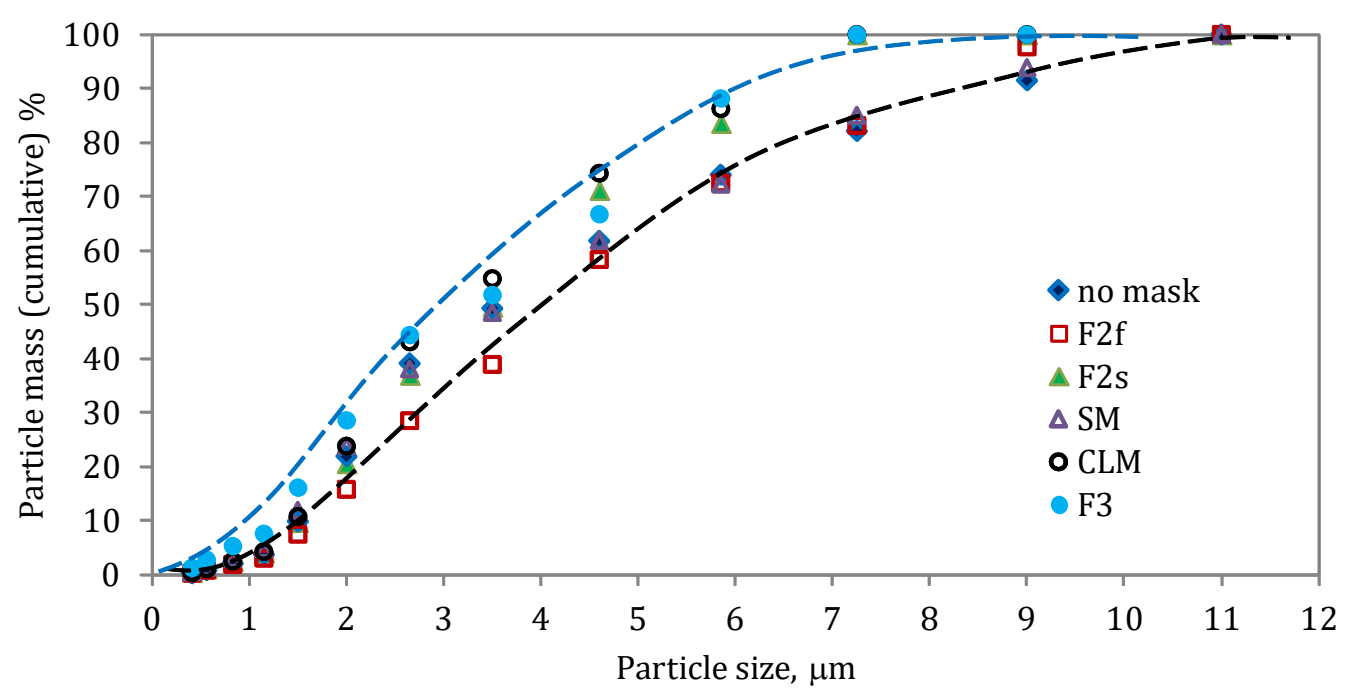

Fig.5. Cumulative mass-based particle size distribution measured beyond the facemasks. Two lines are drawn to visualize the shist of the distribution toward smaller size.

Based on the above results, it may be questioned if the use of facemasks can protect bystanders from the emission of coronavirus present in aerosol droplets exhaled by an infected individual. Let us notice two essential effects that lower the probability of infection in such a situation. The first one is related to the reduction of the number of aerosol particles that may contain the virus. The lower mass or volume median diameter indicates that the number of viruses potentially present in the aerosol suspended in the air is notably decreased (droplet volume is proportional to the third power of droplet size). It is known that the effective infection with SARS-CoV-2 requires many copies penetrating the respiratory system [9], so a reduction in the aerosol concentration matters.

The second factor that should be important for the usefulness of face covers, masks or respirators, is a deflection of the exhaled aerosol cloud, as seen, e.g., in Fig 1c. The droplets are directed not to the front but rather downwards, upwards, or to the sides, reducing the direct exposure of another person located head-to-head, e.g., in a group of people or during a conversation.

One of the limitations of this study is the application of a simplified model of the human head that does not necessarily reflect all essential geometrical features. In the near future we plan to use a standard head geometry according to the ISO/TS 16976-2:2015, which should provide a more realistic fit of the masks to the face. We also plan to continue experiments with the newly 
designed, dedicated cough and sneeze airflow generator, which should provide a more realistic representation of the loss of mask tightness during such events.

\section{Conclusion}

In vitro experiments with a model human head showed that facemasks and respirators do not fully protect the surrounding from aerosol particles emitted from the respiratory tract during flow pulses that correspond to exhalation or sneeze. The main reason is an adequate tightness of masks in the case of outward airflows. Nevertheless, it was demonstrated that masks reduce the concentration of emitted aerosol droplets, change their size distribution by filtering out the largest ones, and deflect the emitted aerosol cloud, so they act as a partial barrier and can reduce the chance of SARS-CoV-2 transmission.

\section{Acknowledgments}

Work supported by "IDUB against COVID" project grant by Warsaw University of Technology under the program Excellence Inititiave: Research University (IDUB).

\section{References}

[1] World Health Organization (2020). Mask use in the context of COVID-19. Interim report, December 2020, https://apps.who.int/iris/handle/10665/337199

[2] Mitze, T., Kosfeld, R., Rode, J., Wälde, K. (2020). Face masks considerably reduce COVID-19 cases in Germany. PNAS 117(51), 32293-32301, https://doi.org/10.1073/ pnas. 2015954117

[3] Vainshelboim, B. (2021). Facemasks in the COVID-19 era: A health hypothesis. Medical Hypotheses, 146, 110411. https://doi.org/10.1016/j.mehy.2020.110411.

[4] Johansson, M. A., Quandelacy, T. M., Kada S., et al. (2021). SARS-CoV-2 transmission from people without COVID-19 symptoms. JAMA Network Open, 4(1), e2035057, https://doi.org/10.1001/jamanetworkopen.2020.35057

[5] Sosnowski, T. R. (2021). Inhaled aerosols: their role in COVID-19 transmission including biophysical interactions in the lungs. Curr. Opin. Coll. Interface Sci., 54, 101451, https://doi.org/10.1016/j.cocis.2021.101451

[6] Bourouiba L. (2020). Turbulent gas clouds and respiratory pathogen emissions potential implications for reducing transmission of COVID-19. J. Am. Med. Assoc., 323 (18), $1837-$ 1838, https://doi.org/10.1001/jama.2020.4756

[7] Tang J. W., Nicolle A.D., Klettner C.A., et al. (2013). Airflow dynamics of human jets: sneezing and breathing - potential sources of infectious aerosols. PloS One 8, e59970, https://doi.org/10.1371/journal.pone.0059970

[8] Lindsley W. G, Reynolds J.S., Szalajda J.V., Noti J.D., Beezhold D. H. (2013). A cough aerosol simulator for the study of disease transmission by human cough-generated aerosols. Aerosol Sci. Technol., 47(8), 937-944, https://doi.org/10.1080/02786826. 2013.803019

[9] Scheuch, G (2020). Breathing is enough: for the spread of influenza virus and SARS-CoV2 by breathing only. J. Aerosol Med. Pulm. Drug. Deliv., 33, 230-234, https://doi.org/ 10.1089 /jamp.2020.1616 


\title{
Immobilisation of metals in the absorption process
}

\author{
Małgorzata Wojtkowska \\ The Faculty of Building Services, Hydro and Environmental Engineering, the Warsaw University of Technology, \\ 00-653 Warsaw, Poland; E-mail:malgorzata.wojtkowska@pw.edu.pl

\begin{abstract}
An important indicator of pollution is the bottom sediments of reservoirs and watercourses, where metals are strongly bound. Depending on the factors at the bottom of the reservoir, metals can be a secondary source of pollution of the water body. Therefore, developing methods to immobilise metals in bottom sediments is one of the priorities for caring for surface water quality.
\end{abstract}

Keywords - heavy metals, bottom sediments, bentonite, adsorption

\section{Introduction}

Today's technological development is having a major impact on the natural and human environment. This development is coupled with the pollution that enters the environment and increases in direct proportion to the demands of society. Environmental pollution results mainly from the economic activities of the energy sectors and heavy industry. An important source is agricultural areas, where pollution from mineral and organic fertilisers predominates, contributing to the pollution of soil and water in reservoirs and watercourses. An increase in the concentration of micropollutants, especially heavy metals, is currently observed in the environment. The sources of heavy metals are wastewater discharged from cities, mines and industrial plants, but also infiltration from landfills, run-off from agricultural areas and areas associated with dust emissions from power plants and steelworks [2].

Due to anthropogenic factors, elevated heavy metal content enters water bodies. In the natural environment metals occur in trace amounts not exceeding $1 \%$ of the total concentration [1]. As a result of binding with solid particles and sedimentation process, chemical compounds of these elements are accumulated in bottom sediments. The form in which metals occur in sediments indicates their different mobility [3].

Increased elemental content in sediments leads to a decrease in surface water quality and can lead to poisoning or contamination of organisms living in ecosystems [4].

Since metals entering the aquatic environment are bound in the solid phase, one way to remove or neutralise harmful elements is to use an adsorption process. The best way to immobilise heavy metals is to use a sorbent with the least negative impact on the biochemical state of the reservoir. One of the most commonly used heavy metal sorbents is bentonite.

The study was undertaken to check the sorption efficiency of the bentonite compound and to determine its effectiveness for selected elements $(\mathrm{Cu}, \mathrm{Ni}, \mathrm{Cd}, \mathrm{Zn}$ and $\mathrm{Pb})$. In our study, adsorption was carried out in a "solid-liquid (solution)" system. As a result of the deposition of atoms, particles, ions on the adsorbent surface, a layer tightly covering the adsorbent medium is formed. This leads to a state in which, when the concentration of the solution is changed, its particles move together on the surface of the adsorbent.

\section{Methods and Results}

Samples of bottom sediments were collected from a lake located in the Warsaw agglomeration, on the area belonging to the Natura 2000. Bentonite was used as an adsorbent. The main aim of the study was to check the effectiveness of heavy metals immobilisation in bottom sediments. The total content of metals in bottom sediment without and with the addition of bentonite was determined in the study. The most mobile ion-exchange fraction of metals was also determined.

$3^{\text {rd }}$ INTERNATIONAL SCIENTIFIC CONFERENCE “CHEMICAL TECHNOLOGY AND ENGINEERING”, JUNE 21-24 ${ }^{\mathrm{TH}}$, 2021, LVIV, UKRAINE 
The obtained results clearly indicate the effectiveness and efficiency of element sorption on bentonite. The studies showed that the metals studied $(\mathrm{Cu}, \mathrm{Cd}, \mathrm{Zn}, \mathrm{Ni}$ and $\mathrm{Pb}$ ) were characterised by selective reaction with bentonite. The best stabilisation was found for lead and zinc. Copper and cadmium were absorbed to a lesser extent, which made it necessary to apply a higher dose of the sorbent or use a mixture allowing to stabilise the studied trace elements more effectively. Nickel was characterised by the lowest degree of adsorption by bentonite, which in the process of water reservoir stabilisation imposes the necessity to use other sorbents with higher nickel binding degree.

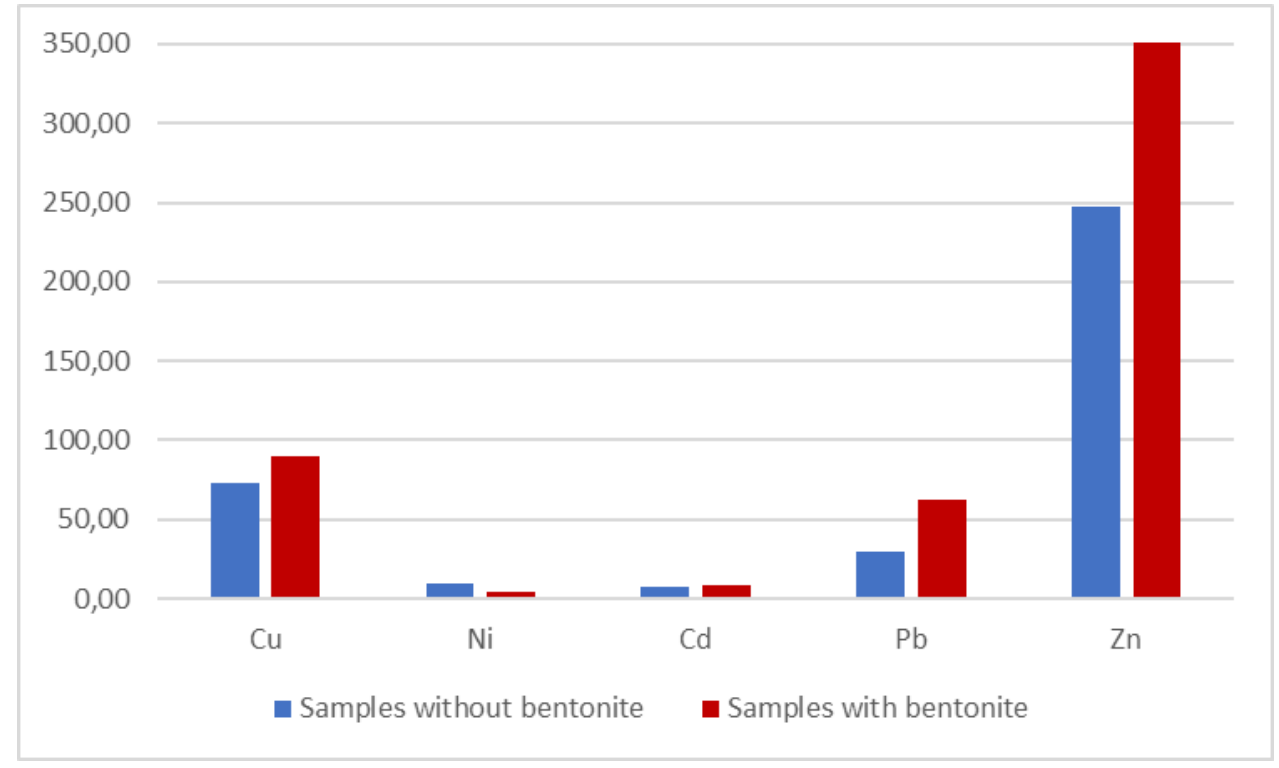

Fig. 1. Average content of heavy metals in the sediment [mg/kg s.m.]

On the basis of the study of the total metal content and the mobile fraction it was found that the ion-exchange fraction, representing a very small percentage of the total metal content, had a similar proportion in all sediment samples for individual metals. The average content of the ion exchange fraction in comparison to the total content of copper and zinc is $0.22 \%$, nickel and lead $25 \%$, cadmium $8.5 \%$.

The lower values of heavy metals in the ion-exchange fraction determined in the sediment with the addition of bentonite indicate that bentonite bound the mobile forms of metals. This testifies to the effectiveness.

Based on the results obtained, it was found that bentonite has sorption capacity for heavy metal ions present in solutions. At the same time, a selective sorption capacity for individual heavy metals is observed, which is due to ion competition. In terms of the level of adsorption, the heavy metals studied can be ranked as follows:

$$
\mathrm{Pb}>\mathrm{Zn}>\mathrm{Cu}=\mathrm{Cd}>\mathrm{Ni}
$$

The results of other researchers [1] who evaluated adsorption on bentonite indicate a different order of the metal sorption series with respect to selectivity:

$$
\mathrm{Pb}>\mathrm{Cu}>\mathrm{Zn}>\mathrm{Ni}>\mathrm{Cd}
$$

Similarities can be observed for the element with the highest adsorption capacity $(\mathrm{Pb})$ and the elements with the lowest absorption capacity ( $\mathrm{Ni}$ and $\mathrm{Cd}$ )

The use of bentonite significantly binds and immobilises metals in the solid phase. Due to changes in chemical parameters resulting from inactivation of positive heavy metal ions, it will be necessary to monitor and adjust the $\mathrm{pH}$ of water and bottom sediments in the reservoir. In the case of improperly calculated adsorbent dose depletion of the sediment layer may occur, not only 
in heavy metals, but also in $\mathrm{H}+$ ions, which will cause acidification of the sediment environment and the overlying water.

\section{Conclusions}

The use of bentonite as a sorbent is a highly effective way to improve the quality of bottom sediments contaminated with trace elements. The sorption time of metals on bentonite is short. Studies indicate that bentonite is selective in the sorption process for individual elements. This method does not imply any serious changes in the sediment chemistry and does not adversely affect its biochemical values. The use of this natural sorbent positively influences the character of sediments and leads to stabilisation and immobilisation of metals contained in them. The only necessity is to constantly monitor the $\mathrm{pH}$ of the sediment and a possible correction by liming the tank.

\section{References}

[1] Alloway, B.J. \& Ayres, D.C. (1999). Chemiczne podstawy zanieczyszczenia środowiska, Warszawa.

[2] Bojakowska, I., (1995). Wpływ odprowadzania ścieków na akumulację metali ciężkich w osadach wybranych rzek Polski. Państwowy Instytut Geologiczny, 55

[3] Wojtkowska, M., Bogacki, J., Witeska, A. (2016). Assessment of the hazard posed by metal forms in water and sediments. Science of the Total Environment, 551-552, 387392, https://DOI:10.1016/j.scitotenv.2016.01.073

[4] Wojtkowska, M. (2020). Heavy metal pollution of water and bottom sediments of the Wilanowskie Lake, w: Desalination and Water Treatment, 191, 110-117, DOI: $10.5004 /$ dwt.2020.25178 


\title{
Design of $\mathrm{Mg}-\mathrm{Al}-\mathrm{CO}_{3}$ layered double hydroxides (LDHs) which are capable to remove aqueous selenate $\left(\mathrm{SeO}_{4}{ }^{2-}\right)$ and selenite $\left(\mathrm{HSeO}_{3}{ }^{-}\right)$via direct exchange of the interlayer anions
}

\author{
Natalia Chubar $^{1}$, Małgorzata Szlachta ${ }^{2}$, Vasyl Gerda $^{3}$, Matej Mičušík ${ }^{4}$, Maria Omastova $^{4}$ \\ 1. Department of Earth Sciences, Utrecht University, NETHERLANDS, Utrecht, Budapestlaan 4, \\ E-mail: natalia.chubar@gmail.com (the affiliation where the results were obtained, not current) \\ 2. Geological Survey of Finland, FINLAND, Espoo, FI-02151, E-mail: malgorzata.szlachta@gtk.fi \\ 3. Faculty of Chemistry, Taras Shevchenko National University of Kyiv, UKRAINE, Kyiv, Lva Tolstogo Street 12, \\ E-mail:vgerda@univ.kiev.ua \\ 4. Polymer Institute, Slovak Academy of Sciences, SLOVAK REPUBLIC, Bratislava, 84541, \\ E-mails: Maria.Omastova@savba.sk; Matej.Micusik@savba.sk

\begin{abstract}
In this work we present the knowledge-based preparation method of Mg-Al layered double hydroxides with predefined properties, purely inorganic synthesis with a step of sol-gel routes. Difference in sorption mechanisms of $S e(V I)$ and $S e(I V)$ was revealed by XPS, EXAFS, FTIR. The removal efficiency was confirmed under static and dynamic conditions.
\end{abstract}

Keywords - layered double hydroxides (LDHs), fine inorganic synthesis, sol-gel routes, selenate, selenite, batch sorption, column sorption experiments, x-ray photoelectron spectroscopy (XPS), extended x-ray absorption fine structure (EXAFS), Fourier transform-infrared (FTIR) spectroscopy.

\section{Introduction}

After arrival of the first commercial inorganic anion exchanger based on (individual) metal oxide (Activated Alumina-AA) for the removal of toxic arsenic species in the beginning of the $21^{\text {st }}$ century, material scientists focus on development of next generations of such inorganic sorbents in order to improve their uptake performance and to broader their sorption applicability. Layered double hydroxides (LDHs) have a greater potential to remove anionic species from water than any bulk structure material of the same chemical nature. Advantage of LDHs consists in existence of the interlayer space which is expected to host aqueous anions, extracted from water solutions. However, despite the well-known superiority of LDHs as anion exchangers, these materials have not reached industrial scale application in water treatment since their discovery in 1842. The list of obstacles in this field includes inertness of the interlayer anions (which are unable to directly exchange with aqueous anions) in all LDHs known from the literature as well as their lower stability in this best solvent. The most popular workaround pathway of using LDHs in the removal of anions (called "memory effect") has been a preliminary ruining of their layered structure followed by further reconstruction of the layered arrangement at contact with water; the latter process results in incorporation of aqueous anions in-between the layers.

In contrast to the "memory effect" approach, the goal of this work was to develop new $\mathrm{Mg}-\mathrm{Al}-\mathrm{CO}_{3} \mathrm{LDHs}$ which is capable to directly exchange its interlayer anions with aqueous anions, first of all, of tetrahedral geometry, such as arsenate $\left(\mathrm{H}_{2} \mathrm{AsO}_{4}{ }^{-}\right)$, phosphate $\left(\mathrm{H}_{2} \mathrm{PO}_{4}^{-}\right)$and selenate $\left(\mathrm{SeO}_{4}{ }^{2-}\right)$, avoiding a stage of destruction of the layered structure via the "memory effect" approach. To achieve this goal, the following tasks had to be carried out:

- using purely inorganic raw materials and reagents to develop a new method of Mg-Al$\mathrm{CO}_{3} \mathrm{LDHs}$ preparation which includes a step of sol-gel routes in the entire synthetic strategy, for application in water treatment; 
- to characterize the synthesis products and to test their sorption affinities to the list of anions;

- to investigate the mechanism of $\mathrm{SeO}_{4}{ }^{2-}$ and $\mathrm{HSeO}_{3}{ }^{-}$sorption on the obtained $\mathrm{Mg}-\mathrm{Al}-\mathrm{CO}_{3}$ LDHs using XPS, EXAFS and FTIR;

- to prove a capability of the developed $\mathrm{Mg}-\mathrm{Al}-\mathrm{CO}_{3} \mathrm{LDHs}$ to remove $\mathrm{Se}(\mathrm{VI})$ and $\mathrm{Se}(\mathrm{IV})$ under both static and dynamic sorption conditions.

\section{Methods: material characterization and sorption experiments}

The developed materials were characterized by greater than usual number of methods: $\mathrm{N}_{2}$ sorption/desorption - surface area, x-ray diffraction (XRD), CHNS elemental analysis, nuclear magnetic resonance (NMR), particle size distribution, thermal gravimetric analysis (TGA), potentiometric titration, zeta-potential, see [1-7] for more details.

In particular, FTIR spectra were recorded on a Nicolet 6700 Fourier transform infrared spectrometer within the range of 400 to $4000 \mathrm{~cm}^{-1}$ with 32 scans at a resolution of $2 \mathrm{~cm}^{-1}$ using the conventional $\mathrm{KBr}$ pellet method in transmission mode, see [4].

The Se K-edge EXAFS spectra $(12658 \mathrm{eV})$ were collected in transmission mode at the ambient temperature at DUBBLE (BM26A) at the European Synchrotron Radiation Facilities (ESRF), Grenoble, France. ESRF. The monochromator was calibrated assigning an energy value of $12658 \mathrm{eV}$ to the first inflection point in the absorption edge.

XPS spectra were written on a Thermo Scientific K-Alpha XPS system (Thermo Fisher Scientific, UK) equipped with a micro-focused, monochromatic Al K $\alpha$ X-ray source (1486.68 $\mathrm{eV}$ ). Conditions of writing the spectra: An X-ray beam of $400 \mu \mathrm{m}$ size at $6 \mathrm{~mA} \times 12 \mathrm{kV}$; constant analyzer energy mode with a pass energy of $200 \mathrm{eV}$ for the survey; a pass energy of $50 \mathrm{eV}$ for narrow regions; the argon partial pressure of $2 \times 10^{-7} \mathrm{mbar}$ in the analysis chamber.

Batch experiments of Se(VI) and Se(IV) removal included: obtaining equilibrium sorption isotherms, kinetics of sorption at Se concentration levels of $\mathrm{mg} / \mathrm{L}$ and $\mu \mathrm{g} / \mathrm{L}$, effects of adsorbent doze and competing ions, as well as mathematical modeling of some data. Major experimental conditions were: solid-liquid ratio (adsorbent doze) $=2 \mathrm{~g}_{\mathrm{dw}} / \mathrm{L}$, background electrolyte $=0.01$ $\mathrm{NaCl}$, ambient temperature $=22 \pm 2{ }^{\circ} \mathrm{C}$. Adsorption was calculated using the well-known equation (1):

$$
q=\frac{\left(C_{0}-C_{e}\right) V}{m}
$$

where $q\left(\mathrm{mg} / \mathrm{g}_{\mathrm{dw}}\right)$ is the amount of selenium sorbed per gram of dry weight of the adsorbent, $C_{o}$ $(\mathrm{mg} / \mathrm{L})$ is the initial concentration of $\mathrm{Se}, C_{e q}(\mathrm{mg} / \mathrm{L})$ is the final (or equilibrium) concentration of the anion in solution, $V(\mathrm{~L})$ the volume of solution, and $m\left(\mathrm{~g}_{\mathrm{dw}}\right)$ is the dry mass of the adsorbent.

Dynamic sorption studies (fixed bed columns) were performed in a glass column with inner diameter of $1.1 \mathrm{~cm}$ and height of $29.55 \mathrm{~cm}$ which was loaded with the previously soaked $\mathrm{Mg}-\mathrm{Al} \mathrm{LDH}$. Influent water was passed through the columns in a down flow mode with the rate of $1 \mathrm{~mL} / \mathrm{min}$, controlled with a Masterflex peristaltic pump (Cole-Parmer, USA) at a constant temperature of $22 \pm 2{ }^{\circ} \mathrm{C}$ until reaching full saturation of the adsorbent with adsorbate. More details can be seen in [5]. Conditions: $\mathrm{Se}(\mathrm{VI}) / \mathrm{Se}(\mathrm{IV})$ initial concentration was $\sim 50 \mu \mathrm{g}[\mathrm{Se}] / \mathrm{L}$; background electrolyte $=0.01 \mathrm{~N} \mathrm{NaCl}$ in absence or presence of competing ions, $\mathrm{PO}_{4}{ }^{2-}$ and $\mathrm{SO}_{4}{ }^{2-}$ - The breakthrough capacity $\left(q_{b}, \mu \mathrm{g} / \mathrm{g}\right)$ of the columns was calculated by the following expression (2):

$$
q=\frac{\int_{V=0}^{V=V}\left(C_{0}-C\right) d V}{m}
$$


where $C_{0}(\mu \mathrm{g} / \mathrm{L})$ is the initial adsorbate concentration; $C(\mu \mathrm{g} / \mathrm{L})$ is the anion concentration in the effluent; $m(\mathrm{~g})$ is the amount of the adsorbent packed in the column; and $V(\mathrm{~L})$ is the volume of water that passes through the column. In the $q_{b}$ case, $V=V_{b}$, or the volume passing through until the breakthrough moment, and in the $q_{s}$ case, $V=V_{s}$, or the volume of total saturation.

The adsorbent exhaustion rate, AER (the mass of adsorbent used per volume of liquid treated at breakthrough), was estimated using the following formula (3):

$$
A E R=\frac{m}{V}
$$

where $m(\mathrm{~g})$ is mass of adsorbent in the column, and $V(\mathrm{~L})$ is the volume of treated water solution until breakthrough.

Chemical analysis: Se concentration (as well as of competing ions) was measured using inductively coupled plasma atomic emission spectroscopy (ICP-AES).

\section{The synthetic strategy for preparation of $\mathrm{Mg}-\mathrm{Al}-\mathrm{CO}_{3} \mathrm{LDHs}$ for water treatment}

To produce an inorganic anion exchanger with wanted properties, the following basic principles (background starting points) had to be taken into account:

---The material shall be a layered structure double hydrous oxides with $\mathrm{CO}_{3}{ }^{-}$in the interlayer space;

--- The entire preparation approach must be a fine inorganic synthesis which avoids using toxic and expensive alkoxides as raw materials, as well as any other organic reagents including neutralizers, additives and background electrolytes;

--- The synthetic strategy shall include a step of purely inorganic sol-gel transformations, using only inorganic raw precursors and neutralizers;

--- The methodology must have a stage of thermal treatment to guarantee a stability of anion exchanger in water;

--- The temperature of thermal treatment shall not be too high to avoid minimization (elimination) of surface $\mathrm{OH}^{-}$groups (which initiates anion exchange with aqueous anions);

---The temperature of $300{ }^{\circ} \mathrm{C}$, if applied to the final product, is too high and can ruin the layered structure (based on an occurrence of the interlayer $\mathrm{CO}_{3}{ }^{2-}$ ) resulting in release of $\mathrm{CO}_{2} \uparrow$; thus, the sense of synthesis would be lost;

--- The synthetic method shall provide high hydration to the final material as it always correlates with considerable anion exchange capacity realized via exchange of surface $\mathrm{OH}^{-}$.

Application of conventional approaches to preparation of inorganic anion exchangers based on metal oxides does not allow to take into account all the conditions mentioned above. In this work we discovered untraditional compromise ways of $\mathrm{Mg}$-Al LDHs preparation which will be presented at the conference.

The synthesis was carried out in two stages, general scheme of which is shown in Fig. 1. This method was described in details in [1]. Briefly: the stage 1 was a gentle preparation of hydrogel; the stage 2 was a careful search for the best pathways for treatment of hydrogel or xerogel. Any tiny violence/inaccuracy could spoil the entire production and may result in a lowquality anion exchanger which would not be an advantageous material compared with commercial analogues. Dozens of ways of hydrogel/xerogel treatments were tested, nine of which are shown in Fig. 1. Depending on small details of the materials chemistry, hydrogel can differ from transparent homogeneous (A) to porous (C-E) as shown in Fig. 2, so differ the properties.

To select the samples for the next stage investigations we assessed their anion removal performance to many anions [1-2]. The materials which demonstrated a promising sorption of 
several anions were further characterized for their structural properties, stability in water, XRDbased phase composition and surface chemistry, see [1]. The best pathway(s) for production of $\mathrm{Mg}-\mathrm{Al}-\mathrm{CO}_{3} \mathrm{LDHs}$ was selected based on combination of the above properties.

Depending on the pathway of hydrogel treatment (see Fig. 1), the material can be a pure layered double hydroxides, an inorganic composite with LDHs or even an amorphous sample. The paths $3 \mathrm{a}$ and $4 \mathrm{a}$ allow preparation of pure phase $\mathrm{Mg}-\mathrm{Al}-\mathrm{CO}_{3} \mathrm{LDHs}$, however the material prepared via 4a was found to be stronger anion remover [1], therefore the pathway-4a-generated LDHs was used in all next investigations shown in [2-7]. The 4a-synthetic procedure was reproduced $>60$ times which resulted in $\mathrm{Mg}-\mathrm{Al}-\mathrm{CO}_{3} \mathrm{LDHs}$ with the same structural and sorption properties.

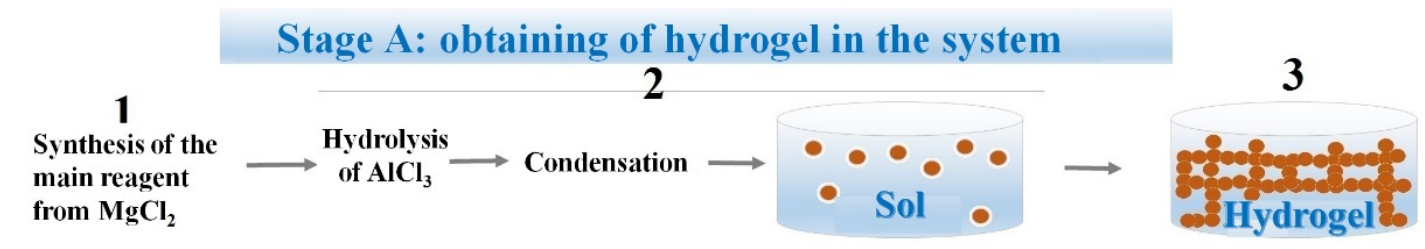

\section{Stage B: preparation of sorbent from hydrogel}

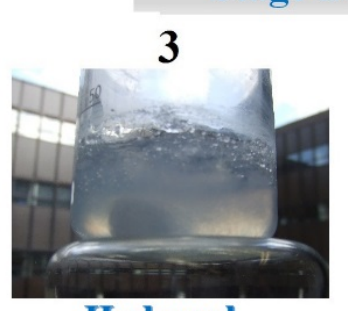

Hydrogel

Drying at room temperature

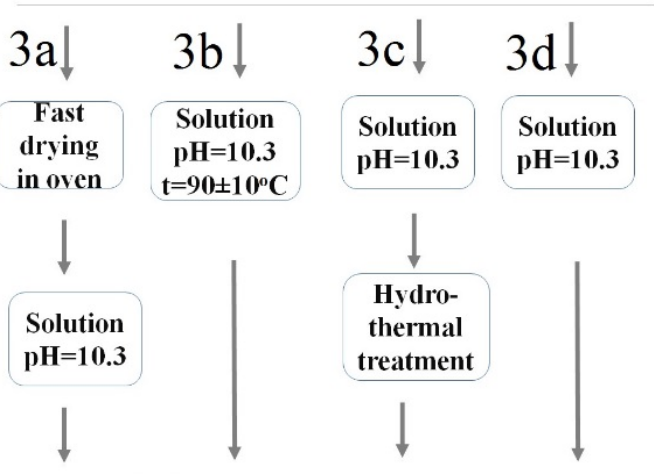

Washing, drying at ambient temperature

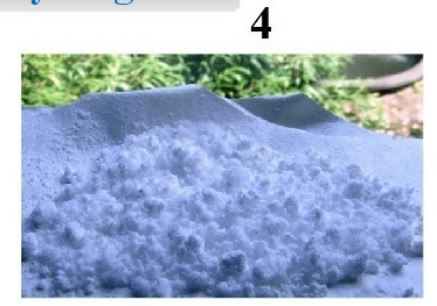

Xerogel

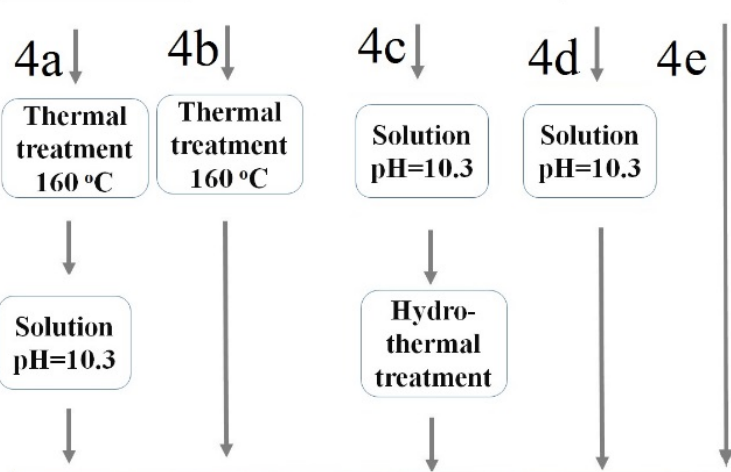

Washing, drying at ambient temperature

Fig.1. The scheme of preparation of $\mathrm{Mg}-\mathrm{Al}-\mathrm{CO}_{3} \mathrm{LDHs}$ via a step of alkoxide-free sol-gel routes.
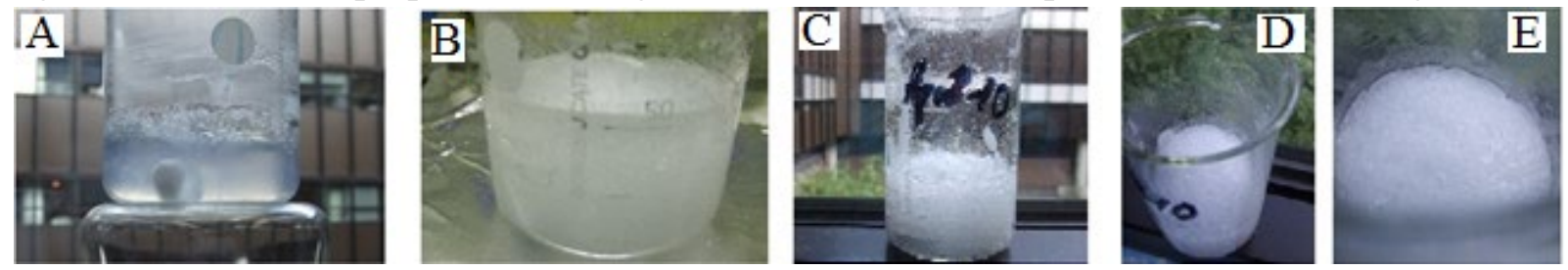

Fig. 2. Photographs of hydrogels as a function of small changes in the preparation conditions.

\section{Results and Discussion: material characterization and sorption studies}

The developed $\mathrm{Mg}-\mathrm{Al}-\mathrm{CO}_{3} \mathrm{LDHs}$ demonstrated exceptional or very competitive sorption of many anions $\left(\mathrm{H}_{2} \mathrm{AsO}_{4}^{-}, \mathrm{SeO}_{4}{ }^{2-}, \mathrm{H}_{2} \mathrm{PO}_{4}{ }^{-}, \mathrm{HSeO}_{3}^{-}, \mathrm{As}(\mathrm{III}), \mathrm{F}^{-}, \mathrm{Br}^{-}, \mathrm{BrO}_{3}^{-}, \mathrm{H}_{3} \mathrm{BO}_{3}\right)$, see [1-7]. However, because the World water authorities considered selenium, especially selenate $\left(\mathrm{SeO}_{4}{ }^{2-}\right)$, as anions which cannot be treated by sorption approach, we began investigating the removal of 
selenium species (Se(VI) and $\mathrm{Se}(\mathrm{IV})$ ), see [4,5,7]. Fig. 3 presents sorption capacities of Mg-Al$\mathrm{CO}_{3} \mathrm{LDHs}$ in comparison with other sorbents.

Many experimental and theoretical studies were carried out to explain the exceptional anion exchange capabilities of the 4a-generated $\mathrm{Mg}-\mathrm{Al}-\mathrm{CO}_{3} \mathrm{LDHs}$ (Fig. 1) and the removal mechanisms, see [2-7]. Comparison of $\mathrm{Mg}-\mathrm{Al}-\mathrm{CO}_{3}$ LDHs with LDHs of the same composition produced by the authors [3] using different methods, as well as the review of all available literature [6], revealed a list of properties which distinguish this material from all other LDHs. They are: rich speciation of the chemical elements $(\mathrm{Mg}, \mathrm{Al}, \mathrm{O})$, phases, interlayer carbonate and high hydration, which altogether provide developed surface area (enriched with $\mathrm{OH}^{-}$) and heterogeneity which result in capability to directly exchange their interlayer $\mathrm{CO}_{3}{ }^{2-}$ with aqueous anions (in contrast to the "memory effect").

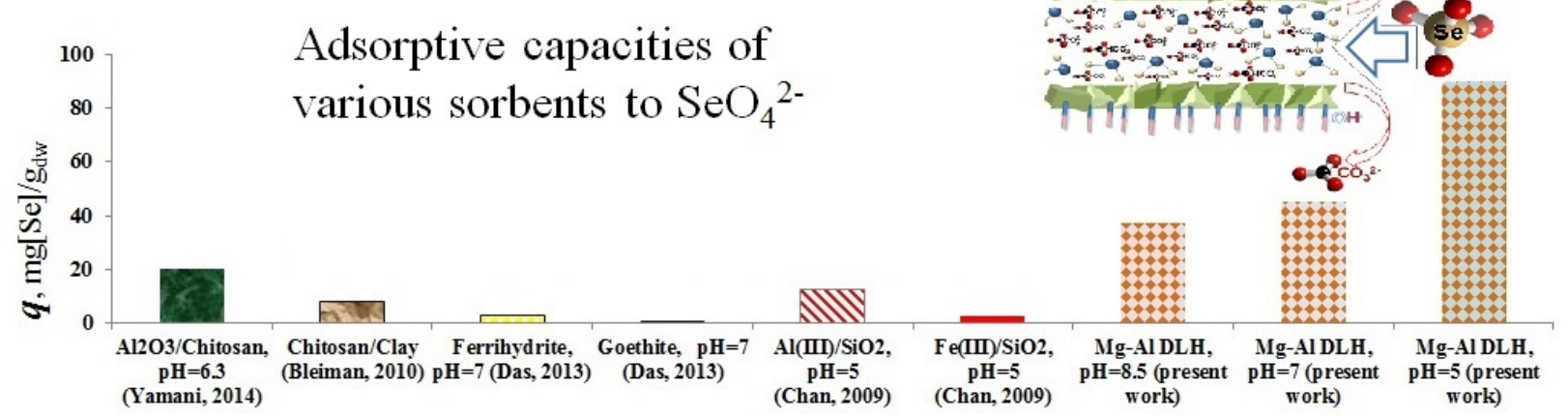

Fig. 3. Sorptive removal of $\mathrm{Mg}-\mathrm{Al}-\mathrm{CO}_{3} \mathrm{LDHs}$ in comparison with other materials [4].

During investigation of the molecular-level mechanism of $\mathrm{Se}(\mathrm{VI}) / \mathrm{Se}(\mathrm{IV})$ sorption [4], for the first time, a theoretical explanation of the unsatisfactory sorption properties of tetrahedral selenium species $\left(\mathrm{SeO}_{4}{ }^{2-}\right)$ was found. Due to using EXAFS/FTIR/XRD, it was shown that innersphere complexation (chemisorption) of selenate is impossible uptake mechanism on highly hydrated surfaces of $\mathrm{Mg}$ and $\mathrm{Al}$ oxides, in contrast to $\mathrm{HSeO}_{3}{ }^{-}$. $\mathrm{SeO}_{4}{ }^{2-}$ is removed by $\mathrm{Mg}-\mathrm{Al}-\mathrm{CO}_{3}$ LDHs exclusively via anion exchange of surface $\mathrm{OH}^{-}$and interlayer $\mathrm{CO}_{3}{ }^{2-}$, with further localization in the interlayer space of this material [4]. The reason for stronger affinity of selenite (compared with selenate) to $\mathrm{Mg}-\mathrm{Al}-\mathrm{CO}_{3} \mathrm{LDHs}$ is a stage of chemisorption in the entire removal process which played a greater role in the uptake of $\mathrm{Se}(\mathrm{IV})$ from aqueous solutions than an exchange with the interlayer carbonate, see Fig. 4.
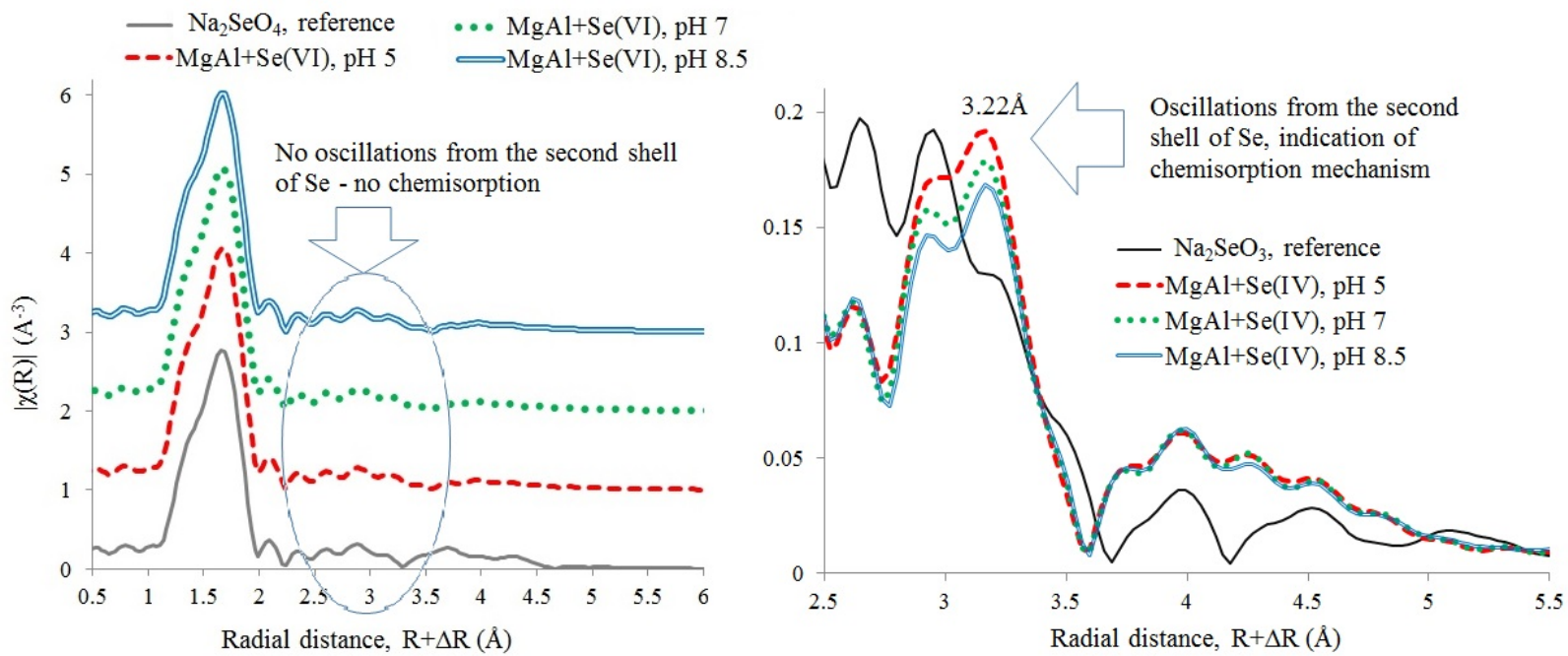

Fig. 4. Radial structure around $\mathrm{Se}\left(\mathrm{Se}(\mathrm{VI})\right.$-left and $\mathrm{Se}(\mathrm{IV})$-right) sorbed to $\mathrm{Mg}-\mathrm{Al}-\mathrm{CO}_{3} \mathrm{LDHs}$ from Fourier transforms of Se K-edge EXAFS oscillations. Modified from [4]. 
Using XPS analysis, the role of various phases of $\mathrm{Mg}-\mathrm{Al}-\mathrm{CO}_{3} \mathrm{LDHs}$ in selenate sorption was established as function of two variables: $\mathrm{pH}(4.5,7.0$ and 8.5) and competing influence of $\mathrm{SO}_{4}{ }^{2-}$, see [7]. It was shown that among the three major Al-containing phases of $\mathrm{Mg}-\mathrm{Al}-\mathrm{CO}_{3}$ LDHs $\left(\mathrm{Al}(\mathrm{OH})_{3}, \mathrm{AlOOH}\right.$ i $\left.\mathrm{Al}_{2} \mathrm{O}_{3}\right), \mathrm{Al}(\mathrm{OH})_{3}$ played predominant role in selenate removal at almost all experimental conditions, see Fig. 5 (a decrease of the respective band). For the first time it was shown that localization of Se(VI) and Se(IV) in the interlayer space of LDHs closes the binding energies of Se $3 d$ in Se(VI)- and Se(IV)-sorbed layered double hydroxides, which allowed to make a contribution to XPS database which had not contained such data yet [7].
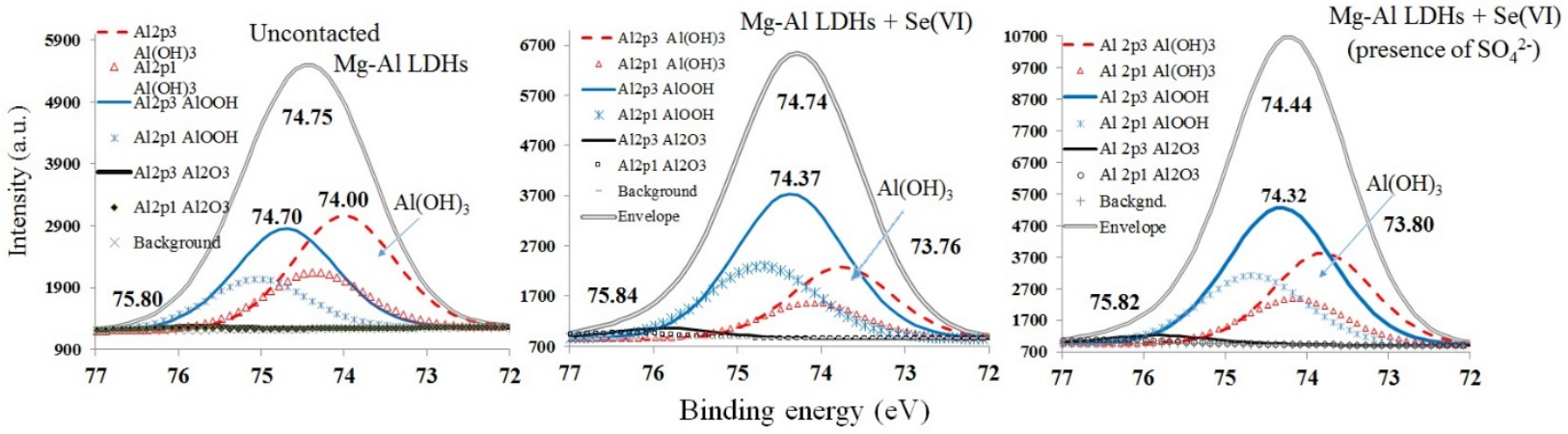

Fig. 5. Al 2p XPS spectra in the uncontacted Mg-Al LDHs (left), and after sorption of $\mathrm{SeO}_{4}{ }^{2-}$ in absence (middle) and presence of sulfate (right) at $\mathrm{pH}=7$. Modified from [7].

Possibility of industrial (water treatment) application of $\mathrm{Mg}-\mathrm{Al}-\mathrm{CO}_{3} \mathrm{LDHs}$, produced by the developed inorganic (sol-gel) synthesis, has been proved under both static and dynamic sorption experiments, see [5]. This material is capable to extract the low (ppb levels) concentrations of both selenium species $\left(\mathrm{SeO}_{4}{ }^{2-} / \mathrm{HSeO}_{3}{ }^{-}\right)$in dynamic sorption conditions in the presence of the main competing anions $\left(\mathrm{H}_{2} \mathrm{PO}_{4}{ }^{-} / \mathrm{SO}_{4}{ }^{2-}\right)$.

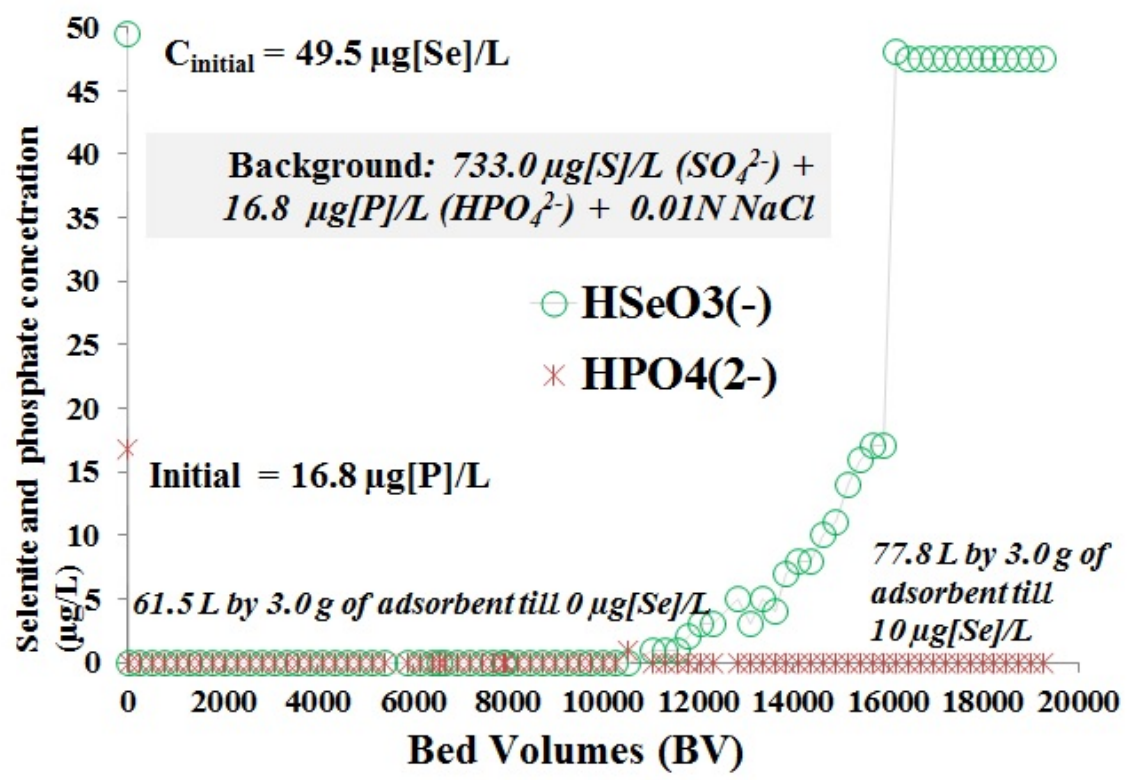

Fig. 6. Breakthrough curve of selenite sorption in the presence of phosphate $(16.8 \mu \mathrm{g} / \mathrm{L})$ and sulphate $(733.0 \mu \mathrm{g} / \mathrm{L})$ by $\mathrm{Mg}-\mathrm{Al} \mathrm{LDHs}$. Experimental conditions: initial concentration of $\mathrm{HSeO}_{3}{ }^{-}$ $=49.5 \mu \mathrm{g} / \mathrm{L}$; background electrolyte $=0.01 \mathrm{~N} \mathrm{NaCl}$; mass of adsorbent $=3.0 \mathrm{~g}$; bed height $=5.6 \mathrm{~cm}$.

A unique property of $\mathrm{Mg}-\mathrm{Al}-\mathrm{CO}_{3} \mathrm{LDHs}$ to preserve its layered structure at thermal treatment up to $600^{\circ} \mathrm{C}$ has been discovered [6]. Such resistance to high temperatures principally distinguishes this material from all other LDHs (fabricated by different synthetic methods) which lose their layered arrangement at $300^{\circ} \mathrm{C}$ transubstantiating into double oxides of bulk (not layered) structure. This property allows to use the thermally treated sample in dynamic sorption 
(in contrast to all other LDHs) which will extend the list of water purification tasks to be solved by inorganic anion exchangers.

\section{Conclusions}

New (fine inorganic with a stage of alkoxide-free sol-gel routes) method of synthesis, which creates complex hydroxides of the layered structure $\mathrm{Mg}-\mathrm{Al}-\mathrm{CO}_{3} \mathrm{LDHs}$ with unique structural properties and sorptive characteristics to tetrahedral anions, has been discovered. The synthetic method is in principle new approach for production of layered double hydroxides, the strategy of which was based on the final purpose, its application as anion exchanger in water treatment. It is a foundation for elaboration of a new technology for production of layered double hydroxides $\mathrm{Mg}-\mathrm{Al}-\mathrm{CO}_{3} \mathrm{LDHs}$ aiming for their utilization in both water purification and other industries.

Trying to proper characterize the developed Mg-Al LDHs and to explain its properties, several theoretical elaborations have been made which greatly contributed to advancement of the entire research areas (inorganic anion exchangers and layered double hydroxides).

\section{Acknowledgments}

The authors gratefully acknowledge: King Abdullah University of Science and Technology (KAUST) (Saudi Arabia) which funded this research via GCR program (award № KUK-C1017-12); the Netherlands Organization for Scientific Research (NWO) (The Netherlands) for EXAFS/ XANES studies at Dutch-Belgian Beamline (DUBBLE) at ESRF (France), and grant VEGA 02/0010/18 (Slovak Republic) for XPS analysis.

\section{References}

[1] Chubar, N. (2011). New inorganic (an)ion exchangers based on Mg-Al hydrous oxides: (Alkoxide-free) sol-gel synthesis and characterization. Journal of Colloid and Interface Science, 357, 198-209, http://doi: 10.1016/j.jcis.2011.01.098

[2] Chubar, N. (2011). New inorganic (an)ion exchangers with a higher affinity for arsenate and a competitive removal capacity towards fluoride, bromate, bromide, selenate, selenite, arsenite and borate. Water Science \& Technology Water Supply, 5, 505-515, https://doi.org/10.2166/ws.2011.080

[3] Chubar, N., Gerda, V., Megantari, O., Mičušík, M., Omastova, M., Heister, K., Man, P., Fraissard, J. (2013). Applications vs properties of Mg-Al layered double hydroxides provided by their syntheses methods: alkoxide and alkoxide-free sol-gel syntheses and hydrothermal precipitation. Chemical Engineering Journal, 234, 284-299, https://doi.org/10.1016/j.cej.2013.08.097

[4] Chubar, N. (2014). EXAFS and FTIR studies of selenite and selenate sorption by alkoxidefree sol-gel generated $\mathrm{Mg}-\mathrm{Al}-\mathrm{CO}_{3}$ layered double hydroxide with very labile interlayer anions. Journal of Materials Chemistry A, 2, 15995-16007, https://doi.org/10.1039/C4TA03463E

[5] Chubar, N. \& Szlachta, M. (2015). Static and dynamic adsorptive removal of selenite and selenate by alkoxide-free sol-gel generated $\mathrm{Mg}-\mathrm{Al}-\mathrm{CO}_{3}$ layered double hydroxide: Effect of competing ions. Chemical Engineering Journal, 279, 885-896. https://doi.org/10.1016/j.cej.2015.05.070

[6] Chubar, N., Gilmour, R., Gerda, V., Mičušík, M., Omastova, M., Heister, K., Man, P., Fraissard, F., Zaitsev, V. (2017) Layered double hydroxides as the next generation anion 
exchangers: Synthetic method versus applicability (a review). Advances in Colloid and Interface Science, 245, 62-80, http://doi: 10.1016/j.cis.2017.04.013

[7] Chubar, N. (2018). The Influence of sulfate on selenate sorption on $\mathrm{Mg}-\mathrm{Al}-\mathrm{CO}_{3}$ layered double hydroxides prepared by fine Inorganic sol-gel gynthesis studied by x-ray photoelectron spectroscopy. Applied Surface Science, 459, 281291,doi.org/10.1016/j.apsusc.2018.07.193 


\title{
Evaluation of Gross Regional Product Waste Intensity in Context of the SDGs Achievement Progress Assessment
}

\author{
$\underline{\text { Iryna Dzhygyrey }}$ \\ Department of Mathematical Methods of Systems Analysis, Igor Sikorsky Kyiv Polytechnic Institute, UKRAINE, \\ Kyiv, Peremogy av.37, E-mail: lab.mes@kpi.ua
}

Abstract - GRP waste intensity assessment is presented for 2015-2019 data years based on GRP values at constant 2015 prices and waste generation by regions from the economic activity of enterprises and organizations. GRP waste intensity indicator values for regions of Ukraine are presented compared to the 2015 base year considering the 2030 SDG 12 benchmark.

Keywords - gross regional product, progress assessment, region, sustainable consumption and production, sustainable development goals, waste intensity.

\section{Introduction}

In 2015, the UN General Assembly adopted the 2030 Agenda for Sustainable Development which includes 17 Sustainable Development Goals (SDGs) to be achieved by 2030. The Ukrainian national SDGs system consists of 86 national SDGs targets with benchmarks and 183 national SDGs monitoring indicators [1]. The economic dimension of SDGs covers of four goals, one of which is «Ensure sustainable consumption and production patterns» or SDG 12 «Sustainable consumption and production» for short.

«Reduce resource consumption of the economy» is one of four national SDG 12 targets. Resource intensity of GDP indicator (ratio of consumed volumes of natural resources, waste generated, and pollutant emissions to GDP, \% to 2015 level) represents the evaluation of progress achievement for this target of the national SDG 12. Five components, GDP energy intensity, GDP material intensity, GDP carbon intensity, GDP water intensity, and GDP waste intensity, express the national indicator of resource intensity of GDP. The 2020 benchmark is established at $90.0 \%$, the 2025 benchmark is $80.0 \%$, and the 2030 benchmark is $60.0 \%$ for all five components. GDP waste intensity is presented in Table 1 as changes to the 2015 level (data of the State Statistics Service of Ukraine as of May 2021, data exclude the temporarily occupied territory of the Autonomous Republic of Crimea, the city of Sevastopol, and a part of temporarily occupied territories in the Donetsk and Luhansk regions, the 2020 data will be available in January of 2022).

Table 1

GDP (2011 PPP \$) waste intensity, \% to 2015 level

\begin{tabular}{|c|c|c|c|c|c|c|c|}
\hline \multirow{2}{*}{2015} & \multirow{2}{*}{2016} & \multirow{2}{*}{2017} & \multirow{2}{*}{2018} & \multirow{2}{*}{2019} & \multicolumn{3}{|c|}{ benchmarks } \\
\cline { 6 - 8 } & & & & & 2020 & 2025 & 2030 \\
\hline 100.0 & 92.5 & 111.6 & 104.0 & 126.2 & 90.0 & 80.0 & 60.0 \\
\hline
\end{tabular}

A negative dynamic compared to 2015 is observed for the GDP waste intensity national sub-indicator. The volume of waste generated by all economic activities per unit of GDP increases from $977.4 \mathrm{~kg}$ per 2011 PPP 1000 USD in 2015 to 1233.5 in 2019. The target value for 2020 will most likely not be achieved.

\section{An assessment of the waste intensity of regional economies of Ukraine}

Gross regional product (GRP) waste intensity is proposed to evaluate using the same approach adopted at the national level with some modifications. GDP and GRP values are taken at constant 2015 prices (UAH) in this assessment by recalculating with the utilization of index- 
deflator values (\% of the previous year) for 2016-2019 data years [2]. Regional consumer price indices ( $\%$ of the previous year) also may be used for the obtainment of GRP values at constant 2015 prices though index-deflator values characterize sectors of the economy more comprehensively and integrated.

Waste generation is considered from the economic activity of enterprises and organizations, excluding households [3] (data exclude the temporarily occupied territory of the Autonomous Republic of Crimea, the city of Sevastopol, and a part of temporarily occupied territories in the Donetsk and Luhansk regions). Values of GDP and GRP waste intensity are presented in Table 2 for constant 2015 prices.

Table 2

GRP waste intensity, $\mathrm{kg}$ per thsd UAH

\begin{tabular}{|c|c|c|c|c|c|}
\hline & 2015 & 2016 & 2017 & 2018 & 2019 \\
\hline Ukraine (GDP waste intensity) & 154.0 & 142.1 & 172.6 & 160.7 & 195.5 \\
\hline Autonomous Republic of Crimea & $\mathrm{n} / \mathrm{a}$ & $\mathrm{n} / \mathrm{a}$ & $\mathrm{n} / \mathrm{a}$ & $\mathrm{n} / \mathrm{a}$ & $\mathrm{n} / \mathrm{a}$ \\
\hline \multicolumn{6}{|l|}{ oblasts } \\
\hline Vinnytsya & 30.3 & 28.3 & 34.1 & 24.2 & 35.3 \\
\hline Volyn & 11.9 & 13.3 & 11.5 & 11.8 & 12.7 \\
\hline Dnipropetrovsk & 1053.3 & 983.0 & 1104.5 & 1085.5 & 1149.8 \\
\hline Donetsk & 145.2 & 170.0 & 191.3 & 205.4 & 227.3 \\
\hline Zhytomyr & 11.1 & 10.9 & 10.0 & 8.1 & 8.1 \\
\hline Zakarpattya & 1.1 & 2.0 & 1.3 & 1.5 & 0.8 \\
\hline Zaporizhzhya & 58.3 & 53.6 & 53.6 & 56.8 & 58.0 \\
\hline Ivano-Frankivsk & 42.8 & 41.5 & 41.1 & 38.8 & 59.1 \\
\hline Kyiv & 12.8 & 10.1 & 5.4 & 6.2 & 7.8 \\
\hline Kirovohrad & 863.2 & 872.0 & 1010.9 & 966.0 & 910.3 \\
\hline Luhansk & 103.2 & 88.7 & 26.1 & 21.7 & 15.5 \\
\hline Lviv & 28.5 & 26.0 & 22.4 & 18.7 & 15.4 \\
\hline Mykolayiv & 42.7 & 43.6 & 44.9 & 47.2 & 42.0 \\
\hline Odesa & 2.0 & 2.1 & 3.1 & 3.1 & 2.2 \\
\hline Poltava & 44.2 & 52.7 & 330.9 & 185.8 & 927.1 \\
\hline Rivne & 20.4 & 18.3 & 10.9 & 10.7 & 10.5 \\
\hline Sumy & 18.3 & 15.2 & 12.8 & 19.5 & 16.9 \\
\hline Ternopil & 27.4 & 29.3 & 62.6 & 50.2 & 30.3 \\
\hline Kharkiv & 7.7 & 9.0 & 8.0 & 7.5 & 7.5 \\
\hline Kherson & 12.1 & 10.7 & 11.0 & 10.7 & 9.8 \\
\hline Khmelnytskiy & 19.2 & 27.2 & 17.5 & 16.0 & 16.5 \\
\hline Cherkasy & 22.3 & 23.5 & 24.6 & 23.6 & 19.6 \\
\hline Chernivtsi & 15.0 & 14.7 & 12.2 & 9.0 & 8.7 \\
\hline Chernihiv & 15.1 & 13.7 & 13.7 & 12.2 & 11.2 \\
\hline \multicolumn{6}{|l|}{ cities } \\
\hline Kyiv & 1.2 & 1.1 & 0.8 & 0.7 & 0.7 \\
\hline Sevastopol & $\mathrm{n} / \mathrm{a}$ & $\mathrm{n} / \mathrm{a}$ & $\mathrm{n} / \mathrm{a}$ & $\mathrm{n} / \mathrm{a}$ & $\mathrm{n} / \mathrm{a}$ \\
\hline
\end{tabular}

GRP waste intensity outsiders are Dnipropetrovsk, Kirovohrad, and Poltava oblasts. Kyiv city, Zakarpattya and Odesa oblasts are leaders by the sub-indicator values. The 2019 ratio of 
GRP waste intensity is about 1500:1 for the Dnipropetrovsk and Zakarpattya oblasts. Obtained GRP waste intensity sub-indicator values show different dynamics at the regional level (Table 3).

Table 3

GRP waste intensity compared to $2015, \%$

\begin{tabular}{|c|c|c|c|c|c|}
\hline & 2015 & 2016 & 2017 & 2018 & 2019 \\
\hline Ukraine (GDP waste intensity) & 100.0 & 92.3 & 112.1 & 104.4 & 126.9 \\
\hline Autonomous Republic of Crimea & $\mathrm{n} / \mathrm{a}$ & $\mathrm{n} / \mathrm{a}$ & $\mathrm{n} / \mathrm{a}$ & $\mathrm{n} / \mathrm{a}$ & $\mathrm{n} / \mathrm{a}$ \\
\hline \multicolumn{6}{|l|}{ oblasts } \\
\hline Vinnytsya & 100.0 & 93.4 & 112.6 & 79.7 & 116.4 \\
\hline Volyn & 100.0 & 111.7 & 97.1 & 99.2 & 107.3 \\
\hline Dnipropetrovsk & 100.0 & 93.3 & 104.9 & 103.1 & 109.2 \\
\hline Donetsk & 100.0 & 117.1 & 131.8 & 141.5 & 156.6 \\
\hline Zhytomyr & 100.0 & 98.2 & 90.4 & 73.5 & 72.6 \\
\hline Zakarpattya & 100.0 & 181.7 & 117.9 & 136.6 & 70.0 \\
\hline Zaporizhzhya & 100.0 & 91.9 & 91.9 & 97.4 & 99.4 \\
\hline Ivano-Frankivsk & 100.0 & 97.0 & 96.0 & 90.7 & 138.2 \\
\hline Kyiv & 100.0 & 78.8 & 42.0 & 47.9 & 60.4 \\
\hline Kirovohrad & 100.0 & 101.0 & 117.1 & 111.9 & 105.5 \\
\hline Luhansk & 100.0 & 85.9 & 25.3 & 21.1 & 15.0 \\
\hline Lviv & 100.0 & 91.0 & 78.5 & 65.7 & 54.1 \\
\hline Mykolayiv & 100.0 & 102.2 & 105.2 & 110.7 & 98.5 \\
\hline Odesa & 100.0 & 106.0 & 153.8 & 150.7 & 107.0 \\
\hline Poltava & 100.0 & 119.3 & 749.3 & 420.9 & 2099.7 \\
\hline Rivne & 100.0 & 89.8 & 53.4 & 52.5 & 51.4 \\
\hline Sumy & 100.0 & 83.3 & 70.3 & 106.9 & 92.4 \\
\hline Ternopil & 100.0 & 106.9 & 228.5 & 183.2 & 110.5 \\
\hline Kharkiv & 100.0 & 116.0 & 103.4 & 97.1 & 96.5 \\
\hline Kherson & 100.0 & 88.7 & 90.6 & 88.6 & 80.7 \\
\hline Khmelnytskiy & 100.0 & 141.5 & 91.2 & 83.1 & 85.6 \\
\hline Cherkasy & 100.0 & 105.4 & 110.4 & 105.8 & 88.0 \\
\hline Chernivtsi & 100.0 & 97.9 & 81.2 & 60.4 & 57.9 \\
\hline Chernihiv & 100.0 & 90.7 & 90.6 & 81.1 & 74.1 \\
\hline \multicolumn{6}{|l|}{ cities } \\
\hline Kyiv & 100.0 & 88.1 & 68.6 & 57.7 & 54.3 \\
\hline Sevastopol & $\mathrm{n} / \mathrm{a}$ & $\mathrm{n} / \mathrm{a}$ & $\mathrm{n} / \mathrm{a}$ & $\mathrm{n} / \mathrm{a}$ & $\mathrm{n} / \mathrm{a}$ \\
\hline
\end{tabular}

Zhytomyr, Kyiv, Luhansk, Lviv, Rivne, Kharkiv, Kherson, Khmelnytskiy, Chernivtsi, and Chernihiv oblasts and the City of Kyiv demonstrate a more or less stable decrease in GRP waste intensity. It should be noticed that Luhansk, Lviv, Rivne, Kyiv, and Chernivtsi oblasts and Kyiv already achieved the 2030 national benchmark of $60.0 \%$ for GRP waste intensity sub-indicator. Extremely high values of the sub-indicator for Poltava oblast result from inclusion in the data set wastes produced in the process of stripping works when creating mines and careers by LLC "Yerystivskuy mining and processing plant" (2017, 2018 years) and wastes produced in the process of mining and enrichment of iron ore PJSC "Poltava Mining and Processing Plant" (2019 
year). The number of reporting enterprises on the volume of waste generation, accuracy and completeness of the data decreased in Donetsk and Luhansk oblasts that also must be taken into account. The obtained results represent the progress made towards the achievement of the nationally determined target of the economic dimension's SDG 12 on the regional level. There are a lot of explicit and hidden factors that affect such variations, mainly the peculiarities of regions' economies.

Values of GRP carbon intensity and GRP water intensity, or other components of resource intensity of GRP, can be evaluated using this comparability approach [4]. These assessments can be implemented as part of SDGs indicators framework at the regional level or become a part of integrated assessments as, for example, metric for sustainable development processes measurement for the regions of Ukraine [5] based on indicators of the quality and security of life components of the sustainable development index (SDI). The SDI quality of life component is an integration of three dimensions of sustainable development, economic, environmental, and social, and based on three pillars' sustainability model. Here GRP resource intensity indicator components can be used for regional level assessment in contexts of environmental management.

\section{Conclusion}

GRP waste intensity assessment is presented for 2015-2019 data years based on GRP values at constant 2015 prices and waste generation by regions from the economic activity of enterprises and organizations. GRP waste intensity sub-indicator values for regions of Ukraine are presented compared to the 2015 base year considering the SDG 12 benchmarks. Best performers in GRP waste intensity decreasing among the regions of Ukraine are identified for the 2019 year namely Luhansk, Lviv, Rivne, Kyiv, and Chernivtsi oblasts and the City of Kyiv.

\section{References}

[1] The Voluntary National Review of the SDGs achievement progress 2020. (2020). Report. The Department of Economic Strategy and Macroeconomic Forecasting of the MDETA. Retrieved from https://sustainabledevelopment.un.org/content/documents/ 26295VNR_2020_Ukraine_Report.pdf

[2] Gross regional product (2004-2019). (2020). State Statistics Service of Ukraine. Retrieved from http://www.ukrstat.gov.ua/operativ/operativ2020/vvp/vrp/vrp2019_ue.xls

[3] Environment of Ukraine. State Statistics Service of Ukraine. (2020). Statistical yearbook. Retrieved from http://www.ukrstat.gov.ua/druk/publicat/kat_u/2020/zb/11/Dovk_19.xlsx

[4] Dzhygyrey I. (2020). Ocinka skladnykiv resursoyemnosti VRP dlya analizu stalogo rozvytku regioniv Ukrayiny. 3-a MNPK "Ekologichni problemy navkolyshnogo seredovyshha ta racionalnogo pryrodokorystuvannya v konteksti stalogo rozvytku". 22-23 zhovtnya 2020 r. Kherson. 199-202.

[5] Sustainable Development Analysis: Global and Regional Contexts. International Council for Science (ICSU) and others; Scientific Supervisor of the Project M. Zgurovsky. Igor Sikorsky KPI. Part 2. Ukraine in Sustainable Development Indicators (2016-2017). 72. (2017). Retrieved from http://wdc.org.ua/sites/default/files/SD2017-P2-FULL-EN.pdf 


\title{
Use of Modified Polyacrylamide for Floccuation of Coal Enrichment Wastes
}

\author{
Vasyl Duleba, Zoriana Gnativ \\ Department of Chemical Endineering, Lviv Polytechnic National University, UKRAINE, Lviv, 12 S.Bandera street, \\ E-mail: zoriana.y.hnativ@lpnu.ua \\ Abstract - In various industrial processes it is necessary to separate liquid and solid phases \\ (condensation, filtration, centrifugation, flotation). Water purification from suspended particles \\ concentration, phase separation in suspension having big problems caused by small particle size and \\ high aggregative and sedimentation stability of the system. Intensification of these processes in many \\ cases can be achieved at the expense of consolidation of particles in aggregates under the action of \\ coagulants and flocculants, and especially their mixtures.
}

Keywords - separation suspension, flocculant, coagulant, polyacrylamide.

\section{Introduction}

Properties of technical polyacrylamides are widely described in the literature. They are widely used in water treatment, industrial waste water purification, flocculation and flocculation flotation (for flotation with pre-aggregation with the help of flocculants) of a large number of mineral suspensions - in the extraction of minerals from various ores, in coal extraction, in the food industry, etc.

The suspension of solid phase precipitation at application of modified flockulants on the basis of polyacrylamide-50 and PAAM-52 obtained in our laboratory were investigated. PAM50 is a polyacrylamide, modified using a mixture of epoxy fatty acids. PAM-52 is a polyacrylamide, partly crosslinked Formaldegìdom, leading to an increase in the molecular mass of polyacrylamide, and, consequently, increases the rate of solid deposition of suspension tails of flotation while reducing the cost of flockulants. However, in the case of use for separation of suspension tails, the flotation of coal enrichment is more effective in the PAAM-50. Its application allows to get the highest rate of deposition of solid phase and to get the most clean drain on the thickness.

\section{Conclusion}

Study of the influence of a PATC expenditure on the rate of deposition of clay particles at different concentrations of solid phase suspension showed that with the concentration of solid phase up to $15 \mathrm{~g} / \mathrm{L}$ deposition rate grows to $7.5 \mathrm{~mm} / \mathrm{s}$. decrease of solid phase concentration Leads to a decrease of deposition rate of clay particles, which can be explained by the formation of smaller-sized floules because the distance between the particles increases sharply.

This effect shows that at the concentration of a solid share of more than $20 \mathrm{~g} / \mathrm{L}$ is the most productive conditions for floccuation, that is, at lower costs polyacrylamide per mass unit of solid phase there is formation of the flocle of optimum size.

\section{References}

[1] Kul`s`ky`j, L.A., \& Strokach, P.P. (1981). Texnology`ya ochy`stky` pry`rodnblx vod. Ky`ev: Vy`shha shkola.

[2] Singh, R. P., Chang, P., Reddy, G. V. (1984). Charakteristiks of so polimer, polimer-fibre combinations and grafied polymers as drag reducing agents and their industrial application. Drag Reduct. $3^{\text {rd }}$ Int Conf. Bristol, D4/1-D4/5. 


\title{
Ecologically safe methods of treatment of wastewater from zinc and nickel ions with complex sorbents
}

\author{
Ihor Petrushka $^{1}$, Volodymyr Mokryi $^{2}$, Kateryna Petrushka $^{3}$
}

1. Department of Ecological Safety and Nature Protection Activity, Lviv Polytechnic National University, UKRAINE, Lviv, 2/4 Karpinskoho Street, Building 1, E-mail: ihor.m.petrushka@lpnu.ua

2. Department of Ecological Safety and Nature Protection Activity, Lviv Polytechnic National University, UKRAINE, Lviv, 2/4 Karpinskoho Street, Building 1, E-mail: volodymyr.i.mokriy@lpnu.ua

3. Department of Chemical Engineering, Lviv Polytechnic National University, UKRAINE, Lviv, 9 Yura square Street, Building 9, E-mail: kateryna.i.petrushka@lpnu.ua

Abstract - Sorption properties of natural and complex sorbents for neutralization of $\mathrm{Ni}^{2+}$ and $\mathrm{Zn}^{2+}$ ions from aqueous medium are investigated. The isotherm of adsorption of $\mathrm{Ni}^{2+}$ and $\mathrm{Zn}^{2+}$ ions was built on complex sorbents in accordance with the Langmuir and Freundlich models, the type of adsorption isotherms according to the classification of S. Brunauer was established.

Keywords - adsorption, adsorbents, isothermal adsorptions, nickel, zinc.

\section{Introduction}

One of the main tasks of environmental protection is the prevention of ingress into wastewater, the ground cover of components that contain heavy metal ions in concentrations higher than the permissible ones. Heavy metal ions have an extremely negative effect on living organisms, because they have cumulative and toxic properties, make it difficult for natural and wastewater treatment plants to operate.

Today, according to experts, with insufficiently treated industrial wastewater in natural water bodies annually get thousands of tons of highly toxic heavy metals, such as zinc - 3.3 thousand tons, nickel -2.4 thousand tons, chromium - 0.5 thousand tons and others, significantly complicating the environmental situation in the country. The main sources of these components are usually industrial facilities with a developed industrial base and a wide range of technological processes and operations, including the aviation industry, which uses the latest methods of materials processing, introduces advanced technologies and more. However, we should not forget about the extent of pollution of the environment with heavy metal ions thrown in the landfill spent batteries.

The most well-known and widespread "finger" batteries contain a lot of manganese and zinc (23-28\% is contained in lead salt batteries), a little less - some other heavy metals and chemical elements.

Approximately 2,500 tons of batteries are imported to Ukraine annually, but only $1 \%$ of them are going for recycling. The battery thrown by us on garbage gets to a landfill of household waste. There, as a result of various organic reactions and corrosion, harmful chemical compounds from batteries get directly into the environment: they pollute water bodies, soil, and get into food chains due to plants.

Numerous scientific publications of domestic and foreign scientists are devoted to the removal of zinc and nickel ions from solutions and the study of the mechanism of the sorption process [1-2].

It is known that the most promising method of wastewater treatment is sorption technology, which is widely used in various industries. Currently, considerable experience has 
been gained in the use of natural clay minerals and their modified forms for wastewater treatment from heavy metal ions.

The prospect of using natural minerals in the process of effluent purification is confirmed not only by their high adsorption capacity, but also by the existence of effective methods for improving the adsorption properties of minerals and the nature of their surface by modification.

However, given the high selectivity of natural minerals, a significant number of scientists are working to improve the sorption properties of natural minerals by modifying them, or using the selectivity of mineral sorbents and integrated use.

In addition to traditional natural sorbents (clinoptilolite, palligorskite, glauconite), which are used to treat waste water from heavy metal ions, shungite rocks are no less interesting mineral in sorption ability.

Shungite rocks are unique in composition, structure and properties. They are an unusual natural composite structure - uniform distribution of highly dispersed crystalline silicate particles in an amorphous carbon matrix. The average size of silicate particles is about $1 \mu \mathrm{m}$. The average rock composition of the deposit is $30 \%$ carbon and $70 \%$ silicates. Rocks are characterized by high strength, density, chemical resistance and electrical conductivity. They have a number of unusual physical, chemical, physicochemical and technological properties.

The bulk (up to 99\%) of shungite is represented by non-crystalline carbon, the defining feature of which is the globular structure. It is based on a ball - a hollow multilayer formation with sizes up to $10 \mathrm{~nm}$. This noticeable curvature of the graphite layers allowed the authors to draw a conclusion about the fullerene-like structure of shungite carbon. Mineral components are represented by fine (from 1 to $10 \mathrm{mkm}$ ) crystals of mica, quartz, albite, and others. This structure allows us to consider shungite as a natural composite material and provides for the possibility of their unique sorption properties.

An important task in studying the sorption properties of sorbents is the process of modeling and predicting the mechanism of absorption of pollutants from liquid media.

Therefore, studies aimed at reducing the anthropogenic load on the environment by improving the adsorption properties of sorbents in wastewater treatment from used batteries containing mercury, cadmium, lead, tin, nickel, zinc, magnesium and others are relevant and important for improving the environmental safety of water environment.

\section{Conclusion}

Based on experimental studies, the adsorption isotherms of $\mathrm{Ni}^{2+}$ and $\mathrm{Zn}^{2+}$ ions on complex sorbents according to the Langmuir and Freundlich models were obtained, and their type was determined according to the classification of S. Brunauer. The value of the maximum sorption capacity $\mathrm{G}_{\max }$ of sorbents relative to $\mathrm{Ni}^{2+}$ and $\mathrm{Zn}^{2+}$ ions was established. Optimal ratios, "solid liquid" to achieve maximum absorption.

\section{References}

[1] Bolshanina, S. B., Vorobiova, I. H., Hlovyn, N. M., \& Malovanyy, M. (2013). Doslidzhennia zdatnosti hlynystykh sorbentiv do adsorbtsii ioniv tsynku. Visnyk KrNU im. M.Ostrohradskoho, 3/2013(80), 203-206.

[2] Yang, K., Yan, L., \& Yang, Y. (2014). Adsorptive removal of phosphate by Mg-Al and Zn-Al layered double hydroxides: Kinetics, isotherms and mechanisms. Sep. Purif. Technol., (124), 36-42.

[3] Zhang, C., Gu, P., Zhao, J., Dhang, Z., \& Deng, Y. (2009). Research on the treatment of liquid waste containing cesium by an adsorption-microfiltration process with potassium zinc hexacyanoferrate. J. Hazard. Mater., (167), 1057-1062. 


\title{
Polylactide composites with calcium-containing fillers
}

\author{
Andrii Masyuk, Diana Katruk, Volodymyr Levytskyi \\ Department of Chemical Technology of Plastics, Lviv Polytechnic National University, UKRAINE, Lviv, S. \\ Bandera Street 12, E-mail: masyukas@gmail.com
}

\begin{abstract}
Polylactide composite materials with calcium-containing fillers, in particular calcium orthophosphate and calcium hydroorthophosphate, have been developed and investigated. A change in the morphology of the obtained materials was revealed, in particular, an increase in the degree of crystallinity of filled and heat-treated polylactide materials was noted. There is a change in surface hardness and thermomechanical characteristics of polylactide materials due to the action of calciumcontaining fillers.
\end{abstract}

Keywords - polylactide, calcium phosphates, composite, surface hardness, crystallinity

\section{Introduction}

Much of the currently used plastic materials are derived from polymers based on petroleum raw materials, because these materials have high barrier and physico-mechanical properties. In addition, their significant advantages are low cost of production and high productivity of the processes of their synthesis and manufacture of products based on them. In addition, the limitations of the widespread use of these materials are due to their low biodegradability and depletion of raw materials. Therefore, more and more attention is paid to the use of biodegradable polymeric materials from renewable raw materials that are capable of rapid decomposition in the environment under the influence of external factors (moisture, heat, microorganisms, ultraviolet radiation, etc.). The most promising and most widely used of these polymers is polylactide (PLA) - a biocompatible biodegradable thermoplastic polymeric material, which has good strength and rigidity and high thermophysical properties [1].

Among the methods of targeted influence on the morphology and properties of polymers, including polylactide, the most promising is the development of composite materials based on them with fillers of different nature (in particular, hydroxyapatite, calcium phosphate, talc, silicates, etc.).

\section{Experimental}

Ingeo 2500 HP polylactide (NatureWorks, USA) and fine fillers of calcium orthophosphate and calcium hydroorthophosphate were used in the work to obtain polymer composite materials.

Polylactide materials were obtained by mixing the bulk components in a drum mixer for 10-15 minutes. The mixture was then homogenized by stirring in a viscous state on a Cellier laboratory extruder, followed by extrusion and cooling of the extrudate. Samples for testing were obtained from crushed on a crusher gear-type extrudates by injection molding on a thermoplastic Krauss Maffei KM-125 C1-520. The filler content was 2\% by weight [2].

Additional heat treatment of materials was carried out in a heat cabinet for $120{ }^{\circ} \mathrm{C}$ for 3,5 , 10 minutes. The samples were heat-treated for $10 \mathrm{~min}$, additionally heat-treated $5 \mathrm{~min}$ after cooling

\section{Results and discussion}

X-ray examinations show that pure PLA crystallites are typical orthorhombic or pseudoorthorhombic crystals with lattice parameters: $\mathrm{a}=10.66 \AA, \mathrm{b}=6.16 \AA, \mathrm{c}=28.88 \AA$. and the type of crystal structure of the PLA does not change even during the introduction of the filler. In addition, the X-ray diffraction patterns of the filled materials show a decrease in the width of the 
main reflex (at $2 \theta-16.5^{\circ}$ ) by half its height. This change is interpreted as an increase in the size of the crystallites, which is proportional to the decrease in the width of the peak.

It was found that the highest value of the degree of crystallinity $(46 \%)$ is characteristic of the heat-treated sample of polylatide material, and the lowest, respectively, for the original unfilled polylatide $(22 \%)$. In this case, the introduction of the filler contributes to some increase in the degree of crystallinity by $4-6 \%$, which is due that the filler particles act as centers of nucleation of polylactide crystallites.

It was investigated that the thermomechanical curves of polylactide composites, regardless of the nature of the fine filler, are characteristic of polymers with a partially crystalline structure. It is established that the transition to the viscous state of composites based on PLA occurs at 190$193^{\circ} \mathrm{C}$. These temperatures are significantly lower than the temperatures of thermo-oxidative destruction of PLA macromolecules $\left(280-340{ }^{\circ} \mathrm{C}\right)$, which allows PLA composites to be processed by injection molding, extrusion, $3 \mathrm{D}$ printing, etc.

It was found that the introduction of calcium-containing fillers slightly increases the Vicat softening point of developed materials. At the same time, additional heat treatment significantly affects the value of Vicat softening point, in particular, there is an increase by $40-50{ }^{\circ} \mathrm{C}$. Such changes are obviously associated with an increase in the degree of crystallinity of polylactide materials and the enhancing effect of filler particles.

Also, additional heat treatment contributes to a significant increase in the surface hardness of polylactide materials, regardless of the nature of the filler. The highest values of hardness are marked by heat-treated filled polylactide materials for $10 \mathrm{~min}$ for $120^{\circ} \mathrm{C}(298 \mathrm{MPa})$. In this case, there is a similar effect of the filler on the value of surface hardness, regardless of the nature of the acid residue of the calcium-containing filler. It was found that composites with $\mathrm{Ca}_{3}\left(\mathrm{PO}_{4}\right)_{2}$ have slightly higher values of surface hardness than composites filled with $\mathrm{CaHPO}_{4}$.

\section{Conclusion}

Polylactide composite materials filled with calcium orthophosphate and calcium hydroorthophosphate were obtained. On the basis of the carried-out X-ray diffraction analysis the growth of degree of crystallinity of the developed materials and change of the sizes of crystallites, in particular, the greatest degree of crystallinity is characteristic of heat-treated polylactide material $-46 \%$ is established.

The change of surface hardness and thermomechanical characteristics of polylactide materials, in particular, the maximum values of Vicat softening point is $122-123^{\circ} \mathrm{C}$ and surface hardness of 295-298 MPa are observed for heat-treated samples with calcium phosphate content of $2 \%$ by weight.

\section{References}

[1] Maria Laura, Di Lorenzo, René Androsch (2018). Industrial Applications of Poly(lactic acid). Cham:Springer. https://www.springer.com/gp/book/9783319754581

[2] Masyuk, A. S., Kysil, Kh. V., Katruk, D. S., Skorokhoda, V. I., Bilyi, L. M. \& Humenetskyi T. V. (2020). Elastoplastic Properties of Polylactide Composites with Finely Divided Fillers. Materials Science, 55, 4, 555-562. https://doi.org/10.1007/s11003-020$00432-\mathrm{y}$ 


\title{
Research of parameters of industrial waters of canning plant and bakery
}

\author{
Marianna Havryshko ${ }^{1}$, Olena Popovych ${ }^{2}$
}

1. Department of Ecology and Sustainable Nature Management, V. Chornovil Institute of Sustainable Development, Lviv Polytechnic National University, Ukraine, Lviv, S. Bandery street, 12, 79013,

E-mail: marianna.i.havryshko@lpnu.ua

2.Department of Ecology and Sustainable Nature Management, V. Chornovil Institute of Sustainable Development, Lviv Polytechnic National University, Ukraine, Lviv, S. Bandery street, 12, 79013, E-mail:lpolenaeko@yahoo.com

Abstract - The food industry plays a significant role in the pollution of the hydrosphere. As a result, surface water sources are becoming more polluted and the use of water for domestic, industrial and other needs determines the need for increasingly complex and costly treatment. Thus, the improvement and creation of conceptually new methods of food wastewater treatment is an urgent scientific and technical task today.

Keywords - bakery, waste, sewage, ecological safety, food industry, cannery.

\section{Introduction}

Wastewater from food industry enterprises is formed during the technological process, washing of raw materials, equipment, production facilities as well as after the use of water and steam in technological processes. The formed wastewater contains aggregatively stable colloids, which include animal and vegetable fats, proteins, starch, sugar as well as salts, carbohydrates, dyes, thickeners, preservatives [1].

Contamination of surface waters with organic substances from food production effluents poses a significant environmental risk. These substances, which are brought in water, cause the development of decay processes in it, disturb the natural balance of water, cause eutrophication and negatively affect fauna and flora.

Wastewater treatment can be performed according to various schemes that provide high treatment efficiency. All methods of wastewater treatment currently used are divided into mechanical, physicochemical, chemical, biological (biochemical). In addition, wastewater disinfection is used to destroy bacterial contamination.

In circulating and wastewater, contaminants in vegetable processing plants are soil particles, fruit pulp and peel, mold and rot bacteria, and other wastes. During the treatment of the same raw material, wastewater can differ significantly. For example, the composition of wastewater from vegetable processing enterprises includes: soluble, insoluble and colloidal substances that are removed from the surface of products during their cleaning and washing; juices and syrups used in the processing of products, impurities, waste from raw materials, etc are accidentally introduced. The size of these contaminants is significant, $12-35 \%$ from weight of raw materials. From 20 to $50 \%$ of waste enters the sewer network together with wastewater.

The technological scheme of industrial wastewater treatment of different composition includes the following units: averaging and accumulation of wastewater; mechanical cleaning from large residues; reagent (chemical, physicochemical, electrochemical, biotechnological) treatment of wastewater with the destruction of toxic and release in the form of a suspension of harmful (aggressive) impurities; aggregate formation (coagulation, flocculation) to intensify the process of removing the suspension from the drain; clarification (settling) of treated wastewater in high-speed (thin-layer) settling tanks; additional treatment (if necessary) of clarified water on granular filters; water disinfection as well as dehydration of the released suspension of pollutants and disposal of the formed sediments [2]. 


\section{Results of the research}

The analysis of wastewater parameters was carried out on the basis of existing food industry enterprises, namely a cannery and a bakery.

Water sampling from the cannery was carried out for 2 months and the control one after a year. Sampling of wastewater from the bakery was analyzed for 6 months. According to standard methods, the main indicators of water were determined and the compliance with the MPC was analyzed.

Thus, in accordance with the final results of wastewater analysis, the maximum allowable norms of ammonium nitrogen, BOD5 and COD were exceeded. Their concentrations at both plants were $9.8 \mathrm{mg} / \mathrm{dm}^{3}, 98 \mathrm{mg} / \mathrm{dm}^{3}$ and $254 \mathrm{mg} / \mathrm{dm}^{3}$ at the cannery and $3.24 \mathrm{mg} / \mathrm{dm}^{3}, 36$ $\mathrm{mg} / \mathrm{dm}^{3}$ and $78 \mathrm{mg} / \mathrm{dm}^{3}$ at the bakery, respectively, which exceeds the permissible norms several times (table.1).

At the same time, it should be noted that according to the latest results of the analysis of wastewater from the bakery, we can see an improvement in the degree of wastewater treatment, which indicates that the treatment system works and practically reaches its quality indicators, which unfortunately cannot be said cannery, where the positive dynamics is not so clear. Also, in the wastewater of the cannery, as the result of changes in raw materials in the production process and the use of other detergents, the maximum permissible levels of phosphates and chlorides were recorded 10 and 2 times respectively, which confirms that all stages of the production process have an impact on high-quality wastewater composition.

Based on the obtained values and analyzing the ratio of $\mathrm{BOD} / \mathrm{COD}$, it is possible to offer the enterprises to improve the stages of biological treatment of industrial water to obtain quality indicators that meet the standards.

In particular, chemical oxygen demand (COD), oxidation by potassium permanganate indicates the presence of substances and their concentration when treated with strong oxidants. The value of the COD parameter is most evident in the determination of wastewater contamination before biochemical oxidation by estimating the ratio of $\mathrm{BOD} / \mathrm{COD}=0.7-0.8$, and for biochemically treated it is $0.4-0.1$.

\section{Conclusions}

Wastewater from the food industry is highly concentrated in terms of organic impurities, suspended solids, may have unfavorable for biological treatment content of nutrients and $\mathrm{pH}$ values, but the analysis of the degree of bio oxidation of organic impurities in relation to $\mathrm{BOD}_{5} / \mathrm{COD}$ showed that wastewater from the vast majority of food industry can be purified by biological methods.

After analyzing the dynamics of changes in pollutants in the wastewater of the bakery and cannery, we can conclude that the biological treatment systems at these enterprises do not function satisfactorily and clearly need improvement.

The considered biotechnology of wastewater treatment, which is successfully used in most food industries, can also be considered as a source of water for watering plants in the area to reduce overall water use in the process and return to the general process, for example to use for washing vegetables and fruit.

\section{References}

[1] Simanina I.V., Sidorskaya S.A. (2016). Wastewater from the food industry. Collection of materials of the $72^{\text {nd }}$ Student Scientific and Technical Conference, April 20-28, 2016, 178-183. Minsk, http://rep.bntu.by/handle/data/27398

[2] Shestopalov O.V., Getta O.S., Rykusova N.I. (2019). Modern methods of wastewater treatment in the food industry. Environmental Sciences, 2(25). 20-27. https://doi.org/10.32846/2306-9716-2019-2-25-4 


\title{
Mineral fillers modified by shoulders from deodoration columns of oil and fat products
}

\author{
Chobit M., Vasylyev V., Panchenko Yu., Shabikova V. \\ Institute of Chemistry and Chemical Technologies, Lviv Polytechnic National University, UKRAINE, Lviv, 3/4 pl. \\ Sviatoho Yura, E-mail: maksym.r.chobit@lpnu.ua
}

\begin{abstract}
The aim of the work was to investigate for the first time the possibility of modification of disperse mineral fillers (chalk and magnesium hydroxide) deodorizing shoulder straps containing fatty acids obtained by refining sunflower oil for create filled polymer composites.
\end{abstract}

Keywords - polymer composite, chalk, magnesium hydroxide, polyethylene, polyester resin, polyvinyl chloride.

For many decades, mankind has been using synthetic materials to replace natural ones. They are widely used because they have a number of advantages, namely, a significant variety of properties, low cost and the possibility of multi-ton production. A significant advantage of synthetic materials is the wide possibility of obtaining new materials having a significant list of different types of raw materials; the possibility of improving existing species. This can also be achieved by combining components of different origins and changing the technological parameters to obtain them. This path will improve the performance of synthetic materials under predetermined conditions and increase the list of opportunities for their technical application.

The oil and fat industry in Ukraine provides a wide range of oils and edible fats for various purposes. In the process of their processing, there is a significant amount of noncondensable fat-containing waste, which not be used for food purposes. That is why it is interesting to try to modification mineral fillers with fatty acids from deodorizing columns of oil and fat productions and to obtain polymeric composite filled with them.

The purpose of this work was to test the possibility of deodorizing shoulder straps containing fatty acids obtained by refining sunflower oil to modify mineral fillers: chalk and magnesium hydroxide.

Table. 1 .

Tensile strength of filled composites by polyvinyl chloride

\begin{tabular}{|c|c|c|c|c|}
\hline Filler & \multicolumn{1}{|c|}{$\begin{array}{c}\text { Tensile } \\
\text { strength, MPa }\end{array}$} & $\begin{array}{c}\text { Increases of tensile } \\
\text { strength, \% }\end{array}$ & $\begin{array}{c}\text { Relative } \\
\text { elongation, \% }\end{array}$ & $\begin{array}{c}\text { Increases of } \\
\text { relative } \\
\text { elongation, \% }\end{array}$ \\
\hline \multicolumn{5}{|c|}{ Chalk } \\
\hline Not modified & 1,92 & & 61,2 & - \\
\hline $\begin{array}{c}\text { Modified (degree of } \\
\text { modification 2 \%) }\end{array}$ & 2,09 & 8,85 & 80,3 & 31,21 \\
\hline $\begin{array}{c}\text { Modified (degree of } \\
\text { modification 5\%) }\end{array}$ & 2,44 & 27,1 & 101,4 & 65,69 \\
\hline \multicolumn{7}{|c|}{ Magnesium hydroxide } & \\
\hline Not modified & 1,83 & - & 70,8 & - \\
\hline $\begin{array}{c}\text { Modified (degree of } \\
\text { modification 2 \%) }\end{array}$ & 2,15 & 17,5 & 89,5 & 30,56 \\
\hline $\begin{array}{c}\text { Modified (degree of } \\
\text { modification 5 \%) }\end{array}$ & 2,65 & 44,8 & 125,4 & 89,22 \\
\hline
\end{tabular}

$3^{\text {rd }}$ INTERNATIONAL SCIENTIFIC CONFERENCE “CHEMICAL TECHNOLOGY AND ENGINEERING”, JUNE 21-24 ${ }^{\text {TH }}, 2021$, LVIV, UKRAINE 
Study of the influence of the degree of modification of fillers on the physic-mechanical properties of polymer based on polyvinyl chloride (PVC), low density polyethylene (PENT) and polyester resin.

The tensile strength of polymeric composite materials based on PVC increases with increasing degree of modification, show in table 1. Accordingly, the relative elongation of the composites increases, i.e. the modification of the filler leads to an improvement in the mechanical properties of the composites, the higher content of the modifying agent increases this effect.

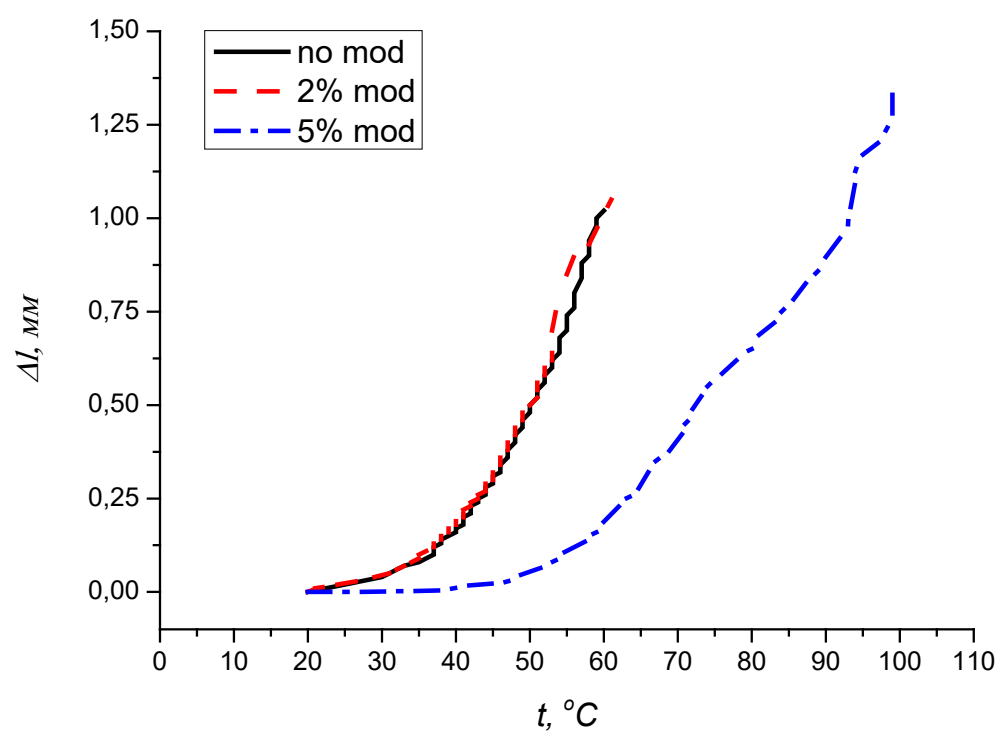

Fig.1. Thermomechanical properties of polymer composite materials polyester resin, filled by chalk: no modified, modified (degree of modification $2 \%$ and $5 \%$ ).

Polymer composite materials polyester resin filled by not modified chalk and chalk with degree of modification $2 \%$ the values of heat resistance are almost the same, show in Fig. 1. Sample of chalk with degree of modification $5 \%$, is an increase in heat resistance relative.

\section{Conclusion}

As a result of the conducted researches, for the first time the possibility of modification of dispersed mineral fillers (chalk and magnesium hydroxide) deodorizing shoulder straps of oil and fat productions was investigated. The aim of this process is further creation of filled polymer composites. Polymer composites based on PVC, PENT and polyester resin filled with modified fillers with different degrees of modification of $2 \%, 5 \%$ and $8 \%$ were obtained. The tensile strength of polymer composites, relative elongation, toughness and thermomechanical properties were studied. In the study of composites based on PVC, it is shown that with increasing degree of modification of the filler, their tensile strength increases, and the increase in strength reaches almost $50 \%$. It is established that the proposed method is not suitable for the creation of composites based on low density polyethylene, as there is a decrease in mechanical properties, at increasing the degree of modification impairs the strength of the composite. This effect is most likely due to the poor compatibility of the modified filler with the polymer matrix. Thermomechanical studies have shown that the heat resistance of composites with modified fillers generally increases. 


\title{
Technological detergents for cleaning compressors of gas turbine installations
}

\author{
Galina Prokofieva ${ }^{1}$, Nina Belousova ${ }^{2}$, Margaryta Berkut $^{1}$, Oleksii Klimenkov ${ }^{1}$ \\ 1. Department of Technology of Inorganic substances, Water Treatment and General chemical technology, National \\ Technical University of Ukraine «Igor Sikorsky Kyiv Polytechnic Institute», UKRAINE, Kyiv, Peremogy Avenue \\ 37, education building №4, E-mail: margo.berkut.00@gmail.com
}

2. Department of Electrochemical Production Technology, National Technical University of Ukraine «Igor Sikorsky Kyiv Polytechnic Institute», UKRAINE, Kyiv, Peremogy Avenue 37, education building №4.

\begin{abstract}
The prospects of using technical detergents to solve environmental and energy saving problems in the operation of compressor equipment are studied. The results of physical and chemical studies of the interaction of environmentally safety technical detergents developed by us with components of technological contamination of compressors are presented, which contributes to their reliability and durability of operation.
\end{abstract}

Keywords -cleaning, detergent, compressor equipment, ecology, surfactants.

\section{Introduction}

During the operation of compressor equipment, its technical condition and characteristics gradually deteriorate, which is associated with operational and technological contamination of the internal and external surfaces of gas transmission system elements. The gradual accumulation of dirt leads to an increase in $\mathrm{e}$

nergy consumption, a decrease in the power of equipment, its reliability and durability of operation.

To solve these problems, environmentally friendly cleaning of equipment elements from contamination remains relevant, which in turn requires the development of effective technical detergents.

\section{Research materials}

One of the promising methods of cleaning compressor equipment is physico-chemical using solutions of technical detergents (TD). The choice of TD composition is preceded by a study of the composition of technological contaminants. The studies were carried out using various physical and chemical methods: thermographic, radiographic, spectral, spectrophotometric, electron paramagnetic resonance, infrared spectroscopy, polarization resistance, etc.

The results of analyses of contamination of the surfaces of gas turbine units of main gas transmission systems showed the presence of organic and inorganic compounds in them. It should be particularly noted that the predominant component of pollutants is iron, the presence of which contributes to the possibility of corrosion and erosion processes during the operation of compressor equipment.

The main components of TD that ensure its effectiveness are surfactants. We considered a wide range of surfactants of different classes, among which non-ionic surfactants with significant dispersing and emulsifying properties showed the greatest effectiveness. Special attention was paid to the study of the ratio of nonionic surfactants to Iron (III) ions which used by TD in alkaline environments, contribute to the reverse deposition of solid sediment of iron-containing compounds on the cleaned surface of equipment, which significantly reduces the effectiveness of TD.

Therefore, the physico-chemical study of the interaction in the "Fe (III) - neoinogenic surfactant" system in an aqueous solution aroused interest. For this purpose, the concentration 
and acid-base conditions of interaction of Fe (III) ions with a number of nonionic pairs were studied. The results of spectrophotometric studies showed the possibility of complex formation processes in the studied systems. Mathematical processing of the obtained results made it possible to establish the composition of complex compounds and the mechanism of their formation. It was experimentally proved that the obtained concentration conditions of complex implementation in the system "pollution component - TD component" is responsible for the greatest efficiency of technological detergent, therefore, can be based on the choice according to the assigned TD.

An important characteristic of technical detergents is its anti-corrosion properties which are provided by the introduction of special impurities in them that counteract corrosion processes both for cleaning from technological contamination and for insufficient flushing of gas turbine units from TD residues. It should be noted that the introduction of anti-corrosive impurities increases the salt content of technical detergents that negatively affects the environmental friendliness of the product.

We considered the possibility of reducing the corrosion activity of TD by using nonionic surfactants with multifunctional action. Positive results were obtained, which were confirmed by industrial tests.

\section{Conclusions}

The composition of technical pollution of compressor equipment elements has been studied by various physicochemical methods. The interaction in aqueous solutions of the systems "Fe (III) - nonionic surfactants", the results of which are the basis for the development of compositions of technical detergents. The anticorrosive properties of the developed ecologically safe TD on the basis of nonionic pairs of semifunctional action are established.

\section{References}

[1] Abramzon, L.A. (1981). Surfactants. Properties and application. Leningrad: Khimiya. [In Russian]

[2] Sukhotin, A.M., Bagachev, A.F., Polish, V.G. (1988). Corrosion under the influence of coolants, refrigerants and working fluids. Corrosion resistance of chemical process equipment. Ref. Izd.Leningrad: Khimiya, 1988. [In Russian]

[3] Prokofieva, G., Belousova, N., Bilenko, N. (2006). The study of anti-corrosion ingredients in technical detergents. VIII International Conference" Problems of Corrosion and Corrosion Protection of Structural Materials Physicomechanical Institute named by G. Karpenko NASU (6-8 June, Lviv, 2006) [In Ukrainian]

[4] Shtupel, G. (1960). Synthetic detergents and cleaners. Moscow: Gosudarstvennoe scientific tehniçeskoe izdatel`stvo himiçeskoy literaturı [In Russian] 


\section{CONTENT}


GREETINGS OF THE PROGRAM COMMITTEE'S CHAIRMAN 3

GREETINGS OF THE ORGANIZING COMMITTEE'S CHAIRMAN .............................. 4

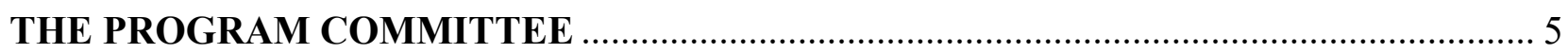

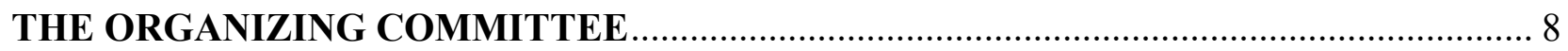

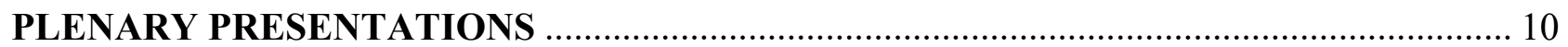

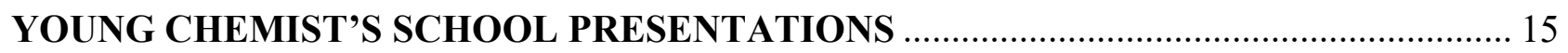

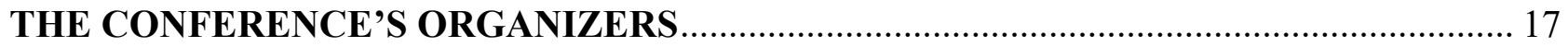

COMPUTER SIMULATION IN THE CHEMICAL TECHNOLOGY

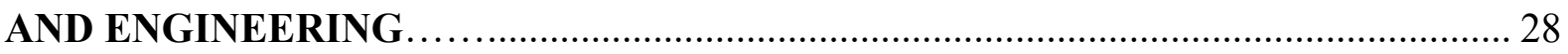

The use of a porous medium method for modeling fixed-bed reactors with a low tube-toparticle diameter ratio. Tymoteusz Świeboda, Renata Krzyżyńska, Anna BryszewskaMazurek, Wojciech Mazurek

Computer prediction of biological activity of 1,2,4-triazole derivatives of 1,4-naphthoquinone.

Nataliia Polish, Oleksii Kurylo, Andriy Karkhut, Lesya Zhurakhivska, Nataliia Marintsova.

The Use of Case-Based Reasoning for the Choice of Methods for Cleaning Exhaust Gases from Sulfur and Nitrogen Oxides. Yurii Beznosyk, Liudmyla Bugaieva.....

Computational Fluid Dynamics Modeling of Mixing Process for Two-Components Mixture in the Large Scale Reactor. Roman Havryliv, Iryna Kostiv, Sophia Vintoniak

Development of the CFD model to the high viscosity fluid mixing modeling. Roman Havryliv, Łukasz Radosiński, Maciej Szudarek, Sylwia Oleś.

Effects caused by vacancies in carbon nanocluster $\mathrm{C}_{96}$ and polyaromatic molecule $\mathrm{C}_{96} \mathrm{H}_{24}$.

O.S. Karpenko

Improving computer simulation of vacuum pumping process of the plasma sputtering system.

Roman Sheremeta .

Modeling Heat and Mass Transfer During Evaporation in the Film Apparatus with Cross

Movement Phases. Lukashov V.K., Kostiuchenko Y.V., Timofeev S.V.

Mathematical modeling of sorption and desorption dynamics in adsorption systems. Natalia

Sorokova, Julia Kolchyk, Rodion Sorokovoi

Multiple linear regression of C9 fraction inverced emulsion oligomerization. Roman

Subtelnyi, Dariia Kichura, Yevhenii Zhuravskyi, Bohdan Dzinyak

DEVELOPMENT, ENERGY AND RESOURCE SAVING IN THE CHEMICAL AND FOOD TECHNOLOGIES

Slag of thermal power plants as an attractive raw material for porous fillers production. Diana

Kindzera, Ihor Mitin, Volodymyr Atamanyuk, Roman Hosovskyi.

Installation for research of hydrogen sulfide chemisorption from gases by a quinhydrone absorbing solution under pressure. Andriy Slyuzar, Zenoviy Znak, Yaroslav Kalymon

Autonomous catalytic hydrogen generator based on bioethanol steam reforming. L.Y. Dolgikh,

A.I. Trypolskyi, I.L. Stolyarchuk, Y.I. Pyatnitsky, P.E. Strizhak.

Study of diffusion processes in carrot particles. Iryna Huzova, Volodymyr Atamanyuk 
Research of the soybean oil extraction using polar solvents. Anna Hlukhaniuk, Oleksandr Ivashchuk, Yevgen Semenyshyn, Roman Chyzhovych, Tetiana Kuzminchuk, Semen Khomyak

Thermal stability of materials of vegetable origin. Tetiana Korinchevska, Viacheslav Mykhailyk.

State of water during dehydration of sugar beet tissue. Viacheslav Mykhailyk, Tetiana Korinchevska

Obtaining bitumen from paraffinic-base crude via joint oxidation of tar and different products of oil processing. Andriy Nagurskyy, Bohdan Korchak.

Research of valuable substances extraction from alcohol distillery stillage. Oleksandr Ivashchuk, Tetiana Kuzminchuk, Roman Chyzhovych, Semen Khomyak,Yevgen Semenyshyn, Sofiia Kiiaieva, Roman Zherebetskyi

Features of Aging of Road Bitumen. Myroslava Donchenko, Oleg Grynyshyn, Yuriy Khlibyshyn

The improved evaluation of the duration of the fouled membrane modules regeneration. Serhii Huliienko, Ihor Tereshenko

Establishment of energy-saving modes of dispersion and fractionation of pectin-containing powder. Raisa Shapar, Olena Husarova

Changes in the properties of semi-synthetic motor oil Castrol $10 \mathrm{~W}-40$ during its use in the diesel engine of commercial vehicles. Roman Prokop, Oleh Hrynyshyn, Taras Chervinskyy

Complex processing of liquid pyrolysis products. Dariia Kichura, Roman Subtelnyi, Bohdan Dzinyak.

\section{THE INNOVATIVE TECHNOLOGIES IN THE CHEMICAL AND FOOD INDUSTRIES}

Se-driven microgel catalysts for oxidation processes. Roman Nebesnyi, Anastasia Pavliuk, Kok Hui Tan, Tetiana Kharandiuk, Volodymyr Ivasiv, Andrij Pich.

Polypyrazolylborate complexes of the lanthanides: structure, optics and materials. Seema $S$. S. Pillai, Roman Kresinski, Emil Bojarski, Peter J. S. Foot

Supported transition metals oxides and N-hydroxyphthalimide in catalysis of the liquid-phase oxidation of cumene. Suprun Wolodymyr, Sheparovych Roman, Hrynda Yurii,

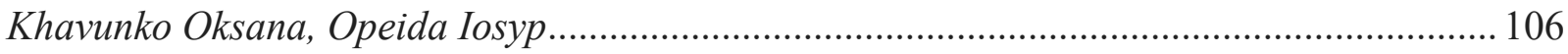

Silicates as fillers for polymer composites. Oleksandra Dzeikala, dr Mirosława Prochoń 108

Hydrodynamics of cotton filtration drying. Volodymyr Atamanyuk, Zoriana Gnativ Dauren Dzhanabaiev, Alisher Khusanov

Hydrodynamics of cotton stalks filtration drying. Zagira Kobeyeva, Alisher Khusanov, Zoriana Gnativ, Volodymyr Atamanyuk, Dauren Dzhanabaiev....

Complex hydrogels based on aquasol and polyacrylamide. Chobit M., Kalin D. , Tokarev V.

The interaction regularities of acetic and oleic acids esters and triethanolamine. Roman Danyliuk, Anastasiia Komaretska, Stepan Melnyk, Yurii Melnyk

Determination of pressure drop in a fixed bed catalytic reactor during ammonia oxidation on nanostructured catalyst. Oksana Dobrovetska, Diana Kindzera, Roman Hosovskyi, Volodymyr Atamanyuk. 
Development of new functional food products based on spreads. Chobit M., Vasylyev V., Panchenko Yu., Usiichuk M.

The degree of complexity of the subsolidus structure of three-component systems $\mathrm{MgO}$ $\mathrm{Al}_{2} \mathrm{O}_{3}-\mathrm{FeO}, \mathrm{MgO}-\mathrm{Al}_{2} \mathrm{O}_{3}-\mathrm{TiO}_{2}, \mathrm{MgO}-\mathrm{TiO}_{2}-\mathrm{FeO}, \mathrm{Al}_{2} \mathrm{O}_{3}-\mathrm{TiO}_{2}-\mathrm{FeO}$. Oksana Borysenko,

Sergey Logvinkov, Galina Shabanova, Andrii Ivashura

Modified polylactide composites. Nataliya Semenyuk, Khrystyna Kysil, Galyna Dudok, Volodymyr Skorokhoda

Comparison of the adsorption capacity of methylene blue nanostructured composites based on

$\mathrm{CoMnO}_{2}$ and CuO. Olena Makido, Galyna Khovanets', Natalya Koretska

Activity of Magnetically Separable Catalyst $\mathrm{Fe}_{3} \mathrm{O}_{4}$ in Fenton Type Reaction during Methyl

Violet Discoloration. Sheparovych Roman, Opeida Lubov.

Biosynthesis of silver nanoparticles using extracts of medicinal plants. Kateryna Yatskiv,

Diana Zahorodnia, Romana Petrina, Semen Khomyak, Viktoriya Havryliak

Improving the Technology of Bitter Tinctures. Iryna Sokolovska, Roman Zherebetskyi,

Oksana Orobchuk, Roman Subtelnyi....

Application of the method od discrete input pulse energy for energy-efficient production of chelidonium majus extract. Liubov Gozhenko, Georgii Ivanitskyi, Bogdan Tselen,

Natalia Radchenko, Anna Nedbailo

Hydrogels membranes obtained by modification in the volume. Nataliia Baran, Oleh Suberlyak, Oleksandr Grytsenko

Kinetics of adsorption of iron ions (III) by natural zeolite. Vira Sabadash, Jaroslaw Gumnitsky

Activation of polyethylene granules. Anastasiya Kucherenko, Olena Nikitchuk, Ludmila

Dulebov, Volodymyr Moravskyi ....

Influence of polymer additives on rheological properties of heavy high-viscosity oil. P.Topilnytskyy, V.Romanchuk, T.Yarmola

Obtaining of modified polyamide from the solution. Natalia Chopyk, Victoria Zemke, Iryna

Dovga

Transesterification of vegetable oil by ethanol in the presence of heterogeneous catalysts.

Yurii Melnyk, Stepan Melnyk, Halyna Mahorivska

The process of catalytic hydration of acetylene compounds using a homogeneous catalyst based on gold (I) complex with water-soluble organophosphorus ligands. Ivan Kokhan,

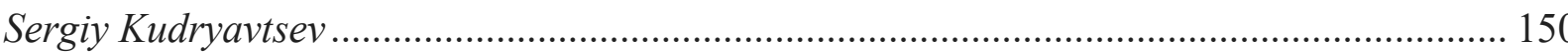

OPTIMIZATION OF BIOCHEMICAL PROCESSES AND BIOENGINEERING 154

Polymer properties to comply with requirements for medical devices. Jorg Vienken 155

Innovative cosmetic raw materials and biologically active compounds in cosmetics chemistry.

Sebastian Grzyb.

Liquid atomization process in medical applications. Tomasz R. Sosnowski, Katarzyna

Dobrowolska.

Atomization of oxygen nanodispersions in isotonic saline for applications in aerosol therapy. Marcin Odziomek, Katarzyna Dobrowolska, Karol Ulatowski, Paweł Sobieszuk, Tomasz R. Sosnowski 
Proliferation of Rindera graeca transgenic roots in oscillatory rocked disposable bioreactor. Kamil Wierzchowski, Mateusz Kawka, Katarzyna Sykłowska-Baranek, Maciej Pilarek....

Adaptation of the sensor method for the determination of mixing time in a rocking single-use bioreactor. Mateusz Bartczak, Kamil Wierzchowski, Maciej Pilarek.

Nanohybrid platform based on carbon material for glucose detection. Maria Kuznowicz, Artur Jędrzak, Teofil Jesionowski.....

Glucose detection in food real samples using an amperometric biosensor. Artur Jędrzak, Maria Kuznowicz, Teofil Jesionowski

GREEN CHEMISTRY

Supercritical $\mathrm{CO}_{2}$ extraction as green and waste-free technology - applications and perspectives. Katarzyna Tyśkiewicz, Marcin Konkol, Agnieszka Dębczak .....

Preparation and characterization of thermoplastic starch/polylactide blends with palmitic acid. Justyna Ostrowska, Magdalena Paluch, Karolina Sottan, Waldemar Sadurski, Piotr Tyński

Convenient and Efficient Suzuki Miyaura Coupling Reactions of Meso-Halogenated BODIPYs. Gökçe Hilal Taşan, Raşit Fikret Yılmaz, Yavuz Derin, Büşra Albayrak Mısır, Ahmet Tutar

Biocidal preparations based on thiosulphonates and biosurfactants. Vira Lubenets, Natalia Monka, Ihor Bobalo, Tetyana Pokynbroda, Alla Prokopalo, Olena Karpenko

Chemical resistance of biopolymers based on the epoxy resin modified with epoxidised and cyclocarbonated soybean oils. Olha Purikova, Larisa Gorbach, Oleksandr Brovko

Synthesis and antibiofilm activity of substituted 1-deazapyrimido[1,2,3-cd]purinium salts. Liubov Muzychka, Oksana Muzychka, Oleg Smolii, Iryna Boiko, Nataliia Hrynchuk

Waterborne polyurethane-polyacrylate dispersions of mixed type. Tamara Travinskaya, Alexandra Brykova, Lyudmila Robota, Yuri Savelyev

ALTERNATIVE AND NON-CONVENTIONAL ENERGY SOURCES

Processing of granules based on peat and sludge. Zhanna Petrova, Yuliia Novikova, Anton Petrov.

Pyrolysis of polymer waste is a source of motor fuels. Ksenya Hrynyshyn, Volodymyr Skorokhoda, Taras Chervinskyy

Research of the calorific value of dried alcohol distillery stillage. Oleksandr Ivashchuk, Volodymyr Atamanyuk, Roman Chyzhovych, Tetiana Kuzminchuk, Roman Zherebetskyi, Sofiia Kiiaieva.

\section{ECOLOGY AND SUSTAINABLE DEVELOPMENT. ENVIRONMENTAL} PROTECTION.

Usefulness of facial masks against COVID-19 transmission - an experimental evidence. Tomasz R. Sosnowski, Marcin Odziomek, Agata Dorosz

Immobilisation of metals in the absorption. Matgorzata Wojtkowska....

Design of $\mathrm{Mg}-\mathrm{Al}-\mathrm{CO}_{3}$ layered double hydroxides (LDHs) which are capable to remove aqueous selenate $\left(\mathrm{SeO}_{4}{ }^{2-}\right)$ and selenite $\left(\mathrm{HSeO}_{3}{ }^{-}\right)$via direct exchange of the interlayer anions. Natalia Chubar, Małgorzata Szlachta, Vasyl Gerda, Matej Mičušik, Maria Omastova 
Evaluation of Gross Regional Product Waste Intensity in Context of the SDGs Achievement Progress Assessment. Iryna Dzhygyrey.....

Use of Modified Polyacrylamide for Floccuation of Coal Enrichment Wastes. Vasyl Duleba, Zoriana Gnativ....

Ecologically safe methods of treatment of wastewater from zinc and nickel ions with complex sorbents. Ihor Petrushka, Volodymyr Mokryi, Kateryna Petrushka...

Polylactide composites with calcium-containing fillers. Andrii Masyuk, Diana Katruk, Volodymyr Levytskyi.

Research of parameters of industrial waters of canning plant and bakery. Marianna Havryshko, Olena Popovych

Mineral fillers modified by shoulders from deodoration columns of oil and fat products.

Chobit M., Vasylyev V., Panchenko Yu., Shabikova V.

Technological detergents for cleaning compressors of gas turbine installations. Galina Prokofieva, Nina Belousova, Margaryta Berkut, Oleksii Klimenkov. 


\section{SPONSORS AND PARTNERS}




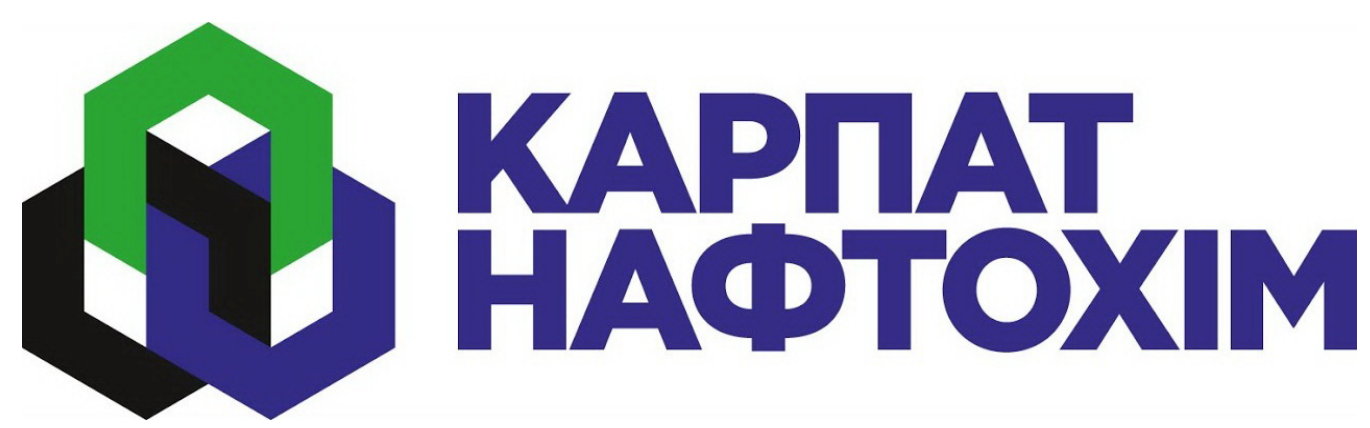

KARPATNAFTOCHIM Ltd.

77306, Ukraine, Kalush, Ivano-Frankivsk region, Promyslova str. 4 Phone/Fax: +38 03472664 60, +380347260425

E-mail: mail@knh.com.ua

www.knh.com.ua

KARPATNAFTOCHIM Ltd. was founded in October 2004. Legal address ID code: 33129683.

The only participant of the Company is KARPATY CHEMICAL B.V., legal entity under the laws of the Kingdom of the Netherlands, whose seat is: Helsinkilaan, 4, 3446 AH Woerden, the Netherlands.

KARPATNAFTOCHIM Ltd. is highly developed economic complex for the production of petrochemical and chemical products. The only producer in Ukraine of ethylene, propylene, benzene, C9-cut, polyethylene, as well as caustic soda and suspension polyvinylchloride. The latter are the new products of the company.

The multi-branched network of automobile roads and railways, close distance to boarders with Poland, Romania, Hungary, Slovakia, availability of ethylene pipe line between KARPATNAFTOCHIM Ltd. and Tiszai chemical works in Hungary creates favourable preconditions for the integration of the enterprise to the European industrial and trade activity.

High quality of products is provided by highly qualified staff of petrochemists as per international integrated management standards ISO 9001, ISO 14001, OHSAS 18001. 


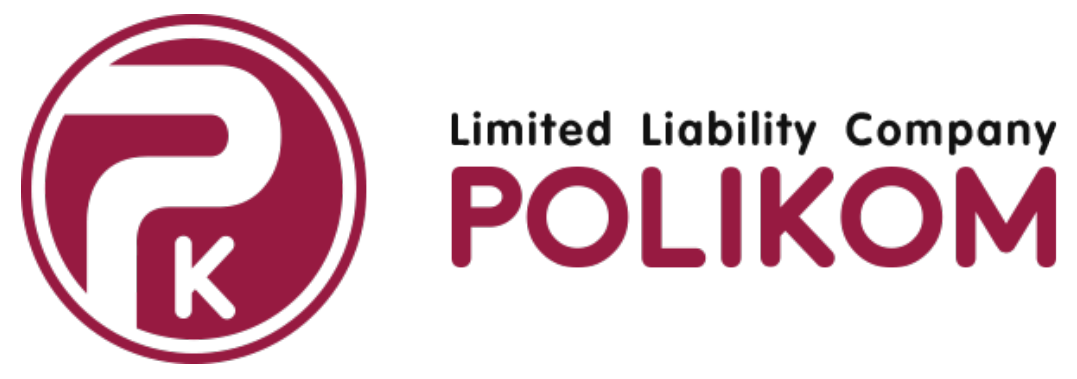

Polikom LLC

77611, Ukraine, Ivano-Frankivsk region, Rozhniativ district, Broshniv-Osada,

Shkilna str. 2a

$$
\text { Phone: +38 } 0347447686,+380347447625
$$

E-mail: office@polikom.net.ua

\section{www.polikom.group}

Limited liability company "Polikom." is innovative, client-oriented production company which develops dynamically. It was founded in 1997 due to the initiative of a group of experts who had more than 30-year scientific and production experience in the sphere of polymer synthesis and processing. Nowadays Polikom is the leader in CIS in development of PVC-based compositions; production of the wide range of commodity PVC-plastisols and PVC-granulates for wallpaper industry, linoleum, artificial leather, sealing gaskets for food and technical designation; as well as production of roll technical materials (awnings, banners, geomembranes), protector working gloves, souvenir products etc. Polikom operates its great experience, which is strengthened by its own researches and following of new tendencies, and constantly improves its products and expands its stock.

As for today our company produces also organic pigment pastes for colouring of PVCplastisols, water-based systems for wallpaper production, pigment pastes for their colouring, undusted effect-pigments and other multifunctional additives for different usage spheres according to their individual properties. 


\title{
Inter Syntez
}

The best chemical solutions

\author{
Inter Syntez LLC \\ 82300, Ukraine, Boryslav Truskavetska str. \\ Phone: +38067 7890464 \\ www.insyntez.com.ua
}

Inter Syntez is a leading supplier of food additives for meat, confectionery, bakery, dairy and other food industries. The company is a developer and manufacturer of «GELEX» stabilizing system.

Our company offers tara gum and locust bean gum as an effective substitution for guar gum.

Inter Syntez is well known for its reasearch in desinfectants production sphere. Trademarks «Crystal 700», «Crystal 900» and «Crystal 1000» successfully compete with imported analogues in Ukraine and abroad.

One of our company's main activities is selling various brands of hydrogen peroxide. We use our own methods for stabilizing hydrogen peroxide, particularly for industries using «TetraPak» and «KombBlok». 


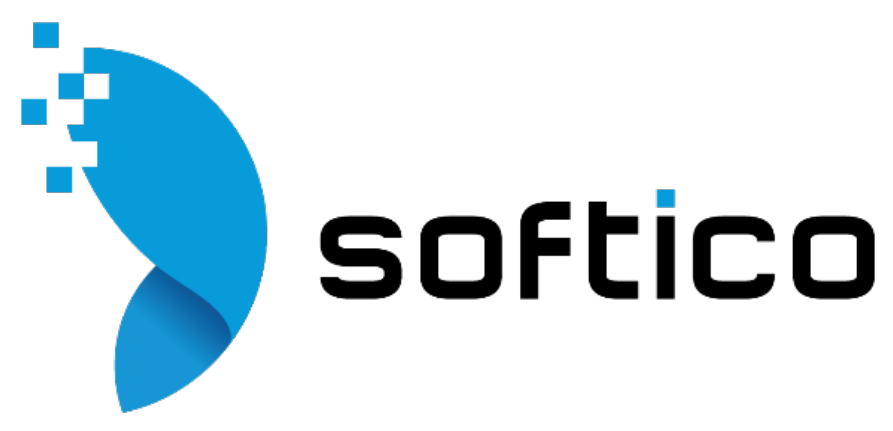

SOFTICO LLC

03150, Ukraine, Kyiv, Malevycha (Bozhenka) str. 86-L, entrance 3, floor 1

Phone: +380443834410

E-mail: info@softico.ua

www.softico.ua

SOFTICO is a company with years of successful experience in the field of IT distribution. The company offers solutions for information security, supply and licensing of software from the world leaders, CAD solutions, IT services for integration and service.

SOFTICO LLC is the world-famous IT solutions, favorable conditions for partners, free and prompt delivery throughout Ukraine, technical support for customers. 


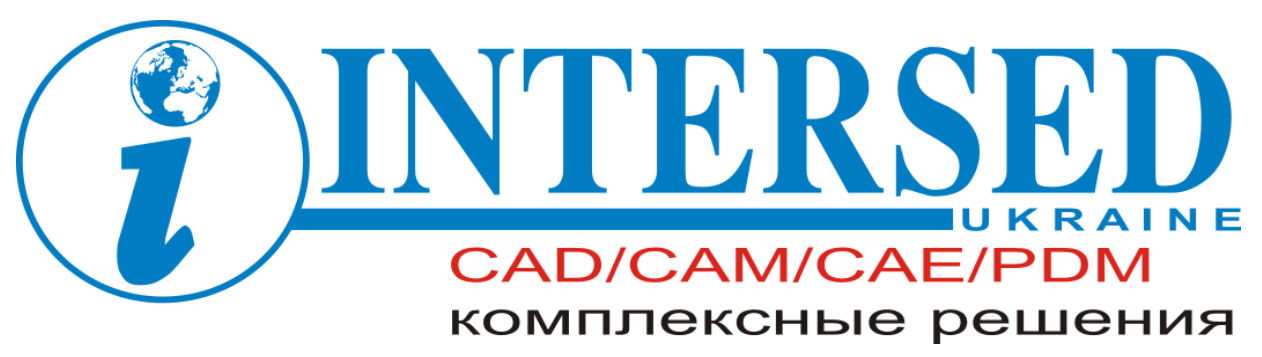

Intersed Ukraine LLC

02091, Ukraine, Kyiv, Kharkivske Sh., 152, office 433

Phone: +380445853210

E-mail: cad@intersed.kiev.ua

www.intersed.kiev.ua

Since 1998, "Intersed Ukraine" supplies the most advanced integrated solutions for automation of design and technological preparation of production for the companies of Ukraine.

"Intersed Ukraine" is an authorized reseller of Dassault Systèmes SOLIDWORKS Corp. on the territory of Ukraine.

More than five hundred scientific research, industrial, power and engineering enterprises with different ownership forms, scale and scope of activities is our customers and partners. Certified staff with years of experience in introduction, customization and support SOLIDWORKS products help enterprises and companies to use the most modern technology.

"Intersed Ukraine" helps to implement the software in schools, allowing students to gain knowledge and practical skills to work in the SOLIDWORKS environment. Unique educational programs and the possibility of passing the certification of students already use more than 50 higher educational institutions in Ukraine.

On all issues of purchasing and implementing software based on SOLIDWORKS and partner programs, please contact «Intersed Ukraine». 


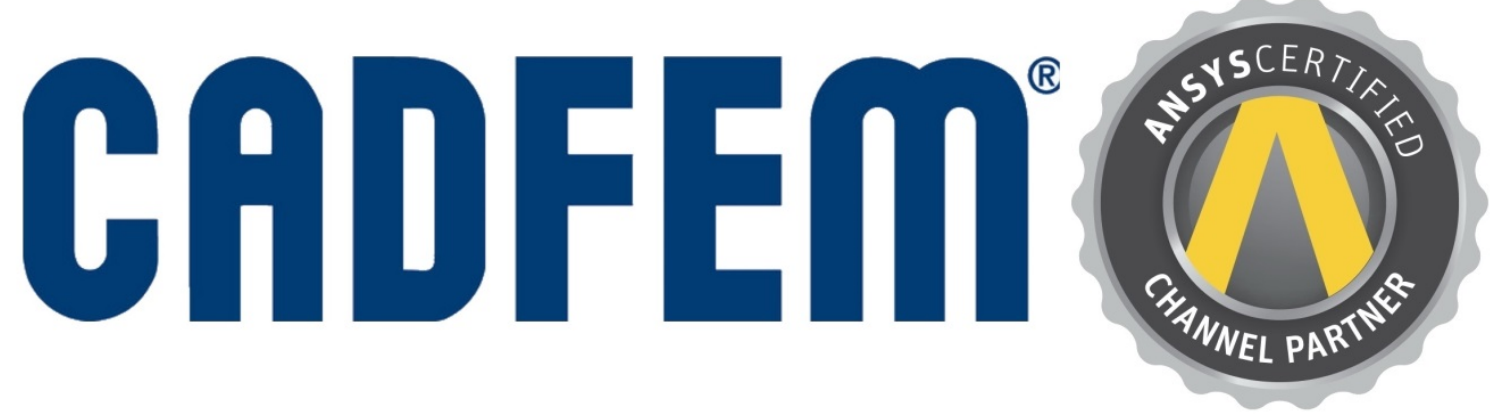

\section{CADFEM Ukraine}

www.cadfem.com.ua

Company CADFEM Ukraine, LTD. has a foreign participation. CADFEM Ukraine is the leading partner of the American company ANSYS, Inc. NASDAQ: ANSS in Ukraine, authorized distributor, engineering consulting and training center.

Head office of the CADFEM Ukraine located in Kyiv, Ukraine. The company employs highly competent professionals and managers.

CADFEM Ukraine is a member of the global engineering and consulting organization TechNetAlliance (www.technet-alliance.com) and is the part of a large European engineering holding.

CADFEM Ukraine is a member of the MECHATRONKA Aerospace Cluster.

Our services are related to sales and quality technical support specialized knowledge-based engineering software ANSYS and provide a wide range of consulting services (education customers, the development of engineering techniques and calculations in order, and adaptation of software development, installation and configuration of high-performance computing clusters, creation of engineering data centers, cloud solving engineering problems).

Customers include more than 20 organizations from large holdings to small enterprises, research institutes, universities, SE «Ivchenko-Progress», JSC «Motor Sich», HPNPKH «DAWN»- «Mashproekt»SE «Giprokoks», SE CB «South»SUMSKE NPO of Frunze,

Lviv Polytechnic National University, Institute of Engineering Thermophysics NAS UKRAINE, National Technical University «KPI», IEE-AES and other organizations. 


\section{(U) UNICHECK}

\section{Unicheck}

04073, Ukraine, Kyiv, Stepana Bandery Ave (letter G) 28A

Phone: +380443311198

E-mail: ukraine@unicheck.com

www.unicheck.com

Unicheck is a plagiarism prevention tool that checks documents for similarity against billions of web sources on the internet and a user private database.

Unicheck supports academic integrity in educational institutions around the world. In Ukraine, it's being used by more than 250 higher education institutions.

It was launched back in 2014 and acquired by a large plagiarism prevention service provider, Turnitin, in 2020.

Unicheck and Turnitin share a deep commitment to ensuring the integrity of education across the globe and provide a much broader set of solutions to secondary and higher education institutions to meet their evolving needs in academic integrity. 


\title{
$3^{\text {rd }}$ International Scientific Conference «Chemical Technology and Engineering»
}

\author{
P R O C E E D I N G S \\ Ukraine, Lviv, June 21-24 $4^{\text {th }}, 2021$
}

The typesetting team:

Anna Hlukhaniuk, MSc

Oleksandr Ivashchuk, PhD

The conference idea and logo design:

Oleksandr Ivashchuk, $\mathrm{PhD}$ 


\section{SPONSORS AND}

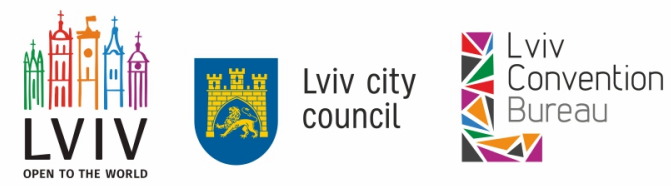

12. KAPחAT HAФTOXIM R POLIKOM

softico

CADFEm @

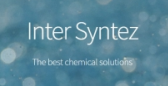

(4) UNICHECK

PARTNERS 